
University of California At Los Angeles The Library

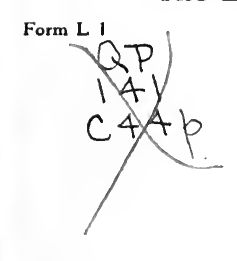


(1)

2 (2)

列 17. , t. b. 5.

(1) (6)

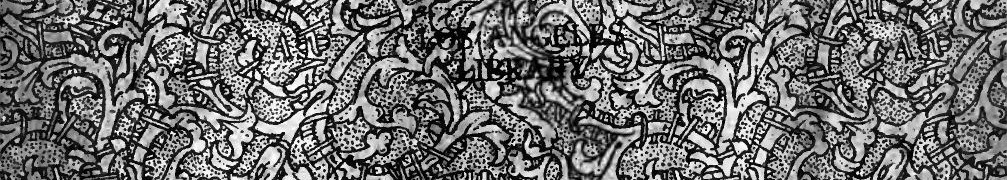

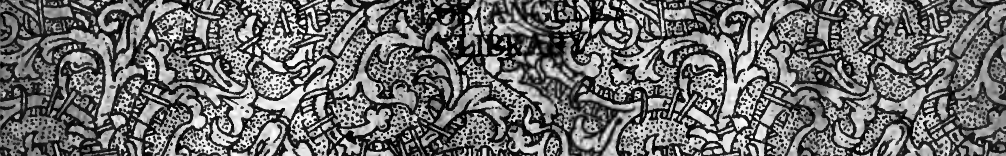
7.7.7.

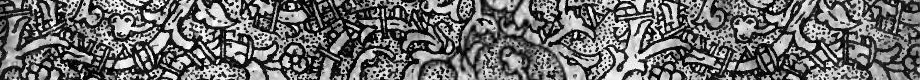
H. 5. 1.

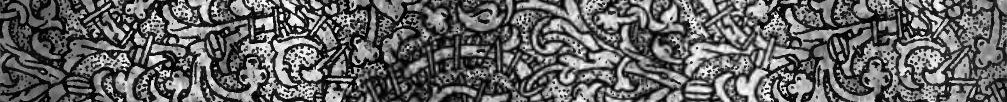
S.1.5. 2) 



\section{PHYSIOLOGICAL ECONOMY}

IN

\section{NUTRITION}

WITH SPECIAL REFERENCE TO THE MINIMAL PROTEID REQUIREMENT OF THE HEALTHY MAN

\section{AN EXPERIMENTAL STUDY}

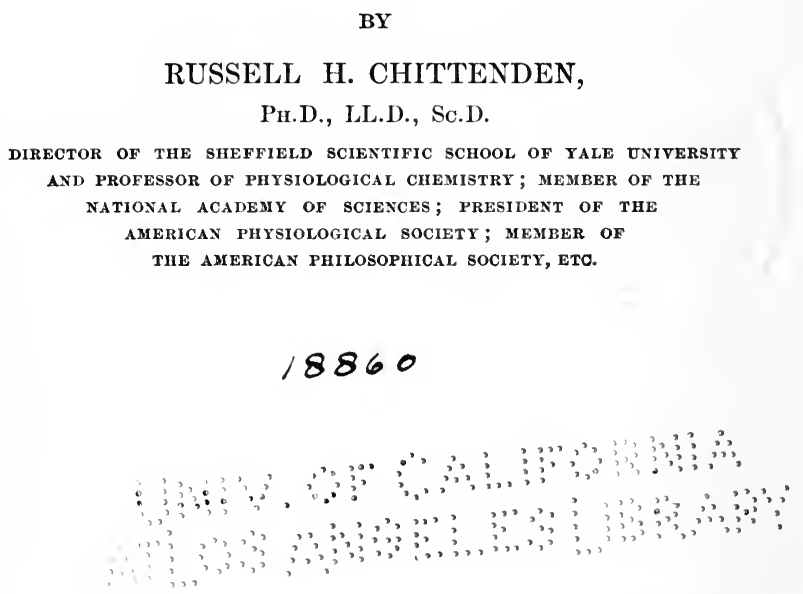

N E W Y O R

FREDERICK A. STOKES COMPANY 1907 
Copyright, 1904,

By Frederick A. Stokes Company

Published in November, 1904

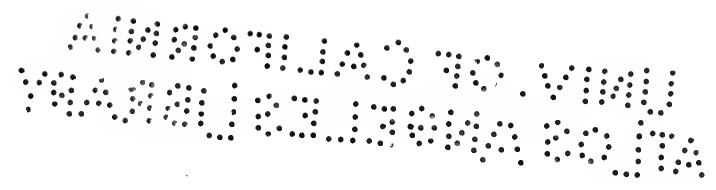

THE INIVERSITY PRFSS, CAMBRIDGE, V. S, A.

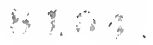




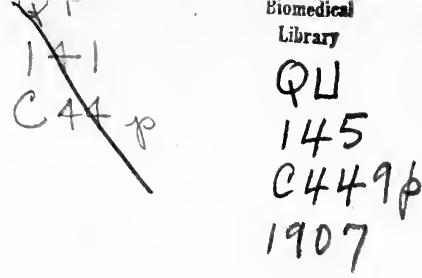

\section{LIST OF ILLUSTRATIONS}

FACING PAGE

Group of soldiers at work in the Gymnasium . . . . . . . 136

Side view of Fritz . . . . . . . . . . . . . . . . . 198

Back view of Fritz . . . . . . . . . . . . . . . . . 204

Front view of Coffman and Steltz . . . . . . . . . . . . . . . 212

Back view of Coffman and Steltz . . . . . . . . . . . . 220

Side view of Zooman and Cohn . . . . . . . . . . . . . 234

Back view of Zooman and Cohn . . . . . . . . . . . . 240

Side view of Loewenthal and Morris . . . . . . . . . . 258

Group of soldiers exercising in the Gymnasium • • • • • • 262

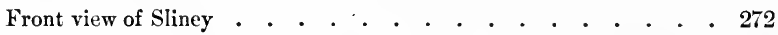

Soldiers exercising in the Gymnasium . . . . . . . . . 284

Soldiers exercising in the Gymnasium • • • • • • • • 296

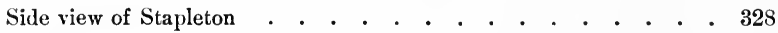

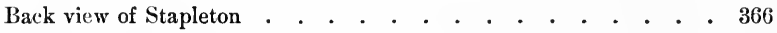

Front view of W. L. Anderson and Bellis . . . . . . . . . 440

Back view of W. L. Anderson and Bellis . . . . . . . . . 442 


\section{ACKNOWLEDGMENTS}

OF FINANCIAL AID IN MEETING THE EXPENSE OF THE EXPERIMENTS HEREIN DESCRIBED

THE writer has been most generously aided by substantial grants from the Bache Fund of the National Academy of Sciences, and from the Carnegie Institution of Washington; also by large donations from Mr. Horace Fletcher of Venice, and from Mr. John H. Patterson of Dayton, Ohio. In addition, the War Department of the United States met in large measure the expense of maintaining at New Haven the Detachment of Volunteers from the Hospital Corps of the United States Army, detailed here through the courtesy of SurgeonGeneral Robert Maitland O'Reilly.

\section{ACKNOWLEDGMENTS}

\section{OF AID IN THE CONDUCT OF THE EXPERIMENTS}

THE successful carrying out of the experiments in all their details, especially the chemical work, has been rendered possible by the active and continuous co-operation of the writer's colleague, Lafayette B. Mendel, Ph.D., Professor of Physiological Chemistry in the Sheffield Scientific School.

Efficient aid in the routine chemical and other work of the laboratory in connection with the experiments has been rendered by Frank P. Underhill, Ph.D., Arthur L. Dean, Ph.D., Harold C. Bradley, B.A., Robert B. Gibson, Ph.B., Oliver E. Closson, Ph.B., and Charles S. Leavenworth, Ph.B.

Dr. William G. Anderson, Director of the Yale Gymnasium, with the co-operation of his assistants, has rendered valuable aid in looking after the physical development of the men 
under experiment, in arranging for frequent strength tests, as well as in prescribing the character and extent of their work in the Gymnasium. The greater portion of the training of the soldiers was under the personal supervision of William H. Callahan, M.D., Medical Assistant at the Gymnasium, while Messis. William Chase, Anton Muller, John Stapleton, and H. R. Gladwin, Assistant Instructors in the Gymnasium, led the drills and looked after the actual muscular training of the men.

In the study of "Reaction Time" and other matters of psychological interest the work was under the direction of Charles H. Judd, Ph.D., in charge of the Yale Psychological Laboratory, aided by Warren M. Steele, B.A., and Cloyd N. McAllister, Ph.D.

In the morphological study of the blood, etc., Dr. Wallace DeWitt, Lieutenant in command of the Army detail, rendered valuable aid. Dr. DeWitt likewise co-operated in all possible ways during his stay in New Haven to maintain the integrity of the conditions necessarily imposed on the soldier detail in an experiment of this character.

Further, acknowledgments are due the several non-commissioned officers of the Hospital Corps for their intelligent co-operation and interest. Finally, to the men of the Hospital Corps who volunteered for the experiment, our thanks are due for their cheerful compliance with the many restrictions placed upon them during their six months' sojourn in New Haven, and for the manly way in which they conducted themselves under conditions not always agreeable.

To the students of the University who volunteered as subjects of experiment our acknowledgments are due for their intelligent co-operation, keen interest, and hearty compliance with the conditions inposed. 


\section{PREFACE}

\section{0}

There is no subjeet of greater physiological importance, or of greater moment for the welfare of the human race, than the subject of nutrition. How best to maintain the body in a condition of health and strength, how to establish the highest degree of efficiency, both physical and mental, with the least expenditure of energy, are questions in nutrition that every enlightened person should know something of, and yet even the expert physiologist to-day is in an uncertain frame of mind as to what constitutes a proper dietary for different conditions of life and different degrees of activity. We hear on all sides widely divergent views regarding the needs of the body, as to the extent and charaeter of the food requirements, contradictory statements as to the relative merits of animal and vegetable foods; indeed, there is great lack of agreement regarding many of the fundamental questions that constantly arise in any consideration of the nutrition of the luman body. Especially is this true regarding the so-called dietary standards, or the food requirements of the healthy adult. Certain general standards have been more or less widely adopted, but a careful

scrutiny of the conditions under which the data were collected leads to the conclusion that the standards in question have a very uncertain value, especially as we see many instanees of people living, apparently in good physical condition, under a régime not at all in harmony with the existing standards.

Especially do we need more definite knowledge of the true physiological necessities of the body for proteid or albuminous foods, i.e., those forms of foods that we are accustomed to speak of as the essential foods, since they are absolutely requisite for life. If our ideas regarding the daily quantities of these foods necessary for the maintenance of health and 
strength are exaggerated, then a possible physiological economy is open to us, with the added possibility that health and vigor may be directly or indirectly increased. Further, if through years and generations of habit we have become addicted to the use of undue quantities of proteid foods, quantities way beyond the physiological requirements of the body, then we have to consider the possibility that this excess of daily food may be more or less responsible for many diseased conditions, which might be obviated by more careful observance of the true physiological needs of the body.

First, however, we must have more definite information as to what the real necessities of the body for proteid food are, and this information can be obtained only by careful scientific experimentation under varying conditions. 'This has been the object of the present study, and the results obtained are now placed before the public with the hope that they will prove not only of scientific interest and value, but that they will also serve to arouse an interest in the minds of thoughtful people in a subject which is surely of primary importance for the welfare of mankind. That the physical condition of the body exercises an all-powerful influence upon the mental state, and that a man's moral nature even is influenced by his bodily condition are equally certain; hence, the subject of nutrition, when once it is fully understood and its precepts obeyed, bids fair to exert a beneficial influence not only upon bodily conditions, but likewise upon the welfare of mankind in many other directions.

In presenting the results of the experiments, herein described, the writer has refrained from entering into lengthy discussions, preferring to allow the results mainly to speak for themselves. They are certainly sufficiently convincing and need no superabundance of words to give them value; indeed, such merit as the book possesses is to be found in the large number of consecutive results, which admit of no contradiction and need no argument to enhance their value. The results presented are scientific facts, and the conclusions they justify are self-evident. 


\section{CONTENTS}

Page

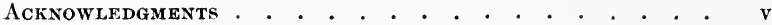

Preface . . . . . . . . . . . . . . . . . . . vii

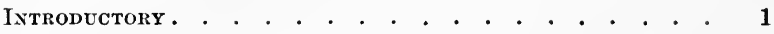

I.

Experiments with Professional Men.

Chittenden : Daily Record of Nitrogen Excretion, etc. . . . . . 24

First Nitrogen Balance, with comparison of income and output, amount and character of the daily food . . . . . . . 34

Second Nitrogen Balance, with composition of daily food, etc. . 433

Mendel: Daily Record of Nitrogen Excretion, etc. . . . . . . 53

First Nitrogen Balance, with comparison of income and output, amount and character of the daily food . . . . . . . 60

Second Nitrogen Balance, with composition of daily food, etc. . $\quad 67$

Underhill : Daily Record of Nitrogen Excretion, etc. . . . . . 79

First Nitrogen Balance, with comparison of income and output, composition of the daily food, etc. . . . . . . . . . $\quad 87$

Second Nitrogen Balance, with composition of daily food, etc. . 93 Dean : Daily Record of Nitrogen Excretion, etc. . . . . . 98

Nitrogen Balance, with comparison of income and output, amount and character of the daily food . . . . . . . . . 103

Beers: Daily Record of Nitrogen Excretion, etc. . . . . . . 111

First Nitrogen Balance, with comparison of income and output, amount and character of the daily food . . . . . . . 114

Second Nitrogen Balance, with composition of daily food, etc. . 121 Summary of Results ; True Proteid Requirements . . . . . . 127

\section{II.}

Experiments with Volunteers from the Hospital Corps of the United States Army.

Description of the Men . . . . . . . . . . . . . . 134

Daily Routine of Work . . . . . . . . . . . 135 
Daily Record of Nitrogen Excretion, etc., for each of the thirteen

men under experiment . . . . . . • . . . . . . . 139

Average Daily Output of Nitrogen . • • • • • • • . . . 199

Nitrogen Metabolized per kilo of Body-Weight . . . . . . 201

Changes in Body-Weight during the Experiment . . . . . . 202

First Nitrogen Balance, with comparison of income and output,

amount and character of the daily food . . . . . . 203

Second Nitrogen Balance, with composition of daily food, etc. . $\quad 223$

Third Nitrogen Balance, with composition of daily food, etc. $\quad$ 242

Summary regarding Nitrogen Requirement . . . . . . . . 254

Physical Training of the Men - Report by Dr. Anderson of the

Yale Gymnasium . . . . . . . . . . . . . . 255

Body Measurements . . . .. . . . . . . . . . . . 261

Strength or Dynamometer Tests . . . . . . . . . . . 262

Comparison of the Total Strength of the Men at the beginning and

end of the Experiment . . . . . . . . . . . . . . 274

Reaction Time Experiments - Report by Dr. Judd of the Yale

Psychological Laboratory • . . . . . . . . . . . 276

Character and Composition of the Blood . . . . . . . . . 283

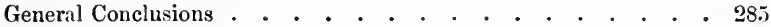

Daily Dietary of the Soldier Detail . . . . . . . . . 288

III.

Experimexts with University Students, trained in Athletics.

Consunıtion of Proteid Food by Athletes . . . . . . . . 327

Description of the Men . . . . . . . . . . . . . . . 329

Daily Record of Nitrogen Excretion, etc., for each of the eight men under Experiment . . . . . . . . . . . . . 332

Average Daily Excretion of Metabolized Nitrogen . . . . . . 364

Metabolized Nitrogen per kilo of Body-Weight . . . . . . . 365

Daily Diet Prescribed . . . . . . . . . . . . . . . 366

Nitrogen Balance, with comparison of income and output, and

amount and character of the daily food, etc. . . . . . . 375

The Physical Condition of the Men . . . . . . . . . . 434

Strength or Dynamometer Tests . . . . . . . . . . 436

Report by Dr. Anderson of the Yale Gymnasum . . . . . . 439

Reaction Time - Report by Dr. Judd of the Yale Psychological

Laboratory . . . . . . . . . . . . . . . . 42

General Summary; True Physiological Requirements for Proteid

Food . . . . . . . . . . . . . . 454 


\section{IV.}

The Systemic Value of Physiological Economy in Nutrition.

Diseases due to Perversion of Nutrition . . . . . . . 455

Waste Products of Proteid Metabolism may be Dangerous to Health 456 Origin and Significance of Uric Acid . . . . . . . . . 458 Modification of Uric Acid Excretion by diminishing the amount of Proteid Food . . . . . . . . . . . . . . . . 463

Tables showing Excretion of Uric Acid by the three groups of men under observation; Uric Acid per kilo of Body-Weight, etc. . 467 V.

Economic and Sociological Importance of the Results • 471 VI.

General Coxclusions VII.

Description of Illugtrations . . . . • . . . 477 



\section{PHYSIOLOGICAL ECONOMY IN NUTRITION}

\section{INTRODUCTORY}

$A_{\text {certain general conclusions have been arrived at regarding }}^{\mathrm{S} \text { the result of many years of observation and experiment }}$ the requisite amounts of food necessary for the maintenance of health and strength. Certain dietary standards have been set up which have found more or less general acceptance in most parts of the civilized world; standards which have been reinforced and added to by man's aptitude for self-indulgence. Carl Voit, of Munich, whose long and successful life as a student of Nutrition renders his conclusions of great value, considers that an adult man of average body-weight (70-75 kilos) doing moderate muscular work requires daily 118 grams of proteid or albuminous food, of which 105 grams should be absorbable, 56 grams of fat, and 500 grams of carbohydrate, with a total fuel value of over 3000 large calories, in order to maintain the body in equilibrium. The Voit standard or daily diet is accepted more or less generally as representing the needs of the body under normal conditions of life, and

Note. - For the benefit of lay readers, metabolism, a word frequently made use of, may be defined as a term applied to the collective chemical changes taking place in living matter. When these metabolic changes are constructive, as in the building up of tissue protoplasm from the absorbed food material, they are termed anabolic; when they are destructive, as in the breaking down of living matter or in the decomposition of the materials stored up in the tissues and organs, they are termed katabolic. Proteid metabolism, or more exactly proteid katabolism, therefore, means the destructive decomposition of proteid or albuminous matter in the living body and is practically synonymous with nitrogenous metabolism, since the entire nitrogen income is mainly supplied by the proteids or albuminous matters of the food. The chief carbon income, on the other hand, is supplied by fats and carbolyy drates, such as starches and sugars. 
the conclusions arrived at by other investigators along these same lines have been more or less in accord with Voit's figures. In confirmation of this statement the following data may be quoted:

\section{AVERAGE DIETS.}

\begin{tabular}{|c|c|c|c|c|c|c|c|}
\hline & 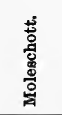 & 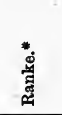 & 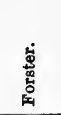 & 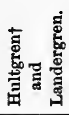 & 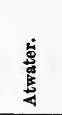 & 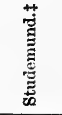 & 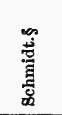 \\
\hline & grams & grams & grams & grams & grams & grams & grams \\
\hline Proteid ... & 130 & 100 & 131 & 134 & 125 & 114 & 105 \\
\hline Carbohydrates. & 550 & 240 & 494 & 523 & 400 & 551 & 541 \\
\hline Fats .... & 40 & 100 & 68 & 79 & 125 & 54 & 63 \\
\hline $\begin{array}{l}\text { Fuel value (calo- } \\
\text { ries) } \| . . .\end{array}$ & 3160 & 2324 & 3195 & 3436 & 3315 & 3229 & 3235 \\
\hline
\end{tabular}

In many of these diets it is to be noted that the proteid requirement is placed at even a higher figure than Voit's standard. Similarly, Erisman, studying the diets of Russian workmen having a free choice of food and doing moderately hard work, found the daily diet to be composed of 131.8 grams of proteid, 79.7 grams of fat, and 583.8 grams of carbohydrate, with a total fuel value of 3675 large calories. Further, Hultgren and Landergren $\uparrow$ found that Swedish laborers doing hard work had as their daily diet 189 grams of proteid, 110 grams of fat, and 714 grams of carbohydrate, with a total fuel value of 4726 large calories. Voit found that German soldiers on active service consumed daily 145 grams of proteid, 100 grams of fat, and 500 grams of carbohydrate, with a total fuel value

* Die Ernährung des Menschen. Munich, 1876.

$\dagger$ Untersuchungen ü. d. Ernälır. schwedischer Arbeiter. Stockholm, 1891.

$\ddagger$ Ein Beitrag zur Lehre vom Eiweissbedarf des gesunden Menschen. Pflüger's Archiv f. d. gesammte Physiologie. Band 48, p. 578.

$\S$ D. Militärärztl. Zeitschr., 1901, p. 622. Quoted by Hirschfeld, Arcliv. f. Physiologie, 1903, p. 381.

II Large calories, or kilogram-degree units of heat.

I Jahresbericht für Thierchemie, 1891, p. 369. The figures given in the above table represent the diet for men doing a moderate amount of work. 
of 3574 large calories. Lichtenfelt, ${ }^{*}$ studying the nutrition of Italians, states that an Italian laborer doing a moderate amount of work requires $\mathbf{1 1 0 . 5}$ grams of proteid and a total fuel value for the daily food of 2698 calories, while at hard labor he needs 146 grams of proteid daily, with carbohydrates and fat sufficient to give 3088 large calories. In our own country Atwater, $\uparrow$ who has made many valuable observations upon the dietetic habits of different classes of people and under different conditions of life, has stated that a somewhat more liberal allowance of proteid would seem desirable, say 125 grams, with a total fuel value of 3500 large calories for a man doing severe muscular labor.

In what is perhaps the latest book on alimentation, Armand Gautier, $\ddagger$ writing of the French people, states that the ordinary man in that climate needs daily 110 grams of albuminous food, 68 grams of fat, and about 423 grams of amylaceous or saccharine food. It is possible, however, says Gautier, that the quantity of albuminous food can be reduced, if necessary, to 78 grams per day in case a man is not doing work and takes in addition at least 50 grams of fat and 485 grams of carbohydrate food. Where, however, an individual works eight to ten hours a day, the ration, says Gautier, must be increased to at least 135 grams of albuminous food, with 85 to 100 grams of fat, and with from 500 to 900 grams of starchy food.

While these figures may be taken as showing quite conclusively the dietetic standards adopted by mankind, there is no evidence whatever that they represent the real needs or requirements of the body. We may even question whether simple observation of the kinds and amounts of food consumed by different classes of people under different conditions of life have any very important bearing upon this question. They

* Ueber die Ernährung der Italiener. Pflüger's Archiv. f. d. gesammte Physiologie, Band 99, p. 1 (1903).

$\dagger$ Bulletin No. 46. United States Department of Agriculture, p. 63.

$\ddagger$ L'Alimentation et les Régimes chez l'Homme sain et chez les Malades, Paris, 1904. 
throw light upon dietetic habits, it is true, but such observations give no information as to how far the-diets in question serve the real needs of the body. We may find, for example, that under certain given conditions of diet the people in question have the appearance of being well nourished, and that they do their work with apparent ease and comfort; but might not these same results follow with smaller amounts of food? If so, there must of necessity be a certain amount of physiological economy under the more restricted diet, and a consequent ultimate gain to the body through diminished wear and tear of the bodily machinery.

Indeed, experimental work and observations scattered through the last few years have suggested the possibility of much lower standards of diet sufficing to meet the real physiological needs of the body. 'Thus, Hirschfeld,* in 1887, found in experimenting on himself (24 years of age and weighing 73 kilos) that it was possible to maintain nitrogen equilibrium on a diet containing only 5 to 7.5 grams of nitrogen per day, or 35 to 45 grams of proteid, for a period of ten to fifteen days. The amount of non-nitrogenous food consumed, however, was fairly large, especially the amount of butter, - frequently 100 grams a day - the average fuel value ranging from 3750 to 3916 large calories daily. In 1888 Hirschfeld, $\uparrow$ again experimenting on himself, maintained nitrogen equilibrium for several days on 7.5 grams of nitrogen per day, with fats and carbohydrate sufficient to yield a total fuel value of 3462 large calories as the daily average. The chief criticism of Hirschfeld's experiments is that he failed to obtain in all cases definite analytical data of the food-stuffs employerl and failed to determine the nitrogen of the faeces. Still his results are of value as indicating the possibility of naintaining nitrogenous equilibrium for a brief time at least on a low proteid intake.

* Untersuchungen über den Fiweissbedarf des Menschen. Pflüger's Archiv f. die gesammte Physiologie. Band 41, p. 533.

$\dagger$ Beiträge zur Ernälırungslehre des Menschen. Virchow's Archiv für pathol. Anat. u. Physiol. Band 114, p. 311. 
Kumagawa, * studying especially the diet of the Japanese and experimenting on himself ( 27 years old and weighing 48 kilos), found with a purely vegetable diet, containing per day 54.7 grams of proteid, 2.5 grams of fat, and 569.8 grams of carbohydrate, that he showed for a period of nine days a plus balance of nitrogen, indicating that his body was laying on about 4 grams of proteid per day. The nitrogen excreted per urine and fæces amounted to 8.09 grams per day, while the nitrogen in the daily food amounted to 8.75 grams. It is interesting to observe in these experiments, as indicating the degree of absorption of the vegetable food (composed in large measure of rice) that the daily average of nitrogen in the urine amounted to 6.069 grams and in the frees 2.029 grams. In other words, of the 54.7 grams of nitrogen-containing food only 37.8 grams were absorbed, 12.69 grams passing out with the fæces. The total fuel value of the absorbed food per day was 2478 large calories. Similarly, Hirschfeld $\dagger$ has called attention to the fact that with many vegetable foods especially, not more than 75 per cent of the ingested proteid can be digested and absorbed, thus emphasizing the necessity of paying heed to the character of the proteid food in considering the nutritive value of a given diet.

In some experiments reported by $\mathrm{C}$. Voit $\ddagger$ in 1889 , on the diet of vegetarians, E. Voit and Constantinidi found that nitrogenous equilibrium was established in one man with about 8 grams of nitrogen, corresponding to 48.5 grams of proteid as the daily diet, with large amounts of starchy foods and some fat. Similarly, Nakahama $\S$ in the same year, studying the diet (mostly vegetable) and nutritive condition of thirteen German laborers in Leipzig, found that their daily

* Vergleichende Untersuchungen über die Ernährung mit gemischter und rein vegetablischer Kost mit Berïcksichtigung des Iiweissbedarfes. Virchow's Archiv für pathol. Anat. u. Physiol. Band 116, p. 370.

$\dagger$ Die Ernährung der Soldaten vom physiologischen und volkswirthschaftlichen Standpunkt. Achiv f. Physiologie 1903, p. 380.

† Ueber die Kost eines Vegetariers. Zeitschr. f. Biologie. Band 25, p. 261.

$\S$ Ueber den Eiweissbedarf des Erwachsenen mit Berücksichtigung der Beküstigung in Japan. Archiv f. Hygiene. Band 8, p. 78. 
food contained on an average 85 grams of proteid, but Carl Voit criticising these results states that the men were of comparatively light body-weight - about 60 kilos - and not well nourished.

Kellner and Mori,* studying the nutrition of a Japanese (weighing 52 kilos and 23 years of age) state that on a purely vegetable diet containing 11.34 grams of nitrogen, of which only 8.58 grams were digested, there was a distinct loss of body-weight, with a daily loss to the body of 1.16 grams of nitrogen. On a mixed diet, however, containing fish, it was possible to establish nitrogenous equilibrium with a daily diet containing 17.48 grams of nitrogen, of which 15.27 grams were digested and utilized. Similarly, Caspari, $\uparrow 29$ years old and weighing $66.2 \mathrm{kilos}$, found that while he could maintain his body in nitrogenous equilibrium on 13.26 grams of nitrogen per day, he could not accomplish it on 10.1 grams of nitrogen, though his daily food contained 3200 large calories.

Other investigators, however, have found no great difficulty in establishing nitrogenous equilibrium in man with much lower quantities of proteid food. Thus, Klemperer $\ddagger$ found in the case of two young men of 64 and $65.5 \mathrm{kilos}$ body-weight respectively, in an experiment lasting eight days, that nitrogenous equilibrium was established on 4.38 and 3.58 grams of nitrogen per day, but with a daily diet containing in addition to the small amount of proteid 264 grams of fat, 470.4 grams of carbohydrate, and 172 grams of alcohol, with a total fuel value of 5020 large calories.

Peschel, $\S$ too, has reported experimental results showing that he was able to establish nitrogenous equilibrium for a

* Untersuchungen ïber die Ernährung der Japaner. Zeitschr. f. Biologie. Band 25, p. 102.

$\dagger$ Ein Beitrag zur Frage der Ernährung bei verringerter Eiweisszufuhr. Archiv f. Physiologie, Jahrgang 1901, p. 323.

$\ddagger$ Untersuchungen über Stoffwechsel und Ernährung in Krankheiten. Zeitschr. f. klin. Medizin. Band 16, p. 550.

$\S$ Untersuchungen über den Eiweissbedarf des gesunden Menschen. Berlin, 1891. 
brief period with 7 grams of nitrogen daily, 5.31 grams appearing in the urine and 1.58 grams in the fieces.

Caspari and Glaessner, ${ }^{*}$ in a five-days' experiment with two vegetarians, found that the wife consumed daily, on an average, 5.33 grams of nitrogen, with fats and carbohydrates to equal 2715 calories, while the man took in 7.82 grams of nitrogen and 4559 calories. Both persons laid on nitrogen in spite of the low intake of proteid food.

Siven's $\dagger$ experiments, however, are perhaps worthy of more careful consideration. Of 60 kilos body-weight and 301 years of age, his experiments conducted on himself extended through thirty-two days with establishment of nitrogenous equilibrium on 6.26 grams of nitrogen. Moreover, in another experiment he was in nitrogen equilibrium for a day or two at least on 4.5 grams of nitrogen. In Siven's experiment, the most noticeable feature is the added fact that the total intake of food per day was comparatively low, with a fuel value of only 2444 large calories. In this connection we may call attention to the recent experiments of Landergren, $\ddagger$ who found with four individuals fed on a daily diet containing only 2.1 to 2.4 grams of nitrogen, but with a large amount of carbohydrate, some fat and alcohol, that on the fourth day of this "specific nitrogen hunger" only 3 to 4 grams of nitrogen were metabolized and appeared in the urine. In other words, a healthy adult man having a sufficient intake of nonnitrogenous food seemingly need not metabolize more proteid than suffices to yield 3 to 4 grams of nitrogen per day.

Such data as these, of which many more might be quoted, surely warrant the question, how far are we justified in assuming the necessity for the rich proteid diet called for by the Voit standard? Voit, however, with many other physiol-

* Ein Stoffwechselversuch an Vegetarianern. Biochemisches Centralblatt Band 2, p. 144 (1903).

$\dagger$ Ueber das Stickstoffgleiclıgewicht beim erwachsenen Menschen. Skandinavisches Archiv f. Physiol. Band 10, p. 91.

$\ddagger$ Untersuchungen über die Eiweissumsetzung des Menschen. Skandinavisches Arehiv f. Physiol. Band 14, p. 121 (1903). 
ogists would apparently object to any diminution of the daily 118 grams of proteid for the moderate worker, on the ground that an abundance of proteid in the food is a necessity for the maintenance of physical vigor and muscular activity. This view is certainly reinforced by the customs and habits of mankind; but we may well query whether our dietetic habits will bear criticism, and in the light of modern scientific inquiry we may even express doubt as to whether a rich proteid diet adds anything to our muscular energy or bodily strength.

How far can our natural instinct be trusted in the choice of diet? We are all creatures of habit, and our palates are pleasantly excited by the rich animal foods with their high content of proteid, and we may well question whether our dietetic habits are not based more upon the dictates of our palates than upon scientific reasoning or true physiological needs. There is a prevalent opinion that to be well nourished the body must have a large excess of fat deposited throughout the tissues, and that all bodily ills and weaknesses are to be met and combated by increased intake of food. There is constant temptation to increase the daily ration, and there is almost universal belief in the efficacy of a rich and abundant diet to strengthen the body and to increase bodily and mental vigor. Is there any justification for these beliefs? None, apparently, other than that which comes from the customs of generations of high living.

It is self-evident that the smallest amount of food that will serve to keep the body in a state of high efficiency is physiologically the most economical, and hence the best adapted for the needs of the organism. Any excess over and above what is really needed is not only uneconomical, but may be directly injurious. 'This is especially true of the proteid or albuminous foods. It is, however, quite proper to question whether a brief experiment of a few days in which nitrogenous equilibrium is perhaps established at the low level of 4 to 5 grams of nitrogen, the equivalent of 25 to 35 grams of proteid, is to be accepted as fixing the daily requirements of the healthy man, offsetting the customs or habits of a lifetime. Voit himself, 
however, has clearly emphasized the general prineiple that the smallest amount of proteid, with non-nitrogenous food arlded, that will suffice to keep the body in a state of continual vigor is the ideal diet. Proteid decomposition products are a constant menace to the well-being of the body; any quantity of proteid or albuminous food beyond the real requirements of the body may prove distinctly injurious. We see the evil effects of uric acid in gout, but there are many other nitrogenous waste products of proteid katabolism, which with excess of proteid food are liable to be unduly conspicuous in the fluids and tissues of the body, and may do more or less damage prior to their excretion through the kidneys. Further, it requires no imagination to understand the constant strain upon the liver and kidneys, to say nothing of possible influence upon the central and peripheral parts of the nervous system, by these nitrogenous waste products which the body ordinarily gets rid of as speedily as possible. They are an ever present evil, but why increase them unnecessarily? This question brings us back to the starting-point. What is the minimal proteid requirement for the healthy man, or rather, how far can we safely and advantageously diminish our proteid intake below the commonly accepted standards?

The question of safety is a pertinent one. Thus, Munk* some years ago (1893) sounded a warning on this point which was later confirmed by Rosenheim. $\dagger$ Both of these observers reported that in dogs fed for some time on a low proteid diet, but with an abundance of carbohydrate and fat, there was after some weeks (6-8) a loss of the power of absorption from the alimentary tract, dependent not alone upon a changed condition of the epithelial cells of the intestine, but also upon a diminished secretion of the digestive juices, loss of bodyweight, strength, and vigor, followed speedily by death. If

* Ueber die Folgen einer ausreichenden, aber eiweissarmen Nahrung. Ein Beitrag zur Lehre vom Eiweissbedarf. Virchow's Archiv für pathol. Anat. u. Physiol. Band 132, p. 91.

$\dagger$ Weitere Untersuchungen über die Schällichkeit eiweissarmer Nahrung. Pflüger's Archiv f. die gesammte Physiol. Band 54, p. 61. 
these results were really due to the low proteid diet, they suggest a grave danger which must not be lightly passed by. Jägerroos * has likewise observed, experimenting on dogs, that there was, after some months, a striking disturbance of the intestines on a low proteid intake, which, however, was eventually traced to a distinct infection, and probably in no manner connected with the diminished amount of proteid in the diet. In these various experiments on dogs carried out by Munk, Rosenheim, and by Jägerroos, there was of necessity great monotony in the diet, and in Munk's experiments no fresh meat at all was fed, but simply dried food. In other words, if the diet was in any sense responsible for the poor health of the animals, it is fully as plausible to attribute the results to the abnormal conditions under which the animals were kept as to any specific effect due to the low proteid intake. It is very essential that the food of dogs, as of men, shall fulfil all ordinary hygienic conditions. It must be not only of sufficient quantity for the true needs of the body, but it should also have the necessary variety with reasonable degree of digestibility, and proper volume or bulk. When these qualities are lacking, it is not strange if deviations from the normal gradually develop. That the low intake of proteid food could be responsible for the condition existing in Munk's and Rosenheim's experiments is not plausible; a view which is strongly reinforced by many observations, notably those of Albu $\dagger$ on a woman thirty-seven years old and weighing 37.5 kilos, who had followed a vegetarian diet for six years, and who while under Albu's care for two years consumed only 34 grams of proteid per day, the total fuel value of the food being only 1400 calories per day. This woman was in nitrogenous equilibrium on 5.4 grams of nitrogen, and on this diet had freed herself from the illness to which she had long been subject.

* Veber die Folgen einer ausreichenden, aber eiweissarmen Nalırung. Skandinavisches Archiv f. Pliysiol. Band 13, p. B75.

$\dagger$ Zur Bewertung der vegetarischen Diät. Berliner klin. Wochenschr. 1901. p. 647 and 670 . See also, Albu, die vegetarishe Diät. Leipzig, 1902. p. 65. 
Voit's * vegetarian is described by Voit himself as a mall twenty-eight years old, weighing 57 kilos, well nourished, with well developed muscles, etc. He had lived on a purely vegetable diet for three years, and was found to be in nitrogenous equilibrium on 8.2 grams of nitrogen. No mention is made of any disagreeable effects connected with this low proteid ration, although persisted in for several years. Jaffa's $\uparrow$ experiments and observations on the fruitarians and nutarians of California "showed in every case (two women and three children) that though the diet had a low protein and energy value, the subjects were apparently in excellent health and had been so during the five to eight years they had been living in this manner." In comparing the income and outgo of nitrogen on a diet composed mainly of nuts and fruits, it was observed in two subjects that 8 grams of nitrogen were sufficient to bring about nitrogen equilibrium, while with two other subjects on a like diet the nitrogen required daily for equilibrium was about 10 grams. The diet used in these experiments, however, was of necessity more or less restricted in variety, and was without doubt somewhat monotonous. Jaffa appears to agree with Caspari that the minimum amount of proteid required daily varies with the individual, and may even vary with the same individual at different times. Further, Jaffa, in harmony with Siven, believes that after the body has suffered a loss of nitrogen, there is at once an effort to attain nitrogenous equilibrium, and that any gain of nitrogenous body material is a comparatively slow process. If this is true, it is obvious that the living substance of the tissue protoplasm must be slowly formed from the proteid of the diet. This, says Jaffa, should serve as a warning to anyone contemplating any appreciable decrease in the proteid of the daily diet.

Another statement made by Jaffa may be quoted in this

* See Zeitschr. f. Biologie. Band 25, p. 255.

$\dagger$ Further Investigations among Fruitarians at the California Agricultural Experiment Station. 1901-1902. U. S. Department of Agriculture. Bulletin No. 132 . 
connection, since it illustrates the attitude taken by many physiologists on this question. "Even if it could be proved," says Jaffa, "by a large number of experiments that nitrogen equilibrium can be maintained on a small amount of protein, it would still be a great question whether or not it would be wise to do so. There must certainly be a coinstant effort on the part of the human organism to attain this condition, and with a low protein supply it might be forced to do so under conditions of strain. In such a case the bad results might be slow in manifesting themselves, but might also be serious and lasting. It has also been suggested that when living at a fairly high protein level the body is more resistant to disease and other strains than when the protein level is low." While these suggestions demand careful consideration, it is equally evident that there is another side to the question, viz., the possible danger to the body from the physiological action of the larger amounts of nitrogenous waste products which result from an excess of proteid food, and which float about through the system prior to their excretion. In addition, we must not overlook the great loss of energy to the body in handling and getting rid of the surplus of unnecessary food of whatever kind introduced into the alimentary tract, to say nothing of the danger of intestinal putrefaction and toxæmia when from any cause the system loses its ability to digest and absorb the excess of food consumed. Further, the possible strain on the kidneys and other organs must not be overlooked. Hence we may well query on which side lies the greater danger. To an unprejudiced observer, one not werlded to old-time tradition, it would seem as if great effort was being made to sustain the claims of a high-proteid intake. It is surely well to be careful, but it is certainly not necessary to magnify imaginary dangers to the extent of suppressing all efforts toward the establishment of possible physiological economy.

In a paper read before the Physiological Section of the British Medical Association in 1901 by Dr. van Someren, claim is made of the existence of a reflex of deglutition, the proper working of which protects from the results of mal- 
nutrition by preventing the intake of any excess of food. Thorough mastication and insalivation aid in the more complete utilization of the food and render possible great economy, so that body-weight and nitrogen equilibrium are both maintained on an exceptionally small amount of food. This principle had been worked out by Mr. Horace Fletcher on himself in an attempt to restore his health to a normal condition, with such beneficial results that he was speedily restored to a state of exceptional vigor and well-being. Deliberation in eating, necessitated by the habit of thorough insalivation, it is claimed results in the occurrence of satiety on the ingestion of comparatively small amounts of food, and hence all excess of food is avoided.

In the autumn of 1901, Mr. Fletcher and Dr. van Someren visited the physiological laboratories of Cambridge University, and as stated by Sir Michael Foster* the matter was more closely inquired into with the assistance of physiological experts. Observations were carried out on various individuals, and as stated by Professor Foster "the adoption of the habit of thorough insalivation of the food was found in a consensus of opinion to have an immediate and very striking effect upon appetite, making this more discriminating, and leading to the choice of a simple dietary, and in particular reducing the craving for flesh food. The appetite, too, is beyond all question fully satisfied with a dietary considerably less in amount than with ordinary habits is demanded." . . . "In two individuals who pushed the method to its limits it was found that complete bodily efficiency was maintained for some weeks upon a dietary which had a total energy value of less than one-half of that usually taken, and comprised little more than one-third of the proteid consumed by the average man." Finally, says Foster, "it may be doubted if continued efficiency could be maintained with such low values as these, and very prolonged observations would be necessary to establish the facts. But all subjects of the experiments who applied the principles

* See Horace Fletcher, The A-B-Z of our own Nutrition. (1903.) New York. p. 48. 
intelligently agreed in finding a very marked reduction in their needs, and experienced an increase in their sense of wellbeing and an increase in their working powers."

In the autumn of 1902 and in the early part of $1903, \mathrm{Mr}$. Fletcher spent several months with the writer, thereby giving an opportunity for studying his habits of life. For a period of thirteen days in January he was under constant observation in the writer's laboratory, when it was found that the average daily amount of proteid metabolised was 41.25 grams, his body-weight (75 kilos) remaining practically constant. Later, a more thorough series of observations was made, involving a careful analysis of the daily diet, together with analysis of the excreta. For a period of six days the daily diet averaged 44.9 grams of proteid, 38.0 grams of fat, and 253 grams of carbohyclate, the total fuel value amounting to only 1606 large calories per day. The daily intake of nitrogen averaged 7.19 grams, while the daily output through the urine was 6.30 grams and in the fæees 0.6 gram; i.e., a daily intake of 7.19 grams of nitrogen, with a total output of 6.90 grams, showing a daily gain to the body of 0.29 gram of nitrogen,. and this on a diet containing less than half the proteid required by the Voit standard and having only half the fuel value of the Voit diet. Further, it was found by careful and thorough tests made at the Yale Gymnasium that Mr. Fletcher, in spite of this comparatively low ration was in prime physical condition. In the words of Dr. Anderson, the Director of the Gymnasium, "the case is unusual, and I am surprised that Mr. Fletcher can do the work of trained athletes and not give marked evidences of over-exertion. ... Mr. Fletcher performs this work with greater ease and with fewer noticeable but results than any man of his age and condition I have ever worked with." * It is not our purpose here to discuss how far these results are due to insalivation, or the more thorough mastication of food. The main point for us is that we have here a striking illustration of the establishment of nitrogen

* For a fuller account of this study, see Chittenden, l'hysiological Economy in Nutrition. Popular Science Monthly, June, 1903. 
equilibrium on a low proteid diet and great physiological economy as shown by the low fuel value of the food consumed, coupled with remarkable physical strength and endurance.

With data such as these before us we see the possible importance of a fuller and more exact knowledge of true dietary standarls. We find here questions suggested, the answers to which are of primary importance in our understanding of the nutritive processes of the body; greater ease in the maintenance of health, increased power of resistance to disease germs, duration of life increased beyond the present average, greater physiological economy and greater efficiency, increased mental and physical vigor with less expenditure of energy on the part of the body. All these questions rise before us in connection with the possibility of maintaining equilibrium on a lowered intake of food, especially nitrogenous equilibrium, with a diminished consumption of proteid or albuminous food. Is it not possible that the accepted dietary standards are altogether too high?

It is of course understood that there can be no fixed dietary standard suitable for all people, ages, and conditions of life. Dietary standards at the best are merely an approximate indication of the amounts of food needed by the body, but these needs are obviously changeable, varying with the degree of activity of the body, especially the amount of physical work performed, to say nothing of differences in body-weight, sex, etc. Further, it is doubtless true that there is what may be called a specific coefficient of nutrition characteristic of the individual, a kind of personal idiosyncrasy which exercises in some degree a modifying influence upon the character and extent of the changes going on in the body. Still, with due recognition of the general influence exerted by these various factors the main question remains, viz., how far the usually accepted standards of diet are correct; or, in other words, is there any real scientific ground for the assumption that the average individual doing an average amount of work requires any such quantity of proteid, or of total nutrients, as the ordinary dietetic standards call for? Cannot all the real phy- 
siological needs of the body be met by a greatly reduced proteid intake, with establishment of continued nitrogenous equilibrium on a far smaller amount of proteid food than the ordinary dietary standards call for, and with actual gain to the body?

Just here we may emphasize why prominence is given to the establishment of nitrogenous equilibrium, and why the proteid intake assumes a greater importance than the daily amounts of fat and carbohydrate consumed. Fats and carbohydrates when oxidized in the body are ultimately burned to simple gaseous products, viz., carbonic acid and water. Hence, these waste products are easily and quickly eliminated and cannot exercise much deleterious influence even when formed in excess. To be sure, there is waste of energy in digesting, absorbing, and oxidizing the fats and carbohydrates when they are taken in excessive amounts. Once introduced into the alimentary canal they must be digested, otherwise they will clog the intestine or undergo fermentation, and so cause trouble. Further, when absorbed they may be transformed into fat and deposited in the various tissues and organs of the body; a process desirable up to a certain point, but undesirable when such accumulation renders the body gross and unwieldy. With proteid foods, on the other hand, the story is quite different. 'These substances, when oxidized, yield a row of crystalline nitrogenous products which ultimately pass out of the body through the kidneys. Prior to their excretion, however, these products - frequently spoken of as toxins - float about through the body and may exercise more or less of a deleterious influence upon the system, or, being temporarily deposited, may exert some specific or local influence that calls for their speedy removal. Hence, the importance of restricting the production of these bodies to the minimal amount, owing to their possible physiological effect and the part they are liable to play in the causation of many diseased conditions. Further, the elimination of excessive amounts of these crystalline nitrogenous bodies through the kidneys places upon these organs an unnecessary burden which 
is liable to endanger their integrity and possibly result in serious injury, to say nothing of an early impairment of function.

The present experiments were undertaken to throw light upon this broad question of a possible physiological economy in nutrition, and with special reference to the minimal proteid requirement of the healthy man under ordinary conditions of life. The writer as a student of physiology has always maintained that man is disposed to eat far more than the needs of the body require, but his active interest in this problem was aroused especially by his observations of Mr. Fletcher and the marked physiological economy the latter was able to practice, not only without detriment, but apparently with great gain to the body as regards strength, vigor, and endurance, coupled with an apparent resistance to disease. While Mr. Fletcher and Dr. Van Someren would doubtless emphasize the importance of insalivation as a means of controlling the appetite and thereby regulating the consumption of food in harmony with the real needs of the body, it is of primary importance for the physiologist and for mankind to know definitely how far it is possible to reduce the intake of food with perfect safety and without loss of that strength, mental and physical, vigor, and endurance which are characteristic of good health. Further, it is equally plain that if there is possible gain to the body from a practice of physiological economy in diet, we should know how far this can be accomplished by simple restriction in the amount of food without complicating the problem by other factors.

In planning the conduct of this series of experiments the writer has clearly recognized that, while it may be possible, as previous experiments have shown, to maintain body equilibrium and nitrogen equilibrium on a low proteid diet for a brief period, this fact does not, as Munk has previously pointed out, by any means establish the view that such a diet will prove efficient in maintaining equilibrium for a long period, or that bodily strength and vigor can be kept up and the proper resistance to disease secured. Hence, it seemed 
necessary to so arrange the experiments that they should continue not for a few days or weeks merely, but through months and years. Further, it is very questionable whether the restricted diet (restricted in variety) frequently made use of for convenience in ordinary metabolism experiments is well adapted for bringing out the best results. Hence, it was decided to avoid so far as possible any monotony of diet, giving due rec ognition to the psychical influences liable to affect secretion, digestion, etc., so admirably worked out by Pawlow in his classical experiments on these subjects; influences which are unquestionably of great importance in controlling and modifying, in some measure at least, the nutritive changes in the body. Again, it is evident that to have experiments of this character broadly useful, they must be tried upon a large number of people and under different conditions of life, in order to avoid so far as possible the influence of personal idiosyncrasy and thereby escape misleading conclusions.

The experiments have been conducted with three distinct types or classes of individuals :

1st. A group of five men of varying ages, connected with the University as professors and instructors; men who while leading active lives have not engaged in very active muscular work. They were selected as representatives of the mental worker rather than the physical worker, although several of them in the performance of their daily duties had to be on their feet in the laboratory a good portion of the day.

2d. A detail of thirteen men, volunteers from the Hospital Corps of the United States Army and representatives of the moderate worker; men who for a period of six months took each week day a vigorous amount of systematic exercise in the gymnasium, in addition to the routine work connected with their daily life as members of the United States Hospital Corps. These men were of different nationalities, ages, and temperaments.

3d. A group of eight young men, students in the University, all thoroughly trained athletes, and some of them with exceptional records in athletic events. 


\section{EXPERIMENTS WITH PROFESSIONAL MEN.}

Before proceding with a detailed account of the experimental work, it may be well again to emphasize that what is especially desired is to ascertain how far, if any, the intake of proteid food can be diminished without detriment to the body, $i$.e., with maintenance of nitrogen and body equilibrium and without impairment of bodily and mental vigor. Further, if a lower proteid standard than that generally adopted can be established, it is desirable to ascertain whether it can be maintained indefinitely, or for a long period of time, without loss of strength and vigor. Obviously, it is of primary importance that we should know quite definitely what the minimal proteid requirement of the healthy man per kilo of body-weight really is, and the experimental work about to be detailed has aimed especially to determine whether it is possible to materially lower the amount of daily proteid food, without detriment to the bodily health and with maintenance of physical and mental vigor.

The writer, fully impressed with his responsibility in the conduct of an experiment of this kind, began with himself in November, 1902. At that time he weighed 65 kilos, was nearly 47 years of age, and accustomed to eating daily an amount of food approximately equal to the so-called dietary standards. Recognizing that the habits of a lifetime should not be too suddenly changed, a gradual reduction was made in the amount of proteid or albuminous food taken each day. In the writer's case, this resulted in the course of a month or two in the complete abolition of breakfast, except for a small cup of coffee. A light lunch was taken at 1.30 P. Mr., followed by a heavier dinner at 6.30 P. M. Occasionally, however, the heartier meal was taken at noontime, as the appetite suggested. It should be added that the total intake of food was gradually diminished, as well as the proteid constituents. There was no change, however, to a vegetable diet, but a simple introduction of physiological economy. Still, there was and is now a distinct tendency toward the exclusion of meat in some meas- 
ure, the appetite not calling for this form of food in the same degree as formerly. At first, this change to a smaller amount of food daily was attended with some discomfort, but this soon passed away, and the writer's interest in the subject was augmented by the discovery that he was unquestionably in improved physical condition. A rheumatic trouble in the knee joint, which had persisted for a year and a half and which only partially responded to treatment, entirely disappeared (and has never recurred since). Minor troubles, such as "sick headaches" and bilious attacks, no longer appeared periodically as before. There was greater appreciation of such food as was eaten; a keener appetite and a more acute taste seemed to be developed, with a more thorough liking for simple foods. By June, 1903, the body-weight had fallen to 58 kilos.

During the summer the same simple diet was persisted in a small cup of coffee for breakfast, a fairly substantial dinner at midday and a light supper at night. Two months were spent in Maine at an inland fishing resort, and during a part of this time a guide was dispensed with and the boat rowed by the writer frequently six to ten miles in a forenoon, sometimes against head winds (without breakfast), and with much greater freedom from fatigue and muscular soreness than in previous years on a fuller dietary. The test of endurance and fitness for physical work which the writer thus carried out "on an empty stomach" tended to strengthen the opinion that it is a mistake to assume the necessity for a hearty meal because heavy work is about to be done. It is certainly far more rational from a physiological standpoint to leave the hearty meal until the day's work is accomplished. We seemingly forget that the energy of nuscular contraction comes not from the food-stuffs present at the time in the stomach and intestinal tract, but rather from the absorbed material stored up in the muscles and which was digested and absorbed a day or two before. Further, it is to be remembered that the very process of digestion draws to the gastro-intestinal tract a large supply of blood, and that a large amount of energy is needed for the processes of secretion, digestion, absorption, and 
peristalsis, which are of necessity incited by the presence of food in the stomach and intestine, thereby actually diminishing the amount of energy available at the place where it is most needed. Why, then, draw upon the resources of the body just at a time, or slightly prior to the time, when the work we desire to perform, either muscular or mental, calls for a copious blood supply in muscle or brain, and when all available energy is needed for the task that is to be accomplished?

We are too wont to compare the working body with a machine, the boiler, engine, etc., overlooking the fact that the animal mechanism differs from the machine in at least one important respect. When we desire to set machinery in operation we must get up steam, and so a fire is started under the boiler and steam is generated in proportion as fuel is burned. The source of the energy made use of in moving the machinery is the extraneous combustible material introduced into the fire- $b \wedge x$, but the energy of muscular contraction, for example, comes not from the oxidizable food material in the stomach, but from the material of the muscle itself. In other words, in the animal body it is a part of the tissue framework, or material that is closely incorporated with the framework, that is burned up, and the ability to endure continued muscular strain depends upon the nutritive condition of the muscles involved, and not upon the amount of food contained in, or introduced into, the stomach. All physiologists will, I think, acknowledge the soundness of this reasoning, but how few of us apply the principle in practice. It is perfectly logical to begin the work of the day with a comparatively empty stomach, - after we have once freed ourselves from the habit of a hearty breakfast, - and in the writer's experience both mental and physical work have become the easier from this change of habit. The muscle and the brain are given opportunity to repair the waste they have undergone, by the taking of food at times when the digestive processes will not draw upon the energy that in activity is needed elsewhere.

Further, it is easy to understand why on a restricted diet, especially of proteid foods, there should be a diminished sense 
of fatigue in connection with vigorous or continued muscular work, and why at the same time there should be an increased power of endurance, with actual increase of strength. With a diminished intake of proteid food there is a decreased formation of crystalline nitrogenous waste products, such as uric acid and the purin bases, to say nothing of other bodies less fully known, which circulating through the system are undoubtedly responsible, in part at least, for what we term fatigue. We need not consider here whether the sense of fatigue is due to an action of these substances upon the muscles themselves, upon the motor nerves or their endplates, or upon the central nervous system; it is enough for the present purpose to emphasize the probable results of their presence in undue amount. Lastly, we may emphasize what is pretty clearly evident to-day, viz., that the energy of muscular contraction comes preferably from the oxidation, not of the nitrogenous or proteid constituents of the muscles, but of the non-nitrogenous components of the tissue; another reason why excess of proteid food may be advantageously avoided. Moreover, proteid food stimulates body metabolism in general, and hence undue amounts of proteid in the diet augment unnecessarily the metabolism or combustion of the non-nitrogenous material of the muscle, thereby destroying what would otherwise be preserved as a source of energy in muscular contraction, when the muscles are called upon for the performance of their daily functions.

On the writer's return to New Haven in the fall of 1903, he was surprised to find that his body-weight was practically the same as early in July. In the period between November, 1902, and July, 1903, the body had lost 8 kilos under the gradual change of diet, but from July to October, 1903, the weight had apparently remained stationary, from which it might fairly be assumed that the body had finally adjusted itself to the new conditions.

What now was the condition of the body as regards nitrogen metabolism? To answer this question the entire twentyfour hours' urine was collected practically every day, from 
October 13,1903 , to June 28, 1904, representing a period of nearly nine months. This daily output through the kidneys was analyzed each day with special reference to the total nitrogen, ${ }^{*}$ as a measure of the amount of proteid material metabolized. Total volume of the urine, specific gravity, uric acid, phosphoric acid, indican, and other points were also considered, the more important results being indicated in the following tables.

* All figures for nitrogen throughout the book, whether referring to food, urine, or fæces, were obtained by exact chemical analysis, using the Kjeldahl-Gunning method.

Uric acid was determined by the method of Folin, i.e., precipitation of the urine with ammonium sulphate, etc., and titration with potassium permanganate.

Plosphoric acid was estimated by titration with a standard uranium solution, using potassium ferrocyanide as an indicator.

At times, as will be seen from the tables, nitrogen, uric acid, etc., were not determined in each day's nrine. In such cases, an aliquot part of each twentyfour hours' urine was taken and the analyses made with the mixed samples for the given period, the figures thus obtained showing the average daily composition for that period. 
CHITTENDEN.

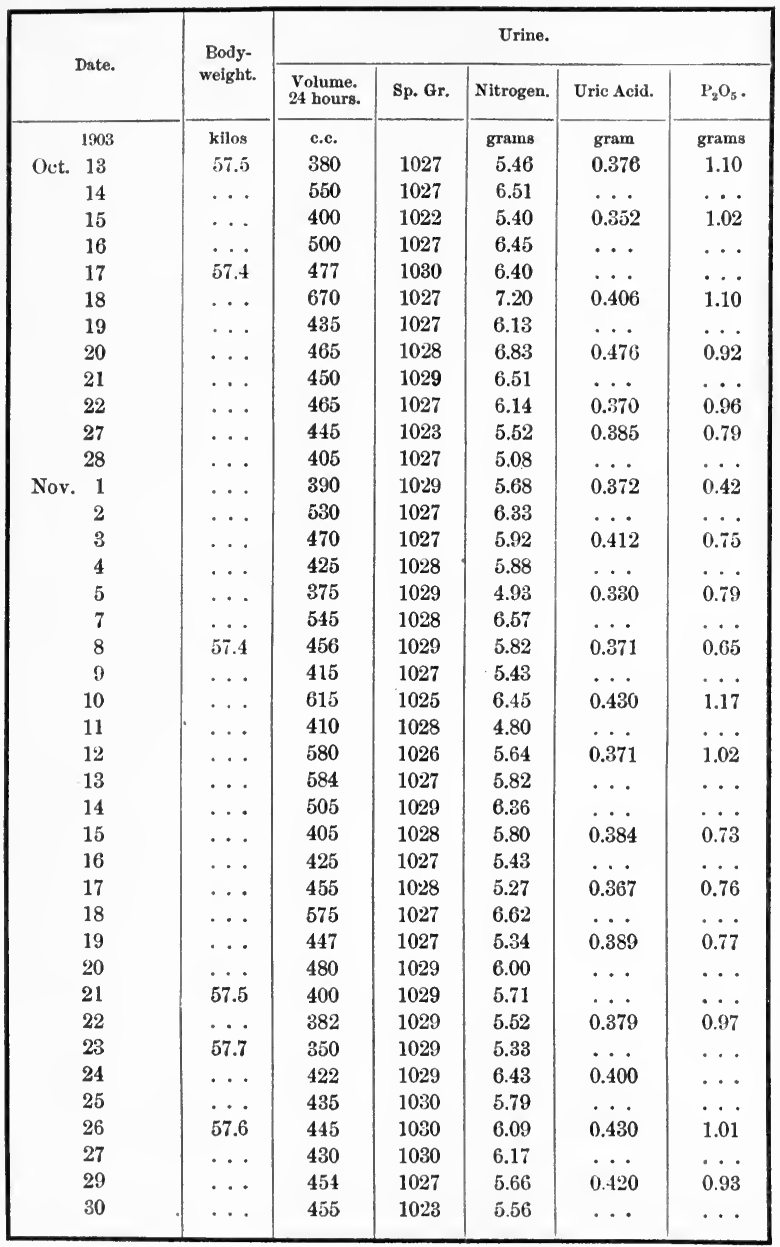


CHITTENDEN.

\begin{tabular}{|c|c|c|c|c|c|c|c|}
\hline \multirow{2}{*}{\multicolumn{2}{|c|}{ Date. }} & \multirow{2}{*}{$\begin{array}{l}\text { Body- } \\
\text { weight. }\end{array}$} & \multicolumn{5}{|c|}{ Urine. } \\
\hline & & & $\begin{array}{l}\text { Volume. } \\
24 \text { hours. }\end{array}$ & Sp. Gr. & Nitrogen. & Uric Acid. & $\mathrm{P}_{2} \mathrm{O}_{5}$ \\
\hline & 1903 & kilos & c.c. & & grams & gram & grams \\
\hline Dec. & 1 & $\ldots$ & 420 & 1028 & 5.31 & 0.450 & 0.92 \\
\hline & 2 & $\ldots$ & 465 & 1027 & 6.17 & $\ldots$ & $\ldots$ \\
\hline & 3 & $\cdots$ & 430 & 1027 & 5.34 & 0.350 & 0.82 \\
\hline & 4 & $\ldots$ & 365 & 1029 & 4.77 & $\ldots$ & $\ldots$ \\
\hline & 5 & $\ldots$ & 430 & 1030 & 5.83 & $\ldots$ & . . \\
\hline & 6 & $\ldots$ & 515 & 1028 & 5.90 & 0.393 & 1.08 \\
\hline & 7 & $\ldots$ & 400 & 1028 & 5.57 & $\ldots$ & $\ldots$ \\
\hline & 8 & $\ldots$ & 390 & 1028 & 4.99 & 0.328 & 1.02 \\
\hline & 9 & $\ldots$ & 405 & 1030 & 5.17 & $\ldots$ & $\ldots$ \\
\hline & 10 & $5 \% .6$ & 370 & 1026 & 4.64 & 0.308 & 0.90 \\
\hline & 11 & $\ldots$ & 327 & 1080 & 4.65 & 0.325 & 1.11 \\
\hline & 12 & $\ldots$ & 390 & 1027 & 5.16 & 0.346 & 1.01 \\
\hline & 13 & $\ldots$ & 429 & 1029 & 5.66 & $\ldots$ & $\ldots$ \\
\hline & 14 & $\ldots$ & 360 & 1030 & 4.81 & . . & $\ldots$ \\
\hline & 15 & $\ldots$ & 295 & 1029 & 4.32 & 0.291 & 0.82 \\
\hline & 16 & $\ldots$ & 445 & 1029 & 6.27 & $\ldots$ & $\ldots$ \\
\hline & 17 & $\ldots$ & 390 & 1032 & 5.59 & 0.358 & 0.73 \\
\hline & 18 & $\cdots$ & 420 & 1030 & 5.62 & $\ldots$ & $\cdots$ \\
\hline & 19 & $\ldots$ & 415 & 1027 & 5.03 & $\cdots$ & $\cdots$ \\
\hline & 20 & 57.5 & 390 & 1030 & 5.71 & 0.402 & 0.78 \\
\hline & 21 & $\ldots$ & 360 & 1023 & 4.25 & $\ldots$ & $\cdots$ \\
\hline & 22 & $\ldots$ & 360 & 1030 & 5.13 & 0.342 & 0.79 \\
\hline & 23 & $\ldots$ & 400 & 1031 & 5.08 & $\ldots$ & $\cdots$ \\
\hline & 24 & $\ldots$ & 435 & 1030 & 6.44 & $\ldots$ & $\ldots$ \\
\hline & 25 & $\ldots$ & 450 & 1029 & 5.13 & 0.329 & 0.77 \\
\hline & 26 & $\ldots$ & 465 & $\ldots$ & 5.55 & $\ldots$ & $\ldots$ \\
\hline & 27 & $\ldots$ & 470 & $\cdots$ & 5.53 & $\cdots$ & $\cdots$ \\
\hline & 28 & $\ldots$ & 585 & $\ldots$ & 8.18 & $\cdots$ & $\cdots$ \\
\hline & 29 & $\ldots$ & 535 & $\cdots$ & 7.67 & $\ldots$ & $\cdots$ \\
\hline & 30 & $\ldots$ & 656 & $\ldots$ & 9.68 & $\ldots$ & $\cdots$ \\
\hline & 31 & 57.6 & 490 & 1031 & 7.61 & 0.455 & 0.92 \\
\hline & 904 & & & & & & \\
\hline Jan. & 1 & $\cdots$ & 415 & 1030 & 6.41 & $\cdots$ & $\cdots$ \\
\hline & 2 & $\cdots$ & 490 & 1031 & 6.56 & $\ldots$ & $\ldots$ \\
\hline & 3 & ... & 460 & 1030 & 5.91 & 0.319 & 0.79 \\
\hline & 4 & 58.1 & 430 & 1030 & 5.72 & $\ldots$ & $\ldots$ \\
\hline & 5 & $\ldots$ & 570 & $10 \div 8$ & 6.36 & 0.402 & $\cdots$ \\
\hline & 6 & $\ldots$ & 445 & 1028 & 5.68 & $\ldots$ & $\ldots$ \\
\hline & 7 & $\ldots$ & 510 & 1028 & 5.91 & 0.367 & 0.99 \\
\hline & 8 & $\ldots$ & 420 & 1028 & 5.37 & . . & $\ldots$ \\
\hline
\end{tabular}


CHITTENDEN.

\begin{tabular}{|c|c|c|c|c|c|c|c|}
\hline & \multirow{2}{*}{ Date. } & \multirow{2}{*}{$\begin{array}{c}\text { Body- } \\
\text { weight. }\end{array}$} & \multicolumn{5}{|c|}{ Urine. } \\
\hline & & & $\begin{array}{l}\text { Volume. } \\
24 \text { hours. }\end{array}$ & Sp. Gr. & Nitrogen. & Uric Acid. & $\mathrm{P}_{2} \mathrm{O}_{5}$. \\
\hline & 1904 & kilos & c.c. & & grams & gram & gram \\
\hline \multirow{23}{*}{ Jan. } & 9 & $\cdots$ & 650 & 1027 & 7.29 & $\cdots$ & $\cdots$ \\
\hline & 10 & $\cdots$ & 635 & 1024 & 6.32 & 0.414 & 0.99 \\
\hline & 11 & $\ldots$ & 410 & 1028 & 4.87 & $\ldots$ & $\cdots$ \\
\hline & 12 & $\ldots$ & 450 & 1027 & 6.48 & $\ldots$ & $\cdots$ \\
\hline & 13 & $\ldots$ & 410 & 1027 & 5.84 & 0.435 & $\cdots$ \\
\hline & 14 & $\ldots$ & 532 & 1028 & 6.22 & 0.502 & $\cdots$ \\
\hline & 15 & $\ldots$ & 530 & 1028 & 5.98 & $\ldots$ & $\cdots$ \\
\hline & 16 & $\ldots$ & 515 & 1030 & 6.18 & $\ldots$ & $\cdots$ \\
\hline & 17 & $\ldots$ & 537 & 1030 & 6.73 & 0.429 & $\ldots$ \\
\hline & 18 & 57.8 & 395 & 1029 & 5.09 & $\cdots$ & $\cdots$ \\
\hline & 19 & $\ldots$ & 450 & 1030 & 5.72 & 0.427 & $\therefore$ \\
\hline & 20 & $\cdots$ & 420 & 1026 & 4.76 & $\cdots$ & $\cdots$ \\
\hline & 21 & $\ldots$ & 410 & $10: 29$ & 5.26 & 0.401 & $\cdots$ \\
\hline & 22 & . & $485^{\circ}$ & 1029 & 5.41 & $\cdots$ & $\cdots$ \\
\hline & 23 & . & 440 & 1031 & 5.07 & $\cdots$ & $\cdots$ \\
\hline & 24 & $\ldots$ & 485 & 1029 & 5.61 & 0.407 & $\ldots$ \\
\hline & 25 & $\ldots$ & 545 & 1027 & 6.18 & $\ldots$ & $\cdots$ \\
\hline & 26 & $\cdots$ & 485 & 1028 & 6.69 & 0.440 & $\cdots$ \\
\hline & 27 & $\ldots$ & 435 & 1028 & 5.64 & . & $\cdots$ \\
\hline & 28 & $\ldots$ & 490 & 1029 & 6.18 & 0.423 & $\cdots$ \\
\hline & 29 & $\ldots$ & 450 & 1029 & 5.68 & $\ldots$ & $\cdots$ \\
\hline & 30 & $\ldots$ & 475 & $\cdots$ & 5.59 & 0.376 & $\ldots$ \\
\hline & 31 & $\ldots$ & 490 & $\cdots$ & 6.61 & $\therefore$ & $\cdots$ \\
\hline \multirow[t]{17}{*}{ Feb. } & 1 & $\cdots$ & 490 & 1030 & 6.47 & $\cdots$ & $\cdots$ \\
\hline & 2 & 57.5 & 400 & 1031 & 6.12 & 0.219 & $\cdots$ \\
\hline & 3 & $\cdots$ & 415 & 1030 & 5.85 & $\cdots$ & $\cdots$ \\
\hline & 4 & $\ldots$ & 545 & 1027 & 6.77 & 0.327 & $\cdots$ \\
\hline & 5 & $\cdots$ & 450 & 1030 & 5.64 & $\ldots$ & $\cdots$ \\
\hline & 6 & $\cdots$ & 485 & 1027 & 6.01 & $\cdots$ & $\cdots$ \\
\hline & 7 & $\cdots$ & 450 & 1026 & 5.62 & $\cdots$ & $\cdots$ \\
\hline & 8 & 57.4 & 415 & 1027 & 5.88 & $\cdots$ & $\cdots$ \\
\hline & 9 & $\ldots$ & 540 & 1026 & 6.67 & 0.449 & $\ldots$ \\
\hline & 10 & $\cdots$ & 410 & 1029 & 5.61 & $\cdots$ & $\cdots$ \\
\hline & 11 & $\ldots$ & 600 & 1025 & 6.70 & $\cdots$ & $\cdots$ \\
\hline & 12 & $\ldots$ & 430 & 1029 & 5.57 & 0.437 & $\ldots$ \\
\hline & 13 & $\cdots$ & 415 & 1028 & 5.50 & $\cdots$ & $\cdots$ \\
\hline & 14 & $\cdots$ & 480 & 1028 & 6.42 & 0.497 & . \\
\hline & 15 & $\ldots$ & 395 & 1030 & 4.95 & $\ldots$ & $\ldots$ \\
\hline & 16 & $\cdots$ & 500 & 1029 & 5.97 & 0.364 & . \\
\hline & 17 & $\cdots$ & 450 & 1030 & 5.62 & $\cdots$ & $\cdots$ \\
\hline
\end{tabular}




\section{CHITTENDEN.}

\begin{tabular}{|c|c|c|c|c|c|c|}
\hline \multirow{2}{*}{ Date. } & \multirow{2}{*}{$\begin{array}{c}\text { Body- } \\
\text { weight. }\end{array}$} & \multicolumn{5}{|c|}{ Urine. } \\
\hline & & $\begin{array}{l}\text { Volume. } \\
24 \text { hours. }\end{array}$ & Sp. Gr. & Nitrogen. & Uric Acid. & $\mathrm{P}_{2} \mathrm{O}_{5}$ \\
\hline 1904 & kilos & c.c. & & grams & gram & grams \\
\hline Feb. 18 & 57.3 & 430 & 1080 & 5.86 & 0.279 & $\cdots$ \\
\hline 19 & $\cdots$ & 450 & 1029 & 6.21 & $\cdots$ & $\cdots$ \\
\hline 20 & $\ldots$ & 455 & 1027 & 5.46 & $\ldots$ & $\ldots$ \\
\hline 21 & $\ldots$ & 500 & 1027 & 6.16 & 0.424 & $\ldots$ \\
\hline 22 & $\ldots$ & 445 & 1028 & 5.15 & . . & $\ldots$ \\
\hline 23 & $\ldots$ & 455 & 1027 & 5.63 & $\ldots$ & ... \\
\hline 24 & $\ldots$ & 420 & 1028 & 6.27 & $\ldots$ & $\ldots$ \\
\hline 25 & $\ldots$ & 560 & 1027 & 6.28 & 0.403 & $\ldots$ \\
\hline 26 & $\ldots$ & 630 & 1026 & 6.27 & $\ldots$ & $\ldots$ \\
\hline 27 & $\cdots$ & 570 & 1026 & 6.87 & $\ldots$ & $\ldots$ \\
\hline 28 & $\ldots$ & 515 & 1028 & 6.27 & 0.496 & $\ldots$ \\
\hline 29 & $\ldots$ & 450 & 1030 & 5.43 & $\ldots$ & $\ldots$ \\
\hline Mar. 1 & $\ldots$ & 450 & 1027 & 6.02 & $\ldots$ & $\ldots$ \\
\hline 2 & $\ldots$ & 445 & 1029 & 5.15 & $\ldots$ & $\ldots$ \\
\hline 3 & $\cdots$ & 590 & 1028 & 6.30 & . & ... \\
\hline 4 & $\ldots$ & 415 & 1029 & 5.40 & $\ldots$ & $\ldots$ \\
\hline 5 & 57.5 & 425 & 1027 & 5.48 & . . & $\ldots$ \\
\hline 6 & $\ldots$ & 548 & 1025 & 5.92 & 0.370 & $\ldots$ \\
\hline 7 & $\ldots$ & 400 & 1029 & 4.68 & $\ldots$ & $\ldots$ \\
\hline 8 & $\ldots$ & 530 & 1028 & 5.77 & $\ldots$ & $\ldots$ \\
\hline 9 & $\ldots$ & 560 & 1028 & 5.84 & $\ldots$ & $\ldots$ \\
\hline 10 & $\ldots$ & 560 & 1028 & 5.64 & $\ldots$ & $\ldots$ \\
\hline 11 & $\ldots$ & 495 & 1028 & 5.79 & $\ldots$ & $\ldots$ \\
\hline 12 & $\ldots$ & 515 & 1021 & 6.80 & $\ldots$ & $\ldots$ \\
\hline 13 & . . & 520 & 1029 & 6.43 & 0.370 & $\ldots$ \\
\hline 14 & $\ldots$ & 600 & 1025 & 6.12 & $\ldots$ & $\ldots$ \\
\hline 15 & $\ldots$ & 520 & 1026 & 5.87 & $\ldots$ & $\ldots$ \\
\hline 16 & 57.5 & 525 & 1026 & 5.13 & $\ldots$ & $\ldots$ \\
\hline 17 & $\ldots$ & 490 & 1026 & 4.97 & $\ldots$ & $\ldots$ \\
\hline 18 & $\ldots$ & 450 & 1027 & 5.08 & $\ldots$ & $\ldots$ \\
\hline 19 & $\cdots$ & 500 & 1024 & 5.85 & $\ldots$ & $\ldots$ \\
\hline .20 & $\ldots$ & 500 & 1022 & 5.91 & & \\
\hline 21 & 57.4 & 430 & 1025 & 5.52 & & \\
\hline 22 & $\ldots$ & 458 & 1033 & 5.94 & & \\
\hline 23 & 57.2 & 400 & 1029 & 5.61 & 0.321 & 1.20 \\
\hline 24 & 57.3 & 365 & 1029 & 4.31 & daily & daily \\
\hline 25 & $\cdots$ & 420 & 1029 & 5.39 & average & average. \\
\hline 26 & 57.5 & 435 & 1027 & 5.85 & $\cdots$ & $\ldots$ \\
\hline 27 & $\ldots$ & 595 & 1026 & 6.33 & . . & $\ldots$ \\
\hline 28 & $\ldots$ & 545 & 1027 & 6.00 & $\ldots$ & $\ldots$ \\
\hline
\end{tabular}


CHITTENDEN.

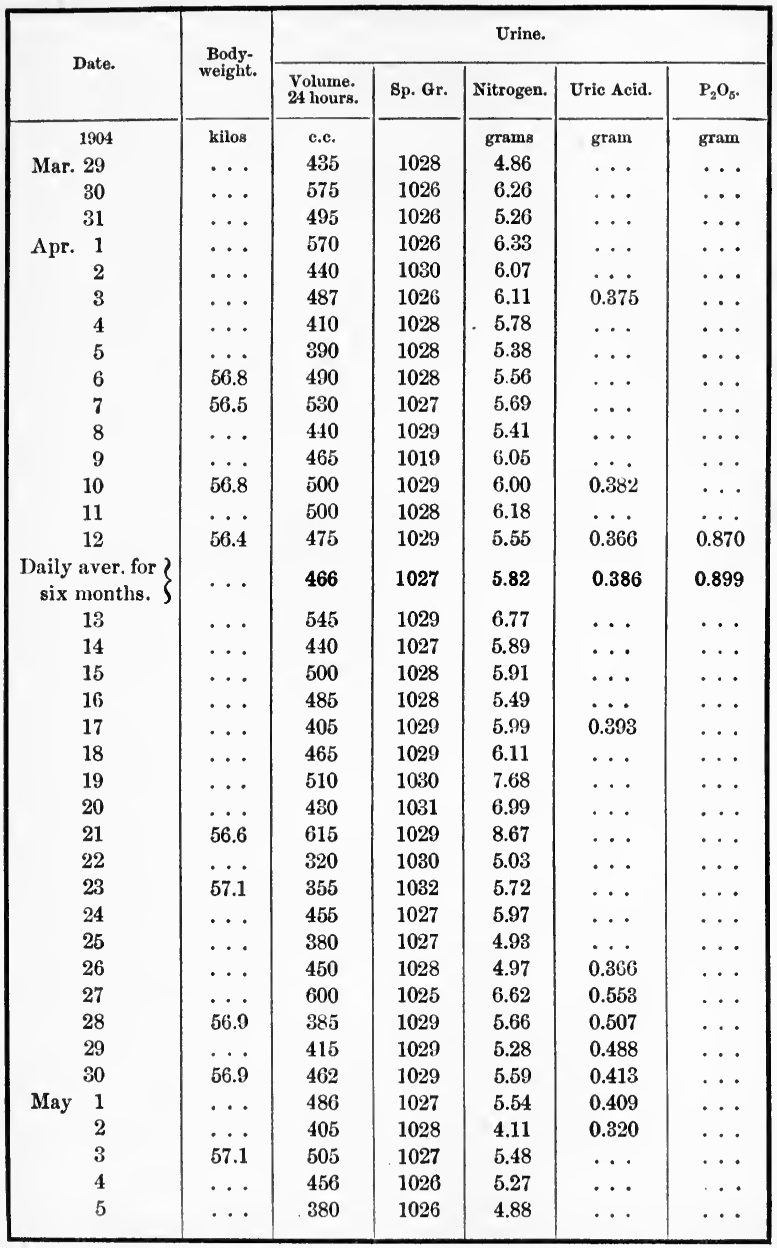




\section{CHITTENDEN.}

\begin{tabular}{|c|c|c|c|c|c|c|c|}
\hline \multirow{2}{*}{\multicolumn{2}{|c|}{ Date. }} & \multirow{2}{*}{$\begin{array}{c}\text { Body- } \\
\text { weight. }\end{array}$} & \multicolumn{5}{|c|}{ Urine. } \\
\hline & & & $\begin{array}{l}\text { Volume. } \\
24 \text { hours. }\end{array}$ & Sp. Gr. & Nitrogen. & Urie Acid. & $\mathrm{P}_{2} \mathrm{O}_{5}$. \\
\hline & 1904 & kilos & c.c. & & grams & gram & gram \\
\hline May & 6 & $\ldots$ & 530 & 1027 & 6.30 & $\cdots$ & $\cdots$ \\
\hline & 7 & $\ldots$ & 470 & 1024 & 5.44 & $\cdots$ & $\cdots$ \\
\hline & 8 & 57.6 & 460 & 1027 & 5.07 & $\cdots$ & $\ldots$ \\
\hline & 9 & $\ldots$ & 460 & 1026 & 4.28 & $\cdots$ & $\cdots$ \\
\hline & 10 & 57.4 & 493 & 1028 & 5.26 & $\cdots$ & $\ldots$ \\
\hline & 11 & $\cdots$ & 415 & 1029 & 4.61 & $\cdots$ & $\cdots$ \\
\hline & 12 & $\ldots$ & 530 & 1029 & 5.98 & $\cdots$ & $\cdots$ \\
\hline & 13 & $\cdots$ & 415 & 1031 & 4.72 & $\cdots$ & $\cdots$ \\
\hline & 14 & 57.2 & 405 & 1031 & 4.98 & 0.468 & $\cdots$ \\
\hline & 15 & $\cdots$ & 500 & 1029 & 5.31 & $\cdots$ & $\cdots$ \\
\hline & 16 & . & 505 & 1027 & 5.03 & $\cdots$ & $\cdots$ \\
\hline & 17 & $\cdots$ & 650 & 1020 & 5.69 & $\cdots$ & $\cdots$ \\
\hline & 18 & $\cdots$ & 550 & 1027 & 5.81 & $\cdots$ & $\cdots$ \\
\hline & 19 & $\cdots$ & 560 & 1027 & 6.05 & $\cdots$ & $\cdots$ \\
\hline & 20 & $\cdots$ & 615 & 1027 & 6.64 & $\cdots$ & $\cdots$ \\
\hline & 21 & 56.9 & 380 & 1032 & 5.20 & 0421 & $\cdots$ \\
\hline & 22 & $\cdots$ & 475 & 1028 & 5.73 & $\cdots$ & $\cdots$ \\
\hline & 23 & $\cdots$ & 378 & 1028 & 4.60 & $\ldots$ & $\cdots$ \\
\hline & 24 & . & 383 & 1029 & 4.48 & $\cdots$ & $\cdots$ \\
\hline & 25 & $\cdots$ & 535 & 1025 & 5.14 & $\cdots$ & $\cdots$ \\
\hline & 26 & 56.9 & 355 & 1028 & 4.37 & $\cdots$ & $\cdots$ \\
\hline & 27 & $\ldots$ & 435 & 1026 & 4.93 & $\cdots$ & $\cdots$ \\
\hline & 28 & 57.5 & 555 & 1028 & 5.99 & 0.397 & $\cdots$ \\
\hline & 29 & 57.7 & 565 & 1027 & 6.27 & $\cdots$ & $\cdots$ \\
\hline & 30 & $\cdots$ & 700 & 1020 & 5.50 & $\cdots$ & $\cdots$ \\
\hline & 31 & $\cdots$ & 500 & 1025 & 5.13 & $\cdots$ & $\cdots$ \\
\hline June & 1 & $\cdots$ & 630 & 1023 & 5.41 & $\cdots$ & $\cdots$ \\
\hline & 2 & $\cdots$ & 510 & 1020 & 4.16 & $\cdots$ & $\cdots$ \\
\hline & 3 & $\cdots$ & 530 & 1023 & 5.25 & $\cdots$ & $\ldots$ \\
\hline & 4 & 57.6 & 390 & 1029 & 5.25 & $\cdots$ & $\cdots$ \\
\hline & 5 & $\cdots$ & 400 & 1025 & 4.87 & $\cdots$ & $\cdots$ \\
\hline & 6 & $\cdots$ & 430 & 1027 & 5.16 & $\cdots$ & $\cdots$ \\
\hline & 7 & $\ldots$ & 480 & 1028 & 5.15 & $\ldots$ & $\cdots$ \\
\hline & 8 & $\ldots$ & 410 & 1027 & 4.95 & $\cdots$ & $\ldots$ \\
\hline & 9 & $\ldots$ & 420 & 1026 & 4.51 & $\cdots$ & $\cdots$ \\
\hline & 10 & $\cdots$ & 395 & 1026 & 4.27 & $\cdots$ & $\ldots$ \\
\hline & 11 & 57.5 & 510 & 1030 & 5.91 & $\ldots$ & $\ldots$ \\
\hline & 12 & $\cdots$ & 530 & 1027 & 5.95 & $\cdots$ & $\cdots$ \\
\hline & 13 & 57.6 & 485 & 1027 & 5.35 & $\cdots$ & $\ldots$ \\
\hline & 14 & $\cdots$ & 470 & 1030 & 5.16 & $\ldots$ & $\cdots$ \\
\hline
\end{tabular}


CHITTENDEN.

\begin{tabular}{|c|c|c|c|c|c|c|}
\hline \multirow{2}{*}{ Date. } & \multirow{2}{*}{$\begin{array}{c}\text { Body- } \\
\text { weight. }\end{array}$} & \multicolumn{5}{|c|}{ Urine. } \\
\hline & & $\begin{array}{l}\text { Volume. } \\
24 \text { hours. }\end{array}$ & Sp. Gr. & Nitrogen. & Uric Acid. & $\mathrm{P}_{2} \mathrm{O}_{5}$ \\
\hline 1904 & kilos & c.c. & & grams & gram & grams \\
\hline June 15 & $\ldots$ & 560 & 1024 & 4.91 & $\ldots$ & $\ldots$ \\
\hline 16 & 57.6 & 390 & 1029 & 5.26 & $\cdots$ & $\cdots$ \\
\hline 17 & $\ldots$ & 408 & 1027 & 5.17 & $\ldots$ & $\ldots$ \\
\hline 18 & 57.9 & 412 & 1080 & 5.07 & $\cdots$ & $\cdots$ \\
\hline 19 & $\cdots$ & 458 & 1025 & 5.44 & $\cdots$ & $\cdots$ \\
\hline 20 & 58.0 & 380 & $10: 6$ & 4.49 & $\cdots$ & $\ldots$ \\
\hline 21 & $\ldots$ & 480 & 1023 & 5.04 & $\cdots$ & $\cdots$ \\
\hline ' 22 & 57.8 & 580 & 1025 & 6.16 & $\cdots$ & $\cdots$ \\
\hline 23 & 57.9 & 535 & 1025 & 5.26 & 1 & \\
\hline 24 & 57.6 & 570 & 1024 & 5.30 & & \\
\hline 25 & $\cdots$ & 410 & 1027 & 4.43 & 0.397 & 1.08 \\
\hline 26 & 57.4 & 400 & 1027 & 4.66 & daily & daily \\
\hline 27 & 57.4 & 405 & 1027 & 4.98 & average. & average. \\
\hline $\left.\begin{array}{c}\text { Daily av. from } \\
\text { Oct. } 13,1903\end{array}\right\}$ & $\cdots$ & 468 & 1027 & 5.69 & 0.392 & 0.904 \\
\hline Daily av. from ) & & & & & & \\
\hline $\left.\begin{array}{l}\text { April } 13 \text { to } \\
\text { June 27 }\end{array}\right\}$ & $\cdots$ & $\cdots$ & $\cdots$ & 540 & $\cdots$ & $\cdots$ \\
\hline June 28 & 57.5 & 595 & 1026 & 6.75 & $\cdots$ & $\cdots$ \\
\hline
\end{tabular}

Scrutiny of the tables shows that during this period of nine months the body-weight was practically constant. The daily volume of urine was exceptionally small and fairly regular in amount, the average daily output for the nine months being 468 c.c. It is a noticeable fact that with a diminished intake of proteid food there is far less thirst, and consequently a greatly decreased demand for water or other fluids. Further, in view of the small nitrogenous waste there is no need on the part of the body for any large amount of fluid to flush out the kidneys. The writer has not had a tribid urine during the nine months' period. With heavier eating of nitrogenous fools, an abundant water supply is a necessity to prevent the kidneys from becoming clogged, thereby explaining the frequent beneficial results of the copious libations of mineral 
waters, spring waters, etc., frequently called for after, or with, heavy eating. Obviously, a small volume of urine each day means so much less wear and tear of the delicate mechanism of the kidneys. Somewhat noticeable, in a general way, is the apparent relationship between the volume of the urine and the nitrogen output, in harmony with the well-known diuretic action of urea. The specific gravity of the urine shows variation only within narrow limits, the daily average for the nine months being 1027.

Uric acid is noticeably small in quantity, the average daily output for the nine months' period, based upon the determinations made, being only 0.392 gram.

Chief interest, however, centres around the figures for total nitrogen, since these figures give for each day the extent of the proteid metabolism; i.e., the amount of proteid material broken down in the body each day in connection with the wear and tear of the bodily machinery. To fully grasp the significance of these data, it should be remembered that the prevalent dietary standards are based upon the assumption that the average adult must metabolize each day at least 16 grams of nitrogen. Indeed, that is what actual analysis of the urine indicates in most cases. If now we look carefully through the figures shown in the above tables, covering a period from Oetober 13, 1903, to June 28, 1904, it is seen that the daily nitrogen excretion is far different from 16 grams. Indeed, the figures for nitrogen are exceedingly low, and, moreover, they vary little from day to day. The average daily output of nitrogen through the urine for the entire period of nearly nine months is only 5.699 grams.

For the first six months the average daily excretion amounted to 5.82 grams of nitrogen, while from April 12 to June 28 the average daily exeretion of nitrogen was 5.40 grams, thus showing a slight tendency downward. On the whole, however, there is shown a somewhat remarkable uniformity in the daily excretion. Thus, the average daily excretion for the month of November was 5.79 grams of nitrogen, for the month of March 5.66 grams, thus showing very little 
difference in the output of nitrogen through the kidneys in these two periods, three months apart. In other words, the extent of proteid katabolism was essentially the same throughout the entire nine months, implying that the amount of pro-

- teid food eaten must have been fairly constant, and that the body had adapted itself to this new level of nutrition from which there was no tendency to deviate. There was no weighing out of food and no attempt to follow any specified diet. The greatest possible variety of simple foods was indulged in, and the dictates of the appetite were followed with the single precaution that excess was avoided. In other words, it was temperance in diet, and not prohibition. Yet it is equally true, in the writer's case at least, that the appetite itself unconsciously served as a regulator, since there was, as a rule, no necessity to hold the appetite in check to avoid excess. Doubtless, the writer's knowledge of the general composition of food-stuffs has had some influence in the choice of foods, and thereby aided in bringing about this somewhat remarkable uniformity in the daily output of nitrogen for such a long period of time on an unrestricted diet.

What now do the nitrogen figures show regarding the amount of proteid material metabolized each day? It will be remembered that the Voit standard calls for 118 grams of proteid or albuminous food daily, of which 105 grams should be absorbable, in order to maintain the body in a condition of nitrogen equilibrium, and in a state of physical vigor and general tone. This would mean a daily excretion through the urine of at least 16 grams of nitrogen. The daily output of nitrogen in the case under discussion, however, was 5.699 grams for a period of nearly nine months. This amount of nitrogen excreted through the urine means only 35.6 grams of proteid metabolized, or about one-third the amount called for by the Voit standard, or the standards generally adopted as expressing man's daily requirement of proteid food. But was the body in nitrogenous equilibrium on this small amount of proteid food? Naturally, this question might be answered in the affirmative, on the basis of the constancy in body- 
weight for the period from October to June, but more decisive proof is needed. The question was therefore settled by a careful comparison of the income and output, in which all the food eaten was carefully weighed and analyzed, while the nitrogen of the urine and freces was determined with equal accuracy. The first experiment of this character to be quoted is for the week commencing March 20, a period of six days.

Following are the diets made use of each day, the weights of the various food-stuffs being given in grams. Likewise is shown the nitrogen content of the several food-stuffs for each day, and also a comparison of the nitrogen intake with the output of nitrogen through the urine: 


\section{CHITTENDEN.}

\section{Sunday, March 20, 1904.}

Breakfast, 7.45 А. M. - One cup coffee, i.e., coffee 137.5 grams, cream 30.5 grams, sugar 9 grams.

Dinner, 1.30 P. м. - Stewed chicken 50 grams, mashed potato 131 grams, biscuit 49 grams, butter 13 grams, chocolate pudding 106 grams, one small cup coffee, i.e., coffee 64 grams, sugar 12 grams, cheese crackers 29 grams.

Supper, 6.30 P. м. - Lettuce sandwiches 56 grams, biscuit 35 grams, butter 6 grams, one cup tea, i.e., tea 170 grams, sugar 7 grams, sponge cake 47 grams, sliced oranges 82 grams.

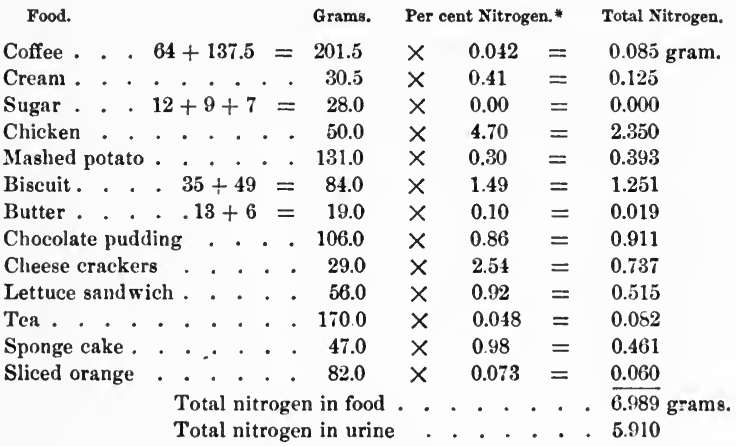

Fuel value of the food . . 1708 calories.

* All foodstuffs were analyzed from large samples, to diminish as much as possible the errors of analysis. Nitrogen was determined by the lijeldalilGunning method, the figures given being the average of closely agreeing duplicate analyses.

While nitrogen was thus determined in every sample of food by direct chemical analysis, the fuel value of the food was calculated mainly by use of the data furnished by the Bulletin issued from the U. S. Department of Agriculture, Office of Experiment Stations. No. 28 


\section{CHITTENDEN.}

\section{Monday, March 21, 1904.}

Breakfast, 7.45 A.M. - Coffee 119 grams, cream 30 grams, sugar 9 grams.

Lunch, 1.30 P. M. - One shredded wheat biscuit 31 grams, cream 116 grams, wheat gems 33 grams, butter 7 grams, tea 185 grams, sugar 10 grams, cream cake 53 grams.

Dinner, 6.30 P.м. - Pea soup 114 grams, lamb chop 24 grams, boiled sweet potato 47 grams, wheat gems 76 grams, butter 13 grams, cream cake 52 grams, coffee 61 grams, sugar 10 grams, cheese crackers 16 grams.

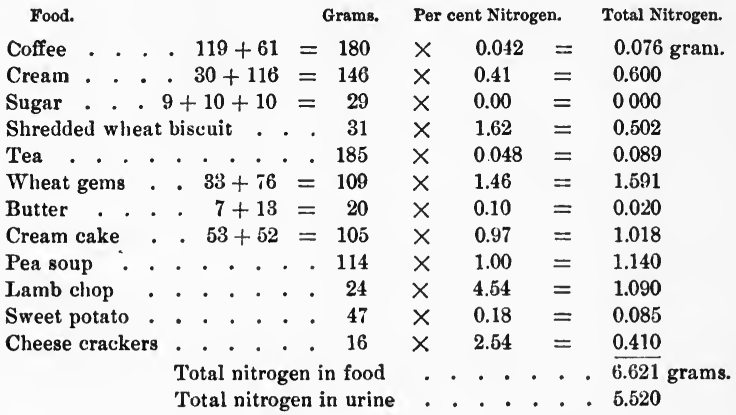

Fuel value of the food . . . 1713 calories. 


\section{CHITTENDEN.}

Tuesday, March $22,1904$.

Breakfast, 7.45 A. M. - Coffee 97 grams, cream 26 grams, sugar 9 grams.

Lunch, 1.30 P. M. - Baked potato 83 grams, fried sausage 26 grams, soda biscuit 39 grams, butter 12 grams, tea 137 grams, sugar 10 grams, cream meringue 59 grams.

Dinner, 6.30 P. M. - Chicken broth 146 grams, bread 52 grams, butter 15 grams, creamed potato 76 grams, custard 76 grams, coffee 50 grams, sugar 11 grams, cheese crackers 10 grams.

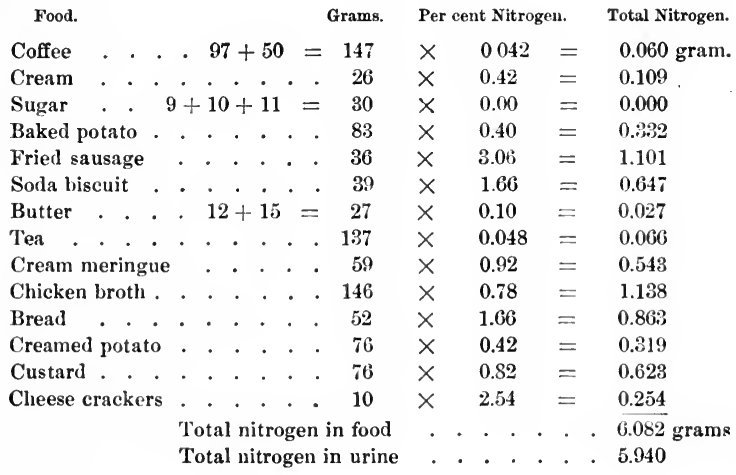

Fuel value of the food . . 1398 calories. 


\section{CHITTENDEN.}

Wednesday, March $23,1904$.

Breakfast, 7.45 A. M. - Coffee 103 grams, cream 30 grams, sugar 10 grams.

Lunch, 1.30 р. м. - Creamed codfish 64 grams, potato balls 54 grams, biscuit 44 grams, butter 22 grams, tea 120 grams, sugar 10 grams, wheat griddle cakes 133 grams, maple syrup 108 grams.

Dinner, 6.30 P. M. - Creamed potato 85 grams, biscuit 53 grams, butter 15 grams, apple-celery-lettuce salad 50 grams, apple pie 127 grams, coffee 67 grams, sugar 8 grams, cheese crackers 17 grams.

Food. Grams. Per cent Nitrogen. Total Nitrogen.

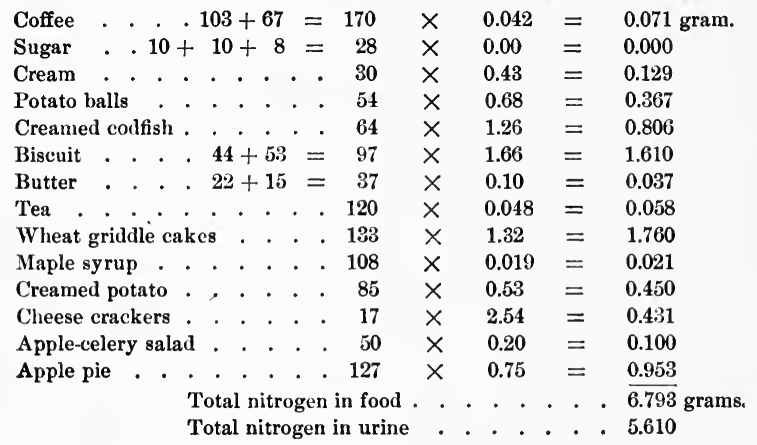

Fuel value of the food . . 1984 calories. 
CHITTENDEN.

\section{Thursday, March $24,1904$.}

Breakfast, 7.45 A. M. - Coffee $10 \mathrm{C}$ grams, cream 25 grams, sugar 8 grams.

Lunch, 1.30 P. M. - Shredded wheat biscuit 29 grams, cream 118 grams, wheat gems 60 grams, butter 8 grams, tea 100 grams, sugar $i$ grams, apple pie 102 grams.

Dinner, 6.30 P. M. - Milk-celery soup 140 grams, bread 15 grams, butter 1 gram, lettuce sandwiches $62 \mathrm{grams}$, tea 100 grams, sugar $10 \mathrm{grams,} \mathrm{lemon} \mathrm{pie}$ 109 granss.

Food. Grams. Per cent Nitrogen. Total Nitrogen.

\begin{tabular}{|c|c|c|c|c|c|c|c|c|c|c|}
\hline Coffee & . & . & . . . & . . & . & 100 & $x$ & 0.042 & $=$ & 0.042 gram. \\
\hline Cream & . & . . & $.25+$ & +118 & $3=$ & 143 & $x$ & 0.43 & $=$ & 0.615 \\
\hline Sugar. & . & . $8+$ & $+7+$ & +10 & $=$ & 25 & $x$ & 0.00 & $=$ & 0.000 \\
\hline Shredded & $\mathrm{d} w \mathrm{w}$ & heat $b$ & biscuit & . & . . & 29 & $x$ & 1.76 & $=$ & $0 . \delta 10$ \\
\hline Wheat $\mathrm{g}$ & ems & 3. & . . . & . & . . & 60 & $\times$ & 1.17 & $=$ & 0.702 \\
\hline Butter & . . & . & - $8+$ & $+\quad 1$ & $1=$ & 9 & $x$ & 0.10 & $=$ & 0.009 \\
\hline Tea . & . . & . & $100+$ & +100 & $=$ & 200 & $x$ & 0.048 & $=$ & 0.096 \\
\hline Apple pi & e. & . . . & . . . & $\cdot$. & . . & 102 & $x$ & 0.75 & $=$ & 0.765 \\
\hline Milk-cele & ery s & soup & . & . & . & 140 & $x$ & 0.42 & $=$ & 0.588 \\
\hline Bread & . . & $\cdot \cdot$ & . & . & . & 15 & $x$ & 1.36 & $=$ & 0.204 \\
\hline Lettuce $\mathrm{s}$ & sand & wich & . & . & . & . $\quad 62$ & $x$ & 1.02 & $=$ & 0.632 \\
\hline Lemon $p$ & pie. & . . & . & . & & 109 & $x$ & 0.82 & $=$ & 0.894 \\
\hline & & & $\begin{array}{l}\text { Total } \\
\text { Total }\end{array}$ & nitro & $\begin{array}{l}\text { ogen } \\
\text { ogen }\end{array}$ & in urin & & $\begin{array}{l}\cdot \cdot \cdot \cdot \\
\cdot \cdot \\
\cdot\end{array}$ & . & $\begin{array}{l}5.057 \text { grams } \\
4.310\end{array}$ \\
\hline
\end{tabular}

Fuel value of the food . . 1594 calories. 


\section{CHITTENDEN.}

\section{Friday, March 25, 1904.}

Breakfast, 7.45 A. M. - Coffee 100 grams, cream 25 grams, sugar 9 grams.

Lunch, 1.30 P. M. - Halibut with egg sauce 108 grams, mashed potato 89 grams, biscuit 48 grams, butter 10 grams, chocolate-cream cake 90 grams, tea 100 grams, sugar 9 grams.

Dinner, 6.30 P. M. - Milk-celery soup 121 grams, lettuce sandwiches 61 grams, creamed potato 65 grams, lettuce-apple-celery salad 74 grams, coffee 70 grams, sugar 10 grams.

Food. Grams. Per cent Nitrogen. Total Nitrogen.

\begin{tabular}{|c|c|c|c|c|c|c|c|c|c|c|c|}
\hline Coffee & . & . & . 100 & + & 70 & $=$ & 170 & $x$ & 0.042 & $=$ & 0.071 gram. \\
\hline Cream & . & . & . . & . & . & . & 25 & $x$ & 0.40 & $=$ & 0.100 \\
\hline Sugar . & . & . & $9+9$ & & 10 & $=$ & 28 & $x$ & 0.00 & $=$ & 0.000 \\
\hline Halibut, & ete & c. & .. & . & . & . & 108 & $x$ & 3.02 & $=$ & 3.262 \\
\hline Mashed & pot & ato & . & . & . & . & 89 & $x$ & 0.26 & $=$ & 0.231 \\
\hline Biscuit & . & . $"$. & . & . & . & . & 48 & $x$ & 1.52 & $=$ & 0.730 \\
\hline Butter & . & . & . & . & . & . & 10 & $x$ & 0.10 & $=$ & 0.010 \\
\hline Tea . & . & . . & . . & - & . & . & 100 & $x$ & 0.048 & $=$ & 0.048 \\
\hline Chocolat & te-cr & ream & cake & . & . & . & 90 & $\times$ & 0.99 & $=$ & 0.891 \\
\hline Celery-m & nilk & soup & . & . & . & - & 121 & $x$ & 0.52 & $=$ & 0.629 \\
\hline Lettuce & san & dwicl & b. & & . & . & 61 & $x$ & 0.98 & $=$ & 0.598 \\
\hline Lettuce- & app & le sal & lad. & . & . & . & 74 & $x$ & 0.21 & $=$ & 0.155 \\
\hline Creamed & d po & otato & - . & . & . & . & 65 & $x$ & 0.37 & $=$ & 0.241 \\
\hline & & & $\begin{array}{l}\text { Total } \\
\text { Total }\end{array}$ & & $\begin{array}{l}\text { itro } \\
\text { itro }\end{array}$ & & $\begin{array}{l}\text { in fool } \\
\text { in urine }\end{array}$ & • & 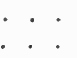 & . $\cdot$ & $\begin{array}{l}6.966 \text { grams. } \\
\text {. } 5.390\end{array}$ \\
\hline
\end{tabular}

Fuel value of the food . . . 1285 calories. 


\section{NITROGEN BALANCE. - Chittenden.}

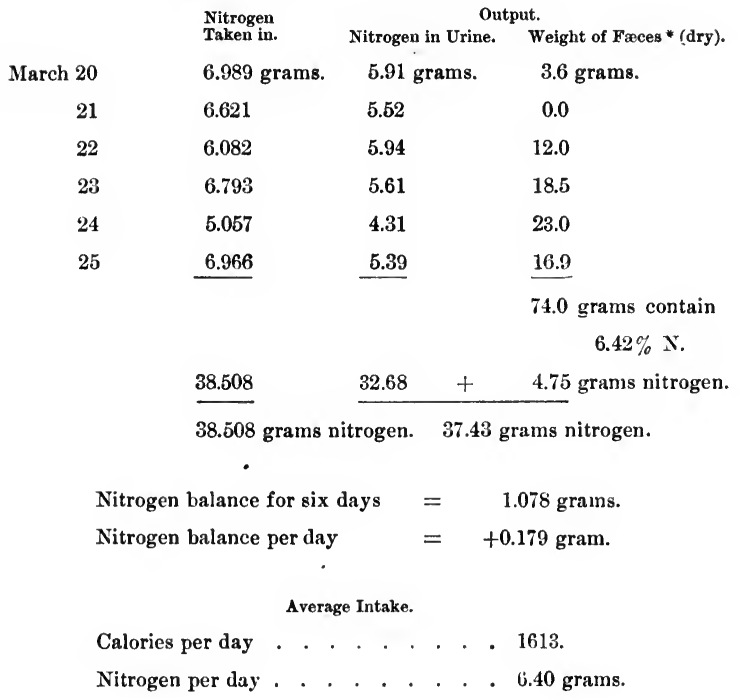

* The fæces of this period were separated by lampblack. They were dried on a water-bath after admixture with alcohol and a little sulphuric acid, nitrogen being determined by the Kjeldahl-Gunning method on samples of the dry mixture from the six-day period. 
Examination of the results shown in the foregoing balance makes it quite clear that the body was essentially in nitrogenous equilibrium. Indeed, there was a slight plus balance, showing that even with the small intake of proteid food the body was storing up nitrogen at the rate of 0.16 gram per day. The average daily intake of nitrogen for the six days' period was 6.40 grams, equal to 40.0 grams of proteid or albuminous food. The average daily output of nitrogen through the urine and fæces was 6.24 grams. The average daily output of nitrogen through the urine for the six days' period was 5.44 grams, corresponding to the metabolism of 34 grams of proteid material. When these figures are contrasted with the usually accepted standards of proteid requirement for the healthy man, they are certainly somewhat impressive, especially when it is remembered that the body at that date had been in essentially this same condition for at least six months, and probably for an entire year. The Voit standard of 118 grams of proteid, with an equivalent of at least 18 grams of nitrogen and calling for the metabolism of 105 grams of proteid, or 16.5 grams of nitrogen per day, makes elear how great a physiological econony had been accomplished. In other words, the consumption of proteid food was reduced to at least one-third the daily amount generally considered as representing the average requirement of the healthy man, and this with maintenance of body-weight at practically a constant point for the preceding ten months, and, so far as the writer can observe, with no loss of vigor, capacity for mental and physical work, or endurance. Indeed, the writer is disposed to maintain that he has done more work and led a more active life in every way during the period of this experiment, and with greater comfort and less fatigue than usual. His health has certainly been of the best during this period.

In this connection it may be well to call attention to the completeness of the utilization of the daily food in this six days' experiment, as shown by the small amount of refuse discharged per rectum, indicating as it does the high efficiency of the digestive processes and of the processes of absorption. 
The refuse matter for the entire period of six days amounted when dry to only 74 grams, and when it is remembered how large a proportion of this refuse must of necessity be composed of the cast-off secretions from the body, it will be seen how thorough must have been the utilization of the food by the system. The loss of nitrogen to the body per day through the fæces amounted to only 0.79 gram, and this on a mixed diet containing considerable matter not especially concentrated, and on some days with noticeable amounts of food, such as salads, not particularly digestible.

Finally, emphasis should be laid upon the fact that this economy of proteid food, this establishment of nitrogen equilibrium on a low proteid intake, was accomplished without increase in the daily intake of non-nitrogenous foods. In fact, the amount of fats and carbohydrates was likewise greatly reduced, far below the minimal standard of 3000 calories as representing the potential energy or fuel value of the daily diet. Indeed, during the balance period of six days just described the average fuel value of the food per day was only a little over 1600 calories.

As the experiment continued and the record for the months of April and May was obtained, it became evident from the nitrogen results that the rate of proteid katabolism was being still more reduced. A second balance experiment was therefore tried with a view to seeing if the body was still in nitrogen equilibrium, and also to ascertain whether the fuel value of the food still showed the same low calorific power. For a period of five days, June 23 to 27 , the intake of food and the entire output were carefully compared, with the results shown in the accompanying tables. 


\section{CHITTENDEN.}

\section{Thursday, June 23, 1904.}

Breakfast. - Coffee 123 grams, cream 50 grams, sugar 11 grams.

Lunch. - Omelette 50 grams. French fried potatoes 70 grams, bacon 10 grams, wheat gems 43 grams, butter 9 grams, strawberries 125 grams, sugar 20 grams, cream cake 59 grams.

Dinner. - Beefsteak 34 grams, peas 60 grams, creamed potato $97 \mathrm{grams}$, bread 26 grams, butter 17 grams, lettuce-orange salad 153 grams, crackers 43 grams, cream cheese 15 grams, coffee 53 grams, sugar 12 grams.

Food. Grams. Per cent Nitrogen. Total Nitrogen.

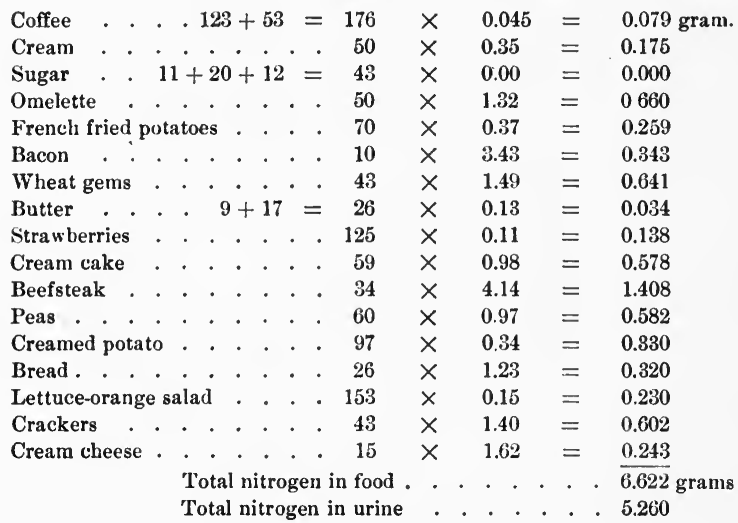

Fuel value of the food . . . 1863 calories. 


\section{PHYSIOLOGICAL ECONOMY IN NUTRITION}

\section{CHITTENDEN.}

Friday, June 24, 1904.

Breakfast. - Coffee 96 grams, sugar 8 grams, milk 32 grams.

Lunch. - Creamed codfisl 89 grams, baked potato 95 grams, butter 10 grams, hominy gems 58 grams, strawberries 86 grams, sugar 26 grams, ginger snaps 47 grams.

Dinner. - Cold tongue 14 grams, fried potato 48 grams, peas 60 grams, wheat gems 30 grams, butter 11 grams, lettuce-orange salad with mayonnaise dressing 155 grams, crackers 22 grams, cream cheese 14 grams, ginger snaps 22 grams, coffee 58 grams, sugar 10 grams.

\begin{tabular}{|c|c|c|c|c|c|c|c|c|}
\hline \multirow{2}{*}{ Food. } & \multirow[b]{2}{*}{..} & \multirow[b]{2}{*}{$96+58$} & \multicolumn{2}{|r|}{ Grams. } & \multicolumn{3}{|c|}{ Per cent Nitrogen. } & \multirow{2}{*}{$\begin{array}{c}\text { Total Nitrogen. } \\
0.069 \text { gram. }\end{array}$} \\
\hline & & & $=$ & 154 & $\times$ & 0.045 & $=$ & \\
\hline Sugar. & $8+$ & $-26+10$ & $=$ & 44 & $x$ & 0.00 & $=$ & 0.000 \\
\hline Milk . & . . & . . . & . . & 32 & $x$ & 0.51 & $=$ & 0.163 \\
\hline Creamed codfis & & . & . & 89 & $\times$ & 1.78 & $=$ & 1.584 \\
\hline Baked potato & . . & . & . & 95 & $x$ & 0.29 & $=$ & 0.276 \\
\hline Butter . & . & $10+11$ & $=$ & 21 & $x$ & 0.13 & $=$ & 0.027 \\
\hline IIominy gems & . & . . . & . . & 58 & $\times$ & 1.20 & $=$ & 0.696 \\
\hline Strawberries & . & . . . & . . & 86 & $\times$ & 0.11 & $=$ & 0.095 \\
\hline Ginger snaps & . . & $47+22$ & $=$ & 69 & $x$ & 1.15 & $=$ & 0.794 \\
\hline Cold tongue & . . & . . . & . . & 14 & $x$ & 4.87 & $=$ & 0.682 \\
\hline Fried potato & . & . & . & 48 & $x$ & 0.37 & $=$ & 0.178 \\
\hline Peas . . & . & . & . & 60 & $x$ & 0.94 & $=$ & 0.564 \\
\hline Wheat gems & . . & . . . & . & 30 & $\times$ & 1.45 & $=$ & 0.435 \\
\hline Lettuce-orange & e sala & d, etc. & . & 155 & $x$ & 0.15 & $=$ & 0.233 \\
\hline Crackers. . & $\because$. & . . . & . & 22 & $x$ & 1.40 & $=$ & 0.308 \\
\hline Cream cheese & . & . . . & . & 14 & $x$ & 1.62 & $=$ & 0.227 \\
\hline & $\begin{array}{l}\mathrm{T} \\
\mathrm{T}\end{array}$ & $\begin{array}{l}\text { otal nitro } \\
\text { otal nitro }\end{array}$ & $\begin{array}{l}\text { gen i } \\
\text { ggen }\end{array}$ & $\begin{array}{l}\text { in food. } \\
\text { in urine }\end{array}$ & . & $\begin{array}{l}\cdot . \\
.\end{array}$ & . & $\begin{array}{l}\overline{6.331} \text { granıs } \\
5.300\end{array}$ \\
\hline
\end{tabular}

Fuel value of the food . . . 1506 calories. 


\section{CHITTENUEN.}

Saturday, June 25, 1904.

Breakfast. - Coffee 101 grams, milk 36 grams, sugar 13 grams.

Lunch. - Omelette 50 grams, bacon 9 grams, French fried potato 23 grams, biscuit 29 grams, butter 8 grams, cream cheese 17 grams, iced tea 150 grams, sugar 15 grams, ginger snaps 42 grams.

Dinner. - Wheat popovers 57 grams, butter 10 grams, lettuce-orange salad with mayonnaise dressing 147 grams, cream cheese 21 grams, crackers 22 grams, cottage pudding 82 grams, coffee 48 grams, sugar 11 grams.

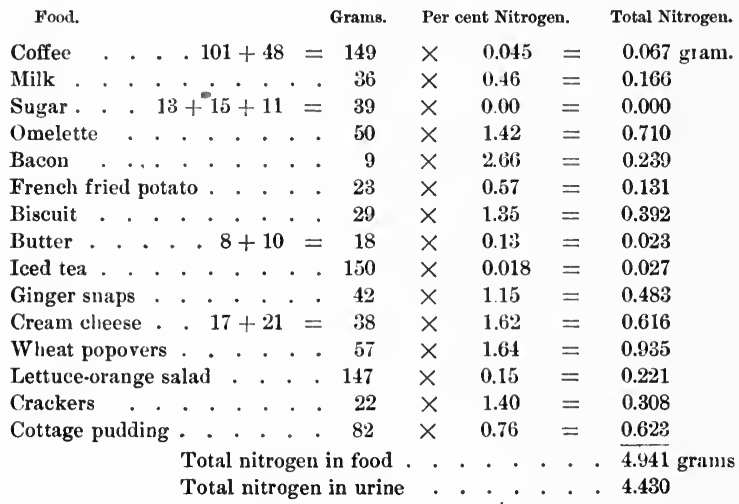

Fuel value of the food . . . 1392 calories. 


\section{CHITTENDEN.}

Sunday, June 26, 1904 .

Breakfast. - Coffee 122 grams, cream 31 grams, sugar 8 grams.

Dinner. - Roast lamb 50 grams, baked potato 52 grams, peas 64 grams, biscuit 32 grams, butter 12 grams, lettuce salad 43 grams, cream cheese 21 grams, toasted crackers 23 grams, blane mange 164 grams.

Supper. - Iced tea 225 grams, sugar 29 grams, lettuce sandwich 51 grans, strawberries 130 grams, sugar 22 grams, cream 40 grams, sponge cake 31 grams.

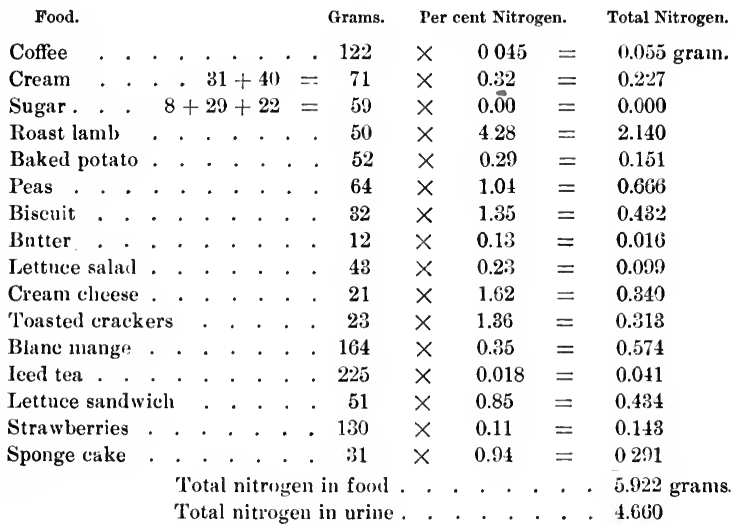

Fuel value of the food . . . . 1533 calories. 


\section{CHITTENDEN.}

\section{Monday, June 2\%, 1904.}

Breakfast. - Coffee 112 grams, cream 22 grams, sugar 10 grams.

Lunch. - Roast lamb 9 grams, baked potato 90 grams, wheat gems 47 grams. butter 12 grams, sugar 25 grams, iced tea 250 grams, vanilla éclair 47 grams.

Dinner. - Lamb chop 32 grams, asparagus 49 grams, butter 17 grans, creamed potato 107 grams, bread 35 grams, lettuce-orange salad with mayonnaise dressing 150 grams, cream cheese 12 grams, crackers 21 grams, coffee 63 grams, sugar 9 grams.

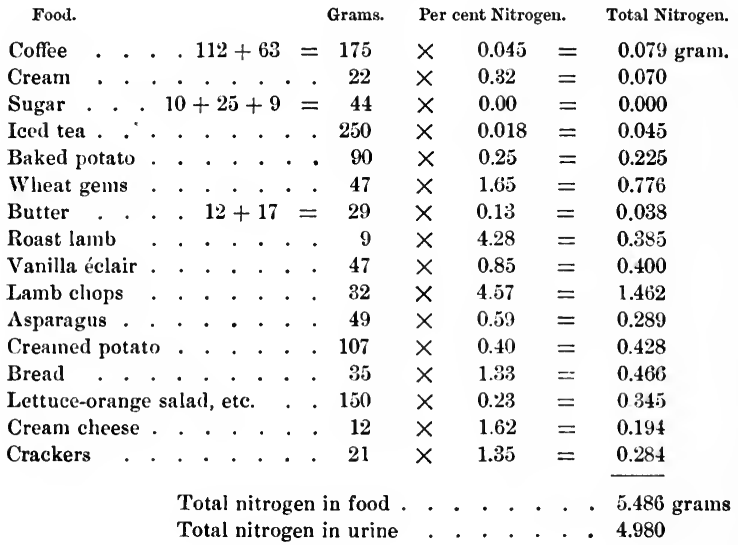

Fuel value of the food . . . 1454 calories. 
NITROGEN BALANCE.-CHITTENDEN.

\begin{tabular}{|c|c|c|c|}
\hline \multirow[b]{3}{*}{ June 23} & \multirow{2}{*}{$\begin{array}{l}\text { Nitrogen } \\
\text { Taken In. }\end{array}$} & \multicolumn{2}{|c|}{ Output. } \\
\hline & & Nitrogen in Urine. & Weight of Fæces (dry). \\
\hline & 6.622 grams. & 5.26 grams. & 10.6 \\
\hline 24 & 6.331 & 5.30 & 30.7 \\
\hline 25 & 4.941 & 4.43 & 14.2 \\
\hline 26 & 5.922 & 4.66 & 11.9 \\
\hline 27 & $\underline{5.486}$ & 4.98 & 15.2 \\
\hline & & & 82.6 grams contain \\
\hline & & & $6.08 \%$ N. \\
\hline & 29.302 & 24.63 & 5.022 grams nitrogen. \\
\hline
\end{tabular}

Nitrogen balance for five days $=-0.850 \mathrm{gram}$.

Nitrogen balance per day $=-0.070$ gram.

A verage Intake.

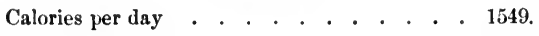

Nitrogen per day . . . . . . . . . 5.860 grams. 
Examination of these figures makes quite clear that the body was still in nitrogen equilibrium, or essentially so, the minus balance being so small as to have little significance. The body-weight was still stationary, and yet during this balance period the average daily intake of nitrogen was only 5.86 grams, corresponding to 36.62 grams of proteid or albuminous food. Further, the average daily fuel value of the food was only 1549 calories, a trifle less than in the preceding period. The average daily output of nitrogen through the urine for this period was 4.92 grams, corresponding to the metabolism of 30.7 grams of proteid food. Hence, the results of this period confirm those of the preceding period and make it quite clear that this subject, with a body-weight of 57.5 kilos, can be maintained in body equilibrium, and in nitrogen equilibrium, on a daily diet containing only 5.8 grams of nitrogen and with a fuel value of about 1600 calories. Under these conditions, as in the last balance period, the daily amount of nitrogen metabolized was very small, averaging only 4.92 grams. Comparison of this figure with the accepted standard of 16 grams of nitrogen makes quite clear the extent of the physiological economy which is attiinable by the body, and emphasizes also the extent of the unnecessary and worse than useless labor put upon the body by the prevalent dietetic habits of the majority of mankind.

It is of course understood that the low fuel value which sufficed to keep the writer in body equilibrium would not meet the requirements of a more active life, with greater physical labor. The writer has led a very busy life during the year of this experiment, but it has been mental activity rather than physical, although doubtless he has exercised as much as the ordinary professional worker not accustomed to athletic sports. The results of the experiment, however, make it quite clear that a man of the above body-weight, even though he lead a very active life - not involving great physical labor can maintain his body in equilibrium indefinitely with an intake of 36 to 40 grams of proteid or albuminous food, and with a total fuel value of about 1600 calories. Further, it is to be 
understood that there is no special form of diet involved in the accomplishment of such a result. Scrutiny of the daily diet, tabulated in the two balance periods, will show the character of the food made use of. Personal likes and dislikes must naturally enter into the choice of any diet, and freedom of choice, freedom to follow the dictates of one's appetite, with such regulation as comes from the use of reason and intelligence, are all that is necessary to secure the desired end. Physiological economy in nutrition is easily attainable and does not involve the adoption of vegetarianism. It does mean, however, temperance and simplicity in diet, coupled with intelligent regulation, which, however, soon becomes a habit and eventually leads to a moderation in diet which fully satisfies all the cravings of appetite as completely as it suffices to maintain the body in equilibrium and in a general condition of health and vigor.

Taking the data recorded above, we may now calculate the nitrogen requirement of the body per kilo of body-weight. With the body-weight placed at 57 kilos and with an average daily elimination of nitrogen for nearly nine months of 5.699 grams, or practically 5.7 grams, it is evident that the nitrogen metabolized per kilo of body-weight in the present instance was exactly 0.1 gram. If we take the lower figure of 5.40 grams of nitrogen, the average daily excretion from April 13 to June 27, we find the nitrogen requirement to be 0.0947 gram per kilo of body-weight. Translating these figures into terms of proteid or albuminous matter, they mean the utilization or metabolism of 0.625 gram of proteid matter daily per kilo of body-weight, under the conditions of life, activity, and general food consumption prevailing throughout this period of nearly nine months with this particular individual.

Whether we are justified in saying that this figure represents the minimal proteid requirement of this particular individual is perhaps questionable, since the proteid or nitrogen requirement will of necessity vary somewhat with the amount of non-nitrogenous food consumed. Doubtless, the nitrogen metabolism could be reduced still lower by increas- 
ing the intake of non-nitrogenous food, but under the above conditions of life, following a plan of living both congenial and satisfactory, one that fully sufficed to keep the body in equilibrium and with the practice of a general physiological economy, we may say that the metabolism of $0.1 \mathrm{gram}$ of nitrogen per kilo of body-weight was quite sufficient to meet all the requirements of the body. Health, strength, mental and physical vigor have been maintained unimpaired, and there is a growing conviction that in many ways there is a distinct improvement in both the physical and mental condition. Greater freedom from fatigue, greater aptitude for work, greater freedom from minor ailments, have gradually become associated in the writer's mind with this lowered proteid metabolism and general condition of physiological economy. The writer, however, is fully alive to the necessity of caution in the acceptance of one's feelings as a measure of physical or mental condition, but he has been keenly watchful for any and every sign or symptom during the course of these experiments, and is now strongly of the opinion that there is much good to be gained in the adoption of dietetic habits that accord more closely with the true physiological needs of the body. If a man of 57 kilos body-weight can maintain a condition of equilibrium, with continuance of health, strength, and vigor (to say nothing of possible improvement), with a daily consumption of say 40 grams of proteid food and sufficient non-nitrogenous food to yield 2000 calories, why should he load up his system each day with three times this amount of proteid food, with enough more fat and carbohydrate to yield 3000 plus calories?

Finally, the writer in summing up his own experience is inclined to say that while he entered upon this experiment simply with a view to studying the question from a purely scientific and physiological standpoint, he has become so deeply impressed with the great gain to the body by this practice of physiological economy, and his system has become so accustomed to the new level of nutrition that there is no desire to return to the more liberal dietetic habits of former years. 


\section{2}

Obviously, it is not wise nor safe to draw too broad deductions from a single individual, nor from a single experiment even though it extends over a long period of time; consequently, we may turn our attention to other individuals with presumably different personality and different habits of life. The writer's colleague, Dr. Lafayette B. Mendel, Professor of Physiological Chemistry in the Sheffield Scientific School, kindly volunteered to become a subject of experiment. With a body-weight of 76 kilos, 32 years of age, and of strong physique, he commenced to modify his diet about the middle of October, 1903, diminishing gradually the amount of proteid food with the results shown in the following tables, where are given, as in the preceding experiment, the amounts of nitrogen in the urine, as a measure of the quantity of proteid metabolized, uric acid, and other factors of interest in this connection.

The collection of data commenced on October 26, 1903. During some weeks the urine of each day was not analyzed by itself, but an aliquot part was taken from the 24 hours' quantity, and at the end of a week the determinations were made on the mixture, thereby giving the average daily composition for the period. With Dr. Mendel, as in the writer's case, there was no prescribing of food, but perfect freedom of choiee. The appetite was satisfied each day, but with a gradual diminution of proteid food, especially of meat. Dr. Mendel appeared to accomplish the desired end best by keeping up a liberal allowance of non-nitrogenous food, and the total potential energy of the daily diet was not so greatly diminished as in the writer's case. In other words, he appeared to need more food, but succeeded without great effort in reducing the proteid intake to nearly as low a level as in the preceding experiment. For the period of three months from January 4 to April 3, 190t, the average daily excretion of nitrogen amounted to 6.46 grams, which means the metabolism of 40.37 grams of proteid or albuminous food per day for this quarter of the year. 
MENDEL.

\begin{tabular}{|c|c|c|c|c|c|c|}
\hline \multirow{2}{*}{ Date. } & \multirow{2}{*}{$\begin{array}{c}\text { Body- } \\
\text { weight. }\end{array}$} & \multicolumn{5}{|c|}{ Urine. } \\
\hline & & $\begin{array}{l}\text { Volume. } \\
24 \text { hours. }\end{array}$ & Sp. Gr. & Nitrogen. & Uric Acid. & $\mathrm{P}_{2} \mathrm{O}_{5}$ \\
\hline 1903 & kilos & c.c. & & grams & gram & grams \\
\hline Oct. 26 & 76.2 & 1310 & 1019 & 10.53 & $\ldots$ & $\ldots$ \\
\hline 27 & 75.0 & 1650 & 1016 & 13.46 & 0.580 & 1.90 \\
\hline 28 & 74.5 & 915 & 1023 & 11.03 & $\cdots$ & $\cdots$ \\
\hline 29 & 745 & 825 & 1025 & 11.48 & 0.629 & 1.87 \\
\hline 30 & 74.6 & 1330 & 1018 & 13.17 & $\cdots$ & $\cdots$ \\
\hline 31 & 74.5 & 1045 & 1021 & 12.37 & $\cdots$ & $\cdots$ \\
\hline Nov. 1 & 74.5 & 1030 & 1020 & 10.38 & 0.602 & 1.59 \\
\hline 2 & $\ldots$ & 1080 & 1017 & 9.59 & $\ldots$ & $\ldots$ \\
\hline 3 & 74.5 & 1058 & 1016 & 8.86 & 0.528 & 1.63 \\
\hline 4 & 74.5 & 975 & 1019 & 866 & $\cdots$ & .. \\
\hline 5 & 74.5 & $10: 30$ & 1021 & 8.90 & 0.514 & 1.83 \\
\hline 6 & $\cdots$ & 1230 & 1015 & 8.11 & $\ldots$ & $\cdots$ \\
\hline 7 & 74.6 & 1450 & 1016 & 8.18 & $\ldots$ & $\ldots$ \\
\hline 8 & 74.0 & 970 & 1019 & 7.91 & 0.424 & 1.92 \\
\hline 9 & 74.0 & 620 & 1028 & 772 & $\cdots$ & $\ldots$ \\
\hline 10 & 74.0 & 543 & $10 \cdot 27$ & 6.60 & 0.390 & 1.17 \\
\hline 11 & 74.0 & 1160 & 1016 & 7.03 & $\ldots$ & $\cdots$ \\
\hline 12 & 74.0 & 863 & 1024 & 5.837 & 0.422 & 1.52 \\
\hline 13 & 74.0 & 1410 & 1015 & 8.12 & $\cdots$ & $\cdots$ \\
\hline 14 & 74.0 & 1265 & 1017 & 8.04 & 0.494 & 1.94 \\
\hline 16 & 74.0 & 760 & 1021 & 6.93 & $\cdots$ & $\cdots$ \\
\hline 17 & 74.0 & 850 & 1021 & 7.34 & 0.393 & 1.50 \\
\hline 18 & 74.0 & 757 & 1020 & 6.84 & 0.364 & $\cdots$ \\
\hline 19 & 74.0 & $7 \cdot 20$ & 1025 & 7.35 & 0.456 & 1.25 \\
\hline 20 & 74.0 & 655 & 1027 & 7.23 & 0.474 & $\ldots$ \\
\hline 21 & 74.0 & 985 & 1021 & 7.44 & 0.397 & $\cdots$ \\
\hline 22 & $74 . \tilde{0}$ & 590 & 1026 & $7.6 \mathrm{\jmath}$ & 0.395 & 1.20 \\
\hline $2: 3$ & 74.5 & 1100 & $\cdots$ & ? & & \\
\hline 24 & 74.0 & 1200 & 1017 & & & \\
\hline 25 & $\cdots$ & 1030 & $\cdots$ & & & \\
\hline 26 & 74.0 & 850 & $\cdots$ & 7.00 & 0.410 & 1.72 \\
\hline 27 & $\cdots$ & 935 & 1020 & daily & daily & daily \\
\hline 28 & 74.5 & 870 & 1021 & average & average & average. \\
\hline 29 & 74.5 & 993 & 1017 & j & & \\
\hline 30 & 74.5 & 650 & 1023 & ) & & \\
\hline Dec. 1 & 74.5 & 960 & 1018 & & & \\
\hline 2 & $\cdots$ & 790 & 1023 & 7.28 & 0.480 & 1.80 \\
\hline 3 & 74.0 & 880 & $10: 23$ & & & \\
\hline 4 & $\cdots$ & 1200 & 1016 & j & & \\
\hline
\end{tabular}


MENDEL.

\begin{tabular}{|c|c|c|c|c|c|c|}
\hline \multirow{2}{*}{ Date. } & \multirow{2}{*}{$\begin{array}{c}\text { Body- } \\
\text { weight. }\end{array}$} & \multicolumn{5}{|c|}{ Urine. } \\
\hline & & $\begin{array}{l}\text { Volume. } \\
24 \text { hours. }\end{array}$ & Sp. Gr. & Nitrogen. & Uric Acid. & $\mathrm{P}_{2} \mathrm{O}_{5}$ \\
\hline 1903 & kilos & c.c. & & grams & gram & grams \\
\hline Dec. 5 & 74.0 & 930 & 1021 & 7.28 & $0.48 v$ & 1.80 \\
\hline 6 & $\cdots$ & 1080 & 1019 & $\int$ daily av. & daily av. & daily av. \\
\hline 7 & 73.5 & 790 & 1023 & & & \\
\hline 8 & 73.5 & 965 & 1025 & & & \\
\hline 9 & 74.0 & 1130 & 1017 & & & \\
\hline 10 & 73.0 & 630 & 1031 & 7.63 & 0.498 & 1.91 \\
\hline 11 & 73.0 & 925 & 1019 & & & \\
\hline 12 & $\ldots$ & 1395 & 1014 & & & \\
\hline 13 & 73.0 & 1010 & 1018 & j & & \\
\hline 14 & $\cdots$ & 1030 & 1020 & 7.73 & $\cdots$ & $\cdots$ \\
\hline 15 & 73.0 & 875 & 1021 & 7.88 & ... & $\cdots$ \\
\hline 16 & $\cdots$ & 625 & 1027 & 6.48 & & \\
\hline 17 & $\ldots$ & 700 & 1027 & 7.60 & & \\
\hline 18 & $\ldots$ & 880 & 1022 & 8.39 & & \\
\hline 19 & $\cdots$ & 935 & 1020 & 7.68 & & \\
\hline 20 & $\ldots$ & 1075 & 1019 & 7.35 & & \\
\hline 21 & $\cdots$ & 523 & 1032 & 6.37 & 0.259 & 1.10 \\
\hline 22 & $\cdots$ & 1455 & 1017 & 8.99 & & \\
\hline 23 & $\ldots$ & 920 & 1021 & 8.33 & & \\
\hline 24 & . . & 725 & 1025 & 8.56 & & \\
\hline 25 & $\cdots$ & 865 & 1024 & 8.51 & & \\
\hline 26 & $\cdots$ & 710 & 1027 & 7.54 & & \\
\hline 27 & $\cdots$ & 910 & 1026 & & & \\
\hline 28 & $\cdots$ & 830 & 1026 & & & \\
\hline 29 & $\ldots$ & 730 & 1027 & & & \\
\hline 30 & $\cdots$ & 670 & 1033 & & & \\
\hline 31 & $\ldots$ & 630 & $\ldots$ & 7.64 & 0.438 & 1.16 \\
\hline 1904. & & & & & & \\
\hline Jan. 1 & $\cdots$ & 550 & $\cdots$ & & & \\
\hline 2 & $\cdots$ & 1030 & 1022 & & & \\
\hline 3 & $\cdots$ & 1020 & 1019 & & & \\
\hline 4 & $\ldots$ & 750 & 1021 & 5.63 & & \\
\hline 5 & $\ldots$ & 1030 & 1016 & 5.31 & & \\
\hline 6 & 730 & 815 & 1023 & 5.77 & & \\
\hline 7 & 72.7 & 930 & 1019 & 6.02 & 0.436 & 1.41 \\
\hline 8 & 73.5 & 1135 & 1017 & 5.72 & & \\
\hline 9 & 72.2 & 995 & 1020 & 639 & & \\
\hline 10 & $\ldots$ & 1175 & 1017 & 6.84 & & \\
\hline 11 & 72.0 & 1050 & 1017 & 6.17 & 0.443 & 1.43 \\
\hline
\end{tabular}


MENDEL.

\begin{tabular}{|c|c|c|c|c|c|c|}
\hline \multirow{2}{*}{ Date. } & \multirow{2}{*}{$\begin{array}{c}\text { Body- } \\
\text { weight. }\end{array}$} & \multicolumn{5}{|c|}{ Urine. } \\
\hline & & $\begin{array}{l}\text { Volume. } \\
24 \text { hours. }\end{array}$ & Sp. Gr. & Nitrogen. & Uric Acid. & $\mathrm{P}_{2} \mathrm{O}_{\bar{i}}$ \\
\hline 1904 & kilos & c.c. & & grams & gram & grams \\
\hline Jan. 12 & 72.2 & 1230 & 1015 & 6.71 & ) & \\
\hline 13 & 71.8 & 1250 & 1016 & 7.43 & & \\
\hline 14 & 71.8 & 1140 & 1015 & 7.05 & & \\
\hline 15 & $\cdots$ & 965 & 1019 & 5.99 & 0.443 & 1.43 \\
\hline 16 & $\cdots$ & 860 & 1023 & 6.71 & daily & daily \\
\hline 17 & $\ldots$ & 1030 & 1018 & 5.81 & f average & average. \\
\hline 18 & $\cdots$ & 730 & 1028 & 5.74 & ) & \\
\hline 19 & $\ldots$ & 825 & 1023 & 6.58 & & • \\
\hline 20 & $\cdots$ & 1035 & 1021 & 6.70 & & \\
\hline 21 & $\cdots$ & 725 & 1030 & 6.96 & 0.465 & 1.48 \\
\hline 22 & $\ldots$ & 815 & 1023 & 6.99 & & \\
\hline 23 & $\cdots$ & 950 & 1018 & 6.27 & & \\
\hline 24 & 71.5 & 790 & 1025 & 5.93 & j & \\
\hline 25 & 71.3 & 740 & 1027 & 5.33 & ) & \\
\hline 26 & $\ldots$ & 600 & 1030 & 5.44 & & \\
\hline 27 & $\ldots$ & 965 & 1020 & 6.89 & & \\
\hline 28 & $\ldots$ & 1045 & 1015 & 6.33 & 0.429 & 1.29 \\
\hline 29 & $\ldots$ & 895 & 1017 & 6.28 & & \\
\hline 30 & 70.6 & 660 & 1027 & 6.53 & & \\
\hline 31 & $\cdots$ & 905 & 1021 & 6.79 & J & \\
\hline Feb. 1 & 71.7 & 695 & 1025 & 5.13 & ) & \\
\hline 2 & $\ldots$ & 950 & 1023 & 6.84 & & \\
\hline 3 & $\cdots$ & 1210 & 1019 & 8.10 & & \\
\hline 4 & 71.5 & 985 & 1020 & 6.74 & 0.451 & 1.40 \\
\hline 5 & $\cdots$ & 1155 & 1020 & 6.51 & & \\
\hline 6 & 71.1 & 1035 & 1019 & 6.27 & & \\
\hline 7 & 70.8 & 760 & 1025 & 6.98 & ) & \\
\hline 8 & 70.5 & 800 & 1022 & 6.29 & $\cdots$ & $\cdots$ \\
\hline 9 & 70.6 & 1150 & 1023 & 7.52 & 0.448 & $\ldots$ \\
\hline 10 & 70.4 & 770 & 1022 & 6.75 & 0.318 & $\cdots$ \\
\hline 11 & 69.2 & 520 & 1031 & 6.71 & 0.458 & $\ldots$ \\
\hline 12 & 69.4 & 565 & 1033 & 8.24 & 0.390 & $\cdots$ \\
\hline 13 & 69.4 & 560 & 1030 & 7.83 & 0.420 & $\cdots$ \\
\hline 14 & 69.2 & 690 & 1027 & 7.99 & 0.447 & $\cdots$ \\
\hline 15 & 69.5 & 680 & 1027 & 7.50 & & \\
\hline 16 & $\ldots$ & 995 & 1019 & 6.86 & & \\
\hline 17 & $\ldots$ & 1055 & 1018 & 5.63 & 0.420 & $\cdots$ \\
\hline 18 & $\cdots$ & 1185 & 1015 & 6.11 & & \\
\hline 19 & $\cdots$ & 712 & 1025 & 5.72 & J & \\
\hline
\end{tabular}


MENDEL.

\begin{tabular}{|c|c|c|c|c|c|c|}
\hline \multirow{2}{*}{ Date. } & \multirow{2}{*}{$\begin{array}{c}\text { Body- } \\
\text { weight. }\end{array}$} & \multicolumn{5}{|c|}{ Urine. } \\
\hline & & $\begin{array}{l}\text { Volume. } \\
24 \text { hours. }\end{array}$ & Sp. Gr. & Nitrogen. & Uric Acid. & $\mathrm{P}_{2} \mathrm{O}_{5}$ \\
\hline 1904 & kilos & c.c. & & grams & gram & gram \\
\hline Feb. 20 & 70.5 & 1000 & 1021 & 7.38 & 0.420 & \\
\hline 21 & 70.6 & 1235 & , 1014 & 593 & \} daily av. & $\cdots$ \\
\hline 22 & $\ldots$ & 900 & 1018 & 6.16 & & \\
\hline 23 & 70.2 & 840 & 1020 & 5.49 & & \\
\hline 24 & $\ldots$ & 875 & 1017 & 5.83 & & \\
\hline 25 & 70.5 & 1450 & 1018 & 8.09 & 0.488 & $\ldots$ \\
\hline 26 & 70.2 & 1485 & 1015 & 6.68 & & \\
\hline 27 & $\ldots$ & 1300 & 1013 & 5.93 & & \\
\hline 28 & 69.2 & 735 & $102 \cdot 2$ & 5.91 & ) & \\
\hline 29 & $\ldots$ & 575 & 1030 & 6.21 & ) & \\
\hline Mar. 1 & $\ldots$ & 975 & 1019 & 7.51 & & \\
\hline 2 & 70.5 & 1240 & 1015 & 7.29 & & \\
\hline 3 & $\ldots$ & 1400 & 1013 & 6.63 & \} 0.462 & $\ldots$ \\
\hline 4 & 70.2 & 1375 & 1016 & 7.34 & & \\
\hline 5 & 69.9 & 1100 & 1017 & 706 & & \\
\hline 6 & 70.0 & 960 & $10: 20$ & 6.51 & $j$ & \\
\hline 7 & 70.5 & 970 & 1017 & $5.5: 3$ & ) & \\
\hline 8 & 70.9 & 1220 & 1015 & 5.56 & . & \\
\hline 9 & 70.9 & 1285 & $101 \overline{5}$ & 5.70 & | & \\
\hline 10 & $\ldots$ & 1000 & $10 \div 0$ & 6.24 & 0.413 & ... \\
\hline 11 & 70.8 & 1120 & 1017 & 5.98 & & \\
\hline 12 & $\ldots$ & 1285 & 1015 & 655 & & \\
\hline 13 & 70.4 & 1110 & 1015 & 5.79 & J & \\
\hline 14 & 70.0 & 690 & 1024 & 5.92 & ) & \\
\hline 15 & 706 & 1240 & 1017 & 729 & & \\
\hline 16 & 70.8 & 1450 & 1016 & 7.47 & & \\
\hline 17 & 70.2 & 780 & $102 * 2$ & 6.41 & 0.485 & $\ldots$ \\
\hline 18 & $\ldots$ & 1290 & 1012 & 6.57 & & \\
\hline 19 & 70.1 & 780 & 1027 & 6.41 & & \\
\hline 20 & $\ldots$ & 950 & 1020 & 6.21 & J & \\
\hline 21 & 70.7 & 1005 & $10: 0$ & 6.36 & ) & \\
\hline 22 & 70.9 & 1525 & 1014 & 6.50 & & \\
\hline 23 & 706 & 825 & 1023 & 6.39 & & \\
\hline 24 & 70.4 & 550 & 1029 & 6.07 & 0527 & $\ldots$ \\
\hline 25 & $\cdots$ & 1070 & 1018 & 6.93 & & \\
\hline 26 & 70.8 & 1100 & 1017 & 6.40 & & \\
\hline 27 & 70.6 & 1115 & 1016 & 5.82 & j & \\
\hline 28 & 70.2 & 1185 & 1015 & 6.22 & 0.389 & \\
\hline 29 & 70.5 & 1370 & 1014 & 6.58 & ¡ 0.389 & $\cdots$ \\
\hline
\end{tabular}


MENDEL.

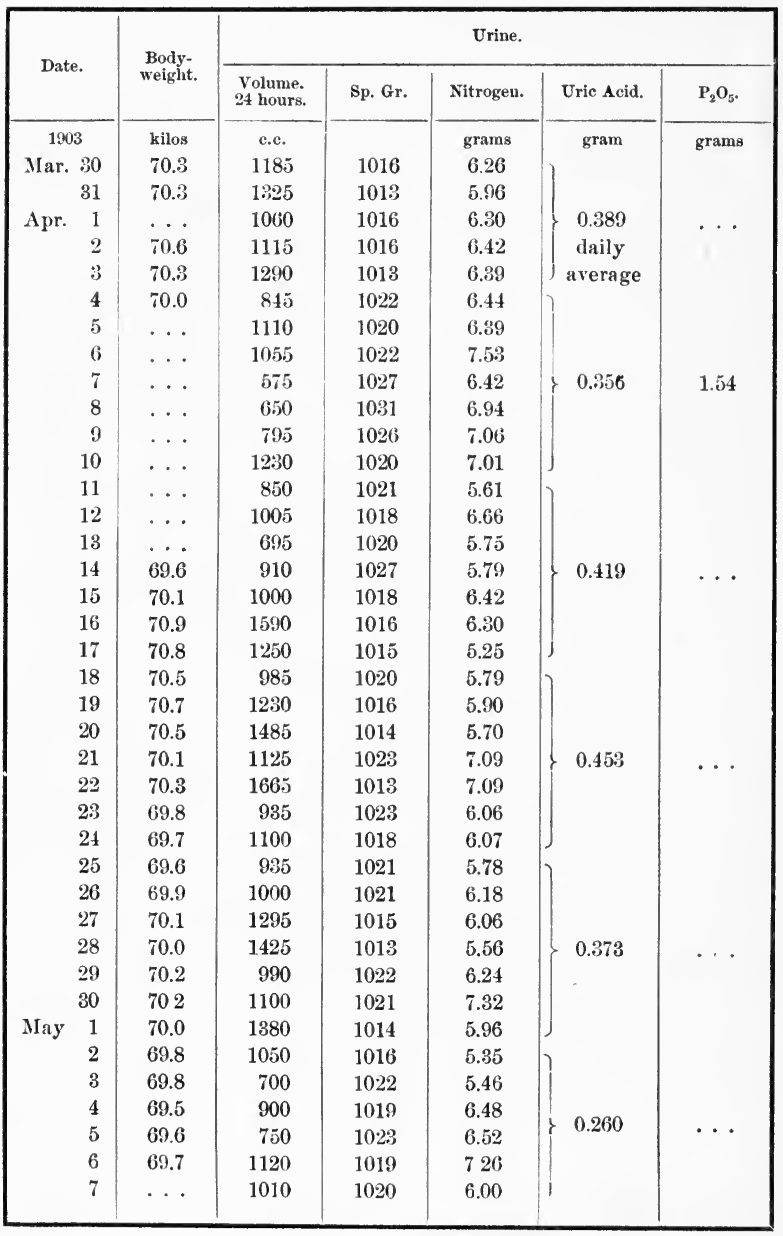


MEN1EL.

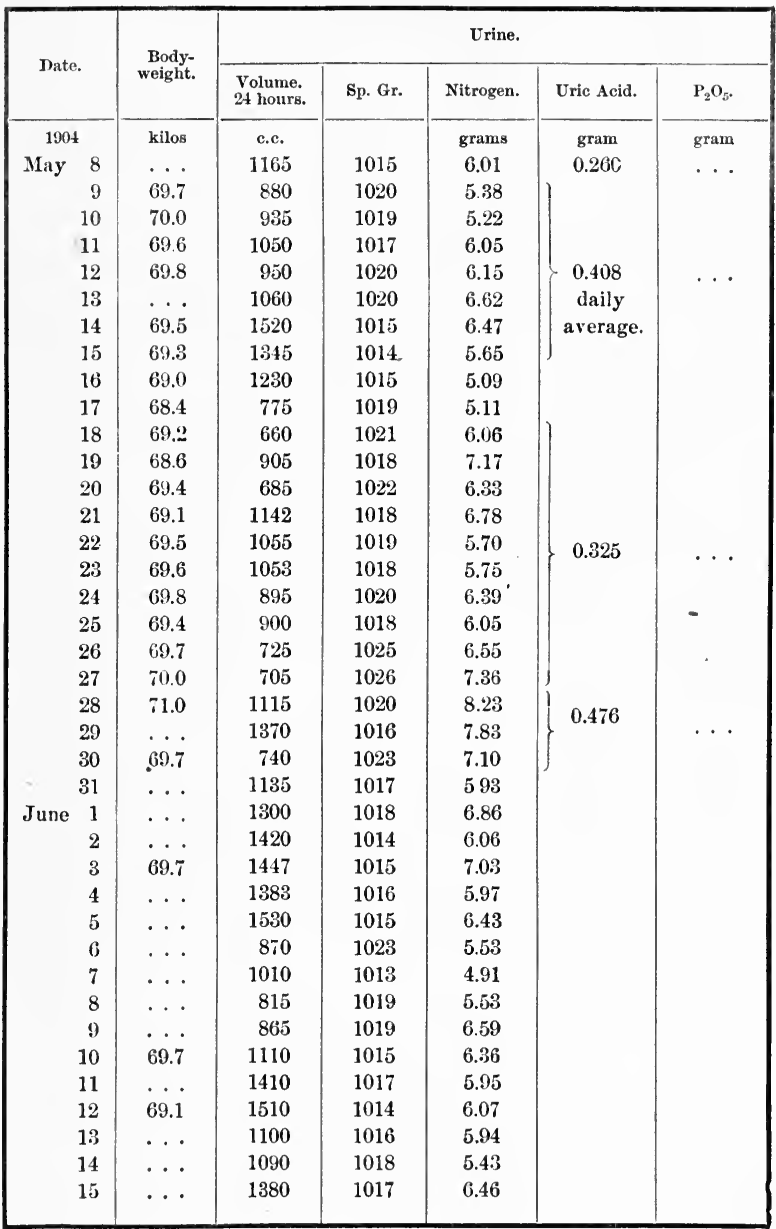


MENDEL.

\begin{tabular}{|c|c|c|c|c|c|c|}
\hline \multirow{2}{*}{ Date. } & \multirow{2}{*}{$\begin{array}{c}\text { Body- } \\
\text { weight. }\end{array}$} & \multicolumn{5}{|c|}{ Urine. } \\
\hline & & $\begin{array}{l}\text { Volume. } \\
24 \text { hours. }\end{array}$ & Sp. Gr. & Nitrogen. & Uric Acid. & $\mathrm{P}_{2} \mathrm{O}_{5}$. \\
\hline 1904 & kilos & c.c. & & grams & gram & grams \\
\hline June 16 & 70.0 & 1760 & 1014 & 6.55 & $\ldots$ & $\ldots$ \\
\hline 17 & $\ldots$ & 1755 & 1013 & 6.63 & $\ldots$ & $\ldots$ \\
\hline 18 & $\ldots$ & 1075 & 1026 & 6.06 & $\ldots$ & $\ldots$ \\
\hline 19 & 70.0 & 1285 & 1016 & 6.55 & $\ldots$ & $\ldots$ \\
\hline 20 & $\ldots$ & 585 & 1022 & 5.44 & $\ldots$ & $\ldots$ \\
\hline 21 & . . & 595 & 1024 & 6.93 & $\ldots$ & $\ldots$ \\
\hline 22 & $\ldots$ & 655 & 1023 & 7.07 & $\ldots$ & $\ldots$ \\
\hline 23 & $\ldots$ & 1230 & 1015 & 7.45 & $\ldots$ & $\ldots$ \\
\hline \multirow{2}{*}{\multicolumn{2}{|c|}{$\begin{array}{c}\text { Daily aver. from } \\
\text { Nov. 10, } 1903 .\end{array}$}} & & & & & \\
\hline & & 1001 & 1020 & 6.53 & 0.419 & 1.46 \\
\hline
\end{tabular}

From November 10, 1903, to June 23, 1904, a period of about seven months and a half, the average daily excretion of nitrogen through the urine was 6.53 grams. In other words, throughout this long period the average daily amount of proteid matter metabolized was 40.8 grams, only a little more than , one-third the amount called for by the Voit standard. Until February, the body-weight gradually fell, but from the early part of February until the end of the experiment the bodyweight remained practically stationary at 70 kilos. Dr. Mendel, however, from the necessities of his daily work in the laboratory was compelled to a much greater degree of physical activity than the subject of the preceding experiment, and consequently required a larger amount of non-nitrogenous food than the latter. Further, owing to his greater physical activity and the necessary variations in this daily activity, it was not so easy at first to attain equilibrium.

On February 9, a balance experiment of six days was commenced, with a careful comparison of the nitrogen intake and output. In the accompanying tables are shown all of the data. By scrutiny of these it will be seen that Dr. Mendel had adopted essentially a vegetarian diet. During this period of 
six days, however, he was not in nitrogen equilibrium, neither was he strictly in body equilibrium, since there was a distinct tendency for the body to fall off in weight. In this connection it may be mentioned that there is always a tendency during a balance experiment of this character for the subject to eat less than he is ordinarily accustomed to, owing to the tediousness of weighing every particle of food consumed. Further, for the same reason, and to avoid excess of chemical work in the analysis of samples of food, he is inclined to limit his diet to a few articles and thereby unconsciously restricts his intake of food, sometimes disastrously so.

\section{MENDEL.}

Tuesday, February 9, 190.4.

Breakfast. - Bread 33 grams, sugar 20 grams, coffee and milk 210 grams.

Lunch. - Consonmé 150 grams, sweet potato 170 grams, bread 135 grams, tomato 106 grams, coffee and milk 210 grans, sugar 20 grams.

Dinner. - Bread 75 grams, mashed potato 200 grams, string beans 91 grams, apple pie 282 grams, coffee and milk 210 grams, sugar 20 grams, water 100 grams.

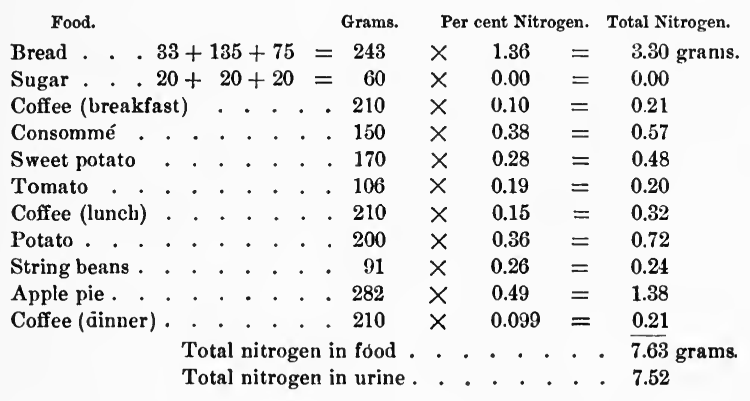




\section{MENDEL.}

\section{Wednesday, February 10, 1904.}

Breakfast. - Bread 37 grams, sugar 20 grams, coffee and milk 210 grams.

Lunch. - Bread 110 grams, sugar 7 grams, milk 250 grams, apple fritters 90 grams.

Dinner. - Bread 37 grams, sugar 21 grams, baked beans 100 grams, cranberry sauce 125 grams, coffee and milk 210 grams, molasses candy 54 grams.

Food.

Grams. Per cent Nitrogen. Total Nitrogen.

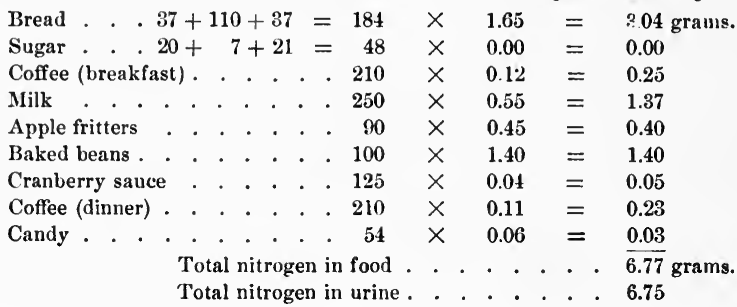

Fuel value of the food . . . 1673 calories.

\section{Thursday, February 11, 1904.}

Breakfast. - Bread 40 grams, sugar 20 grams, coffee and nilk 210 grams.

Lunch. - Bread 95 grams, sweet potato 130 grams, sugar 7 grams, milk 250 grams, peach preserve 93 grams.

Dinner. - Bread 90 grams, mashed potato 100 grams, tomato purée 135 grams, baked beans 75 grams, lemon pie 110 grams, coffee and milk 210 grams, sugar 21 grams.

Food. Grams. Per cent Nitrogen. Total Nitrogen.

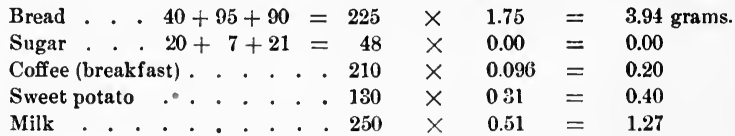


MENDEL.

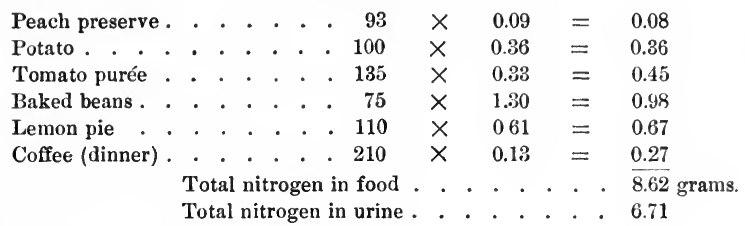

Fuel value of the food . . . 1828 calories.

\section{Friday, February 12, 1904.}

Breakfast. - Bread 58 grams, sugar 21 grams, coffee and milk 210 grams.

Lunch. - Bread 120 grams, sugar 21 grams, custard 76 grams, milk 250 grams, coffee and milk 125 grams.

Dinner. - Bread 67.5 grams, sugar 21 grams, mashed potato 150 grams, lima beans 80 grams, coffee and milk 210 grams, apple dumpling 131 grams, molasses candy 27 grams.

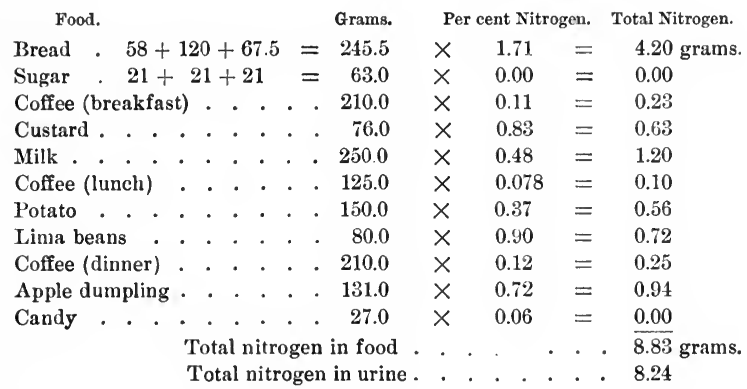

Fuel value of the food . . . . 1929 calories. 


\section{MENDEL.}

Saturday, February 13, 1904.

Breakfast. - Bread 47.5 grams, sugar 28 grams, coffee and nilk 210 grams.

Lunch. - Bread 57 grams, sugar 40 grams, siveet potato 135 grams, quince preserve 73 grams, apple turnovers 118 grams, coffee and milk 310 grains.

Dinner. - Bread 59 grams, mashed potato 175 grams, peas 80 grams, apple pie 141.5 grams, sugar 21 grams, coffee and milk 210 grams.

\begin{tabular}{|c|c|c|c|c|c|c|c|c|c|c|}
\hline \multicolumn{5}{|l|}{ Food. } & \multicolumn{2}{|r|}{ Grams. } & \multicolumn{3}{|c|}{ Per cent Nitrogen. } & \multirow{2}{*}{$\begin{array}{l}\text { Total Nitrogen. } \\
2.69 \text { grams. }\end{array}$} \\
\hline Bread . . 47.5 & $5+5$ & $57+$ & -59 & & $=$ & 164.0 & $x$ & 1.64 & $=$ & \\
\hline Sugar . . 28 & +4 & $40+$ & -21 & & $=$ & 89.0 & $x$ & 0.00 & $=$ & 0.00 \\
\hline Coffee (breakfast) & t) . & . & . & & . & 210.0 & $x$ & 0.11 & $=$ & 0.23 \\
\hline Sweet potato. & . & 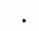 & . & 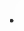 & . & 135.0 & $x$ & 0.37 & $=$ & 0.50 \\
\hline Quince preserve. & . & . & . & . & . & 73.0 & $x$ & 0.047 & $=$ & 0.03 \\
\hline Apple turnovers . & & . & . & & . & 118.0 & $x$ & 0.96 & $=$ & 1.13 \\
\hline Coffee (lunch) . & . & . & . & . & . & 310.0 & $x$ & 0.15 & $=$ & 0.47 \\
\hline Potato . . & . & . & . & $\cdot$ & . & 175.0 & $x$ & 0.37 & $=$ & 0.65 \\
\hline Peas . . . . & & . & & & . & 80.0 & $x$ & 0.96 & $=$ & 0.77 \\
\hline Apple pie . & . & . & . & & - & 141.5 & $x$ & 0.43 & $=$ & 0.61 \\
\hline Coffee (dinner) & . . & & & & & 210.0 & $x$ & 0.11 & $=$ & 0.23 \\
\hline & & & & & & in urine . & - & 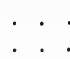 & $\cdot$ & $\begin{array}{l}\text {. } \overline{7.31} \text { grams } \\
\text {. } \quad 7.83\end{array}$ \\
\hline
\end{tabular}

Fuel value of the food . . . 2057 calories. 
MENDEL.

Sunday, February 14, 1904.

Breakfast. - Bread 50 grams, sugar 21 grams, banana 92.5 grams, coffee and milk 210 grams.

Lunch. - Bread 108.5 grams, sugar 28 grams, baked potato 165 grams, apple sauce 114 grams, coffee and milk 210 grams.

Dinner. - Bread 63 grams, sugar 28 grams, succotash 75 grams, mashed potato 200 grams, cliocolate layer cake 80 grams, ice cream 73 grams, coffee and milk 210 grams.

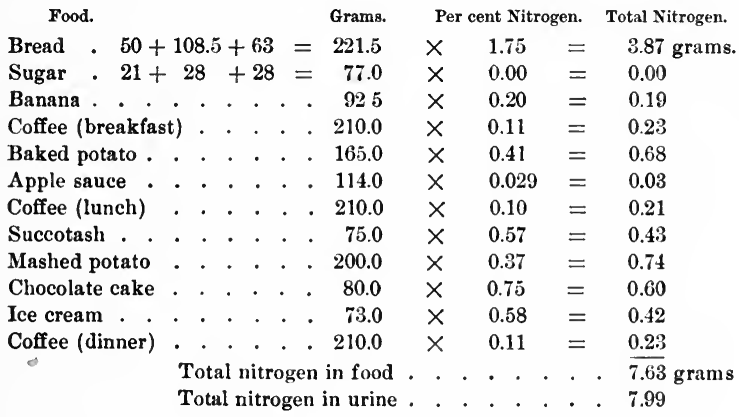

Fuel value of the food . . . 2065 calories. 


\section{NITROGEN BALANCE.-Mendel.}

Nitrogen
Taken in.

Feb. $9 \quad 7.63$ grams. 7.52 grams. . .

$\begin{array}{lll}10 & 6.77 & 6.75\end{array}$

$11 \quad 8.62 \quad 6.71$

$\begin{array}{lll}12 & 8.83 & 8.24\end{array}$

$\begin{array}{lll}13 & 7.31 & 7.83\end{array}$

$\left.{ }_{54}^{53}\right\}$ contain $5.84 \% \mathrm{~N}=6.248 \mathrm{grm} . \mathrm{N}$.
\begin{tabular}{l}
14 \\
\hline
\end{tabular}
39.2 contain $6.72 \% \mathrm{~N}=2.684$
$\overline{146.2} \overline{8.882} \mathrm{grm} . \mathrm{N}$

$46.79 \quad 45.04+8.882$ grams nitrogen.

46.79 grams $\mathrm{N} . \quad 53.92$ grams nitrogen.

Nitrogen balance for six days $=-7.13$ grams.

Nitrogen balance per day $\quad=\quad-1.19$ grams.

Average Intake.

Calories per day . . . . . . . . 1975.

Nitrogen per day . . . . . . 7.83 grams. 
In this balince period of six days the average daily intake of nitrogen was 7.83 grams, coupled with an average fuel value of the food per day of 1975 calories. This latter value was obviously too small for a man of Dr. Mendel's body-weight, and doing the amount of physical work he was called upon to perform. Being on one's feet in a laboratory six to eight hours a day, in addition to the ordinary activity of a vigorous man leading a strenuous life, necessitates the utilization and oxidation of considerable food material. The average daily output of nitrogen through the urine amounted to 7.50 grams, considerably above the average daily excretion for the seven months' period. Still, under these conditions there was a minus balance of 7.13 grams of nitrogen for the six days' period, indicating that the body was drawing upon its stock of proteid material to the extent of 1.19 grams of nitrogen per day. This does not necessarily mean that the body had need of that additional amount of proteid matter each day, but rather that the amount of total energy required was beyond the potential energy supplied by the food. There not being sufficient non-nitrogenous food at hand, the body was compelled to draw upon its own resources, and in so doing utilized some of its tissue proteid. This is made quite clear by the results of the second balance period shortly to be described.

It is evident, however, that while the body was not in nitrogen equilibrium for this particular period of six days, there must have been a general condition of both body and nitrogen equilibrium, otherwise the body-weight would not have remained practically stationary for so long a period as from February 7 to June 20.

Commencing May 18, a second nitrogen balance was attempted, in which, as in the preceding case, there was a careful comparison of income and output for seven days. There was as before a free choice of food, but it was essentially vegetable in character. A greater variety of foods was taken, however, and an effort was made to have the non-nitrogenous food somewhat more liberal in amount, though in as close harmony as possible with the desires of the appetite. 


\section{MENDEL.}

Wednesday, May 18, 1904.

Breakfast. - Banana 92 grams, bread rolls 28 grams, cream 50 grams, coffee 150 grams, sugar 21 grams.

Lunch. - Bread 66 grams, soup 150 grams, farina 154 grams, sweet potato 123 grams, beans 70 grans, syrup 50 grams, coffee 150 grams, cream 50 grams, sugar 14 grams.

Dinner. - Bread 42 grams, consommé 100 grams, spinach 100 grams, mashed potato 250 grams, apple pie 97 grams, coffee 150 grams, cream 50 grams, sugar 21 grams.

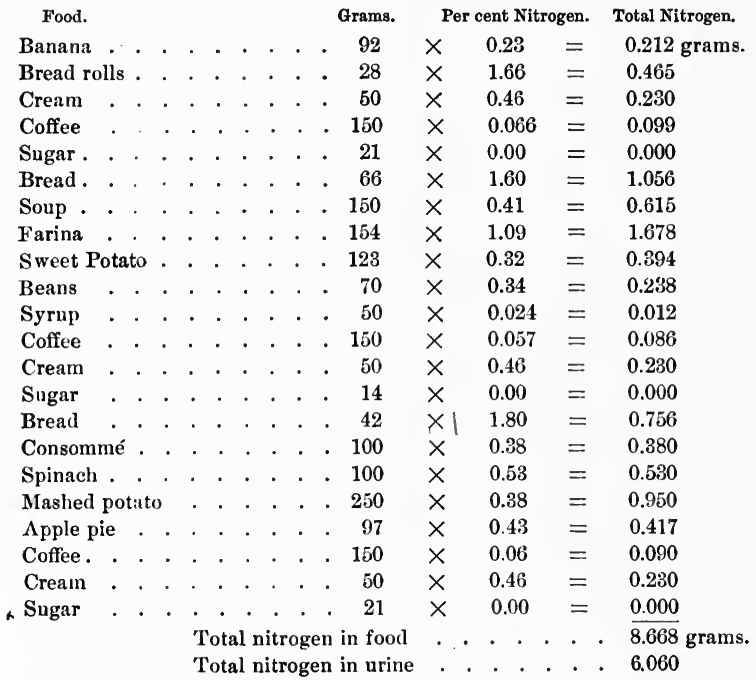

Fuel value of the food . . . 2359 calories. 


\section{MENDEL.}

\section{Thursday, May 19, 1904}

Breakfast. - Banana 102 grams, bread rolls 50 grams, coffee 150 grams, cream 50 grams, sugar 21 grams.

Lunch. - Bread 57 grams, egg omelette 20 grams, hominy 137 grams, syrup 68 grams, potatoes 128 grams, coffee 100 grams, sugar 21 grams, cream 50 grams.

Dinner. - Tomato pureé 200 grams, bread 24 grams, fried sweet potato 100 grams, spinach 70 grams, Indian meal 100 grams, syrup 25 grams, coffee 100 grams, sugar 21 grams, cream 40 grams.

Food. Grams. Per cent Nitrogen. Total Nitrogen.

\begin{tabular}{|c|c|c|c|c|c|c|c|c|c|c|c|c|c|}
\hline \multirow{2}{*}{\multicolumn{2}{|c|}{$\begin{array}{l}\text { Banana } \\
\text { Bread rolls }\end{array}$}} & • & • & • & . & & • & . & 102 & $x$ & 0.23 & $=$ & 0.235 grams. \\
\hline & & • & • & . & . & • & . & . & 50 & $x$ & 1.54 & $=$ & 0.770 \\
\hline Coffee & . . & . & . & . & - & . & . & . & 150 & $x$ & 0.06 & $=$ & 0.090 \\
\hline Cream & . & & . & . & . & . & . & . & 50 & $x$ & 0.47 & $=$ & 0.285 \\
\hline Sugar . & . & . & . & . & . & . & . & . . & 21 & $x$ & 0.00 & $=$ & 0.000 \\
\hline Bread . & . & · & . & . & . & • & . & . . & 57 & $\times$ & 1.60 & $=$ & 0.912 \\
\hline $\mathrm{Egg} \mathrm{Om}$ & elett & te & . & . & . & . & . & . . & 20 & $x$ & 1.58 & $=$ & 0.316 \\
\hline IIominy & . & . & . & . & $\cdot$ & • & . & . . & 137 & $\times$ & 0.20 & $=$ & 0.274 \\
\hline Syrup. & . & . & . & . & . & . & . & . . & 68 & $x$ & 0.024 & $=$ & 0.016 \\
\hline Potatoes & . & . & • & . & . & . & . & . . & 128 & $x$ & 0.49 & $=$ & 0.627 \\
\hline Coffee & . & . & . & . & . & • & . & . . & 100 & $x$ & 0.06 & $=$ & 0.060 \\
\hline Cream & . & & . & . & . & . & . & . & 50 & $x$ & 0.47 & $=$ & 0.235 \\
\hline Sugar. & . & . & . & . & . & • & . & . & 21 & $x$ & 0.00 & $=$ & 0.000 \\
\hline Tomato & pure & & & . & . & . & . & . & 200 & $x$ & 0.53 & $=$ & 1.060 \\
\hline Bread. & . & • & . & . & . & . & . & . & 24 & $x$ & 1.74 & $=$ & 0.418 \\
\hline Sweet p & otat & & . & . & . & . & . & . & 100 & $x$ & 0.38 & $=$ & 0.380 \\
\hline Spinach & . . & . & . & . & . & . & . & . & 70 & $x$ & 0.56 & $=$ & 0.392 \\
\hline Indian $\mathrm{m}$ & peal & & • & . & $\therefore$ & . & . & . & 100 & $x$ & 0.20 & $=$ & 0.200 \\
\hline Syrup & . . & • & . & . & . & & . & . & 25 & $x$ & 0.024 & $=$ & 0.006 \\
\hline Coffee & . & . & . & . & . & . & . & . & 100 & $\times$ & 0.06 & $=$ & 0.060 \\
\hline Sugar. & . & • & . & . & . & . & . & . & 21 & $\times$ & 000 & $=$ & 0.000 \\
\hline Cresm & . & & . & . & & & . & . & 40 & $x$ & 0.47 & $=$ & 0.188 \\
\hline & & & & & & & $\begin{array}{l}\text { tros } \\
\text { tros }\end{array}$ & & $\begin{array}{l}\text { in food. } \\
\text { in urine }\end{array}$ & . & $\begin{array}{lll}\cdot & \cdot & \cdot \\
\cdot & . & \cdot\end{array}$ & $\cdot$ & $\begin{array}{l}\overline{6.44} \text { grams. } \\
7.170\end{array}$ \\
\hline
\end{tabular}

Fuel value of the food . . . 2072 calories. 
MENDEL.

Friday, May 20, 1904.

Breakfast. - Sliced orange 140 grams, coffee 100 grams, cream 30 grams, sugar 21 grams.

Lunch. - Bread 28 grams, mashed potato 250 grams, lima beans 40 grams, coffee 100 grams. sugar 21 grams, cream 30 grams, fried hominy 115 grams, syrup 48 grams.

Dinner - Bread 19 grams, consommé 150 grams, string beans 140 grams, mashed potato 250 grams, rice croquette 93 grams, cranberry jam 95 grams, coffee 100 grams, sugar 21 grams, cream 30 grams, syrup 25 granıs.

Food.

Grams. Per cent Nitrogen. Total Nitrogen.

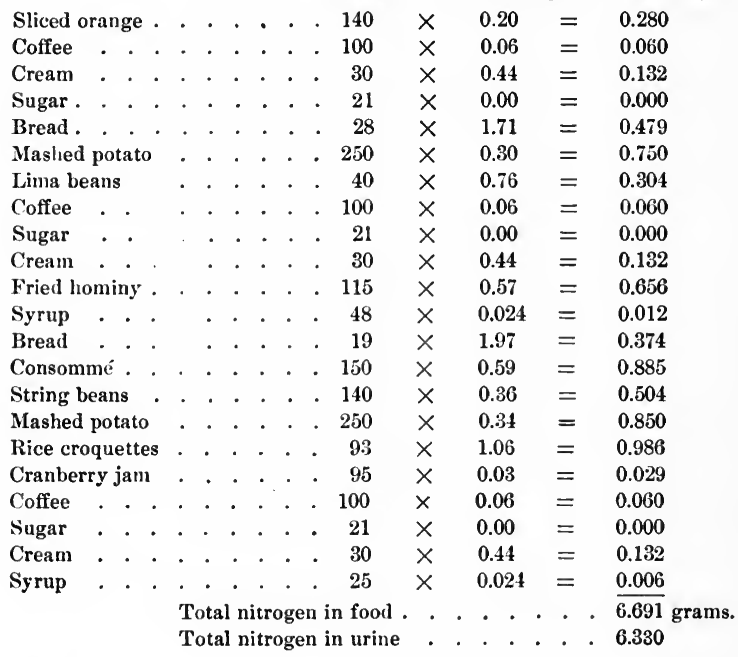

Fuel value of the food . . . . 1915 calories. 
MENDEL.

\section{Saturday, May 21, 1904.}

Breakfast. - Banana 153 grams, coffee 150 grams, sugar 21 grams, cream 30 grams.

Lunch. - Bread 25 grams, potato croquette 229 grams, Indian meal 109 grams, tomato 123 grams, syrup 48 grams, coffee 100 grams, sugar 14 grams, cream 20 grams.

Dinner. - Bread 31 grams, bean soup 100 grams, fried potato 200 grams, bacon 5 grams, lettuce-orange salad 47 grams, prunes 137 grams, coffee 100 grams, sugar 21 grams, cream 25 grams, banana 255 grams.

\begin{tabular}{|c|c|c|c|c|c|c|c|c|c|c|c|c|c|}
\hline \multirow{2}{*}{$\begin{array}{c}\text { Food. } \\
\text { Banana }\end{array}$} & \multirow[b]{2}{*}{ - } & \multirow[b]{2}{*}{. } & \multirow[b]{2}{*}{ • } & \multirow{2}{*}{\multicolumn{2}{|c|}{. }} & \multirow[b]{2}{*}{ - } & \multirow[b]{2}{*}{. } & \multirow{2}{*}{\multicolumn{2}{|c|}{$\begin{array}{c}\text { Grams. } \\
. \quad 153\end{array}$}} & \multicolumn{3}{|c|}{ Per cent Nitrogen. } & \multirow{2}{*}{$\begin{array}{c}\text { Total Nitrogen. } \\
0.3052 \text { grams. }\end{array}$} \\
\hline & & & & & & & & & & $x$ & 0.23 & $=$ & \\
\hline Coffee & . & . & . & . & & . & . & . & . 150 & $x$ & 0.06 & $=$ & 0.090 \\
\hline Sugar & . & . & . & . & . & . & . & . & 21 & $x$ & 0.00 & $=$ & 0.000 \\
\hline Cream & . & . & . & . & & . & . & . & 30 & $x$ & 0.43 & $=$ & 0.129 \\
\hline Bread . & . & . & . & . & . & . & . & . & 25 & $x$ & 1.82 & $=$ & 0.455 \\
\hline Potato er & roq & uet & tte & . & & . & . & . & - 229 & $x$ & 0.71 & $=$ & 1.626 \\
\hline Indian $\mathrm{n}$ & eal & & . & . & & . & . & . & . 109 & $x$ & 1.09 & $=$ & 1.188 \\
\hline Tomato & · & . & . & . & & . & . & . & 123 & $x$ & 0.17 & $=$ & 0.209 \\
\hline Syrup & . & . & . & . & & . & . & . & 48 & $x$ & 0.024 & $=$ & 0.012 \\
\hline Coffee & . & & . & . & & . & . & . & 100 & $x$ & 0.06 & $=$ & 0.060 \\
\hline Sugar. & . & . & . & . & . & . & . & . & 14 & $x$ & 0.00 & $=$ & 0.000 \\
\hline Cream & . & . & . & . & . & . & . & . & 20 & $x$ & 0.43 & $=$ & 0.086 \\
\hline Bread . & . & . & . & . & . & . & . & . & 31 & $x$ & 1.62 & $=$ & 0.502 \\
\hline Bean sou & & $\cdot$ & - & . & . & . & . & . & 100 & $x$ & 1.21 & $=$ & 1.210 \\
\hline Fried po & tatc & & . & . & . & . & . & . & 200 & $x$ & 0.60 & $=$ & 1.200 \\
\hline Bacon & . & . & . & . . & & . & . & . & 5 & $x$ & 3.05 & $=$ & 0.153 \\
\hline Lettuce-o & ora & nge & e sa & alat & & . & . & . & 47 & $x$ & 0.21 & $=$ & 0.099 \\
\hline Prunes & . & . & . & . . & . & . & . & . & 137 & $x$ & 0.16 & $=$ & 0.219 \\
\hline Coffee . & . & . & . & . & . & . & . & . & 100 & $x$ & 0.06 & $=$ & 0.060 \\
\hline Sugar. & . & . & . & . & . & . & . & . & 21 & $x$ & 0.00 & $=$ & 0.000 \\
\hline Cream & . & . & . & . & . & . & . & . & 25 & $x$ & 0.43 & $=$ & 0.108 \\
\hline Banana & . & . & . & . . & & . & . & . & . 255 & $x$ & 0.23 & $=$ & 0.587 \\
\hline & & & & $\begin{array}{l}\text { Tot } \\
\text { To }\end{array}$ & & $\mathrm{ni}$ & & & in urine & & $\begin{array}{l}\cdot . \\
. \\
.\end{array}$ & . & $\begin{array}{l}8 . \overline{345} \text { grams. } \\
\text {. } 6.780\end{array}$ \\
\hline
\end{tabular}

Fuel value of the food . . . 2485 calories. 


\section{MENDEL.}

Sunday, May 22, 1904.

Breakfast. - Banana 220 grams, orange 60 grams, coffee 100 grams, sugar 21 grams, cream 25 grams.

Lunch. - Bread 35 grams, potato 300 grams, fried rice 160 grams, syrup 63 grams, ice cream 84 grams, coffee 100 grams, sugar 14 grams.

Dinner. - Cream of celery soup 100 grams, bread 21 grams, mashed potato 250 grams, spinach 40 grams, French fried potato 100 grams, strawberry short-cake 120 grams.

\begin{tabular}{|c|c|c|c|c|c|c|c|c|c|c|c|}
\hline \multirow{2}{*}{$\begin{array}{c}\text { Food. } \\
\text { Banana }\end{array}$} & \multirow{2}{*}{\multicolumn{2}{|c|}{ • }} & \multirow[b]{2}{*}{ • } & \multirow[b]{2}{*}{. } & \multirow[b]{2}{*}{. } & \multicolumn{2}{|r|}{ Grams. } & \multicolumn{3}{|c|}{ Per cent Nitrogen. } & \multirow{2}{*}{$\begin{array}{l}\text { Total Nitrogen. } \\
0.506 \text { grams. }\end{array}$} \\
\hline & & - & & & & - & - 220 & $x$ & 0.23 & $=$ & \\
\hline Orange & . & . & . & . & . & . & 60 & $x$ & 0.20 & $=$ & 0.120 \\
\hline Coffee & . & . & . & . & . & . & 100 & $x$ & 0.06 & $=$ & 0.060 \\
\hline Sugar & . & . & . & . & . & . & 21 & $\times$ & 0.00 & $=$ & 0.000 \\
\hline Cream & - & . & . & . & - & . & 25 & $x$ & 0.45 & $=$ & 0.113 \\
\hline Bread . & . . & & . . & . & . & . & 35 & $x$ & 1.57 & $=$ & 0.550 \\
\hline Potato & . & . & . & . & . & . & . :300 & $x$ & 0.30 & $=$ & 0.900 \\
\hline Fried rice & e & . & . & . & . & . & . 160 & $\times$ & 0.75 & $=$ & 1.200 \\
\hline Syrup . & . & - & . & . & . & . & . $\quad 63$ & $\times$ & 0.024 & $=$ & 0.015 \\
\hline Ice cream & . & . & . . & . & . & . & 84 & $x$ & 0.53 & $=$ & 0.445 \\
\hline Coffee & . . & . & . . & . & . & . & 100 & $\times$ & 0.06 & $=$ & 0.060 \\
\hline Sugar . & . . & . & . . & . & . & , & 14 & $x$ & 0.00 & $=$ & 0.000 \\
\hline Cream of & f cele & ery & soup & . & . & . & . 100 & $\times$ & 0.33 & $=$ & 0.330 \\
\hline Bread . & . . & . & . . & . & . & 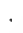 & . 21 & $x$ & 1.91 & $=$ & 0.401 \\
\hline Mashed $p$ & potat & & . $\cdot$ & . & . & . & . 250 & $\times$ & 0.37 & $=$ & 0.925 \\
\hline Spinach & . . & . & . . & . & . & . & . 40 & $\times$ & 0.55 & $=$ & 0.220 \\
\hline French $\mathrm{fr}$ & ried & pot: & ato. & . & . & & . 100 & $x$ & 0.57 & $=$ & 0.570 \\
\hline Strawber & rry sl & hort & t-cake & & . & & . 120 & $x$ & 0.50 & $=$ & 0.600 \\
\hline
\end{tabular}

Fuel value of the food . . , , 2321 calories. 
MENDEL.

\section{Monday, May 23, 1904.}

Breakfast. - Banana 229 grams, coffee 125 grams, sugar 21 grams, cream 25 grams.

Lunch. - Bread 58 grams, apple sauce 125 grams, scrambled egg 15 grams, consommé 75 grams, fried potato 170 grams, rice croquette 197 grams, syrup 68 grams, coffee 100 grams, sugar 21 grams, cream 30 grams.

Dinner. - Bread 72.5 grams, vegetable soup 100 grams, potato croquette 198 grams, bacon 7 grams, string beans 120 grams, water ice 77 grams, coffee 100 grams, cream 30 grams, sugar 14 grams, banana 270 grams.

\begin{tabular}{|c|c|c|c|c|c|c|c|c|c|c|c|c|c|}
\hline Food. & & & & & & & & & Grams. & & $r$ cent $N i t r$ & ogen. & Total Nitrogen. \\
\hline Banana & . & . & & . & . & . & . & . & . $\quad 229$ & $x$ & 0.23 & $=$ & 0.527 grams \\
\hline Coffee & . & . & . & . & . & . & . & . & 125 & $\times$ & 0.06 & $=$ & 0.075 \\
\hline Sugar & . & . & . & . & . & . & . & . & 21 & $x$ & 0.00 & $=$ & 0.000 \\
\hline Crean & . & . & . & . & . & . & . & . & 25 & $x$ & 0.45 & $=$ & 0.113 \\
\hline Bread & . & . & . & . & . & . & . & . & 58 & $x$ & 1.63 & $=$ & 0.945 \\
\hline Apple sa & auce & & . & . & . & . & . & . & 125 & $x$ & 0.02 & $=$ & 0.025 \\
\hline Scramble & ed e & egg & & . & . & . & . & . & 15 & $x$ & 2.07 & $=$ & 0.311 \\
\hline Consomn & & & . & . & . & . & . & . & 75 & $x$ & 0.65 & $=$ & 0.488 \\
\hline Fried pot & tato & & . & . & . & . & . & . & . 170 & $x$ & 0.60 & $=$ & 1.020 \\
\hline Rice croq & quet & tte & & . & . & . & . & . & . 197 & $x$ & 0.61 & $=$ & 1.202 \\
\hline Syrup & . & . & . & . & . & . & . & . & 68 & $\times$ & 0.024 & $=$ & 0.016 \\
\hline Coffee & . & . & . & . & . & . & . & . & . 100 & $x$ & 0.06 & $=$ & 0.060 \\
\hline Sugar . & . & . & . & . & . & . & . & . & . 21 & $x$ & 0.00 & $=$ & 0.000 \\
\hline Cream & . & . & . & . & . & . & . & . & 30 & $x$ & 0.45 & $=$ & 0.135 \\
\hline Bread & . & . & . & . & . & . & . & . & . $\quad 72.5$ & $x$ & 1.75 & $=$ & 1.269 \\
\hline Soup . & . . & . & . & - & . & . & . & . & . 100 & $\times$ & 0.70 & $=$ & 0.700 \\
\hline Potato er & roq 1 & uet & tte & . & . & . & . & . & . 198 & $\times$ & 0.77 & $=$ & 1.525 \\
\hline Bacon & . & · & . & . & . & . & . & . & . $\quad 7$ & $x$ & 3.28 & $=$ & 0.230 \\
\hline String be & eans & & . & . & . & . & . & . & . 120 & $\times$ & 0.22 & $=$ & 0.264 \\
\hline Water ic & & . & . & . & . & . & . & . & . $\quad 77$ & $x$ & 0.006 & $=$ & 0.005 \\
\hline Coffee & . & . & . & . & . & . & . & . & . 100 & $\times$ & 0.06 & $=$ & 0.060 \\
\hline Cream & . & . & . & . & . & . & . & . & . $\quad 30$ & $x$ & 0.45 & $=$ & 0.135 \\
\hline Sugar. & . & . & - & . & . & . & . & . & . 14 & $x$ & 0.00 & $=$ & 0.000 \\
\hline Banana & . & . & . & . & - & . & . & . & . 270 & $x$ & 0.23 & $=$ & 0621 \\
\hline & & & & & & & & & $\begin{array}{l}n \text { in food } \\
n \text { in urine }\end{array}$ & . & $\begin{array}{l}\cdot \cdot \cdot \\
\cdot \cdot \cdot\end{array}$ & $\begin{array}{l}\cdot \cdot \cdot \\
\cdot \quad \cdot\end{array}$ & $\begin{array}{l}\overline{9.726} \text { gran } \\
5.750\end{array}$ \\
\hline
\end{tabular}




\section{MENDEL.}

Tuesday, May 24, 1904.

Breakfast. - Orange 100 grams, rolls 87 grams, rice 50 grams, syrup 25 grams, coffee 125 grams, sugar 21 grams, cream 50 grams.

Lunch. - Bread 77 grams, crean of celery soup 125 grams, mashed potato 270 grams, tomato sauce 50 grams, farina croquette 191 grams, syrup 78 grans, coffee 75 grams, cream 20 grams, sugar 7 grams.

Dimer. - Bread 49 grams, tomato soup 200 grams, French fried potato 200 grams, spinach 50 grams, farina croquette 276 grams, syrup 100 grams, coffee 100 grams, sugar 14 grams, cream 50 grams.

Food. Grams. Per cent Nitrogen. Total Nitrogen.

\begin{tabular}{|c|c|c|c|c|c|c|c|c|c|c|c|}
\hline Orange & & . & . & . & . & . & . 100 & $x$ & 0.20 & $=$ & 0.200 grams. \\
\hline Bread ro & ls . & . & . & . & . & . & . $\quad 37$ & $x$ & 1.64 & $=$ & 0.607 \\
\hline Rice . & . . & . & . & . & . & . & 50 & $x$ & 0.36 & $=$ & 0.180 \\
\hline Syrup & . & . & . & . & . & . & 25 & $x$ & 0.024 & $=$ & 0.006 \\
\hline Coffee & . & . & . & . & . & . & . 125 & $x$ & 006 & $=$ & 0.075 \\
\hline Sugar & . & . & . & . & . & . & . $\quad 21$ & $x$ & 0.00 & $=$ & 0.000 \\
\hline Cream & . & . & . & . & . & . & 50 & $x$ & 0.45 & $=$ & 0.225 \\
\hline Bread. & . . & . & . & . . & . & . & . 77 & $x$ & 1.66 & $=$ & 1.278 \\
\hline Celery so & up & . & . & . . & . & . & . 125 & $x$ & 0.48 & $=$ & 0.600 \\
\hline Mashed & pota & & . & . . & . & . & 270 & $x$ & 0.26 & $=$ & 0.702 \\
\hline Tomato : & sauc & e. & . & . . & . & . & 50 & $x$ & 0.23 & $=$ & 0.115 \\
\hline Farina er & roqu & lette & . & . . & . & . & . 191 & $\times$ & 0.74 & $=$ & 1.413 \\
\hline Syrup &.$\quad$. & . & . & . . & . & . & . 78 & $x$ & 0.024 & $=$ & 0.019 \\
\hline Coffee & . & .. & . & . . & . & . & 75 & $x$ & 0.06 & $=$ & 0.045 \\
\hline Cream & . & . & . & . . & . & . & 20 & $x$ & 0.45 & $=$ & 0.090 \\
\hline Sugar & . & . & . & . . & . & . & 7 & $x$ & 0.00 & $=$ & 0.000 \\
\hline Bread. & . . & . & . & $\ldots$ & . & . & 49 & $x$ & 1.82 & $=$ & 0.892 \\
\hline Tomato $\mathrm{s}$ & soun & . & . & $\therefore$ & . & * & 200 & $x$ & 0.19 & $=$ & 0.380 \\
\hline French $f$ & ried & pot & ato & . & . & . & 200 & $x$ & 0.46 & $=$ & 0.920 \\
\hline Spinach & . . & . & . & . & . & . & 50 & $x$ & 054 & $=$ & 0.270 \\
\hline Farina er & roqu & ette & . & . & . & . & . 276 & $x$ & 0.76 & $=$ & 2.098 \\
\hline Syrup & . . & . & . & . . & . & . & 100 & $x$ & 0.024 & $=$ & 0.024 \\
\hline Coffee & . & : & . & . . & . & . & 100 & $x$ & 0.06 & $=$ & 0.060 \\
\hline Sugar. & . & . & . & . & . . & . & 14 & $x$ & 0.00 & $=$ & 0.000 \\
\hline Cream. & . . & . & . & . & . . & . & 50 & $x$ & 0.45 & $=$ & 0.225 \\
\hline
\end{tabular}

Fuel value of the food . . . 3229 calories. 


\section{NITROGEN BALANCE. - Mendel.}

Nitrogen
Taken in. Nitrogen in Urine. Weight of Freces (dry).

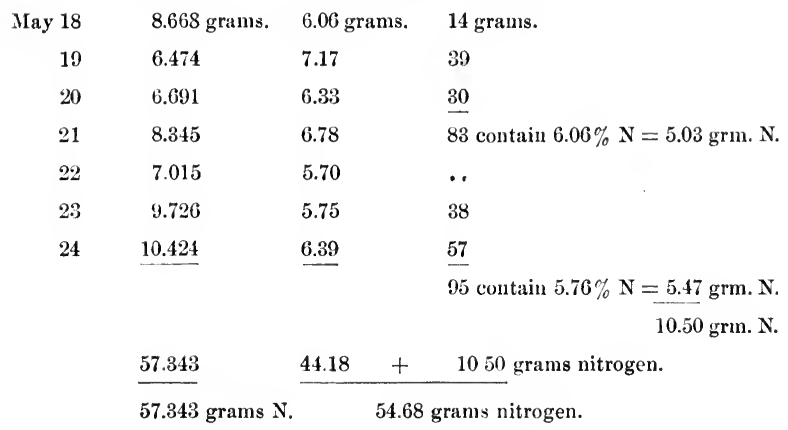

Nitrogen balançe for seven days $=\quad+2.663$ grams.

Nitrogen balance per day $=\quad+0.380$ gram.

Average Intake.

Calories per day . . . . . . . . . . 2448.

Nitrogen per day . . . . . . 8.192 grams. 
In this period of seven days the average daily intake of nitrogen was 8.192 grams, or only 0.36 gram per day more than in the first balance period, while the average fuel value of the food amounted to 2448 calories per day. Yet the average daily output of nitrogen through the urine for this period was 6.31 grams, or 1.2 grams per day less than in the first balance experiment. Further, under the conditions of this balance experiment, the body was laying up 0.380 gram of nitrogen per day, $i$. e., showing a plus balance of 2.66 grams of nitrogen for the seven days' period. Again, it is to be noted that the average daily amount of nitrogen metabolized, 6.31 grams, was 0.22 gram less than the average daily nitrogen excretion for the entire seven months' period, 6.53 grams. Evidently, this subject was quite able to maintain nitrogen equilibrium with a metabolism of only 6.31 grams of nitrogen per day, on a daily diet having a fuel value of about 2400 calories. Indeed, taking into account the amount of the plus nitrogen balance, it is evident that the daily food was somewhat in excess of the real requirements of the body, under the then existing conditions of body-weight and bodily activity.

Again, we would call attention to the thorough utilization of the food in this experiment, emphasizing at the same time the voluminous character of the diet, together with its largely vegetable nature. The contrast between the diet made use of by Dr. Mendel and that used by the subject of the first experiment is quite striking, since the latter employed a much more concentrated diet with an average fuel value of only 1600 calories. Yet with a total intake of 57.343 grams of nitrogen for the seven days of Dr. Mendel's balance period, 10.5 grams only passed out through the rectum, or 18.3 per cent, while in the second nitrogen balance of the first subject, with the more concentrated diet, 17.1 per cent of the total ingested nitrogen appeared in the frees. In view of the great divergence in the character and volume of the intake, it is rather remarkable there should be so little difference in the relative utilization of the two diets. 
Finally, taking the average daily excretion of nitrogen through the kidneys from November 10 to June 23, as a measure of the nitrogen metabolized daily, viz., 6.53 grams, and taking the body-weight at 70 kilos, it is plain to see that the nitrogen metabolized per kilo of body-weight throughout this experiment was 0.093 gram, closely similar to the result obtained with the first subject. In other words, both of these subjects, though widely different in body-weight, under different degrees of physical activity, and living on different forms of diet, seemingly required for the maintenance of equilibrium essentially the same amount of nitrogen per kilo of body-weight; viz., with the first subject 0.0947 gram, if we take the lower figure of the last two months, and 0.093 gram with the second subject.

Regarding the fuel value of the daily food, Dr. Mendel with a body-weight of 70 kilos, during the second balance period, apparently utilized on an average 34.9 calories per kilo of body-weight daily, while the first subject, of 57 kilos boly-weight, made use of only 28 calories per kilo. The fuel value of the daily food must, however, as is well known, vary greatly with differing degrees of physical activity, from which arises the necessity for corresponding variation in the amounts of non-nitrogenous foods ingested.

Dr. Frank P. Underhill, instructor in physiological chemistry in the Sheffield Scientific School, is another subject of experiment who volunteered to study on himself the effects of a lowered proteid intake. Prior to the experiment he was in the habit of eliminating from 16 to 16.5 grams of nitrogen per day through the kidneys, representing the usual 105 grams of proteid food metabolized.

Dr. Underhill, at the beginning of the experiment, July 1, 1903, was twenty-six years of age and weighed 67.6 kilos. For a period of two weeks, from July 14 to August 2, he gradually reduced the intake of proteid food as well as the total amount of food consumed, doing this in part by diminishing the quantity eaten at breakfast, and in smaller meas- 
ure at the two other meals of the day. Iuring this period of two weeks, the urine and fæces were analyzed with the results shown in the accompanying table. Regarding the extent of proteid metabolism, it will be seen that the nitrogen content of the urine fell from 14.28 grams per day down to 5 to 6 grams per day. Having reached this level, the subject maintained it throughout the summer of 1903, occasional analyses being made to demonstrate the level of nitrogen excretion.

\begin{tabular}{|c|c|c|c|c|c|c|c|c|}
\hline \multirow{2}{*}{ Date. } & \multirow{2}{*}{$\begin{array}{c}\text { Body- } \\
\text { weight. }\end{array}$} & \multicolumn{3}{|c|}{ Urine. } & \multicolumn{3}{|c|}{ Fæces. } & \multirow{2}{*}{$\begin{array}{c}\text { Total } \\
\text { Nitrogen. }\end{array}$} \\
\hline & & Volume. & Sp. Gr. & Nitrogen. & Moist. & Dry. & Nitrogen. & \\
\hline 1903. & & c.c. & & grams. & grams. & grams. & grams. & grams. \\
\hline July 14 & 67.6 & 1300 & 1018 & 14.28 & 156.0 & 30.5 & 1.59 & 15.87 \\
\hline 15 & 67.6 & 1095 & 1020 & 11.72 & 70.0 & 17.0 & 0.80 & 12.52 \\
\hline 16 & 67.1 & 860 & 1021 & 11.72 & 182.5 & 44.5 & 2.12 & 13.84 \\
\hline 17 & 66.9 & 675 & 1022 & 9.39 & 134.0 & 43.0 & 2.05 & 11.44 \\
\hline 18 & 66.3 & 865 & 1021 & 10.45 & 57.5 & 20.0 & 0.95 & 11.40 \\
\hline 19 & 65.7 & 785 & 1021 & 10.34 & 170.0 & 41.0 & 1.95 & 12.29 \\
\hline 20 & 65.7 & 740 & 1024 & 10.34 & 76.0 & 35.0 & 1.66 & 12.00 \\
\hline 21 & 65.7 & 910 & 1017 & 11.61 & 96.0 & 32.0 & 1.52 & 13.13 \\
\hline 22 & 65.7 & 900 & 1013 & 9.50 & 56.0 & 31.0 & 1.75 & 11.25 \\
\hline 23 & 65.3 & 600 & 1017 & 8.65 & 41.0 & 14.0 & 0.79 & 9.35 \\
\hline 24 & 65.0 & 640 & 1013 & 6.65 & 151.0 & 33.0 & 1.86 & 8.51 \\
\hline 25 & 65.3 & 690 & 1012 & 6.01 & 86.0 & 29.0 & 1.63 & 7.64 \\
\hline 26 & 65.3 & 410 & 1023 & 6.65 & 57.0 & 19.0 & 1.06 & 7.71 \\
\hline 27 & 65.7 & 530 & 1017 & 6.75 & 202.0 & 33.0 & 1.86 & 8.61 \\
\hline 28 & 65.7 & 610 & 1013 & 5.49 & 1550 & 26.0 & 1.46 & 6.95 \\
\hline 29 & 66.4 & 620 & 1017 & 5.96 & 121.0 & 26.0 & 1.46 & 7.42 \\
\hline 30 & 66.3 & $\tau 00$ & 1016 & 5.80 & 2333.0 & 48.0 & 2.71 & 8.51 \\
\hline 31 & 65.8 & 1265 & 1010 & 6.70 & 211.0 & 36.0 & 2.03 & 8.73 \\
\hline Aug. 1 & 653 & 1240 & 1009 & 6.23 & 172.0 & 23.0 & 1.29 & 7.52 \\
\hline 2 & 653 & 760 & 1016 & 6.75 & 214.0 & 27.0 & 1.42 & 8.17 \\
\hline 11 & 65.3 & 5010 & 1017 & 6.44 & 152.0 & $2 \cdot 2.0$ & 1.34 & 7.78 \\
\hline 12 & 65.3 & 405 & 1024 & 6.86 & 70.0 & 15.0 & $0 ! 1$ & 7.77 \\
\hline 13 & 65.3 & 540 & 1019 & 6.23 & 90.0 & 10.0 & 0.61 & 6.84 \\
\hline
\end{tabular}


In connection with the accompanying table of results, attention is called to the composition of the freces with special reference to their content of nitrogen. The point to be emphasized is the gradual increase in the percentage content of frecal nitrogen, associated with the changed diet and the general diminution of food intake. This is well illustrated by the following figures, giving the percentage of nitrogen in the dry frees for the three periods of July 14-21, July 22-30, and August 11-13:

$\begin{array}{lllll}\text { July } & 14-21, & 4.77 & \text { per cent Nitrogen } \\ \text { July } 22-30, & 5.65 & \text { " } & \text { " } & \text { " } \\ \text { Aug. 11-13, } & 6.11 & \text { " } & \text { " } & \text { " }\end{array}$

The diminished amount of fæcal discharge moans naturally not only a smaller intake of food, but implies also a greater utilization of the food ingested, and as a result the increased percentage of nitrogen in the discharges shows itself because of the relatively larger preponderance of nitrogenous secretions from the intestinal tract.

The latter part of September, 1903, Dr. Underhill attempted to return to his original methods of living, but found difficulty in consuming the daily quantities of food he had formerly been in the habit of taking. From October 11 to October 25, 1903, however, he raised the consumption of proteid food to such a degree that the nitrogen excretion through the urine averaged from 10 to 12 grams per day. After this date he fell back to the lower proteid intake, and from that period to June 23,1904 , he maintained a low level of proteid metabolism without detriment to his bodily vigor, and, as he believes, with a distinct betterment.

The following tables of results extending from October 11, 1903, to June 23, 1904, show the data collected. 
UNDERHILL.

\begin{tabular}{|c|c|c|c|c|c|c|}
\hline \multirow{2}{*}{ Date. } & \multirow{2}{*}{$\begin{array}{c}\text { Body- } \\
\text { weight. }\end{array}$} & \multicolumn{5}{|c|}{ Erine. } \\
\hline & & $\begin{array}{l}\text { Volume. } \\
24 \text { hours. }\end{array}$ & Sp. Gr. & Nitrogen. & Uric Acid. & $\mathrm{P}_{2} \mathrm{O}_{5}$. \\
\hline 1903. & kilos & c.c. & & grams & gram & grams \\
\hline Oet. 11 & 65.4 & 1300 & 1015 & 10.37 & 0.611 & 1.72 \\
\hline 12 & $\ldots$ & 700 & 1022 & 907 & $\ldots$ & $\cdots$ \\
\hline 13 & $\cdots$ & 1050 & 1022 & 12.35 & 0820 & 2.15 \\
\hline 14 & $\ldots$ & 1400 & 1017 & 12.01 & $\ldots$ & $\ldots$ \\
\hline 15 & $\cdots$ & 870 & 1020 & 11.48 & 0.671 & 1.76 \\
\hline 16 & $\ldots$ & 1165 & 1013 & 12.09 & $\ldots$ & $\ldots$ \\
\hline 17 & . & 840 & 1020 & 11.24 & $\ldots$ & $\cdots$ \\
\hline 18 & $\cdots$ & 1150 & 1017 & 10.00 & 0.613 & 1.77 \\
\hline 19 & $\ldots$ & 678 & 1022 & 7.79 & $\ldots$ & $\ldots$ \\
\hline 20 & $\ldots$ & 1165 & 1018 & 10.76 & 0.603 & 1.60 \\
\hline 21 & $\ldots$ & 1460 & 1017 & 11.91 & $\cdots$ & $\ldots$ \\
\hline 22 & $\cdots$ & 950 & 1019 & 10.71 & 0.643 & 1.73 \\
\hline 23 & $\ldots$ & 1165 & 1017 & 12.82 & $\ldots$ & $\ldots$ \\
\hline 24 & 65.4 & 850 & 1025 & 12.49 & $\cdots$ & $\ldots$ \\
\hline 25 & $\ldots$ & 850 & 1022 & 11.07 & 0.645 & 1.76 \\
\hline 26 & $\ldots$ & 1025 & 1018 & & & \\
\hline 27 & $\ldots$ & 775 & 1018 & & & \\
\hline 28 & $\ldots$ & 1140 & 1015 & & & \\
\hline 29 & $\ldots$ & 765 & 1020 & $\begin{array}{l}0.51 \\
d a i l y\end{array}$ & 0.400 & 1.18 \\
\hline 80 & $\ldots$ & 860 & 1019 & dany & diverage & uany \\
\hline 31 & $\ldots$ & 1150 & 1015 & average & average & average \\
\hline Nov. 1 & $\ldots$ & 750 & 1020 & & & - \\
\hline 2 & $\cdots$ & 675 & 1022 & & & \\
\hline 3 & $\cdots$ & 955 & 1014 & & & \\
\hline 4 & $\cdots$ & 1270 & 1012 & 7.91 & 0.469 & 1.30 \\
\hline 5 & $\ldots$ & 885 & 1015 & & & \\
\hline 6 & $\ldots$ & 770 & 1020 & & & \\
\hline 7 & $\ldots$ & 860 & 1021 & & & \\
\hline 8 & $\ldots$ & 775 & 1020 & & & \\
\hline 9 & $\ldots$ & 890 & 1018 & & & \\
\hline 10 & $\ldots$ & 1070 & 1018 & & & \\
\hline 11 & $\ldots$ & 755 & 1020 & 786 & 0.5737 & 140 \\
\hline 12 & $\ldots$ & 950 & 1023 & & & \\
\hline 13 & $\ldots$ & 1100 & 1017 & & & \\
\hline 14 & $\ldots$ & 980 & 1015 & & & \\
\hline 15 & $\ldots$ & 630 & 1020 & & & \\
\hline 16 & 65.0 & 700 & 1020 & & & \\
\hline 17 & $\ldots$ & 1000 & 1015 & 782 & 0.467 & 149 \\
\hline 18 & $\ldots$ & 940 & 1018 & 1.02 & & \\
\hline 19 & $\ldots$ & 770 & 1023 & & & \\
\hline
\end{tabular}


UNIDERHILL.

\begin{tabular}{|c|c|c|c|c|c|c|}
\hline \multirow{2}{*}{ Date. } & \multirow{2}{*}{$\begin{array}{c}\text { Body. } \\
\text { weight. }\end{array}$} & \multicolumn{5}{|c|}{ Urine. } \\
\hline & & $\begin{array}{l}\text { Volume. } \\
24 \text { hours. }\end{array}$ & Sp. Gr. & Nitrogen. & Uric Acid. & $\mathrm{P}_{2} \mathrm{O}_{5}$ \\
\hline 1903. & kilos & c.c. & & grams & gram & grams \\
\hline Nov. 20 & $\cdots$ & 770 & 1025 & & & \\
\hline 21 & $\cdots$ & 790 & 1020 & 7.82 & 0.467 & 1.49 \\
\hline 22 & $\cdots$ & 770 & 1021 & daily av. & daily av. & daily av. \\
\hline 23 & $\cdots$ & 590 & 1025 & & & \\
\hline 27 & $\cdots$ & 710 & 1024 & 8.55 & 0.476 & 1.67 \\
\hline 28 & $\cdots$ & 1080 & 1017 & 0.00 & 0.470 & 1.06 \\
\hline 29 & $\ldots$ & 760 & 1019 & j & & \\
\hline 30 & $\cdots$ & 870 & 1018 & ) & & \\
\hline Dec. 1 & $\cdots$ & 860 & 1017 & & & \\
\hline 2 & $\cdots$ & 1120 & 1015 & & & \\
\hline 3 & $\cdots$ & 1450 & 1009 & 7.72 & 0.506 & 1.43 \\
\hline 4 & $\cdots$ & 720 & 1019 & & & \\
\hline 5 & $\cdots$ & 720 & 1019 & & & \\
\hline 6 & $\cdots$ & 510 & 1027 & f & & \\
\hline 7 & 65.1 & 700 & 1018 & ) & & \\
\hline 8 & $\cdots$ & 650 & 1018 & & & \\
\hline 9 & $\cdots$ & 860 & 1013 & & & \\
\hline 10 & $\cdots$ & 975 & . 1020 & 7.36 & 0.474 & 1.44 \\
\hline 11 & $\cdots$ & 800 & 1021 & & & \\
\hline 12 & $\ldots$ & 830 & 1018 & & & \\
\hline 13 & $\cdots$ & 750 & 1019 & J & & \\
\hline 14 & $\cdots$ & 860 & 1018 & & & \\
\hline 15 & $\cdots$ & 870 & 1019 & & & \\
\hline 16 & $\cdots$ & 880 & 1015 & & & \\
\hline 17 & $\cdots$ & 820 & $\cdots$ & 8.11 & 0.497 & 1.85 \\
\hline 18 & $\cdots$ & 760 & 1021 & & & \\
\hline 19 & $\cdots$ & 860 & 1017 & & & \\
\hline 20 & $\cdots$ & 520 & 1023 & j & & \\
\hline 21 & $\cdots$ & 1200 & 1014 & 7.18 & . . & 1.05 \\
\hline 22 & 65.0 & 510 & 1025 & \} & $\cdots$ & \\
\hline 23 & $\ldots$ & 650 & $\cdots$ & ) & & \\
\hline 24 & $\cdots$ & 670 & $\cdots$ & & & \\
\hline 25 & $\cdots$ & 500 & $\cdots$ & 6.70 & 0.356 & 0.97 \\
\hline 26 & $\cdots$ & 550 & $\cdots$ & & & \\
\hline 27 & $\cdots$ & 850 & $\cdots$ & J & & \\
\hline 28 & 65.2 & 980 & $\cdots$ & & • & \\
\hline 29 & $\cdots$ & 1200 & $\cdots$ & 8.70 & 0.626 & 1.21 \\
\hline 30 & $\cdots$ & 750 & $\cdots$ & & & \\
\hline 31 & $\cdots$ & 1280 & $\cdots$ & J & & \\
\hline
\end{tabular}


UNDERHILL.

\begin{tabular}{|c|c|c|c|c|c|c|c|}
\hline \multirow{2}{*}{\multicolumn{2}{|c|}{ Date. }} & \multirow{2}{*}{$\begin{array}{c}\text { Body- } \\
\text { weight. }\end{array}$} & \multicolumn{5}{|c|}{ Urine. } \\
\hline & & & $\begin{array}{l}\text { Volume. } \\
24 \text { hours. }\end{array}$ & Sp. Gr. & Nitrogen. & Uric Acid. & $\mathrm{P}_{2} \mathrm{O}_{5}$. \\
\hline \multicolumn{2}{|l|}{1904} & kilos & c.c. & & grams & gram & grams. \\
\hline Jan. & 1 & $\ldots$ & 750 & . & & & \\
\hline & 2 & $\cdots$ & 750 & $\cdots$ & 8.7 & 0.626 & 1.21 \\
\hline & 3 & $\cdots$ & 870 & $\cdots$ & daily av. & daily av. & daily av. \\
\hline & 4 & $\cdots$ & 1230 & $\cdots$ & & & . \\
\hline & 5 & $\ldots$ & 720 & 1023 & & & \\
\hline & 6 & $\ldots$ & 960 & 1020 & & & \\
\hline & 7 & $\ldots$ & 760 & 1022 & & & \\
\hline & 8 & $\ldots$ & 1000 & 1017 & 8.23 & 0.580 & 1.24 \\
\hline & 9 & $\ldots$ & 720 & 1025 & & & \\
\hline & 10 & 65.1 & 730 & 1021 & & & \\
\hline & 11 & $\ldots$ & 700 & 1016 & 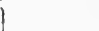 & & \\
\hline & 12 & $\cdots$ & 650 & 1020 & & & \\
\hline & 13 & $\cdots$ & 700 & 1024 & & & \\
\hline & 14 & $\ldots$ & 660 & 1025 & 7.74 & 0.618 & 1.20 \\
\hline & 15 & $\ldots$ & 610 & 1025 & & & \\
\hline & 16 & $\ldots$ & 710 & 1024 & & & \\
\hline & 17 & $\ldots$ & 660 & 1022 & & & \\
\hline & 18 & $\ldots$ & 770 & 1016 & ) & & \\
\hline & 19 & 64.8 & 700 & 1022 & & & \\
\hline & 20 & $\ldots$ & 1130 & 1018 & & & \\
\hline & 21 & $\ldots$ & 8.30 & 1020 & 7.80 & 0.705 & 1.14 \\
\hline & 22 & $\ldots$ & 600 & 1019 & & & \\
\hline & 23 & $\ldots$ & 480 & 1021 & & & \\
\hline & 24 & $\ldots$ & 750 & 1019 & & & \\
\hline & 25 & $\ldots$ & 680 & 1020 & & & \\
\hline & 26 & $\ldots$ & 800 & 1018 & & & \\
\hline & 27 & $\ldots$ & 800 & 1020 & & & \\
\hline & 28 & $\ldots$ & 700 & 1020 & 6.85 & 0.500 & 1.07 \\
\hline & 29 & 64.4 & 1010 & 1014 & & & \\
\hline & 30 & $\ldots$ & 980 & 1018 & & & \\
\hline & 31 & $\ldots$ & 820 & 1015 & & & \\
\hline Feb. & 1 & $\ldots$ & 990 & 1015 & & & \\
\hline & 2 & $\cdots$ & 660 & 1020 & & & \\
\hline & 3 & 64.4 & 1060 & 1015 & & & \\
\hline & 4 & . & 980 & 1017 & 7.98 & 0.535 & 1.24 \\
\hline & 5 & $\cdots$ & 970 & 1014 & • & & \\
\hline & 6 & $\ldots$ & 790 & 1019 & & & \\
\hline & 7 & $\ldots$ & 1120 & 1015 & & & \\
\hline & 8 & $\cdots$ & 715 & 1021 & 8.11 & $\cdots$ & $\cdots$ \\
\hline & 9 & 64.4 & 1225 & 1014 & 7.49 & 0.450 & $\ldots$ \\
\hline
\end{tabular}


UNIERIIILL.

\begin{tabular}{|c|c|c|c|c|c|c|}
\hline \multirow{2}{*}{ Date. } & \multirow{2}{*}{$\begin{array}{c}\text { Body- } \\
\text { weight. }\end{array}$} & \multicolumn{5}{|c|}{ Urine. } \\
\hline & & $\begin{array}{l}\text { Volume. } \\
24 \text { hours. }\end{array}$ & $\mathrm{S}_{i}, \mathrm{Gr}$. & Nitrogen. & Uric Acid. & $\mathrm{P}_{2} \mathrm{O}_{5}$. \\
\hline 1904. & kilos & c.c. & & grams & gram & grams \\
\hline Feb. 10 & 64.4 & 770 & 1018 & 6.14 & 0.505 & $\ldots$ \\
\hline 11 & 64.5 & 715 & $10 \cdot 2$ & 8.112 & 0.568 & $\cdots$ \\
\hline 12 & $\cdots$ & 850 & 1021 & 8.82 & 0.589 & $\cdots$ \\
\hline 13 & $\cdots$ & 490 & 1028 & 7.17 & 0.505 & $\ldots$ \\
\hline 14 & 64.4 & 795 & 1020 & 7.73 & 0.543 & $\ldots$ \\
\hline 15 & $\ldots$ & 780 & 1021 & & & \\
\hline 16 & $\cdots$ & $9 \cdot 20$ & 1023 & & & \\
\hline 17 & $\cdots$ & 660 & 1021 & & & \\
\hline 18 & $\ldots$ & 640 & 1027 & 8.27 & 0.558 & $\ldots$ \\
\hline 19 & $\ldots$ & 730 & $102: 3$ & daily & daily & \\
\hline 20 & $\ldots$ & 840 & 1027 & average & average & \\
\hline 21 & $\ldots$ & 700 & 1018 & & & \\
\hline 22 & $\ldots$ & 440 & 1025 & & & \\
\hline 23 & $\ldots$ & 600 & 1023 & & & \\
\hline 24 & $\ldots$ & 750 & 1022 & & & \\
\hline 25 & $\ldots$ & 830 & 1017 & 7.47 & 0.556 & $\ldots$ \\
\hline 26 & 64.0 & 870 & 1021 & & & \\
\hline 27 & $\ldots$ & 910 & 1015 & & & \\
\hline 28 & $\ldots$ & 950 & 1014 & & & \\
\hline 29 & . & 600 & 1021 & & & \\
\hline Mar. 1 & $\ldots$ & 680 & 1021 & & & \\
\hline 2 & $\ldots$ & 1120 & 1011 & & & \\
\hline 3 & $\cdots$ & 610 & 1021 & 7.15 & 0.526 & $\cdots$ \\
\hline 4 & $\ldots$ & 1080 & 1016 & & & \\
\hline 5 & $\ldots$ & 1220 & 1034 & & & \\
\hline 6 & $\ldots$ & 890 & 1015 & & & \\
\hline 7 & $\ldots$ & 1000 & 1014 & & & \\
\hline 8 & $\ldots$ & 650 & 1020 & & & \\
\hline 9 & $\ldots$ & 750 & 1020 & & & \\
\hline 10 & $\ldots$ & 850 & 1018 & 8.18 & 0.682 & $\ldots$ \\
\hline 11 & $\cdots$ & 950 & 1014 & & & \\
\hline 12 & $\ldots$ & 1000 & 1016 & & & t \\
\hline 13 & 64.2 & 860 & 1019 & & & \\
\hline 14 & $\ldots$ & 840 & 1020 & & & \\
\hline 15 & $\ldots$ & 920 & 1016 & & & \\
\hline 16 & $\ldots$ & 750 & 1020 & & & \\
\hline 17 & $\cdots$ & 820 & 1017 & 7.83 & 0.540 & $\ldots$ \\
\hline 18 & $\ldots$ & 1220 & 1012 & & & \\
\hline 19 & $\ldots$ & 920 & 1015 & & & \\
\hline 20 & $\ldots$ & 700 & $10 \div 2$ & & & \\
\hline
\end{tabular}


UNDERHILL.

\begin{tabular}{|c|c|c|c|c|c|c|}
\hline \multirow{2}{*}{ Date. } & \multirow{2}{*}{$\begin{array}{c}\text { Body- } \\
\text { weight. }\end{array}$} & \multicolumn{5}{|c|}{ Urine. } \\
\hline & & $\begin{array}{l}\text { Volume } \\
24 \text { hours. }\end{array}$ & Sp. Gr. & Nitrogen. & Uric Acid. & $\mathrm{P}_{2} \mathrm{O}_{5}$ \\
\hline 1904. & kilos & c.c. & & grams & gram & grams \\
\hline Mar. 21 & $\cdots$ & 900 & 1015 & & & \\
\hline 22 & $\ldots$ & 980 & 1013 & & & \\
\hline 23 & $\cdots$ & 990 & 1014 & & & \\
\hline 24 & $\cdots$ & 750 & 1020 & 8.04 & 0.733 & $\cdots$ \\
\hline 25 & $\ldots$ & 820 & 1017 & daily & daily & \\
\hline 26 & $\cdots$ & 700 & 1021 & average & average & \\
\hline 27 & $\cdots$ & 910 & 1020 & & & \\
\hline 28 & $\ldots$ & 930 & 1017 & $\cdots$ & $\cdots$ & $\cdots$ \\
\hline 30 & $\cdots$ & 900 & 1020 & $\cdots$ & $\cdots$ & $\ldots$ \\
\hline 31 & $\cdots$ & 450 & $\cdots$ & 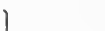 & & \\
\hline Apr. 1 & $\ldots$ & 500 & $\cdots$ & & & \\
\hline & $\cdots$ & 420 & $\cdots$ & & & \\
\hline 3 & $\ldots$ & 600 & $\ldots$ & & & \\
\hline 4 & $\cdots$ & 950 & $\cdots$ & & & \\
\hline 5 & $\ldots$ & 930 & $\cdots$ & 7.87 & 0.530 & 1.44 \\
\hline 6 & $\cdots$ & 980 & $\cdots$ & & & daily \\
\hline 7 & $\cdots$ & 600 & $\ldots$ & & & average \\
\hline 8 & $\cdots$ & 980 & $\ldots$ & & & \\
\hline 9 & $\cdots$ & 800 & $\ldots$ & - & & \\
\hline 10 & $\cdots$ & 810 & $\cdots$ & 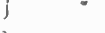 & & \\
\hline 11 & 65.2 & 940 & 1017 & & ) & \\
\hline 12 & $\cdots$ & 710 & 1024 & 9.46 & & \\
\hline 13 & $\cdots$ & 750 & 1024 & J & & \\
\hline 14 & $\cdots$ & 740 & $10: 20$ & 7.55 & 0.496 & . \\
\hline 15 & $\cdots$ & 590 & 1024 & 6.51 & & \\
\hline 16 & $\cdots$ & 900 & 1016 & 7.51 & & \\
\hline 17 & $\cdots$ & 1290 & 1009 & 511 & & \\
\hline 18 & 65.2 & 590 & 1017 & 5.96 & & \\
\hline 19 & $\cdots$ & 630 & 1024 & 6.39 & & \\
\hline 20 & $\cdots$ & 670 & 1022 & 7.48 & & \\
\hline 21 & $\cdots$ & 900 & 1021 & 8.10 & 0.527 & $\cdots$ \\
\hline 22 & $\cdots$ & 980 & 1017 & 7.00 & & \\
\hline 23 & $\cdots$ & 850 & 1019 & 7.60 & & \\
\hline 24 & $\cdots$ & 610 & 1023 & 733 & & \\
\hline 25 & 65.0 & 600 & 1021 & 8.23 & & \\
\hline 26 & $\cdots$ & 610 & 1014 & 5.82 & & \\
\hline 27 & $\ldots$ & 600 & 1023 & 7.27 & 0.490 & \\
\hline 28 & $\ldots$ & 970 & 1015 & 7.05 & 0.490 & $\cdots$ \\
\hline 29 & $\ldots$ & 795 & 1017 & 5.91 & & \\
\hline 30 & $\ldots$ & 700 & 1021 & 6.80 & & \\
\hline
\end{tabular}


UNDERHILL.

\begin{tabular}{|c|c|c|c|c|c|c|c|}
\hline \multirow{2}{*}{\multicolumn{2}{|c|}{ Date. }} & \multirow{2}{*}{$\begin{array}{c}\text { Body- } \\
\text { weight. }\end{array}$} & \multicolumn{5}{|c|}{ Urine. } \\
\hline & & & $\begin{array}{l}\text { Volume. } \\
24 \text { hours. }\end{array}$ & Sp. Gr. & Nitrogen. & Uric Acíd. & $\mathrm{P}_{2} \mathrm{O}_{5}$. \\
\hline \multicolumn{2}{|l|}{1904} & kilos & c.c. & & grams & gram & grams \\
\hline \multirow[t]{31}{*}{ May } & 1 & $\cdots$ & 795 & 1016 & 5.72 & 0.490 & . \\
\hline & 2 & 65.2 & 860 & 1017 & 6.50 & & \\
\hline & 3 & $\cdots$ & 1120 & 1016 & 6.92 & & \\
\hline & 4 & $\ldots$ & 1090 & 1015 & 6.54 & & \\
\hline & 5 & $\ldots$ & 580 & 1021 & 5.92 & 0.344 & $\cdots$ \\
\hline & 6 & $\cdots$ & 700 & 1020 & 7.29 & daily & \\
\hline & 7 & $\cdots$ & 895 & 1017 & 8.97 & average & \\
\hline & 8 & $\ldots$ & 800 & 1016 & 7.30 & & \\
\hline & 9 & 65.2 & 895 & 1019 & 6.28 & & \\
\hline & 10 & $\ldots$ & 850 & 1019 & 6.27 & & \\
\hline & 11 & $\ldots$ & 960 & 1019 & 7.26 & & \\
\hline & 12 & $\cdots$ & 690 & 1022 & 6.29 & 0.416 & $\cdots$ \\
\hline & 13 & . & 990 & 1017 & 7.96 & & \\
\hline & 14 & $\cdots$ & 690 & 1022 & 7.21 & & \\
\hline & 15 & $\ldots$ & 900 & 1015 & 6.15 & & \\
\hline & 16 & 65.1 & 945 & 1014 & 5.10 & & \\
\hline & 17 & $\ldots$ & 1090 & 1016 & 6.15 & & \\
\hline & 18 & $\cdots$ & 620 & 1020 & 5.21 & & \\
\hline & 19 & $\ldots$ & 1110 & 1015 & 6.53 & & \\
\hline & 20 & $\cdots$ & 895 & 1016 & 6.12 & 0.364 & $\cdots$ \\
\hline & 21 & $\cdots$ & 810 & 1019 & 6.95 & & \\
\hline & 22 & $\cdots$ & 1110 & 1016 & 8.72 & & \\
\hline & 23 & 65.0 & 685 & 1020 & 7.07 & & \\
\hline & 24 & $\cdots$ & 560 & 1021 & 6.78 & & \\
\hline & 25 & $\cdots$ & 1090 & 1010 & 6.02 & & \\
\hline & 26 & $\ldots$ & 610 & 1017 & 5.97 & & \\
\hline & 27 & $\ldots$ & 790 & 1016 & 6.83 & & \\
\hline & 28 & $\ldots$ & 1100 & 1014 & 7.65 & 0.420 & $\cdots$ \\
\hline & 29 & $\cdots$ & 650 & 1021 & 6.12 & & \\
\hline & 30 & 65.0 & 630 & 1021 & 5.21 & & \\
\hline & 31 & $\cdots$ & 660 & 1018 & 5.07 & & \\
\hline \multirow[t]{9}{*}{ June } & 1 & 65.1 & 920 & 1014 & 5.96 & $\cdots$ & $\cdots$ \\
\hline & 2 & 65.1 & 800 & 1013 & 5.81 & $\cdots$ & . \\
\hline & 3 & 65.0 & 950 & 1014 & 7.30 & $\cdots$ & $\cdots$ \\
\hline & 4 & $\ldots$ & 790 & 1015 & 6.78 & $\cdots$ & . \\
\hline & 5 & $\cdots$ & 780 & 1020 & 8.28 & $\cdots$ & . \\
\hline & 6 & 65.1 & 890 & 1015 & 6.89 & $\cdots$ & . \\
\hline & 7 & $\cdots$ & 720 & 1017 & 5.87 & . & . \\
\hline & 8 & $\ldots$ & 950 & 1015 & 5.93 & $\cdots$ & . \\
\hline & 9 & $\ldots$ & 1060 & 1014 & 4.96 & $\ldots$ & . \\
\hline
\end{tabular}




\section{UNDERHILL.}

\begin{tabular}{|c|c|c|c|c|c|c|}
\hline \multirow{2}{*}{ Date. } & \multirow{2}{*}{$\begin{array}{c}\text { Body- } \\
\text { weight. }\end{array}$} & \multicolumn{5}{|c|}{ Urine. } \\
\hline & & $\begin{array}{l}\text { Volume. } \\
24 \text { hours. }\end{array}$ & Sp. Gr. & Nitrogen. & Uric Acid. & $\mathrm{P}_{2} \mathrm{O}_{5}$. \\
\hline 1904 & kilos & c.c. & & grams & gram & grams \\
\hline June 10 & $\ldots$ & 940 & 1017 & 5.92 & $\ldots$ & $\ldots$ \\
\hline 11 & $\cdots$ & 1050 & 1019 & 7.62 & $\ldots$ & $\ldots$ \\
\hline 12 & $\ldots$ & 1000 & 1017 & 6.66 & $\ldots$ & $\ldots$ \\
\hline 13 & $\cdots$ & 890 & 1021 & 7.26 & $\cdots$ & $\ldots$ \\
\hline 14 & $\ldots$ & 1340 & 1016 & 6.91 & $\ldots$ & $\ldots$ \\
\hline 15 & $\cdots$ & 1190 & 1015 & 6.86 & $\ldots$ & $\ldots$ \\
\hline 16 & $\cdots$ & 720 & 1025 & 7.99 & $\ldots$ & $\ldots$ \\
\hline 17 & 65.2 & 800 & 1017 & 7.25 & $\ldots$ & $\ldots$ \\
\hline 18 & $\cdots$ & 820 & 1018 & 6.99 & $\ldots$ & $\ldots$ \\
\hline 19 & $\ldots$ & 920 & 1014 & 6.18 & $\ldots$ & $\ldots$ \\
\hline 20 & $\cdots$ & 890 & 1015 & 6.03 & $\ldots$ & $\cdots$ \\
\hline 21 & $\ldots$ & 900 & 1016 & 6.37 & $\ldots$ & $\ldots$ \\
\hline 22 & $\cdots$ & 760 & 1018 & 6.79 & $\ldots$ & $\cdots$ \\
\hline 23 & $\cdots$ & 630 & 1020 & 6.06 & $\cdots$ & $\ldots$ \\
\hline \multirow{2}{*}{\multicolumn{2}{|c|}{$\begin{array}{l}\text { Daily average from } \\
\text { Oct. } 26,1903\end{array}$}} & & & & & \\
\hline & & 833 & 1.018 & 7.43 & 0.516 & 1.28 \\
\hline
\end{tabular}

It will be seen by a study of the analytical data that Dr. Underhill had an average daily excretion of nitrogen through the kidneys from October 26, 1903, to June 23, 1904, of 7.43 grams. From October 26 to April 13, a period of nearly six months, the average daily excretion was 7.81 grams of nitrogen, while from the latter date to June 23 the average daily excretion amounted to 6.68 grams of nitrogen. Taking the body-weight at 65 kilos, the lower nitrogen figure would mean a metabolism of 0.102 gram of nitrogen per kilo of bodyweight, closely akin to the figures obtained with the two preceding subjects.

An excretion of 6.68 grams of nitrogen corresponds to the metabolism of 41.75 grams of proteid matter, while the excretion of 7.43 grams of nitrogen implies the metabolism of 46.4 grams of proteid, being less than one-half the ordinarily accepted requirement for the healthy adult. 
During this long period of eight months the body-weight was stationary, carrying with it the assumption that the body was in a condition of nitrogen equilibrium. It should be emphasized in connection with Dr. Underhill's case, that throughout the entire period of eight months, and more, there was perfect freedom in the choice of food. Further, it will be noticed by a study of the dietary made use of in the balance experiments that Dr. Underhill did not reduce his nitrogen intake by any exclusion of meat. He practically made use of his ordinary diet, such as he had always been accustomed to, but with a decided diminution of the amount of proteid food, accompanied by a gradual reduction in the total amount of food consumed each day. His diet, therefore, was in no sense a regetable diet. Meat was conspicuous in his daily food, but naturally in reduced quantities.

On February 9 a nitrogen balance was attempted, in which a careful comparison of the nitrogen content of all intake and output was made for a period of six days. By a study of the results of this balance period, shown in the accompanying tables, it will be noticed that not only was there no deficiency of nitrogen, but the body was laying on nitrogen at the rate of 0.158 gram per day. Further, it will be observed that the fuel value of the food per day averaged only a little over 2000 calories. Yet this amount of food, with its comparatively low fuel value, carried with it only 8.83 grams of nitrogen per day. Upon this quantity of food the body was able to maintain itself, with a little nitrogen to spare and with sufficient fuel value in the food to supply all the energy required for muscular contraction, mental effort, and the maintenance of body temperature. 


\section{UNDERHILL.}

\section{Tuesday, February 9 1904.}

Breakfast. - Bread 22 grams, tea 146 grams.

Lunch. - Macaroni 129 grams, fried sweet potato 85.5 grams, bread 59 grams, butter 15 grams, fig cake with wine sauce 115 grams, sugar 15 grams, coffee 210 grams.

Dinner. - Bread 27.9 grams, beef 48 grams, potato 207.5 grams, butter 19 grams, pie 272 grams, coffee 210 grams, sugar 10 grams.

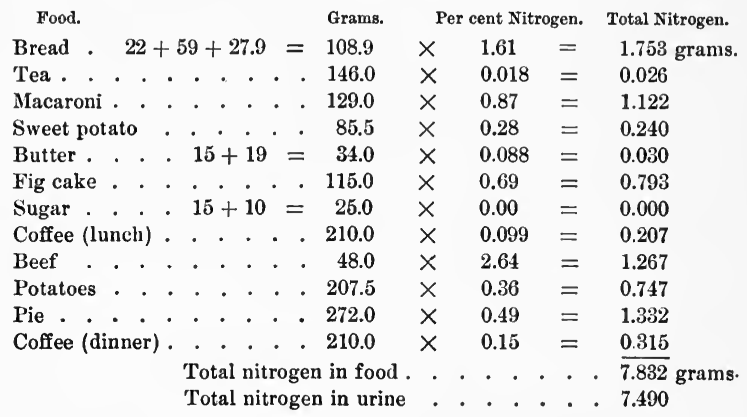

Fuel value of the food . . 2232 calories.

Wednesday, February 10, 1904.

Breakfast. - Bread 33 grams, tea 146 grams.

Lunch. - Bread 71 grams, butter 10.5 grams, apple fritters 119 grams, coffee 210 grams, sugar 21 grams.

Dinner. - Roast pork 80 grams, bread 55.7 grams, butter 27.8 grams, cranberry sauce 150 grams, coffee 210 grams, sugar 21 grams.

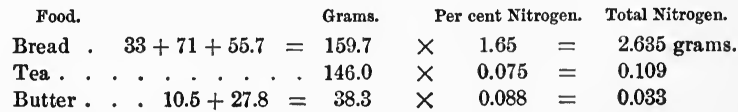




\section{UNDERHILL.}

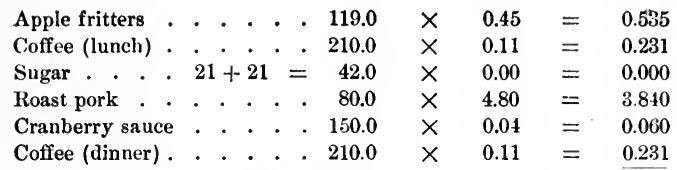

Total nitrogen in food . . . . . . . 7.674 grams.

Total nitrogen in urine . . . . . . . 6.140

Fuel value of the food . . . 1694 calories.

Thursday, February 11, 1904.

Breakfast. - Bread 38.7 grams, tea 146 grams.

Lunch. - Bread 97.5 grams, butter 31.5 grams, sweet potato 108.7 grams, spaghetti 82.5 grams, peaches 89.4 grams, coffee 210 grams, sugar 21 granis.

Dinner. - Bread 75 grams, butter 21.5 grams, roast beef 116 grams, lemon pie 188.5 grams, coffee 210 grams, sugar 21 grams.

\begin{tabular}{|c|c|c|c|c|c|c|c|}
\hline \multicolumn{3}{|l|}{ Food. } & Grams. & \multicolumn{3}{|c|}{ Per cent Nitrogen. } & \multirow{2}{*}{$\begin{array}{c}\text { Total Nitrogen. } \\
3.696 \text { grams. }\end{array}$} \\
\hline Bread . 38.7 & $+97.5+75$ & $=$ & 211.2 & $x$ & 1.75 & $=$ & \\
\hline Tea . . . & . . . . & . . & 146.0 & $x$ & 0.084 & $=$ & 0.122 \\
\hline Butter. . & $31.5+21.5$ & $=$ & 53.0 & $x$ & 0.088 & $=$ & 0.016 \\
\hline Sweet potato & . . . . & . . & 108.7 & $x$ & 0.31 & $=$ & 0.336 \\
\hline Spaghetti. . & $\cdot \cdot \cdot$ & . & 82.5 & $\times$ & 0.47 & $=$ & 0.387 \\
\hline Peaches . . & . . & . & 89.4 & $x$ & 0.09 & $=$ & 0.080 \\
\hline Coffee (lunch) & . . . & . . & 210.0 & $\times$ & 0.096 & $=$ & 0.201 \\
\hline Sugar . . & . $21+21$ & $=$ & 42.0 & $x$ & 0.00 & $=$ & 0.000 \\
\hline Roast beef & . $\cdot$ & . . & 116.0 & $x$ & 3.00 & $=$ & 3.480 \\
\hline Lemon pie . & . . & . & 188.5 & $x$ & 0.61 & $=$ & 1.149 \\
\hline Coffee (dinner) & . . . & . & 210.0 & $x$ & 0.13 & $=$ & 0.273 \\
\hline & $\begin{array}{l}\text { Total nit } \\
\text { Total nit }\end{array}$ & $\begin{array}{l}\text { roge } \\
\text { troge }\end{array}$ & in urine & - & .. & . & $\begin{array}{l}9.770 \text { grams. } \\
8.020\end{array}$ \\
\hline
\end{tabular}

Fuel value of the food . . . 2334 calories. 


\title{
UNDERHILL.
}

\author{
Friday, February I2, 1904.
}

Breakfast. - Bread 34 grams, tea 146 grams.

Lunch. - Bread 42 grams, butter 20 grams, codfish cake 72 grams, potato 100 grams, custard 100 grains, coffee 210 grams, sugar 21 grams.

Dinner. - Bread 46 grams, butter 25.5 grams, veal 53 grams, potato 75 grams, lima beans 50 grams, apple dumpling 120 grams, coffee 210 grams, sugar 21 grams.

Food. Grams. Per cent Nitrogen. Total Nitrogen.

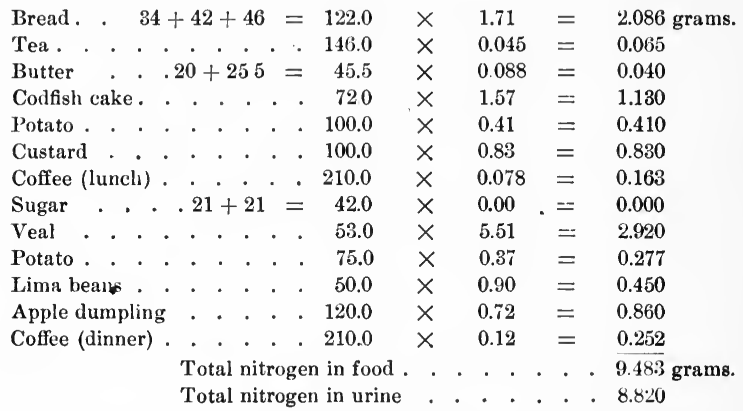

Fuel value of the food . . . 1735 calories.

Saturday, February 13, 1904.

Breakfast. - Bread 35 grams, tea 146 grams.

Lunch. - Bread 57.5 grams, butter 28 grams, sweet potato 100 grams, coffee 210 grams, sugar 21 grams, quince 105.5 granıs, apple turnovers 153 grams.

Dinner. - Bread 35.5 grams, butter 11 grams, peas 70 grams, roast beef 50 grams, pie 169 grams, coffee 210 grams, sugar 21 grams.

Food. Grams. Per cent Nitrogen. Total Nitrogen.

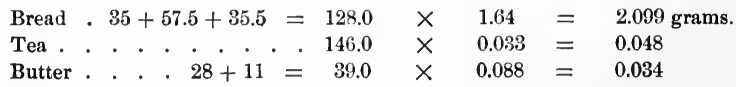




\section{UNDERHILL.}

\begin{tabular}{|c|c|c|c|c|c|c|c|c|c|}
\hline Sweet potato & : & - & . & . & 100.0 & $x$ & 0.37 & $=$ & 0.370 \\
\hline Coffee (lunch) & . & . . & . & . & 210.0 & $x$ & 0.15 & $=$ & 0.815 \\
\hline Sugar . . & . & $21+$ & -21 & $=$ & 42.0 & $\times$ & 0.00 & $=$ & 0.000 \\
\hline Quince . . & . & . . & . & . & 105.5 & $x$ & 0.047 & $=$ & 0.049 \\
\hline Apple turnover & & . & . & . & 153.0 & $x$ & 0.96 & $=$ & 1.468 \\
\hline Peas . . & . & . & . & . & 70.0 & $x$ & 0.96 & $=$ & 0.672 \\
\hline Roast beef & . & . & . & . & 50.0 & $x$ & 3.22 & $=$ & 1.610 \\
\hline Pie . . . . & . & . & . & . & 169.0 & $\times$ & 0.43 & $=$ & 0.726 \\
\hline Coffee (dinner) & . & . . & & & 210.0 & $x$ & 0.11 & $=$ & 0.231 \\
\hline & & $\begin{array}{l}\text { Cotal } \\
\text { Cotal }\end{array}$ & & & $\begin{array}{l}\mathrm{n} \text { in food } \\
\mathrm{n} \text { in urine }\end{array}$ & . & . & $\cdot$ & $\begin{array}{l}7.622 \text { grams } \\
7.170\end{array}$ \\
\hline
\end{tabular}

Fuel value of the food . . . . 2186 calories.

Sunday, February 14, 1904.

Breakfast. - Bread 31 grams, tea 146 grams.

Lunch. - Bread 70.5 grams, butter 29 grams, potato 123 grams, apple sauce 127.5 grams, coffee 210 grams, sugar 21 grams.

Dinner. - Bread 20.5 grams, butter 23 grams, chicken 101.5 grams, potato 80 grams, succotash 80 grams, chocolate cake 103 grams, ice cream 125.8 grams, coffee 210 grams, sugar 21 grams.

Food. Grams. Per cent Nitrogen. Total Nitrogen.

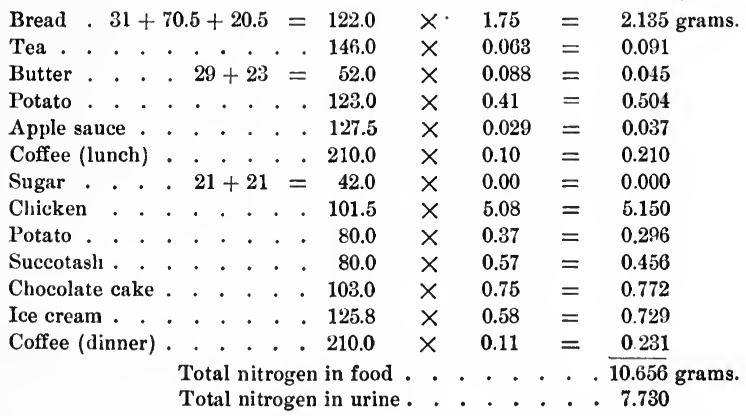

Fuel value of the food . . . 2231 calories. 


\section{NITROGEN BALANCE. - Underhill.}

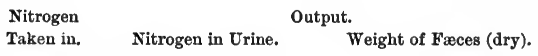

Feb. 9
7.832 grams. $\quad 7.49$ grams. $\quad 9.5$ grams.

10

7.674

6.14

11

9.770

8.02

32.0

12

9.483

8.82

9.5

13

7.622

7.17

28.0

14

$\underline{10.656}$

7.73

24.0

103.0 grams contain

$$
6.52 \% \mathrm{~N} \text {. }
$$

$\frac{53.037}{53.037}$ grams nitrogen. $\quad \begin{array}{lll}45.37 & +085 \text { grams nitrogen. }\end{array}$

Nitrogen balance for six days $=+0.952$ gram.
Nitrogen balance per day $=\quad+0.158$ gram.

Average Intake.

Calories per day . . . . . . . . 2068.

Nitrogen per day . . . . . . . 8.83 grams. 
On June 1, near the close of the experiment, a second nitrogen balance was attempted, with a view to seeing if under the existing conditions of life and activity it was possible to reduce the fuel value of the food, and at the same time diminish in still greater measure the quantity of proteid food taken. The results of this trial are seen in the accompanying tables, where for four days a eareful comparison of output and intake is shown. It will be observed from these tables that the average fuel value of the food per day was reduced to 1785 calories, and that the average intake of nitrogen was restricted to 6.73 grams per day. The balance shown is a minus balance. although the deficiency per diem is not large. It is very obvious that both the nitrogen and fuel value of the food can be reduced considerably below the average maintained during the period of the first balance, but not to the degree attempted in the second balance, and secure nitrogen or body equilibrium. It will be noted in this last nitrogen balance, that the average daily output of nitrogen through the urine amounted to 6.46 grams, while the average nitrogen intake was 6.73 grams. The fuel value of the food, however, averaged only 1785 calories per day. It is quite evident, if the non-nitrogenous food had not been reduced quite so much, that a plus nitrogen balance would have been obtained. Still, it is obvious that under the conditions of life and activity, this subject needed to metabolize only about 40 grams of proteid per day, with the total fuel value of his food equal to about 2000 calories, in order to secure both body and nitrogen equilibrium. Here, again, we have an illustration of the possibility of physiological economy which shows itself in a reduction of the daily proteid food more than 50 per cent, with a reduction of the non-nitrogenous food fully 30 per cent, and with maintenance of health, strength and vigor equal, if not superior, to that which the subject has ever experienced. 


\section{UNDERHILL.}

\section{Wednesday, June 1, 1904.}

Breakfast. - Champagne wafer 21.5 grams, tea 146 grams, sugar 15 grams.

Dinner. - Bread 67.4 grams, butter 15.1 grams, beefsteak 55.5 grams, potato 128 grams, asparagus 103.5 grams, tea 146 grams, sugar 15 grams, banana 83.5 grams.

Supper. - Bread 15.7 grams, butter 11.8 grams, banana and nuts 106 grams, crullers 90.2 grams, coffee 145 grams, sugar 15 grams.

Food. Grams. Per cent Nitrogen. Total Nitrogen.

\begin{tabular}{|c|c|c|c|c|c|c|c|c|c|c|c|c|}
\hline Champa & agn & e wafer & . & • & - & - & - & 21.5 & $x$ & 0.64 & $=$ & 0.138 gram. \\
\hline Tea & . & . . . & . & . & . & - & . & 146.0 & $x$ & 0.015 & $=$ & 0.022 \\
\hline Sugar & . & $15+$ & +15 & + & 15 & & $=$ & 45.0 & $x$ & 0.000 & $=$ & 0.000 \\
\hline Breall & & . 67 & $7.4-$ & +1 & 5.7 & & $=$ & 83.1 & $x$ & 1.46 & $=$ & 1.212 \\
\hline Butter & & . 15 & .1 & +1 & 1.8 & & $=$ & 26.9 & $x$ & 0.10 & $=$ & 0.027 \\
\hline Banana & & . . & . & . & $\cdot$ & - & - & 83.5 & $x$ & 0.23 & $=$ & 0.192 \\
\hline Beefstea & & . & . & . & . & . & . & 55.5 & $x$ & 4.72 & $=$ & 2.620 \\
\hline Potato & & . & . & . & . & - & . & 128.0 & $x$ & 0.32 & $=$ & 0.410 \\
\hline Asparag & gus & . & . & . & . & . & . & 103.5 & $\times$ & 0.35 & $=$ & 0.362 \\
\hline Tea . & & . . . & . & . & . & . & . & 146.0 & $x$ & 0.033 & $=$ & 0.048 \\
\hline Crullers & & . . . & . & . & . & . & . & 90.2 & $x$ & 1.04 & $=$ & 0.938 \\
\hline Banana & anc & d nuts & . & . & . & . & - & 106.0 & $x$ & 0.69 & $=$ & 0.731 \\
\hline Coffee & . & . $\cdot \cdot$ & - & . & . & . & ${ }^{\circ}$ & 145.0 & $x$ & 0.060 & $=$ & 0.087 \\
\hline
\end{tabular}

Fuel value of the food . . . 1913 calories.

\section{Thursday, June 2, 1904 .}

Breakfast. - Bread 30 grams, tea 146 grams, sugar 15 grams.

Dinner. - Clam chowder 270.5 grams, bread 64 grams, butter 14.5 grams, lobster 36.5 grams, Saratoga chips 15 grams, caramel custard 79 grams, tea 146 grams, sugar 15 grams.

Supper. - Bread 35.2 grams, butter 13.8 grams, pineapple 148.7 grams, crullers 84.8 grams, tea 140 grams, sugar 15 grams.

\begin{tabular}{|c|c|c|c|c|c|c|c|c|c|c|}
\hline \multicolumn{6}{|c|}{ Food. } & Grams. & \multicolumn{3}{|c|}{ Per cent Nitrogen. } & Total Nitrogen. \\
\hline & . & - & • & . & - & 30.0 & $x$ & 1.46 & $=$ & 0.438 gra \\
\hline & . & . & . & & . & 146.0 & $x$ & 0.045 & $=$ & 0.066 \\
\hline agar & . & $15+$ & +15 & +15 & $=$ & 45.0 & $x$ & 0.00 & $=$ & 0.000 \\
\hline
\end{tabular}




\section{UNDERHILL.}

\begin{tabular}{|c|c|c|c|c|c|c|c|c|c|c|c|c|}
\hline Bread . & . & & 64 & +8 & 35.2 & & $=$ & 99.2 & $x$ & 1.44 & $=$ & 1.428 \\
\hline Butter . & 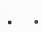 & & 14.5 & +1 & 13.8 & & $=$ & 28.3 & $x$ & 0.10 & $=$ & 0.028 \\
\hline Clam chow & wder & . & . & . & . & • & . & 270.5 & $x$ & 0.34 & $=$ & 0.920 \\
\hline Lobster & . . & . & . & . & . & . & . & 36.5 & $x$ & 373 & $=$ & 1.361 \\
\hline Saratoga & chips & s & . & . & . & . & . & 15.0 & $x$ & 0.97 & $=$ & 0.146 \\
\hline Caramel c & eusta & & . & . & . & . & . & 79.0 & $x$ & 0.77 & $=$ & 0.608 \\
\hline Tea . . & . . & - & . & . & . & ${ }^{\circ}$ & ${ }^{\circ}$ & 146.0 & $x$ & 0.036 & $=$ & 0.053 \\
\hline Tea. . & . & . & . & . & . & . & . & 140.0 & $x$ & 0.036 & $=$ & 0.050 \\
\hline Pineapple & . & - & ${ }^{\circ}$ & . & 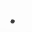 & . & . & 148.7 & $x$ & 0.054 & $=$ & 0.080 \\
\hline Crullers & . & . & . . & • & . & . & . & 84.8 & $x$ & 1.04 & $=$ & 0.882 \\
\hline & & & $\begin{array}{l}\text { To } \\
\text { To }\end{array}$ & & ni & & & in foo & & $\cdot$ & . & $\begin{array}{l}\text {. } \overline{6.060} \text { grams. } \\
\text {. } 5.810\end{array}$ \\
\hline
\end{tabular}

Fuel value of the food . . . . 1921 calories.

\section{Friday, June 3, 1904.}

Breakfast. - Bread 31 grams, tea 146 grams.

Dinner. - Fried ham 61 granss, asparagus 124.2 grams, baked potato 85 grams, bread 29 grams, butter 23.5 grams, tea 140 grams, sugar 15 grams, pineapple 74.8 grams.

Supper.-Bread 34 grams, butter 17.8 grams, pineapple 158.5 grams, tomato 132.5 grams, cup cake 121 grams, tea 140 grams, sugar 15 grams.

\begin{tabular}{|c|c|c|c|c|c|c|c|c|}
\hline Food. & & & & Grams. & & cent Nitro & gen. & Total Nitrogen. \\
\hline Bread & . & $31+29+34$ & $=$ & 94.0 & $x$ & 1.44 & $=$ & 1.354 grams \\
\hline Tea. . & . &.... & . & 146.0 & $x$ & 0.039 & $=$ & 0.057 \\
\hline Fried han & & . . . . . & . & 61.0 & $x$ & 4.90 & $=$ & 2.989 \\
\hline Asparagus & & . . & . & 124.2 & $x$ & 0.50 & $=$ & 0.621 \\
\hline Baked pot & tato & . . . . & . . & 85.0 & $x$ & 0.55 & $=$ & 0.468 \\
\hline Butter . & . & . $23.5+17.8$ & $=$ & 41.3 & $x$ & 0.10 & $=$ & 0.041 \\
\hline Tea . & . & . . . . . & . . & 140.0 & $x$ & 0.027 & $=$ & 0.038 \\
\hline Sugar . & . & . . $15+15$ & $=$ & 30.0 & $x$ & 0.000 & $=$ & 0.000 \\
\hline Pineapple & . & $.74 .8+158.5$ & $=$ & 233.3 & $x$ & 0.065 & $=$ & 0.152 \\
\hline Tea. . & . & . $\cdot \cdot \cdot \cdot$ & . . & 140.0 & $x$ & 0.054 & $=$ & 0.076 \\
\hline Tomato & . & . . & . & 132.5 & $x$ & 0.150 & $=$ & 0.199 \\
\hline Cup cake & & . . . . & . . & 121.0 & $x$ & 0.85 & $=$ & 1.029 \\
\hline & & $\begin{array}{l}\text { Total nit } \\
\text { Total nit }\end{array}$ & $\begin{array}{l}\text { roge } \\
\text { roger }\end{array}$ & in urine & & $\begin{array}{l}\cdot \cdot \cdot \\
\cdot \quad \cdot\end{array}$ & . $\cdot$ & $\begin{array}{ll} & 7.024 \\
\text {. } & 7.300\end{array}$ \\
\hline
\end{tabular}

Fuel value of the food . . . 2011 calories. 


\section{UNDERHILL.}

\section{Saturday, June 4, 1904.}

Breakfast. - Bread 32 grams, tea 140 grams.

Dinner. - Hash 133 grams, peas 151.5 grams, bread 61.4 grams, butter 16.1 grams, custard 150 grams, sugar 15 grams, tea 140 grams.

Supper.-Bread 62.5 grams, butter 17 grams, tea 140 grams, sugar 15 grams.

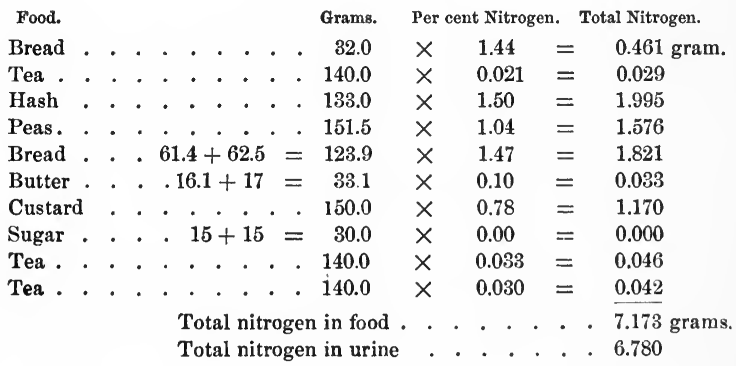

Fuel value of the food . . . 1297 calories. 


\section{PHYSIOLOGICAL ECONOMY IN NUTRITION}

\section{NITROGEN BALANCE.-Underhill.}

\section{Nitrogen Output.}

Taken in. Nitrogen in Urine. Weight of Frees (dry).

$\begin{array}{rlll}\text { June } 1 & 6.787 \text { grams. } & 5.96 \text { grams. } & 10 \text { grams. } \\ 2 & 6.060 & 5.81 & 10 \\ 3 & 7.024 & 7.30 & 25 \\ 4 & \underline{7.173} & 6.78 & \underline{6} \\ & & & 51 \text { grams contain } \\ & & & 5.81 \% \mathrm{~N} . \\ & 27.044 & 25.85 & 2.96 \% \text { grams nitrogen } \\ & 27.044 & \text { grams nitrogen. } & 28.81: 3 \text { grams nitrogen. }\end{array}$

Nitrogen balance for four days $=-1.76$ grams.

Nitrogen balance per day $=-0.442$ grams.

Average Intake.

Calories per day . . . . . . . . 1785 .

Nitrogen per lay . . . . . . . . 6.73 grams. 
Dr. Arthur L. Dean, Instructor in Plant Physiology in the Sheffield Scientific School, twenty-five years of age, and weighing 64 kilos, likewise became a subject of study in this investigation. He is a man of strong physique, and as an undergraduate student at Harvard University trained for various athletic events. He began on the experiment October 13, 1903, and continued until April 3, 1904. From October 13th to October 27 he followed his usual dietary habits, simply reducing in some measure the amount of food consumed. During this period of fifteen days, the average excretion of nitrogen per day through the kidneys was about 12 grams. On the 28th of October he began to reduce in still greater measure the amount of proteid food eaten, and gradually diminished the extent of his proteid metabolism, although not to the same degree as the preceding subjects. He had full freedom of choice in the character and quantity of his diet, but his food was characterized by a predominance of vegetable matter, with an.almost complete exclusion of meat.

For a period of nearly six months, or more exactly, from October 28 to April 3, the average daily output of nitrogen through the kidneys amounted to 8.99 grams, while the average daily output of uric acid was 0.386 gram. This daily excretion of 8.99 grams of nitrogen implies a metabolism of 56.18 grams of proteid. This, to be sure, means a reduction in proteid metabolism of about 50 per cent, as compared with the Voit and other standards, but does not show an economy equal to that practised by the preceding subjects. It is to be noted, however, in Dr. Dean's case, that the body-weight did not show at any time in the experiment a tendency to diminish. In fact, all through the experiment his body-weight was a little higher than at the beginning. 
DEAN.

\begin{tabular}{|c|c|c|c|c|c|c|}
\hline \multirow{2}{*}{ Date. } & \multirow{2}{*}{$\begin{array}{c}\text { Body- } \\
\text { weight. }\end{array}$} & \multicolumn{5}{|c|}{ Urine. } \\
\hline & & $\begin{array}{l}\text { Volume. } \\
24 \text { hours. }\end{array}$ & Sp. Gr. & Nitrogen. & Uric Acid. & $\mathrm{P}_{2} \mathrm{O}_{5}$. \\
\hline 1903 & kilos & c.c. & & grams & gram & grams \\
\hline Oct. 13 & 63.2 & 1100 & 1017 & 10.63 & 0.323 & 2.38 \\
\hline 14 & $\cdots$ & 1050 & 1020 & 9.83 & $\cdots$ & $\cdots$ \\
\hline 15 & $\ldots$ & 1390 & 1018 & 14.93 & 0.432 & 1.98 \\
\hline 16 & $\cdots$ & 1370 & 1017 & 11.26 & $\ldots$ & $\cdots$ \\
\hline 17 & $\cdots$ & 1350 & 1019 & 11.18 & $\cdots$ & $\cdots$ \\
\hline 18 & $\cdots$ & 1670 & 1017 & 11.62 & 0.490 & 2.51 \\
\hline 19 & 63.2 & 1075 & 1018 & 10.19 & $\cdots$ & $\cdots$ \\
\hline 20 & $\cdots$ & 1260 & 1015 & 9.98 & 0.483 & 1.88 \\
\hline 21 & $\cdots$ & 1350 & 1020 & 13.04 & $\cdots$ & $\cdots$ \\
\hline 22 & $\therefore$ & 1405 & 1015 & 11.38 & 0.431 & 2.07 \\
\hline 23 & $\cdots$ & 1240 & 1020 & 11.98 & $\cdots$ & $\cdots$ \\
\hline 24 & $\cdots$ & 1200 & 1023 & 11.16 & $\ldots$ & $\cdots$ \\
\hline 25 & $\ldots$ & 1365 & 1018 & 11.97 & 0.395 & 2.02 \\
\hline 26 & $\cdots$ & 1195 & 1020 & 10.75 & $\ldots$ & $\cdots$ \\
\hline 27 & $\cdots$ & 1240 & 1021 & 11.90 & 0.477 & 1.97 \\
\hline 28 & $\cdots$ & 1704 & $\cdots$ & ) & & \\
\hline 29 & $\cdots$ & 1105 & $\cdots$ & 9.29 & 0.398 & 1.69 \\
\hline 30 & 64.5 & 1180 & $\ldots$ & daily & daily & daily \\
\hline 31 & $\ldots$ & 910 & $\ldots$ & average & average & average \\
\hline Nov. 1 & $\cdots$ & 710 & $\cdots$ & & & \\
\hline 2 & $\cdots$ & 1540 & $\cdots$ & & & \\
\hline 3 & $\cdots$ & 1250 & $\cdots$ & & & \\
\hline 4 & $\cdots$ & 1300 & $\cdots$ & 8.54 & 0.354 & 1.65 \\
\hline 5 & $\cdots$ & 975 & $\cdots$ & & & \\
\hline 6 & $\cdots$ & 1150 & $\cdots$ & & & \\
\hline 8 & 64.6 & 1192 & 1025 & 10.86 & 0.493 & $\cdots$ \\
\hline 9 & $\cdots$ & 845 & $\cdots$ & & & \\
\hline 10 & $\cdots$ & 1255 & $\cdots$ & & & \\
\hline 11 & $\cdots$ & 1245 & $\cdots$ & & & \\
\hline 12 & $\cdots$ & 1540 & $\cdots$ & 8.81 & 0.368 & 1.85 \\
\hline 13 & $\cdots$ & 940 & $\cdots$ & & & \\
\hline 14 & $\cdots$ & 1300 & $\cdots$ & & & \\
\hline 15 & $\cdots$ & 1065 & $\cdots$ & & & \\
\hline 16 & 64.5 & 1165 & $\cdots$ & & & \\
\hline 17 & $\cdots$ & 910 & $\cdots$ & 9.45 & $\cdots$ & $\cdots$ \\
\hline 18 & $\ldots$ & 840 & $\cdots$ & 10.59 & 0.444 & $\ldots$ \\
\hline 19 & $\cdots$ & 1720 & 1012 & 10.32 & 0.331 & 1.95 \\
\hline 20 & $\cdots$ & 640 & $10: 2$ & 8.60 & 0.336 & 1.75 \\
\hline
\end{tabular}


DEAN.

\begin{tabular}{|c|c|c|c|c|c|c|}
\hline \multirow{2}{*}{ Date. } & \multirow{2}{*}{$\begin{array}{c}\text { Body- } \\
\text { weight. }\end{array}$} & \multicolumn{5}{|c|}{ Urine. } \\
\hline & & $\begin{array}{l}\text { Volume. } \\
24 \text { hours. }\end{array}$ & Sp. Gr. & Nitrogen. & Uric Acid. & $\mathrm{P}_{2} \mathrm{O}_{6}$ \\
\hline 1903 & kilos & c.c. & & grams & gram & grams \\
\hline Nov. 21 & $\ldots$ & 1310 & 1016 & 9.27 & 0.378 & \\
\hline 22 & $\ldots$ & 720 & 1026 & 8.42 & 0.415 & 1.75 \\
\hline 23 & 64.7 & 900 & $\ldots$ & & & daily av. \\
\hline 24 & $\ldots$ & 1520 & $\ldots$ & & & \\
\hline 25 & $\ldots$ & 1095 & $\ldots$ & & & \\
\hline 26 & $\ldots$ & 710 & $\ldots$ & 822 & 0.322 & 1.74 \\
\hline 27 & $\cdots$ & 700 & $\cdots$ & daily & daily & \\
\hline 28 & $\cdots$ & 1140 & $\cdots$ & a verage & average & \\
\hline 29 & $\ldots$ & 1200 & $\cdots$ & & & \\
\hline 30 & $\cdots$ & 820 & $\cdots$ & & & \\
\hline Dec. 1 & $\ldots$ & 1335 & $\cdots$ & & & \\
\hline 2 & 64.5 & 940 & $\cdots$ & & & \\
\hline 3 & $\cdots$ & 970 & $\cdots$ & 8.15 & 0.362 & 1.68 \\
\hline 4 & $\cdots$ & 1240 & $\cdots$ & & & \\
\hline 5 & $\cdots$ & 1190 & $\cdots$ & & & \\
\hline 6 & $\cdots$ & 720 & $\cdots$ & & & \\
\hline 7 & $\cdots$ & 1160 & $\cdots$ & & & \\
\hline 8 & $\cdots$ & 960 & $\cdots$ & & & \\
\hline 9 & $\cdots$ & 850 & $\cdots$ & & & \\
\hline 10 & $\cdots$ & 935 & $\cdots$ & 9.12 & 0.342 & 2.11 \\
\hline 11 & $\cdots$ & 945 & $\cdots$ & & & \\
\hline 12 & $\because$ & 1425 & $\cdots$ & & & \\
\hline 13 & 64.3 & 1065 & $\cdots$ & & & \\
\hline $\begin{array}{l}14 \\
15\end{array}$ & $\cdots$ & $\begin{array}{l}770 \\
790\end{array}$ & $\cdots$ & 9.08 & $\cdots$ & $\cdots$ \\
\hline 30 & $\ldots$ & 1230 & 1017 & & & \\
\hline 31 & 66.1 & 1525 & 1020 & & & \\
\hline 1904 & & & & & & \\
\hline Jan. 1 & $\ldots$ & 1010 & 1021 & 8.60 & 0.375 & 1.80 \\
\hline 2 & $\ldots$ & 1270 & 1020 & & & \\
\hline 3 & $\ldots$ & 1230 & 1020 & & & \\
\hline 4 & $\ldots$ & 820 & $\ldots$ & & & \\
\hline 5 & $\cdots$ & 1425 & 1018 & & & \\
\hline 6 & $\cdots$ & 1100 & 1021 & & & \\
\hline 7 & $\cdots$ & 1025 & 1021 & 8.42 & 0.338 & 1.76 \\
\hline 8 & $\ldots$ & 760 & $\cdots$ & & & \\
\hline 9 & $\ldots$ & 1450 & 1019 & & & \\
\hline 10 & 65.8 & 1410 & 1016 & & & \\
\hline 11 & $\cdots$ & 1030 & 1017 & 8.51 & 0.428 & $\cdots$ \\
\hline
\end{tabular}


DEAN.

\begin{tabular}{|c|c|c|c|c|c|c|}
\hline \multirow{2}{*}{ Date } & \multirow{2}{*}{$\begin{array}{c}\text { Body- } \\
\text { weight. }\end{array}$} & \multicolumn{5}{|c|}{ Urine. } \\
\hline & & $\begin{array}{l}\text { Volume. } \\
24 \text { hours. }\end{array}$ & Sp. Gr. & Nitrogen. & Uric Acid. & $\mathrm{P}_{2} \mathrm{O}_{5}$ \\
\hline 1904 & silos & c.c. & & grams & gram & grams \\
\hline Jan. 12 & 65.0 & 830 & 1023 & & & \\
\hline 13 & $\cdots$ & 790 & 1025 & & & \\
\hline 14 & $\ldots$ & 1070 & 1020 & 8.51 & 0.428 & 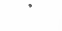 \\
\hline 15 & $\cdots$ & 1300 & 1019 & daily & daily & $\cdots$ \\
\hline 16 & $\cdots$ & 925 & 1025 & average & average & \\
\hline 17 & $\cdots$ & 1100 & 1023 & & & \\
\hline 18 & $\cdots$ & 850 & 1025 & ) & & \\
\hline 19 & $\cdots$ & 1120 & 1019 & & & \\
\hline 20 & $\cdots$ & 1005 & 1020 & & & \\
\hline 21 & $\cdots$ & 1270 & 1020 & 8.23 & $\cdots$ & $\cdots$ \\
\hline 22 & $\cdots$ & 980 & 1020 & & · & \\
\hline 23 & $\cdots$ & 650 & $\cdots$ & & & \\
\hline 24 & $\cdots$ & 980 & 1024 & j & & \\
\hline 25 & 65.5 & 1000 & $\cdots$ & & & \\
\hline 26 & $\cdots$ & 940 & $\cdots$ & & & \\
\hline 27 & $\cdots$ & 1350 & $\cdots$ & & & \\
\hline 28 & $\cdots$ & 840 & $\cdots$ & 8.85 & 0.395 & 1.67 \\
\hline 29 & $\cdots$ & 675 & $\cdots$ & & & \\
\hline 30 & $\cdots$ & 740 & $\cdots$ & & & \\
\hline 31 & $\cdots$ & 1160 & 1017 & j & & \\
\hline Feb. 1 & $\cdots$ & 700 & $\cdots$ & ) & & \\
\hline 2 & $\cdots$ & 860 & $\cdots$ & & & \\
\hline 3 & $\cdots$ & 925 & $\cdots$ & & & \\
\hline 4 & $\cdots$ & 590 & $\cdots$ & 8.22 & 0.381 & 1.19 \\
\hline 5 & $\cdots$ & 835 & $\cdots$ & & & \\
\hline 6 & $\cdots$ & 935 & $\cdots$ & & & \\
\hline 7 & $\cdots$ & 980 & $\cdots$ & ) & & \\
\hline 8 & $\cdots$ & 1035 & 1017 & 9.00 & $\cdots$ & $\cdots$ \\
\hline 9 & 64.1 & 800 & 1027 & 8.64 & 0.432 & $\cdots$ \\
\hline 10 & $\cdots$ & 940 & 1020 & 8.29 & 0.314 & $\cdots$ \\
\hline 11 & $\cdots$ & 720 & 1030 & 8.55 & 0.364 & $\cdots$ \\
\hline 12 & $\cdots$ & 860 & 1023 & 9.93 & 0.348 & $\cdots$ \\
\hline 13 & $\cdots$ & 980 & 1022 & 8.87 & 0.379 & $\cdots$ \\
\hline 14 & 63.9 & 1285 & 1022 & 8.33 & 0.385 & $\cdots$ \\
\hline 15 & $\ldots$ & 910 & $\cdots$ & ) & & \\
\hline 16 & $\cdots$ & 1210 & $\cdots$ & 9.30 & 0.301 & $\cdots$ \\
\hline 17 & $\cdots$ & 1455 & $\dot{*} \cdot$ & & & \\
\hline 18 & $\cdots$ & 1000 & 1022 & & & \\
\hline
\end{tabular}


DEAN.

\begin{tabular}{|c|c|c|c|c|c|c|}
\hline \multirow{2}{*}{ Date. } & \multirow{2}{*}{$\begin{array}{c}\text { Body- } \\
\text { weight. }\end{array}$} & \multicolumn{5}{|c|}{ Urine. } \\
\hline & & $\begin{array}{l}\text { Volume. } \\
24 \text { hours. }\end{array}$ & Sp. Gr. & Nitrogen. & Uric Acid. & $\mathrm{P}_{2} \mathrm{O}_{5}$ \\
\hline 1904. & kilos & c.c. & & grams & gram & gram \\
\hline Feb. 19 & $\cdots$ & 1420 & . & & & \\
\hline 20 & $\cdots$ & 1050 & $\ldots$ & 9.30 & 0.301 & $\ldots$ \\
\hline 21 & 64.5 & 1365 & $\ldots$ & daily av. & daily av. & \\
\hline 22 & $\cdots$ & 765 & $\cdots$ & & & \\
\hline 23 & $\ldots$ & 1070 & $\ldots$ & & & \\
\hline 24 & $\ldots$ & 1080 & $\ldots$ & 9.685 & 0.423 & \\
\hline 25 & $\ldots$ & 1495 & $\ldots$ & 9.000 & & $\cdots$ \\
\hline 26 & $\ldots$ & 970 & $\cdots$ & & & \\
\hline 28 & $\ldots$ & 750 & $\ldots$ & & & \\
\hline 29 & $\ldots$ & 725 & $\cdots$ & & & \\
\hline Mar. 1 & $\ldots$ & 1100 & . & & & \\
\hline 2 & $\ldots$ & 990 & 1024 & & & \\
\hline 3 & $\cdots$ & 1180 & $\cdots$ & 10.31 & 0.410 & $\cdots$ \\
\hline 4 & $\ldots$ & 1100 & $\ldots$ & & & \\
\hline 5 & $\cdots$ & 1010 & $\ldots$ & & & \\
\hline 6 & $\cdots$ & 970 & $\cdots$ & j & & \\
\hline 7 & $\ldots$ & 790 & $\ldots$ & & & \\
\hline 8 & 64.4 & 670 & $\ldots$ & & & \\
\hline 9 & $\cdots$ & 840 & $\cdots$ & & & \\
\hline 10 & $\ldots$ & 1110 & $\ldots$ & 8.99 & 0.433 & $\cdots$ \\
\hline 11 & $\ldots$ & 1090 & $\ldots$ & & & \\
\hline 12 & $\cdots$ & 755 & $\cdots$ & & & \\
\hline 13 & $\cdots$ & 1220 & $\cdots$ & 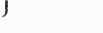 & & \\
\hline 14 & $\cdots$ & 745 & $\ldots$ & ) & & \\
\hline 15 & $\cdots$ & 1030 & $\cdots$ & & & \\
\hline 16 & $\cdots$ & 1040 & $\cdots$ & & & \\
\hline 17 & $\cdots$ & 1080 & $\ldots$ & 8.24 & 0.368 & $\ldots$ \\
\hline 18 & $\cdots$ & 1390 & $\cdots$ & & & \\
\hline 19 & $\cdots$ & 795 & $\cdots$ & & & \\
\hline 20 & 64.0 & 840 & $\cdots$ & j & & \\
\hline 21 & $\cdots$ & 720 & $\cdots$ & 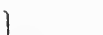 & & $\downarrow$ \\
\hline 22 & $\cdots$ & 970 & $\cdots$ & & & \\
\hline 23 & $\ldots$ & 1200 & $\ldots$ & & & \\
\hline 24 & $\cdots$ & 815 & $\cdots$ & 9.26 & 0.545 & $\cdots$ \\
\hline 25 & $\cdots$ & 1000 & $\ldots$ & & & \\
\hline 26 & $\cdots$ & 1180 & $\ldots$ & & & \\
\hline 27 & $\cdots$ & 1750 & $\cdots$ & & & \\
\hline 28 & $\cdots$ & 820 & $\cdots$ & 9.59 & 0.409 & $\cdots$ \\
\hline
\end{tabular}


DEAN.

\begin{tabular}{|c|c|c|c|c|c|c|}
\hline \multirow{2}{*}{ Date. } & \multirow{2}{*}{$\begin{array}{c}\text { Body- } \\
\text { weight. }\end{array}$} & \multicolumn{5}{|c|}{ Urine. } \\
\hline & & $\begin{array}{l}\text { Volume. } \\
24 \text { hours. }\end{array}$ & Sp. Gr. & Nitrogen. & Uric Acid. & $\mathrm{P}_{2} \mathrm{O}_{5}$. \\
\hline 1904 & kilos & c.c. & & grams & gram & grams \\
\hline Mar. 29 & $\ldots$ & 710 & $\cdots$ & 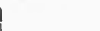 & & $\ldots$ \\
\hline 30 & $\cdots$ & 1100 & $\cdots$ & & & $\ldots$ \\
\hline 31 & $\cdots$ & 770 & $\cdots$ & 9.59 & 0.409 & $\cdots$ \\
\hline Apr. 1 & $\cdots$ & 1250 & $\cdots$ & daily & daily & $\cdots$ \\
\hline 2 & $\because \dot{0}$ & 885 & $\cdots$ & average & average & $\cdots$ \\
\hline 3 & 65.0 & 630 & $\cdots$ & & & $\cdots$ \\
\hline \multirow{2}{*}{\multicolumn{2}{|c|}{$\begin{array}{l}\text { Daily average from } \\
\text { Oct. } 28,1903\end{array}$}} & & & & & \\
\hline & & 1035 & 1021 & 8.99 & 0.386 & 1.73 \\
\hline
\end{tabular}

On February 9, a nitrogen balance was attempted, when for a period of six days a careful comparison of intake and output of nitrogen was made. The results show that while during this period of six days 52.999 grams of nitrogen were ingested, there was an output through the urine and fæces of 61.13 grams of nitrogen, thus indicating a minus balance for this period of 1.355 grams of nitrogen per day. 'The average daily intake of nitrogen was 8.83 grams. The average daily output of nitrogen through the kidneys was 8.77 grams, being 0.22 gram less than the average daily excretion through the fidneys for the six months' period. The fuel value of the food for this period averaged 2529 calories per day. The nitrogen balance, however, is so strikingly a minus balance that we are forced to conclude the above quantities of food were not quite sufficient to meet the needs of the body under the then existing condi. tions. Still, the fact that the body-weight during the entire period of six months showed no tendency downward implies that during this longer period the body must have been essentially in nitrogen equilibrium, under conditions whereby there was a metabolism of only 56 grams of proteid per day. As before stated, this means a physiological economy, as contrasted with existing standards, of about 50 per cent in pro- 
teid food. So far as was to be seen, the bodily strength and vigor of the subject, like his body-weight, were fully maintained under the restricted diet, but, for some reason, he did not apparently take as kindly to a reduction of proteid food, and did not accomplish so great a lowering in the rate of proteid metabolism.

Following are the data of the balance experiment:

\section{DEAN.}

\section{Tuesday, February 9, 1904.}

Breakfast. - Coffee 210 grams, bread 38.5 grams, oatmeal 127 grams, cream 92 grans, sugar 20 grams.

Lunch.-Bread 63.5 grams, butter 12.5 grams, potato 155 grams, consommé 150 grams, stewed tomato 109 grams, coffee 210 grams, sugar 20 grams, pudding 85 grams.

Dinner. - Roast beef 17.5 grams, potato 177 grams, bread 39.1 grams, butter 12 grams, string beans 110 grams, apple pie 237.6 grams.

\begin{tabular}{|c|c|c|c|c|c|c|c|c|c|}
\hline \multirow{2}{*}{$\begin{array}{l}\text { Food. } \\
\text { Coffee . }\end{array}$} & \multirow[b]{2}{*}{. } & \multirow[b]{2}{*}{. . } & \multirow[b]{2}{*}{ - . } & \multirow{2}{*}{\multicolumn{2}{|c|}{$\begin{array}{l}\text { Grams. } \\
210.0\end{array}$}} & \multicolumn{3}{|c|}{ Per cent Nitrogen. } & \multirow{2}{*}{$\begin{array}{l}\text { Total Nitrogen. } \\
0.210 \text { grams. }\end{array}$} \\
\hline & & & & & & $x$ & 0.10 & $=$ & \\
\hline Bread 38.5 & + & $63.5+3$ & 39.1 & $=$ & 141.1 & $x$ & 1.36 & $=$ & 1.918 \\
\hline Oatmeal . & . & . . . & . & . . & 127.0 & $x$ & 0.64 & $=$ & 0.812 \\
\hline Cream. . & . & . . & . & . & 92.0 & $x$ & 0.40 & $=$ & 0.368 \\
\hline Butter . . & . & $.12 .5+$ & -12 & $=$ & 24.5 & $x$ & 0.088 & $=$ & 0.021 \\
\hline Potato . . & . & . . . & . & . . & 155.0 & $x$ & 0.28 & $=$ & 0.434 \\
\hline Consommé & . & . & . & - & 1500 & $x$ & 0.38 & $=$ & 0.570 \\
\hline Tomato . & . & . & . & . . & 109.0 & $x$ & 0.19 & $=$ & 0.207 \\
\hline Sugar . & . & . $20+$ & -20 & $=$ & 40.0 & $x$ & 0.00 & $=$ & 0.000 \\
\hline Pudding . & . & . . & . & . . & 85.0 & $x$ & 0.69 & $=$ & 0.586 \\
\hline Roast beef & . & . & . & . & 17.5 & $x$ & 2.64 & $=$ & 0.462 \\
\hline Potato. & . & - & - & . & 177.0 & $x$ & 0.36 & $=$ & 0.637 \\
\hline String beans & & . & . & . & 110.0 & $x$ & 0.26 & $=$ & 0.286 \\
\hline Apple pie & . & . & . & . & 237.6 & $x$ & 0.49 & $=$ & 1.164 \\
\hline Coffee. & . & . . . & . & . . & 210.0 & $x$ & 0.099 & $=$ & 0.208 \\
\hline & & $\begin{array}{l}\text { Total } \\
\text { Total }\end{array}$ & nitr & troge & $\begin{array}{l}\text { in food. } \\
\text { in urine }\end{array}$ & . & $\cdot \cdot$ & $\dot{\cdot}$ & $\begin{array}{l}\overline{7.883} \text { grams. } \\
8.610\end{array}$ \\
\hline
\end{tabular}

Fuel value of the food . . . . 2576 calories. 


\title{
104 PHYSIOLOGICAL ECONOMY IN NU'TRITION
}

\author{
DEAN.
}

Wednesday, February 10, 1904.

Breakfast. - Coffee 210 grams, bread 31.8 grams, cream 50 grams, sugar 40 grams, oatmeal 155 grams.

Lunch. - Bread 77 grams, butter 14.5 grams, apple fritters 193.5 grams, coffee 210 grams, sugar 20 grams.

Dinner. - Bread 82 grams, butter 20 grams, cranberries 150 grams, baked beans, 150 grams, coffee 210 grams, sugar 32 grams.

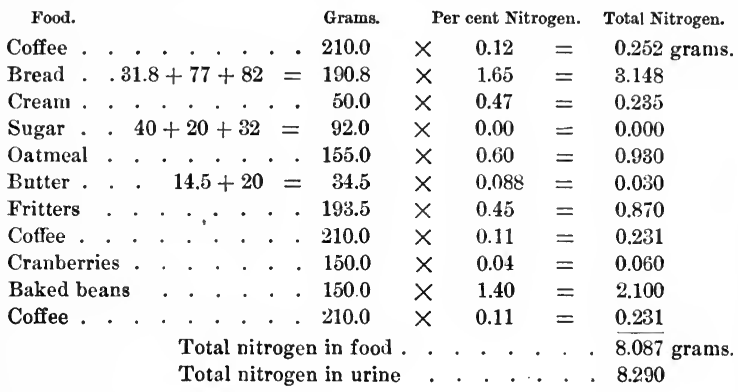

Fuel value of the food . . 2145 calories.

Thursday, February 11, 1904.

Breakfast. - Bread 49 grams, oatmeal 185.7 grams, cream 64 grams, coffee 210 grams, sugar 35 grams.

Lunch.- Bread 111.8 grams, butter 40.5 grams, sweet potato 287 grams, peach preserve 109.3 grams.

Dinner. - Tomato purée 99 grams, bread 945 grams, butter 21.5 grams, beans 138 grams, lemon pie 155 grams, coffee 210 grams, sugar 21 grams.

Food. Grams. Per cent Nitrogen. Total Nitrogen.

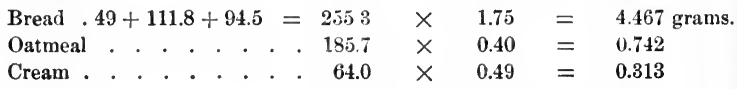




\section{DEAN.}

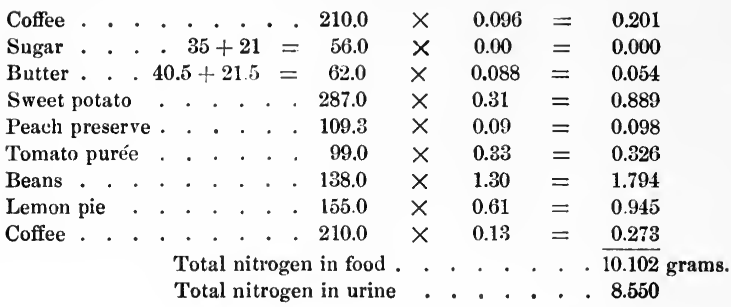

Fuel value of the food . . . 2854 calories.

\section{Friday, February 18, 1904.}

Breakfast. - Oatmeal 192.3 grams, cream 75.5 grams, bread 41.6 grams, coffee 210 grams, sugar 20 grams.

Lunch. - Bread 64.1 grams, butter 14 grams, fish cakes 60 grams, potato 200 grams, eustard 107.3 grams.

Dinner. - Bread 60 grams, butter 15 grams, lima beans 100 grams, potato 150 grams, apple dumpling 259 grams.

Food. Grams. Per cent Nitrogen. Total Nitrogen.

\begin{tabular}{|c|c|c|c|c|c|c|c|c|c|c|c|c|}
\hline Oatmeal & . & & . & . & . & . & . & 192.3 & $>$ & 0.52 & $=$ & 0.999 grams. \\
\hline Cream. & . & . & . & . & . & . & . & 75.5 & & 0.50 & $=$ & 0.377 \\
\hline Bread . & 41.6 & + & 64.1 & $1+$ & -60 & & $=$ & 165.7 & $>$ & 1.71 & $=$ & 2.833 \\
\hline Coffee . & . . & . & . & . & . & . & . & 210.0 & $>$ & 0.11 & $=$ & 0.231 \\
\hline Sugar . & . & . & . & . & . & . & . & 20.0 & $>$ & 0.00 & $=$ & 0.000 \\
\hline Butter . & . & . & & $14+$ & 15 & & $=$ & 29.0 & $y$ & 0.088 & $=$ & 0.025 \\
\hline Fisl cakes & . & . & . & . & . & $\cdot$ & . & 60.0 & $>$ & 1.57 & $=$ & 0.942 \\
\hline Potato & & . & . & . & 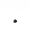 & 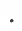 & . & 200.0 & $>$ & 0.41 & $=$ & 0.820 \\
\hline Custard & . & . & . & . & . & - & . & 107.3 & $>$ & 0.83 & $=$ & 0.890 \\
\hline Lima bean & as & . & . & . & & • & 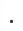 & 100.0 & $>$ & 0.90 & $=$ & 0.900 \\
\hline Potato . & & . & . & . & . & - & . & 150.0 & $>$ & 0.37 & $=$ & 0.555 \\
\hline Apple dum & npli & ing & • & . & & & • & 259.0 & $>$ & 0.72 & $=$ & 1.864 \\
\hline
\end{tabular}

Fuel value of the food . . . 2363 calories. 
DEAN.

Saturday, February 13, 1904.

Breakfast. - Oatıneal 150 grams, cream 42 grams, sugar 31 grams, bread 31 grams, coffee 210 grams.

Lunch. - Bread 36 grams, sweet potato 222 grams, butter 17 grams, quince preserve 81.5 grams, apple turnover 154.5 grams.

Dinner. - Potato 175 grams, bread 62 grams, butter 15 grams, peas 100 grams, apple pie 177 grams, coffee 210 grams, sugar 21 grams.

\begin{tabular}{|c|c|c|c|c|c|c|c|c|c|c|c|c|}
\hline Food. & & & & & & & & Grams. & & cent Nitr & ogen. & Total Nitrogen. \\
\hline Oatmeal & . & . & . & . & . & . & . & 150.0 & $\times$ & 0.43 & $=$ & 0.645 grams. \\
\hline Cream. & . & . & . & . & . & . & . & 42.0 & $x$ & 0.50 & $=$ & 0.210 \\
\hline Sugar . & . & . & 31 & & 21 & & $=$ & 52.0 & $x$ & 0.00 & $=$ & 0.000 \\
\hline Bread . & . & 31 . & +36 & & 62 & & $=$ & 129.0 & $x$ & 1.64 & $=$ & 2.115 \\
\hline Coffee . & . . & . . & . & . & & . & . & 210.0 & $x$ & 0.11 & $=$ & 0.231 \\
\hline Siveet pot & ato & . & . & . & . & . & . & 222.0 & $x$ & 0.37 & $=$ & 0.821 \\
\hline Butter . & . . & . & 17 & $7+$ & 15 & $=$ & $=$ & 32.0 & $x$ & 0.088 & $=$ & 0028 \\
\hline Quince pr & eser & rve & . & . & . & . & . & 81.5 & $x$ & 0.047 & $=$ & 0.038 \\
\hline Apple turi & nove & & . & . & . & . & . & 154.5 & $x$ & 0.96 & $=$ & 1.483 \\
\hline Potato. & . . & . . & . & . & . & . & . & 175.0 & $x$ & 0.37 & $=$ & 0.647 \\
\hline Peas. & . & . & . & . & . & . & . & 100.0 & $x$ & 0.96 & $=$ & 0.960 \\
\hline Apple pie & & . & . & . & - & . & . & 177.0 & $x$ & 0.43 & $=$ & 0.761 \\
\hline Coffee . & . & . & . & . & . & & & 210.0 & $x$ & 0.11 & $=$ & 0.231 \\
\hline & & & $\begin{array}{l}\text { Tot } \\
\text { To }\end{array}$ & & & & & $\begin{array}{l}\text { in food. } \\
\text { in urine }\end{array}$ & . & $\begin{array}{cc}\cdot & \cdot \\
. & . \\
\end{array}$ & . & $\begin{array}{l}\overline{8.170} \text { grams. } \\
8.870\end{array}$ \\
\hline
\end{tabular}

Fuel value of the food . . . 2606 calories. 


\section{DEAN.}

Sunday, February 14, 1904.

Breakfast. - Quaker oats 150 grams, bread 42.5 grams, coffee 210 grams, sugar 31 grams, banana 88.2 grams, cream 87.6 grams.

Lunch. - Bread 87.3 grams, butter 28.7 grams, potato 210 grams, apple sauce 116.5 grams.

Dinner. - Bread 51.5 grams, butter 12.2 grams, sugar 21 grams, potato 150 grams, succotash 100 grams, chocolate cake 122.5 grams, vanilla ice 110.7 grams.

Food. Grams. Per cent Nitrogen. Total Nitrogen.

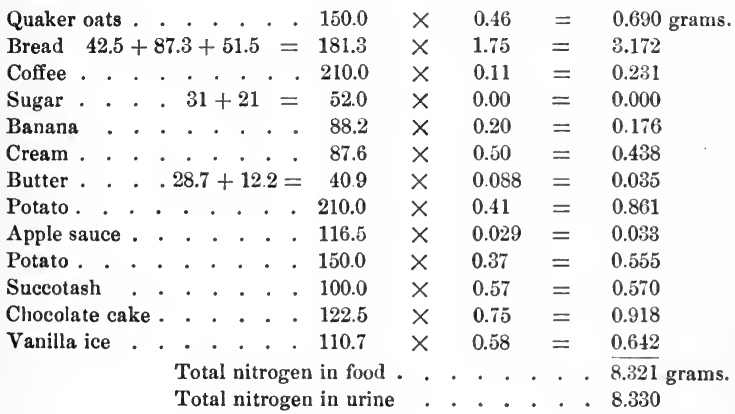

Fuel value of the food . . . 2635 calories. 


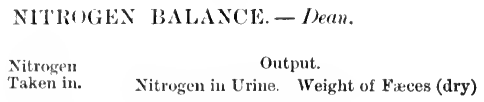

\begin{tabular}{|c|c|c|c|}
\hline Feb. 9 & 7.883 grams. & 8.64 grams. & $\cdots$ \\
\hline 10 & 8.087 & 8.29 & $\cdots$ \\
\hline 11 & 10.102 & 8.55 & 18 grams. \\
\hline 12 & $10.4: 3$ & 9.93 & 18 \\
\hline 1:) & 8.170 & 8.87 & 80 \\
\hline \multirow[t]{4}{*}{14} & 8.321 & 8.3:3 & 58 \\
\hline & & & 174 grams contain \\
\hline & & & $4.00 \% \mathrm{x}$ \\
\hline & 52.999 & 52.61 & 852 grams nitrogen \\
\hline
\end{tabular}

Nitrogen balance for six days $=-8.131$ grams.

Nitrogen balance per day $=-1.355$ grams.

Average Intake.

Calories per day . . . . . . . . . . 2529 .

Nitrogen per day . . . . . . . . . 8.83 grams. 
Mr. George M. Beers, Clerk in the Treasurer's office of the Sheffield Scientific School, became a subject of study in January, 1903. Mr. Beers was thirty-eight years of age, and had always enjoyed fairly good health, although of somewhat frail physique. His occupation has always been indoor work as accountant, etc. His body-weight was 61 kilos.

Mr. Beers came to the writer for advice as to possible ways of improving his general health, and when it was learned that he was in the habit of eating large amounts of meat, the suggestion was made to him that it might be wise to ascertain the effect of a diminished quantity of proteid food, and as a result of this advice Mr. Beers began to cut down the amount of meat consumed daily. The effect of this abstention from meat was so noticeable that voluntarily all meat was withdrawn from his diet. With this change in dietary habits there came about a loss of body-weight, which, however, was soon regained.

Commencing with May 14, 1903, the amount of nitrogen excreted from the kidneys was determined from time to time, but not each day, since it was very soon found that Mr. Beers showed great regularity in his dietary habits, and a corresponding regularity in the composition of the output. This regularity was due in large measure to the fact that the subject became, for the time at least, practically a vegetarian. The beneficial effects noted in his own experience with abstention from meat led to his voluntarily excluding it from his daily diet, so that from January, 1903, to June, 1904, the subject practically tasted meat, fish, or eggs on only four occasions, namely, the 26th day of November, 1903, May 19, 20, and 21, 1904. With this limitation to a vegetable diet and with regular methods of living, the nitrogenous waste material was found to be constant within very narrow limits. Emphasis, however, should be laid upon the fact that there was no prescription of diet, but perfect freedom of choice, although this choice was limited wholly to vegetable and cereal foods.

The accompanying tables give the output of nitrogen, uric acid, etc., through the kidneys for various dates between May 
14, 1903, and June 15, 1904. Scrutiny of these tables shows that the average daily output of nitrogen, so far as the data show, amounted to 8.58 grams. This indicates an average daily metabolism of 53.62 grams of proteid material.

Likewise noticeable is the perfectly steady body-weight throughout this whole period of time, while the low level of 8.5 grams of metabolized nitrogen testifies to an economy in the use of proteid food, which indicates that in this subject at least the needs of the body for proteid food could easily be met by an amount equal to about one-half that called for by the Voit and similar standard dietaries. 
BEERS.

\begin{tabular}{|c|c|c|c|c|c|c|c|}
\hline \multirow{2}{*}{\multicolumn{2}{|c|}{ Date. }} & \multirow{2}{*}{$\begin{array}{c}\text { Body- } \\
\text { weight. }\end{array}$} & \multicolumn{5}{|c|}{ Urine. } \\
\hline & & & $\begin{array}{l}\text { Volume. } \\
24 \text { hours. }\end{array}$ & Sp. Gr. & Nitrogen. & Uric Acid. & $\mathbf{P}_{2} \mathrm{O}_{5}$ \\
\hline 1904 & & kilos & c.c. & & grams & gram & grams \\
\hline May 14 & & 61.1 & 940 & 1020 & 8.23 & 0.330 & 1.82 \\
\hline Oct. 8 & & $\cdots$ & 920 & 1014 & 6.40 & 0.374 & 1.47 \\
\hline 13 & 3 & 61.1 & 740 & 1026 & 8.74 & 0.375 & 1.61 \\
\hline 14 & 4 & $\cdots$ & 780 & 1024 & 8.37 & $\cdots$ & $\ldots$ \\
\hline 15 & 5 & $\ldots$ & 970 & 1018 & 8.90 & 0.374 & 1.04 \\
\hline 16 & 6 & $\cdots$ & 1365 & 1014 & 9.09 & $\ldots$ & $\ldots$ \\
\hline 17 & & $\cdots$ & 1295 & 1013 & 8.86 & $\ldots$ & $\cdots$ \\
\hline 18 & 8 & $\cdots$ & 1400 & 1013 & 7.56 & 0.347 & 1.57 \\
\hline 20 & 0 & 61.1 & 1304 & 1014 & 8.14 & 0.328 & 1.44 \\
\hline 21 & & $\ldots$ & 1510 & 1012 & 7.97 & $\ldots$ & $\ldots$ \\
\hline 22 & & $\cdots$ & 1450 & 1012 & 8.26 & 0.338 & 1.95 \\
\hline 23 & & $\cdots$ & 1130 & 1013 & 7.86 & $\cdots$ & $\cdots$ \\
\hline & 4 & $\ldots$ & 1060 & 1019 & 8.46 & $\ldots$ & $\cdots$ \\
\hline 25 & 5 & $\cdots$ & 1275 & 1015 & 8.25 & 0.375 & 1.74 \\
\hline & 6 & $\ldots$ & 1390 & 1014 & 7.34 & $\ldots$ & $\cdots$ \\
\hline & 27 & 61.4 & 1000 & 1020 & 7.50 & 0.344 & 1.38 \\
\hline Nov. 21 & 1 & 61.4 & 670 & 1025 & 8.72 & $\ldots$ & $\cdots$ \\
\hline 22 & 2 & $\cdots$ & 925 & 1017 & 8.21 & 0.335 & 1.28 \\
\hline & 3 & $\ldots$ & 585 & $102 \vec{i}$ & 8.36 & $\ldots$ & $\cdots$ \\
\hline & 24 & $\cdots$ & 885 & 1023 & 8.02 & 0.354 & $\ldots$ \\
\hline 25 & 25 & $\ldots$ & 800 & 1026 & 7.92 & $\ldots$ & $\cdots$ \\
\hline 26 & 6 & $\cdots$ & 1095 & 1020 & $10.77 *$ & 0.364 & 1.53 \\
\hline Jan. & 5 & 61.4 & 1110 & 1018 & 8.99 & 0.324 & $\cdots$ \\
\hline & 7 & $\ldots$ & 650 & 1024 & 8.15 & 0.278 & 1.29 \\
\hline & 8 & $\cdots$ & 710 & 1020 & 7.88 & $\cdots$ & $\cdots$ \\
\hline & 9 & $\cdots$ & 910 & 1023 & 8.73 & $\ldots$ & $\cdots$ \\
\hline & 0 & $\cdots$ & 890 & 1020 & 8.01 & 0327 & 1.21 \\
\hline 11 & 1 & $\cdots$ & 875 & 1017 & 7.51 & $\cdots$ & $\cdots$ \\
\hline & 2 & $\cdots$ & 480 & 1029 & 6.77 & $\cdots$ & $\cdots$ \\
\hline 13 & 13 & $\cdots$ & 580 & 1023 & 8.00 & 0.398 & $\cdots$ \\
\hline & 4 & $\cdots$ & 765 & 1022 & 8.35 & $\cdots$ & $\cdots$ \\
\hline 15 & 5 & $\ldots$ & 1360 & 1017 & 9.22 & $\ldots$ & $\cdots$ \\
\hline 16 & 6 & 61.4 & 990 & 1020 & 8.79 & $\cdots$ & $\cdots$ \\
\hline 17 & 7 & $\cdots$ & 835 & 1024 & 8.47 & 0.354 & $\cdots$ \\
\hline 18 & 8 & $\ldots$ & 780 & 1020 & 8.05 & $\cdots$ & $\cdots$ \\
\hline 19 & 19 & $\ldots$ & 790 & 1022 & 8.10 & 0.382 & $\cdots$ \\
\hline Feb. 9 & 9 & $\ldots$ & 860 & 1023 & 8.46 & 0.355 & $\cdots$ \\
\hline
\end{tabular}

* Turkey eaten on this day. 
BEERS.

\begin{tabular}{|c|c|c|c|c|c|c|}
\hline \multirow{2}{*}{ Date. } & \multirow{2}{*}{$\begin{array}{c}\text { Body- } \\
\text { weight. }\end{array}$} & \multicolumn{5}{|c|}{ Urine. } \\
\hline & & $\begin{array}{l}\text { Volume. } \\
24 \text { hours. }\end{array}$ & Sp. Gr. & Nitrogen. & Uric Acid. & $\mathrm{P}_{2} \mathrm{O}_{5}$ \\
\hline 1904 & kilos & c.c. & & gramis & gram & gram \\
\hline Feb. 10 & 61.4 & 850 & 1024 & 8.57 & 0.226 & $\ldots$ \\
\hline 11 & 61.4 & 750 & 1022 & 8.55 & 0.352 & $\ldots$ \\
\hline 12 & 61.4 & 595 & 1026 & 8.46 & 0.368 & $\ldots$ \\
\hline 13 & 61.4 & 640 & 1027 & 8.75 & 0.425 & $\cdots$ \\
\hline 14 & 60.8 & 730 & 1025 & 8.28 & 0.353 & $\cdots$ \\
\hline Apr. 18 & 61.5 & 610 & 1025 & 7.69 & 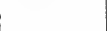 & \\
\hline 19 & 61.5 & 870 & 1020 & 9.87 & & \\
\hline 20 & 61.5 & 985 & 1019 & 8.87 & & \\
\hline 21 & 61.5 & 795 & 1024 & 8.25 & 0.365 & $\cdots$ \\
\hline 22 & 615 & 1090 & 1019 & 9.02 & daily & \\
\hline 23 & 61.5 & 970 & $10^{\prime} 22$ & 8.44 & average & \\
\hline 24 & 61.5 & 810 & 1021 & 7.30 & & \\
\hline 25 & 61.5 & 850 & 1018 & 6.94 & & \\
\hline 26 & 61.5 & 620 & 1024 & 7.11 & & \\
\hline 28 & $\ldots$ & 450 & 1027 & 8.58 & & \\
\hline 29 & $\ldots$ & 650 & 1025 & 9.52 & 0.691 & $\cdots$ \\
\hline 30 & $\ldots$ & 1260 & 1018 & 10.20 & & \\
\hline May 1 & $\ldots$ & 1060 & 1017 & 8.71 & j & \\
\hline 2 & $\cdots$ & 610 & 1025 & 8.16 & $\cdots$ & $\cdots$ \\
\hline 3 & $\cdots$ & 650 & 1022 & 8.70 & $\cdots$ & $\cdots$ \\
\hline 4 & 61.5 & 870 & 1019 & 8.51 & $\cdots$ & $\cdots$ \\
\hline 5 & 61.3 & 610 & 1025 & 8.31 & $\cdots$ & $\cdots$ \\
\hline 6 & 61.3 & 655 & 1026 & 8.72 & 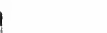 & \\
\hline 7 & $\ldots$ & 680 & 1025 & 8.53 & & \\
\hline 8 & 60.8 & 490 & 1026 & 7.00 & & \\
\hline 9 & 61.3 & 550 & 1026 & 7.59 & 0.356 & $\cdots$ \\
\hline 10 & $\ldots$ & 705 & 1025 & 7.78 & & \\
\hline 11 & $\ldots$ & 730 & 1025 & 8.28 & & \\
\hline 12 & $\ldots$ & 800 & 1025 & 9.36 & & \\
\hline 16 & $\ldots$ & 715 & 1022 & 7.29 & $\cdots$ & $\cdots$ \\
\hline 17 & $\cdots$ & 990 & 1018 & 6.95 & $\cdots$ & $\cdots$ \\
\hline 18 & $\cdots$ & 715 & 1026 & 7.81 & . . & $\cdots$ \\
\hline 19 & $\ldots$ & 845 & 1926 & $10.45^{*}$ & $\ldots$ & $\ldots$ \\
\hline 20 & 61.5 & 1170 & 1020 & $11.02 \%$ & $\cdots$ & .. \\
\hline 21 & 612 & 795 & 1025 & $10.02^{*}$ & ... & $\cdots$ \\
\hline 22 & $\cdots$ & 835 & 1020 & 8.42 & $\cdots$ & $\ldots$ \\
\hline 23 & $\cdots$ & 695 & 1025 & 9.42 & $\cdots$ & $\cdots$ \\
\hline 24 & $\cdots$ & 660 & 1025 & 9.82 & $\cdots$ & $\cdots$ \\
\hline
\end{tabular}

On these three days, meat, fish, and eggs were eaten. 
PHYSIOLOGICAL ECONONY IN NUTRITION 113

BEERS.

\begin{tabular}{|c|c|c|c|c|c|c|}
\hline \multirow{2}{*}{ Date. } & \multirow{2}{*}{$\begin{array}{c}\text { Body- } \\
\text { weight. }\end{array}$} & \multicolumn{5}{|c|}{ Urine. } \\
\hline & & $\begin{array}{l}\text { Volume. } \\
24 \text { hours. }\end{array}$ & Sp. Gr. & Nitrogen. & Uric Acid. & $\mathrm{P}_{2} \mathrm{O}_{5}$. \\
\hline 1904 & kilos & c.c. & & grams & gram & grams \\
\hline \multirow{6}{*}{ May } & $\ldots$ & 700 & 1025 & 9.91 & & \\
\hline & $\ldots$ & 620 & 1026 & 8.59 & & \\
\hline & $\ldots$ & 665 & 1026 & 9.53 & 0.434 & $\ldots$ \\
\hline & 61.2 & 960 & 1021 & 10.31 & daily & \\
\hline & $\ldots$ & 790 & 1023 & 9.24 & average & \\
\hline & $\ldots$ & 930 & 1025 & 10.44 & $\ldots$ & . \\
\hline \multirow[t]{15}{*}{ June } & $\ldots$ & 855 & 1018 & 8.76 & $\ldots$ & $\ldots$ \\
\hline & $\ldots$ & 850 & 1023 & 8.01 & $\ldots$ & $\ldots$ \\
\hline & $\ldots$ & 860 & 1020 & 9.24 & $\ldots$ & $\ldots$ \\
\hline & 61.4 & 1145 & 1021 & 10.17 & $\ldots$ & . . \\
\hline & $\ldots$ & 590 & 1024 & 7.47 & $\ldots$ & $\ldots$ \\
\hline & $\ldots$ & 510 & 1029 & 7.53 & $\ldots$ & $\ldots$ \\
\hline & $\ldots$ & 620 & 1027 & 8.26 & $\cdots$ & . \\
\hline & $\ldots$ & 985 & 1020 & 8.45 & $\ldots$ & $\ldots$ \\
\hline & $\ldots$ & 1220 & 1020 & 8.49 & $\cdots$ & $\cdots$ \\
\hline & $\ldots$ & 1220 & 1017 & 8.28 & $\ldots$ & $\ldots$ \\
\hline & $\ldots$ & 1710 & 1013 & 8.82 & $\cdots$ & $\cdots$ \\
\hline & $\ldots$ & 925 & 1017 & 7.11 & $\ldots$ & $\cdots$ \\
\hline & . . & 920 & 1020 & 8.01 & $\ldots$ & . \\
\hline & $\ldots$ & 1090 & 1015 & 8.64 & $\ldots$ & . \\
\hline & 61.5 & 915 & 1022 & 8.68 & $\ldots$ & $\ldots$ \\
\hline \multicolumn{2}{|c|}{ Daily average } & 880 & 1021 & 8.58 & 0.365 & 1.49 \\
\hline
\end{tabular}

On February 9, a nitrogen balance was attempted covering a period of six days, in which there was an exact comparison of the nitrogen income and output. In this balance period it will be observed that the total amount of nitrogen taken in for the six days was 53.108 grams, while the output of nitrogen through the kidneys amounted to 51.07 grams. The nitrogen excreted through the fæees, however, brought the total nitrogen output up to 58.83 grams, thus making a minus balance for the six days of 5.722 grams of nitrogen. During this period the average fuel value of the food per day was 2168 calories. The average daily output of metabolized 


\section{PHYSIOLOGICAL ECONOMY IN NUTRITION}

nitrogen during the period was 8.5 grams, practically identical with the average daily excretion of nitrogen through the kidneys for the entire year, so far as determined. We have here a distinct minus balance, due either to an insufficient amount of proteid food, or an insufficient fuel value.

\section{BEERS.}

Tuesday, February 9, 1904.

Breakfast. - Oatmeal 237.5 grams, butter 10 grams, sugar 35 grams, milk 60 grams, coffee 210 grams.

Lunch. - Macaroni 142 grams, cheese 10.5 grams, bread 71.5 grams, sweet potato 119.5 grams, milk 250 grams.

Dinner. - Bread 80.7 grams, butter 20 grams, mashed potato 176 grams, string beans 77.5 grams, apple pie 82 grams, milk 250 grams.

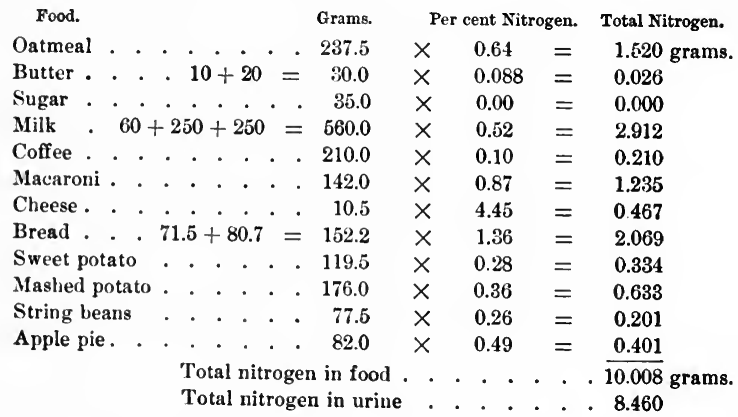

Fuel value of the food . . . . 2094 calories. 
BEERS.

Wednesday, February 10, 1904.

Breakfast. - Oatmeal 299 grams, butter 19 grams, cream 71 grams, sugar 41 grams, coffee 210 grams.

Lunch.- Bread 79 grams, butter 11 grams, boiled potato 155.2 grams, milk 250 grams.

Dinner. - Bread 56 grams, butter 12 grams, baked beans 100 grams, cranberry sauce 150 grams, sugar 21 grams, coffee 210 grams.

Food. Grams. Per cent Nitrogen. Total Nitrogen.

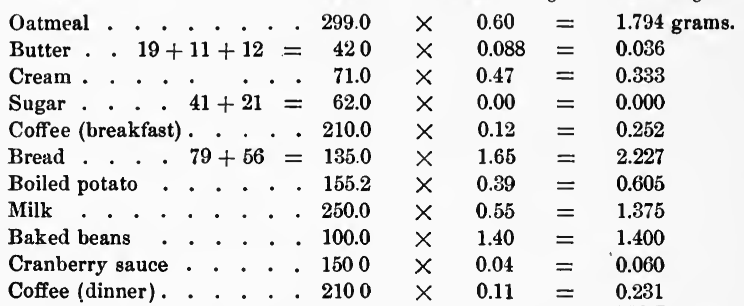

Total nitrogen in food . . . . . . $\overline{8.313}$ grams.

Total nitrogen in urine....$+ \quad 8.570$

Fuel value of the food . . . 1723 calories.

Thursday, February 11, 1904.

Breakfast. - Oatmeal 300 grams, cream 71 grams, butter 10 grams, sugar 41 grams, coffee 210 grams.

Lunch. - Butter 14 grams, bread 126 grams, boiled sweet potato 205 grams, milk 250 grams.

Dinner. - Bread 22 grams, butter 7.5 grams, mashed potato 100 grams, sugar 14 grams, milk 250 grams.

Food. Grams. Per cent Nitrogen. Total Nitrogen.

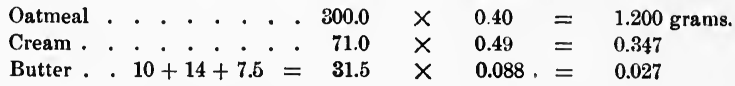




\section{PHYSIOLOGICAL ECONOMY IN NU'TRITION}

\section{BEERS.}

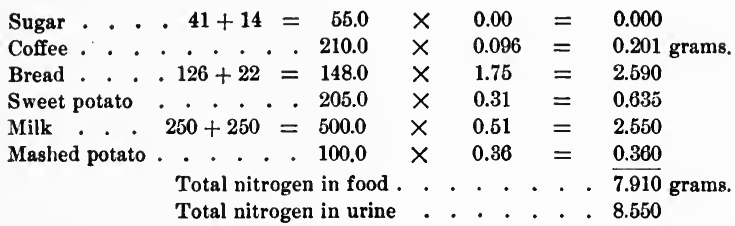

Fuel value of the food . . . 1979 calories.

$$
\text { Friday, February 12, } 1904 .
$$

Breakfast. - Oatmeal 300 grams, butter 10 grams, cream 74 grams, sugar 41 grams, coffee 210 grams.

Lunch. - Bread 86 grams, butter 9 grams, potato 200 grams, sugar 14 grams, milk 250 grams.

Dinner. - Bread 63 grams, butter 14 grams, mashed potato 150 grams, apple dumpling 136 grams, milk 250 grams.

Food. Grams. Per cent Nitrogen. Total Nitrogen.

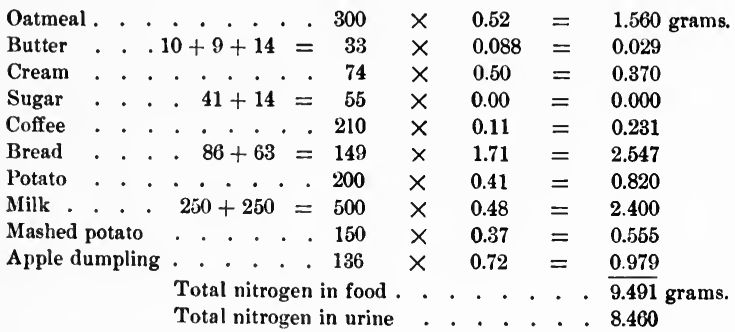

Fuel value of the food . . . 2209 calories. 


\section{BEERS.}

Saturday, February 13, 1904.

Breakfast. - Oatmeal 300 grams, butter 12 grams, cream 70 grams, sugar 41 grams, coffee 210 grams.

Luncl. - Bread 80 grams, butter 11 grams, sweet potato 132 grans, sugar 20 grams, milk 250 grams.

Dinner. - Bread 59.5 grams, mashed potato 175 grams, butter 11 grams, sugar 20 grams, apple pie 141 grams, milk 250 grams.

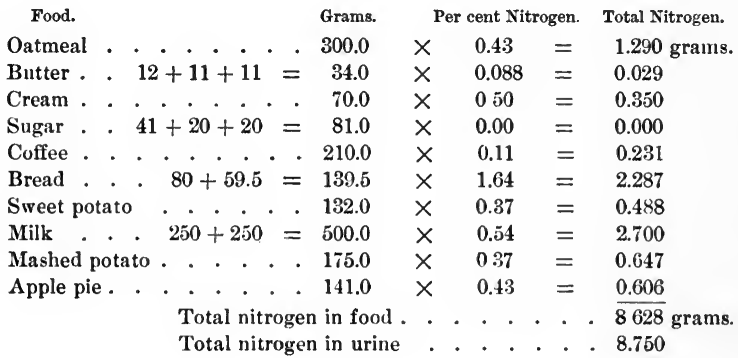

Fuel value of the food . . . 2395 calories. 


\title{
118 PHYSIOLOGICAL ECONOMY IN NUTRITION
}

\author{
BEERS.
}

Sunday, February 14, 1904.

Breakfast. - Oatmeal 300 grams, butter 16 grams, cream 70 grams, sugar 41 grams, coffee 210 grams.

Lunch. - Baked potato 171 grams, bread 72 grams, butter 15 grams, sugar 21 grams, apple sauce 38 grams, milk 250 grams.

Dinner. - Bread 35.5 grams, butter 13.5 grams, mashed potato 180 grams, sugar 20 grams, chocolate cake 111 grams, ice cream 115 grams, milk 250 grams.

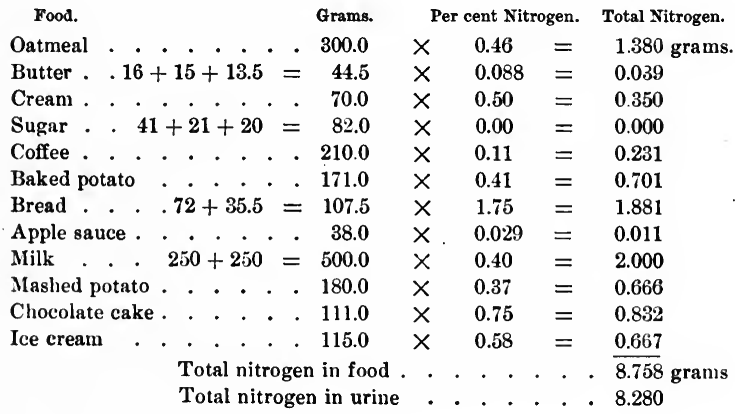

Fuel value of the food . . . . 2610 calories. 


\section{NITROGEN BALANCE.-Beers.}

Nitrogen
Taken in.

\begin{tabular}{|c|c|c|c|}
\hline Feb. 9 & 10.008 grams. & 8.46 grams. & $\ldots$ \\
\hline 10 & 8.313 & 8.57 & 44.7 grams. \\
\hline 11 & 7.910 & 8.55 & 19.0 \\
\hline 12 & 9.491 & 8.46 & 30.0 \\
\hline 13 & 8.628 & 8.75 & 28.0 \\
\hline \multirow[t]{4}{*}{14} & 8.758 & 8.28 & 5.0 \\
\hline & & & 126.7 grams contain \\
\hline & & & $6.13 \% \mathrm{~N}$ \\
\hline & 53.108 & 51.07 & 7.76 grams nitrogen. \\
\hline
\end{tabular}

Nitrogen balance for six days $=-5.722$ grams.

Nitrogen balance per day $=-0.953 \mathrm{gram}$

Average Intake.

Calories per day . . . . . . . . 2168.

Nitrogen per day . . . . . . . 8.85 grams. 
On May 6, a second nitrogen balance was attempted covering a period of seven days, in which, as before, there was an exact comparison of the income and output of nitrogen. In this period of seven days, as shown in the accompanying tables, the fuel value of the food was essentially the same as in the preceding period, but the amount of proteid food was increased to an average intake of $\mathbf{1 0 . 1 0}$ grams per day. Under these conditions there was a distinct plus balance for the seven days amounting to 2.425 grams, thus showing that with this quantity of nitrogenous food the body was laying on nitrogen to the extent of 0.346 gram per day. The average daily amount of nitrogen metabolized during this period was only 8.18 grams, being quite noticeably below the average daily amount for the year. In other words, the results of this balance period show that with a consumption of food sufficient to yield about 2200 calories per day, the body of this subject needed to metabolize only 8.25 grams of nitrogen per day to more than maintain nitrogen equilibrium. Following are the tables of results: 


\section{BEERS.}

\section{Friday, May 6, 1904.}

Breakfast. - Oatmeal 345 grams, butter 7 grams, sugar 30 grams, milk 100 grams, coffee 180 grams.

Dinner.- Bread 67 grams, potato 71 grams, corn 179 grams, pie 133 grams, milk 200 grams.

Supper. - Biscuit 75 grams, butter 11 grams, potato 106 grams, cake 52 grams, apricots 75 grams, milk 230 grams.

Food. Grams. Per cent Nitrogen. Total Nitrogen.

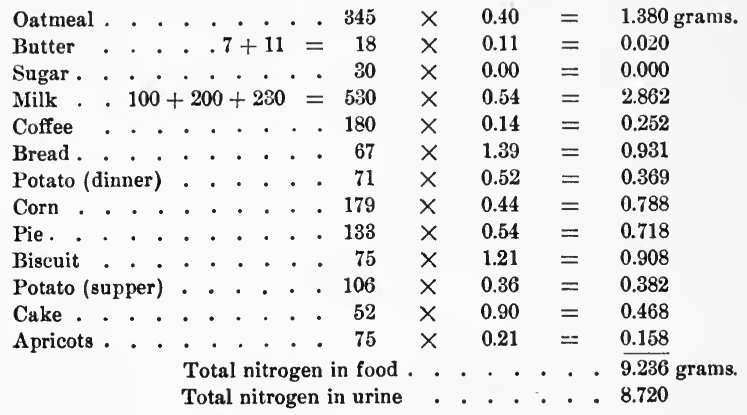

Fuel value of the food . . . 2080 calories.

\section{Saturday, May \%, 1904.}

Breakfast. - Oatmeal 382 grams, milk 100 grams, coffee 185 grams, butter 10 grams, sugar 30 grams.

Dinner. - Bread 93 grams, potato 67 grams, rice pudding 141 grams, milk 200 grams.

Supper. - Bread 67 grams, butter 13 grams, potato salad 122 grams, milk 240 grams, coffee 120 grams.

Food. Grams. Per cent Nitrogen. Total Nitrogen.

Oatmeal . . . . . . . . $382 \times 0.41=1.566$ grams.

Milk . $100+200+240=540 \times 0.54=2.916$

Coffee (breakfast) . . . . . $185 \times 0.13=0.241$ 


\section{BEELS.}

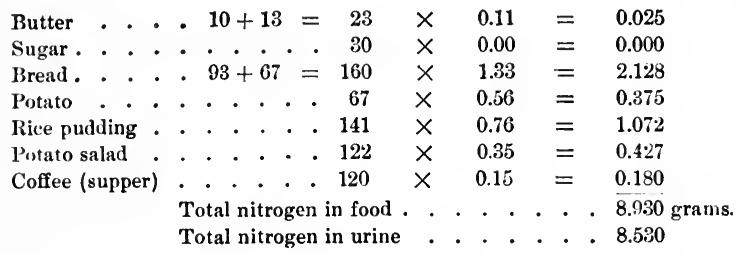

Fuel value of the food . . . 1714 calories.

Sunday, May 8, 1904.

Breakfast. - Oatmeal 386 grams, butter 10 grams, sugar 35 grams, milk 100 grams, coffee 185 grams.

Dinner. - Rice and chicken gravy 178 grams, boiled onions 136 grams, chocolate pudding 141 grams, milk 150 grams.

Supper. - Potato salad 73 grams, bread 28 grams, chocolate cake 104 grams, milk 220 grams.

Food. Grams. Per cent Nitrogen. Total Nitrogen.

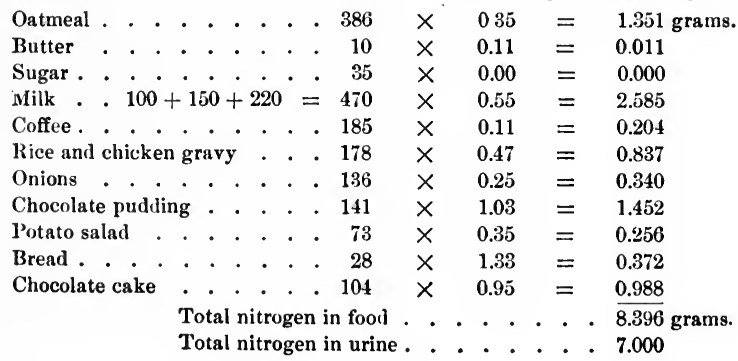

Fuel value of the food . . . 1995 calories. 


\author{
BEERS.
}

\title{
Monday, May 9, 1904.
}

Breakfast. - Oatmeal 330 grams, butter 10 grams, sugar 35 grams, milk 100 grams, coffee 185 grains.

Dinner. - Bread 73 grams, fried potato 125 grams, boiled onions 118 grams, macaroni and cheese 128 grains, apple pie 110 grams, milk 200 grams.

Supper. - Bread 82 grams, boiled potato 130 grams, butter 12 grams, chocolate cake 114 grams, milk 245 grams.

Food. Grams. Per cent Nitrogen. Total Nitrogen.

\begin{tabular}{|c|c|c|c|c|c|c|c|c|c|c|c|}
\hline Oatmeal & . $\cdot$ & & - & - $\cdot$ & $\cdot$ & . $\cdot$ & 330 & $x$ & 0.44 & $=$ & 1.452 grams. \\
\hline Butter & . & - & - & & +10 & $0=$ & 22 & $x$ & 0.11 & $=$ & 0.024 \\
\hline Sugar . & . & . & . & . . & . & . & 35 & $x$ & 0.00 & $=$ & 0.000 \\
\hline Milk . & . 10 & $00+$ & +200 & $0+$ & 245 & $5=$ & 545 & $x$ & 0.58 & $=$ & 3.161 \\
\hline Coffee & - & . & . & . . & • & - . & 185 & $x$ & 0.099 & $=$ & 0.183 \\
\hline Bread. & . $\cdot$ & - & . & $73+$ & +82 & $2=$ & 155 & $x$ & 1.33 & $=$ & 2.062 \\
\hline Fried pota & ato & . & . & . & • & . . & 125 & $\times$ & 0.48 & $=$ & 0.600 \\
\hline Onions & .. & · & . & - & . & - & 118 & $x$ & 0.25 & $=$ & 0.295 \\
\hline Macaront & and & che & eese & - & - & . & 128 & $x$ & 1.53 & $=$ & 1.958 \\
\hline Apple pie & & - & . . & . & • & - & 110 & $x$ & 0.55 & $=$ & 0.605 \\
\hline Boiled pot & tato & . & . & - & . & . . & 130 & $x$ & 0.30 & $=$ & 0.390 \\
\hline Chocolote & cak & & & • & . & . . & 114 & $x$ & 0.95 & $=$ & 1.083 \\
\hline
\end{tabular}

Fuel value of the food . . . 2620 calories.

$$
\text { Tuesday, May 10, } 1904 \text {. }
$$

Breakfast. - Oatmeal 357 grams, butter 11 grams, sugar 35 grams, milk 100 grams, coffee 185 grams.

Dinner. - Soda biscuit 68 grams, boiled potato 160 grams, butter 20 grams, stewed tomato 103 grams, custard pie 103 grams, milk 200 grams.

Supper. - Soda biscuit 81 grams, butter 14 grams, stewed potato 97 grams, chocolate cake 66 grams, milk 200 grams.

Food.

Oatmeal . 357

Butter . $11+20+14=45$

Sugar . . . . . . . 35
Per cent Nitrogen. Total Nitrogen.

$\times \quad 0.42=1.499$ grams.

$\times \quad 0.11=0.050$

$\times \quad 0.00=0.000$ 


\section{PHYSIOLOGICAL ECONOMY IN NUTRITION}

BEERS.

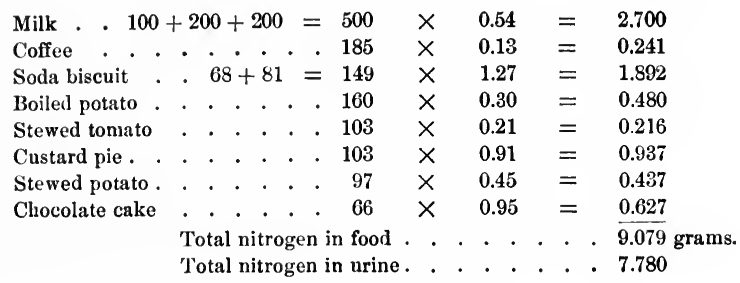

Fuel value of the food . . . 2190 calories.

Wednesday, May 11, 1904.

Breakfast. - Oatmeal 394 grams, butter 10 grams, sugar 35 grams, milk 100 grams, coffee 185 grams.

Dinner. - Soup 141 grams, bread 78 grams, butter 14 grams, boiled potato 101 grams, corn 128 grams, rice pudding 116 grams, milk 200 grams.

Supper. - Biscuit 103 grams, butter 11 grams, corn 113 grams, cake 60 grams, milk 205 grams.

Food. Grams. Per cent Nitrogen. Total Nitrogen.

\begin{tabular}{|c|c|c|c|c|c|c|c|c|c|c|c|}
\hline Oatmeal & & . & . . . & . & . & . . & 394 & $\times$ & 0.46 & $=$ & 1.812 grams. \\
\hline Butter & . & . & $10+1$ & $4+$ & -11 & $=$ & 35 & $x$ & 0.11 & $=$ & 0.039 \\
\hline Sugar & . & . . & . . . & . & . & . . & 35 & $x$ & 0.00 & $=$ & 0.000 \\
\hline Milk . & . 1 & 100 & +200 & +2 & 205 & $5=$ & 505 & $x$ & 0.54 & $=$ & 2.727 \\
\hline Coffee & . . & . . & . . . & . & . & . . & 185 & $x$ & 0.13 & $=$ & 0.241 \\
\hline Soup . & . & . & . & . & . & . & 141 & $x$ & 0.48 & $=$ & 0.677 \\
\hline Bread & . & . & . & . & . & . & 78 & $x$ & 1.25 & $=$ & 0.975 \\
\hline Boiled pc & otatc & to. & . . & . & . & . & 101 & $x$ & 0.31 & $=$ & 0.313 \\
\hline Corn . & . . & . . & 113 & +1 & 128 & $3=$ & 241 & $x$ & 0.46 & $=$ & 1.109 \\
\hline Rice pud & ding & $\lg$ & . . & . & . & . . & 116 & $x$ & 0.63 & $=$ & 0.731 \\
\hline Biscuit & . . & . & . & . & . & . & . 103 & $x$ & 1.42 & $=$ & 1.463 \\
\hline Cake . & . & . . & . & . & . & . & . 60 & $x$ & 0.78 & $=$ & 0.468 \\
\hline
\end{tabular}

Fuel value of the food . . . 2183 calories. 


\section{BEERS.}

Thursday, May 12, 1904.

Breakfast. - Oatmeal 349 grams, butter 10 grams, sugar 35 grams, milk 100 grams, coffee 185 grams.

Dinner. - Soup 137 grams, fried potato 43 grams, bread 100 grams, macaroni and cheese 122 grams, bread pudding 80 grams, milk 200 grams.

Supper. - Stewed potato 126 grams, bread 122 grams, cake 73 grams, apricots 81 grams, milk 220 grams.

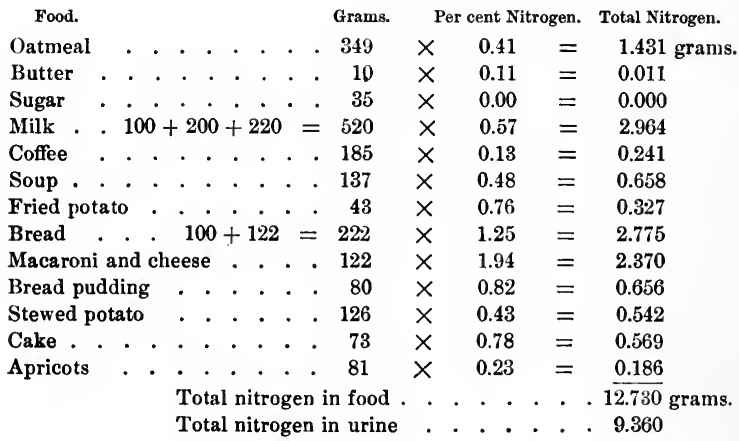

Fuel value of the food . . . . 2283 calories. 


\section{NITROGEN BALANCE. - Beers.}

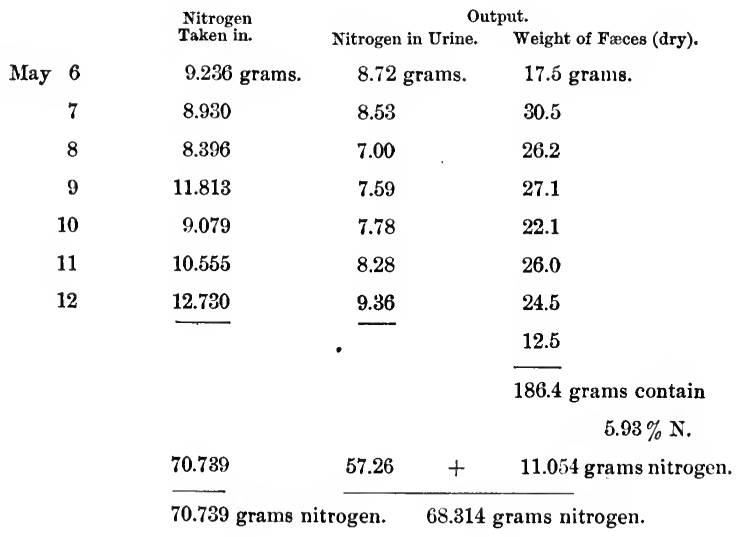

Nitrogen balance for seven days $=\quad+2.425$ grams.

Nitrogen balance per day $=\quad+0.346$ gram.

Average Intake.

Calories per day . . . . . . . . 2152.

Nitrogen per day . . . . . . . 10.10 grams. 
Here we have, as in the preceding cases, marked physiological economy of non-nitrogenous as well as of nitrogenous food material. Further, taking the body-weight of the subject as 61.5 kilos, and with an average daily excretion of 8.58 grams of metabolized nitrogen, it is evident that under the existing conditions of life and activity there was need for the metabolism of only 0.139 gram of nitrogen per kilo of body-weight. Doubtless, however, still greater economy was possible.

Finally, while it hardly savors of scientific accuracy to quote simple sensations, yet it may be stated that the subject asserts a betterment of his condition, with continuance of mental and physical vigor in such a degree that he has persisted now for more than a year and a half in the maintenance of these dietetic habits which are characterized by this lowered rate of proteid metabolism. The quantity of nitriogen metabolized daily means the breaking down of approximately 50 grams of proteid, and it is very evident that this amount of proteid food, one-half the amount called for by the ordinary diet, is quite sufficient to meet all of the subject's bodily needs, even with a total fuel value considerably below 2500 calories.

\section{Summary}

Certain general conclusions seem to be justified by the results reported. A healthy man, whose occupation is such as not to involve excessive muscular work, but whose activity is mainly mental rather than physical, though by no means excluding the latter, can live on a much smaller amount of proteid or albuminous food than is usually considered essential for life, without loss of mental or physical strength and vigor, and with maintenance of body and nitrogen equilibrium. This means that the ordinary professional man who leads an active and even strenuous life, with its burden of care and responsibility, need not clog his system and inhibit his power for work by the ingestion of any such quantities of proteid food as the ordinary dietetic standards call for. 
There is no real physiological need - that is apparent - for the adoption of such dietetic habits as ordinarily prevail, or as are called for by the dietary standards set by most authorities in this branch of physiology. There is no justifiable ground for the dictum, or the assumption, that the adult man of average body-weight needs daily 118 grams of proteid food for the maintenance of health, strength and vigor, or that there is need for the metabolism of at least 16 grams of nitrogen daily. If such were the case, how could these five subjects, whose experiences have been detailed in the foregoing pages, have maintained their body-weight, established nitrogen equilibrium, pursued their ordinary vocations without loss of strength and vigor, and kept in a perpetual condition of good health, with an average daily metabolism of from 5.4 grams of nitrogen to 8.99 grams of nitrogen for periods ranging from six to eighteen months? Surely, if 16 to 18 grams of nitrogen are a daily requisite for the healthy adult, there should have been some sign of nitrogen starvation during these long periods of low proteid diet, but the sharpest scrutiny failed to find it. On the contrary, there were not wanting signs of improved conditions of the body which could not well be associated with anything but the changes in diet.

Let us briefly consider the main facts. The writer, of 57 kilos body-weight, showed for nearly nine consecutive months an average daily metabolism of 5.7 grams of nitrogen. During the last two months the daily metabolism averaged 5.4 grams of nitrogen. As body-weight and nitrogen equilibrium were both maintained under these conditions, it is certainly fair to assume that the physiological needs of the body were fally met. These figures imply a metabolism, in the first instance, of 0.1 gram of nitrogen per kilo of body-weight, while the lower figure shows a metabolism of 0.094 gram of nitrogen per kilo of body-weight. We may call this latter amount the minimal nitrogen requirement for this particular individual, under which health, strength, and vigor can be fully maintained. This lower nitrogen figure shows 
that the needs of this particular individual for proteid material are met by the metabolism of 33.75 grams of proteid per day. Hence, one-third the usually accepted standard of proteid is quite suffieient for the wants of this particular person, and this too with a quantity of non-nitrogenous food far below the daily amount called for by ordinary physiologieal rules. A fuel value of 2000 ealories per day was fully adequate to meet the ordinary wants of the body.

Dr. Mendel, with a body-weight of 70 kilos, showed for seven consecutive months an average daily metabolism of 6.53 grams of nitrogen, likewise with maintenance of health, strength, body equilibrium, and nitrogenous equilibrium. This figure implies a nitrogen metabolism of 0.093 gram per kilo of body-weight and shows that the wants of the body - in his case - can be fully met by a metabolism of 40.8 grams of proteid matter daily, and this likewise without increasing the amount of non-nitrogenous food ingested. Indeed, a total fuel value of 2500 calories per day was quite sufficient for all the needs of his body under the existing conditions.

Dr. Underhill, with a body-weight of 65 kilos, showed for six consecutive months a proteid metabolism equal to 7.81 grams of nitrogen per day, while for the last two months the daily average excretion of nitrogen was only 6.68 grams. These figures mean respectively a nitrogen metabolism of 0.120 and 0.102 gram of nitrogen per kilo of bolly-weight. Here, too, as in the preceding eases, this lowered rate of proteid metabolism was maintained without increasing the total fuel value of the food and with a continuance of health and strength.

Messrs. Dean and Beers, with body-weights of 64 and 61.5 kilos respeetively, likewise kept up their health and strength for a long period of time with a nitrogen metabolism averaging 8.99 and 8.58 grams of nitrogen per day, i.e., with a metabolism of 0.140 and 0.139 gram of nitrogen per kilo of body-weight respectively, and this with a total fuel value in their daily food averaging not more than 2500 ealories. 
With this general concurrence of results, we are certainly warranted in the assertion that the professional man can safely practise a physiological economy in the use of proteid food equal to a saving of one-half to two-thirds the amount called for by existing dietary standards, and this without increasing the amount of non-nitrogenous food consumed. Indeed, the latter class of foods can likewise be diminished in amount without detriment to health or strength, where there is no call for great physical exertion. Lastly, the so-called minimal proteid requirement of the healthy man - which for this group of individuals we may place at the low level of 0.093 to 0.130 gram of nitrogen per kilo of body-weight - represents the real physiological needs of the system for nitrogen, and in so far as our present data show, anything beyond this quantity may be considered as an excess over and above what is required for the actual physiological necessities of the body. Naturally, however, there may be nothing detrimental in a slight exeess of proteid beyond the daily needs. That is a subject, however, to be discussed later in connection with other results.

In view of the close agreement in the amount of nitrogen metabolized by these different individuals per kilo of bodyweight, emphasis should be laid upon the fact that the resuits recorded were all obtained with perfect freedom of choice in the matter of diet, without prescription of any kind, so that the close concurrence in the final figures tends to strengthen the value of the data as pointing to a certain minimal requirement easily attainable, and fully adequate for meeting the needs of the body. 


\section{EXPERIMENTS WITH VOLUNTEERS FROM THE HOSPITAL CORPS OF THE UNITED STATES ARMY.}

The original Detachment from the Hospital Corps of the United States Army detailed to serve in this series of experiments arrived in New Haven September 28, 1903, under the command of Dr. Wallace DeWitt, 1st Lieutenant and assistant Surgeon of the United States Army. The detail was composed of twenty men, of whom fourteen were privates, volunteers for the experiment, the remainder being made up of non-commissioned officers, cook, cook's helper, etc. The detachment was located in a convenient house on Vanderbilt Square belonging to the Sheffield Scientific School, and there they lived during their six months' stay in New Haven under military discipline, and subject to the constant surveillance of the commanding officer and the non-commissioned officers.

In selecting the men for the experiment particular attention ws paid to securing as great a variety of types as possible, representing different nationalities, temperaments, etc. Naturally, among such a group of enlisted men brought together for the purpose in view many were found unsuited for various reasons, and were quickly exchanged for others better adapted for the successful carrying out of the experiment. Several quickly deserted, apparently not relishing the restrictions under which they were compelled to live. The restriction which constituted the greatest hardship in the eyes of several of the men was the regularity of life insisted upon, and the consequent restraint placed upon their movements in the city when relieved from duty. The following Statement from Dr. DeWitt will explain the causes of removal of the men who dropped out of the experiment during the natural sifting process of the first few weeks and later. 


\section{Hospital Corps Detachment U. S. Army, 332 Temple St., New Haven, Cons. March 17, 1904.}

Professor Russell H. Chittenden,

Director Sheffield Scientific School.

New Haves, Coss.

Sir, - In compliance with your verbal request concerning men of this detachment lost by transfer and desertion and the reasons therefor, I have the honor to inform you that the following men were lost by transfer, at my request, for the reasons set after their respective names:

Private Edward McDermott (October 17, 1903). Mentally and morally unsuited.

Private Paul Forkel (October 18, 1903). Physically unsuited.

Private David Acker (October 24, 1903). Physically unsuited by reason of Acute Pulmonary 'Tuberculosis Bilateral.

Private William C. Witzig (November 17, 1903). Physically unsuited by reason of Cardiac Irritability.

Private Pillorp S. Mrer (December 11, 1903). Physically unsuited by reason of very high grade of Myopia both eyes.

Private first class Charles P. Davis (January 14, 1904). Physically unsuited by reason of Acute Melancholia.

Private Barnard Bates (February 12, 1904). Morally and mentally unsuited by reason of Drunkenness.

In all these men, except Private Davis, the condition for which they were transferred was present when they reported for duty with the detachment.

In the case of Private Davis, his condition of acute melancholia in my opinion was incident to the experiment, - due to the necessary restrictions of liberty and food, assisted by a natural gloomy disposition.

The following men were lost by desertion :

Private first class Samoel R. Curtis (November 3, 1903).

Private first class IVildia Surth (November 5, 1903).

Private Simox Prixs (January 23, 1904).

Private Edwin A. Rinard (February 3, 1904). 
Of these men Private first class Smith and Private Prins were on duty in the kitchen and were at no time subject to restriction of diet and liberty. Private first class Curtis deserted before the experiment was well under way and can not be attributed to any cause arising out of the investigation. Private Rinard's desertion was in my opinion due to the restrictions of diet and liberty incident to the experiment. I would say, however, that this man was a worthless character and was discharged "without honor" from the army during a previous enlistment.

\section{Very respectfully,}

(Signed) Wallace DeWitt,

1st Lieut. and Asst. Surgeon U. S. Army, Commdg. Detachment.

As supplementing Dr. DeWitt's statement it may be mentioned that Rinard reported for the experiment at New Haven on December 11, 1903, and remained here until February 2, 1904. On December 11 he weighed 59.8 kilos, while on February 2, the last day he was here, his body-weight was 60 kilos. Evidently, any restriction of diet he may have suffered had not made any great impression upon his bodily condition.

There were thirteen men of the detachment who really took part in the experiment, and of these all but four were in the original detail. Of these four, two joined in October and two early in November. Of these thirteen, all but two continued to the close of the experiment, April 4, 1904.

The following statement gives the name, age, birthplace, occupation, length of service (U. S. Army), etc. of the thirteen men.

It will be noted that the men range in age from twenty-one years six months to forty-three years, and that representatives of many countries are on the list.

Regarding the duties of the men, i. e., their daily work, the following statement from Dr. DeWitt will give all needed information on this point. The character of the Gymnasium work will be referred to later. 


\section{PIIYSIOLOGICAL ECONOMY IN NUTRITION}

\begin{tabular}{|c|c|c|c|c|c|}
\hline 离 & 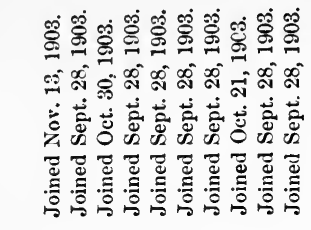 & 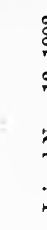 & 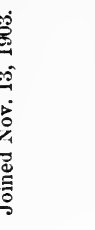 & 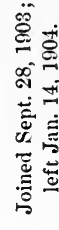 & 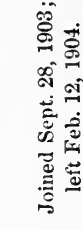 \\
\hline 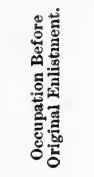 & 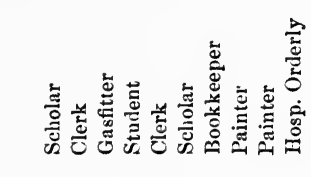 & & 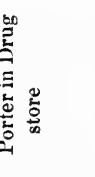 & 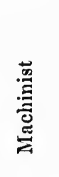 & 䓌 \\
\hline 竎 & 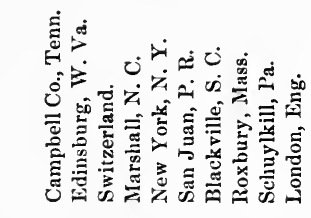 & & 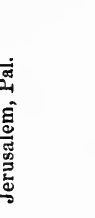 & 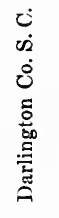 & 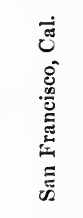 \\
\hline 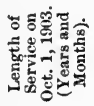 & 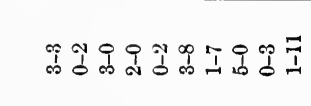 & & ] & ơ & $\stackrel{9}{I}$ \\
\hline 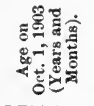 & 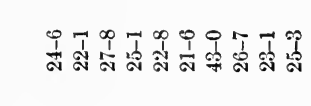 & & 交 & $\frac{1}{1}$ & 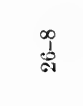 \\
\hline 产 & 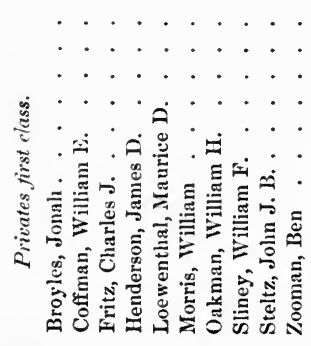 & : & 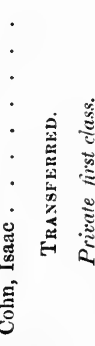 & 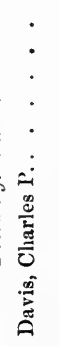 & 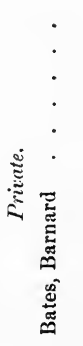 \\
\hline
\end{tabular}




\section{Hospital Corps Detachment U. S. Army, 332 Temple Street, New Haven, Cons., March 17, 1904.}

Professor R. H. Chittenden,

Director Sheffield Scientific School,

New Haven, Cons.

Sin, - In compliance with your verbal request I have the honor to inform you that the duties of this detachment during the tour of duty at this station have been as follows:-

At $6.45 \mathrm{~A}$. $\mathrm{x}$. the men arise and their body-weights are taken immediately, after which they dress and assemble for reveille rollcall.

7.15. Breakfast. After this meal they are all engaged in various duties about the quarters, such as inside and outside police, kitchen police, assisting in measurement of urine and fæces and transportation of the same to the laboratory; cleansing of fæces cans and urine bottles, etc. They are occupied with these various duties until about 9 A. м.

9 A. м. Detachment proceeds to Gymnasium under charge of a non-commissioned officer, and by him reported to the gymnastic instructor.

11 A. м. Detachment returns from Gymnasium.

12 м. Dinner.

$1 \mathrm{r} . \mathrm{M}$. Drill, weather permitting, otherwise a walk in charge of a non-commissioned officer, or indoor instruction relative to the duties of a soldier.

2 г. м. Relief from drill; walk, or instruction.

2.30 P. M. Instruction by a non-commissioned officer in their duties as nurses, etc.

3.30 Р. м. Relief from instruction.

5 P. I. Supper.

5.30 P. .r. Retreat roll-eall.

10 p. .. All men in bed.

This routine is the same for every day in the week except Saturday and Sunday. On Saturday drill and instruction in the afternoon are omitted, and on Sundays the men are also free from gymnasium work.

In addition to the duties mentioned above, a special detail of two men is made every morning to assist in the weighing and serv- 
ing of the food, and from time to time details are sent to the laboratory and reported to Dr. Mendel for such work connected with the investigation as he might assign them.

Very respectfully,

(Signed) Wallack: DeWrtt,

1st Lieut. and Asst. Surgeon U. S. Army, Commdg. Det. H. C.

Here we have a group of men, thirteen in number, quite different in type from the preceding group; men accustomed to living a vigorous life under varying conditions, and who naturally had great liking for the pleasures of eating. Further, they were men who had no personal interest whatever in the experiment or in the principles involved. To be sure, they had volunteered for the work, and the objects of the experiment had been fully explained to them. Like good soldiers they no doubt desired to obey orders, and they doubtless preferred to see the experiment a success rather than a failure, but they had not that interest that would lead them to undergo any great personal discomfort. This point should be kept in mind, since it has a distinct bearing upon the possibility of establishing physiological economy of diet in persons who would not willingly incommode themselves or suffer personal inconvenience.

The experiment commenced on October 4, 1903, and for a period of six months every detail bearing upon the nutrition and condition of the men under the gradually changed conditions was carefully observed. Every precaution to preserve the health and good spirits of the men was taken. Pure distilled water was sent to the quarters each morning, magazines and other periodicals were supplied through the courtesy of friends, occasional visits to the theatre were indulged in; in fact all that conld be done to counterbalance any possible depressing influence from the partial restraints of the experiment was arranged for.

Regarding the details of the work; the twenty-four hours' urine was collected by each man, also the fæces for each day, and these were subjected to chemical analysis with a view to 


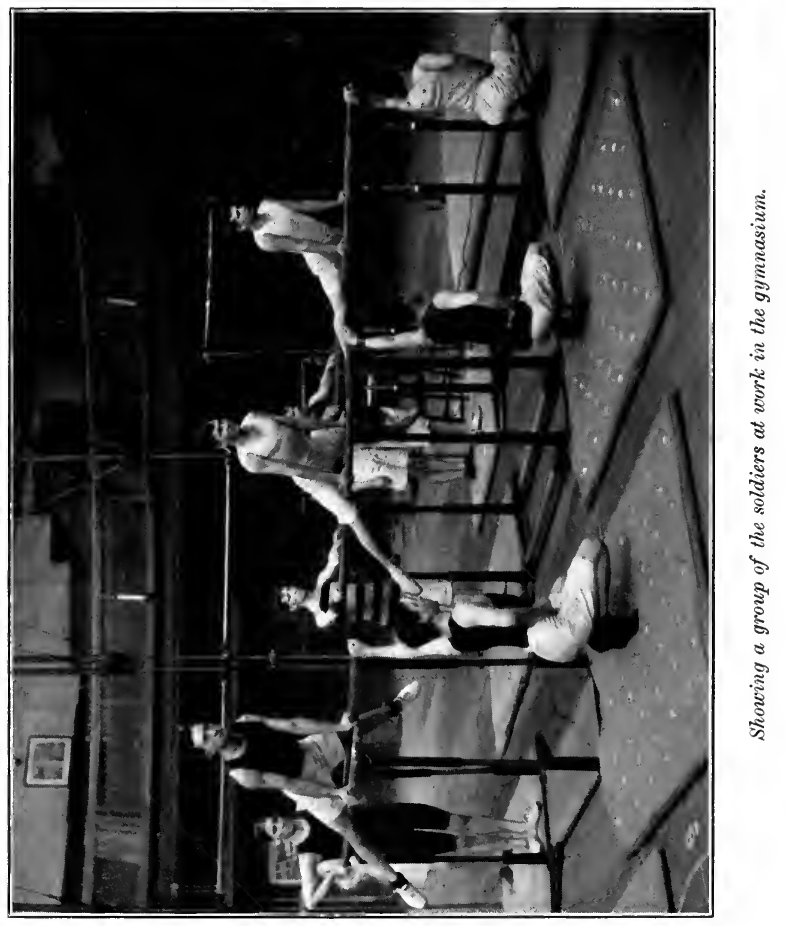



following out the various changes in the amount and character of the proteid metabolism going on in the body as measured by the output of total nitrogen, uric acid, and phosphoric acid in the urine, and by the amount of nitrogen in the fæces with reference to the degree of digestion and utilization of the proteid foods ingested.

During the first two weeks the ordinary army rations were given to the men; later a gradual change was made, accompanied by a reduction in the amount of proteid food, with some reduction likewise in the total fuel value of the food. All the food placed before each man was carefully weighed, and at the close of every meal any uneaten food was weighed and the amount subtracted from the initial weights. During the balance periods, when the income and output of nitrogen were carefully compared, the food materials were weighed with greater care and large samples of each article were taken for analysis, to determine the exact content of nitrogen. Every figure for nitrogen shown in the tables was verified by at least a duplicate chemical analysis so as to avoid any possibility of error.

It is not necessary to give here any detailed description of the changes made in the character of the diet, since on pages 288 to 326 may be found the daily dietary from October 2, 1903, to April 4, 1904, - each meal of the day, - showing the amount and character of the food given the men during the six months period. It should be stated, however, that at no time were the men placed on a cereal diet or on a truly vegetable diet. The object in view was simply to study the possibilities of a general physiological economy in diet, with special reference to the minimal proteid requirement of the healthy man. To be sure, in doing this meats, owing to their high content of proteid, were very much reduced in amount and on many days no meat at all was given, but as the dietary is looked through it will be seen that the main change was from a heavy meat diet (rich in proteid) to a lighter diet, comparatively poor in proteid, with an increasing predominance of vegetable and cereal foods. Condiments are also 


\section{PIIYSIOLOGICAL ECONOMY IN NUTRITION}

noticeable in the diet, together with the ordinary accessories, coffee and tea. Variety was also considered as a necessary factor, not to be overlooked, as contributing largely to the maintenance of a proper physiological condition.

From a study of the tables which follow, showing the chemical composition of the daily urine, it will be seen that during the first sixteen days, viz., from October 4 until October 20 or 21 , when the men were on the ordinary army ration with opportunity to eat an abundance of meat, the daily urine frequently contained 16 to $1 \tau$ grams of nitrogen, showing a metabolism of over 100 grams of proteid on such days. Sliney, indeed, averaged for four days an "output of 18.19 grams of nitrogen, while Coffman, Henderson, and Zooman showed an average daily excretion of about 15 grams of nitrogen each for the sixteen days from October 4. 
OAKMAN.

\begin{tabular}{|c|c|c|c|c|c|c|c|}
\hline \multirow{2}{*}{\multicolumn{2}{|c|}{ Date. }} & \multirow{2}{*}{$\begin{array}{c}\text { Body- } \\
\text { weight. }\end{array}$} & \multicolumn{5}{|c|}{ Urine. } \\
\hline & & & $\begin{array}{l}\text { Voluune. } \\
24 \text { hours. }\end{array}$ & Sp. Gr. & Nitrogen. & Uric Acid. & $\mathrm{P}_{2} \mathrm{O}_{5}$. \\
\hline \multicolumn{2}{|c|}{1903} & kilos & c.c. & & grams & gram & grams \\
\hline \multirow[t]{28}{*}{ Oct. } & 4 & 66.7 & 1160 & 1019 & 16.37 & 0.549 & 2.76 \\
\hline & 5 & 66.7 & 1030 & 1025 & 12.36 & $\ldots$ & $\ldots$ \\
\hline & 6 & 66.0 & 740 & 1029 & 11.85 & 0.703 & 1.15 \\
\hline & 7 & 66.0 & 480 & 1031 & 10.31 & $\ldots$ & $\cdots$ \\
\hline & 8 & 65.4 & 660 & 1030 & 14.30 & 0.574 & 1.32 \\
\hline & 9 & 65.4 & 830 & 1029 & 15.94 & $\cdots$ & $\ldots$ \\
\hline & 10 & 65.4 & 1440 & 1018 & 17.02 & $\cdots$ & $\ldots$ \\
\hline & 11 & 66.1 & 2220 & 1012 & 16.12 & 0.591 & 2.64 \\
\hline & 12 & 66.7 & 1300 & 1020 & 13.33 & $\ldots$ & . . \\
\hline & 13 & 66.8 & 2140 & 1013 & 15.67 & 0.610 & 2.56 \\
\hline & 14 & 66.4 & 1290 & 1017 & 12.38 & $\ldots$ & $\ldots$ \\
\hline & 15 & 66.7 & 1730 & 1017 & 14.95 & 0.653 & 1.93 \\
\hline & 16 & 66.7 & 1520 & 1017 & 13.68 & $\ldots$ & $\cdots$ \\
\hline & 17 & 66.2 & 1490 & 1018 & 15.20 & $\ldots$ & $\ldots$ \\
\hline & 18 & 66.2 & 2030 & 1014 & 16.44 & 0.646 & 2.66 \\
\hline & 19 & 65.8 & 1580 & 1017 & 16.78 & $\ldots$ & $\ldots$ \\
\hline & 20 & 65.3 & 1900 & 1014 & 16.19 & 0.626 & 1.95 \\
\hline & 21 & 65.4 & 1100 & 1024 & 12.07 & $\ldots$ & $\ldots$ \\
\hline & 22 & 66.0 & 1200 & 1018 & 11.30 & 0.502 & 1.11 \\
\hline & 23 & 66.4 & 2060 & 1015 & 11.37 & $\ldots$ & $\ldots$ \\
\hline & 24 & 67.2 & 1970 & 1015 & 11.88 & $\ldots$ & $\ldots$ \\
\hline & 25 & 67.1 & 1480 & 1014 & 8.64 & 0.411 & 2.07 \\
\hline & 26 & 67.2 & 1510 & 1018 & 11.78 & $\ldots$ & . \\
\hline & 27 & 67.2 & 1890 & 1015 & 12.13 & 0.406 & 1.99 \\
\hline & 28 & 67.4 & 1620 & 1014 & 9.82 & $\ldots$ & $\ldots$ \\
\hline & 29 & 67.6 & 980 & 1018 & 6.82 & 0.493 & 1.62 \\
\hline & 30 & 67.5 & 820 & 1022 & 10.91 & $\ldots$ & $\ldots$ \\
\hline & 31 & 67.0 & 930 & $\ldots$ & $\ldots$ & $\ldots$ & $\ldots$ \\
\hline \multirow[t]{12}{*}{ Nov. } & 1 & 67.4 & 1480 & 1015 & 10.20 & 0.460 & 1.49 \\
\hline & 2 & 67.6 & 1160 & 1018 & 10.37 & $\ldots$ & $\ldots$ \\
\hline & 3 & 67.4 & 1160 & 1020 & 10.44 & 0.489 & 1.53 \\
\hline & 4 & 67.1 & 720 & 1024 & 6.61 & $\cdots$ & $\ldots$ \\
\hline & 5 & 66.6 & 640 & 1029 & 8.02 & 0.495 & 1.17 \\
\hline & 6 & 66.5 & 1200 & 1016 & 9.57 & $\ldots$ & $\ldots$ \\
\hline & 7 & 66.0 & 840 & 1023 & 8.57 & $\ldots$ & $\ldots$ \\
\hline & 8 & 66.0 & 1100 & 1017 & 8.32 & 0.452 & 1.67 \\
\hline & 9 & 66.0 & 720 & 1030 & 8.53 & $\ldots$ & $\ldots$ \\
\hline & 10 & 66.4 & 880 & 1022 & 10.19 & 0.515 & 1.30 \\
\hline & 11 & 66.6 & 1080 & 1018 & 9.72 & $\ldots$ & $\ldots$ \\
\hline & 12 & 66.9 & 920 & 1025 & 8.38 & 0.616 & 1.54 \\
\hline
\end{tabular}


OAKMAN.

\begin{tabular}{|c|c|c|c|c|c|c|}
\hline \multirow{2}{*}{ Date. } & \multirow{2}{*}{$\begin{array}{c}\text { Body- } \\
\text { weight. }\end{array}$} & \multicolumn{5}{|c|}{ Urine. } \\
\hline & & $\begin{array}{l}\text { Volume. } \\
24 \text { hours. }\end{array}$ & Sp. Gr. & Nitrogen. & Uric Acid. & $\mathrm{P}_{2} \mathrm{O}_{5}$. \\
\hline 1903 & kilos & c.c. & & grams & gram & grams \\
\hline Nov. 13 & 67.2 & 800 & 1025 & 6.43 & $\cdots$ & $\ldots$ \\
\hline 14 & 66.5 & 600 & 1026 & 7.38 & $\ldots$ & $\ldots$ \\
\hline 15 & 66.3 & 1360 & 1014 & 8.98 & 0.403 & 1.44 \\
\hline 16 & 66.4 & 1160 & 1025 & 9.88 & $\cdots$ & $\ldots$ \\
\hline 17 & 66.4 & 900 & 1020 & 6.69 & 0.343 & 0.94 \\
\hline 18 & 66.0 & 1820 & 1010 & 7.92 & & \\
\hline 19 & 65.4 & 1160 & 1017 & 5.57 & 0.436 & \\
\hline 20 & 66.0 & 1120 & 1020 & 8.73 & daily av & $\begin{array}{l}1.09 \\
\text { daily }\end{array}$ \\
\hline 21 & 66.4 & 1020 & 1020 & 7.89 & damy av. & \\
\hline 22 & 66.1 & 1860 & 1016 & 8.16 & 0.413 & 1.83 \\
\hline 23 & 67.0 & 2600 & 1008 & 8.11 & $\cdots$ & $\cdots$ \\
\hline 24 & 65.9 & 1140 & 1015 & 6.43 & 0.380 & 1.90 \\
\hline 25 & 65.9 & 1800 & 1011 & 7.56 & $\cdots$ & $\cdots$ \\
\hline 26 & 65.6 & 1200 & 1020 & 7.63 & 0.377 & 1.71 \\
\hline 27 & 66.2 & 1300 & 1015 & 7.41 & $\cdots$ & $\ldots$ \\
\hline 28 & 65.9 & 1200 & 1012 & 6.70 & $\cdots$ & $\ldots$ \\
\hline 29 & 65.9 & 1480 & 1019 & 8.79 & 0.531 & 1.73 \\
\hline 30 & 65.4 & 1540 & 1011 & 8.41 & $\cdots$ & $\cdots$ \\
\hline Dec. 1 & 65.0 & 1080 & 1015 & 7.13 & 0.484 & 1.45 \\
\hline 2 & 65.6 & 1440 & 1012 & 8.38 & $\cdots$ & $\because$ \\
\hline 3 & 64.5 & 940 & 1021 & 8.58 & 0.438 & 1.66 \\
\hline 4 & 65.0 & 780 & 1022 & 7.22 & $\cdots$ & $\cdots$ \\
\hline 5 & 65.4 & 1280 & 1016 & 8.06 & $\ldots$ & $\ldots$ \\
\hline 6 & 65.4 & 1880 & 1012 & 7.67 & 0.320 & 1.86 \\
\hline 7 & 65.0 & 1600 & 1013 & 6.24 & $\cdots$ & $\cdots$ \\
\hline 8 & 64.9 & 1680 & 1011 & 7.86 & 0.304 & 1.77 \\
\hline 9 & 65.0 & 1180 & 1013 & 7.74 & $\cdots$ & $\cdots$ \\
\hline 10 & 64.7 & 1120 & 1016 & 7.59 & 0.308 & 1.37 \\
\hline 11 & 64.7 & 860 & 1021 & 7.58 & $\cdots$ & $\cdots$ \\
\hline 12 & 64.8 & 700 & 1026 & 6.34 & $\ldots$ & $\ldots$ \\
\hline 13 & 64.6 & 880 & 1022 & 7.87 & 0.404 & 1.47 \\
\hline 14 & 64.7 & 1540 & 1017 & 9.33 & $\ldots$ & $\ldots$ \\
\hline 15 & 64.2 & 1140 & 1015 & 6.98 & 0.436 & 1.71 \\
\hline 16 & 64.3 & 1040 & 1018 & 6.74 & $\cdots$ & $\cdots$ \\
\hline 17 & 64.4 & 980 & 1018 & 6.94 & 0.368 & 1.05 \\
\hline 18 & 64.7 & 1605 & 1015 & 8.57 & $\cdots$ & $\cdots$ \\
\hline 19 & 64.2 & 1250 & 1013 & 8.77 & $\cdots$ & $\cdots$ \\
\hline 20 & 63.4 & 1000 & 1016 & 7.56 & 0.462 & 1.25 \\
\hline 21 & 63.6 & 1190 & 1016 & 8.35 & $\cdots$ & $\because \cdot$ \\
\hline 22 & 63.0 & 1470 & 1011 & 8.47 & 0.245 & 1.26 \\
\hline
\end{tabular}


OAKMAN.

\begin{tabular}{|c|c|c|c|c|c|c|}
\hline \multirow{2}{*}{ Date. } & \multirow{2}{*}{$\begin{array}{c}\text { Body- } \\
\text { weight. }\end{array}$} & \multicolumn{5}{|c|}{ Urine. } \\
\hline & & $\begin{array}{l}\text { Volume. } \\
24 \text { hours. }\end{array}$ & Sp. Gr. & Nitrogen. & Uric Acid. & $\mathrm{P}_{2} \mathrm{O}_{5}$ \\
\hline 1903 & kilos & c.c. & & grams & gram & grams \\
\hline Dec. 23 & 63.6 & 672 & 1028 & 5.88 & $\cdots$ & $\ldots$ \\
\hline 24 & 63.8 & 980 & 1017 & 6.55 & 0.294 & 0.89 \\
\hline 25 & 63.5 & 2310 & 1008 & 6.37 & $\ldots$ & $\ldots$ \\
\hline 26 & 63.9 & 1860 & 1016 & 6.92 & $\ldots$ & $\ldots$ \\
\hline 27 & 63.5 & $15 \%$ & 1015 & 7.54 & 0.380 & 1.11 \\
\hline 28 & 63.0 & 1840 & 1018 & 8.39 & $\ldots$ & $\ldots$ \\
\hline 29 & 62.9 & 1145 & 1018 & 6.11 & 0.546 & 0.72 \\
\hline 30 & 63.2 & 1300 & 1020 & 6.78 & $\cdots$ & $\cdots$ \\
\hline 31 & 63.5 & 1080 & 1020 & 5.96 & 0.421 & 1.18 \\
\hline $190 t$ & & & & & & \\
\hline Jan. 1 & 64.0 & 2360 & 1013 & 8.64 & & \\
\hline 2 & 63.6 & 1270 & 1018 & 5.33 & & \\
\hline 3 & 64.0 & 2475 & 1012 & 7.42 & & \\
\hline 4 & 63.6 & 1820 & 1012 & 5.63 & 0.529 & $1.4 \%$ \\
\hline 5 & 63.0 & 1520 & 1013 & 6.66 & daily & datiy \\
\hline 6 & 63.5 & 1270 & 1016 & 6.71 & & \\
\hline 7 & 63.0 & 1135 & 1016 & 6.74 & 0.344 & 1.06 \\
\hline 8 & 63.5 & 870 & 1022 & 6.06 & $\cdots$ & $\ldots$ \\
\hline 9 & 63.6 & 1640 & 1010 & 689 & $\ldots$ & $\ldots$ \\
\hline 10 & 63.6 & 1240 & 1015 & 5.95 & 0.409 & 1.42 \\
\hline 11 & 63.5 & 1740 & 1012 & 7.31 & $\ldots$ & $\ldots$ \\
\hline 12 & 63.0 & 840 & 1020 & 6.00 & 0.439 & $\ldots$ \\
\hline 13 & 62.9 & 885 & 1021 & 733 & 0.490 & $\ldots$ \\
\hline 14 & 63.0 & 1425 & 1015 & 8.29 & 0.441 & $\ldots$ \\
\hline 15 & 62.8 & 1000 & 1023 & 7.14 & 0.390 & . . \\
\hline 16 & 62.9 & 1525 & 1015 & 8.23 & 0.372 & $\ldots$ \\
\hline 17 & 62.7 & 1740 & 1017 & 8.14 & 0.400 & $\ldots$ \\
\hline 18 & 62.3 & 1200 & 1020 & 8.42 & & \\
\hline 19 & 62.7 & $9 \% 0$ & 1023 & 7.60 & & \\
\hline 20 & 62.7 & 985 & 1020 & 7.51 & & \\
\hline $21^{\circ}$ & 62.7 & 1080 & 1021 & 8.23 & 0.423 & 1.32 \\
\hline 22 & 62.7 & 1670 & 1010 & 7.01 & & \\
\hline 23 & 62.2 & 970 & 1017 & 6.58 & & \\
\hline 24 & 62.2 & 1800 & 1013 & 7.99 & & \\
\hline 25 & 62.2 & 1630 & 1013 & 7.43 & ) & \\
\hline 26 & 62.0 & 880 & 1026 & 6.86 & & \\
\hline 27 & 62.5 & 1250 & 1017 & 9.07 & 0,412 & 1.45 \\
\hline 28 & 62.4 & 1560 & 1016 & 8.61 & 0.412 & 1.40 \\
\hline 29 & 62.7 & 1325 & 1018 & 6.28 & & \\
\hline 30 & 62.9 & 2015 & 1013 & 7.25 & & \\
\hline
\end{tabular}


OAKMAN.

\begin{tabular}{|c|c|c|c|c|c|c|}
\hline \multirow{2}{*}{ Date. } & \multirow{2}{*}{$\begin{array}{l}\text { Body- } \\
\text { weight. }\end{array}$} & \multicolumn{5}{|c|}{ Urine. } \\
\hline & & $\begin{array}{l}\text { Volume. } \\
24 \text { hours. }\end{array}$ & Sp. Gr. & Nitrogen. & Uric Acid. & $\mathrm{P}_{2} \mathrm{O}_{5}$ \\
\hline 1904 & kilos & c.c. & & grams & gram & grams \\
\hline Jan. 31 & 62.4 & 1730 & 1018 & 6.64 & 0.412 & 1.45 \\
\hline Feb. 1 & 62.8 & 910 & 1027 & 5.51 & ) & \\
\hline 2 & 63.0 & 1610 & 1016 & 7.15 & & \\
\hline 3 & 62.5 & 1330 & 1020 & 7.18 & & \\
\hline 4 & 62.7 & 1480 & 1023 & 7.46 & ) 0.395 & 1.42 \\
\hline 5 & 63.0 & 1600 & 1020 & 6.62 & daily & daily \\
\hline 6 & 63.2 & 1980 & 1012 & 6.53 & average & average \\
\hline 7 & 63.0 & 1775 & 1015 & 6.39 & j & \\
\hline 8 & 62.3 & 1860 & 1013 & 8.26 & ) & • \\
\hline 9 & 62.9 & 2010 & 1013 & 7.36 & & \\
\hline 10 & 62.0 & 1195 & 1025 & 7.60 & & \\
\hline 11 & 62.9 & 1580 & 1016 & 8.82 & 0.233 & $\cdots$ \\
\hline 12 & 62.5 & 1900 & 1013 & 8.09 & & \\
\hline 13 & 62.4 & 1560 & 1016 & 7.30 & & \\
\hline 14 & 62.5 & 1480 & 1017 & 7.90 & j & \\
\hline 15 & 62.5 & 1610 & 1023 & 8.93 & ) & \\
\hline 16 & 68.0 & 1570 & 1019 & 7.86 & v & \\
\hline 17 & 62.8 & 2375 & 1014 & 9.69 & & \\
\hline 18 & 62.2 & 1060 & 1022 & 7.80 & 0.430 & $\cdots$ \\
\hline 19 & 62.0 & 910 & 1029 & 8.13 & & \\
\hline 20 & 62.3 & 1710 & 1012 & 8.10 & & \\
\hline 21 & 62.6 & 1940 & 1010 & 7.33 & j & \\
\hline 22 & 62.4 & 1250 & 1021 & 7.73 & ) & \\
\hline 23 & 62.7 & 1700 & 1012 & 6.53 & & \\
\hline 24 & 62.4 & 1525 & 1017 & 8.65 & & \\
\hline 25 & 62.2 & 1980 & 1013 & 8.55 & 0.489 & $\cdots$ \\
\hline 26 & 62.0 & 1145 & 1017 & 677 & & \\
\hline 27 & 61.8 & 1150 & 1019 & 6.87 & & \\
\hline 28 & 62.0 & 1445 & 1020 & 7.46 & ) & \\
\hline 29 & 62.2 & 1015 & 1024 & 6.88 & $\cdots$ & $\cdots$ \\
\hline Mar. 1 & 62.6 & 1225 & 1019 & 7.42 & $\cdots$ & $\cdots$ \\
\hline 2 & 62.5 & 1620 & 1017 & 7.58 & $\cdots$ & $\cdots$ \\
\hline 3 & 62.3 & 1585 & 1016 & 6.85 & $\cdots$ & $\cdots$ \\
\hline 4 & 62.3 & 1815 & 1015 & 7.95 & $\cdots$ & $\cdots$ \\
\hline 5 & $€ 2.0$ & 1565 & 1014 & 6.10 & $\cdots$ & $\cdots$ \\
\hline 6 & 62.0 & 1700 & 1020 & 7.96 & $\cdots$ & \\
\hline 7 & 62.0 & 1240 & 1016 & 7.44 & 1 & \\
\hline 8 & 62.5 & 1710 & 1015 & 8.72 & 0.411 & $\ldots$ \\
\hline 9 & 62.0 & 1670 & 1016 & 7.71 & 0.411 & $\cdots$ \\
\hline 10 & 62.5 & 1590 & 1016 & 7.63 & j & \\
\hline
\end{tabular}


OAKMAN.

\begin{tabular}{|c|c|c|c|c|c|c|}
\hline \multirow{2}{*}{ Date. } & \multirow{2}{*}{$\begin{array}{c}\text { Body- } \\
\text { weight. }\end{array}$} & \multicolumn{5}{|c|}{ Urine. } \\
\hline & & $\begin{array}{l}\text { Volume. } \\
24 \text { hours. }\end{array}$ & Sp. Gr. & Nitrogen. & Uric acid. & $\mathrm{P}_{2} \mathrm{O}_{5}$ \\
\hline 1904 & kilos & c.c. & & grams & gram & grams \\
\hline Mar. 11 & 62.0 & 1410 & 1021 & 8.71 & & $\ldots$ \\
\hline 12 & 62.1 & 1530 & 1018 & 7.44 & 0.411 & \\
\hline 13 & 62.1 & 1780 & 1016 & 8.65 & daily av. & \\
\hline 14 & 62.0 & 1300 & 1019 & 8.11 & & \\
\hline 15 & 62.0 & 1820 & 1012 & 7.29 & & \\
\hline 16 & 62.2 & 1670 & 1017 & 9.12 & & \\
\hline 17 & 62.4 & 1380 & 1020 & 8.20 & 0.468 & $\ldots$ \\
\hline 18 & 62.7 & 1785 & 1015 & 7.82 & & \\
\hline 19 & 62.5 & 1910 & 1017 & 7.68 & & \\
\hline 20 & 62.7 & 1965 & 1013 & 6.72 & & \\
\hline 21 & 62.1 & 980 & 1026 & 5.72 & 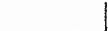 & \\
\hline 22 & 62.4 & 1770 & 1012 & 7.86 & & \\
\hline 23 & 62.0 & 1560 & 1017 & 7.21 & & \\
\hline 24 & 62.0 & 1860 & 1015 & 8.15 & 0.429 & $\cdots$ \\
\hline 25 & 61.6 & 1130 & 1023 & 7.19 & & \\
\hline 26 & 62.0 & 2000 & 1013 & 8.88 & & \\
\hline 27 & 61.9 & 1320 & 1019 & 7.13 & & \\
\hline 28 & 62.0 & 1025 & 1025 & 6.64 & & \\
\hline 29 & 62.4 & 1830 & 1018 & 8.34 & & \\
\hline 30 & 62.3 & 1500 & 1020 & 6.30 & (.379 & $\ldots$ \\
\hline 31 & 62.0 & 1600 & 1021 & 7.10 & & \\
\hline Apr. 1 & 62.0 & 2070 & 1014 & 6.83 & & \\
\hline 2 & 62.0 & 1250 & 1025 & 5.55 & $\cdots$ & $\ldots$ \\
\hline 3 & 62.0 & 2115 & 1009 & 4.57 & $\cdots$ & $\cdots$ \\
\hline 4 & 62.1 & 2110 & 1013 & 5.95 & $\cdots$ & $\cdots$ \\
\hline \multirow{2}{*}{\multicolumn{2}{|c|}{$\begin{array}{l}\text { Daily average from } \\
\text { Oct. } 21\end{array}$}} & & & & & \\
\hline & & 1437 & 1017 & 7.42 & 0.405 & 1.39 \\
\hline
\end{tabular}


MORRIS.

\begin{tabular}{|c|c|c|c|c|c|c|c|}
\hline \multirow{2}{*}{\multicolumn{2}{|c|}{ Datc. }} & \multirow{2}{*}{$\begin{array}{c}\text { Body- } \\
\text { weight. }\end{array}$} & \multicolumn{5}{|c|}{ Urine. } \\
\hline & & & $\begin{array}{l}\text { Volume. } \\
24 \text { hours. }\end{array}$ & Sp. Gr. & Nitrogen. & Uric Acid. & $\mathrm{P}_{2} \mathrm{O}_{5}$ \\
\hline \multicolumn{2}{|c|}{190} & kilos & c.c. & & grams & gram & grams \\
\hline \multirow{28}{*}{$\begin{array}{l}1 \\
1 \\
1 \\
1 \\
2 \\
2 \\
2 \\
2 \\
2 \\
2 \\
2 \\
2 \\
2 \\
2 \\
3 \\
3\end{array}$} & 4 & 59.2 & 970 & 1023 & 13.74 & 0563 & 1.46 \\
\hline & $\dot{j}$ & 59.2 & 1340 & 1018 & 13.43 & $\cdots$ & $\cdots$ \\
\hline & 6 & 58.4 & 720 & 1026 & 9.16 & 0.546 & 1.42 \\
\hline & $i$ & 58.9 & 685 & 1028 & 12.70 & $\ldots$ & $\cdots$ \\
\hline & 8 & 58.4 & 400 & 1019 & 5.27 & 0.179 & 0.54 \\
\hline & 9 & 58.4 & 820 & 1027 & $\cdots$ & $\cdots$ & $\cdots$ \\
\hline & 10 & 58.4 & 1260 & 1023 & 1368 & $\ldots$ & . \\
\hline & 11 & 58.5 & 1400 & 1020 & 18.48 & 0.782 & 2.32 \\
\hline & 12 & 58.5 & 1220 & 1021 & 13.40 & $\ldots$ & $\ldots$ \\
\hline & 13 & 586 & 1580 & 1016 & 13.84 & 0.614 & 2.21 \\
\hline & 14 & 58.2 & 1070 & 1027 & 16.05 & $\ldots$ & $\cdots$ \\
\hline & 15 & 58.9 & 850 & $10^{2} 9$ & 13.82 & 0.626 & 1.50 \\
\hline & 16 & 58.9 & 940 & 1020 & 15.40 & $\cdots$ & $\cdots$ \\
\hline & 17 & 59.2 & 1500 & 1015 & 11.70 & $\cdots$ & $\cdots$ \\
\hline & 18 & 59.0 & 1150 & 1026 & 15.73 & 0.796 & 2.19 \\
\hline & 19 & 58.5 & 1160 & 1028 & 18.86 & $\cdots$ & $\ldots$ \\
\hline & 20 & 58.4 & 1160 & $10 \div 6$ & 7 & & \\
\hline & 21 & 58.4 & 1050 & 1030 & & & \\
\hline & 22 & 58.6 & 910 & 1027 & 1462 & 0.602 & 1.77 \\
\hline & 23 & 58.6 & 1100 & 1024 & 14.02 & 0.002 & 1.18 \\
\hline & 24 & 58.8 & 1030 & 1029 & daily & daily & daily \\
\hline & 25 & 59.0 & 1080 & 1022 & average & average & average \\
\hline & 26 & 59.1 & 1060 & 1028 & & & \\
\hline & 27 & 58.1 & 1240 & 1021 & & & \\
\hline & 28 & 59.1 & 860 & 1025 & & & \\
\hline & 29 & 60.0 & 800 & 1026 & $>10.30$ & 0.638 & 1.37 \\
\hline & 30 & 597 & 880 & 1022 & & & \\
\hline & 31 & 59.6 & 640 & $\ldots$ & & & \\
\hline \multirow[t]{12}{*}{ Nov. } & 1 & 60.0 & 990 & 1020 & & & \\
\hline & 2 & 59.6 & 750 & 1028 & & & \\
\hline & 3 & 59.9 & 900 & 1027 & & & \\
\hline & 4 & 60.0 & 980 & 1018 & & & \\
\hline & 5 & 59.0 & 1180 & 1018 & 7.60 & 0.437 & 1.26 \\
\hline & 6 & 59.5 & 320 & 1026 & & & \\
\hline & 7 & 58.7 & 620 & 1029 & & & \\
\hline & 8 & 58.8 & $12: 20$ & 1013 & & & \\
\hline & 9 & 58.6 & 860 & 1023 & 1 & & \\
\hline & 10 & 59.4 & 800 & 1024 & 7.03 & 0413 & 1.02 \\
\hline & 11 & 590 & $80 ; 0$ & 1020 & & & \\
\hline & 12 & 591 & 760 & 1025 & & & \\
\hline
\end{tabular}


MORRIS.

\begin{tabular}{|c|c|c|c|c|c|c|c|}
\hline \multirow{2}{*}{\multicolumn{2}{|c|}{ Date. }} & \multirow{2}{*}{$\begin{array}{c}\text { Body- } \\
\text { weight. }\end{array}$} & \multicolumn{5}{|c|}{ Urine. } \\
\hline & & & $\begin{array}{l}\text { Volume. } \\
24 \text { hours. }\end{array}$ & Sp. Gr. & Nitrogen. & Uric Acid. & $\mathrm{P}_{2} \mathrm{O}_{5}$ \\
\hline \multicolumn{2}{|c|}{$\begin{array}{c}1903 \\
\text { Noy } 13\end{array}$} & kilos & c.c. & & grams & gram & grams \\
\hline & & 59.2 & 740 & 1027 & & & \\
\hline & 14 & 59.1 & 1160 & 1014 & 7.03 & 0.413 & 1.02 \\
\hline & 15 & 59.0 & 560 & 1027 & daily av. & daily av. & daily av. \\
\hline & 16 & 58.6 & 860 & 1026 & & & \\
\hline & 17 & 58.7 & 680 & 1020 & & & \\
\hline & 18 & 58.6 & 580 & 1022 & & & \\
\hline & 19 & 58.4 & 920 & 1016 & 5.88 & 0.345 & 0.84 \\
\hline & 20 & 59.0 & 880 & 1027 & & & \\
\hline & 21 & 59.5 & 810 & 1019 & & & \\
\hline & 22 & 59.0 & 680 & 1029 & & & \\
\hline & 23 & 59.3 & 1040 & 1015 & & & \\
\hline & 24 & 59.5 & 1260 & 1020 & & & \\
\hline & 25 & 59.3 & 820 & 1020 & & & \\
\hline & 26 & 59.3 & 740 & 1032 & 7.34 & 0.477 & 1.12 \\
\hline & 27 & 60.0 & 1020 & 1016 & & & \\
\hline & 28 & 59.4 & 860 & 1023 & & & \\
\hline & 29 & 59.4 & 700 & 1028 & & & \\
\hline & 30 & 59.5 & 880 & 1020 & & & \\
\hline \multirow[t]{22}{*}{ Dec. } & 1 & 59.1 & 1020 & 1019 & & & \\
\hline & 2 & 59.8 & 1420 & 1021 & & & \\
\hline & 3 & 59.2 & 1240 & 1027 & 9.55 & 0.607 & 1.63 \\
\hline & 4 & 59.5 & 720 & 1031 & & & \\
\hline & 5 & 59.6 & 800 & 1022 & & & \\
\hline & 6 & 59.6 & 820 & 1028 & & & \\
\hline & 7 & 59.4 & 840 & 1029 & ) & & \\
\hline & 8 & 59.6 & 540 & 1020 & & & \\
\hline & 9 & 59.4 & 880 & 1026 & & & \\
\hline & 10 & 59.7 & 900 & 1018 & 7.73 & 0.410 & 1.48 \\
\hline & 11 & 59.2 & 780 & 1025 & & & \\
\hline & 12 & 59.1 & 740 & 1028 & & & \\
\hline & 13 & 59.1 & 820 & 1022 & & & \\
\hline & 14 & 59.0 & 840 & 1028 & & & \\
\hline & 15 & 58.9 & 1020 & 1018 & & & \\
\hline & 16 & 58.9 & 810 & 1025 & & & \\
\hline & 17 & 59.0 & 1020 & 1019 & 6.68 & 0.332 & 1.24 \\
\hline & 18 & 58.6 & 720 & 1026 & & & \\
\hline & 19 & 58.5 & 785 & 1023 & & & \\
\hline & 20 & 58.2 & 670 & 1020 & & & \\
\hline & 21 & 58.2 & 810 & 1081 & 6.97 & 0.375 & \\
\hline & 22 & 58.5 & 680 & 1026 & 0.0 & 0.010 & $\cdots$ \\
\hline
\end{tabular}


MORRIS.

\begin{tabular}{|c|c|c|c|c|c|c|}
\hline \multirow{2}{*}{ Date. } & \multirow{2}{*}{$\begin{array}{c}\text { Body- } \\
\text { weight. }\end{array}$} & \multicolumn{5}{|c|}{ Urine. } \\
\hline & & $\begin{array}{l}\text { Volume. } \\
24 \text { hours. }\end{array}$ & Sp. Gr. & Nitrogen. & Uric Acid. & $\mathrm{P}_{2} \mathrm{O}_{5}$ \\
\hline 1903 & kilos & c.c. & & grams & gram & grams \\
\hline Dec. 23 & 58.6 & 785 & 1024 & ) & & \\
\hline 24 & 58.6 & 930 & 1020 & & & \\
\hline 25 & 58.8 & 1040 & 1017 & 6.97 & 0.375 & $\cdots$ \\
\hline 26 & 57.6 & 945 & 1020 & daily & daily & \\
\hline 27 & 58.6 & 840 & 1023 & average & a verage & \\
\hline 28 & 58.8 & 1070 & 1020 & ) & & \\
\hline 29 & 58.4 & 1205 & 1018 & & & \\
\hline 30 & 59.0 & 1000 & 1026 & & & \\
\hline 31 & 59.0 & 935 & 1027 & 6.70 & 0.296 & 1.20 \\
\hline 1904 & & & & & & dailv \\
\hline Jan. 1 & 58.5 & 1475 & 1016 & & & daily \\
\hline 2 & 58.6 & 1350 & 1018 & & & average \\
\hline 3 & 58.6 & 545 & 1028 & & & \\
\hline 4 & 58.7 & 840 & 1022 & ) & & \\
\hline 5 & 58.6 & 1040 & 1020 & & & \\
\hline 6 & 58.8 & 680 & 1024 & & & \\
\hline 7 & 59.0 & 1040 & 1020 & 6.41 & 0.332 & 1.11 \\
\hline 8 & 58.4 & $\cdots$ & $\cdots$ & & & \\
\hline 9 & 58.4 & 1110 & 1019 & & & \\
\hline 10 & 58.6 & 1120 & 1016 & J & & \\
\hline 11 & 58.9 & 1010 & 1017 & 5.58 & $\cdots$ & $\cdots$ \\
\hline 12 & 58.8 & 685 & 1019 & 4.19 & 0.405 & $\cdots$ \\
\hline 18 & 58.5 & 800 & 1029 & 7.92 & 0.785 & $\cdots$ \\
\hline 14 & 58.0 & 785 & 1027 & 7.91 & 0.494 & $\cdots$ \\
\hline 15 & 58.0 & 800 & 1030 & 7.44 & 0.488 & $\cdots$ \\
\hline 16 & 58.0 & 1195 & 1018 & 7.38 & 0.421 & $\cdots$ \\
\hline 17 & 58.0 & 880 & 1020 & 5.28 & 0.304 & $\cdots$ \\
\hline 18 & 58.0 & 1080 & 1026 & & & \\
\hline 19 & 58.0 & 1075 & 1019 & & & \\
\hline 20 & 58.0 & 920 & 1019 & & & \\
\hline 21 & 57.9 & 715 & 1031 & 731 & 0.449 & 1.40 \\
\hline 22 & 58.0 & 820 & 1022 & & & \\
\hline 23 & 58.0 & 1065 & 1024 & & & \\
\hline 24 & 58.2 & 1370 & 1014 & & & \\
\hline 25 & 58.1 & 1490 & 1015 & & & \\
\hline 26 & 58.2 & 1300 & 1025 & & & \\
\hline 27 & 58.2 & 1335 & 1019 & 7.18 & 0.369 & 133 \\
\hline 28 & 58.3 & 1110 & 1014 & 7.18 & 0.369 & 1.33 \\
\hline 29 & 58.4 & 915 & 1028 & & & \\
\hline 30 & 58.4 & 1200 & 1020 & & & \\
\hline
\end{tabular}


MORRIS.

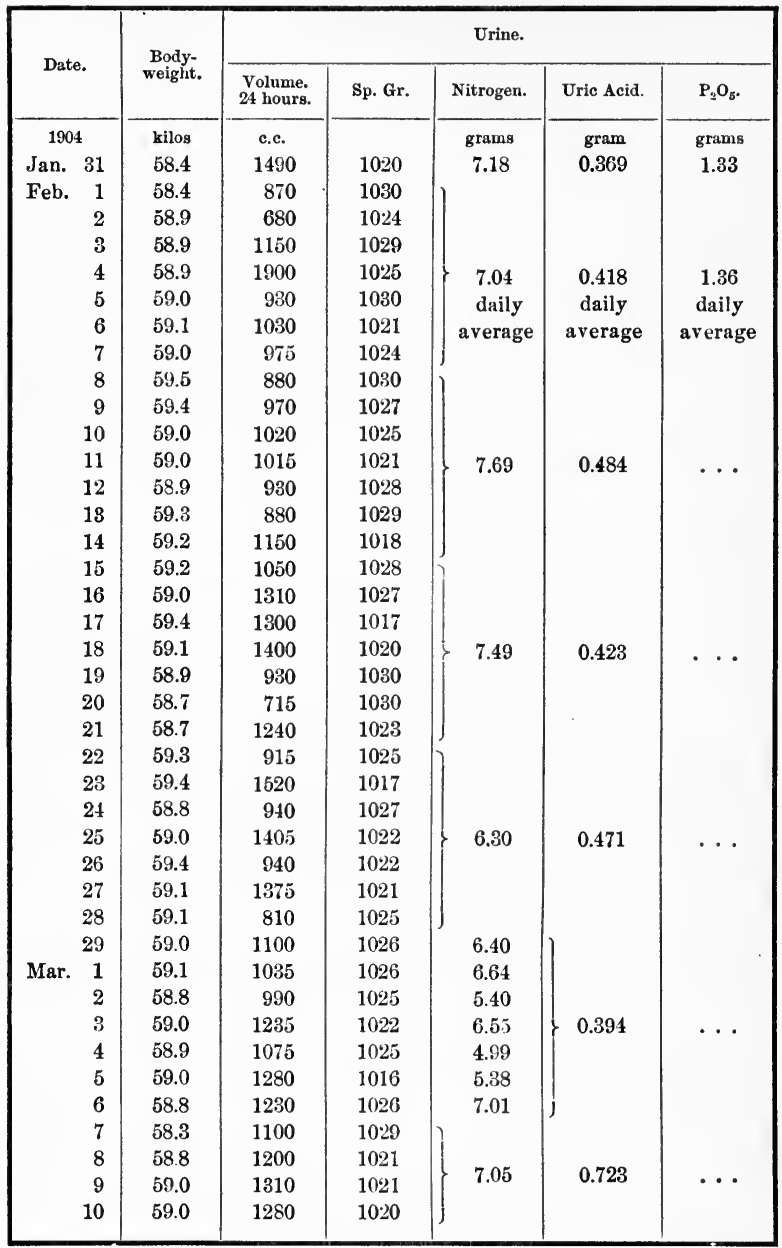


MORRIS.

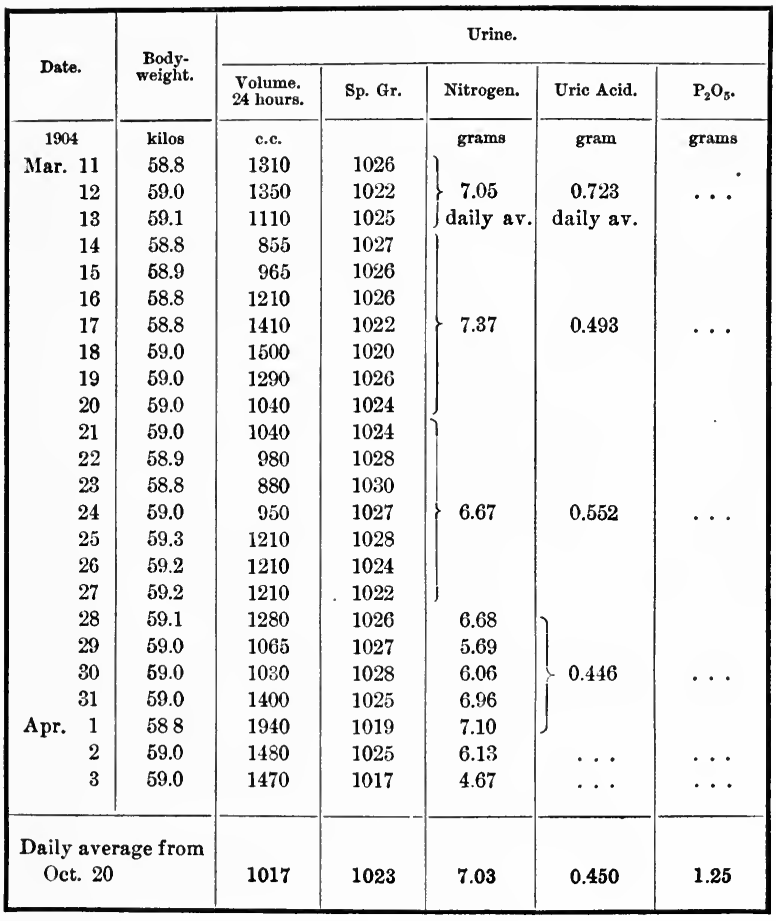


BROYLES.

\begin{tabular}{|c|c|c|c|c|c|c|c|}
\hline \multirow{2}{*}{\multicolumn{2}{|c|}{ Date. }} & \multirow{2}{*}{$\begin{array}{l}\text { Body- } \\
\text { weight. }\end{array}$} & \multicolumn{5}{|c|}{ Urine. } \\
\hline & & & $\begin{array}{l}\text { Volume. } \\
24 \text { hours. }\end{array}$ & Sp. Gr. & Nitrogen. & Uric Acid. & $\mathbf{P}_{2} \mathbf{O}_{5}$ \\
\hline \multicolumn{2}{|c|}{1903} & kilos & c.c. & & grams & gram & grams \\
\hline \multicolumn{2}{|c|}{ Nov. 15} & 59.4 & 2500 & 1008 & 7.35 & $\ldots$ & $\ldots$ \\
\hline & 16 & 59.0 & 2600 & 1006 & $\ldots$ & $\ldots$ & $\ldots$ \\
\hline & 17 & 59.3 & 2600 & 1009 & & & \\
\hline & 18 & 58.7 & 2400 & $\ldots$ & & & \\
\hline & 19 & 58.0 & 1280 & 1014 & & & \\
\hline & 20 & 58.7 & 1800 & 1013 & 7.95 & 0.381 & 1.93 \\
\hline & 21 & 58.5 & 2240 & 1008 & daily & daily & daily \\
\hline & 22 & 59.0 & 2100 & 1011 & average & & average \\
\hline & 23 & 58.0 & 1500 & 1009 & & & \\
\hline & 24 & 57.7 & 1700 & 1011 & & & \\
\hline & 25 & 58.0 & 1080 & 1014 & & & \\
\hline & 26 & 57.8 & 1620 & 1016 & 6.98 & 0.326 & 1.36 \\
\hline & 27 & 58.0 & 700 & 1026 & & & \\
\hline & 28 & 58.0 & 2100 & 1007 & & & \\
\hline & 29 & 58.0 & 1240 & 1015 & & & \\
\hline & 30 & 58.0 & 1880 & 1010 & & & \\
\hline \multirow[t]{11}{*}{ Dec. } & 1 & 57.5 & 1760 & 1010 & & & \\
\hline & 2 & 57.4 & 1700 & 1009 & & & \\
\hline & 3 & 57.4 & 1680 & 1011 & 7.40 & 0.333 & 1.68 \\
\hline & 4 & 57.0 & 1280 & 1013 & & & \\
\hline & 5 & 57.0 & 1420 & 1017 & & & \\
\hline & 6 & 57.6 & 2600 & 1009 & & & \\
\hline & 7 & 57.6 & 600 & 1021 & 7.39 & 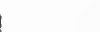 & \\
\hline & 8 & 57.5 & 1960 & 1012 & 10.09 & & \\
\hline & 9 & 57.5 & 2060 & 1010 & 8.53 & & \\
\hline & 10 & 57.2 & 2280 & 1010 & 8.89 & 0.265 & 1.68 \\
\hline & 11 & 56.4 & 800 & 1021 & 6.67 & & \\
\hline \multirow[t]{13}{*}{ - } & 12 & 56.8 & 660 & 1030 & 6.77 & & \\
\hline & 13 & 56.5 & 920 & 1021 & 8.00 & je & \\
\hline & 14 & 56.6 & 1620 & 1013 & ) & & \\
\hline & 15 & 56.4 & 1100 & 1015 & & & \\
\hline & 16 & 56.4 & 1090 & 1017 & & & \\
\hline & 17 & 56.2 & 990 & 1019 & 7.48 & 0.319 & 1.28 \\
\hline & 18 & 56.2 & 590 & 1026 & & & \\
\hline & 19 & 56.0 & 750 & 1027 & & & \\
\hline & 20 & 56.1 & 630 & 1022 & J & & \\
\hline & 21 & 56.1 & 1560 & 1012 & ) & & \\
\hline & 22 & 56.0 & 1050 & 1014 & 6.41 & 0.289 & 0.91 \\
\hline & 23 & 56.5 & 680 & 1023 & & & \\
\hline & 24 & 56.4 & 960 & 1020 & & & \\
\hline
\end{tabular}


BROYLES.

\begin{tabular}{|c|c|c|c|c|c|c|}
\hline \multirow{2}{*}{ Date. } & \multirow{2}{*}{$\begin{array}{c}\text { Body- } \\
\text { weight. }\end{array}$} & \multicolumn{5}{|c|}{ Urine. } \\
\hline & & $\begin{array}{l}\text { Volume. } \\
24 \text { hours. }\end{array}$ & Sp. Gr. & Nitrogen. & Uric Acid. & $\mathrm{P}_{2} \mathrm{O}_{5}$. \\
\hline 1903 & kilos & c.c. & & grams & gram & grams \\
\hline Dec. 25 & 56.6 & 1235 & 1017 & & & \\
\hline 26 & 56.5 & 950 & 1020 & 6.41 & 0.289 & 0.91 \\
\hline 27 & 56.9 & 1520 & 1012 & daily av. & daily av. & daily av. \\
\hline 28 & 56.0 & 1265 & 1019 & & & \\
\hline 29 & 55.8 & 1560 & 1018 & & & \\
\hline 30 & 55.6 & 1710 & 1009 & & & \\
\hline 31 & 56.3 & 1135 & 1016 & 6.70 & 0.297 & 1.17 \\
\hline 1904 & & & & & & \\
\hline Jan. 1 & 56.0 & 1110 & 1016 & & & \\
\hline 2 & 56.7 & 1470 & 1014 & & & \\
\hline 3 & 56.9 & $\cdots$ & $\cdots$ & $\cdots$ & $\cdots$ & $\cdots$ \\
\hline 4 & 57.2 & 1790 & 1010 & & & \\
\hline 5 & 58.0 & 1100 & 1013 & & & \\
\hline 6 & 57.1 & 640 & 1028 & & & \\
\hline 7 & 56.6 & 1180 & 1004 & 5.99 & 0.371 & 1.27 \\
\hline 8 & 57.0 & 1190 & 1016 & & & \\
\hline 9 & 57.6 & 810 & 1025 & & & \\
\hline 10 & 56.8 & 1590 & 1010 & & & \\
\hline 11 & 57.0 & 1820 & 1011 & 6.99 & $\cdots$ & $\cdots$ \\
\hline 12 & 55.7 & 525 & 1027 & 5.38 & 0.621 & $\cdots$ \\
\hline 13 & 55.9 & 530 & 1031 & 6.99 & 0.595 & $\cdots$ \\
\hline 14 & 55.5 & 530 & 1032 & 7.47 & 0.514 & $\cdots$ \\
\hline 15 & 55.0 & 1300 & 1077 & 9.67 & 0.428 & $\cdots$ \\
\hline 16 & 56.0 & 1355 & 1016 & 7.65 & 0.386 & $\cdots$ \\
\hline 17 & 55.6 & 800 & 1020 & 5.28 & 0.291 & $\cdots$ \\
\hline 18 & 55.4 & 1770 & 1016 & & & \\
\hline 19 & 55.0 & 2080 & 1010 & & & \\
\hline 20 & 55.6 & 1285 & 1017 & & & \\
\hline 21 & 55.6 & 1570 & 1013 & 7.80 & 0.364 & 1.29 \\
\hline 22 & 56.0 & 2630 & 1007 & & & \\
\hline 23 & 55.7 & 1330 & 1015 & & & \\
\hline 24 & 56.9 & 1470 & 1015 & & & \\
\hline 25 & 57.0 & 2140 & 1009 & & & \\
\hline 26 & 57.2 & 1670 & 1013 & & & \\
\hline 27 & 58.4 & 2140 & 1015 & & & \\
\hline 28 & 58.0 & 1030 & 1018 & 6.81 & 0.369 & 1.43 \\
\hline 29 & 58.0 & 1080 & 1010 & & & \\
\hline 30 & 58.6 & 1080 & 1021 & & & \\
\hline 31 & 58.8 & 1670 & 1015 & & & \\
\hline Feb. 1 & 58.4 & 770 & 1029 & 7.06 & 0.409 & 1.54 \\
\hline
\end{tabular}


BROYLES.

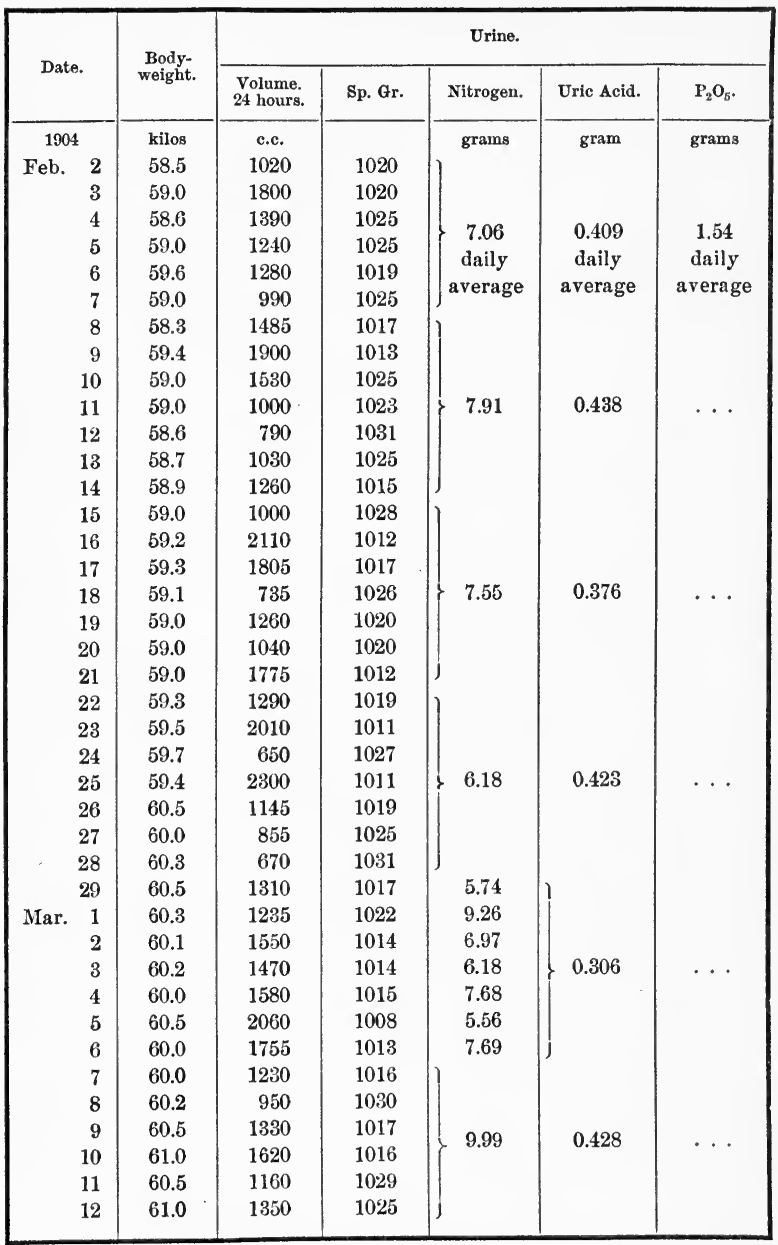


BROYLES.

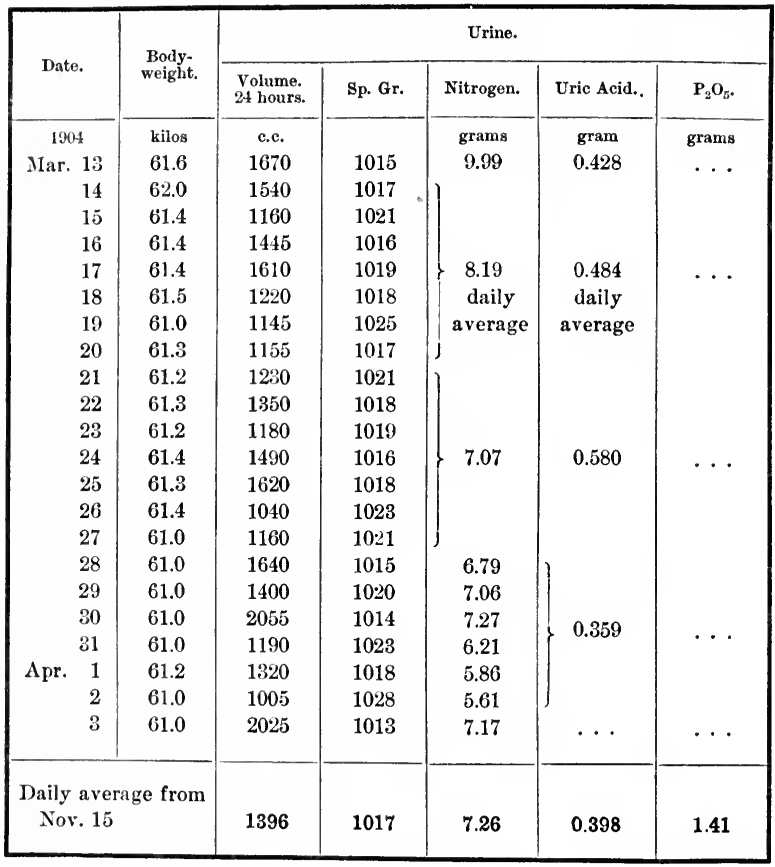


COEFMAN.

\begin{tabular}{|c|c|c|c|c|c|c|c|}
\hline \multirow{2}{*}{\multicolumn{2}{|c|}{ Date. }} & \multirow{2}{*}{$\begin{array}{c}\text { Body- } \\
\text { weight. }\end{array}$} & \multicolumn{5}{|c|}{ Urine. } \\
\hline & & & $\begin{array}{l}\text { Volume. } \\
24 \text { hours. }\end{array}$ & Sp. Gr. & Nitrogen. & Uric Acid. & $\mathrm{P}_{2} \mathrm{O}_{5}$ \\
\hline \multicolumn{2}{|l|}{1903} & kilos & c.c. & & grams & gram & grams \\
\hline \multirow[t]{27}{*}{ Oct. } & 4 & 59.1 & 2140 & 1012 & 17.33 & 0.373 & 2.03 \\
\hline & 5 & 59.1 & 1780 & 1015 & 15.27 & $\cdots$ & $\ldots$ \\
\hline & 6 & 58.7 & 1070 & 1024 & 12.62 & 0.641 & 2.05 \\
\hline & 7 & 58.6 & 1800 & 1016 & 16.96 & $\cdots$ & $\cdots$ \\
\hline & 8 & 58.6 & 1120 & 1024 & 14.49 & 0.480 & 1.89 \\
\hline & 9 & 58.4 & 1150 & 1024 & 10.14 & $\ldots$ & $\cdots$ \\
\hline & 10 & 58.3 & 2180 & 1012 & 16.06 & $\cdots$ & $\cdots$ \\
\hline & 11 & 59.1 & 1580 & 1014 & 13.55 & 0.474 & 1.75 \\
\hline & 12 & 59.1 & 980 & 1025 & 12.99 & $\cdots$ & $\cdots$ \\
\hline & 13 & 59.0 & 1820 & 1014 & 14.85 & 0.613 & 2.50 \\
\hline & 14 & 59.2 & 1150 & 1025 & 13.94 & $\cdots$ & $\cdots$ \\
\hline & 15 & 58.9 & 2120 & 1013 & 16.03 & 0.337 & 2.23 \\
\hline & 16 & 59.0 & $12: 0$ & 1019 & 14.41 & $\ldots$ & $\cdots$ \\
\hline & 17 & 59.0 & 1680 & 1019 & 12.60 & $\cdots$ & $\cdots$ \\
\hline & 18 & 59.6 & 2720 & 1011 & 13.87 & 0.453 & 1.86 \\
\hline & 19 & 59.4 & 2360 & 1017 & 23.64 & $\ldots$ & 3.01 \\
\hline & 20 & 58.3 & 1320 & 1019 & & & \\
\hline & 21 & 59.1 & 1030 & 1024 & & & \\
\hline & 22 & 59.2 & 650 & 1029 & & & \\
\hline & 23 & 59.6 & 1640 & 1017 & 13.21 & 0.475 & 1.76 \\
\hline & 24 & 59.8 & 1320 & 1022 & daily & daily & daily \\
\hline & 25 & 60.0 & 2300 & 1013 & average & average & average \\
\hline & 26 & 59.8 & 1440 & 1022 & & & \\
\hline & 27 & 59.8 & 1280 & 1020 & & & \\
\hline & 28 & 60.2 & 1200 & 1017 & 11.40 & 0.524 & 101 \\
\hline & 29 & 60.2 & 1000 & 1017 & 11.40 & 0.024 & 1.81 \\
\hline & 30 & 59.6 & 820 & 1030 & & & \\
\hline \multirow[t]{13}{*}{ Nov. } & 1 & 59.7 & 1020 & 1020 & & & \\
\hline & 2 & 59.4 & 700 & 1031 & & & \\
\hline & 3 & 60.0 & 880 & 1025 & & & \\
\hline & 4 & 59.6 & 560 & 1031 & & & \\
\hline & 5 & 59.3 & 540 & 1032 & 8.71 & 0.430 & 1.61 \\
\hline & 6 & 59.1 & 440 & 1036 & & & \\
\hline & 7 & 58.6 & 460 & 1035 & & & \\
\hline & 8 & 58.4 & 420 & 1035 & & & \\
\hline & 9 & 58.6 & 700 & 1030 & & & \\
\hline & 10 & 59.0 & 620 & 1030 & & & \\
\hline & 11 & 58.5 & 600 & 1029 & 8.61 & 0.431 & 1.12 \\
\hline & 12 & 58.7 & 840 & 1028 & & & \\
\hline & 13 & 58.7 & 600 & 1032 & & & \\
\hline
\end{tabular}


COFFMAN.

\begin{tabular}{|c|c|c|c|c|c|c|}
\hline \multirow{2}{*}{ Date. } & \multirow{2}{*}{$\begin{array}{c}\text { Body- } \\
\text { weight. }\end{array}$} & \multicolumn{5}{|c|}{ Urine. } \\
\hline & & $\begin{array}{l}\text { Volume. } \\
24 \text { hours. }\end{array}$ & Sp. Gr. & Nitrogen. & Uric Acid. & $\mathrm{P}_{2} \mathrm{O}_{5}$ \\
\hline 1903 & kilos & c.c. & & grams & gram & grams \\
\hline Nov. 14 & 58.7 & 600 & 1033 & 861 & 0431 & 119 \\
\hline 15 & 58.9 & 920 & 1021 & 0.01 & 0.451 & 1.12 \\
\hline 16 & 58.7 & 720 & 1030 & ) & & \\
\hline 17 & 58.4 & 720 & 1031 & & & \\
\hline 18 & 59.3 & 720 & 1027 & & & \\
\hline 19 & 58.7 & 980 & 1026 & 8.41 & 0.395 & 1.30 \\
\hline 20 & 59.0 & 1400 & 1022 & daily & daily & daily \\
\hline 21 & 59.2 & 600 & 1029 & average & average & average \\
\hline 22 & 58.7 & 800 & 1031 & j & & \\
\hline 23 & 59.0 & 640 & 1026 & 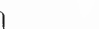 & & \\
\hline 24 & 59.5 & 1120 & 1022 & & & \\
\hline 25 & 59.6 & 1280 & 1017 & & & \\
\hline 26 & 59.0 & $8: 0$ & 1028 & 8.72 & 0.439 & 1.49 \\
\hline 27 & 59.0 & 740 & 1030 & & & \\
\hline 28 & 59.0 & 360 & 1081 & & & \\
\hline 29 & 592 & 1060 & $10: 29$ & J & & \\
\hline 30 & 59.2 & 760 & 1032 & ) & & \\
\hline Dec. 1 & 58.9 & 1140 & 1027 & & . & \\
\hline 2 & 59.5 & 780 & $10 \div 6$ & & & \\
\hline 3 & 58.5 & 800 & 1030 & 11.14 & 0.586 & 1.52 \\
\hline 4 & 59.5 & 860 & 1030 & & & \\
\hline 5 & 59.5 & 920 & 1030 & & & \\
\hline 6 & 595 & 760 & 1032 & j & & \\
\hline 7 & 59.4 & 860 & $10 \$ 0$ & ) & & \\
\hline 8 & 59.4 & 540 & 1080 & & & \\
\hline 9 & 59.0 & 660 & $10: 94$ & & & \\
\hline 10 & 59.0 & 640 & 1033 & 9.95 & 0.400 & 1.62 \\
\hline 11 & 58.3 & 580 & 1034 & & & \\
\hline 12 & 59.1 & 800 & 1032 & & & \\
\hline 19 & 58.5 & 680 & 1030 & & & \\
\hline .14 & 57.3 & 560 & 1032 & ) & & \\
\hline 15 & 58.3 & 680 & 1025 & & ' & \\
\hline 16 & 58.5 & 910 & 1021 & & & \\
\hline 17 & 58.4 & 700 & 1024 & 7.79 & 0.372 & 1.25 \\
\hline 18 & 58.4 & 1110 & 1018 & & & \\
\hline 19 & 57.8 & 600 & 1030 & & & \\
\hline 20 & 57.3 & 550 & 1032 & & & \\
\hline 21 & 58.0 & 600 & 1031 & & & \\
\hline 22 & 57.7 & 470 & 1037 & 7.81 & 0.288 & $\cdots \cdot$ \\
\hline 23 & 58.0 & 645 & 1031 & & & \\
\hline
\end{tabular}


COFFMAN.

\begin{tabular}{|c|c|c|c|c|c|c|}
\hline \multirow{2}{*}{ Date. } & \multirow{2}{*}{$\begin{array}{c}\text { Body- } \\
\text { weight. }\end{array}$} & \multicolumn{5}{|c|}{ Urine. } \\
\hline & & $\begin{array}{l}\text { Volume. } \\
24 \text { hours. }\end{array}$ & Sp. Gr. & Nitrogen. & Uric Acid. & $\mathrm{P}_{2} \mathrm{O}_{5}$. \\
\hline 1903 & kilos & c.c. & & grams & gram & grams \\
\hline Dec. 24 & 58.3 & 900 & 1014 & & & \\
\hline 25 & 57.8 & 730 & 1028 & 731 & 0288 & \\
\hline 26 & 58.0 & 1085 & 1014 & dailv & $\begin{array}{c}0.280 \\
d y^{2}\end{array}$ & $\cdots$ \\
\hline 27 & 58.0 & 1000 & 1021 & & dany av. & \\
\hline 28 & 57.6 & 1035 & 1016 & & & \\
\hline 29 & 57.2 & 1145 & 1015 & 7.14 & $\cdots$ & $\cdots$ \\
\hline 30 & 57.4 & 1002 & 1023 & & & \\
\hline 31 & 57.4 & 1300 & 1016 & 7.60 & 0.246 & 1.20 \\
\hline 1904 & & & & & & daily \\
\hline Jan. 1 & 57.6 & 1240 & 1020 & & & average \\
\hline 2 & 56.4 & 950 & 1018 & & & \\
\hline 3 & 57.0 & 1038 & 1021 & J & & \\
\hline 4 & 57.6 & 1325 & 1008 & ) & & \\
\hline 5 & 58.2 & 1640 & 1014 & & & \\
\hline 6 & 58.6 & 1090 & 1017 & & & \\
\hline 7 & 58.0 & 1090 & 1015 & 7.16 & 0.271 & 1.28 \\
\hline 8 & 57.4 & 785 & 1026 & & & \\
\hline 9 & 57.7 & 710 & 1028 & & & \\
\hline 10 & 57.4 & 1080 & 1014 & j & & \\
\hline 11 & 57.0 & 600 & 1027 & 8.14 & $\cdots$ & $\cdots$ \\
\hline 12 & 57.0 & 930 & 1020 & 8.82 & 0.508 & $\cdots$ \\
\hline 13 & 56.9 & 580 & 1031 & 8.28 & 0.508 & $\cdots$ \\
\hline 14 & 56.7 & 1040 & 1018 & 8.30 & 0.312 & $\cdots$ \\
\hline 15 & 56.5 & 650 & 1033 & 7.91 & 0.352 & $\cdots$ \\
\hline 16 & 56.5 & 1130 & 1017 & 7.32 & 0.305 & $\cdots$ \\
\hline 17 & 56.5 & 800 & 1025 & 7.44 & 0.315 & $\cdots$ \\
\hline 18 & 56.4 & 1540 & 1012 & 6.19 & $\cdots$ & $\cdots$ \\
\hline 19 & 56.4 & 1510 & 1016 & & & \\
\hline 20 & 56.5 & 1220 & 1016 & & & \\
\hline 21 & 56.2 & 505 & 1033 & 6.95 & 0.301 & 1.11 \\
\hline 22 & 56.3 & 900 & 1019 & & & \\
\hline 23 & 56.4 & 1325 & 1013 & & & \\
\hline 24 & 56.2 & 510 & 1030 & j & & \\
\hline 25 & 56.6 & 1460 & 1012 & ) & & \\
\hline 26 & 56.7 & 1400 & 1015 & & & \\
\hline 27 & 56.7 & 1520 & 1018 & & & \\
\hline 28 & 57.0 & 1720 & 1013 & 7.55 & 0.340 & 1.09 \\
\hline 29 & 56.5 & 520 & 1035 & & & \\
\hline 30 & 56.5 & 870 & 1028 & & & \\
\hline 31 & 56.7 & 980 & 1024 & J & & \\
\hline
\end{tabular}




\section{PIIYSIOLOGICAL ECONOMY IN NUTRITION}

COFFMAN.

\begin{tabular}{|c|c|c|c|c|c|c|c|}
\hline \multirow{2}{*}{\multicolumn{2}{|c|}{ Date. }} & \multirow{2}{*}{$\begin{array}{l}\text { Body- } \\
\text { weight. }\end{array}$} & \multicolumn{5}{|c|}{ Urine. } \\
\hline & & & $\begin{array}{l}\text { Volume. } \\
24 \text { hours. }\end{array}$ & Sp. Gr. & Nitrogen. & Uric Acid. & $\mathbf{P}_{2} \mathrm{O}_{5}$ \\
\hline \multicolumn{2}{|c|}{1904} & kilos & c.c. & & grams & gram & grams \\
\hline \multirow[t]{29}{*}{ Feb. } & 1 & 56.2 & 700 & 1032 & & & \\
\hline & 2 & 56.9 & 1910 & 1020 & & & \\
\hline & 3 & 57.2 & 1120 & 1024 & & & \\
\hline & 4 & 57.3 & 1260 & 1028 & 7.56 & 0.362 & 1.24 \\
\hline & 5 & 58.0 & 1970 & 1018 & daily & daily & daily \\
\hline & 6 & 57.0 & 810 & 1022 & average & average & average \\
\hline & 7 & 56.8 & 780 & 1030 & 0 & & \\
\hline & 8 & 56.6 & 1130 & 1021 & & & \\
\hline & 9 & 57.0 & 1900 & 1020 & & & \\
\hline & 10 . & 568 & 1140 & 1025 & & & \\
\hline & 11 & 57.4 & 1340 & 1020 & 8.65 & 0.420 & $\ldots$ \\
\hline & 12 & 57.2 & 1360 & 1023 & & & \\
\hline & 13 & 57.0 & 1020 & 1025 & & & \\
\hline & 14 & 57.0 & $17: 20$ & 1014 & & & \\
\hline & 15 & 56.5 & 890 & 1032 & & & \\
\hline & 16 & 57.2 & 1190 & 1025 & . & & \\
\hline & 17 & 57.4 & 1250 & 1019 & & & \\
\hline & 18 & 57.0 & 1630 & 1015 & 8.18 & 0.318 & $\ldots$ \\
\hline & 19 & 56.7 & 1225 & 1025 & & & 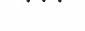 \\
\hline & 20 & 57.0 & 900 & 1025 & & & \\
\hline & 21 & 57.0 & 1590 & 1016 & & & \\
\hline & 22 & 57.0 & 985 & 1028 & & & \\
\hline & 23 & 57.0 & 1465 & 1013 & & & \\
\hline & 24 & 56.7 & 1160 & 1020 & & & \\
\hline & 25 & 56.5 & 1340 & 1016 & 7.62 & 0.395 & $\ldots$ \\
\hline & 26 & 56.3 & 1015 & 1017 & & & \\
\hline & 27 & 56.0 & 630 & 1032 & & & \\
\hline & 28 & 56.7 & 1205 & 1027 & ) & & \\
\hline & 29 & 57.0 & 1530 & 1017 & 8.63 & & \\
\hline \multirow[t]{11}{*}{ Mar. } & 1 & 57.0 & 1030 & 1022 & 7.48 & & \\
\hline & 2 & 56.8 & 1295 & 1020 & 8.62 & & \\
\hline & 8 & 56.7 & 1040 & 1022 & 7.18 & 0.365 & $\ldots$ \\
\hline & 4 & 56.0 & 1130 & 1023 & 7.93 & & \\
\hline & 5 & 56.5 & 1540 & 1014. & 7.67 & & \\
\hline & 6 & 56.6 & 1105 & 1024 & 7.95 & & \\
\hline & 7 & 56.3 & 1190 & 1018 & ) & & \\
\hline & 8 & 56.5 & 1350 & 1017 & & & \\
\hline & 9 & 56.2 & 880 & 1031 & 8.27 & 0.338 & $\ldots$ \\
\hline & 10 & 56.8 & 1500 & 1016 & & & \\
\hline & 11 & 56.9 & 1120 & 1024 & J & & \\
\hline
\end{tabular}


COFFMAN.

\begin{tabular}{|c|c|c|c|c|c|c|}
\hline \multirow{2}{*}{ Date. } & \multirow{2}{*}{$\begin{array}{c}\text { Body- } \\
\text { weight. }\end{array}$} & \multicolumn{5}{|c|}{ Urine. } \\
\hline & & $\begin{array}{l}\text { Volume. } \\
24 \text { hours. }\end{array}$ & Sp. Gr. & Nitrogen. & Uric Acid. & $\mathrm{P}_{2} \mathrm{O}_{5}$. \\
\hline 1904 & kilos & c.c. & & grams & gram & grams \\
\hline Mar. 12 & 56.6 & 1600 & 1018 & 8.27 & 0.338 & . \\
\hline 13 & 57.2 & 1230 & 1022 & \} daily av. & daily av. & \\
\hline 14 & 57.0 & 1150 & 1022 & & & \\
\hline 15 & 57.3 & 1580 & 1014 & & & \\
\hline 16 & 57.3 & 1290 & 1023 & & & \\
\hline 17 & 57.5 & 1355 & 1018 & 8.07 & 0.288 & $\cdots$ \\
\hline 18 & 58.0 & 1635 & 1016 & & & \\
\hline 19 & 56.8 & 1320 & 1020 & & & \\
\hline 20 & 57.0 & 1085 & 1021 & & & \\
\hline 21 & 57.4 & 1030 & 1023 & 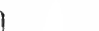 & & \\
\hline 22 & 57.7 & 1970 & 1013 & & & \\
\hline 23 & 57.4 & 1670 & 1013 & & & \\
\hline 24 & 57.0 & 870 & 1031 & 8.50 & 0.478 & . \\
\hline 25 & 57.0 & 1000 & 1024 & & & \\
\hline 26 & 57.3 & 1320 & 1023 & & & \\
\hline 27 & 58.0 & 1500 & 1018 & & & \\
\hline 28 & 58.1 & 1485 & 1019 & 8.37 & & \\
\hline 29 & 58.0 & 1580 & 1021 & 8.06 & & \\
\hline 30 & 57.8 & 1415 & 1019 & 6.88 & 0.371 & . \\
\hline 31 & 57.8 & 1285 & 1026 & 7.78 & & \\
\hline Apr. 1 & 57.8 & 1135 & 1023 & 7.32 & & \\
\hline 2 & 57.0 & 1415 & 1022 & 6.45 & $\cdots$ & $\cdots$ \\
\hline 3 & 58.0 & 2000 & 1018 & 4.12 & $\ldots$ & $\ldots$ \\
\hline \multirow{2}{*}{\multicolumn{2}{|c|}{$\begin{array}{l}\text { Daily average from } \\
\text { Nov. } 2\end{array}$}} & & & & & \\
\hline & & 1034 & 1024 & 8.17 & 0.379 & 1.23 \\
\hline
\end{tabular}


SLINEY.

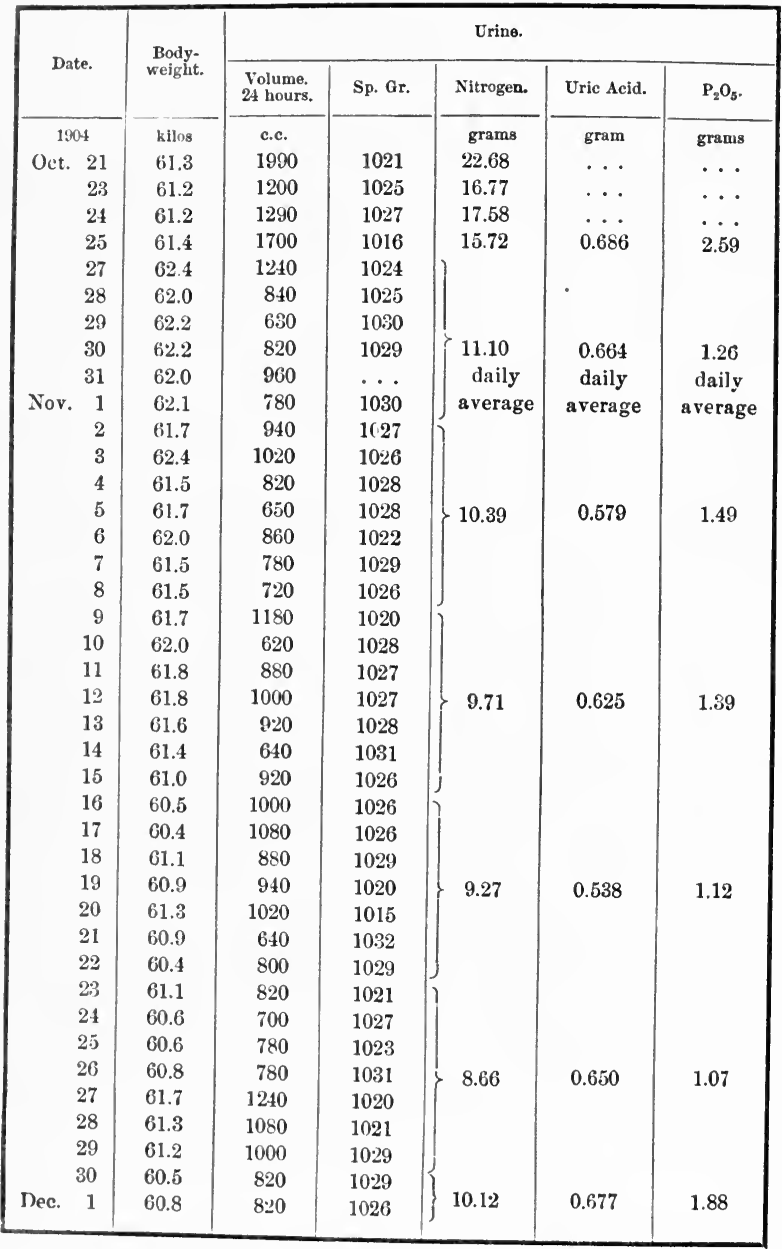


SLINEY.

\begin{tabular}{|c|c|c|c|c|c|c|c|}
\hline \multirow{2}{*}{\multicolumn{2}{|c|}{ Date. }} & \multirow{2}{*}{$\begin{array}{c}\text { Body- } \\
\text { weight. }\end{array}$} & \multicolumn{5}{|c|}{ Urine. } \\
\hline & & & $\begin{array}{l}\text { Volume. } \\
24 \text { hours. }\end{array}$ & Sp. Gr. & Nitrogen. & Uric Acid. & $\mathrm{P}_{2} \mathrm{O}_{5}$ \\
\hline \multicolumn{2}{|c|}{1903} & kilos & c.c. & & grams & gram & grams \\
\hline \multirow[t]{30}{*}{ Dec. } & 2 & 60.0 & 600 & 1030 & & & \\
\hline & 3 & 60.9 & 940 & 1015 & & & \\
\hline & 4 & 60.9 & 1000 & 1024 & 10.12 & 0.677 & 1.88 \\
\hline & 5 & 59.9 & 1580 & 1016 & daily & daily & daily \\
\hline & 6 & 61.0 & 840 & 1029 & average & average & average \\
\hline & 7 & 60.4 & 760 & 1028 & 8.40 & & \\
\hline & 8 & 60.4 & 920 & 1022 & 9.71 & & \\
\hline & 9 & 61.0 & 1000 & 1020 & 8.94 & & \\
\hline & 10 & 60.5 & 740 & 1025 & 8.66 & 0.671 & 1.66 \\
\hline & 11 & 59.9 & 760 & 1031 & 11.43 & & \\
\hline & 12 & 60.0 & 660 & 1033 & 9.78 & & \\
\hline & 13 & 59.9 & 880 & 1030 & 11.98 & & \\
\hline & 14 & 60.3 & 1120 & 1024 & & & \\
\hline & 15 & 59.5 & 1060 & 1021 & & & \\
\hline & 16 & 59.9 & 710 & 1030 & & & \\
\hline & 17 & 59.9 & 880 & 1027 & 10.20 & 6.52 & 1.23 \\
\hline & 18 & 60.2 & 1200 & 1021 & & & \\
\hline & $19^{-}$ & 60.0 & 1125 & 1015 & & & \\
\hline & 20 & 60.0 & 1210 & 1021 & & & \\
\hline & 21 & 60.0 & 715 & 1026 & & & \\
\hline & 22 & 59.5 & 940 & 1021 & & & \\
\hline & 23 & 60.0 & 895 & 1023 & & & \\
\hline & 24 & 59.9 & 1010 & 1018 & 8.97 & 0.606 & $\cdots$ \\
\hline & 25 & 59.8 & 1084 & 1026 & & & \\
\hline & 26 & 61.0 & 940 & 1028 & & & \\
\hline & 27 & 60.0 & 735 & 1023 & & & \\
\hline & 28 & 59.8 & 1250 & 1019 & & & \\
\hline & 29 & 59.7 & 1020 & 1020 & & & \\
\hline & 30 & 60.0 & 1760 & 1016 & & & \\
\hline & 31 & 60.0 & 980 & 1022 & 7.20 & 0.515 & 1.29 \\
\hline Jan. & 1 & 60.0 & 1370 & 1014 & & & \\
\hline & 2 & 60.0 & 1152 & 1017 & & & \\
\hline & 3 & 60.4 & 1035 & 1025 & & & \\
\hline & 4 & 61.0 & 1210 & 1014 & & & \\
\hline & 5 & 61.0 & 1090 & 1017 & & & \\
\hline & 6 & 61.0 & 1400 & 1020 & 6.67 & 0.535 & 135 \\
\hline & 7 & 60.8 & 1140 & $10: 20$ & & & 1.30 \\
\hline & 8 & 60.0 & $\ldots$ & $\cdots$ & & & \\
\hline & 9 & 60.0 & 620 & 1028 & & & \\
\hline
\end{tabular}


SLINEY.

\begin{tabular}{|c|c|c|c|c|c|c|c|}
\hline \multirow{2}{*}{\multicolumn{2}{|c|}{ Date. }} & \multirow{2}{*}{$\begin{array}{c}\text { Body- } \\
\text { weight. }\end{array}$} & \multicolumn{5}{|c|}{ Urine. } \\
\hline & & & $\begin{array}{l}\text { Volume. } \\
24 \text { hours. }\end{array}$ & Sp. Gr. & Nitrogen. & Uric Acid. & $\mathrm{P}_{2} \mathrm{O}_{5}$ \\
\hline \multirow{2}{*}{\multicolumn{2}{|c|}{$\begin{array}{c}1904 \\
\text { Jan. } 10\end{array}$}} & kilos & c.c. & & grams & gram & grams \\
\hline & & 60.6 & 1200 & 1020 & 6.67 & 0.585 & 1.85 \\
\hline & 11 & 61.8 & 1230 & 1015 & 7.23 & $\cdots$ & $\cdots$ \\
\hline & 12 & 61.3 & 560 & 1027 & 5.94 & 0.953 & $\cdots$ \\
\hline & 13 & 60.7 & 625 & 1029 & 8.44 & 0.988 & $\cdots$ \\
\hline & 14 & 60.7 & 600 & 1030 & 7.42 & 0.674 & $\cdots$ \\
\hline & 15 & 60.4 & 675 & 1032 & 7.89 & 0.693 & $\cdots$ \\
\hline & 16 & 60.5 & 500 & 1030 & 7.23 & 0.584 & $\cdots$ \\
\hline & 17 & 60.5 & 700 & 1030 & 8.15 & 0.691 & \\
\hline & 18 & 60.3 & 500 & 1032 & l & & \\
\hline & 19 & 60.5 & 730 & 1026 & & & \\
\hline & 20 & 60.6 & 920 & 1021 & & & \\
\hline & 21 & 60.4 & $\ldots$ & $\ldots$ & 8.13 & 0.303 & 1.22 \\
\hline & 22 & 60.4 & 660 & 1017 & daily & daily & daily \\
\hline & 23 & 60.0 & 920 & 1030 & average & average & average \\
\hline & 24 & 60.0 & 1320 & 1018 & 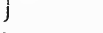 & & \\
\hline & 25 & 60.2 & 、 1220 & 1017 & ) & & \\
\hline & 26 & 60.0 & 1260 & 1018 & & & \\
\hline & 27 & 60.2 & 845 & 1024 & & & \\
\hline & 28 & 60.3 & 560 & 1031 & 7.14 & 0.686 & 0.98 \\
\hline & 29 & 60.0 & 1030 & 1024 & & & \\
\hline & 30 & 60.4 & 1330 & 1020 & & & \\
\hline & 31 & 60.6 & 1125 & 1019 & j & & \\
\hline Feb. & 1 & 60.7 & 830 & 1027 & & & \\
\hline & 2 & 60.8 & 1695 & 1016 & & & \\
\hline & 3 & 61.0 & 1760 & 1015 & & & \\
\hline & 4 & 61.3 & 1060 & 1025 & 7.13 & 0.645 & 1.17 \\
\hline & 5 & 61.2 & 1300 & 1021 & & & \\
\hline & 6 & 61.8 & 1880 & 1014 & & & \\
\hline & 7 & 61.8 & 1260 & 1027 & J & & \\
\hline & 8 & 62.4 & 920 & 1021 & ? & & \\
\hline & 9 & 62.5 & 1500 & 1022 & & & \\
\hline & 10 & 62.6 & 1145 & 1026 & & & \\
\hline & 11 & 62.3 & 710 & 1019 & 7.66 & 0.647 & $\cdots$ \\
\hline & 12 & 61.0 & 1350 & 1015 & & & \\
\hline & 13 & 61.6 & 1030 & 1027 & & & \\
\hline & 14 & 61.5 & 780 & 1029 & & & \\
\hline & 15 & 61.5 & 1010 & 1030 & & & \\
\hline & 16 & 61.7 & 1175 & 1025 & & & \\
\hline & 17 & 62.1 & 1680 & 1017 & 8.07 & 0.600 & $\cdots$ \\
\hline & 18 & 62.0 & 1010 & 1024 & J & & \\
\hline
\end{tabular}




\section{SLINEY.}

\begin{tabular}{|c|c|c|c|c|c|c|}
\hline \multirow{2}{*}{ Date. } & \multirow{2}{*}{$\begin{array}{c}\text { Body. } \\
\text { weight. }\end{array}$} & \multicolumn{5}{|c|}{ Urine. } \\
\hline & & $\begin{array}{l}\text { Volume. } \\
24 \text { hours. }\end{array}$ & Sp. Gr. & Nitrogen. & Uric Acid & $\mathrm{P}_{2} \mathrm{O}_{5}$ \\
\hline 1904 & kilos & grams & & grams & gram & grams \\
\hline Feb. 19 & 61.6 & 770 & 1028 & ) & & \\
\hline 20 & 61.0 & 710 & 1030 & 8.07 & 0.600 & $\cdots$ \\
\hline 21 & 61.0 & 1240 & 1021 & daily av. & daily av. & \\
\hline 22 & 61.2 & 1450 & 1017 & & & \\
\hline 23 & 61.6 & 1425 & 1017 & & & \\
\hline 24 & 62.0 & $\cdots$ & $\cdots$ & 8.86 & 0.746 & $\cdots$ \\
\hline 26 & 62.4 & $\cdots$ & $\cdots$ & & & \\
\hline 27 & 61.4 & 1080 & 1019 & & & \\
\hline 28 & 61.4 & 835 & 1029 & j & & \\
\hline 29 & 61.0 & 800 & 1030 & 9.50 & 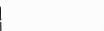 & \\
\hline Mar. 1 & 61.4 & 775 & 1028 & 8.09 & & \\
\hline 2 & 61.0 & 760 & 1030 & 7.97 & & \\
\hline 3 & 60.8 & 920 & 1023 & 7.78 & 0.697 & $\cdots$ \\
\hline 4 & 61.0 & 960 & 1027 & 7.49 & & \\
\hline 5 & 61.0 & 790 & 1029 & 7.54 & & \\
\hline 6 & 61.0 & 980 & 1028 & 8.23 & & \\
\hline 7 & 61.0 & $\cdots$ & $\cdots$ & $\cdots$ & $\cdots$ & $\cdots$ \\
\hline 8 & 61.0 & 1480 & 1017 & & & \\
\hline 9 & 61.2 & 1960 & 1012 & & & \\
\hline 10 & 61.0 & 740 & 1028 & 7.65 & 0.672 & $\cdots$ \\
\hline 11 & 60.8 & 950 & 1029 & 1.00 & & \\
\hline 12 & 61.0 & 1370 & 1020 & & & \\
\hline 13 & 60.8 & 1310 & 1021 & j & & \\
\hline 14 & 61.0 & 1460 & 1014 & ) & & \\
\hline 15 & 61.2 & 1155 & 1019 & & & \\
\hline 16 & 61.3 & 1100 & 1025 & & & \\
\hline 17 & 61.0 & 1465 & 1013 & 7.72 & 0.572 & $\cdots$ \\
\hline 18 & 60.9 & 1300 & 1020 & & & \\
\hline 19 & 61.3 & 2270 & 1012 & & & \\
\hline 20 & 61.6 & 1040 & 1025 & j & & \\
\hline 21 & 61.2 & 1020 & 1027 & ) & & \\
\hline 22 & 61.4 & 1210 & 1019 & & & \\
\hline 23 & 61.0 & 760 & 1029 & & & \\
\hline 24 & 60.5 & 900 & 1024 & 8.64 & 0.765 & $\cdots$ \\
\hline 25 & 60.6 & 840 & 1029 & & & \\
\hline 26 & 60.8 & 890 & 1030 & & & \\
\hline 27 & 61.0 & 1000 & 1024 & & & \\
\hline 28 & 610 & 870 & 1026 & 7.09 & 0.502 & \\
\hline 29 & 61.0 & 825 & 1030 & 7.37 & & $\cdots$ \\
\hline
\end{tabular}




\section{PHYSIOLOGICAL ECONOMY IN NUTRITION}

\section{SLINEY.}

\begin{tabular}{|c|c|c|c|c|c|c|}
\hline \multirow{2}{*}{ Date. } & \multirow{2}{*}{$\begin{array}{c}\text { Body- } \\
\text { weight. }\end{array}$} & \multicolumn{5}{|c|}{ Urine. } \\
\hline & & $\begin{array}{l}\text { Volume. } \\
24 \text { hours. }\end{array}$ & Sp. Gr. & Nitrogen. & Uric Acid. & $\mathrm{P}_{2} \mathrm{O}_{5}$. \\
\hline 1904 & kilos & c.c. & & grams & gram & grams \\
\hline Mar. 30 & 60.8 & 1080 & 1027 & 8.10 & & \\
\hline 31 & 60.6 & 1030 & 1026 & 7.47 & 0.502 & $\ldots$ \\
\hline Apr. 1 & 60.6 & 1130 & 1021 & 6.78 & daily av. & \\
\hline 2 & 60.0 & 1590 & 1016 & 6.20 & . & . \\
\hline 3 & 60.6 & 1860 & 1013 & 6.59 & $\cdots$ & $\ldots$ \\
\hline \multirow{2}{*}{\multicolumn{2}{|c|}{$\begin{array}{l}\text { Daily average from } \\
\text { Nov. } 1\end{array}$}} & & & & & \\
\hline & & 1021 & 1024 & 839 & 0.647 & 1.32 \\
\hline
\end{tabular}


STELTZ.

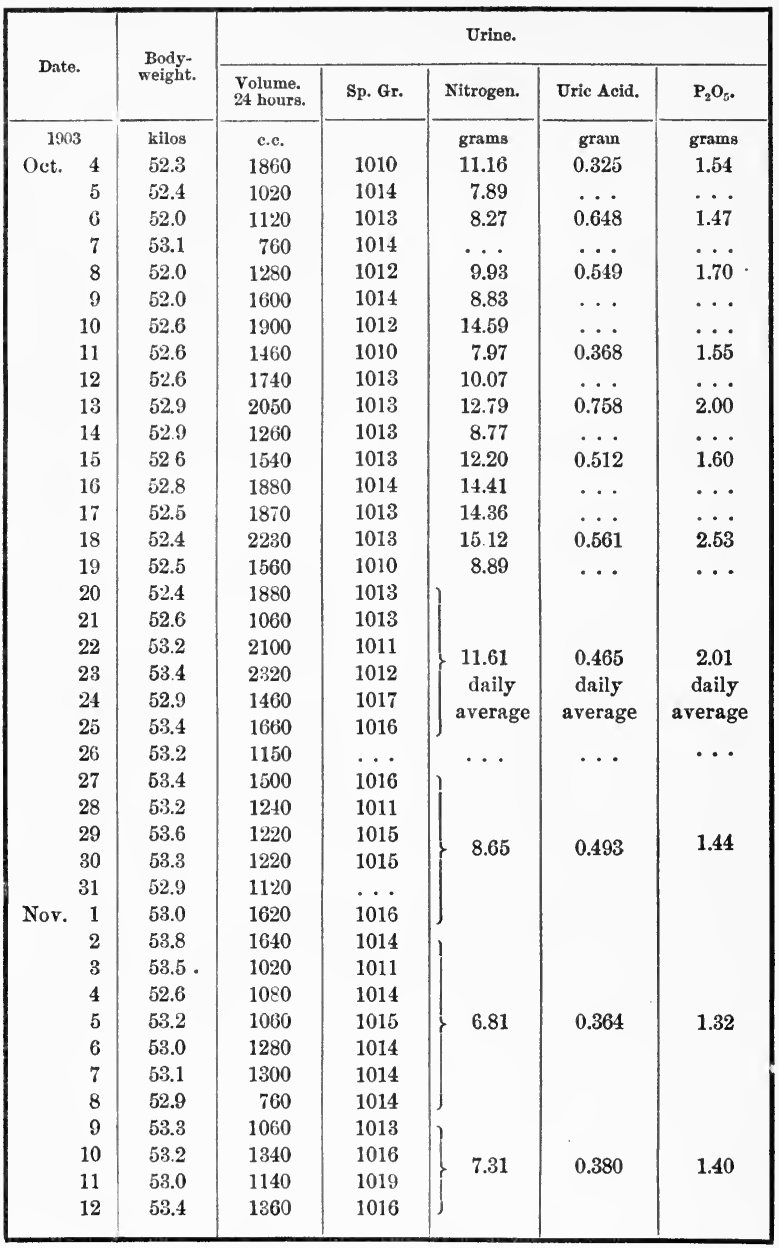


STELTZ

\begin{tabular}{|c|c|c|c|c|c|c|}
\hline \multirow{2}{*}{ Date. } & \multirow{2}{*}{$\begin{array}{c}\text { Body- } \\
\text { weight. }\end{array}$} & \multicolumn{5}{|c|}{ Urine. } \\
\hline & & $\begin{array}{l}\text { Volume. } \\
24 \text { hours. }\end{array}$ & Sp. Gr. & Nitrogen. & Urie Acid. & $\mathbf{P}_{2} \mathrm{O}_{5}$ \\
\hline 1903 & kilos & c.c. & & grams & gram & grams \\
\hline Nov. 13 & 53.4 & 1300 & 1016 & 7.31 & 0380 & 1.40 \\
\hline 14 & 53.2 & 960 & 1017 & $\int$ daily av. & daily av. & daily av. \\
\hline 15 & 53.3 & $\cdots$ & $\cdots$ & $\cdots$ & $\cdots$ & $\cdots$ \\
\hline 16 & 53.2 & 1640 & 1016 & ) & & \\
\hline 17 & 53.4 & 1620 & 1015 & & & \\
\hline 18 & 53.4 & 1160 & 1017 & & & \\
\hline 19 & 52.9 & 1910 & 1015 & 8.07 & 0.409 & 1.45 \\
\hline 20 & 53.4 & 1800 & 1014 & & & \\
\hline 21 & 58.4 & 1240 & 1015 & & & \\
\hline 22 & 53.0 & 1180 & 1020 & J & & \\
\hline 23 & 53.4 & 1320 & 1013 & 1 & & \\
\hline 24 & 53.4 & 2000 & 1013 & & & \\
\hline 25 & 53.5 & 1400 & 1016 & & & \\
\hline 26 & 53.7 & 780 & 1026 & 6.71 & 0.390 & 1.35 \\
\hline 27 & 53.5 & 1000 & 1015 & & & \\
\hline 28 & 53.3 & 1600 & 1014 & & & \\
\hline 29 & 53.5 & 1340 & 1018 & J & & \\
\hline 30 & 53.6 & 860 & 1020 & ) & & \\
\hline Dec. 1 & 53.9 & 1960 & 1013 & & & \\
\hline 2 & 53.4 & 1060 & 1015 & & & \\
\hline 3 & 52.9 & 940 & 1018 & 7.49 & 0.394 & 1.50 \\
\hline 4 & 53.6 & 1580 & 1019 & & & \\
\hline 5 & 53.6 & 980 & 1014 & & & \\
\hline 6 & 54.2 & 1280 & 1022 & J & & \\
\hline 7 & 53.7 & 960 & 1021 & 7.01 & ) & \\
\hline 8 & 53.4 & 620 & 1020 & 4.98 & & \\
\hline 9 & 53.4 & 1000 & 1016 & 5.88 & & \\
\hline 10 & 53.5 & 1420 & 1015 & 7.67 & 0.420 & 1.46 \\
\hline 11 & 53.5 & 1360 & 1018 & 8.20 & & \\
\hline 12 & 53.4 & 1040 & 1024 & 7.92 & & \\
\hline 13 & 52.7 & 920 & 1022 & 5.57 & $j$ & \\
\hline 14 & 53.0 & 1340 & 1024 & 10.21 & $\cdots$ & $\cdots$ \\
\hline 15 & 52.9 & 1000 & 1019 & 7.98 & $\ldots$ & $\cdots$ \\
\hline 16 & 52.9 & 940 & 1016 & 4.79 & 0.226 & 0.75 \\
\hline 17 & 53.4 & 820 & 1015 & ) & & \\
\hline 18 & 534 & $1: 30$ & 1016 & 9.04 & 0.452 & 1.48 \\
\hline 19 & 53.4 & 1395 & 1014 & 9.04 & & \\
\hline 20 & 53.1 & 1300 & 1017 & & & \\
\hline 21 & 53.2 & 1220 & 1016 & 7.42 & 0.387 & 0.80 \\
\hline 22 & 53.1 & 1200 & 1018 & 1.42 & & \\
\hline
\end{tabular}


STELTZ.

\begin{tabular}{|c|c|c|c|c|c|c|}
\hline \multirow{2}{*}{ Date. } & \multirow{2}{*}{$\begin{array}{c}\text { Body- } \\
\text { weight. }\end{array}$} & \multicolumn{5}{|c|}{ Urine. } \\
\hline & & $\begin{array}{l}\text { Volume. } \\
24 \text { hours. }\end{array}$ & Sp. Gr. & Nitrogen. & Uric Acid. & $\mathrm{P}_{2} \mathrm{O}_{5}$. \\
\hline 1903 & kilos & c.c. & & grams & gram & grams \\
\hline Dec. 23 & 53.2 & 1465 & 1017 & & & \\
\hline 24 & 53.1 & 1100 & 1021 & & & \\
\hline 25 & 53.2 & 970 & 1016 & 7.42 & 0.387 & 0.80 \\
\hline 26 & 54.0 & 1350 & 1020 & daily & daily & daily \\
\hline 27 & 53.2 & 1105 & 1023 & average & average & average \\
\hline 28 & 53.0 & 1240 & 1020 & ) & & \\
\hline 29 & 53.0 & 1180 & 1023 & & & \\
\hline 30 & 53.4 & 910 & 1018 & & & \\
\hline 31 & 53.4 & 810 & 1018 & 644 & 0.356 & 0.92 \\
\hline 1904 & & & & & & \\
\hline Jan. 1 & 53.8 & 1220 & 1019 & & & \\
\hline 2 & 53.0 & 925 & 1024 & & & \\
\hline 3 & 53.6 & 870 & 1021 & & & \\
\hline 4 & 54.0 & 1055 & 1022 & & & \\
\hline 5 & 54.0 & 1050 & 1020 & & & \\
\hline 6 & 53.9 & 1195 & 1017 & & & \\
\hline 7 & 53.6 & 980 & 1021 & 6.78 & 0.392 & 1.15 \\
\hline 8 & 53.4 & 1020 & 1021 & & & \\
\hline 9 & 53.3 & 1080 & 1022 & & & \\
\hline 10 & 53.6 & 1010 & 1021 & & & \\
\hline 11 & 53.9 & 960 & 1020 & 6.05 & $\cdots$ & $\cdots$ \\
\hline 12 & 53.0 & 620 & 1021 & 4.61 & 0.487 & $\cdots$ \\
\hline 13 & 53.6 & 1165 & 1019 & 7.90 & 0.609 & $\cdots$ \\
\hline 14 & 52.9 & 645 & 1022 & 4.99 & 0.298 & $\cdots$ \\
\hline 15 & 53.0 & 1450 & 1020 & 9.05 & 0.478 & $\cdots$ \\
\hline 16 & 53.4 & 1300 & 1018 & 7.56 & 0.405 & $\cdots$ \\
\hline 17 & 53.0 & 1440 & 1021 & 8.55 & 0.476 & $\ldots$ \\
\hline 18 & 53.0 & 1440 & 1023 & & & \\
\hline 19 & 53.0 & 1115 & 1021 & & & \\
\hline 20 & 53.0 & 1180 & 1020 & & & \\
\hline 21 & 52.6 & 790 & 1024 & 6.40 & 0.386 & 1.21 \\
\hline 22 & 52.7 & 660 & 1026 & & & \\
\hline 23 & 52.8 & 1750 & 1018 & & & \\
\hline 24 & 52.8 & 1440 & 1018 & & & \\
\hline 25 & 52.6 & 1200 & 1020 & & & \\
\hline 26 & 52.8 & 715 & 1023 & & & \\
\hline 27 & 52.7 & 1625 & 1015 & 639 & 0.414 & 1.21 \\
\hline 28 & 52.8 & 1080 & 1016 & & & 1.21 \\
\hline 29 & 52.8 & 1400 & 1020 & & & \\
\hline 30 & 53.0 & 1300 & 1021 & & 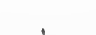 & \\
\hline
\end{tabular}


16i) PHYSIOLOGICAL ECONOMY IN NUTRITION

STELTZ.

\begin{tabular}{|c|c|c|c|c|c|c|}
\hline \multirow{2}{*}{ Date. } & \multirow{2}{*}{$\begin{array}{c}\text { Body- } \\
\text { weight. }\end{array}$} & \multicolumn{5}{|c|}{ Urine. } \\
\hline & & $\begin{array}{l}\text { Volume. } \\
24 \text { hours. }\end{array}$ & Sp. Gr. & Nitrogen. & Uric Acid. & $\mathrm{P}_{2} \mathrm{O}_{5}$ \\
\hline 1904 & kilos & c.c. & & grams & gram & grams \\
\hline Jan. 31 & 53.4 & 1670 & 1019 & 6.39 & 0.414 & 1.21 \\
\hline Feb. 1 & 53.0 & 1800 & 1022 & 1 & & \\
\hline 2 & 53.2 & 770 & 1018 & & & \\
\hline 3 & 53.3 & 1230 & 1022 & & & \\
\hline 4 & 53.4 & 1530 & 1018 & 6.06 & 0.351 & 1.31 \\
\hline 5 & 53.2 & 1400 & 1023 & daily & daily & daily \\
\hline 6 & 53.0 & 1440 & 1021 & average & average & average \\
\hline 7 & 53.4 & 1330 & 1018 & (1) 0 & & \\
\hline 8 & 53.0 & 1500 & 1022 & 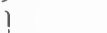 & & \\
\hline 9 & 53.0 & 940 & 1021 & & & \\
\hline 10 & 53.2 & 1400 & 1022 & & & \\
\hline 11 & 53.4 & 1620 & 1023 & 7.71 & 0.523 & $\ldots$ \\
\hline 12 & 53.6 & 1645 & 1018 & & & \\
\hline 13 & 53.4 & 1370 & 1018 & & & \\
\hline 14 & 53.0 & 1200 & 1024 & & & \\
\hline 15 & 53.2 & 1560 & 1025 & ) & & \\
\hline 16 & 53.0 & 1540 & 1021 & & & \\
\hline 17 & 53.5 & 1610 & 1020 & & & \\
\hline 18 & 53.2 & 1280 & 1024 & 7.85 & 0.423 & $\ldots$ \\
\hline 19 & 53.0 & 1560 & 1017 & & & \\
\hline 20 & 53.2 & 1635 & 1016 & & & \\
\hline 21 & 53.0 & 1110 & 1020 & j & & \\
\hline 22 & 53.0 & 1860 & 1016 & ) & & \\
\hline 23 & 53.2 & 1470 & 1018 & & & \\
\hline 24 & 53.5 & 1205 & 1019 & & & \\
\hline 25 & 53.5 & 2140 & 1014 & 7.40 & 0.497 & $\ldots$ \\
\hline 26 & 53.8 & 1080 & 1016 & & & \\
\hline 27 & 53.0 & 1165 & 1020 & & & \\
\hline 28 & 53.7 & 1360 & 1020 & & & \\
\hline 29 & 54.0 & 1400 & 1022 & 7.90 & $\ldots$ & $\ldots$ \\
\hline Mar. 1 & 53.9 & 1095 & 1021 & 5.98 & -6 & \\
\hline 2 & 53.4 & 1355 & 1020 & 6.58 & & \\
\hline 3 & 53.2 & 2125 & 1015 & 8.09 & & \\
\hline 4 & 53.0 & 1160 & 1016 & 4.66 & 0.389 & $\cdots$ \\
\hline 5 & 53.2 & 1610 & 1022 & 8.69 & & \\
\hline 6 & 53.0 & 1220 & 1022 & 8.20 & & \\
\hline 7 & 53.0 & 720 & 1023 & ) & & \\
\hline 8 & 53.2 & 1160 & 1021 & 701 & & \\
\hline 9 & 53.0 & 1280 & 1020 & 7.21 & 0.466 & $\cdots$ \\
\hline 10 & 52.5 & 1210 & 1017 & & & \\
\hline
\end{tabular}


PHYSIOLOGICAL ECONOMY IN NUTRITION 167

STELTZ.

\begin{tabular}{|c|c|c|c|c|c|c|}
\hline \multirow{2}{*}{ Date. } & \multirow{2}{*}{$\begin{array}{c}\text { Body- } \\
\text { weight. }\end{array}$} & \multicolumn{5}{|c|}{ Urine. } \\
\hline & & $\begin{array}{l}\text { Volume. } \\
24 \text { heurs. }\end{array}$ & sp. Gr. & Nitrogen. & Uric Acíd. & $\mathrm{P}_{2} \mathrm{O}_{5}$ \\
\hline 1904 & kilos & c.c. & & grams & gram & grams \\
\hline Mar. 11 & 52.6 & 1770 & 1016 & & & \\
\hline 12 & 52.6 & 1510 & 1018 & 7.21 & 0.466 & $\cdots$ \\
\hline 13 & 52.3 & 1110 & 1020 & daily av. & daily av. & - \\
\hline 14 & 526 & 700 & 1023 & & & \\
\hline 15 & 52.7 & 1215 & 1018 & & & \\
\hline 16 & 53.0 & 1840 & 1013 & & & \\
\hline 17 & 52.6 & 1685 & 1014 & 7.22 & 0.414 & $\cdots$ \\
\hline 18 & 52.4 & 1770 & 1015 & & & \\
\hline 19 & 53.2 & 1350 & 1012 & & & \\
\hline 20 & 52.6 & 910 & 1018 & & & \\
\hline 21 & 52.8 & 1210 & 1020 & & & \\
\hline 22 & 52.7 & 1680 & 1013 & & & \\
\hline 23 & 53.0 & 1630 & 1021 & & & \\
\hline 24 & 52.8 & 900 & 1020 & 7.70 & 0.550 & $\cdots$ \\
\hline 25 & 52.6 & 1600 & 1018 & & & \\
\hline 26 & 53.0 & 1330 & 1019 & & & \\
\hline 27 & 52.8 & 1750 & 1020 & & & \\
\hline 28 & 53.0 & 845 & 1019 & 3.60 & & \\
\hline 29 & 52.8 & 1490 & 1021 & 6.79 & & \\
\hline 30 & 52.6 & 1790 & 1018 & 7.20 & 0.334 & $\cdots$ \\
\hline 31 & 52.6 & 1560 & 1019 & 7.11 & & \\
\hline Apr. 1 & 52.4 & 1670 & 1021 & 7.82 & & \\
\hline 2 & 52.6 & 1165 & 1013 & 3.28 & $\cdots$ & $\cdots$ \\
\hline 3 & 53.0 & 1570 & 1018 & 6.50 & $\cdots$ & $\cdots$ \\
\hline \multirow{2}{*}{\multicolumn{2}{|c|}{$\begin{array}{l}\text { Daily average from } \\
\text { Nov. } 2\end{array}$}} & & & & & \\
\hline & & 1271 & 1018 & 7.13 & 0.416 & 1.24 \\
\hline
\end{tabular}


HENDERSON.

\begin{tabular}{|c|c|c|c|c|c|c|c|}
\hline \multirow{2}{*}{\multicolumn{2}{|c|}{ Date. }} & \multirow{2}{*}{$\begin{array}{c}\text { Body- } \\
\text { weight. }\end{array}$} & \multicolumn{5}{|c|}{ Urine. } \\
\hline & & & $\begin{array}{l}\text { Volume. } \\
24 \text { hours. }\end{array}$ & Sp. Gr. & Nitrogen. & Uric Acid. & $\mathrm{P}_{2} \mathrm{O}_{5}$. \\
\hline \multicolumn{2}{|c|}{1903} & kilos. & c.c. & & grams & gram & grams \\
\hline \multirow[t]{28}{*}{ Oct. } & 4 & 71.3 & 1320 & 1020 & 17.50 & 0.635 & 1.97 \\
\hline & 5 & 71.3 & 1110 & 1019 & 9.79 & $\ldots$ & $\ldots$ \\
\hline & 6. & 71.8 & 1020 & 1028 & 12.67 & 0.515 & 1.93 \\
\hline & 7 & 71.6 & 1000 & 1017 & 12.00 & $\ldots$ & $\ldots$ \\
\hline & 8 & 71.2 & 840 & 1023 & 11.29 & 0.379 & 1.85 \\
\hline & 9 & 71.2 & 910 & 1030 & 14.20 & $\ldots$ & $\ldots$ \\
\hline & 10 & 71.5 & 2220 & 1013 & 16.78 & $\ldots$ & $\ldots$ \\
\hline & 11 & 71.7 & 1280 & 1022 & 16.28 & 0.587 & 2.04 \\
\hline & 12 & 72.2 & 1360 & 1021 & 15.59 & $\ldots$ & $\cdots$ \\
\hline & 13 & 72.4 & 910 & 1025 & 12.34 & 0.532 & 1.95 \\
\hline & 14 & 72.4 & 1400 & 1020 & 16.04 & $\ldots$ & $\ldots$ \\
\hline & 15 & 72.8 & 1700 & 1019 & 18.46 & 0.672 & 2.57 \\
\hline & 16 & 72.8 & 1740 & 1015 & 16.70 & $\ldots$ & $\ldots$ \\
\hline & 17 & 72.5 & 1620 & 1021 & 17.59 & $\ldots$ & $\cdots$ \\
\hline & 18 & 72.7 & 2260 & 1015 & 19.26 & 0.602 & 2.27 \\
\hline & 19 & 72.8 & 1150 & 1027 & 17.73 & $\ldots$ & $\cdots$ \\
\hline & 20 & 72.5 & $9 \check{0} 0$ & 1080 & 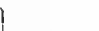 & & \\
\hline & 21 & 72.5 & 1060 & 1029 & & & \\
\hline & 22 & 72.6 & 940 & 1017 & & & \\
\hline & 23 & 724 & 1880 & 1017 & 14.31 & 0.612 & 1.60 \\
\hline & 24 & 72.8 & 1100 & 1029 & daily & daily & daily \\
\hline & 25 & 72.6 & 920 & 1027 & average & average & average \\
\hline & 26 & 72.4 & 1120 & 1023 & & & \\
\hline & 27 & 73.0 & $19: 30$ & 1017 & & & \\
\hline & 28 & 73.1 & 1340 & 1020 & & & \\
\hline & 29 & 73.6 & 820 & 1026 & 12.10 & 0.557 & 1.91 \\
\hline & 30 & 73.4 & 960 & 1028 & & & \\
\hline & 81 & 74.0 & 1040 & $\cdots$ & & & \\
\hline \multirow[t]{12}{*}{ Nov. } & 1 & 74.3 & 1540 & 1017 & j & & \\
\hline & 2 & 74.0 & 860 & 1031 & 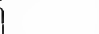 & & \\
\hline & 3 & 74.0 & 1240 & 1024 & & & \\
\hline & 4 & 74.0 & 840 & 1029 & & & $\cdot$ \\
\hline & 5 & 73.0 & 1280 & 1012 & 9.90 & 0.518 & 1.71 \\
\hline & 6 & 73.6 & 1340 & 1017 & & & \\
\hline & 7 & 72.9 & 500 & 1032 & & & \\
\hline & 8 & $72 . \overline{5}$ & 920 & 1023 & & & \\
\hline & 9 & 72.4 & 800 & 1029 & 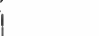 & & \\
\hline & 10 & 72.4 & 600 & 1030 & & 0562 & 160 \\
\hline & 11 & 72.7 & 900 & 1022 & 9.98 & 0.563 & 1.60 \\
\hline & 12 & 72.8 & 780 & 1032 & j & & \\
\hline
\end{tabular}


HENDERSON.

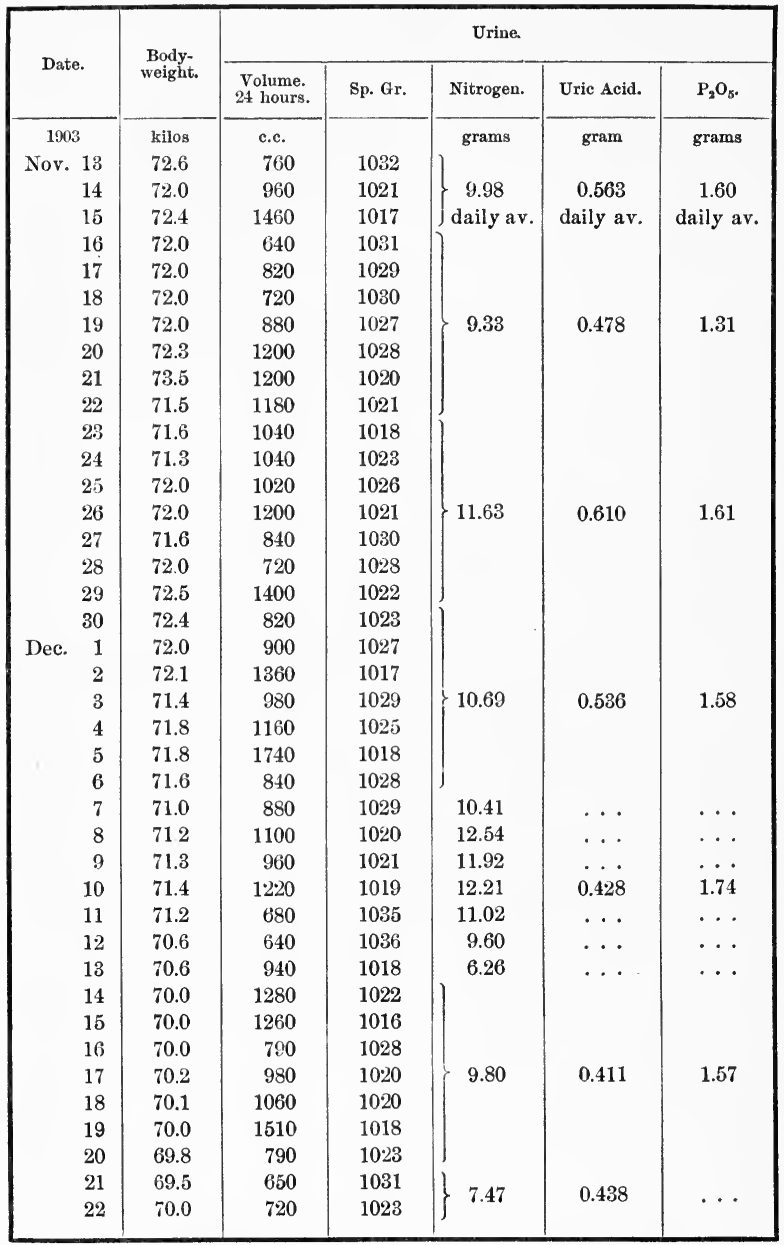


HENDERSON.

\begin{tabular}{|c|c|c|c|c|c|c|}
\hline \multirow{2}{*}{ Date. } & \multirow{2}{*}{$\begin{array}{c}\text { Body- } \\
\text { weight. }\end{array}$} & \multicolumn{5}{|c|}{ Urine. } \\
\hline & & $\begin{array}{l}\text { Volume } \\
24 \text { hours. }\end{array}$ & Sp. Gr. & Nitrogen. & Uric Acid. & $\mathrm{P}_{5} \mathrm{O}_{2}$ \\
\hline 1903 & kilos & c.c. & & grams & gram & grams \\
\hline Dec. 23 & 70.0 & 450 & 1026 & & & \\
\hline 24 & 69.6 & 880 & 1024 & & & \\
\hline 25 & 69.5 & 1300 & 1019 & 7.47 & 0.438 & $\cdots$ \\
\hline 26 & 69.0 & 930 & 1024 & daily & daily & \\
\hline 27 & 69.0 & 840 & 1024 & f average & average & \\
\hline 28 & 69.0 & 920 & 1023 & 1 & & \\
\hline 29 & 68.8 & 1180 & 1020 & & & \\
\hline 30 & 69.4 & 865 & 1024 & & & \\
\hline $1904 \quad 31$ & 70.0 & 1330 & 1026 & 7.77 & 0.407 & 1.24 \\
\hline Jan. 1 & 68.9 & 890 & 1021 & & & \\
\hline 2 & 69.0 & 947 & 1027 & & & \\
\hline 3 & 69.1 & 1025 & 1030 & 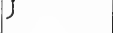 & & \\
\hline 4 & 69.2 & 890 & 1028 & ) & & \\
\hline 5 & 69.3 & 925 & 1027 & & & \\
\hline 6 & 69.3 & 550 & 1034 & & & \\
\hline 7 & 69.0 & 600 & 1029 & 7.78 & 0.439 & 1.25 \\
\hline 8 & 68.8 & 880 & $10: 28$ & & & \\
\hline 9 & 69.0 & 850 & 1027 & & & \\
\hline 10 & 69.0 & 1360 & 1015 & J & & \\
\hline 11 & 68.9 & 610 & 1025 & 5.89 & $\cdots$ & $\cdots$ \\
\hline 12 & 68.5 & 715 & 1024 & 7.68 & 0.498 & $\cdots$ \\
\hline 13 & 68.6 & 835 & 1023 & 8.22 & 0.551 & $\cdots$ \\
\hline 14 & 68.2 & 1040 & 1020 & 8.24 & 0.461 & $\cdots$ \\
\hline 15 & 68.2 & 880 & 1025 & 7.76 & 0.440 & $\cdots$ \\
\hline 16 & 68.2 & 970 & 1023 & 7.56 & 0.575 & $\cdots$ \\
\hline 17 & 68.0 & 810 & 1023 & 7.87 & 0.441 & $\cdots$ \\
\hline 18 & 68.0 & 1130 & 1020 & ) & & \\
\hline 19 & 68.0 & 1290 & 1018 & & & \\
\hline 20 & 68.2 & 670 & 1027 & & & \\
\hline 21 & 67.8 & 720 & 1030 & 7.82 & 0.445 & 1.18 \\
\hline 22 & 67.5 & 520 & 1029 & & & \\
\hline $2 \ddot{3}$ & 67.6 & 710 & 1030 & & & \\
\hline 24 & 67.6 & 775 & 1031 & P & & \\
\hline 25 & 68.0 & 1220 & 1018 & ) & & \\
\hline 26 & 68.0 & 815 & 1016 & & & \\
\hline 27 & 68.3 & 920 & 1029 & & & \\
\hline 28 & 68.1 & 950 & 1023 & 7.50 & 0.422 & 1.06 \\
\hline 29 & 68.2 & 670 & 1028 & & & \\
\hline 30 & 68.4 & 720 & $10: 30$ & & & \\
\hline 31 & 68.4 & 1285 & 1020 & & & \\
\hline
\end{tabular}


HENDERSON.

\begin{tabular}{|c|c|c|c|c|c|c|c|}
\hline \multirow{2}{*}{\multicolumn{2}{|c|}{ Date. }} & \multirow{2}{*}{$\begin{array}{c}\text { Body- } \\
\text { weight. }\end{array}$} & \multicolumn{5}{|c|}{ Urinc. } \\
\hline & & & $\begin{array}{l}\text { Volume. } \\
24 \text { hours. }\end{array}$ & Sp. Gr. & Nitrogen. & Uric Acid. & $\mathrm{P}_{2} \mathrm{O}_{5}$ \\
\hline \multicolumn{2}{|l|}{1904} & kilos & c.c. & & grams & gram & grams \\
\hline \multirow[t]{29}{*}{ Feb. } & 1 & 68.0 & 790 & 1030 & ) & & \\
\hline & 2 & 68.1 & 830 & 1031 & & & \\
\hline & 3 & 68.5 & 1335 & 1024 & & & \\
\hline & 4 & 68.5 & 1250 & 1026 & 8.27 & 0.360 & 1.17 \\
\hline & 5 & 69.0 & 1160 & 1031 & daily & daily & daily \\
\hline & 6 & 69.0 & 1150 & 1022 & average & average & a verage \\
\hline & 7 & 685 & 1210 & 1024 & & & \\
\hline & 8 & 68.0 & 935 & 1030 & ) & & \\
\hline & 9 & 68.0 & 975 & 1030 & & & \\
\hline & 10 & 68.2 & 990 & 1032 & & & \\
\hline & 11 & 68.6 & 870 & 1032 & 10.40 & 0.582 & $\cdots$ \\
\hline & 12 & 69.0 & 1130 & 1027 & & & \\
\hline & 13 & 69.4 & 1440 & 1019 & & & \\
\hline & 14 & 69.0 & 715 & 1029 & & & \\
\hline & 15 & 69.0 & 940 & 1029 & ) & & \\
\hline & 16 & 68.0 & 1070 & 1027 & & & \\
\hline & 17 & 68.1 & 1080 & 1027 & & & \\
\hline & 18 & 68.0 & 945 & 1029 & 11.80 & 0.510 & $\cdots$ \\
\hline & 19 & 68.2 & 1010 & 1029 & & & \\
\hline & 20 & 68.3 & 925 & 1029 & & & \\
\hline & 21 & 69.0 & 1200 & 1020 & & & \\
\hline & 22 & 68.6 & 1165 & 1024 & ) & & \\
\hline & 23 & 68.2 & 1170 & 1022 & & & \\
\hline & 24 & 68.6 & 1035 & 1027 & & & \\
\hline & 25 & 68.4 & 1735 & 1016 & 7.53 & 0.610 & $\cdots$ \\
\hline & 26 & 69.0 & 775 & 1029 & & & \\
\hline & 27 & 68.6 & 1090 & 1027 & & & \\
\hline & 28 & 69.0 & 1020 & 1030 & & & \\
\hline & 29 & 69.0 & 1995 & 1016 & 8.36 & & \\
\hline \multirow[t]{11}{*}{ Mar. } & 1 & 68.7 & 840 & 1029 & 6.80 & & \\
\hline & 2 & 68.4 & 1160 & 1023 & 8.28 & & \\
\hline & 3 & 68.2 & 920 & 1026 & 7.37 & 0.521 & $\cdots$ \\
\hline & 4 & 68.0 & 1000 & 1029 & 8.22 & & \\
\hline & 5 & 68.0 & 1645 & 1018 & 8.09 & & \\
\hline & 6 & - 68.0 & 1020 & 1030 & 8.20 & & \\
\hline & 7 & 68.0 & 740 & 1030 & & & \\
\hline & 8 & 68.2 & 1470 & 1020 & & & \\
\hline & 9 & 68.0 & 1660 & 1019 & 8.21 & 0.455 & $\cdots$ \\
\hline & 10 & 68.0 & 2040 & 1014 & & & \\
\hline & 11 & 68.0 & 1030 & $10 \cdot 29$ & & & \\
\hline
\end{tabular}


HENDERSON.

\begin{tabular}{|c|c|c|c|c|c|c|}
\hline \multirow{2}{*}{ Date. } & \multirow{2}{*}{$\begin{array}{c}\text { Body- } \\
\text { weight. }\end{array}$} & \multicolumn{5}{|c|}{ Urine. } \\
\hline & & $\begin{array}{l}\text { Volume. } \\
24 \text { hours. }\end{array}$ & Sp. Gr. & Nitrogen. & Uric Acid. & $\mathrm{P}_{2} \mathrm{O}_{3}$. \\
\hline 1904 & kilos & c.c. & & grams & gram & grams \\
\hline Mar. 12 & 68.2 & 2450 & 1014 & 8.21 & 0.455 & . . \\
\hline & 68.6 & 2300 & 1014 & daily av. & daily av. & \\
\hline 14 & 68.4 & 925 & 1026 & & & \\
\hline 15 & 68.4 & 1610 & 1016 & & & \\
\hline 16 & 68.5 & 1360 & 1019 & & & \\
\hline 17 & 68.0 & $\ldots$ & $\cdots$ & 8.82 & 0.483 & $\ldots$ \\
\hline 18 & 68.6 & 1975 & 1016 & & & \\
\hline 19 & 69.0 & 2410 & 1015 & & & \\
\hline 20 & 69.3 & 2480 & 1011 & & & \\
\hline 21 & 68.6 & 850 & 1028 & & & \\
\hline 22 & 68.7 & 1800 & 1012 & & & : \\
\hline 23 & 68.7 & 950 & 1023 & & & \\
\hline 24 & 69.0 & 1040 & 1030 & 8.64 & 0.632 & $\cdots$ \\
\hline 25 & 69.2 & 1360 & 1022 & & & \\
\hline 26 & 69.2 & 2470 & 1013 & & & \\
\hline 27 & 69.3 & 2110 & 1015 & j & & \\
\hline 28 & 69.4 & 1415 & 1020 & 8.40 & 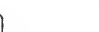 & \\
\hline 29 & 69.4 & 1815 & 1019 & 9.04 & & \\
\hline 30 & 69.4 & 1600 & 1017 & 5.95 & c. 337 & $\ldots$ \\
\hline 31 & 69.0 & 1390 & 1018 & 5.42 & & \\
\hline Apr. 1 & 69.0 & 1930 & 1015 & 6.60 & & \\
\hline 2 & 69.5 & 1405 & 1012 & 3.20 & $\cdots$ & $\cdots$ \\
\hline 8 & 71.0 & 1330 & 1018 & 7.42 & $\cdots$ & . . \\
\hline \multicolumn{2}{|c|}{$\begin{array}{l}\text { Daily average from } \\
\text { Nov. } 1\end{array}$} & 1102 & 1024 & 8.91 & 0.488 & 1.42 \\
\hline
\end{tabular}


PHYSIOLOGICAL ECONOMY IN NUTRITION 173

FRITZ.

\begin{tabular}{|c|c|c|c|c|c|c|c|}
\hline \multirow{2}{*}{\multicolumn{2}{|c|}{ Date. }} & \multirow{2}{*}{$\begin{array}{c}\text { Body- } \\
\text { weight. }\end{array}$} & \multicolumn{5}{|c|}{ Urine. } \\
\hline & & & $\begin{array}{l}\text { Volume. } \\
24 \text { hours. }\end{array}$ & Sp. Gr. & Nitrogen. & Uric Acid. & $\mathrm{P}_{2} \mathrm{O}_{5}$ \\
\hline \multicolumn{2}{|c|}{1903} & kilos & c.c. & & grams & gram & grams \\
\hline \multirow{30}{*}{ Nov. } & 1 & 76.0 & 1000 & 1024 & 11.34 & 1.14 & $\cdots$ \\
\hline & 2 & 76.4 & 950 & 1022 & 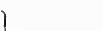 & & \\
\hline & 3 & 77.8 & 2200 & 1017 & & & \\
\hline & 4 & 76.0 & 960 & 1020 & & & \\
\hline & 5 & 76.5 & 1420 & 1015 & 8.97 & 0.418 & 1.45 \\
\hline & 6 & 76.4 & 720 & 1018 & daily & daily & daily \\
\hline & 7 & 75.8 & 940 & 1020 & average & average & average \\
\hline & 8 & 75.3 & 1580 & 1012 & & & \\
\hline & 9 & 75.3 & 2240 & 1012 & & & \\
\hline & 10 & 75.6 & 480 & 1021 & & - & \\
\hline & 11 & 76.0 & 1600 & 1015 & & & \\
\hline & 12 & 76.2 & 1640 & 1013 & 8.27 & 0.491 & 1.31 \\
\hline & 13 & 76.2 & 880 & 1020 & & & \\
\hline & 14 & 75.8 & 1320 & 1010 & & & \\
\hline & 15 & 75.3 & 2000 & 1013 & j & & \\
\hline & 16 & 75.6 & 760 & 1017 & & & \\
\hline & 17 & 75.6 & 1520 & 1013 & & & \\
\hline & 18 & 76.0 & 1740 & 1013 & & & \\
\hline & 19 & 75.1 & 1580 & 1015 & 8.13 & 0.528 & 1.54 \\
\hline & 20 & 76.0 & 1800 & 1015 & & & \\
\hline & 21 & 75.7 & 1140 & 1017 & & & \\
\hline & 22 & 75.7 & 1440 & 1013 & & & \\
\hline & 23 & 76.0 & 2060 & 1011 & & & \\
\hline & 24 & 76.2 & 2360 & 1011 & & & \\
\hline & 25 & 756 & 2380 & 1011 & & & \\
\hline & 26 & 75.8 & 2200 & 1013 & 8.68 & 0.555 & 1.63 \\
\hline & 27 & 77.2 & 1200 & 1014 & & & \\
\hline & 28 & 755 & 920 & 1021 & & & \\
\hline & 29 & 75.9 & 1240 & 1022 & & & \\
\hline & 30 & 75.4 & 700 & 1026 & & & \\
\hline \multirow[t]{10}{*}{ Dec. } & 1 & 75.7 & 1480 & 1017 & & & \\
\hline & 2 & 75.9 & 1160 & 1013 & & & \\
\hline & 3 & 75.5 & 1480 & 1009 & 8.16 & 0.656 & 1.74 \\
\hline & 4 & 75.6 & 1860 & 1015 & & & \\
\hline & 5 & 76.2 & 1480 & 1012 & & & \\
\hline & 6 & 76.5 & 1460 & 1018 & & & \\
\hline & 7 & 75.7 & 800 & 1024 & 5.81 & & \\
\hline & 8 & 75.6 & 880 & 1023 & 10.61 & 0746 & 1.97 \\
\hline & 9 & 76.0 & $\cdots$ & $\cdots$ & $\cdots$ & $0.1 \pm 0$ & 1.06 \\
\hline & 10 & 76.0 & 1840 & 1016 & 12.91 & & \\
\hline
\end{tabular}


17. PHYSIOLOGICAL ECONOMY IN NUTRITION

FRITZ.

\begin{tabular}{|c|c|c|c|c|c|c|}
\hline \multirow{2}{*}{ Date. } & \multirow{2}{*}{$\begin{array}{c}\text { Body- } \\
\text { weight. }\end{array}$} & \multicolumn{5}{|c|}{ Urine. } \\
\hline & & $\begin{array}{l}\text { Volume. } \\
24 \text { hours. }\end{array}$ & Sp. Gr. & Nitrogen. & Uric Acid. & $\mathrm{P}_{2} \mathrm{O}_{5}$. \\
\hline 1903 & kilos & c.c. & & grams & gram & grams \\
\hline Dec. 11 & 75.6 & 1240 & 1017 & 10.04 & 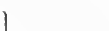 & \\
\hline 12 & 75.4 & 1740 & 1013 & 8.31 & 0.746 & 1.97 \\
\hline 13 & 75.4 & 1400 & 1018 & 7.72 & daily av. & daily av. \\
\hline 14 & 74.5 & 1260 & 1020 & ) & & \\
\hline 15 & 74.9 & 1040 & 1013 & & & \\
\hline 16 & 75.0 & 1390 & 1019 & & & \\
\hline 17 & 75.2 & 1220 & 1015 & 8.13 & 0.624 & 1.65 \\
\hline 18 & 75.0 & 1520 & 1016 & daily & & \\
\hline 19 & 752 & 1380 & 1017 & average & & \\
\hline 20 & 75.0 & 890 & 1020 & & & \\
\hline 21 & 74.8 & 1315 & 1018 & & & \\
\hline 22 & 74.8 & 880 & 1016 & 6.07 & $\cdots$ & $\cdots$ \\
\hline 23 & 74.6 & 1135 & 1022 & & & \\
\hline 24 & 74.6 & 1596 & 1006 & 7.42 & 0.584 & $\ldots$ \\
\hline 25 & 74.6 & 1300 & 1012 & & & \\
\hline 26 & 75.0 & 1090 & 1025 & & & \\
\hline 27 & 75.0 & 1520 & 1022 & & & \\
\hline 28 & 74.0 & 1150 & 1018 & & & \\
\hline 29 & 74.0 & 1250 & 1017 & & & \\
\hline 30 & 74.4 & 1610 & 1020 & & & \\
\hline 31 & 74.5 & 1025 & 1024 & 7.27 & 0.592 & 1.41 \\
\hline 1904 & & & & & & \\
\hline Jan. 1 & 74.2 & 1620 & 1010 & & & \\
\hline 2 & 736 & 1990 & 1017 & & & \\
\hline 3 & 73.7 & 1036 & 1029 & & & \\
\hline 4 & $74.0^{\circ}$ & 2070 & 1011 & & & \\
\hline 5 & 74.1 & 1320 & 1021 & & & \\
\hline 6 & 73.9 & 1690 & 1015 & & & \\
\hline 7 & 74.0 & $\cdots$ & $\cdots$ & 8.06 & 0.650 & 1.73 \\
\hline 8 & 73.4 & 1940 & 1020 & & & \\
\hline 9 & 73.6 & 1560 & 1012 & & & \\
\hline 10 & 74.0 & 2200 & 1015 & j & & \\
\hline 11 & 74.0 & 1300 & 1019 & 10.29 & $\cdots$ & $\cdots$ \\
\hline 12 & 73.7 & 810 & 1023 & 8.99 & 1.100 & $\cdots$ \\
\hline 13 & 74.0 & 680 & 1024 & 6.49 & 0.691 & $\cdots$ \\
\hline 14 & 73.3 & 1230 & 1019 & 10.26 & 0.998 & $\cdots$ \\
\hline 15 & 73.6 & 1030 & 1024 & 7.97 & 0.730 & $\cdots$ \\
\hline 16 & 73.9 & 1045 & 1015 & 5.20 & 0.466 & $\cdots$ \\
\hline 17 & 73.9 & 1910 & 1014 & 9.40 & 0.673 & $\ldots$ \\
\hline 18 & 73.0 & 1060 & 1017 & 7.01 & 0.631 & 1.23 \\
\hline
\end{tabular}


FRITZ.

\begin{tabular}{|c|c|c|c|c|c|c|}
\hline \multirow{2}{*}{ Date. } & \multirow{2}{*}{$\begin{array}{l}\text { Body- } \\
\text { weight. }\end{array}$} & \multicolumn{5}{|c|}{ Urine. } \\
\hline & & $\begin{array}{l}\text { Volume. } \\
24 \text { hours. }\end{array}$ & Sp. Gr. & Nitrogen. & Uric Acid. & $\mathrm{P}_{2} \mathrm{O}_{5}$ \\
\hline 1904 & kilos & c.c. & & grams & gram & grams \\
\hline Jan. 19 & 73.0 & 1510 & 1020 & & & \\
\hline 20 & 73.4 & 865 & 1023 & & & \\
\hline 21 & 73.4 & 1410 & 1020 & & & \\
\hline 22 & 73.0 & 610 & 1025 & .01 & 0631 & 1.23 \\
\hline 23 & 73.0 & 1630 & 1020 & daily & daily & daily \\
\hline 24 & 72.4 & 1125 & 1018 & & & average \\
\hline 25 & 72.6 & 2400 & 1011 & & & \\
\hline 26 & 72.8 & 2100 & 1010 & & & \\
\hline 27 & 72.6 & 795 & 1018 & & & \\
\hline 28 & 73.0 & 1425 & 1019 & 8.13 & 0.722 & 1.64 \\
\hline 29 & 73.0 & 1770 & 1013 & & & \\
\hline 30 & 73.2 & 1910 & 1015 & & & \\
\hline 31 & 73.0 & 2180 & 1016 & & & \\
\hline Feb. 1 & 73.2 & 2075 & 1015 & & & \\
\hline 2 & 73.1 & 2280 & 1012 & & & \\
\hline 3 & 73.0 & 2360 & 1023 & & & \\
\hline 4 & 73.4 & $2 \cdot 200$ & 1012 & 7.24 & 0.532 & 1.74 \\
\hline 5 & 73.0 & 1600 & 1019 & & & \\
\hline 6 & 73.3 & 1745 & 1019 & & & \\
\hline 7 & 73.0 & 745 & 1023 & & & \\
\hline 8 & 73.5 & 2280 & 1012 & & & \\
\hline 9 & 73.2 & 2150 & 1015 & & & \\
\hline 10 & 73.1 & 1985 & 1018 & & & \\
\hline 11 & 73.4 & 2240 & 1010 & 9.02 & 0.699 & $\cdots$ \\
\hline 12 & 73.0 & 2020 & 1016 & & & \\
\hline 13 & 73.6 & 1800 & 1016 & & & \\
\hline 14 & 73.0 & 1355 & 1021 & & & \\
\hline 15 & 73.0 & 1280 & 1024 & & & \\
\hline 16 & 73.5 & 2440 & 1014 & & & \\
\hline 17 & 73.4 & 1380 & 1022 & & & \\
\hline 18 & 73.6 & 1840 & 1020 & 8.43 & 0.632 & $\cdots$ \\
\hline 19 & 73.6 & 2340 & 1016 & & & \\
\hline 20 & 73.6 & 2480 & 1010 & & & \\
\hline 21 & 73.4 & 850 & 1024 & & & \\
\hline 22 & 73.3 & 1985 & 1019 & & & \\
\hline 23 & 73.4 & 1535 & 1011 & & & \\
\hline 24 & 73.5 & 1940 & 1015 & 7.68 & 0.799 & \\
\hline 25 & 73.5 & 1520 & 1017 & 1.08 & 0.105 & $\cdots$ \\
\hline 26 & 73.3 & 1030 & 1017 & & & \\
\hline 27 & 73.0 & 2270 & 1015 & & & \\
\hline
\end{tabular}


FRI'TZ.

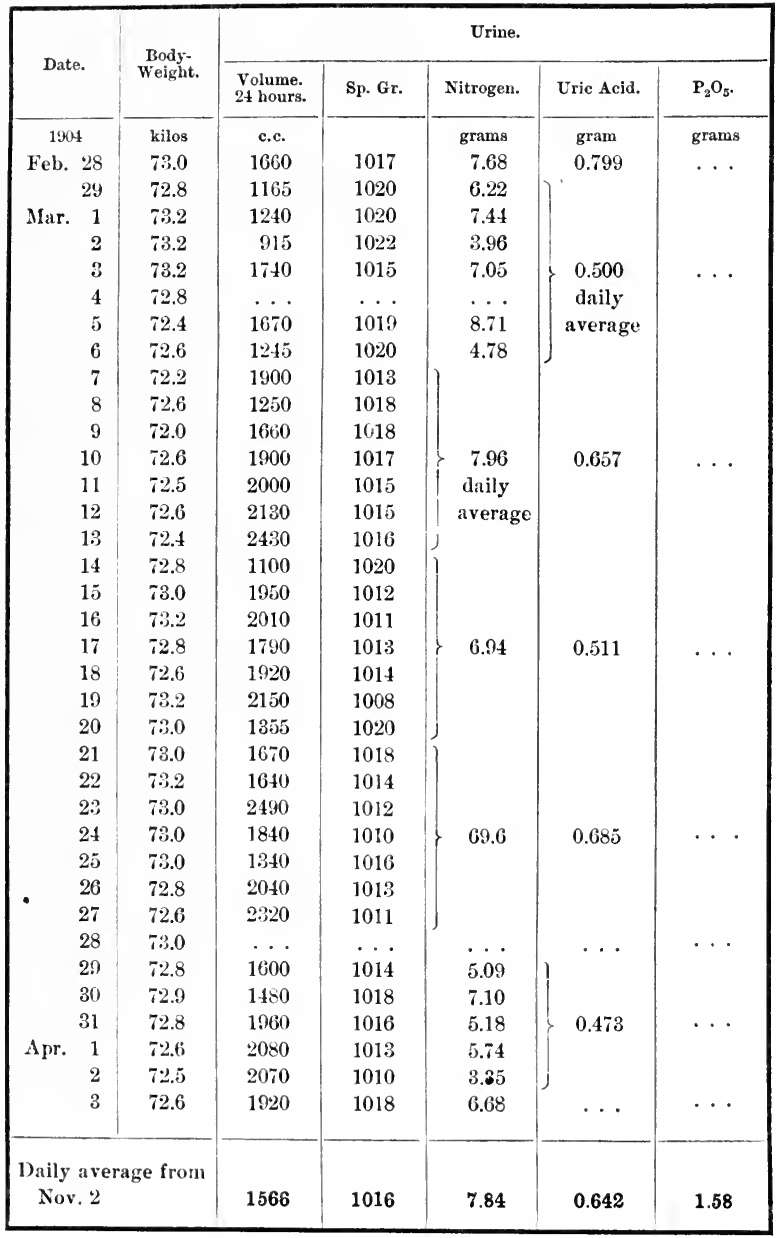


COHN.

\begin{tabular}{|c|c|c|c|c|c|c|}
\hline \multirow{2}{*}{ Date. } & \multirow{2}{*}{$\begin{array}{c}\text { Body- } \\
\text { weight. }\end{array}$} & \multicolumn{5}{|c|}{ Urine. } \\
\hline & & $\begin{array}{l}\text { Volume. } \\
24 \text { hours. }\end{array}$ & Sp. Gr. & Nitrogen. & Uric Acid. & $\mathrm{P}_{2} \mathrm{O}_{5}$. \\
\hline 1903 & kilos & c.c. & & grams & gram & grams \\
\hline Nov. 15 & 65.0 & 1140 & 1019 & 11.22 & $\cdots$ & $\cdots$ \\
\hline 16 & 65.1 & 840 & 1024 & 1 & & \\
\hline 17 & 65.6 & 1280 & 1024 & & & \\
\hline 18 & 65.5 & 1420 & 1022 & & & \\
\hline 19 & 65.1 & 1500 & 1020 & 10.86 & 0.605 & 1.60 \\
\hline 20 & 65.9 & 1540 & 1021 & daily & daily & daily \\
\hline 21 & 66.2 & 1340 & 1012 & average & average & average \\
\hline 22 & 65.6 & 840 & 1026 & & & \\
\hline 23 & 65.5 & 1040 & 1018 & & & \\
\hline 24 & 65.9 & 1260 & 1021 & & & \\
\hline 25 & 66.1 & 1500 & 1016 & & & \\
\hline $2 i$ & 65.8 & 800 & 1027 & 8.85 & 0.542 & 1.26 \\
\hline 27 & 65.3 & 840 & 1022 & & & \\
\hline 28 & 65.4 & 940 & 1016 & & & \\
\hline 29 & 65.7 & 1200 & 1023 & j & & \\
\hline 30 & 65.6 & 1480 & 1016 & ) & & \\
\hline Dec. 1 & 64.8 & 740 & 1024 & & & \\
\hline 2 & 65.3 & 600 & 1026 & & & \\
\hline 3 & 64.8 & 920 & 1023 & 9.89 & 0.621 & 1.51 \\
\hline 4 & 65.0 & 940 & 1020 & & & \\
\hline 5 & 64.8 & 680 & 1029 & & & \\
\hline 6 & 64.8 & 1460 & 1016 & & & \\
\hline 7 & 64.9 & 940 & 1027 & 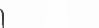 & & \\
\hline 8 & 65.0 & 900 & 1023 & & & \\
\hline 9 & 65.0 & 1040 & 1018 & & & \\
\hline 10 & 64.9 & 960 & 1021 & 8.60 & 0.392 & 1.32 \\
\hline 11 & 64.0 & 580 & 1033 & & & \\
\hline 12 & 64.8 & 860 & 1026 & & & \\
\hline 13 & 64.0 & 660 & 1028 & ) & & \\
\hline 14 & 64.0 & 1060 & 1021 & ) & & \\
\hline 15 & 63.9 & 880 & 1019 & & & \\
\hline 16 & 63.9 & 470 & 1031 & & & \\
\hline 17 & 63.9 & 760 & 1026 & 7.29 & 0.424 & 1.29 \\
\hline 18 & 64.3 & 1180 & 1020 & & & \\
\hline 19 & 64.4 & 1760 & 1011 & & & \\
\hline 20 & 64.0 & 1100 & 1017 & & & \\
\hline 21 & 64.4 & 615 & 1025 & & & \\
\hline 22 & 64.0 & 1050 & 1018 & 750 & 0424 & \\
\hline 23 & 64.0 & 860 & 1019 & 1.00 & 0.424 & $\cdots$ \\
\hline 24 & 64.2 & 1420 & 1019 & & & \\
\hline
\end{tabular}


COHN.

\begin{tabular}{|c|c|c|c|c|c|c|}
\hline \multirow{2}{*}{ Date. } & \multirow{2}{*}{$\begin{array}{c}\text { Body- } \\
\text { weight. }\end{array}$} & \multicolumn{5}{|c|}{ Urine. } \\
\hline & & $\begin{array}{l}\text { Volume. } \\
24 \text { hours. }\end{array}$ & Sp. Gr. & Nitrogen. & Uric Acid. & $\mathrm{P}_{2} \mathrm{O}_{5}$. \\
\hline 1903 & kilos & c.c. & & grams & gram & grams \\
\hline Dec. 25 & 64.2 & 1690 & 1017 & & & \\
\hline 26 & 64.0 & 740 & 1026 & 7.50 & 0.424 & . \\
\hline 27 & 68.9 & 1370 & 1017 & daily av. & daily av. & \\
\hline 28 & 63.7 & 690 & 1025 & & & \\
\hline 29 & 63.6 & 1065 & 1024 & & & \\
\hline 30 & 64.0 & 960 & 1024 & & & \\
\hline 31 & 64.0 & 700 & 1026 & 7.70 & 0.358 & \\
\hline 1904 & & & & & 0.000 & daily \\
\hline Jan. 1 & 63.4 & 1630 & 1017 & & & $\begin{array}{l}\text { daily } \\
\text { average }\end{array}$ \\
\hline 2 & 63.5 & 460 & 1030 & & & \\
\hline 3 & 63.0 & 970 & 1031 & & & \\
\hline 4 & 63.4 & 1365 & 1012 & & & \\
\hline 5 & 63.5 & 980 & 1021 & & & \\
\hline 6 & 64.0 & 1175 & 1022 & & & \\
\hline 7 & 64.1 & 1250 & 1017 & 8.03 & 0.498 & 1.12 \\
\hline 8 & 64.0 & 1500 & 1018 & & & \\
\hline 9 & 63.3 & 920 & 1027 & & & \\
\hline 10 & 63.3 & 1250 & 1019 & J & & \\
\hline 11 & 63.3 & 880 & 1022 & 8.08 & . . & $\cdots$ \\
\hline 12 & 62.8 & 510 & 1026 & 6.49 & 0.510 & $\ldots$ \\
\hline 13 & 63.0 & 900 & 1024 & 9.10 & 0.679 & $\ldots$ \\
\hline 14 & 62.8 & 630 & 1026 & 7.33 & 0.523 & $\ldots$ \\
\hline 15 & 62.4 & 950. & 1025 & 8.04 & 0.497 & $\ldots$ \\
\hline 16 & 62.6 & 1300 & 1018 & 8.58 & 0.473 & $\ldots$ \\
\hline 17 & 62.4 & 905 & 1026 & 7.44 & 0.431 & $\ldots$ \\
\hline 18 & 62.0 & 835 & 1026 & & & \\
\hline 19 & 62.7 & 1510 & 1020 & & & \\
\hline 20 & 63.0 & 980 & 1023 & & & \\
\hline 21 & 62.4 & 935 & 1026 & 8.97 & 0.552 & 1.43 \\
\hline 22 & 62.6 & 1610 & 1019 & & & \\
\hline 23 & 62.7 & 970 & 1024 & & & \\
\hline 24 & 62.2 & 1275 & 1020 & & & \\
\hline 25 & 63.0 & 1600 & 1017 & & & \\
\hline 26 & 62.3 & 770 & 1025 & & & \\
\hline 27 & 62.2 & 940 & 1023 & & & \\
\hline 28 & 62.4 & 980 & 1021 & 7.34 & 0.539 & 1.30 \\
\hline 29 & 62.0 & 705 & 1025 & & & \\
\hline 30 & 62.9 & 890 & 1024 & & & \\
\hline 31 & 63.4 & 1560 & 1020 & & & \\
\hline Feb. 1 & 63.5 & 1040 & 1028 & 8.15 & 0.532 & 1.87 \\
\hline
\end{tabular}


COHN.

\begin{tabular}{|c|c|c|c|c|c|c|}
\hline \multirow{2}{*}{ Date. } & \multirow{2}{*}{$\begin{array}{c}\text { Body- } \\
\text { weight. }\end{array}$} & \multicolumn{5}{|c|}{ Urine. } \\
\hline & & $\begin{array}{l}\text { Volume. } \\
24 \text { hours. }\end{array}$ & Sp. Gr. & Nitrogen. & Uric Acid. & $\mathrm{P}_{2} \mathrm{O}_{5}$. \\
\hline 1904 & kilos & c.c. & & grams & gram & grams \\
\hline Feb. 2 & 63.4 & 960 & 1026 & & & \\
\hline 3 & 63.0 & 1500 & 1022 & & & \\
\hline 4 & 68.2 & 1430 & 1023 & & & \\
\hline 5 & 63.6 & 1890 & 1018 & daily & dailv & daily \\
\hline 6 & 63.0 & 730 & 1025 & daily & dally & dally \\
\hline 7 & 63.0 & 920 & 1026 & average & & \\
\hline 8 & 63.3 & 935 & 1027 & & & \\
\hline 9 & 64.0 & 1625 & 1016 & & & \\
\hline 10 & 63.5 & 1615 & 1017 & & & \\
\hline 11 & 64.0 & 1325 & 1020 & 8.00 & 0.522 & $\cdots$ \\
\hline 12 & 64.0 & 1275 & 1021 & & & \\
\hline 13 & 64.0 & 770 & 1024 & & & \\
\hline 14 & 63.4 & 940 & 1023 & & & \\
\hline 15 & 63.5 & 1300 & 1027 & & & \\
\hline 16 & 63.1 & 1430 & 1020 & & & \\
\hline 17 & 63.6 & 1280 & 1024 & & & \\
\hline 18 & 63.3 & 870 & 1025 & 8.59 & 0.510 & $\cdots$ \\
\hline 19 & 63.2 & 1250 & 1026 & & & \\
\hline 20 & 63.1 & 1250 & 1017 & & & \\
\hline 21 & 63.5 & 900 & 1016 & & & \\
\hline 22 & 63.3 & 1345 & 1026 & & & \\
\hline 23 & 63.5 & 1185 & 1019 & & & \\
\hline 24 & 63.3 & 1560 & 1020 & & & \\
\hline 25 & 63.4 & 1200 & 1015 & 8.45 & 0.633 & $\cdots$ \\
\hline 26 & 63.0 & 750 & 1029 & & & \\
\hline 27 & 63.5 & 1140 & 1019 & & & \\
\hline 28 & 63.4 & 1220 & 1020 & & & \\
\hline 29 & 63.6 & 1160 & 1023 & 9.74 & $\cdots$ & $\cdots$ \\
\hline Mar. 1 & 63.5 & 900 & 1025 & 6.86 & $\cdots$ & $\cdots$ \\
\hline 2 & 63.5 & 1030 & 1020 & 7.29 & $\cdots$ & $\cdots$ \\
\hline 3 & 62.7 & 920 & 1021 & 6.40 & 0.480 & $\cdots$ \\
\hline 4 & 62.7 & 1225 & 1014 & 5.59 & $\cdots$ & $\cdots$ \\
\hline 5 & 62.5 & 1170 & 1026 & 9.55 & $\cdots$ & $\cdots$ \\
\hline 6 & 62.6 & 940 & 1025 & 6.77 & $\cdots$ & $\cdots$ \\
\hline 7 & 62.5 & 900 & 1026 & & & \\
\hline 8 & 63.0 & 1230 & 1020 & & & \\
\hline 9 & 62.7 & 1260 & 1020 & 8.41 & 0.608 & \\
\hline 10 & 62.5 & 980 & 1019 & 0.41 & 0.000 & $\cdots$ \\
\hline 11 & 62.4 & 1150 & 1024 & & & \\
\hline 12 & 62.4 & 830 & 1027 & & & \\
\hline
\end{tabular}


COHN.

\begin{tabular}{|c|c|c|c|c|c|c|c|}
\hline \multirow{2}{*}{\multicolumn{2}{|c|}{ Date. }} & \multirow{2}{*}{$\begin{array}{l}\text { Body- } \\
\text { weight. }\end{array}$} & \multicolumn{5}{|c|}{ Urine. } \\
\hline & & & $\begin{array}{l}\text { Volume. } \\
24 \text { hours. }\end{array}$ & Sp. Gr. & Nitrogen. & Uric Acid. & $\mathrm{P}_{2} \mathrm{O}_{5}$. \\
\hline 190 & & kilos & c.c. & & grams & gram & grams \\
\hline Mar. & & 62.4 & 1500 & 1020 & 8.41 & 0.608 & $\ldots$ \\
\hline & 14 & 62.0 & 825 & 1025 & ) & & \\
\hline & 15 & 62.5 & 1200 & 1017 & & & \\
\hline & 16 & 62.5 & 1490 & 1018 & & & \\
\hline & 17 & 62.5 & 1145 & 1021 & 7.59 & 0.488 & .. \\
\hline & 18 & 63.7 & 975 & 1021 & daily & daily & \\
\hline & 19 & 63.0 & 825 & 1023 & average & average & \\
\hline & 20 & 63.5 & 1450 & 1020 & & & \\
\hline & 21 & 63.6 & 1480 & 1018 & & & \\
\hline & 22 & 63.0 & 1100 & 1025 & & & \\
\hline & 23 & 62.6 & 1050 & 1023 & & & \\
\hline & 24 & 62.7 & 1050 & 1025 & 7.74 & 0.654 & . . \\
\hline & 25 & 62.0 & 900 & 1027 & & & \\
\hline & 26 & 62.4 & 750 & 1025 & & & \\
\hline & 27 & 62.6 & 1530 & 1016 & & & \\
\hline & 28 & $6 \cdot 2.0$ & 1060 & 1023 & 6.61 & & \\
\hline & 29 & 62.4 & 1460 & 1020 & 6.48 & & \\
\hline & 30 & 62.4 & 1020 & 1023 & 6.36 & 0.399 & $\ldots$ \\
\hline & 31 & 62.6 & 1730 & 1022 & 7.47 & & \\
\hline Apr. & 1 & 62.4 & 895 & 1022 & 4.35 & & \\
\hline & 2 & 62.4 & 1465 & 1014 & 5.11 & $\cdots$ & $\cdots$ \\
\hline & 3 & 62.6 & 1165 & 1023 & 9.37 & $\cdots$ & $\ldots$ \\
\hline \multirow{2}{*}{\multicolumn{3}{|c|}{$\begin{array}{l}\text { Daily average from } \\
\text { Nov. } 22\end{array}$}} & & & & & \\
\hline & & & 1092 & 1022 & 8.05 & 0.512 & 1.28 \\
\hline
\end{tabular}


LOEWENTHAL.

\begin{tabular}{|c|c|c|c|c|c|c|c|}
\hline \multirow{2}{*}{\multicolumn{2}{|c|}{ Date. }} & \multirow{2}{*}{$\begin{array}{c}\text { Body- } \\
\text { weight. }\end{array}$} & \multicolumn{5}{|c|}{ Urine. } \\
\hline & & & $\begin{array}{l}\text { Volume. } \\
24 \text { hours. }\end{array}$ & Sp. Gr. & Nitrogen. & Uric Acid. & $\mathrm{P}_{2} \mathrm{O}_{5}$ \\
\hline \multicolumn{2}{|c|}{1903} & kilos & c.c. & & grams & gram & grams \\
\hline \multirow[t]{28}{*}{ Oet. } & 4 & 60.1 & 960 & 1025 & 15.78 & 0.606 & 1.78 \\
\hline & 5 & 60.1 & 780 & 1025 & 10.90 & $\ldots$ & $\cdots$ \\
\hline & 6 & 603 & 820 & 1024 & 11.23 & 0.576 & 0.96 \\
\hline & 7 & 60.0 & 980 & 1022 & 14.99 & $\ldots$ & $\ldots$ \\
\hline & 8 & 60.0 & 1080 & 1019 & 11.34 & 0.351 & 1.55 \\
\hline & 9 & 60.0 & 990 & 1025 & 13.07 & $\ldots$ & $\ldots$ \\
\hline & 10 & 60.0 & 1120 & 1021 & 12.37 & $\ldots$ & $\ldots$ \\
\hline & 11 & 59.8 & 930 & 1019 & 10.83 & 0.389 & 1.05 \\
\hline & 12 & 60.4 & 1580 & 1022 & 17.06 & $\ldots$ & $\ldots$ \\
\hline & 13 & 60.2 & 1380 & 1017 & 13.00 & 0.516 & 2.13 \\
\hline & 14 & 61.0 & 640 & 1026 & 7.41 & $\ldots$ & $\ldots$ \\
\hline & 15 & 61.2 & 1220 & 1026 & 15.66 & 0.674 & 1.68 \\
\hline & 16 & 60.8 & 1060 & 1024 & 15.01 & $\ldots$ & $\ldots$ \\
\hline & 17 & 60.5 & 1130 & 1021 & 13.63 & $\ldots$ & $\ldots$ \\
\hline & 18 & 60.4 & 1580 & 1016 & 12.70 & 0.520 & $1.0 ั 9$ \\
\hline & 19 & 60.0 & 1350 & 1022 & 17.82 & $\ldots$ & $\cdots$ \\
\hline & 20 & 59.8 & 1250 & 1019 & & & \\
\hline & 21 & 60.0 & 1120 & 1024 & & & \\
\hline & 22 & 60.4 & 1060 & 1025 & & & \\
\hline & 23 & 61.0 & 1800 & 1020 & 13.72 & 0.489 & 1.90 \\
\hline & 24 & 61.2 & 1320 & 1021 & daily av. & daily av. & daily av. \\
\hline & 25 & 61.4 & 1620 & 1015 & & & \\
\hline & 26 & 62.4 & 1160 & 1024 & & & \\
\hline & 27 & 62.6 & 1520 & 1021 & & & \\
\hline & 28 & 62.6 & 860 & 1022 & & & \\
\hline & 29 & 63.4 & 660 & $1 \mathrm{C} 24$ & 9.80 & 0.430 & 1.40 \\
\hline & 30 & 62.5 & 1200 & 1023 & & & \\
\hline & 31 & 62.2 & 920 & $\ldots$ & & & \\
\hline \multirow[t]{12}{*}{ Nov. } & 1 & 62.4 & 1050 & 1019 & & & \\
\hline & 2 & 62.6 & 1330 & 1023 & & & \\
\hline & 3 & 62.0 & 1020 & 1022 & & & \\
\hline & 4 & 61.8 & 920 & 1020 & & & \\
\hline & 5 & 62.4 & 580 & 1029 & 8.23 & 0.401 & 1.60 \\
\hline & 6 & 62.4 & 1400 & 1016 & & & \\
\hline & 7 & 62.0 & 780 & 1022 & & & \\
\hline & 8 & 61.9 & 760 & 1021 & & & \\
\hline & 9 & 61.8 & 840 & 1031 & & & \\
\hline & 10 & 60.5 & 440 & 1028 & 808 & 0300 & 134 \\
\hline & 11 & 61.0 & 1060 & 1028 & 8.28 & 0.390 & 1.54 \\
\hline & 12 & 61.2 & 880 & 1027 & & & \\
\hline
\end{tabular}


LOEWENTHAL.

\begin{tabular}{|c|c|c|c|c|c|c|}
\hline \multirow{2}{*}{ Date. } & \multirow{2}{*}{$\begin{array}{c}\text { Body- } \\
\text { weight. }\end{array}$} & \multicolumn{5}{|c|}{ Urine. } \\
\hline & & $\begin{array}{l}\text { Volume. } \\
24 \text { hours. }\end{array}$ & Sp. Gr. & Nitrogen. & Uric Acid. & $\mathrm{P}_{2} \mathrm{O}_{5}$. \\
\hline 1903 & kilos & c.c. & & grams & gram & grams \\
\hline Nov. 13 & 61.4 & 320 & 1023 & & & \\
\hline 14 & 61.4 & 660 & 1023 & 8.28 & 0.390 & 1.34 \\
\hline 15 & 61.2 & 1020 & 1023 & daily av. & daily av. & daily av. \\
\hline 16 & 61.4 & 960 & 1025 & & & \\
\hline 17 & 61.0 & 680 & 1028 & & & \\
\hline 18 & 61.0 & 940 & 1023 & & & \\
\hline 19 & 60.9 & 880 & 1024 & 8.62 & 0.349 & 1.30 \\
\hline 20 & 61.5 & 1540 & 1018 & & & \\
\hline 21 & 61.7 & 1220 & $10: 22$ & & & \\
\hline 22 & 61.2 & 1120 & 1022 & & & \\
\hline 23 & 61.1 & 1440 & 1014 & & & \\
\hline 24 & 60.2 & 810 & 1024 & & & \\
\hline 25 & 60.3 & 680 & 1026 & & & \\
\hline 26 & 60.8 & 900 & 1022 & 8.36 & 0.392 & 1.43 \\
\hline 27 & 60.5 & 860 & 1025 & & & \\
\hline 28 & 60.3 & 800 & 1023 & & & \\
\hline 29 & 60.3 & 1040 & 1025 & & & \\
\hline 30 & 60.8 & 1040 & 1021 & & & \\
\hline Dec. 1 & 60.4 & 1120 & 1017 & & & \\
\hline 2 & 60.0 & 660 & 1027 & & & \\
\hline 3 & 59.9 & 900 & 1022 & 7.59 & 0.408 & 1.26 \\
\hline 4 & 59.5 & 1120 & 1025 & & & \\
\hline 5 & 59.0 & 400 & 1028 & & & \\
\hline 6 & 58.6 & 480 & 1033 & & & \\
\hline 7 & 58.2 & 960 & 1027 & 9.03 & ) & \\
\hline 8 & 58.0 & 800 & 1020 & 8.78 & & \\
\hline 9 & 58.6 & 700 & 1028 & 10.04 & & \\
\hline 10 & 60.0 & 1000 & 1019 & 9.06 & 0.379 & 1.49 \\
\hline 11 & 60.0 & 800 & 1025 & 8.71 & & \\
\hline 12 & 60.0 & 680 & 1032 & 7.51 & & \\
\hline 13 & 59.5 & 620 & 1030 & 7.74 & & \\
\hline 14 & 59.5 & 940 & 1022 & & & \\
\hline 15 & 59.0 & 920 & 1019 & & & \\
\hline 16 & 59.6 & 690 & 1027 & & & \\
\hline 17 & 59.3 & 800 & 1020 & 6.90 & 0.408 & 1.14 \\
\hline 18 & 59.7 & 1145 & 1020 & & & \\
\hline 19 & 59.7 & 1110 & 1016 & & & \\
\hline 20 & 59.0 & 840 & 1020 & & & \\
\hline 21 & 59.0 & 775 & 1025 & 6.29 & & \\
\hline 22 & 58.4 & 510 & 1027 & 6.29 & 0.210 & $\cdots$ \\
\hline
\end{tabular}


LOEWENTHAL.

\begin{tabular}{|c|c|c|c|c|c|c|}
\hline \multirow{2}{*}{ Date. } & \multirow{2}{*}{$\begin{array}{l}\text { Body- } \\
\text { weight. }\end{array}$} & \multicolumn{5}{|c|}{ Urine. } \\
\hline & & $\begin{array}{l}\text { Volume. } \\
24 \text { hours. }\end{array}$ & Sp. Gr. & Nitrogen. & Uric Acid. & $\mathrm{P}_{2} \mathrm{O}_{5}$ \\
\hline 1903 & kilos & c.c. & & grams & gram & grams \\
\hline Dec. 23 & 59.2 & 700 & 1026 & ) & & \\
\hline 24 & 59.0 & 890 & 1015 & & & \\
\hline 25 & 58.3 & 900 & 1027 & 6.29 & 0.275 & $\cdots$ \\
\hline 26 & 59.0 & 930 & 1015 & daily & daily & \\
\hline 27 & 58.4 & 990 & 1018 & average & average & \\
\hline 28 & 58.5 & 672 & 1028 & & & \\
\hline 29 & 58.4 & 795 & 1023 & & & \\
\hline 30 & 59.0 & 870 & 1025 & & & \\
\hline 31 & 58.8 & 920 & 1027 & 6.92 & 0.515 & 1.17 \\
\hline 1904 & & & & & & daily \\
\hline Jan. 1 & 58.7 & 1340 & 1022 & & & average \\
\hline 2 & 58.2 & 1232 & 1019 & & & \\
\hline 3 & 58.6 & 842 & 1025 & 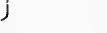 & & \\
\hline 4 & 58.8 & 1030 & 1017 & 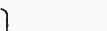 & & \\
\hline 5 & 58.6 & 1020 & 1026 & & & \\
\hline 6 & 58.8 & 890 & 1024 & & & \\
\hline 7 & 59.0 & 1350 & 1016 & 7.27 & 0.344 & 0.97 \\
\hline 8 & 57.7 & 900 & 1026 & & & \\
\hline 9 & 58.0 & 735 & 1033 & & & \\
\hline 10 & 57.9 & 760 & 1024 & & & \\
\hline 11 & 58.0 & 795 & 1021 & 6.68 & $\cdots$ & $\cdots$ \\
\hline 12 & 58.2 & 1110 & 1017 & 7.33 & 0.383 & $\cdots$ \\
\hline 13 & 58.1 & 1190 & 1015 & 7.64 & 0.379 & $\cdots$ \\
\hline 14 & 57.0 & 620 & 1027 & 6.21 & 0.415 & $\cdots$ \\
\hline 15 & 57.2 & 825 & 1028 & 8.18 & 0.409 & $\cdots$ \\
\hline 16 & 57.8 & 1100 & 1019 & 7.92 & 0.305 & $\cdots$ \\
\hline 17 & 57.5 & 1185 & 1021 & 7.26 & 0.338 & $\cdots$ \\
\hline 18 & 57.3 & 630 & 1019 & $\cdots$ & $\cdots$ & $\cdots$ \\
\hline 19 & 57.5 & 525 & 1030 & ) & & \\
\hline 20 & 58.0 & 1050 & 1026 & & & \\
\hline 21 & 57.7 & 790 & 1027 & 6.84 & 0.321 & 0.99 \\
\hline 22 & 57.7 & 850 & 1030 & 0.07 & & \\
\hline 23 & 57.4 & 605 & 1024 & & & \\
\hline 24 & 57.4 & 800 & 1030 & & & \\
\hline 25 & 57.9 & 1050 & 1020 & & & \\
\hline 26 & 58.0 & 850 & 1026 & & & \\
\hline 27 & 58.2 & 1270 & 1018 & $6 . \overline{8} 3$ & 0.312 & 1.14 \\
\hline 28 & 59.0 & 1255 & 1013 & & & \\
\hline 29 & 58.0 & 615 & 1028 & & & \\
\hline 30 & 58.0 & 1025 & 1029 & & & \\
\hline
\end{tabular}


LOEWENTHAL.

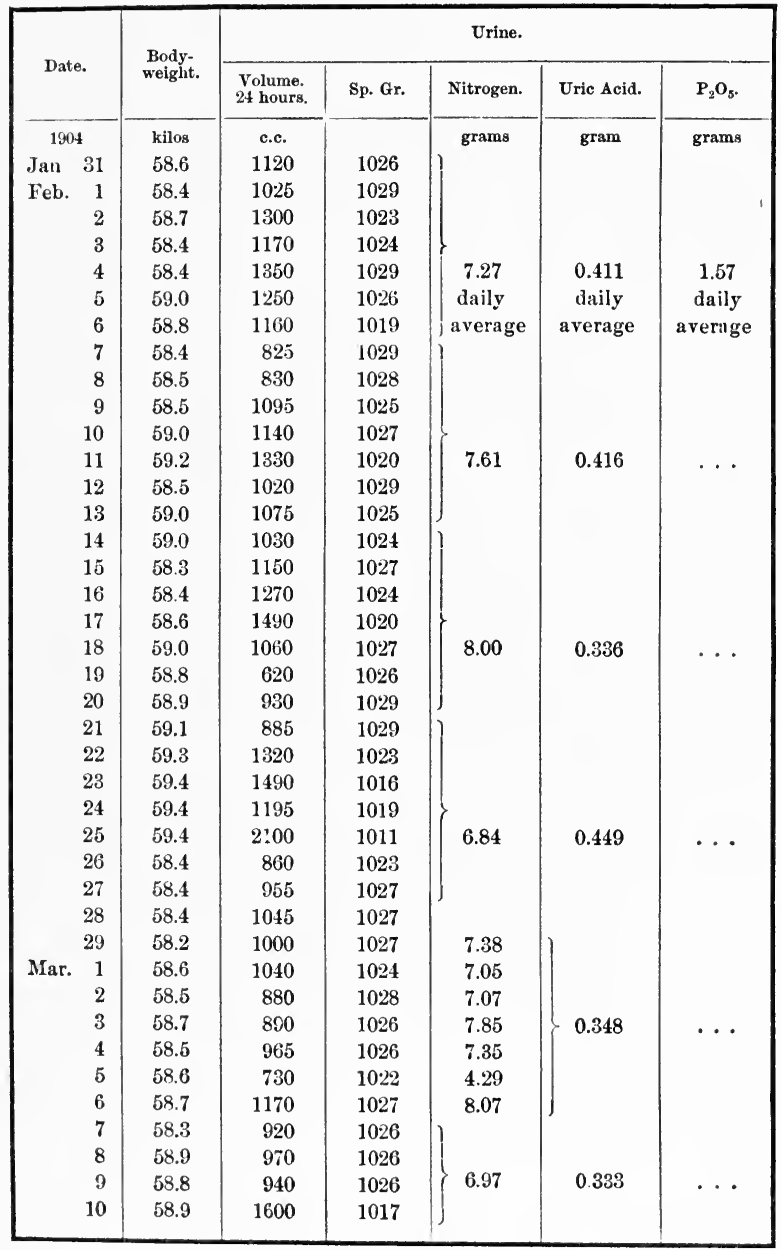


PHYSIOLOGICAL ECONONY IN NUTRITION 185

\section{LOEWENTHAL.}

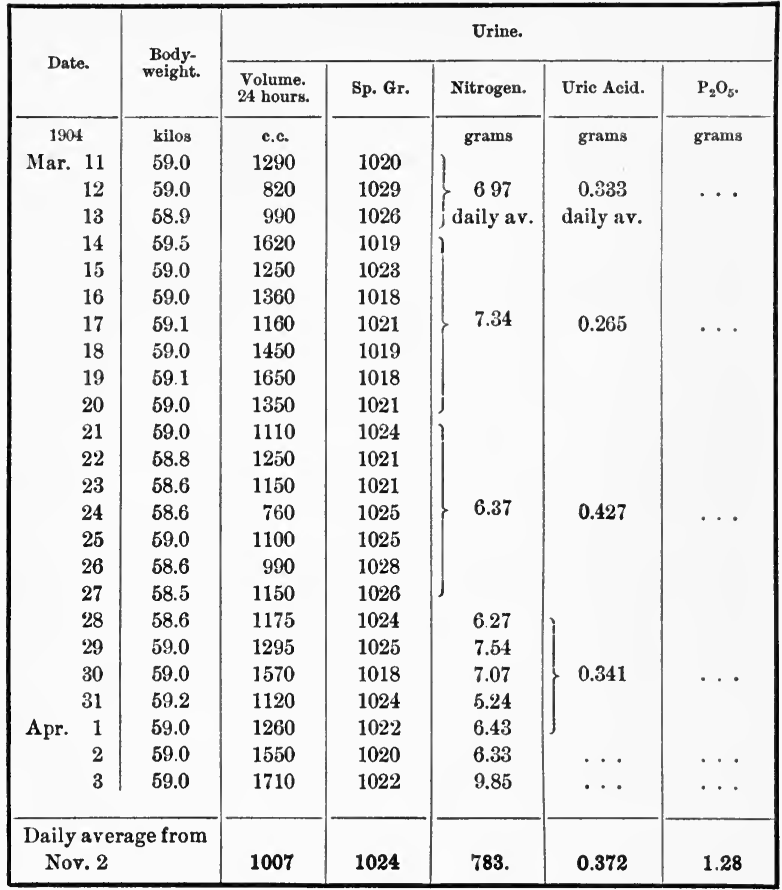


ZOOMAN.

\begin{tabular}{|c|c|c|c|c|c|c|c|}
\hline \multirow{2}{*}{\multicolumn{2}{|c|}{ Date. }} & \multirow{2}{*}{$\begin{array}{c}\text { Body- } \\
\text { weight. }\end{array}$} & \multicolumn{5}{|c|}{ Urine. } \\
\hline & & & $\begin{array}{l}\text { Volume. } \\
24 \text { hours. }\end{array}$ & Sp. Gr. & Nitrogen. & Uric Acid. & $\mathrm{P}_{2} \mathrm{O}_{5}$ \\
\hline \multicolumn{2}{|c|}{1903} & kilos & c.c. & & grams & gram & grams \\
\hline \multirow[t]{28}{*}{ Oct. } & 4 & 54.0 & 540 & 1026 & 8.88 & 0.434 & 0.56 \\
\hline & 5 & 54.0 & 940 & 1027 & 15.28 & $\ldots$ & $\ldots$ \\
\hline & 6 & 53.6 & 1140 & 1024 & 16.42 & 0.730 & 2.21 \\
\hline & 7 & 54.5 & 1640 & 1016 & 17.52 & $\ldots$ & $\ldots$ \\
\hline & 8 & 54.4 & 930 & 1017 & 10.10 & 0275 & 1.21 \\
\hline & 9 & 54.4 & 1160 & 1022 & 15.80 & $\ldots$ & $\ldots$ \\
\hline & 10 & 54.3 & 1080 & 1019 & 15.24 & $\ldots$ & $\ldots$ \\
\hline & 11 & 54.5 & 1340 & 1014 & 13.65 & 0.450 & 1.73 \\
\hline & 12 & 54.8 & 1080 & 1022 & 11.73 & $\ldots$ & $\ldots$ \\
\hline & 13 & 55.4 & 1140 & 1022 & 13.48 & 0.839 & 1.70 \\
\hline & 14 & 557 & 1020 & 1018 & 9.85 & $\ldots$ & $\ldots$ \\
\hline & 15 & 55.2 & 1560 & 1021 & 20.40 & 0.779 & 2.92 \\
\hline & 16 & 56.0 & 1240 & 1024 & 17.33 & $\ldots$ & $\ldots$ \\
\hline & 17 & 55.6 & 1070 & 1025 & 16.11 & $\ldots$ & $\ldots$ \\
\hline & 18 & 55.6 & 1730 & 1017 & 20.86 & 0.736 & 2.26 \\
\hline & 19 & 55.4 & 1370 & 1020 & 18.57 & . & $\ldots$ \\
\hline & 20 & 55.6 & 1290 & 1024 & 1 & & \\
\hline & 21 & 55.6 & 1120 & 1025 & & & \\
\hline & 22 & 55.8 & 1140 & 1023 & & & \\
\hline & 23 & 55.9 & 1120 & 1025 & 15.38 & 0.683 & 1.87 \\
\hline & 24 & 56.2 & 1600 & 1020 & daily & daily & daily \\
\hline & 25 & 56.5 & 1620 & 1015 & average & average & average \\
\hline & 26 & 56.6 & 1140 & 1024 & 1 & & \\
\hline & 27 & 56.6 & 1770 & 1015 & & & \\
\hline & 28 & 56.6 & 960 & 1021 & & & \\
\hline & 29 & 57.3 & 1120 & 1019 & 11.70 & 0.583 & 1.56 \\
\hline & 30 & 56.8 & 1160 & 1019 & & & \\
\hline & 31 & 57.0 & $8: 0$ & .. & & & \\
\hline \multirow[t]{12}{*}{ Nov. } & 1 & 56.9 & 1730 & 1016 & J & & \\
\hline & 2 & 56.5 & 750 & $10: 26$ & ) & & \\
\hline & 3 & 57.1 & 1380 & 1018 & & & \\
\hline & 4 & 57.1 & 1040 & 1019 & & & \\
\hline & 5 & 56.6 & 900 & 1018 & 10.01 & 0.564 & 1.39 \\
\hline & 6 & 56.6 & 1220 & 1016 & & & \\
\hline & 7 & 56.2 & 640 & 1026 & & & \\
\hline & 8 & 55.8 & 900 & 1020 & $\int$ & & \\
\hline & 9 & 56.1 & 1100 & 1021 & ) & & \\
\hline & 10 & 56.2 & 680 & 1024 & & & \\
\hline & 11 & 564 & 660 & 1016 & 8.76 & 0.512 & 1.33 \\
\hline & 12 & 56.7 & 1320 & 1024 & j & & \\
\hline
\end{tabular}


ZOOMAN.

\begin{tabular}{|c|c|c|c|c|c|c|}
\hline \multirow{2}{*}{ Date. } & \multirow{2}{*}{$\begin{array}{c}\text { Body- } \\
\text { weight. }\end{array}$} & \multicolumn{5}{|c|}{ Urine. } \\
\hline & & $\begin{array}{l}\text { Volume. } \\
24 \text { hours. }\end{array}$ & Sp. Gr. & Nitrogen. & Uric Acid. & $\mathrm{P}_{2} \mathrm{O}_{5}$. \\
\hline 1903 & kilos & c.c. & & grams & gram & grams \\
\hline Nov. 13 & 56.7 & 420 & 1024 & & & \\
\hline 14 & 56.0 & 920 & 1029 & 8.76 & 0.512 & 1.33 \\
\hline 10 & 560 & 1540 & 1015 & daily av. & daily av. & daily av. \\
\hline 16 & 55.7 & 1080 & 1022 & 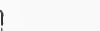 & & \\
\hline 17 & 54.4 & 700 & 1027 & & & \\
\hline 18 & 54.6 & 700 & 1025 & & & \\
\hline 19 & 54.8 & 700 & 1025 & 7.79 & 0.398 & 1.02 \\
\hline 20 & 55.4 & 940 & 1021 & & & \\
\hline 21 & 55.2 & 740 & 1025 & & & \\
\hline 22 & 54.7 & 720 & 1023 & J & & \\
\hline 23 & 54.5 & 740 & 1014 & ) & & \\
\hline 24 & 54.0 & 860 & 1025 & & & \\
\hline 25 & 54.3 & 620 & 1025 & & & \\
\hline 26 & 54.4 & 980 & 1023 & 7.44 & 0.420 & 1.06 \\
\hline 27 & 54.5 & 940 & 1024 & & & \\
\hline 28 & 54.3 & 460 & 1026 & & & \\
\hline 29 & 54.4 & 1000 & 1018 & & & \\
\hline 30 & 54.0 & 980 & 1022 & & & \\
\hline Dec. 1 & 54.2 & 1120 & 1020 & & & \\
\hline 2 & 54.2 & 940 & 1017 & & & \\
\hline 3 & 54.0 & 1200 & 1018 & 10.26 & 0.494 & 1.45 \\
\hline 4 & 54.0 & 1080 & 1024 & & & \\
\hline 5 & 53.9 & 640 & 1031 & & & \\
\hline 6 & 54.0 & 960 & 1026 & j & & \\
\hline 7 & 54.1 & 880 & 1028 & ) & & \\
\hline 8 & 54.6 & 680 & 1029 & 9.79 & $\cdots$ & $\cdots$ \\
\hline 9 & 54.6 & 680 & 1030 & & & \\
\hline 10 & 550 & 1220 & 1019 & 10.15 & 0.423 & 1.39 \\
\hline 11 & 54.7 & 920 & 1028 & & & \\
\hline 12 & 55.1 & 780 & 1028 & 8.33 & $\cdots$ & $\cdots$ \\
\hline 13 & 54.7 & 1140 & 1020 & 8.89 & $\cdots$ & $\cdots$ \\
\hline 14 & 54.4 & 840 & 1021 & 7.46 & $\cdots$ & $\cdots$ \\
\hline 15 & 54.0 & 1200 & 1016 & 8.71 & $\cdots$ & $\cdots$ \\
\hline 16 & 54.0 & 860 & 1021 & & & \\
\hline 17 & 54.5 & 1140 & 1018 & 7.66 & 0.389 & 1.20 \\
\hline 18 & 54.0 & 820 & 1022 & & & \\
\hline 19 & 54.1 & 980 & 1018 & & & \\
\hline 20 & 54.0 & 885 & 1023 & & & \\
\hline 21 & 54.0 & 660 & 1027 & 8.26 & 0.401 & 0.78 \\
\hline 22 & 53.5 & 570 & 1025 & 0.0 & & \\
\hline
\end{tabular}


ZOOMAN.

\begin{tabular}{|c|c|c|c|c|c|c|}
\hline \multirow{2}{*}{ Date. } & \multirow{2}{*}{$\begin{array}{c}\text { Body- } \\
\text { weighit. }\end{array}$} & \multicolumn{5}{|c|}{ Urine. } \\
\hline & & $\begin{array}{l}\text { Volume. } \\
24 \text { hours. }\end{array}$ & Sp. Gr. & Nitrogen. & Uric Acid. & $\mathrm{P}_{2} \mathrm{O}_{s}$ \\
\hline 1903 & kilos & c.c. & & grams & gram & grams \\
\hline Dec. 23 & 54.0 & 770 & 1028 & ? & & \\
\hline 24 & 54.0 & 920 & 1025 & & & \\
\hline 25 & 54.3 & 1820 & 1018 & 8.26 & 0.401 & 0.78 \\
\hline 26 & 54.7 & 1075 & 1020 & daily & daily & daily \\
\hline 27 & 54.5 & 1240 & 1018 & average & average & average \\
\hline 28 & 54.1 & 880 & 1022 & & & \\
\hline 29 & 54.0 & 1080 & 1019 & & & \\
\hline 30 & 54.3 & 775 & 1029 & & & \\
\hline 31 & 54.4 & 1010 & 1023 & 8.00 & 0.440 & 0.88 \\
\hline 1904 & & & & & & \\
\hline Jan. 1 & 54.0 & 900 & 1022 & & & \\
\hline 2 & 53.6 & 625 & 1026 & & & \\
\hline 3 & 53.9 & 730 & 1026 & & & \\
\hline 4 & 53.0 & 1030 & 1019 & & & \\
\hline 5 & 53.4 & 1100 & 1022 & & & \\
\hline 6 & 54.0 & 980 & 1020 & & 0.379 & 1.15 \\
\hline 7 & 54.0 & 860 & 1022 & 7.24 & & \\
\hline 8 & 54.0 & 960 & 1026 & & & \\
\hline 9 & 53.5 & 695 & 1025 & & & \\
\hline 10 & 54.0 & 980 & 1016 & & 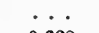 & $\cdots$ \\
\hline 11 & 53.5 & 930 & 1020 & 8.98 & 0.632 & $\cdots$ \\
\hline 12 & 53.8 & 1030 & 1023 & 11.31 & 0.657 & $\cdots$ \\
\hline 13 & 53.6 & 980 & 1024 & 11.63 & 0.445 & $\cdots$ \\
\hline 14 & 53.5 & 1150 & 1017 & 9.38 & 0.443 & $\cdots$ \\
\hline 15 & 53.0 & 700 & 1030 & 8.44 & 0.442 & $\cdots$ \\
\hline 16 & 53.4 & 920 & 1020 & 8.89 & 0.381 & $\cdots$ \\
\hline 17 & 53.5 & 1270 & 1019 & 8.99 & & \\
\hline 18 & 53.5 & 1180 & 1020 & & & \\
\hline 19 & 53.6 & 755 & 1026 & & & \\
\hline 20 & 53.6 & 1190 & 1015 & & 0.428 & 1.27 \\
\hline 21 & 53.0 & 800 & 1030 & 7.78 & & \\
\hline 22 & 53.2 & 660 & 1080 & & & \\
\hline 29 & 53.4 & 770 & 1025 & & & \\
\hline 24 & 53.4 & 1035 & 1017 & & & \\
\hline 25 & 53.6 & 1250 & 1013 & & & \\
\hline 26 & 54.0 & 1140 & 1024 & & & \\
\hline 27 & 54.2 & 1170 & 1018 & 6.87 & 0.302 & 1.18 \\
\hline 28 & 54.6 & 1120 & 1018 & 0.81 & 0.002 & 1.10 \\
\hline 29 & 54.5 & 690 & 1026 & & & \\
\hline 30 & 54.5 & 1020 & 1025 & & & \\
\hline
\end{tabular}


ZOOMAN.

\begin{tabular}{|c|c|c|c|c|c|c|}
\hline \multirow{2}{*}{ Date. } & \multirow{2}{*}{$\begin{array}{l}\text { Body- } \\
\text { weight. }\end{array}$} & \multicolumn{5}{|c|}{ Urine. } \\
\hline & & $\begin{array}{l}\text { Volume. } \\
24 \text { hours. }\end{array}$ & Sp. Gr. & Nitrogen. & Uric Acid. & $\mathrm{P}_{2} \mathrm{O}_{5}$. \\
\hline 1904 & kilos & c.c. & & grams & gram & grams. \\
\hline Jan. 31 & 54.8 & 1320 & 1019 & 6.87 & 0.302 & 1.18 \\
\hline Feb. 1 & 54.3 & 1060 & 1026 & 1 & & \\
\hline 2 & 54.5 & 1170 & 1019 & & & \\
\hline 3 & 54.5 & 1350 & 1022 & & & \\
\hline 4 & 54.3 & 1280 & 1022 & 8.15 & 0.405 & 1.31 \\
\hline 5 & 54.0 & 1015 & 1025 & daily & daily & daily \\
\hline 6 & 54.6 & 1610 & 1014 & average & average & average \\
\hline 7 & 54.3 & 1010 & 1028 & & & \\
\hline 8 & 54.6 & 1065 & 1026 & & & \\
\hline 9 & 55.0 & 925 & 1027 & & & \\
\hline 10 & 55.0 & 1195 & 1023 & & & \\
\hline 11 & 55.0 & 880 & 1024 & 8.37 & 0.497 & $\ldots$ \\
\hline 12 & 55.0 & 960 & 1016 & & & \\
\hline 13 & 55.2 & 1565 & 1020 & & & \\
\hline 14 & 55.0 & 1415 & 1023 & & & \\
\hline 15 & 55.0 & 1060 & 1029 & ) & & \\
\hline 16 & 54.8 & 1130 & 1025 & & & \\
\hline 17 & 55.0 & 1910 & 1019 & & & \\
\hline 18 & 55.2 & 1260 & 1020 & 9.34 & 0.408 & $\cdots$ \\
\hline 19 & 55.0 & 970 & 1027 & & & \\
\hline 20 & 54.4 & 670 & 1031 & & & \\
\hline 21 & 54.7 & 1070 & 1022 & & & \\
\hline 22 & 54.4 & 760 & 1025 & & & \\
\hline 23 & 54.6 & 1225 & 1020 & & & \\
\hline 24 & 55.2 & 1050 & 1026 & & & \\
\hline 25 & 55.2 & 730 & 1027 & 7.38 & 0.559 & $\cdots$ \\
\hline 26 & 55.4 & 1145 & 1019 & & & \\
\hline .27 & 55.0 & 990 & 1021 & & & \\
\hline 28 & 54.9 & 985 & 1026 & & & \\
\hline 29 & 55.0 & 765 & 1027 & 7.02 & ) & \\
\hline Mar. 1 & 55.3 & 810 & 1024 & 6.66 & & \\
\hline 2 & 55.0 & 880 & 1027 & 7.26 & & \\
\hline 3 & 54.8 & 1020 & 1020 & 7.59 & 0.401 & $\cdots$ \\
\hline 4 & 54.5 & 955 & 1025 & 7.51 & & \\
\hline 5 & 54.0 . & 1035 & 1020 & 7.08 & & \\
\hline 6 & 54.0 & 880 & 1027 & 6.81 & j. & \\
\hline 7 & 54.7 & 885 & 1023 & I & & \\
\hline 8 & 55.0 & 970 & 1017 & & & \\
\hline 9 & 54.6 & 940 & 1025 & 8.24 & 0.428 & . . \\
\hline 10 & 54.7 & 1460 & 1022 & & & \\
\hline
\end{tabular}




\section{PHYSIOLOGICAL ECONOMY IN NUTRITION}

ZOOMAN.

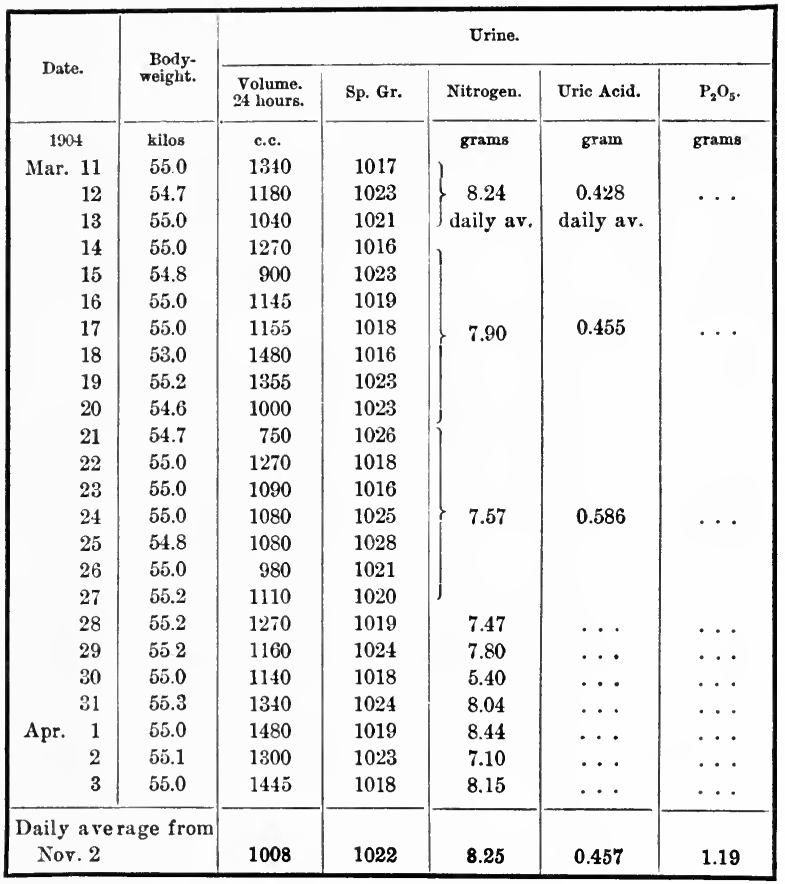


BATES.

\begin{tabular}{|c|c|c|c|c|c|c|c|}
\hline \multirow{2}{*}{\multicolumn{2}{|c|}{ Date. }} & \multirow{2}{*}{$\begin{array}{c}\text { Body- } \\
\text { weight. }\end{array}$} & \multicolumn{5}{|c|}{ Urine. } \\
\hline & & & $\begin{array}{l}\text { Volume. } \\
24 \text { hours. }\end{array}$ & Sp. Gr. & Nitrogen. & Uric Acid. & $\mathrm{P}_{2} \mathrm{O}_{5}$ \\
\hline \multicolumn{2}{|c|}{1903.} & kilos & c.c. & & grams & gram & grams \\
\hline \multirow[t]{28}{*}{ Oct. } & 4 & 72.7 & 870 & 1033 & 14.56 & 0.651 & 2.18 \\
\hline & 5 & 72.7 & 1120 & 1022 & 13.13 & $\cdots$ & $\ldots$ \\
\hline & 6 & 72.4 & 760 & 1027 & 9.44 & 0.489 & 1.38 \\
\hline & 7 & 72.3 & 920 & 1022 & 12.86 & $\cdots$ & $\ldots$ \\
\hline & 8 & 72.0 & 630 & 1029 & 11.11 & 0.415 & 1.29 \\
\hline & 9 & 72.0 & 1030 & 1025 & $\ldots$ & . & $\ldots$ \\
\hline & 10 & 72.0 & 1230 & 1022 & 14.46 & $\ldots$ & $\ldots$ \\
\hline & 11 & 72.3 & 740 & 1024 & 10.79 & 0.397 & 1.44 \\
\hline & 12 & 72.3 & 860 & 1024 & 10.54 & $\cdots$ & . \\
\hline & 13 & 72.1 & 1040 & 1025 & 14.23 & 0.769 & 2.46 \\
\hline & 14 & 72.3 & 1010 & 1027 & 13.70 & $\ldots$ & $\ldots$ \\
\hline & 15 & 72.4 & 1300 & 1021 & 14.43 & 0.510 & 1.88 \\
\hline & 16 & 72.4 & 1040 & 1025 & 15.35 & $\ldots$ & $\cdots$ \\
\hline & 17 & 72.4 & 1440 & 1020 & 16.33 & $\ldots$ & $\ldots$ \\
\hline & 18 & 72.2 & 1420 & 1021 & 18.66 & 0.657 & 2.51 \\
\hline & 19 & 71.8 & 780 & 1026 & 13.14 & . & $\ldots$ \\
\hline & 20 & 71.3 & 1060 & 1027 & & & \\
\hline & 21 & 72.0 & 1020 & 1025 & & & \\
\hline & 22 & 72.5 & 1080 & 1024 & & & \\
\hline & 23 & 72.4 & 1200 & 1024 & $\begin{array}{l}14.21 \\
\text { dailv }\end{array}$ & daily & 1.26 \\
\hline & 24 & 72.4 & 1100 & 1025 & oany & average & dany \\
\hline & 25 & 72.4 & 1030 & 1024 & & & \\
\hline & 26 & 72.4 & 1060 & $\ldots$ & $\cdots$ & $\cdots$ & $\cdots$ \\
\hline & 27 & 72.6 & 1020 & 1022 & & & \\
\hline & 28 & 72.4 & 720 & 1027 & & & \\
\hline & 29 & 72.4 & 400 & 1032 & 9.90 & 0.409 & \\
\hline & 30 & 72.3 & 720 & 1027 & 9.20 & 0.409 & 1.27 \\
\hline & 31 & 72.8 & 720 & : . & & & \\
\hline \multirow[t]{12}{*}{ Nov. } & 1 & 72.3 & 820 & 1027 & & & \\
\hline & 2 & 72.0 & 960 & 1026 & & & \\
\hline & 3 & 72.4 & 920 & 1025 & & & \\
\hline & 4 & 71.9 & 700 & 1025 & & & \\
\hline & 5 & 71.6 & 900 & 1012 & 9.01 & 0.487 & 1.53 \\
\hline & 6 & 71.5 & 700 & 1029 & & & \\
\hline & 7 & 70.5 & 600 & 1023 & & & \\
\hline & 8 & 70.0 & 680 & 1031 & & & \\
\hline & 9 & 70.3 & 660 & 1026 & & & \\
\hline & 10 & 70.6 & 660 & 1028 & 7.97 & 0460 & 120 \\
\hline & 11 & 70.6 & 560 & 1030 & & 0.400 & 1.20 \\
\hline & 12 & 71.0 & 740 & 1027 & & & \\
\hline
\end{tabular}


BATES.

\begin{tabular}{|c|c|c|c|c|c|c|}
\hline \multirow{2}{*}{ Date. } & \multirow{2}{*}{$\begin{array}{l}\text { Body- } \\
\text { weight. }\end{array}$} & \multicolumn{5}{|c|}{ Urine. } \\
\hline & & $\begin{array}{l}\text { Volume. } \\
24 \text { hours. }\end{array}$ & Sp. Gr. & Nitrogen. & Uric Acid. & $\mathrm{P}_{2} \mathrm{O}_{5}$. \\
\hline 1903. & kilos & c.c. & & grams & gram & grams \\
\hline Nov. 13 & 71.0 & 660 & 1027 & 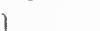 & & \\
\hline 14 & 70.6 & 480 & 1032 & 7.97 & 0.460 & 1.20 \\
\hline 15 & 70.4 & 800 & 1026 & daily av. & daily av. & daily av. \\
\hline 16 & 70.8 & 860 & 1025 & & & \\
\hline 17 & 70.0 & 860 & 1023 & & & \\
\hline 18 & 69.8 & 540 & 1025 & & & \\
\hline 19 & 69.4 & 700 & 1026 & 6.94 & 0.374 & 1.04 \\
\hline 20 & 70.3 & 1080 & 1023 & & & \\
\hline 21 & 70.2 & 640 & 1025 & & & \\
\hline 22 & 69.3 & 720 & 1027 & & & \\
\hline 23 & 69.1 & 720 & 1025 & ) & & \\
\hline 24 & 68.7 & 600 & 1028 & & & \\
\hline 25 & 68.7 & 620 & 1028 & & & \\
\hline 26 & 69.0 & 840 & 1031 & 8.04 & 0.394 & 1.56 \\
\hline 27 & 68.6 & 820 & $10: 26$ & & & \\
\hline 28 & 67.9 & 800 & 1022 & & & \\
\hline 29 & 69.4 & 700 & 1027 & & & \\
\hline 30 & 69.0 & 780 & $10: 25$ & 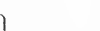 & & \\
\hline Dec. 1 & 68.5 & 760 & $10: 26$ & & & \\
\hline 2 & 68.7 & 640 & 1027 & & & \\
\hline 3 & 68.1 & 940 & 1027 & 8.24 & 0.393 & 1.37 \\
\hline 4 & 690 & 540 & 1023 & & & \\
\hline 5 & 68.0 & 1360 & 1011 & & & \\
\hline 6 & 69.0 & 880 & 1027 & & & \\
\hline 7 & 67.9 & 960 & 1026 & 10.14 & ) & \\
\hline 8 & 68.2 & 700 & 1026 & 7.85 & & \\
\hline 9 & 68.0 & 800 & 1025 & 10.45 & & \\
\hline 10 & 68.7 & 700 & 1027 & 8.74 & 0.392 & 1.57 \\
\hline 11 & 67.9 & 780 & 1028 & 9.27 & & \\
\hline 12 & 68.0 & 820 & 1029 & 8.85 & & \\
\hline 13 & 67.6 & 860 & 1028 & 9.44 & J & \\
\hline 14 & 67.8 & 700 & 1029 & 7.36 & & \\
\hline 15 & 67.4 & 540 & 1028 & 6.51 & & \\
\hline 16 & 67.4 & 640 & 1032 & 1 & & \\
\hline 17 & 67.6 & 680 & 1027 & & & \\
\hline 18 & 68.8 & 1000 & 1023 & 7.61 & 0.367 & 1.36 \\
\hline 19 & 68.3 & 800 & 1023 & & & \\
\hline 20 & 67.0 & 660 & 1027 & J & & \\
\hline 21 & 67.0 & 595 & 1027 & 677 & & \\
\hline 22 & 66.2 & 560 & 1028 & 6.77 & 0.345 & $\cdots$ \\
\hline
\end{tabular}


BATES.

\begin{tabular}{|c|c|c|c|c|c|c|}
\hline \multirow{2}{*}{ Date. } & \multirow{2}{*}{$\begin{array}{c}\text { Body- } \\
\text { weight. }\end{array}$} & \multicolumn{5}{|c|}{ Urine. } \\
\hline & & $\begin{array}{l}\text { Volume. } \\
24 \text { hours. }\end{array}$ & Sp. Gr. & Nitrogen. & Uric Acid. & $\mathrm{P}_{2} \mathrm{O}_{5}$ \\
\hline 1903 & kilos & c.c. & & grams & gram & grams \\
\hline Dec. 23 & 66.5 & 660 & 1027 & ) & & \\
\hline 24 & 66.4 & 610 & 1021 & & & \\
\hline 25 & 65.6 & 1057 & 1021 & 6.77 & 0.345 & ... \\
\hline 26 & 66.0 & 700 & 1029 & daily av. & daily av. & \\
\hline 27 & 66.2 & 755 & 1026 & J & & \\
\hline 28 & 65.8 & 740 & 1024 & ) & & \\
\hline 29 & 65.5 & 710 & 1026 & & & \\
\hline 30 & 66.0 & 900 & 1025 & & & \\
\hline 31 & 65.7 & 710 & 1028 & 6.53 & 0.269 & \\
\hline 1904 & & & & 0.00 & 0.200 & daily ay \\
\hline Jan. 1 & 65.7 & 690 & 1027 & & & \\
\hline 2 & 65.3 & 1015 & 1010 & & & \\
\hline 3 & 65.0 & 850 & 1027 & & & \\
\hline 4 & 65.0 & 730 & 1024 & & & \\
\hline 5 & 65.1 & 835 & 1022 & & & \\
\hline 6 & 65.6 & 1045 & 1027 & & & \\
\hline 7 & 66.2 & 900 & 1024 & 8.54 & 0.405 & 1.13 \\
\hline 8 & 65.4 & 1030 & 1025 & & & \\
\hline 9 & 66.0 & 840 & 1028 & & & \\
\hline 10 & 66.0 & 965 & 1025 & j & & \\
\hline 11 & 65.8 & 700 & 1026 & 6.80 & .. & ... \\
\hline 12 & 65.5 & 740 & 1025 & 7.46 & 0.365 & $\ldots$ \\
\hline 13 & 65.2 & 630 & 1027 & 7.03 & 0.399 & $\ldots$ \\
\hline 14 & 64.5 & 550 & 1028 & 7.13 & 0.357 & $\ldots$ \\
\hline 15 & 64.6 & 680 & 1022 & 8.04 & 0.434 & $\ldots$ \\
\hline 16 & 65.0 & 620 & 1029 & 7.66 & 0.470 & $\ldots$ \\
\hline 17 & 65.0 & 925 & 1024 & 7.38 & 0.347 & $\ldots$ \\
\hline 18 & 65.0 & 590 & 1032 & I & & \\
\hline 19 & 65.0 & 650 & 1028 & & & \\
\hline 20 & 64.8 & 575 & 1029 & & & \\
\hline 21 & 64.4 & 735 & 1028 & 6.69 & 0.356 & 0.80 \\
\hline 22 & 64.8 & 640 & 1029 & & & \\
\hline 23 & 64.6 & 760 & 1026 & & & \\
\hline 24 & 64.3 & 870 & 1023 & & & \\
\hline 25 & 64.0 & 740 & 1027 & & & \\
\hline 26 & 64.5 & 975 & 1024 & & & \\
\hline 27 & 63.8 & 910 & 1024 & & & \\
\hline 28 & 64.0 & 600 & 1030 & 8.54 & 0.359 & 1.27 \\
\hline 29 & 63.8 & 1300 & 1017 & & & \\
\hline 30 & 64.0 & 1135 & 1024 & & & \\
\hline
\end{tabular}




\section{PHYSIOLOGICAL ECONOMY IN NUTRITION}

BATES.

\begin{tabular}{|c|c|c|c|c|c|c|}
\hline \multirow{2}{*}{ Date. } & \multirow{2}{*}{$\begin{array}{c}\text { Body- } \\
\text { weight. }\end{array}$} & \multicolumn{5}{|c|}{ Urine. } \\
\hline & & $\begin{array}{l}\text { Volume. } \\
24 \text { hours. }\end{array}$ & Sp. Gr. & Nitrogen. & Uric Acid. & $\mathrm{P}_{2} \mathrm{O}_{5}$ \\
\hline 1904 & kilos & c.c. & & grams & gram & grams \\
\hline Jan. 31 & 64.0 & 1460 & 1018 & 8.54 & 0.359 & 1.27 \\
\hline Feb. 1 & 64.0 & 910 & 1027 & ) & & \\
\hline 2 & 63.9 & 1250 & 1021 & & & \\
\hline 3 & 63.5 & 1080 & 1026 & & & \\
\hline 4 & 63.5 & 970 & 1024 & 9.19 & 0.362 & 1.07 \\
\hline 5 & 63.6 & 1250 & 1024 & daily & daily & daily \\
\hline 6 & 64.0 & 1260 & 1018 & average & average & average \\
\hline 7 & 64.0 & 785 & 1026 & & & \\
\hline 8 & 64.6 & 1235 & 1022 & & & \\
\hline 9 & 64.3 & 1460 & 1018 & 9.94 & $\cdots \cdot$ & $\cdots$ \\
\hline 10 & 64.2 & $\ldots$ & $\ldots$ & $\ldots$ & $\ldots$ & $\cdots$ \\
\hline 11 & 64.3 & $\cdots$ & $\ldots$ & $\ldots$ & $\cdots$ & $\ldots$ \\
\hline 12 & 64.3 & $\cdots$ & $\cdots$ & $\cdots$ & $\cdots$ & $\cdots$ \\
\hline \multicolumn{2}{|c|}{$\begin{array}{l}\text { Daily average from } \\
\text { Oct. } 27\end{array}$} & 805 & 1025 & 808 & 0.387 & 1.23 \\
\hline
\end{tabular}


DAVIS.

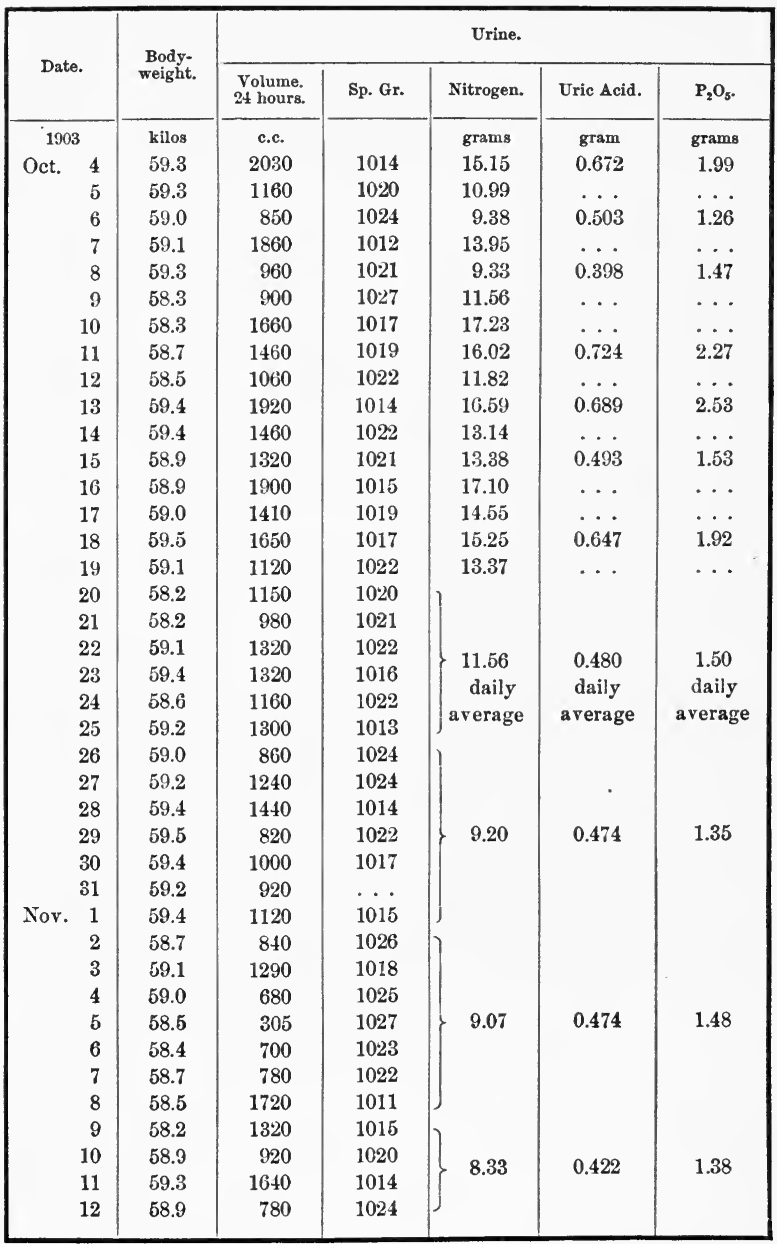


196 PHYSIOLOGICAL ECONOMY IN NUTRITION

DAVIS.

\begin{tabular}{|c|c|c|c|c|c|c|}
\hline \multirow{2}{*}{ Date. } & \multirow{2}{*}{$\begin{array}{c}\text { Body- } \\
\text { weight. }\end{array}$} & \multicolumn{5}{|c|}{ Urine. } \\
\hline & & $\begin{array}{l}\text { Volume. } \\
24 \text { hours. }\end{array}$ & Sp. Gr. & Nitrogen. & Uric Acid. & $\mathrm{P}_{2} \mathrm{O}_{5}$ \\
\hline 1904 & kilos & c.c. & & grams & gram & grams \\
\hline Nov. 13 & 59.0 & 940 & 1025 & 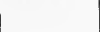 & & \\
\hline & 59.0 & 1180 & 1016 & 8.33 & 0.422 & 1.38 \\
\hline 15 & 59.0 & 1900 & 1013 & daily av. & daily av. & daily av. \\
\hline 16 & 58.8 & 1080 & 1022 & & & \\
\hline 17 & 59.0 & 1080 & 1018 & & & \\
\hline 18 & 58.4 & 1500 & 1017 & & & \\
\hline 19 & 58.2 & 1260 & 1018 & 9.60 & 0.398 & 1.50 \\
\hline 20 & 58.1 & 1220 & 1025 & & & \\
\hline 21 & 58.7 & 1120 & 1022 & & & \\
\hline 22 & 58.7 & 1100 & 1021 & & & \\
\hline 23 & 58.6 & 1140 & 1017 & & & \\
\hline 24 & 58.4 & 1360 & 1017 & & & \\
\hline 25 & 58.3 & 1700 & 1010 & & & \\
\hline 26 & 58.2 & 1120 & 1023 & 9.00 & 0.447 & 1.52 \\
\hline 27 & 59.4 & 1620 & 1017 & & & \\
\hline 28 & 58.0 & 700 & 1027 & & & \\
\hline 29 & 58.7 & 1660 & 1025 & 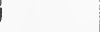 & & \\
\hline 30 & 58.5 & 800 & 1025 & & & \\
\hline Dec. 1 & 58.0 & 700 & 1020 & & & \\
\hline 2 & 57.4 & 680 & 1028 & & & \\
\hline 3 & 57.0 & 640 & 1028 & 11.41 & 0.417 & 2.12 \\
\hline 4 & 57.0 & 940 & 1032 & & & \\
\hline 5 & 56.2 & 660 & 1032 & & & \\
\hline 6 & 56.0 & 800 & 1029 & & & \\
\hline 7 & 56.0 & 800 & 1026 & & & \\
\hline 8 & 56.1 & 780 & 1030 & & & \\
\hline 9 & 57.0 & 820 & 1022 & & & \\
\hline 10 & 58.0 & 500 & 1025 & 8.91 & 0.412 & 1.43 \\
\hline 11 & 57.1 & 580 & 1029 & & & \\
\hline 12 & 57.3 & 820 & 1031 & & & \\
\hline 13 & 57.8 & 580 & 1027 & & & \\
\hline 14 & 57.5 & 740 & 1027 & & & \\
\hline 15 & 57.5 & 1680 & 1015 & & & \\
\hline 16 & 57.9 & 900 & 1021 & & & \\
\hline 17 & 57.4 & 780 & 1013 & 7.96 & 0.413 & 1.50 \\
\hline 18 & 56.9 & 800 & 1026 & & & \\
\hline 19 & 57.4 & 730 & 1025 & & & \\
\hline 20 & 57.4 . & 800 & 1023 & & & \\
\hline 21 & 57.4 & 1310 & 1017 & 7.35 & 0.319 & $\ldots$ \\
\hline 22 & 57.0 & 1370 & 1014 & & & \\
\hline
\end{tabular}


DAVIS.

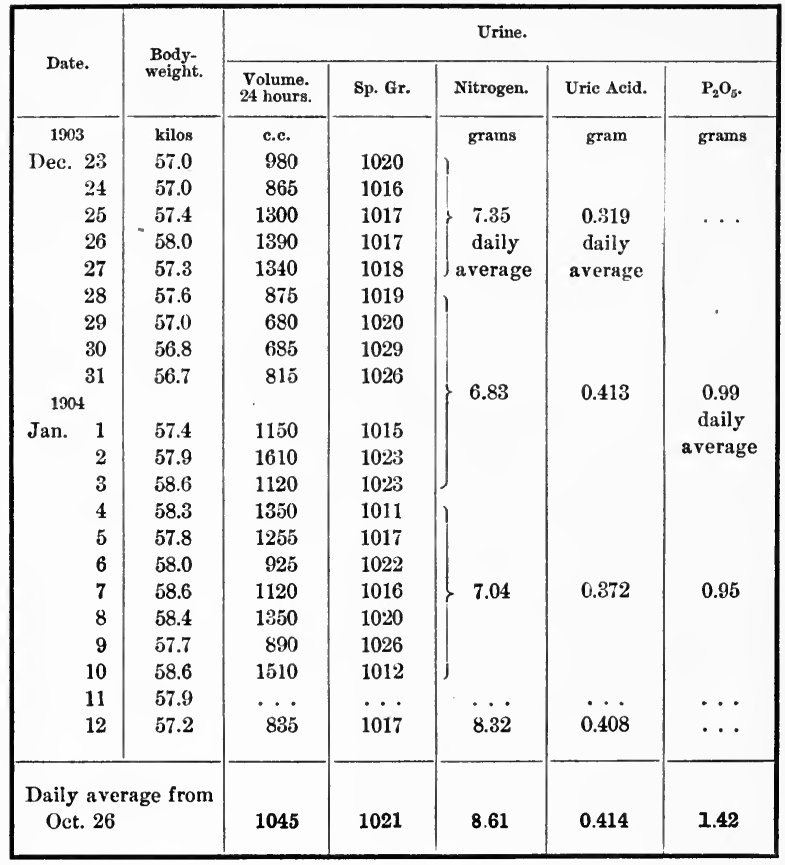


Any elaborate discussion of the individual results, tabulated in the foregoing tables, seems hardly necessary. To any one interested in the details of the work, a study of the tables themselves will give the necessary information. It may be well, however, to emphasize at once a few of the fundamental points most striking in character which bear upon the main problem. Take, for instance, the case of Oakman, where the data are recorded for every day from October 4, 1903, to April 4, 1904. The degree of proteid metabolism, as indicated by the excretion of nitrogen through the kidneys, is here shown for each day of the six months. Up to November 3, practically for a month, there was not observable any very noticeable change in the rate of proteid metabolism, but commencing with November 4, the nitrogen excretion dropped very rapidly, and as one glances through the daily records for month after month, it is seen that the daily nitrogen output through the kidneys fell to 6 to 8 grams per day, with a daily average excretion of 7.42 grams of nitrogen, as figured from October 21 to April 4.

Further, it will be noted that while the body-weight gradually declined during the first three months, falling from 66.7 kilos down to 62.3 kilos on January 18, from that date on to the close of the experiment the body-weight was practically constant. Here, then, we see, under the use of a prescribed diet quite sufficient in amount to satisfy the cravings of the appetite, a lowering of proteid metabolism equal to that obtained by the individuals of the preceding group. Again, if the body-weight of Oakman is placed at 64 kilos, as representing the average between the initial body-weight and the weight during the last three months, it will be found that the output of metabolized nitrogen per kilo of body-weight amounted to 0.116 gram; not widely different from similar data obtained with men of the preceding group.

Moreover, these results obtained with Oakman are practically duplicated by every other member of this group of soldiers detailed from the United States Army. No exception whatever is to be seen, but every man shows the same lowered 


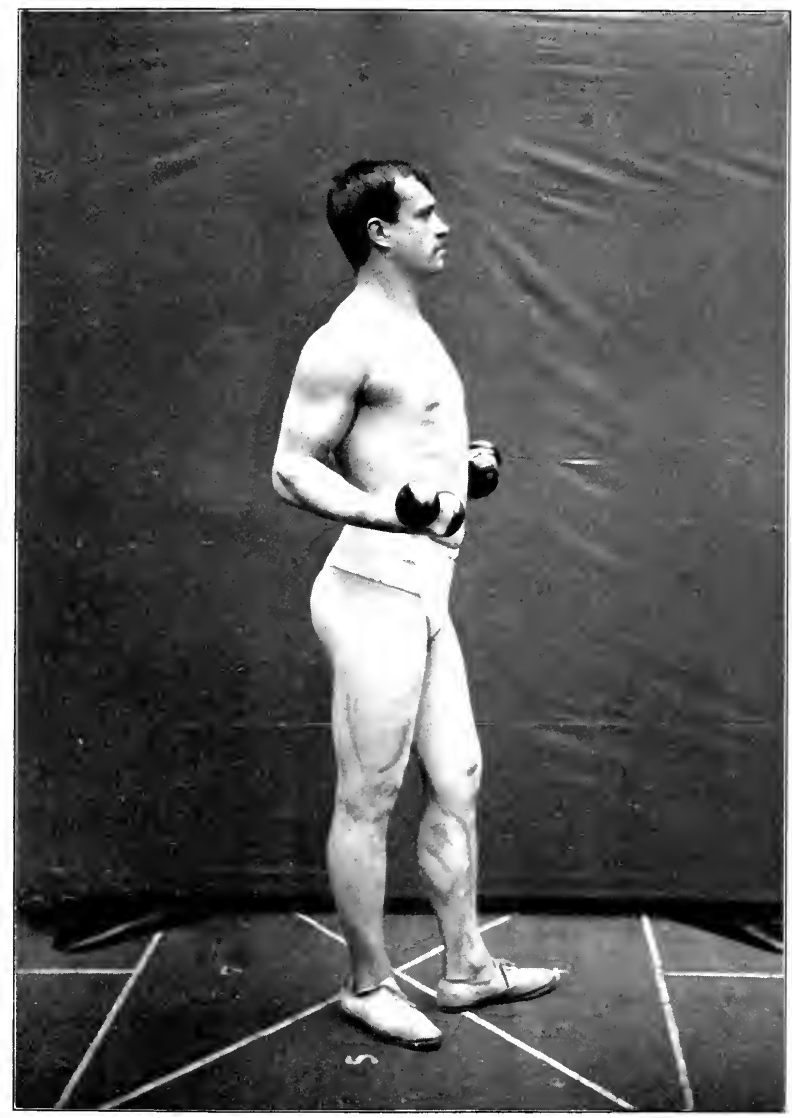

FRIT'

Photograph taken at the close of the experiment. 

proteid metabolism, with practical maintenance of bodyweight, with complete satisfying of the appetite, and without loss of health, strength, or vigor, as will be enlarged upon later.

While in the case of Oakman, the nitrogen excreted was determined by an analysis made each day, in the case of the other men of this group the data are given mainly for weekly periods; the results being expressed, however, in the average daily amount for each seven days' period. By comparing the figures for the daily excretion of nitrogen with the daily dietary, it is easy to trace out the influence of the changes in diet on the extent of nitrogen metabolism.

In considering the changes in the rate of proteid metabolism shown by all the members of this group, it will suffice for present purposes to deal mainly with the average results.

Compare now the average daily output of nitrogen through the urine from November 1 until April 4-a period of five months - of each of these men.

\section{AVERAGE DAILY OUTPUT OF NITROGEN.}

\begin{tabular}{|c|c|c|}
\hline Norris . . & . . 7.03$)$ & \\
\hline Steltz & . . 7.13 & \\
\hline Broyles . & 7.26 & \\
\hline Loewenthal. & $7: 38$ & \\
\hline Oakman. . & .7 .42 & \\
\hline Fritz. . & . .7 .84 & $=7.80$ grams Nitrogen as \\
\hline Cohn . & . 8.05 & the grand average. \\
\hline Coffman . & 8.17 & \\
\hline Zooman . & .8 .25 & \\
\hline Sliney. . & . 8.39 & \\
\hline Henderson . & . 8.91 & \\
\hline Bates. . . & . . 8.08 & - Oct. 27-Feb. 11. \\
\hline Davis. & 8.61 & - Oct. 26-Jan. 12. \\
\hline
\end{tabular}

The figures given show an astonishingly low proteid metabolism for the five months' period; 7.5 grams of nitrogen in the day's urine correspond to 46.8 grams of proteid metabolized, while 8.5 grams of nitrogen mean the metabolism of 53.1 
grams of proteid. In other words, all of these men during a period of five months practically averaged a daily output of nitrogen through the kidneys corresponding to the metabolism of less than one-half the 105 grams of absorbable proteid called for by the so-called standard diets. Further, close scrutiny of the results in the individual tables shows that during many weeks much lower results were obtained than is indicated by the general averages.

Just here emphasis should be laid upon one fact, doubtless of primary importance in any modification of the rate or extent of metabolism in any individual, viz., that in this experiment the daily diet was prescribed, thereby taking from the individual freedom of choice in the selection of food. The writer has no question in his own mind that an intelligent choice of food, coupled with the satisfying of a natural or acquired appetite in moderation, will lead to better results than any system of prescription as to what shall be eaten each day and in what quantity. Still, this is the method necessarily made use of in the present experiment, the writer having prescribed the character and amount of each meal throughout the entire six months' period, with due regard, of course, to the expressed likes and dislikes of the men.

One feature in the diet compelled by the circumstances of the case also needs to be referred to, namely, the necessity of keeping the men thoroughly satisfied, so that there should be no feeling of hunger, no craving for food. With a person interested in the experiment and desirous of ascertaining the effect of a low nitrogen intake, there would naturally be a willingness to endure, if necessary, for a time some personal discomfort; but with this detail of the United States Army it could not be expected that the men would remain satisfied if they were compelled to undergo the pangs of hunger even for a day or two. Consequently, it was necessary in prescribing the daily diet to see that the quantity of the food was such as to completely satisfy the appetite. This necessitated the use of considerable bulky food of low fuel, and low nitrogen, value. In this way only was it feasible to reduce the 
nitrogen intake, as well as the fuel value of the food, to the desired level. Practically during the entire six months' period, with the possible exception of a few days, the men were given sufficient food to completely satisfy their appetites. Throughout the entire period of the experiment, the men all manifested a keen appetite and utilized their food to good advantage, with establishment of the nitrogen metabolism indicated by the foregoing results.

Still confining our attention to the average results regarding nitrogen excretion, we may ask the question, what was the excretion of metabolized nitrogen per kilo of body-weight in the different individuals? This is easily calculated and the data are shown in the following table, in which the figures standing for body-weight are either the data for the month of April, 1904, or else the average between the October and April weights, as in those cases where the body-weight fell off during the experiment.

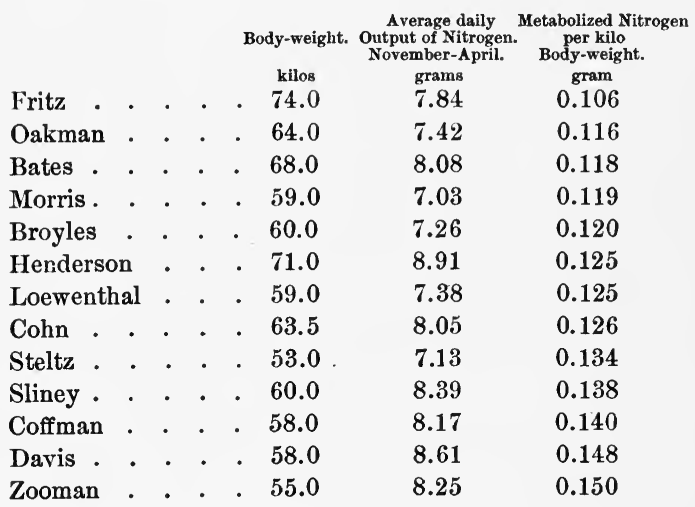

Scrutiny of these results shows that the daily excretion of metabolized nitrogen ranged in this period of five months from 0.106 gram per kilo of body-weight up to 0.150 gram per kilo of body-weight. Since these men were on essentially the 
same diet, it is obvious that there were some peculiarities, or personal idiosyncrasies, that tended to modify the exact extent of proteid metabolism, and in some cases at least constituted a more potent factor than body-weight in determining the rate of metabolism. This fact is clearly emphasized in the case of Morris, who, with a body-weight of 59 kilos, showed a proteid metabolism equivalent to only 7.03 grams of nitrogen per day, and Coffman, who, with a body-weight of $58 \mathrm{kilos}$, showed under the same conditions an average excretion of 8.17 grams of nitrogen per day.

What was the effect of this lowered proteid metabolism upon the bodily condition, especially body-weight? To answer this question the weights of the men are given in the following table, the one column of figures showing the body-weight at the commencement of the experiment, the other column showing the weight at the close of the experiment.

TABLE OF BODY-WEIGHTS.

\begin{tabular}{|c|c|c|c|c|c|c|}
\hline & & & & & $\begin{array}{l}\text { October, } 1903 . \\
\text { kilos }\end{array}$ & $\begin{array}{l}\text { April, } 1904 . \\
\text { kilos }\end{array}$ \\
\hline Steltz. & . & . & . & . & . 52.3 & 53.0 \\
\hline Zooman . & . & . & . & . & . 54.0 & 55.0 \\
\hline Coffman . & . & . & . & . & 59.1 & 58.0 \\
\hline Morris . & . & . & . & . & 59.2 & 59.0 \\
\hline Broyles & . & . & . & . & . $\quad 59.4$ & 61.0 \\
\hline Loewentha & . & . & . & . & . 60.1 & 59.0 \\
\hline Sliney . & . & . & . & . & 61.3 & 60.6 \\
\hline Cohn . & . & . & . & . & . 65.0 & 62.6 \\
\hline Oakman . & . & . & . & . & . $\quad 66.7$ & 62.1 \\
\hline Henderson & . & . & . & . & . 71.3 & 71.0 \\
\hline Fritz. & . & . & . & . & 76.0 & 72.6 \\
\hline Bates . & & . & . & . & . $\quad 72.7$ & 64.3 February \\
\hline Davis. & - & . & . & . & . 59.3 & 57.2 January \\
\hline
\end{tabular}

Comparison of these figures shows that six of the men were practically of the same body-weight at the close of the experiment as at the beginning. Of the others, Oakman, Fritz, Cohn, and Bates lost somewhat. Bates, however, was quite stout, and 
the work in the gymnasium as well as the change of diet tended to reduce his weight. In fact, with the possible exception of Oakman, the slight loss of weight these latter men underwent was a distinct gain to their bodily condition. The most significant feature, however, is to be found on scrutiny of the tables of results for each man, where is seen the bodyweight for each day of the six months. Here it will be noticed that, as the experiment progressed, there was, as a rule, a tendency for the body-weight to increase; this was followed by a decline, after which the weight remained practically stationary. This is well illustrated in Oakman's case. Starting with a body-weight of 66.7 kilos on October 4 , he reached 67.6 kilos on November 29, then declining in weight to 62.3 on January 18, after which he remained practically stationary, or varied only within narrow limits.

Finally, it should be said that the low proteid metabolism on which these men were apparently maintaining body-weight was not associated with any increase of non-nitrogenous food. At no time did the fuel value of the daily food reach 3000 calories; in fact, about January 12 the average fuel value of the food was only a little over 2000 calories per day.

\section{First Nitrogen Balance.}

Early in January, the body-weight of the men having become practically stationary and the proteid metabolism, as measured by the output of metabolized nitrogen, having been reduced to a low level, an attempt was made to see if the men were truly in a condition of nitrogenous equilibrium. A six-day period was used, during which all the food for each meal was carefully analyzed, the nitrogen in every sample of food being determined in duplicate by the Kjeldahl-Gunning process. The fæces of the period were separated by lampblack, given at appropriate times in gelatin capsules, and all necessary precautions observed to insure an accurate nitrogen balance. The accompanying tables of results give all the necessary data. 
The average nitrogen intake per day was 8.23 grams, and the average fuel value of the food per day was 2078 calories. These are the figures for Oakman. With some of the other men there were slight variations from these figures, as shown in the tables - owing to slight variations in diet. Without exception, all the men showed a minus balance, indicating that on this diet the body was losing nitrogen. In other words, the diet as a whole was insufficient for the needs of the body in every case. Whether this was due to lack of sufficient proteid or to an insufficient amount of fat and carbohydrate, $i$. e., a too low fuel value, cannot be said definitely, but there is every reason to believe that the amount of non-nitrogenous food was insufficient to furnish the requisite fuel value, and consequently body proteid was drawn upon to supply the deficiency. The loss of nitrogen to the body per day varied as a rule from 0.5 to 2.0 grams. In one case only, viz., Broyles, was there a close approach to a balance. In his case there was a minus balance of only 0.12 gram of nitrogen per day.

The average daily output of nitrogen through the urine for this six-days period (Oakman's case) was 7.52 grams. 


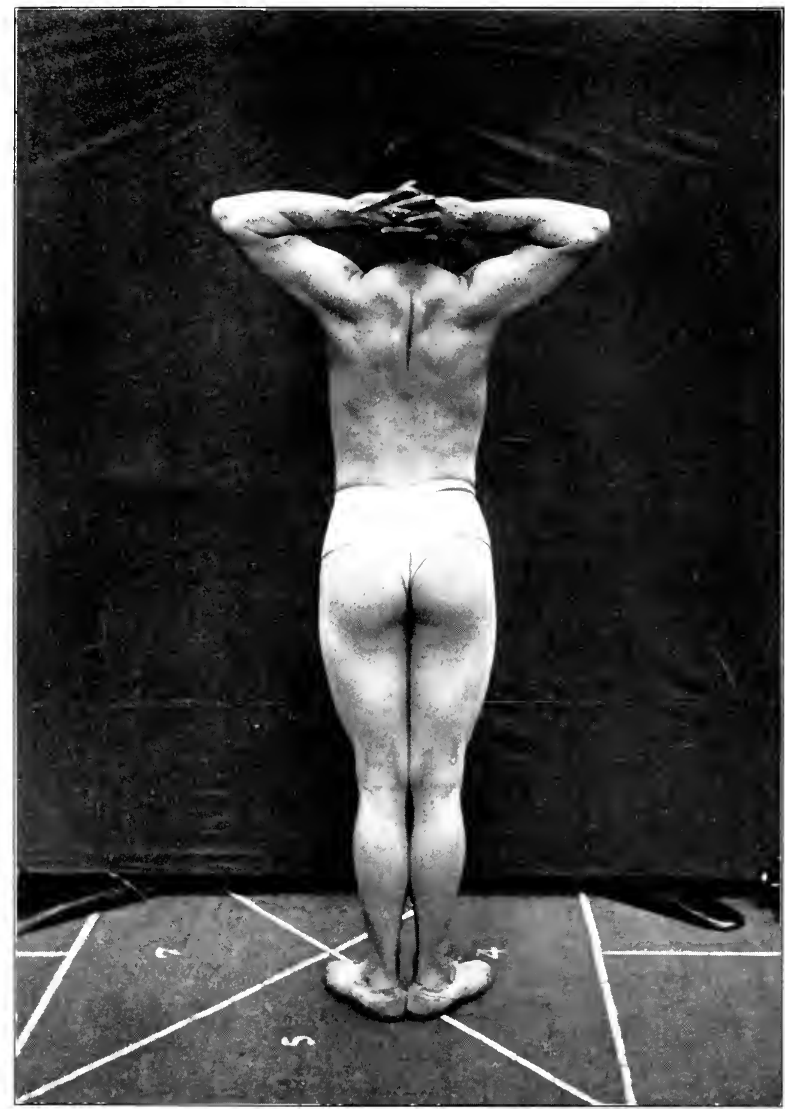

FRIT\%

Photigraph taken at the plose of the experiment. 



\section{OAKMAN.}

Tuesday, January 12, 1904.

Breakfast. - Fried Indian-meal 100 grams, syrup 50 grams, one cup coffee 350 grams, bread 50 grams, butter 15 grams.

Dinner. - Boiled macaroni 250 grams, stewed tomato 250 grams, bread 75 grams, one cup coffee 350 grams.

Supper. - Potato chips 100 grams, fried bacon 25 grams, bread 75 grams, jam 7o grams, one cup tea 350 grams.

Food. Grams. Per cent Nitrogen. Total Nitrogen.

\begin{tabular}{|c|c|c|c|c|c|c|c|c|c|}
\hline Fried Indian-mea & eal & • & - & . & . 100 & $x$ & 0.38 & $=$ & 0.380 gram. \\
\hline Syrup. . . & . & . & . & . & . 50 & $x$ & 0.051 & $=$ & 0.025 \\
\hline Coffee (breakfast & & . & . & . & . 350 & $x$ & 0.075 & $=$ & 0.262 \\
\hline Butter . . . & & . & . & . & - 15 & $\times$ & 0.10 & $=$ & 0.015 \\
\hline Macaroni . . & . & . & . & . & . 250 & $x$ & 0.53 & $=$ & 1.325 \\
\hline Stewed tomato & & . & . & . & - 250 & $\times$ & 0.15 & $=$ & 0.375 \\
\hline Bread. . 50 & $50+$ & $75+$ & & $=$ & 200 & $x$ & 1.48 & $=$ & 2.960 \\
\hline Potato chips & . & . . & . & . . & - 100 & $x$ & 1.09 & $=$ & 1.090 \\
\hline Bacon. . & 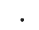 & . & . & . & 25 & $x$ & 3.13 & $=$ & 0.780 \\
\hline Jam · · & - & • & - & . & 75 & $x$ & 0.039 & $=$ & 0.029 \\
\hline Tea . . . & . & . & . & . & - 350 & $\times$ & 0.067 & $=$ & 0.234 \\
\hline Coffee (dinner) & . & . & . & . & . 350 & $\times$ & 0.091 & $=$ & 0.818 \\
\hline & & tal ni & & & $\begin{array}{l}\text { in food } \\
\text { in urine }\end{array}$ & & $\begin{array}{l}\cdot \cdot \\
\cdot\end{array}$ & & $\begin{array}{l}\overline{7.793} \text { grams. } \\
6.000\end{array}$ \\
\hline
\end{tabular}

Fuel value of the food . . . 2404 calories. 


\title{
206 PIIYSIOLOGICAL ECONOMY IN NUTRITION
}

\author{
OAKMAN
}

Wednesday, January 13, 1904.

Breakfast.-Boiled rice 150 grams, milk 125 grams, sugar 30 grams, butter 10 grams, bread 30 grams, one cup coffee 350 grams.

Dinner. - Hamburg steak with plenty of bread, fat, and onions chopped together 150 grams, boiled potato 200 grams, apple sauce 200 grams, bread 75 grams, one cup coffee 350 grams.

Supper. - Fried rice 100 grams, syrup 50 grams, one cup tea 350 grams, bread 50 grams, butter 15 grams.

Food. Grams. Per cent Nitrogen. Total Nitrogen.

\begin{tabular}{|c|c|c|c|c|c|c|c|c|c|c|c|}
\hline Boiled rice & . & . & . & . & . & . & . 150 & $\times$ & 0.36 & $=$ & 0.540 grams. \\
\hline Milk . . & . & . & . & . & . & . & . 125 & $x$ & 0.55 & $=$ & 0.687 \\
\hline Sugar. . & . . & . & . & . & . & . & . 30 & $x$ & 0.00 & $=$ & 0.000 \\
\hline Butter (brea & $\mathrm{kfa}$ & st) & . & . & . & . & 10 & $x$ & 0.10 & $=$ & 0.010 \\
\hline Bread & $"$. & . & . & . & . & . & 30 & $x$ & 1.66 & $=$ & 0.498 \\
\hline Coffee & “ & . & . & . & . & . & . 350 & $x$ & 0.066 & $=$ & 0.231 \\
\hline IIamburg st & eak, & atc & & . & . & . & . 150 & $x$ & 2.80 & $=$ & 4.200 \\
\hline Potato . & . . & . & . & . & . & . & . 200 & $x$ & 0.29 & $=$ & 0.580 \\
\hline Apple sauce & & . & . & . & . & . & . 200 & $x$ & 0.067 & $=$ & 0.134 \\
\hline Bread (dinn & er) & . & . & . & . & . & 75 & $x$ & 1.66 & $=$ & 1.245 \\
\hline Coffee (dinn & her) & . & . & . & . & . & . 350 & $x$ & 0.076 & $=$ & 0.266 \\
\hline Fried rice & . . & . & . & . & . & . & . 100 & $x$ & 0.50 & $=$ & 0.500 \\
\hline Syrup. . & . & . & . & . & . & . & . 50 & $\times$ & 0.051 & $=$ & 0.025 \\
\hline Tea . . & . . & . & . & $\cdot$ & - & . & . 350 & $x$ & 0.066 & $=$ & 0.231 \\
\hline Bread (supp & per) & . & . & ${ }^{\circ}$ & 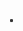 & . & . 50 & $x$ & 1.66 & $=$ & 0.830 \\
\hline Butter . & .. & $\cdot$ & . & . & . & . & . 15 & $x$ & 0.10 & $=$ & 0.015 \\
\hline & & & & & & & $\begin{array}{l}n \text { in food } \\
n \text { in urine }\end{array}$ & . & $\cdot \cdot \cdot$ & . & $\begin{array}{l}9.992 \text { grams. } \\
7.330\end{array}$ \\
\hline
\end{tabular}

Fuel value of the food . . . 2133 calories. 


\title{
PHYSIOLOGICAL ECONOMY IN NUTRITION 207
}

\author{
OAKMAN.
}

Thursday, January 14, 1904.

Breakfast. - Boiled hominy 150 grams, milk 125 grams, sugar 30 grams, butter 10 grams, bread 30 grams, one cup coffee 350 grams.

Dinner. - Split pea soup (thick) 200 grains, bread 75 grams, mashed potato 100 granss, pickles 30 grams, one cup coffee 350 grams, pie 120 grams.

Supper. - Suet pudding 150 grams, apple sauce 125 grams, crackers 25 grams, one cup tea 350 grams.

Food. Grams. Per cent Nitrogen. Total Nitrogen.

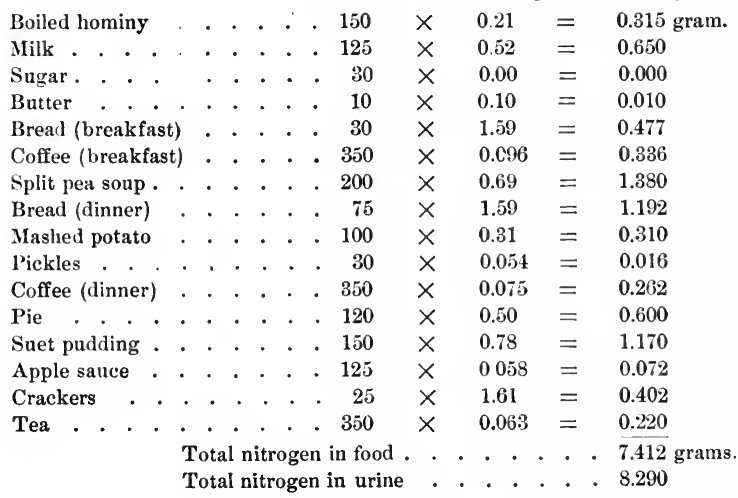

Fuel value of the food . . . . 2000 calories. 


\section{OAKMAN.}

$$
\text { Friday, January 15, 1904. }
$$

Breakfast. - Wheat gridlle cakes 200 grams, syrup 50 grams, one cup coffee 350 grams.

Dinner. - Codfish-balls ( 4 parts potato, 1 part fish, fried in pork fat) 150 grams, stewed tomato 200 grams, bread 75 grams, one cup coffee 350 grams, apple pie 95 grams.

Supper. - Apple fritters 200 grams, stewed prunes 125 grams, bread 50 grams, butter 15 grams, one cup tea 350 grams.

Food. Grams. Per cent Nitrogen. Total Nitrogen.

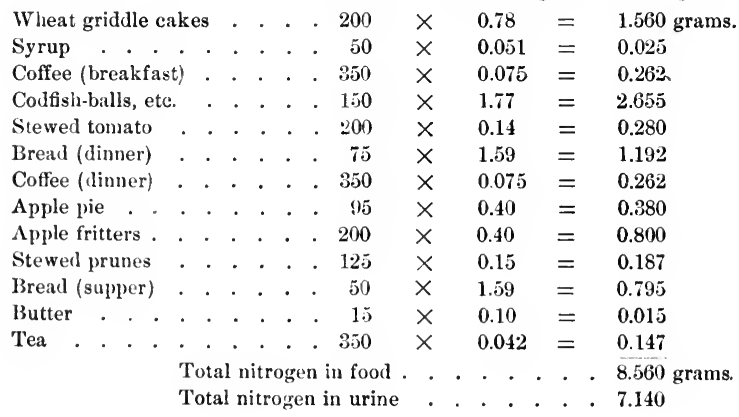

Fuel value of the food . . . 2030 calories. 


\section{OAKMAN.}

Saturday, January 16, 1904.

Breakfast. - Soft oat-meal 150 grams, milk 100 grams, sugar 30 grams, bread 30 grams, butter $10^{\circ}$ grams, one cup coffee 350 grams.

Dinner. - Baked macaroni with a little cheese 200 grams, stewed tomato 200 grams, bread 50 grams, tapioca-peach pudding 150 grams, one cup coffee 350 grams.

Supper. - French fried potato 100 grams, fried bacon 20 grams, bread 75 grams, jan 75 grams, one cup tea 350 grams.

Food. Grams. Per cent Nitrogen. Total Nitrogen.

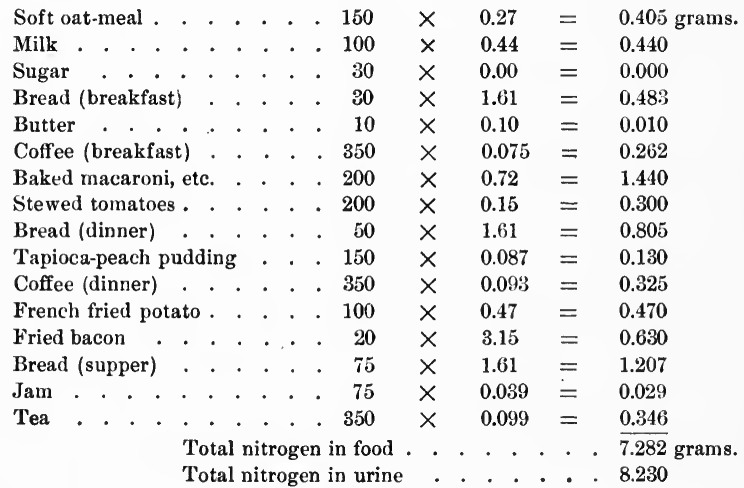

Fuel value of the food . . . . 1824 calories. 


\section{OAKMAN.}

Sunday, January 17, 1904.

Breakfast. - Boiled Indian-meal 125 grams, milk 125 grams, sugar 30 grams, butter 10 grams, bread 30 grams, one cup coffee 350 grams.

Dinner. - Bean soup (thick) 200 grams, bread 75 grams, mashed potato 100 grams, pickles 25 grams, one cup coffee 350 grams, custard pie 105 grams. Supper. - Crackers 50 grams, butter 15 grams, stewed prunes 125 grams, sponge cake 100 grams, one cup tea 350 grams.

Food. Grams. Per cent Nitrogen. Total Nitrogen.

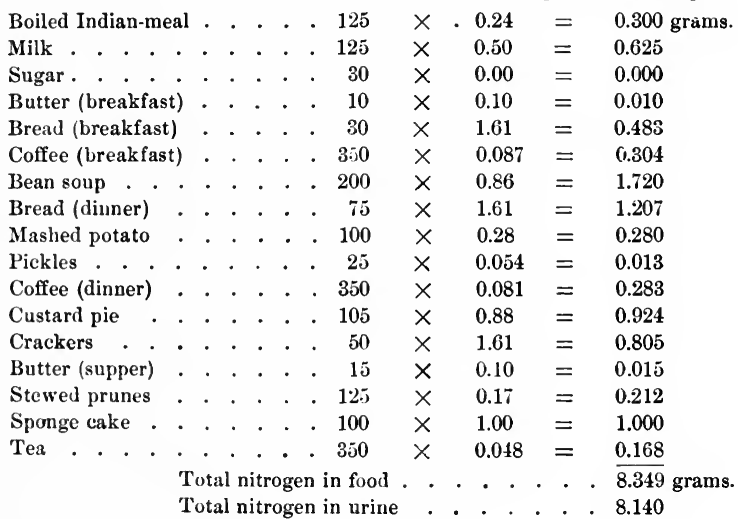

Fuel value of the food . . . 2081 calories. 


\section{NITROGEN BALANCE.-Oakman.}

Nitrogen

Output.

Taken in. Nitrogen in Urine. Weight of Faces (dry).

$\begin{array}{clll}\text { Jan. } 12 & 7.793 \text { grams. } & 6.00 \text { grams. } & \ldots \\ 13 & 9.992 & 7.33 & \ldots \\ 14 & 7.412 & 8.29 & 5.0 \text { grams. } \\ 15 & 8.560 & 7.14 & 76.0 \\ 16 & 7.282 & 8.23 & 13.5 \\ 17 & 8.349 & 8.14 & 9.5 \\ & & & 104.0 \text { grams contain } \\ & & & 7.39 \% \text { N. } \\ & & & 4.685 \text { granı nitrogen. }\end{array}$

Nitrogen balance for six days $=-3.427$ grams.

Nitrogen balance per day $=-0.571$ gram.

Average Intake.

Calories per day . . . . . . . . . 2078.

Nitrogen per day . . . . . . . 8.23 grams. 


\section{NITROGEN BALANCE. - Loewenthal.}

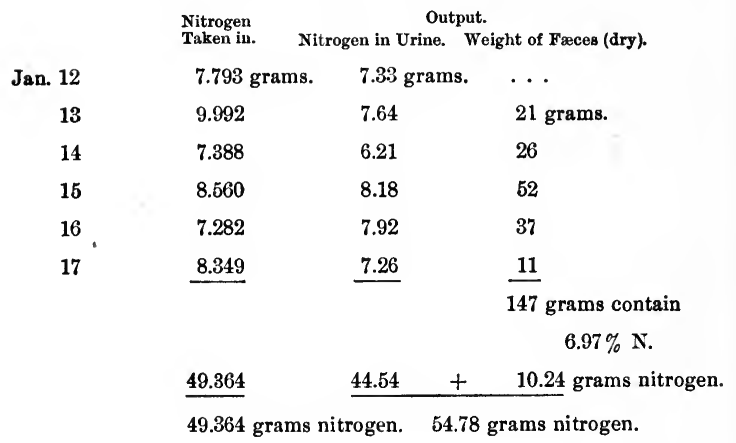

Nitrogen balance for six days $=-5.416$ grams.

Nitrogen balance per day $\quad=-0.902$ gram.

Daily diet same as Oakman's, except that a smaller amount of coffee was taken at breakfast on the 14 th. Nitrogen correction made accordingly. 


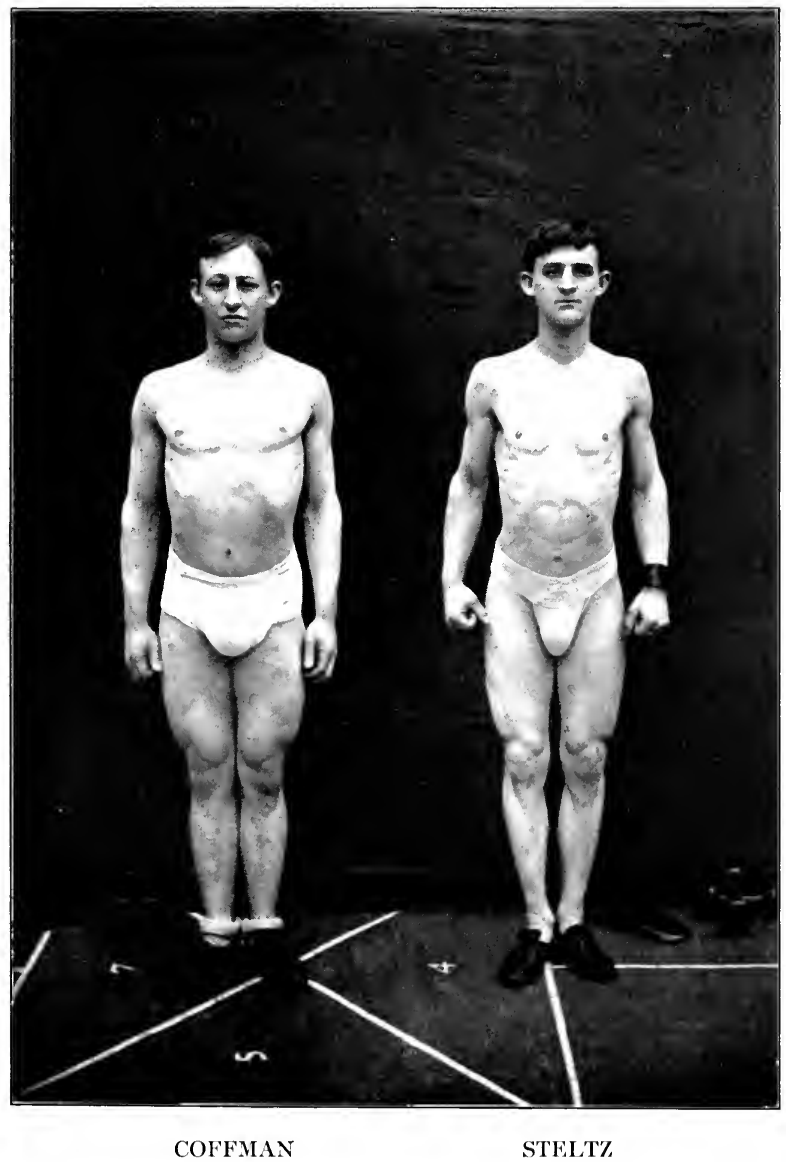

Photographs taken at the close of the experiment. 


\title{
NITROGEN BALANCE. - Steltz.
}

\author{
Nitrogen Output. \\ Taken in. Nitrogen in Urine. Weight of Fæces (dry).
}

Jan. 12

7.793 grams. 4.61 grams. $\quad 15.0$ grams

13

9.463

7.90

34.0

14

7.412

4.99

21.0

15

8.560

9.05

31.5

16

7.282

7.56

33.0

17

8.349

8.55

18.0

152.5 grams contain

$$
6.52 \% \mathrm{~N} \text {. }
$$

48.859

$42.66+9.94$ grams nitrogen.

48.859 grams nitrogen. $\quad 52.60$ grams nitrogen.

Nitrogen balance for six days $=-\mathbf{3 . 7 4 1}$ grams.

Nitrogen balance per day $\quad=\quad-0.623$ gram.

Daily diet same as Oakman's, except on January 13, when 8 grams of boiled rice were uneaten at breakfast and 100 grams of fried rice at supper. Correction in nitrogell-content made accordingly. 


\section{NITROGEN BALANCE. - Bates.}

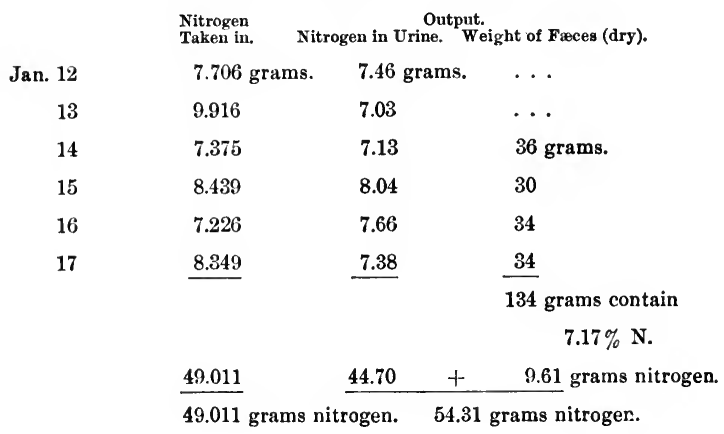

Nitrogen balance for six days $=-5.299$ grams.

Nitrogen balance per day $=-0.883$ gram.

Daily diet same as Oakman's, with the following exceptions :

\begin{tabular}{|c|c|c|c|c|c|}
\hline Jan. 12 & Supper : & \multicolumn{4}{|c|}{8 grams Potato chips, uneaten. } \\
\hline 13 & Dinner: & 113 & “ & Apple sauce, & “ \\
\hline 14 & $“$ & 50 & “ & Coffee, & “ \\
\hline 15 & Supper : & 81 & “ & Prunes, & “ \\
\hline 16 & Breakfast: & 75 & “ & Coffee, & “ \\
\hline
\end{tabular}




\section{NITROGEN BALANCE. - Coffman.}

Nitrogen
Taken in. Nitrogen in Urine. $\quad$ Weight of Fæces (dry)

Jan. 12

$$
7.793 \text { grams. } \quad 8.82 \text { grams. } \quad \ldots
$$

13

9.992

8.28

14

7.412

8.30

57.00 grams.

15

8.560

7.91

41.25

16

7.282

7.32

47.00

17

\begin{tabular}{|c|c|c|c|c|}
\hline 8.349 & 7.44 & & 21.50 & \\
\hline & & & $166.75 \mathrm{~g}$ & grams contain \\
\hline & & & & $6.66 \% \mathrm{~N}$ \\
\hline 49.388 & 48.07 & + & $11.10 \mathrm{~g}$ & grams nitrogen. \\
\hline
\end{tabular}

Nitrogen balance for six days $=-9.782$ grams.

Nitrogen balance per day $\quad=\quad-1.630$ grams.

Daily diet same as Oakman's. 


\section{PIISIOLOGICAL ECONOMY IN NUTRITION}

\section{NITROGEN BALANCE. - Fritz.}

Nitrogen
Taken in. Nitrogen in Urine. Output.

\begin{tabular}{|c|c|c|c|c|}
\hline Jan. 12 & 7.793 grams. & 8.99 grams. & $\cdots$ & \\
\hline 13 & 9.992 & 6.49 & $\cdots$ & \\
\hline 14 & 7.412 & 10.26 & 64.0 & grams. \\
\hline 15 & 8.560 & 7.97 & 29.5 & \\
\hline 16 & 7.282 & 5.20 & 62.0 & \\
\hline \multirow[t]{4}{*}{17} & 8.186 & 9.40 & 31.0 & \\
\hline & & & $\overline{186.5}$ & grams contain \\
\hline & & & & $6.49 \%$ N. \\
\hline & 49.225 & 48.81 & 12.10 & grams nitrogen. \\
\hline
\end{tabular}

$\begin{array}{lll}\text { Nitrogen balance for six days } & =-11.185 \text { grams. } \\ \text { Nitrogen balance per day } & = & -1.864 \text { grams. }\end{array}$

Daily diet same as Oakman's, except that on the 17th inst. a portion of the prunes was uneaten. Correction made accordingly. 


\section{PHYSIOLOGICAL ECONOMY IN NUTRITION 217}

NITROGEN BALANCE.-Henderson.

Nitrogen
Taken in. Nitrogen in Urine.

Jan. 12

7.639 grams. $\quad 7.68$ grams. $\quad \ldots$

13

9.794

8.22

14

7.487

8.24

15

8.560

7.76

45 grams.

16

7.068

7.56

26

17
8.045

7.87

22

93 grams contain

$6.45 \% \mathrm{~N}$.

48.593

47.33

6.00 grams nitrogen.

$\overline{48.593}$ grams nitrogen. 53.33 grams nitrogen.

Nitrogen balance for six days $=-4.737$ grams.

Nitrogen balance per day $\quad=\quad-0.789 \mathrm{gram}$.

Daily diet same as Oakman's, except that on several days smaller amounts of coffee and tea were taken. Corrections made accordingly. 


\section{PHYSIOLOGICAL ECONONY IN NUTRITION}

\section{NITROGEN BALANCE.-Morris.}

Nitrogen Output.

Taken in. Nitrogen in Urine. Weight of Fæces (dry).

\begin{tabular}{|c|c|c|c|}
\hline Jan. 12 & 7.255 grams. & 4.19 grams. & $\cdots$ \\
\hline 13 & 9.573 & 7.92 & $\cdots$ \\
\hline 14 & 7.325 & 7.91 & 4.75 grams. \\
\hline 15 & 8.538 & 7.44 & 38.00 \\
\hline 16 & 7.282 & 7.38 & 71.00 \\
\hline \multirow[t]{4}{*}{17} & 8.349 & 5.28 & 53.00 \\
\hline & & & 166.75 grams contain \\
\hline & & & $6.45 \% \mathrm{~N}$. \\
\hline & 48.322 & 40.12 & 10.75 grams nitrogen \\
\hline
\end{tabular}

$$
\begin{array}{lll}
\text { Nitrogen balance for six days } & =-2.548 \text { grams. } \\
\text { Nitrogen balance per day } & =-0.424 \text { gram. }
\end{array}
$$

Daily diet same as Oakman's except that on the first three days smaller amounts of tea and coffee were taken. Corrections made accordingly. 


\section{NITROGEN BALANCE.-Zooman.}

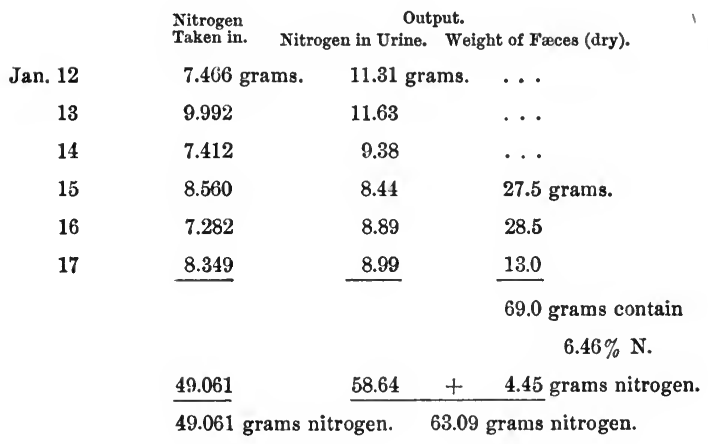

Nitrogen balance for six days $=-14.029$ grams.

Nitrogen balance per day $=-2.338$ gram.

Daily diet same as Oakman's, except that on January 12th 30 grams potato chips were not eaten. Nitrogen intake corrected accordingly. 
NITROGEN BALANCE. - Sliney.

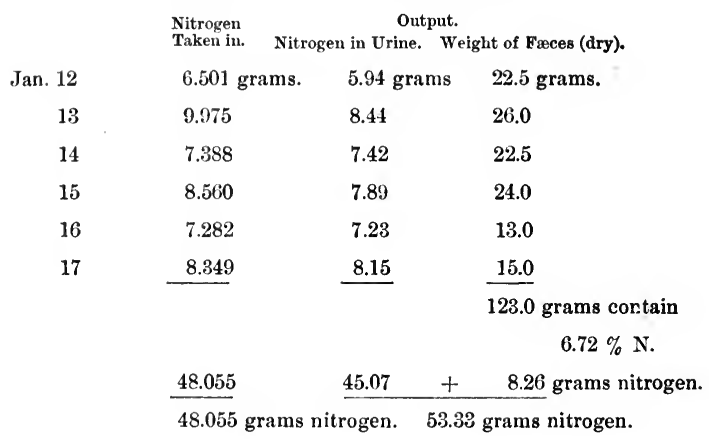

Nitrogen balance for six days $=-5.275$ grams.

Nitrogen balance per day $=-0.879 \mathrm{gram}$.

Daily diet same as Oakman's, except that on the 12 th 190 grams stewed tomatoes and 190 grams macaroni were uneaten; on the 13th at breakfast 25 grams of coffee were left, and on the 14th at breakfast 25 grams coffee were not taken. Corrections in intake of nitrogen made accordingly. 


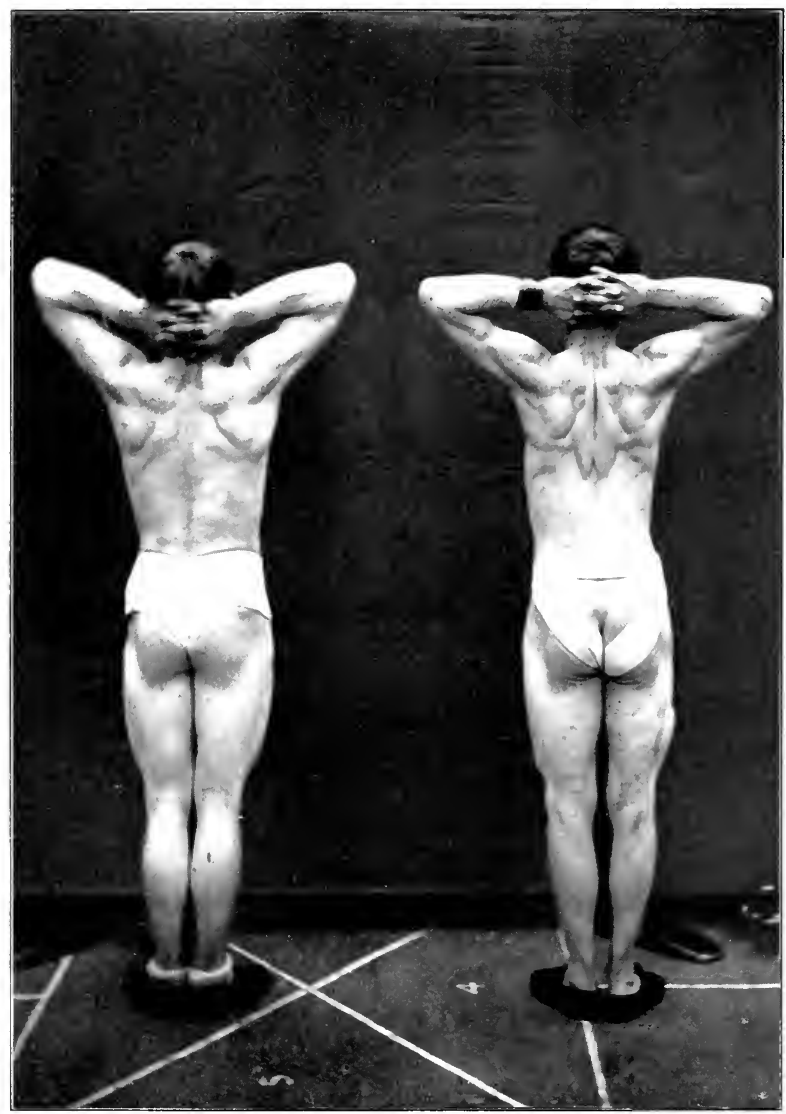

COFFIAN

STELTZ

Photographs tuken at the close of the experiment. 



\section{PHYSIOLOGICAL ECONOMY IN NUTRITION 221}

NITROGEN BALANCE. - Cohn.

Nitrogen

Nitrogen in Urine. Weight of Fæces (dry).

Taken in.

Jan. 12

7.793 granıs.

6.49 grams.

13

9.957

9.10

29.0 grams.

14

7.412

7.33

8.5

15

8.320

8.04

44.0

16

7.282

8.58

19.0

17

8.349

7.44

$\frac{5.5}{106.0}$ grams contain

$6.48 \% \mathrm{~N}$.

49.113

46.98 6.87 grams nitrogen

49.113 grams nitrogen. $\quad 53.85$ grams nitrogen.

Nitrogen balance for six days $=-4.737$ grams.

Nitrogen balance per day $\quad=\quad-0.789$ gram.

Daily diet same as Oakman's, except that on the 15th inst. at supper 60 grams fritters were uneaten, and on the 13th at breakfast 30 grams coffee, and at dinner 22 grams apple sauce were uneaten. Corrections made accordingly. 


\begin{tabular}{|c|c|c|c|}
\hline \multirow[b]{2}{*}{ Jan. 12} & \multirow{2}{*}{$\begin{array}{l}\text { Nitrogen } \\
\text { Taken in. } \\
7.475 \text { grams. }\end{array}$} & \multicolumn{2}{|c|}{ Nitrogen in Urine. Weight of Fæces (dry). } \\
\hline & & 5.38 grams. & $\cdots$ \\
\hline 13 & 9.495 & 6.99 & $\cdots$ \\
\hline 14 & 6.814 & 7.47 & $\ldots$ \\
\hline 15 & 8.036 & 9.67 & 35 grams. \\
\hline 16 & 6.695 & 7.65 & 14 \\
\hline \multirow[t]{4}{*}{17} & 7.762 & 5.28 & $\underline{20}$ \\
\hline & & & $\overline{69}$ grams contain \\
\hline & & & $6.61 \% \mathrm{~N}$ \\
\hline & 46.277 & 42.44 & 4.56 grams nitrogen. \\
\hline
\end{tabular}

$\begin{array}{lll}\text { Nitrogen balance for six days } & =-0.723 \text { gram. } \\ \text { Nitrogen balance per day } & =-0.120 \text { gram. }\end{array}$

Daily diet same as Oakman's, except that each day coffee was omitted from breakfast and dinner. Corrections made accordingly. 


\section{Second Nitrogen Balance.}

Commencing February 29, a second nitrogen balance was attempted with very different results. This balance period extended through seven days and was characterized by an average daily intake of 9.50 grams of nitrogen, an increase of 1.3 grams of nitrogen per day over the preceding period, together with an average fuel value of the food equal to 2500 calories per day.

The daily diet with its content of nitrogen, etc., is detailed under Oakman. Any variations (only slight ones) from this diet are indicated on the individual balance-sheets, corrections being made in the nitrogen intake.

In all of the men, with one exception, a distinct plus balance is seen, showing that under the conditions of this experiment the men were all storing up nitrogen. The plus balance per day varied from 0.132 gram to 1.231 grams of nitrogen.

The average daily output of nitrogen through the urine for this seven days' period (Oakman's case) was 7.24 grams, being 0.28 gram less per day than in the preceding period. Sliney, the one man who failed to show a positive balance, was apparently losing nitrogen at the rate of 0.48 gram per day during this period.

All of the individual data are shown in the accompanying tables of results : 


\section{PHYSIOLOGICAL ECONOMY IN NUTRITION}

OAKMAN.

Monday February 29, 1904.

Breakfast. - Boiled rice 175 grams, milk 125 grams, sugar 25 grams, baked potato 150 grams, one cup coffee 350 grams, butter 10 grams.

Dinner. - Baked spaghetti 250 grams, mashed potato 250 gran:s, bread 75 grams, boiled tomato 150 grams, apple pie 112 grams, one cup coffee 350 grams.

Supper. - Biscuit 175 grams, fried bacon 20 grams, fried sweet potato 150 grams, butter 20 grams, one cup tea 350 grams.

Food.

Boiled rice

Milk . . . . . . . . 125

Sugar. . . . . . . . $25 \times$

Baked potato . . . . . . 150 . $\times$

Coffee (breakfast; . . . . . $350 \times$

Butter . . . $10+20=30 \times$

Spaghetti . . . . . . . $250 \times$

Mashed potato. . . . . . $250 \times$

Bread. . . . . . . . $75 \times$

Tomato . . . . . . $150 \times$

Apple pie . . . . . . . $112 \times$

Biscuit . . . . . . . $175 \times$

Fried bacon . . . . . . $20 \times$

Fried sweet potato . . . . . $150 \times$

Tea . . . . . . . . . $350 \times$

Coffee (dinner) . . . . . $350 \times$

Total nitrogen in food

Total nitrogen in urine

Per cent Nitrogen. Total Nitrogen.

X $0.34=0.595$ grams.

$\times \quad 0.55=0.687$

$0.00=0.000$

$0.34=0.510$

$0.082=0.287$

$0.16=0.480$

$0.73=1.825$

$0.30=0.750$

$1.61=1.207$

$0.16=0.240$

$0.46=0.515$

$1.21=2.117$

$3.80=0.760$

$0.22=0.330$

$0.06=0.210$

$0.11=0.385$

. $\overline{10.466}$ grams.

6.880

Fuel value of the food . . . 2670 calories. 


\section{OAKMAN.}

Tuesday, March 1, 1904.

Breakfast. - Fried rice 150 grams, syrup 50 grams, baked potato 150 grams, butter 10 grans, one cup coffee 350 grams.

Dinner. - Thick pea soup 250 grams, boiled onions 150 grams, boiled sweet potato 150 grams, bread 75 grams, butter 20 grams, one cup coffee 350 grans.

Supper. - Celery-lettuce-apple salad 120 grams, crackers 32 grams, American cheese 20 grams, Saratoga chips 79 grams, one cup tea 350 grams, rice custard 100 grams.

Food. Grams. Per cent Nitrogen. Total Nitrogen.

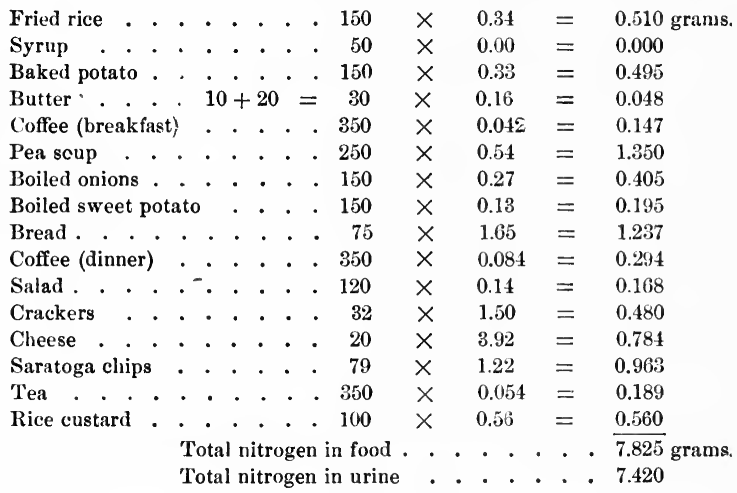

Fuel value of the food . . . 2279 calories. 


\section{OAKMAN.}

\section{Wednesday, March 2, 1904.}

Breakfast. - Wheat griddle cakes 200 grams, syrup 50 grams, butter 10 grams, one cup coffee 350 grams, banana 75 grams.

Dinner. - Boiled salt mackerel 25 grams, boiled potato 250 grams, boiled turnip 150 grams, bread 75 grams, one cup coffee 350 grams, apple sauce 150 grams.

Supper. - Chopped fresh cabbage with salt, pepper, and vinegar 100 grams, bread 75 grams, butter 20 grams, chocolate cake 150 grams, cranberry sauce 100 grams, one cup tea 350 grams.

Food. Grams. Per cent Nitrogen. Total Nitrogen.

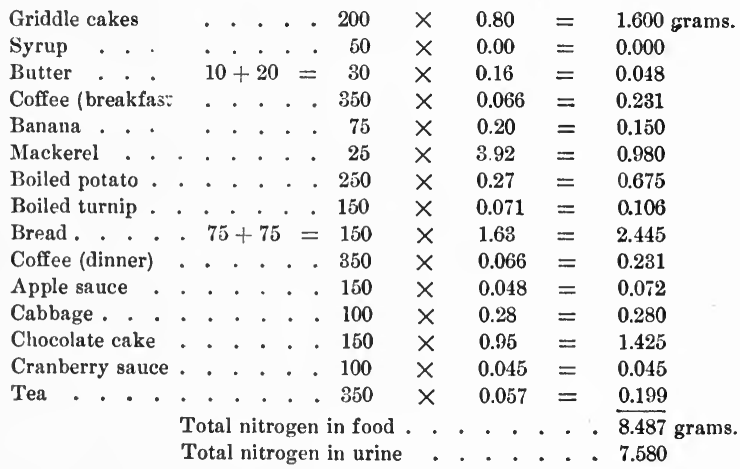

Fuel value of the food . . . 2391 calories. 


\section{OAKMAN.}

\section{Thursday, March 3, 1904.}

Breakfast. - Boiled hominy 175 grams, milk 125 grams, sugar 25 grams, baked potato 150 grams, butter 10 grams, one cup coffee 350 grams.

Dinner. - Hamburg steak with much bread, fat, and onions 150 grams, boiled potato 250 grams, bread 75 grams, butter 10 grams, one cup coffee 350 grams.

Supper. - 'lapioca-peach pudding 250 grams, bread 75 grams, jam 75 grams, butter 20 grams, one cup tea 350 grams.

Food. Grams. Per cent Nitrogen. Total Nitrogen.

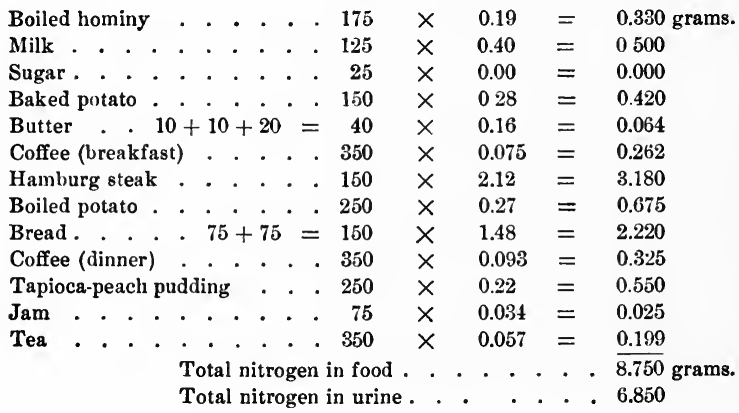

Fuel value of the food . . . 2375 calories. 


\section{OAKMAN.}

\section{Friday, March 4, 1904.}

Breakfast. - Fried hominy 150 grams, syrup 50 grams, baked potato 150 grams, one eup coffee 350 grams, butter 10 grams.

Dinner. - Codfislı-balls ( 1 part fish, 4 parts potatoes, fried in pork fat) 150 grams, stewed tomato 200 grams, stewed potato 150 grams, bread 75 grams, one cup coffee 350 grams, apple pie 130 grams.

Supper. - French fried potato 200 grams, fried sausage 50 grams, butter 10 grams, bread 50 grams, stewed prunes 125 grams, sponge cake 35 grams, one cup tea 350 grams.

Food.

Grams. Per cent Nitrogen.

Total Nitrogen.

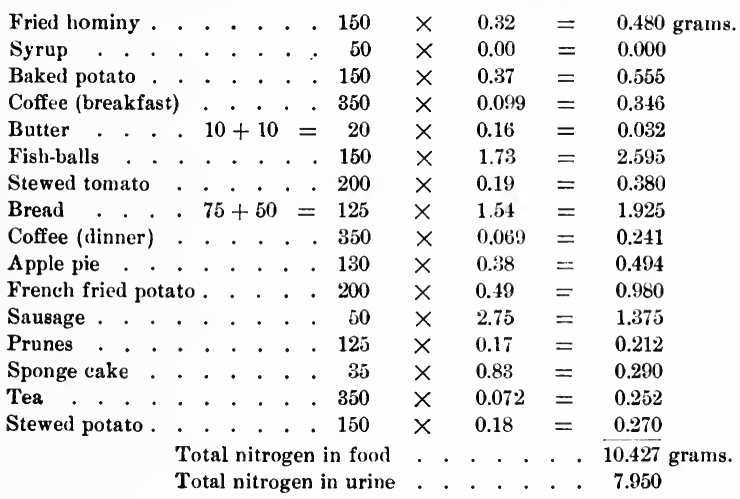

Fuel value of the food . . . 2374 calories. 


\title{
OAKMAN.
}

\author{
Saturday, March 5, 1904.
}

Breakfast. - Boiled Indian-meal 200 grams, nilk 125 grams, sugar 25 grams, one cup coffee 350 grams, fried sweet potato 150 grams, butter 10 grams. Dinner. - Tomato soup, thick with potatoes and onions boiled together 325 grams, bread 100 grams, scrambled eggs 50 grams, mashed potato 150 grams, one cup coffee 350 .

Supper. - Bread pudding with raisins 250 grams, stewed peaches 150 grams, bacon 20 grams, French fried potato 150 grams, bread 50 grams, butter 10 grams, one cup tea 350 grams.

Food. Grams. Per cent Nitrogen. Total Nitrogen.

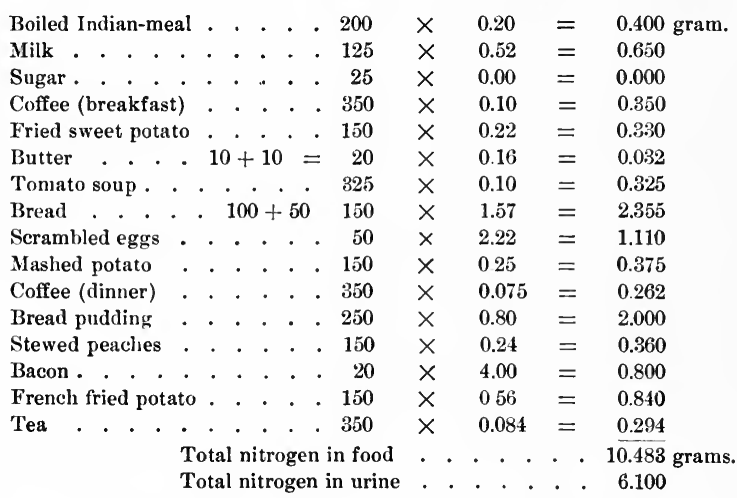

Fuel value of the food . . . 2502 calories. 


\section{2:30 PHYSIOLOGICAL ECONOMY IN NUTRITION}

\section{OAKMAN.}

Sunday, March 6, 190\%.

Breakfast. - Fried Indian-meal 150 grams, syrup 50 grams, sliced banana 100 grams, baked potato 150 grams, one cup coffee 350 grams, butter 10 grams.

Dinner. - Corned beef 50 grams, boiled cabbage 200 grams, mashed potato 250 grams, bread 75 grams, one cup coffee 350 grams, fried rice 100 grams, jam 75 grams.

Supper. - Sponge cake 150 grams, apple sauce 150 grams, crackers 32 grams, butter 10 grams, one cup tea 350 grams, sardine 14 grams.

Food.

Fried Indian-meal . . . . 150

Syrup . . . . . . . 50

Banana . . . . . . 100

Baked potato . . . . . . 150

Coffee (breakfast) . . . . . 350

Butter . . . $10+10=20$

Corned beef . . . . . . . 50

Cabbage . . . . . . . 200

Mashed potato . . . . . . 250

Bread. . . . . . . . 75

Coffee (dinner) . . . . . . 350

Fried rice . . . . . . . . 100

Janı . . . . . . . . 75

Sponge cake . . . . . . . 150

Apple sauce . . . . . . . 150

Crackers . . . . . . . 32

Tea . . . . . . . . . 350

Sardine . . . . . . . . $14 \times$
Per cent Nitrogen. Total Nitrogen.

$\times \quad 0.28=0.570$ gram.

$\times \quad 0.00=0.000$

$\times \quad 0.19=0.190$

$\times \quad 0.37=0.555$

$\times \quad 0.072=0.252$

$\times \quad 0.16=0.032$

$\times \quad 5.24=2.620$

$\times \quad 0.34=0.680$

$\times \quad 0.32=0.800$

$\times \quad 167=1.252$

$\times \quad 0.093=0.325$

$\times 0.23=0.230$

$\times \quad 0.034=0.025$

$\times \quad 1.02=1.530$

$\times \quad 0.044=0.066$

$\times \quad 1.50=0.480$

$\times \quad 0.054=0.189$

$\times \quad 3.35=0.469$

Total nitrogen in food . . . . . . $10.265 \mathrm{grams}$

Total nitrogen in urine . . . . . . . 7.960

Fuel value of the food . . . 3173 calories. 


\section{PHYSIOLOGICAL ECONOMY IN NUTRITION 231}

NITROGEN BALANCE.-Oakman.

Nitrogen

Output.

Taken in. Nitrogen in Urine. Weight of Fæces* (dry).

\begin{tabular}{|c|c|c|c|}
\hline Feb. 29 & 10.466 grams. & 6.88 grams. & $\ldots$ \\
\hline Mar. 1 & 7.825 & 7.42 & $\ldots$ \\
\hline 2 & 8.487 & 7.58 & 17 grams \\
\hline 3 & $8.750^{\circ}$ & 6.85 & 72 \\
\hline 4 & 10.427 & 7.95 & 39 \\
\hline 5 & 10.483 & 6.10 & 19 \\
\hline \multirow[t]{4}{*}{6} & 10.265 & $\underline{7.96}$ & 35 \\
\hline & & & 182 grams contain \\
\hline & & & $6.81 \% \mathrm{~N}$ \\
\hline & 66.703 & 50.74 & 12.394 grams nitrogen. \\
\hline
\end{tabular}

$\begin{array}{lll}\text { Nitrogen balance for seven days } & =\quad+3.569 \mathrm{grams} . \\ \text { Nitrogen balance per day } & =\quad+0.509 \mathrm{gram} .\end{array}$

A verage Intake.

Calories per day . . . . . . . 2509.

Nitrogen per day . . . . . . . 9.50 grams.

* The figures given for weight of fæces during this balance period are tabulated for convenience as above, but naturally the last yield was not obtained until the 8 th of March. The total of 182 grams, however, is the exact amount of air-dry fæces collected between the two charcoal layers, marking off accurately the balance period. 


\section{PHYSIOLOGICAL ECONOMY IN NUTRITION}

\section{NITROGEN BALANCE. - Henderson.}

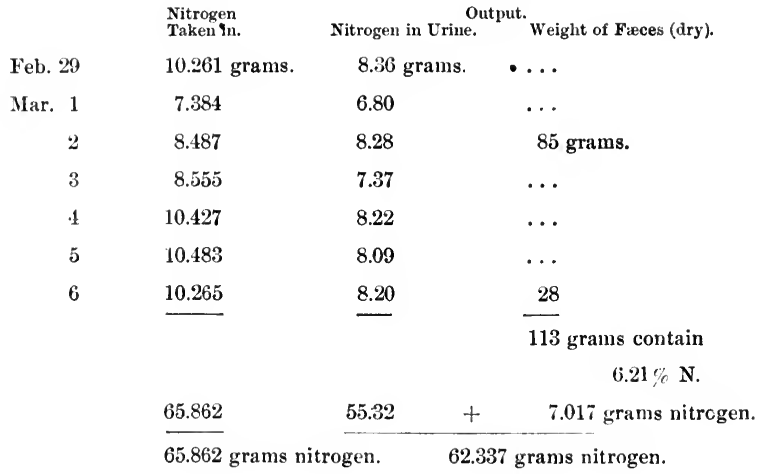

Nitrogen balance for seven days $=\quad+3.525$ grams.

Nitrogen balance per day $=\quad+0.503$ grams. 


\section{NITROGEN BALANCE.-Morris.}

Nitrogen
Taken in. Nitrogen in Urine.

Feb. 29 10.466 grams.

6.40 grams.

7.720

6.64

45 grams.

2

8.319

5.40

43

3

8.750

6.55

41

4

10.427

4.99

45

5

10.483

5.38

38

6

10.265

7.01

13

225 grams contain

$7.18 \% \mathrm{~N}$.

66.430

42.37

16.155 grams nitrogen.

66.430 grams nitrogen. $\quad 58.525$ grams nitrogen.

Nitrogen balance for seven days $=\quad+7.905$ grams.

Nitrogen balance per day $=\quad+1.129$ grams. 


\section{NITROGEN BALANCE. - Coffman.}

Nitrogen Nitrogen in Urine. ${ }^{\text {Output. }}$ Weight of Fæces (dry).

Feb. 29

Taken in.

8.63 grams.

10.466 grams.

7.48

Mar. 1

7.825

8.62

3

8.487

7.18

4

8.750

7.93

65 grams

10.427

7.67

83

6

10.483

7.95

20

168 grams contain $6.14 \% \mathrm{~N}$.

66.703

55.46 10.315 grams nitrogen.

66.703 grams nitrogen. $\quad 65.775$ grams nitrogen.

Nitrogen balance for seven days $=\quad+0.928$ gram.

Nitrogen balance per day $=\quad+0.132$ gram. 


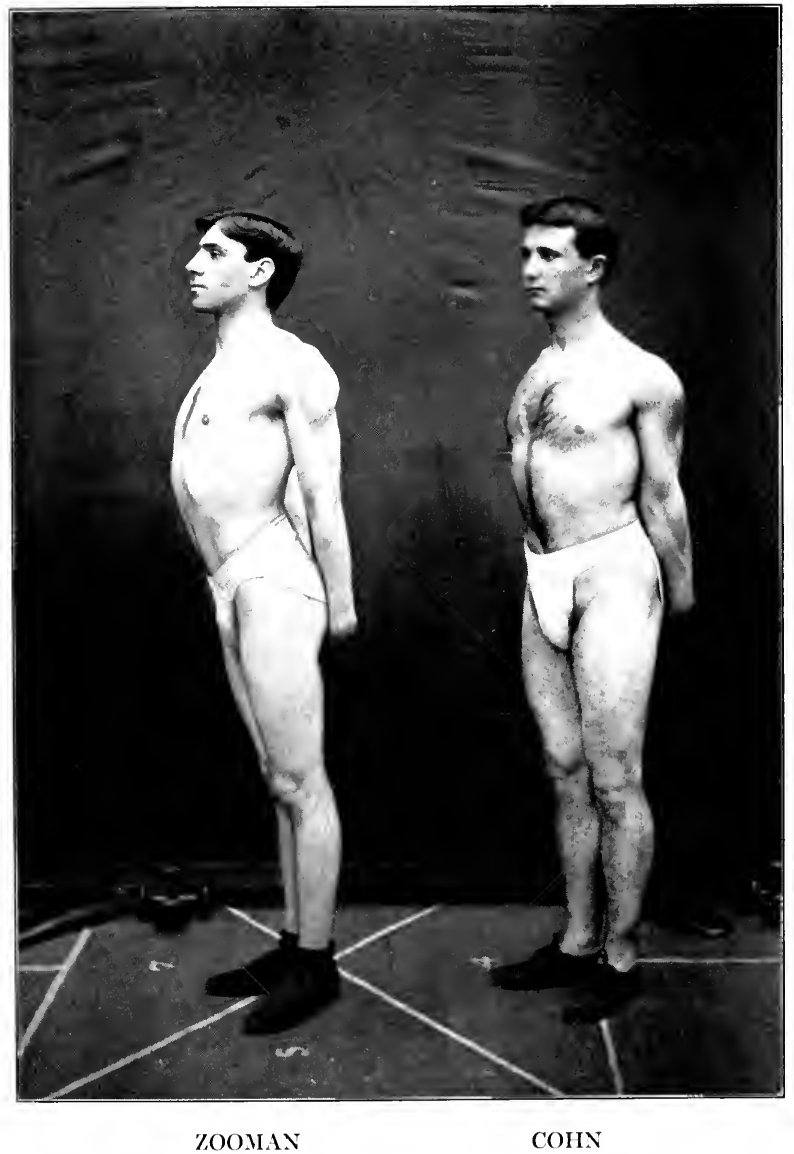

Photographs taken at the close of the experiment. 
$$
\text { . }
$$ 


\section{NITROGEN BALANCE. - Steltz.}

Nitrogen
Taken in. Nitrogen in Urine.

Feb. 29

7.90 grams.

23 grams.

Mar. 1

8.090

5.98

22

2

8.487

6.58

21

3

9.300

8.10

45

4

11.107

4.66

18

5

10.024

8.69

36

6

10.392

8.20

31

10

$$
\begin{array}{r}
\overline{206} \text { grams contain } \\
6.66 \% \mathrm{~N} .
\end{array}
$$

67.389

13.719 grams nitrogen.

67.389 grams nitrogen. $\quad 63.829$ grams nitrogen.

Nitrogen balance for seven days $=\quad+3.560$ grams.

Nitrogen balance per day $=\quad+0.508$ gram. 


\section{NITROGEN BALANCE. - Loewenthal.}

Nitrogen

Taken in.

Feb. 29

Mar. 1

2

3

4

5

6
10.466 grams.

7.825

8.487

8.750

10.427

10.654

10.886

67.495 Nitrogen in Urine. Weight of Fæces (dry). 7.38 grams. $\quad 16.5$ grams. $7.05 \quad 38.0$ $7.07 \quad 21.0$ 7.83

7.35

15.0

4.29

22.0

8.07 $\frac{56.0}{168.5}$ grams contain $7.11 \% \mathrm{~N}$. 67.495 grams nitrogen. 61.020 grams nitrogen.

Nitrogen balance for seven days $=\quad+6.475$ grams.

Nitrogen balance per day $=\quad+0.925$ gram. 
NITROGEN BALANCE. - Cohn.

Feb. 29

Mar. 1

2

4

5

6

Nitrogen

Nitrogen in Urine. Weight of Fæces (dry).

10.442 grams.

9.74 grams.

7.825

6.86

8.487

7.29

10.215
10.483

5.59

43 grams.

9.55

24

$\underline{8.164}$

6.77

57

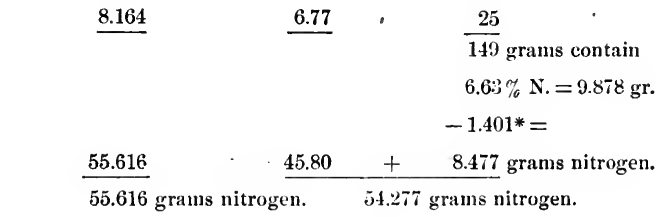

Nitrogen balance for six days $=\quad+1.339$ grams.

Nitrogen balance per day $=.+0.22 \% 3$ gram.

* This balance is complicated by the loss of the urine on March 3. Consequently one-seventh of the total vitrogen of the faces of the period, namely 1.401 grams, was deducted from the total fæcal nitrogen. 


\section{PHYSIOLOGICAL ECONOMY IN NUTRITION}

\section{NITROGEN BALANCE. - Zooman.}

\section{Nitrogen} Taken in.

Feb. 29

Mar. 1

2

3

4

5

6
10.466 grams

7.604

8.487

8.750

10.427

10.483

10.265

66.482

\begin{tabular}{cc}
\multicolumn{2}{c}{ Output. } \\
Ni rogen in Urine. & Weight of Fæces (dry). \\
7.02 grams. & 18 grams. \\
6.66 & 25 \\
7.26 & 52 \\
7.56 & 40 \\
7.51 & 14 \\
7.08 & 30 \\
6.81 & 10 \\
& 189 grams contain \\
49.90 & $+\quad 12.36$ grains nitrogen. \\
\hline & 62.26 grams nitrogen.
\end{tabular}

$\begin{array}{ll}\text { Nitrogen balance for seven days } & =\quad+4.222 \text { grams. } \\ \text { Nitrogen balance per day } & =\quad+0.603 \text { gram. }\end{array}$ 


\section{PHYSIOLOGICAL ECONOMY IN NUTRITION 239}

NITROGEN BALANCE. - Sliney.

Feb. 29

Nitrogen Output.

Taken in.

Mar. 1

10.466 grams.

Nltrogen in Urine. Wutput. Weight of Fæces (dry).

1

7.825

9.50 grams.

15 grams.

2

8.487

8.09

35

3

8.734

7.97

25

4

10.427

7.78

45

7.49

28

5

10.475

7.54

21

6

$\underline{10.265}$

8.23

$\frac{32}{201}$ grams contain $6.70 \% \mathrm{~N}$.

$\frac{66.679}{66.679}$ grams nitrogen. $\frac{56.60+13.467}{70.067 \text { grams nitrogen. }}$

Nitrogen balance for seven days $=-3.388$ grams.

Nitrogen balance per day $=\quad-0.484 \mathrm{gram}$. 


\section{NITROGEN BALANCE.-Broyles.}

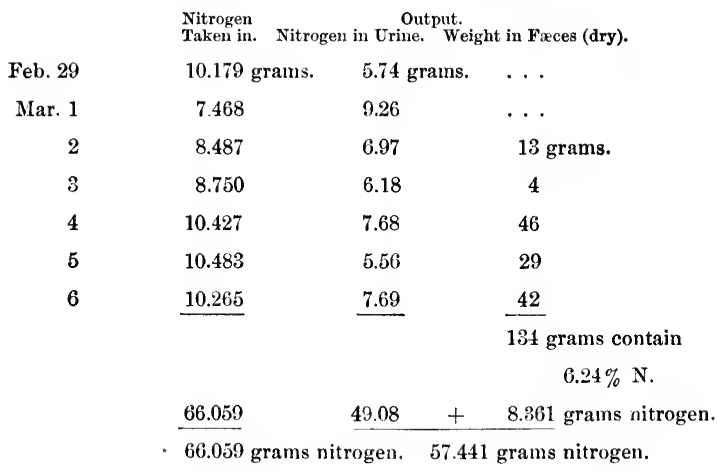

Nitrogen balance for seven days $=\quad+8.618$ grams.

Nitrogen balance per day $=\quad+1.231$ grams. 



\section{PHYSIOLOGICAL ECONOMY IN NUTRITION 241}

\section{. NITROGEN BALANCE. - Fritz.}

Nitrogen

Taken in.

Feb. 29

Mar. 1

2

3

5

$6 \quad \underline{10.265}$

$6 \quad \underline{10.265}$
10.466 grams.

7.825

8.487

8.750

10.483

56.276
Output.

Iritrogen in Urine. Weight of Fæces (dry).

56.276 grams nitrogen.

7.44

4.00

71

7.05

28

8.71

49

$\underline{4.78}$

44

192 grams contain

$$
6.61 \% \mathrm{~N} .=12.691 \mathrm{gr} \text {. }
$$$$
=1.813 *
$$

38.20 $10.878 \mathrm{grm} . \mathrm{N}$.

Nitrogen balance for six days $\quad-\quad+7.198$ grams.

Nitrogen balance per day $\quad-\quad+1.199$ grams.

* This balance is somewhat complicated by the fact that on March 4 the urine was lost, so that this day had to be thrown out. Correction on the fæces, however, was made by deducting one-seventh of the total fæcal nitrogen, on the assumption that the nitrogen-content was essentially the same for each day of the seven-day period. 


\section{Third Nitrogen Balance.}

The last of March, a third nitrogen balance was tried on a slightly lowered nitrogen intake and with a slight increase in the fuel value of the daily food. In this period of five days, March 28 to April 1, the nitrogen taken in per day averaged 8.62 grams, or nearly one gram per day less than in the preceding period. The fuel value of the food averaged 2840 calories per day, or about 300 calories more than in the preceding period.

The daily diet, with its content of nitrogen, etc., is detailed for each day under Oakman. Any deviation from this diet in the cases of the other men is indicated on the accompanying balance-sheets.

The results obtained in this balance period indicate that the lowest level had been practically reached, at least under the conditions of body-weight, food, and work prevailing. Coln, Fritz, and Broyles showed a distinct positive balance. Steltz and Loewenthal were practically in equilibrium, the deviation being within the limits of error. The remaining six men showed a minus balance, although in no case was it very marked.

It is interesting to note in this connection that the average daily output of nitrogen through the urine for this five days' period (Oakman's case) amounted to 7.04 grams, being 0.2 gram less per day than in the preceding period. This figure for nitrogen in the urine means the metabolism daily of 44 grams of proteid.

Undoubtedly, the rate of proteid metabolism for these men could have been lowered considerably beyond the present level by increasing largely the intake of carbohydrates and fats, but it has been the intent throughout all of these experiments to learn the minimal proteid requirement under conditions precluding the use of any excess of non-nitrogenous foods; also, to study the effect of a general physiological economy in nutrition, with a view to ascertaining the real necessities of the body for both proteid and non-proteid foods 
with maintenance of bodily strength and vigor. Hence, we may again emphasize the fact that the low proteid metabolism maintained by all these men throughout the period of the experiment, with establishment of nitrogenous equilibrium on a consumption of proteid or albuminous food averaging onehalf the amount ordinarily specified as the daily requirement of the healthy man, has been accomplished with even less total food - fats and carbohydrates - than the ordinary standards call for, $i$. e., considerably less than 3000 calories per day in fuel value.

\section{OAKMAN.}

Monday, March 28, 1904.

Breakfast. - Fried rice 150 grams, syrup 75 grams, baked potato 250 grams, butter 20 grams, one cup coffee 850 grams.

Dinner. - Thick pea soup 200 grams, boiled onions 100 grams, boiled sweet potato 250 grams, bread 50 grams, mashed potato 200 grams, butter 20 grams, one cup coffee 350 grams.

Supper. - Sliced banana 150 grams, biscuit 125 grams, fried bacon 20 grams, French fried potato 200 grams, butter 25 grams, one cup tea 350 grams.

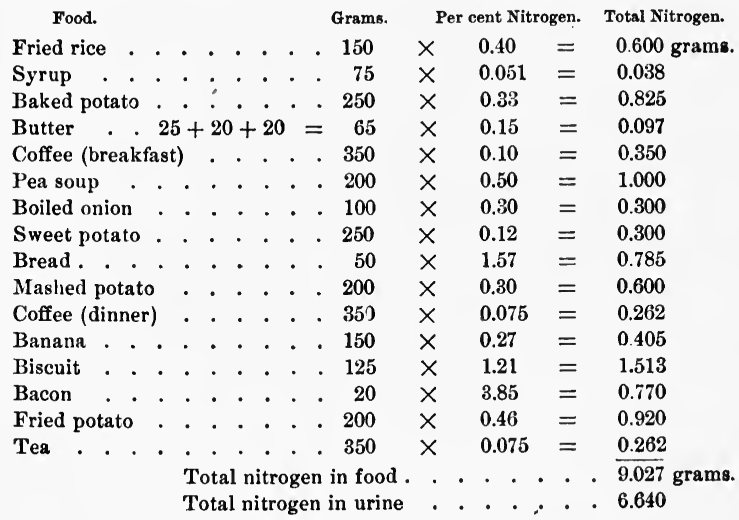

Fuel value of the food . . . 2935 calories. 


\section{OAKMAN.}

Tuesday, March $29,1904$.

Breakfast. - Boiled hominy 175 grams, milk 75 grams, sugar 25 grams, baked potato 250 grams, butter 20 grams, one cup coffee $\mathbf{3 5 0}$ grams.

Dinner. - Hamburg steak with much bread, fat, and onions 125 grams, boiled potato 300 grams, butter 10 grams, one cup coffee 350 grams, bread 35 grams, boiled carrots 125 grams.

Supper. - Tapioca-peach pudding 300 grams, bread 35 grams, Saratoga chips 75 grams, butter 20 grams, jam 75 grams, one cup tea 350 grams.

Food. Grams. Per cent Nitrogen. Total Nitrogen.

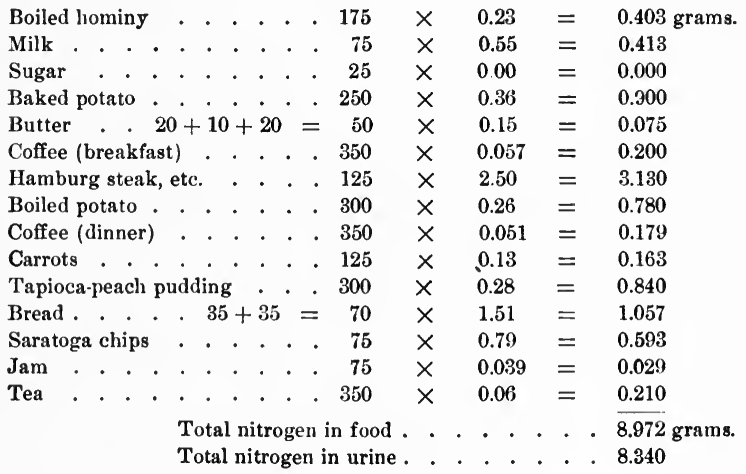

Fuel value of the food . . . . 2840 calories. 


\author{
OAKMAN.
}

Wednesday, March 30, 1904.

Breakfast. - Fried hominy 150 grams, syrup 75 grams, butter 10 grams, sliced banana 250 grams, one cup coffee 350 grams.

Dinner. - Codfish-balls ( 1 part fish, 5 parts potatoes, fried in pork fat) 125 grams, mashed potato 250 grams, stewed tomato 200 grams, bread 35 grams, apple sauce 200 grams, one cup coffee 350 grams.

Supper. - Chopped fresh cabbage with salt, pepper, and vinegar 75 grams, - bread 50 grams, butter 20 grams, fried sweet potato 250 grams, cranberry sauce 200 grams, sponge cake 50 grams, one cup tea 350 grams.

Food. Grams. Per cent Nitrogen. Total Nitrogen.

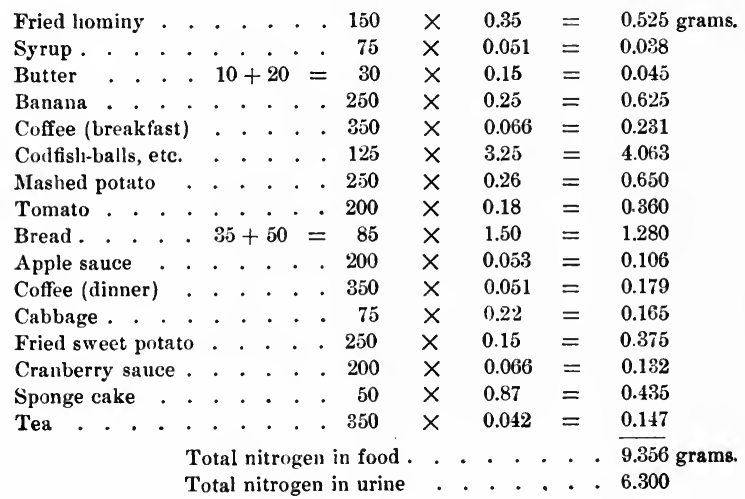

Fuel value of the food . . . 2657 calories. 
OAKMAN.

Thursday, March 31, 1904.

Breakfast. - Fried Indian meal 100 grams, syrup 75 grams, baked potato 250 grams, one cup coffee 350 grams, butter 20 grams.

Dinner. - 'Tomato soup, thick, with potatoes and onions boiled together 300 grams, mashed potato 200 grams, scrambled egg 50 grams, bread 50 grams, butter 10 grams, one cup coffee 350 grams.

Supper. - Bread pudding 150 grams, sliced banana 200 grams, fried bacon 20 grams, boiled potato 200 grams, butter 10 grams, one cup tea 350 grams.

Food.

Grams. Per cent Nitrogen. Total Nitrogen.

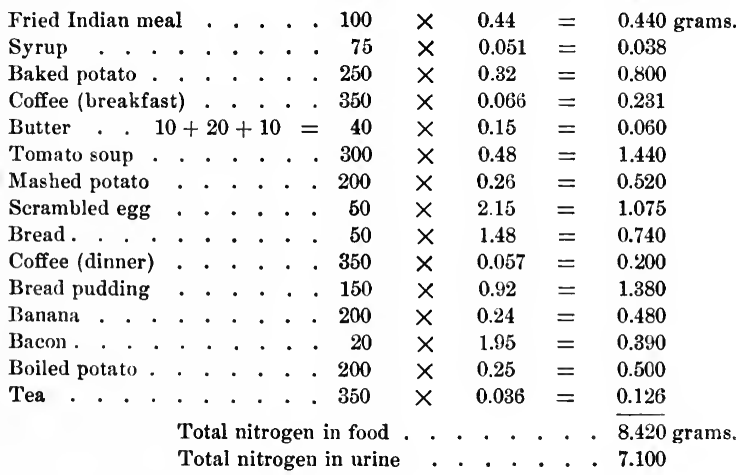

Fuel value of the food . . . 2466 calories. 


\section{OAKMAN.}

Friday, April 1, 1904.

Breakfast. - Fried hominy 150 grams, syrup 75 grams, baked potato 200 grams, butter 20 grams, one cup coffee 350 grams.

Dinner. - Baked spaghetti 250 grams, mashed potato 250 grams, boiled turnip 150 grams, bread 35 grans, butter 10 grams, apple sauce 200 grams, one cup coffee 350 grams.

Supper. - Apple-tapioca pudding 300 grams, fried sweet potato 200 grams, butter 20 grams, jam 100 grams, fried bacon 25 grams, bread 35 grams, one cup tea 350 grams.

Food. Gramz. Per cent Nitrogen. Total Nitrogen.

\begin{tabular}{|c|c|c|c|c|c|c|c|c|c|c|}
\hline Fried hominy & . & - & - & • & - & 150 & $x$ & 0.24 & $=$ & 0.360 grams. \\
\hline Syrup. . & . & . & . & . & . & 75 & $x$ & 0.051 & $=$ & 0.038 \\
\hline Baked potato & . . & . & . & . & . . & 200 & $x$ & 0.33 & $=$ & 0.660 \\
\hline Butter . & $20-$ & +10 & $0+$ & 20 & $=$ & 50 & $x$ & 0.15 & $=$ & 0.075 \\
\hline Coffee (breakfa & st) & . & . & . & . . & 350 & $x$ & 0.06 & $=$ & 0.210 \\
\hline Spaghetti . & . . & . & . & . & . & 250 & $x$ & 0.64 & $=$ & 1.600 \\
\hline Mashed potato & . & . & . & . & . & 250 & $x$ & 0.28 & $=$ & 0.700 \\
\hline Boiled turnip & . & . & . & . & . & 150 & $x$ & 0.61 & $=$ & 0.915 \\
\hline Bread. . . & . & 35 & $5+$ & 35 & $=$ & 70 & $x$ & 1.56 & $=$ & 1.092 \\
\hline Apple sauce & . & . & . & $\cdot$ & . . & 200 & $x$ & 0.053 & $=$ & 0.106 \\
\hline Coffee (dinner) & . & . & . & . & . & 350 & $\times$ & 0.072 & $=$ & 0.252 \\
\hline Apple-tapioca $p$ & pudd & ding & . & . & . & 300 & $x$ & 0.043 & $=$ & 0.129 \\
\hline Fried sweet po & tato & . & . & . & . & 200 & $x$ & 0.15 & $=$ & 0.300 \\
\hline Jam . . & . . & . & . & . & $\cdot$ & 100 & $\times$ & 0.039 & $=$ & 0.039 \\
\hline Bacon. . & . & . & . & . & . & 25 & $\times$ & 2.96 & $=$ & 0.740 \\
\hline Tea . . & . & . & . & . & & 350 & $x$ & 0.036 & $=$ & 0.126 \\
\hline & & $\begin{array}{l}\text { Total } \\
\text { Total }\end{array}$ & $\mathrm{lni}$ & & & in urine & . & $\begin{array}{l}\cdot \cdot \cdot \\
\cdot \cdot \cdot\end{array}$ & .. & $\begin{array}{l}7.342 \text { grams } \\
6.830\end{array}$ \\
\hline
\end{tabular}

Fuel value of the food . . . 3248 calories. 


\section{NITROGEN BAI.ANCE.-Oakman.}

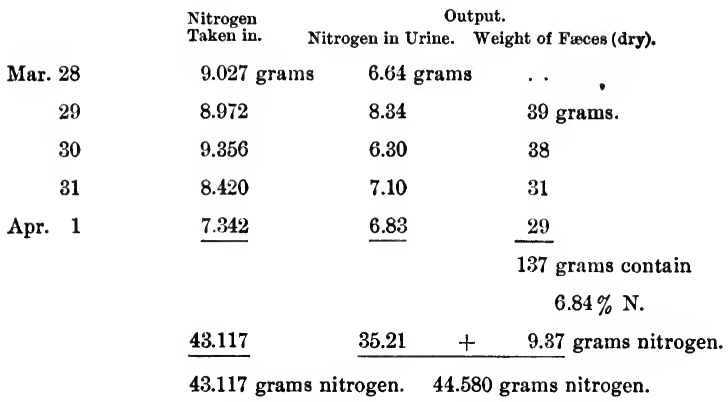

Nitrogen balance for five days $=-1.463$ grams.

Nitrogen balance per day $=-0.292$ gram.

Average Intake.

Calories per day . . . . . . . 2840.

Nitrogen per day . . . . . . . 8.62 gram8. 


\title{
PHYSIOLOGICAL ECONOMY IN NU'TRITION 249
}

\author{
NITROGEN BALANCE.-Broyles. \\ Nitrogen Output. \\ Taken in. Nitrogen in Urive. Weight of Fæces (dry).
}

Mar. 28

9.027 grams. $\quad 6.79$ grams. $\quad 27.0$ grams.

29

8.972

7.06

45.5

30

9.356

7.27

41.0

31

8.640

6.21

25.0

Apr. 1

7.342

5.86

20.0

158.5 grams contain

$5.92 \% \mathrm{~N}$.

48.837

$33.19+\quad 9.383$ grams nitrogen

43.337 grams nitrogen. $\quad 42.573$ grams nitrogen.

Nitrogen balance for five days $=+0.764$ gram.

Nitrogen balance per day $=\quad+0.153$ gram.

\section{NITROGEN BALANCE. - Fritz.}

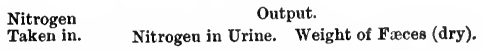

Mar. 29

7.229 grams. $\quad 5.09$ grams. ..

30

9.235

7.10

25 grams.

31

8.640

5.18

43

Apr. 1

7.439

5.74

34

102 grams contain

$6.42 \% \mathrm{~N}$.

32.543

$23.11+6.548$ grams nitrogen.

32.543 grams nitrogen. 29.658 grams nitrogen.

Nitrogen balance for four days $=\quad+2.885$ grams.

Nitrogen balance per day $=\quad+0.721$ gram. 


\section{NITROGEN BALANCE. - Loewenthal.}

\begin{tabular}{|c|c|c|c|}
\hline \multirow[b]{3}{*}{ Mar. 28} & \multirow{2}{*}{$\begin{array}{l}\text { Nitrogen } \\
\text { Taken in. }\end{array}$} & \\
\hline & & \multicolumn{2}{|c|}{$\begin{array}{l}\text { Output. } \\
\text { Nitrogen in Urine. Weight of Fæces (dry). }\end{array}$} \\
\hline & 9.027 grams. & 6.27 grams. & 13.5 grams. \\
\hline 29 & 8.760 & 7.54 & 52.0 \\
\hline 30 & 9.341 & 7.07 & 41.0 \\
\hline 31 & 8.112 & 5.24 & 21.0 \\
\hline \multirow[t]{4}{*}{ Apr. 1} & 7.342 & 6.43 & 17.0 \\
\hline & & & 144.5 grams contain \\
\hline & & & $7.00 \% \mathrm{~N}$ \\
\hline & 42.582 & 32.55 & 10.115 grams nitrogen \\
\hline
\end{tabular}

Nitrogen balance for five days $=-0.083 \mathrm{gram}$.

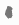

Nitrogen balance per day

$=-0.016 \mathrm{gram}$.

\section{NITROGEN BALANCE.-Cohn.}

\begin{tabular}{|c|c|c|c|}
\hline \multirow[b]{3}{*}{ Mar. 28} & \multirow{2}{*}{$\begin{array}{l}\text { Nitrogen } \\
\text { Taken in. }\end{array}$} & \\
\hline & & \multicolumn{2}{|c|}{$\begin{array}{l}\text { Output. } \\
\text { Nitrogen in Urine. Weight of Fæces (dry). }\end{array}$} \\
\hline & 8.825 grams. & 6.61 grams. & $\cdots$ \\
\hline 29 & 8.151 & 6.48 & 27 grams. \\
\hline 30 & 9.211 & 6.36 & 25 \\
\hline 31 & 8.030 & 7.47 & 23 \\
\hline Apr. 1 & 7.246 & 4.35 & 39 \\
\hline & & & 114 grams contain \\
\hline & & & $6.84 \% \mathrm{~N}$. \\
\hline & 41.463 & 31.27 & 7.797 grams nitrogen. \\
\hline
\end{tabular}

Nitrogen balance for five days $=\quad+2.396$ grams.

Nitrogen balance per day $=\quad+0.479$ gram. 


\section{PHYSIOLOGICAL ECONOMY IN NUTRITION 251}

\section{NITROGEN BALANCE. - Coffman.}

Nitrogen
Taken in. Nitrogen in Urine. Weight of Fæces (dry).

Mar. 28

9.027 grams. $\quad 8.38$ grams. ...

29

8.972

8.06

42 grams.

30

9.356

6.88

24

31

8.640

7.78

29

Apr. 1

7.342

7.22

32

127 grains contain

$$
6.54 \% \mathrm{~N} \text {. }
$$

43.337

38.32

8.306 grams nitrogen.

43.337 grams nitrogen. 46626 grams nitrogen.

Nitrogen balance for five days $=-3.289$ grams.

- Nitrogen balance per day $=-0.657$ gram.

\section{NITROGEN BALANCE.-Sliney.}

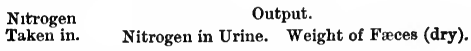

Mar. 28

8.527 grams. $\quad \mathbf{7 . 0 9}$ grams. $\quad 28.0$ grams.

29

8.630

7.37

31.5

30

9.356

8.10

33.0

31

8.420

7.47

26.0

Apr. 1

$\underline{7.342}$

6.78

50.0

168.5 grams contain

$$
6.42 \% \mathrm{~N} \text {. }
$$

42.275

$36.81+10.82$ grams nitrogen.

42.275 grams nitrogen. $\quad 47.63$ grams nitrogen.

Nitrogen balance for five days $=-5.355$ grams.

Nitrogen balance per day $=\quad-1.071$ grams. 


\section{PHYSIOLOGICAL ECONOMY IN NUTRITION}

\section{NITROGEN BALANCE. - Steltz.}

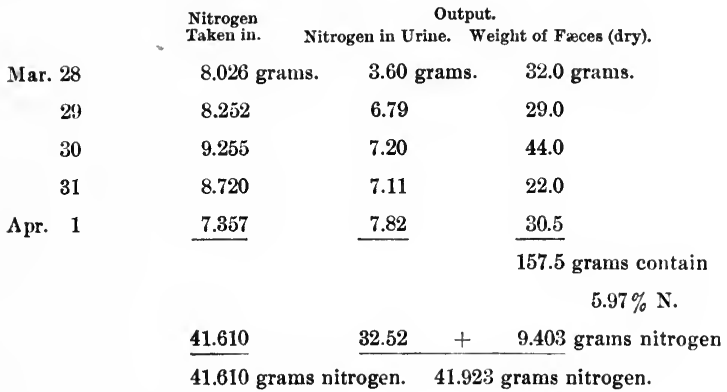

Nitrogen balance for five days $=-0.313$ gram.

Nitrogen balance per day $=-0.062 \mathrm{gram}$.

\section{NITROGEN BALANCE.-Zooman.}

Nitrogen Output.

Taken in. Nitrogen in Urine. Weight of Frees (dry).

Mar. 28

9.027 grams. $\quad 7.47$ grams. $\quad 33.0$ grams.

29

8.379

7.80

45.0

30

9.356

5.40

30.0

31

8.420

8.04

28.0

Apr. 1

7.269

8.44

11.5

147.5 grams contain $6.39 \% \mathrm{~N}$.

42.451 $37.15+9.425$ grams nitrogen $\mathbf{4 2 . 4 5 1}$ grams nitrogen. $\mathbf{4 6 . 5 7 5}$ grams nitrogen.

Nitrogen balance for five days $=\mathbf{- 4 . 1 2 4}$ grams.

Nitrogen balance per day $=\quad-0.824$ gram. 


\section{NITROGEN BALANCE. - Henderson.}

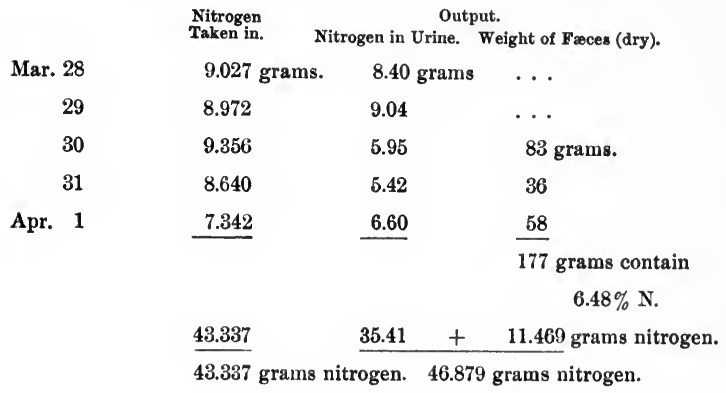

Nitrogen balance for five days $=-3.542$ grams.

Nitrogen balance per day $=-0.708 \mathrm{gram}$.

NITROGEN BALANCE.-Morris.

\begin{tabular}{|c|c|c|c|}
\hline \multirow{3}{*}{ Mar. 28} & \multirow{2}{*}{$\begin{array}{l}\text { Nitrogen } \\
\text { Taken in. }\end{array}$} & \multicolumn{2}{|c|}{ Output. } \\
\hline & & Nitrogen in Urine. & Weight of Fæces (dry). \\
\hline & 8.877 grams. & 6.68 grams. & 12 grams. \\
\hline 29 & 8.774 & 5.69 & 48 \\
\hline 30 & 8.941 & 6.06 & 34 \\
\hline 31 & 8.420 & 6.96 & 34 \\
\hline Apr. 1 & 7.286 & 7.10 & 33 \\
\hline & & & 161 grams contain \\
\hline & & & $7.08 \% \mathrm{~N}$. \\
\hline & 42.298 & 32.49 & 11.399 grams nitrogen. \\
\hline
\end{tabular}

Nitrogen balance for five days $=-1.591$ grams.

Nitrogen balance per day $=-0.317$ gram. 


\section{PHYSIOLOGICAL ECONOMY IN NUTRITION}

\section{Summary Regarding Nitrogen Requirement.}

These results obtained with this body of United States soldiers, living on a prescribed diet and exposed to the stress and strain of military discipline with its attendant duties, together with the gymnastic work and training required each day, confirm in every detail the conclusions arrived at with the preceding group of professional workers. Once accustomed to a more sparing proteid diet, less rich in nitrogen, each one of these subjects had no difficulty in maintaining body-weight on the simpler and lighter food provided. No great difficulty was experienced in establishing a condition of nitrogenous equilibrium with this lowered intake of proteid food, neither was it necessary to increase the amounts of nonnitrogenous foods (fats and carbohydrates) to accomplish this end. The bodies of these men were quite able to adjust themselves to a lowered proteid metabolism, and physiologically speaking, one might well conjecture whether we have not in this condition a nearer approach to the normal and ideal state of the body than when the latter is struggling daily with 118 grams of proteid food, reinforced by fats and carbohydrates correspondingly increased in amount. However this may be, the members of the soldier detail were able to live for five consecutive months with a proteid metabolism corresponding to 7 to 8 grams of nitrogen per day, with maintenance of body-weight and without discomfort or loss of bodily vigor.

It was easy in most instances to prove the establishment of nitrogen equilibrium with a daily intake of 8.5 to 9.5 grams of nitrogen, and with a total fuel value of the daily food equal to 2500 to 2800 calories. In other words, a metabolism of less than 50 grams of proteid per day was quite sufficient for the needs of the body, and a fuel value of 2500 to 2600 calories was ample to meet the requirements of the men under the then existing conditions of bodily and mental activity. Are we not justified, therefore, in again asking the question, why should we hold and teach the doctrine that the healthy adult 
needs to metabolize 105 grams of proteid food daily? . As Voit has well said, the smallest amount of food that will serve to maintain physiological equilibrium and keep up health and strength is the ideal diet. The eleven subjects of this Hospital detachment, who remained throughout the experiment, were apparently able to maintain physiological equilibrium and preserve their health and strength under the conditions of diet as described, thereby demonstrating the possibilities of a physiological economy corresponding to a saving of full fifty per cent or more in proteid food; a saving of possibly great physiological import, to say nothing of the possible economic and sociological importance of the saving. Further, we may add that the minimal proteid requirement as evidenced by the results of these experiments is more than fifty per cent lower than the figures quoted by most physiologists as necessary for the maintenance of life and strength; and we are certainly justified in the additional statement that if the figures obtained in these experiments truly represent the minimal proteid requirement of the men under observation, then this minimal requirement is quite sufficient to meet the physiological needs of the body for an indefinite period.

\section{Physical Condition of the Men.}

Recalling the fact that this condition of lowered proteid inetabolism was maintained for a period of five months, we may next consider the effect of this changed nutritive condition upon the health and strength of the men. 'The question of body-weight we have already considered. More pertinent is the question, to how great an extent was the strength and bodily vigor of the men modified by the diminished amount of proteid food? The answer to this question is found in the subjoined report from Dr. William G. Anderson, Director of the Yale University Gymnasium. 
Yale Unitersity GymisidM, New Haven, Cons., April 6, 1904.

To Professor Russell H. Cuittenden,

Director of the Sheffield Scientific

School, Yale University,

New Havex, Conv.

Dear SIr, - I hand you herewith a report of the physical training of the squad of soldiers sent by you to the Yale Gymnasium.

These men have taken one hour's exercise daily for six months, Sundays excepted, - October 1, 1903, to April 1, 1904. .

Before beginning the bodily development of the men we measured each one and took what are known as the American Collegiate Strength 'Tests. These measurements and tests have been taken twice each month. For details as to measurements and methods of testing the strength of the body, see the "Notes" attached to this report.

The members of the squad were called to the floor each morning as soon after nine-thirty as they could don the required suit. For twenty minutes they were put through a series of setting up exercises and body-building movements; then followed exercises on the apparatus, such as bars, rings, ladders, etc. This was followed by a jump or game.

The exercises were progressive as to duration, force, extent, and number of movements. At the end of the six months the men were being put through gymnastics that were exacting and fatiguiug. As the progression was carefully made, the men did not suffer from soreness to any marked degree. By way of comparison it may be said, the gymnastic training given the soldiers was much more severe than is given to the Freshmen of Yale in their required physical training. Perhaps the Varsity Crew are "put through" as rigid gymnastic training as any of the athletes in college, so we copied the exercises taken hy oarsmen in order to "try out" the soldiers. This work was easily taken by all the "Dieters," - no complaint, so far as I know, having been entered.

The improvement in accuracy and grace of movement has been noticeable, while there has been a gain in skill as well.

I do not consider these men, as a body, well put up. They did not rank favorably with applicants for policeman or fireman and 
were noticeably timid in exercises that called for courage. In the vault over a fence there was a very marked fear. This was the poorest and least satisfactory test of all we made. At the end of the six months the hesitancy to vault had entirely disappeared, the event being looked upon by the men as a " cinch."

The gain in self-reliance and courage has been as evident as the increase in the figures of the strength test. I consider this a valuable acquisition as it stands for a good body condition. Among athletes, especially gymnasts, a weakened or tired body is made known by fear or uncertainty. Our students, as well as professional athletes, admit this.

I attribute the timidity of the soldiers in these seemingly simple tests to their general physical condition at the outset, and the increase in self-reliance to the better condition of their bodies at the end of the six months' training. 'The story told by the measurements is both interesting and significant, but of less importance than the ability to improve under training, which ability cannot be measured with a tape or weighed with scales.

In the majority of cases there was a loss in body-weight, but this we look for, as the larger number of soldiers were fairly well supplied with adipose tissue. Both Sliney and Oakman are exceptions, these men being "fine" at the outset. I mean thin and muscular with little fat. 'The latter, Oakman, is an old man judged from the physical activity standpoint, and lost noticeably during the tests and exercise. I refer to weight and girth measurements only. He made a very large gain in his strength tests and was among the leading men in all that called for courage and self-control. Sliney, nervous, irritable, and aggressive, balanced his losses with his gains in the tape and scale events, but made great improvement in the use of the dynamometers. Fritz and Cohn were quite fat and showed the expected loss in weight, but not in other respects.

For comparison I have quoted from Dr. J. W. Seaver's anthropometric charts and have selected the "Average Student Measurements" (2390 men) as well as the mean measurements of 500 athletes and gymnasts. A glance at either set of figures will give an idea of how the soldiers eompare with men living on a regular diet and surrounded with the very best environment.

The strength tests stand for mental states more than the tape line and calipers, and are suggestive of improvement in body con- 
ditions for the reasons mentioned above. These records are far above those made by Academic Freshmen in Yale, but it must be added that the soldiers have taken more exercise than the collegians.

The hearts and lungs of the men are in excellent condition, while the soldiers as a body are in better shape physically, are stronger and healthier than in October. The skin of the men is clear and ruddy.

The figures for comparison in the Strength Test Table are from the records sent me by Dr. Geo. Meylan, the Director of the Columbia University Gymnasium. I understand that others than college men are represented in his data. In the figures given in my own tables I have omitted the small fractions in the main body of the tables, but have recorded them in the totals.

The greater portion of the training of the soldiers has been under the personal supervision of Wm. H. Callahan, M. D., the Medical Assistant at the Gymnasium, to whom I am indebted for help and suggestions. Mr. Wm. Chase, Mr. Anton Muller, Mr. John Stapleton, and Mr. H. R. Gladwin, Assistant Instructors in the Gymnasium, have led the drills and liave looked after the actual muscular training of the men. I gladly acknowledge the co-operation of these gentlemen in the physical development of the squad.

A brief summary of my conclusions :-

The men were not above the average standard, physically, when they began their work, this standard being set by applicants for firemen and policemen, not by college students. At the end of their training they were much above the same standard, while their strength tests were far greater than the averages made by college men. They showed less improvement in increase in size than University men do under like gymnastic treatment, but the gain in self-confidence and in body-fibre was very evident. The gain in accuracy and skill was marked. The men showed interest in their work throughout the six months. At the end of the period of training the soldiers were in excellent condition in spite of the fact that in some cases there was a slight loss of bodyweight. This loss is not to be attributed necessarily to the diet, because most men who exercise lose slightly if there is an excess of adipose tissue.

Respectfully yours,

(Signed) W. G. Anderson. 
Dr. Anderson furnishes the following "Notes" descriptive of the methods by which the strength tests were made:

"Strength of Back. The subject, standing upon the iron foot-rest with the dynamometer so arranged that when grasping the handles with both hands his body will be inclined forward at an angle of 60 degrees, should take a full breath and, without bending the knees, give one hard lift, mostly with the back.

"Strength of Legs. The subject while standing on the footrest with body and head erect, and chest thrown forward, should sink down, by bending the knees, until the handle grasped rests against the thighs, then taking a full breath, he should lift hard principally with the legs, using the hands to hold the handle in place.

"Strength of Chest. The subject with his elbows extended at the sides until the forearms are on the same horizontal plane and holding the dynamometer so that the dial will face outward and the indicator point upward, should take a full breath and push vigorously against the handles, allowing the back of the instrument to press on the chest.

"Strength of Upper Arms, Triceps. The subject, while holding the position of rest upon the parallel bars, supporting his weight with arms straight, should let the body down until the ehin is level with the bars, and then push it up again until the arms are fully extended. Note the number of times that he can lift himself in this manner.

"Strength of Upper Arms, Biceps. The subject should grasp a horizontal bar or pair of rings and hang with the feet clear from the floor while the arms are extended. Note the number of times that he can haul his body up until his chin touches the bar or ring.

"Strength of Forearms. The subject, while holding the dynamometer so that the dial is turned inward, should squeeze the spring as hard as possible, first with the right hand then with the left. The strength of the muscles between the shoulders may be tested with the same instrument. The subject, while holding the dynamometer on a level with the chest, should 
grasp it with handles and pull both arms from the centre outward.

" The total strength is ascertained by multiplying the weight by the number of times it has been raised (push up and pull up), to this product we add the strength of hands, legs, back, and chest. The result is the total strength of the man. In some cases the product obtained by multiplying the weight by push up and pull up is divided by ten to reduce the size of the figures. We have not done so here.

"The run, vault, and ladder tests are not figured in. The lung capacity is also omitted from the final figures."

The following tables furnished-by Dr. Anderson and Dr. Callahan give (1) the measurements of the eleven men who completed the experiment, taken on October 12, 1903, and April 2, 1904. For comparison are also given measurements of Yale College students, athletes, etc. (2) Strength or dynanometer tests, $i$. $e$., the first test taken in October and the final test taken in April, 1904, together with Columbia University strength tests for comparison. (3) A series of eleven tables giving for each man the individual strength tests, two or three each month, taken during the stay of the detachment in New Haven. Study of these individual results is quite interesting, since it shows very strikingly the gradual gain in strength of the men, and at the same time illustrites how temporary conditions, bodily or mental, may influence a record of this character, more noticeable in some individuals than in others. Mental stimulus, as is well known, counts for much in the manifestation of muscular power, but the neuro-muscular mechanism depends for its highest efficiency upon the nutritive condition of the tissues as much as does the inuscle tissue alone. In the obtaining of a strength test, it is usually found that the best results are recorded when there is competition among the men; $i . e$, under the influence of an outside stimulus. 
MEASUREMENTS.

(October 12-April 2.)

\begin{tabular}{|c|c|c|c|c|c|c|c|c|c|c|c|c|c|}
\hline & & 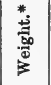 & 起苞 & 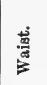 & 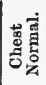 & 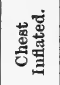 & 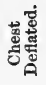 & 趍商 & 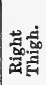 & 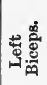 & జ્ّు & 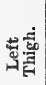 & 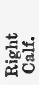 \\
\hline \multirow{2}{*}{ Henderson } & & 157 & 362 & 755 & 953 & 1035 & 890 & 316 & 510 & 291 & 362 & 500 & 51 \\
\hline & 3 & 153 & 369 & 731 & 942 & 1025 & 886 & 311 & 503 & 287 & 357 & 495 & 347 \\
\hline \multirow{2}{*}{ Oakman } & 1 & 145 & 344 & 738 & 888 & 947 & 793 & 305 & 508 & 289 & 335 & 512 & $3: 30$ \\
\hline & \{ & 137 & 336 & 727 & 869 & 938 & 795 & 297 & 502 & 282 & 331 & 507 & 331 \\
\hline \multirow{2}{*}{ Morris } & f & 129 & 340 & 713 & 850 & 932 & 831 & 280 & 519 & 283 & 327 & 502 & 325 \\
\hline & \{ & 131 & 351 & 719 & 862 & 938 & 834 & 285 & 525 & 290 & 333 & 509 & 332 \\
\hline \multirow{2}{*}{ Zooman } & s & 120 & 350 & 713 & 868 & 920 & 804 & 290 & 479 & 286 & 312 & 478 & 313 \\
\hline & \{ & 122 & 360 & 712 & 859 & 914 & 803 & 307 & 486 & 293 & 315 & 484 & 314 \\
\hline \multirow{2}{*}{ Coffman } & $\int$ & 129 & 352 & 738 & 860 & 923 & 815 & 309 & 518 & 311 & 354 & 520 & 350 \\
\hline & 3 & 127 & 349 & 716 & 857 & 931 & 818 & 314 & 527 & 316 & 859 & 529 & 354 \\
\hline \multirow{2}{*}{ Steltz } & $\int$ & 116 & 330 & 713 & 815 & 850 & 779 & 291 & 487 & 283 & 319 & 483 & 318 \\
\hline & \{ & 115 & 330 & 717 & 821 & 857 & 771 & 287 & 492 & 281 & 324 & 478 & 322 \\
\hline \multirow{2}{*}{ Loewenthal } & f & 133 & 338 & 680 & 835 & 881 & 822 & 315 & 510 & 311 & 338 & 512 & 338 \\
\hline & 3 & 130 & 341 & 684 & 840 & 890 & 819 & 306 & 504 & 302 & 342 & 505 & 337 \\
\hline \multirow{2}{*}{ Sliney } & $\int$ & 135 & 359 & 718 & 824 & 930 & 823 & 314 & 476 & 302 & 331 & 473 & 330 \\
\hline & 3 & 133 & 361 & 702 & 834 & 926 & 813 & 306 & 475 & 298 & 333 & 475 & 332 \\
\hline \multirow{2}{*}{ Fritz } & $\int$ & 167 & 390 & 860 & 880 & 930 & 860 & 360 & 560 & 343 & 377 & 562 & 375 \\
\hline & \{ & 161 & 361 & 795 & 892 & 997 & 855 & 358 & 555 & 340 & 372 & 559 & 373 \\
\hline \multirow{2}{*}{ Colın } & $\int$ & 142 & 363 & 810 & 871 & 912 & 832 & 326 & 536 & 310 & 374 & 528 & 375 \\
\hline & \{ & 138 & 354 & 771 & 878 & 914 & 818 & 324 & 529 & 308 & 371 & 520 & 371 \\
\hline \multirow{2}{*}{ Broyles } & $\int$ & 130 & 356 & 710 & 851 & 941 & 805 & 281 & 500 & 282 & 341 & 498 & 334 \\
\hline & \{ & 133 & 370 & 720 & 864 & 966 & 798 & 283 & 506 & 284 & 344 & 501 & 338 \\
\hline \multicolumn{2}{|l|}{ Yale College $\dagger$} & 139 & 350 & 730 & 861 & 910 & $\cdots$ & 295 & 515 & $\cdots$ & 350 & 509 & 350 \\
\hline \multicolumn{2}{|l|}{ Yale College $\ddagger$} & 147 & 357 & 747 & 886 & 940 & & 308 & 534 & & 358 & 527 & 361 \\
\hline
\end{tabular}

* Given here in pounds.

$\dagger$ Yale College students, $50 \%$ class of the mass of students (2,390 men).

$\ddagger$ Yale College students, $50 \%$ or mean of 500 athletes and gymnasts, picked men. 


\section{STRENGTH OR DYNAMOMETER TESTS.}

First Trials October, 1903; Final Test April, 1904.

\begin{tabular}{|c|c|c|c|c|c|c|c|c|c|c|c|c|c|c|}
\hline & 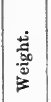 & 象 & 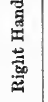 & 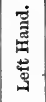 & 离 & 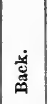 & $\begin{array}{l}\text { 离 } \\
\text { 心 }\end{array}$ & 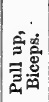 & 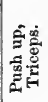 & 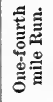 & 莡 & 苋 & 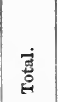 & \\
\hline Henderson & 157 & 465 & 103 & 105 & 130 & 340 & 560 & 8 & 3 & 1.25 & $\mathbf{D} \dagger$ & $E \dagger$ & 2970 & Oct. \\
\hline & 153 & 555 & 135 & 105 & 135 & 600 & 865 & 9 & 9 & 1.08 & E & $\mathrm{E}$ & 4598 & Apr. \\
\hline Oakman & 145 & 365 & 110 & 115 & 95 & 305 & 500 & 12 & 4 & 1.24 & D & D & 3445 & \\
\hline 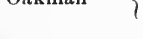 & 137 & 410 & 130 & 100 & 120 & 560 & 720 & 15 & 10 & 1.21 & E & $\mathrm{E}$ & 5055 & \\
\hline Morris & 129 & 320 & 90 & 75 & 75 & 270 & 350 & 9 & 4 & 1.30 & D & $\mathrm{D}$ & 2543 & \\
\hline Morris & 131 & 360 & 100 & 85 & 105 & 450 & 710 & 14 & 12 & 1.09 & E & E & 4869 & \\
\hline Zooman & 120 & 400 & 110 & 90 & 130 & 350 & 350 & 8 & 9 & 1.40 & F & $\mathrm{E}$ & 3070 & \\
\hline Zooman & 122 & 420 & 115 & 95 & 100 & 440 & 910 & 13 & 18 & 1.13 & E & $\mathrm{E}$ & 5457 & \\
\hline Coffiman & 129 & 290 & 105 & 103 & 100 & 320 & 530 & 7 & 6 & 1.20 & F & $\mathbf{F}$ & 2835 & \\
\hline - tomanan & 127 & 400 & 105 & 85 & 110 & 440 & 830 & 20 & 17 & 1.13 & $\mathrm{E}$ & E & 6269 & \\
\hline Steltz & 116 & 300 & 80 & 85 & 105 & 300 & 400 & 10 & 6 & 1.30 & $\mathrm{E}$ & E & 2838 & \\
\hline Stenz & 115 & 380 & 100 & 90 & 135 & 410 & 490 & 19 & 10 & 1.06 & E & E & 4581 & \\
\hline Loewenthal & 133 & 365 & 100 & 95 & 85 & 260 & 460 & 6 & 5 & 1.20 & E & E & 2463 & \\
\hline & 130 & 425 & 130 & 115 & 115 & 570 & 700 & 16 & 12 & 1.08 & E & E & 5277 & \\
\hline Sliney & 135 & 380 & 125 & 130 & 100 & 400 & 600 & 8 & 6 & 1.15 & E & E & 3245 & \\
\hline & 133 & 420 & 145 & 135 & 115 & 508 & 800 & 15 & 12 & 1.08 & $\mathrm{E}$ & E & 5307 & \\
\hline Fritz & 167 & 480 & 121 & 85 & 120 & 310 & 615 & 4 & 3 & 2.40 & D & D & 2504 & \\
\hline 171062 & 161 & 495 & 140 & 110 & 115 & 720 & 1030 & 11 & 8 & 1.17 & E & E & 5178 & \\
\hline Cohn & 142 & 320 & 50 & 75 & 80 & 245 & 340 & 3 & 6 & 2.30 & D & D & 2210 & \\
\hline & 138 & 400 & 90 & 90 & 97 & 370 & 580 & 9 & 11 & 1.14 & E & $\mathbf{E}$ & 4002 & \\
\hline Broyles & 130 & 485 & 105 & 95 & 90 & 340 & 560 & 6 & 4 & 1.45 & D & F & 2560 & \\
\hline Sirogies & 134 & 515 & 105 & 110 & 135 & 560 & 875 & 15 & 13 & 1.15 & $\mathrm{E}$ & $\mathrm{E}$ & 5530 & \\
\hline $\begin{array}{l}\text { Columbia } \\
\text { University } *\end{array}$ & 138 & 410 & 103 & 100 & & 332 & 417 & 9 & 8 & & & & & \\
\hline
\end{tabular}

* Columbia University strength test records for comparison. The $50 \%$ or mean test. From Dr. Meylan.

$\dagger \mathrm{D}=$ difficult $; \mathrm{E}=$ easy $; \mathrm{F}=$ failure. 


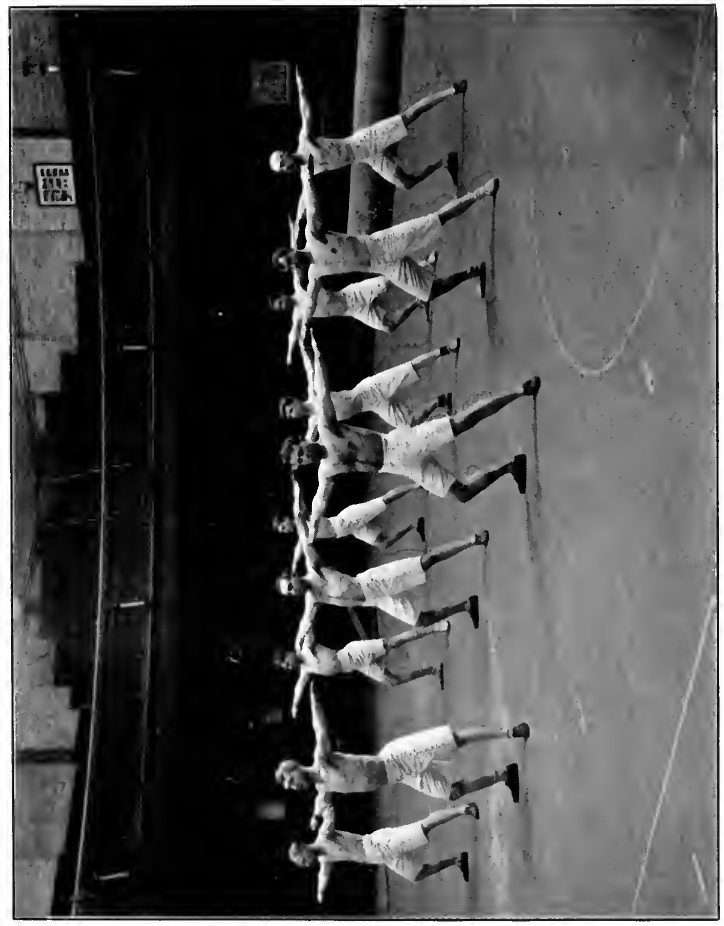

בే. 


$$
\text { . }
$$


INDIVIDUAL STRENGTH TESTS.

MORRIS.

\begin{tabular}{|c|c|c|c|c|c|c|c|c|c|c|c|c|c|}
\hline & 莣 & 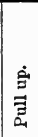 & 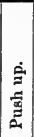 & 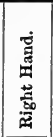 & 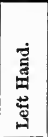 & $\begin{array}{l}\text { 芯 } \\
\text { 苟 }\end{array}$ & $\begin{array}{l}\text { 苋 } \\
\text { }\end{array}$ & 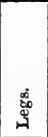 & 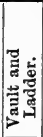 & 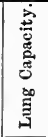 & 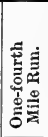 & 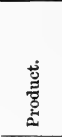 & \\
\hline Oct. $\quad 1,{ }^{\prime} 03$ & 129 & 9 & 4 & 90 & 75 & 75 & 270 & 350 & $\mathrm{D}$ & 320 & 130 & 1683 & 2543 \\
\hline ct. $12,{ }^{\prime} 03$ & 130 & 7 & 2 & 95 & 75 & 75 & 250 & 430 & $\mathrm{D}$ & 310 & 1.40 & 1170 & 2095 \\
\hline ct. $26,{ }^{\prime} 03$ & 132 & 8 & 5 & 85 & 70 & 80 & 250 & 400 & $\mathrm{D}$ & 320 & & 1120 & 2667 \\
\hline v. $9,{ }^{\prime} 03$ & 133 & 12 & 7 & 108 & 84 & 85 & 340 & 457 & $\mathbf{F}$ & 380 & 1.45 & 2536 & 3620 \\
\hline Nov. $23,{ }^{\prime} 03$ & 132 & 12 & 3 & 95 & 70 & 90 & 315 & 450 & $\mathrm{~F}$ & 325 & 1.18 & 2046 & 3066 \\
\hline Dec. $1,{ }^{\prime} 03$ & 134 & 10 & 6 & 95 & 85 & 75 & 350 & 455 & $\mathrm{~F}$ & 350 & 1.14 & 2152 & 3212 \\
\hline Dec. 15 , '03 & 130 & 7 & 4 & 100 & 100 & 85 & 400 & 490 & $\mathrm{~F}$ & 340 & 1.12 & 1430 & 2605 \\
\hline Dec. 29, ' 03 & 129 & 10 & 6 & 100 & 85 & 90 & 260 & 475 & $\mathbf{E}$ & 330 & 1.11 & 2075 & 3085 \\
\hline an. $12,{ }^{\prime} 04$ & 131 & 10 & 6 & 95 & 69 & 90 & 260 & 445 & E & 345 & 1.15 & 2108 & 3067 \\
\hline Jan. $24,{ }^{\prime} 04$ & 132 & 10 & 5 & 80 & 80 & 85 & 340 & 510 & $\mathbf{E}$ & 350 & 1.18 & 1980 & 3075 \\
\hline Feb. $\quad 9,{ }^{\prime} 04$ & 130 & 7 & 6 & 80 & 70 & 85 & 280 & & $\mathrm{E}$ & 345 & 1.14 & 1699 & 2214 \\
\hline Feb. $23,{ }^{\prime} 04$ & 134 & 5 & 6 & 100 & 100 & 90 & 310 & 450 & $\mathrm{E}$ & 360 & 1.09 & 1479 & 2529 \\
\hline Mar. 8 & 131 & 10 & 10 & 90 & 85 & 95 & 375 & 550 & $\mathbf{E}$ & 320 & 1.14 & 2620 & 3815 \\
\hline Mar. $22,{ }^{\prime} 04$ & 132 & 10 & 9 & 98 & 82 & 100 & 370 & 500 & $\mathbf{E}$ & 360 & 1.15 & 2508 & 3658 \\
\hline April $2,{ }^{\prime} 04$ & 131 & 14 & 12 & 100 & 85 & 105 & 450 & 710 & $\mathrm{E}$ & 360 & 1.09 & 3419 & 4869 \\
\hline
\end{tabular}


COFFMAN.

\begin{tabular}{|c|c|c|c|c|c|c|c|c|c|c|c|c|c|}
\hline & 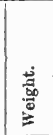 & 音 & 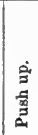 & 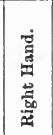 & 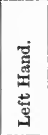 & $\begin{array}{l}\dot{\mathbf{\omega}} \\
\text { சٌ }\end{array}$ & 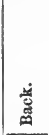 & 离 & 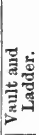 & 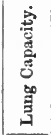 & 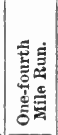 & 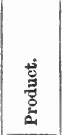 & 呓 \\
\hline ct. $1,{ }^{\prime} 03$ & 129 & 7 & 6 & 105 & 103 & 100 & 320 & 530 & D & 290 & 1.20 & 1677 & 2835 \\
\hline ct. $12,{ }^{\prime} 03$ & 129 & 9 & 8 & 110 & 85 & 120 & 350 & 500 & $\mathrm{~F}$ & 310 & 1.09 & 2193 & 3358 \\
\hline ct. $26,{ }^{\prime} 03$ & 129 & 9 & 12 & 100 & 100 & 110 & 350 & 610 & F & 345 & 1.11 & 2719 & 4119 \\
\hline ov. $9,,^{\prime} 03$ & 131 & 13 & 12 & 105 & 100 & 125 & 370 & 725 & $\mathrm{E}$ & 350 & 1.12 & 3287 & 4727 \\
\hline Nov. $23,{ }^{\prime} 03$ & 120 & 12 & 11 & 95 & 85 & 120 & 320 & 620 & $\mathrm{E}$ & 360 & 1.12 & 2990 & 4230 \\
\hline ec. $1,{ }^{\prime} 03$ & $13: 3$ & 13 & 13 & 107 & 83 & 111 & 330 & 530 & $\mathrm{E}$ & 380 & 1.12 & 3471 & 4632 \\
\hline Dec. $15,{ }^{\prime} 03$ & 129 & 15 & 12 & 100 & 98 & 120 & 390 & 649 & $\mathbf{E}$ & 375 & 1.12 & 3483 & 4840 \\
\hline Dec. $29,{ }^{\prime} 0: 3$ & 126 & 12 & 12 & 100 & 85 & 100 & 250 & 580 & $\mathrm{E}$ & 365 & 1.07 & 3042 & 4157 \\
\hline Jan. $12,{ }^{\prime} 04$ & 127 & 12 & 12 & 100 & 86 & 107 & 350 & 575 & $\mathrm{E}$ & 360 & 1.12 & 8060 & 4278 \\
\hline Jan. $26,{ }^{\prime} 04$ & 127 & 15 & 11 & 105 & 97 & 100 & 465 & 680 & $\mathrm{E}$ & 400 & 1.13 & 3312 & 4759 \\
\hline Feb. $\quad 9,{ }^{\prime} 04$ & 126 & 15 & 14 & 95 & $8 j$ & 100 & 410 & 725 & E & 390 & 1.11 & 3675 & 5090 \\
\hline Feb. $23,{ }^{\prime} 04$ & 126 & 17 & 14 & 100 & 95 & 90 & 460 & 555 & E & 380 & 1.09 & 3921 & 5221 \\
\hline Mar. $8,{ }^{\prime} 04$ & 126 & 18 & 16 & 90 & 95 & 100 & 425 & 675 & E & 390 & 1.14 & 4284 & 5669 \\
\hline Mar. 22, '04 & 129 & 19 & 16 & 115 & 93 & 100 & 430 & 600 & $\mathbf{E}$ & 400 & 1.10 & 4515 & 5913 \\
\hline Apr. $\quad 2,{ }^{\prime} 04$ & 127 & 20 & 17 & 105 & 85 & 110 & 440 & 830 & E & 400 & 1.13 & 4699 & 6269 \\
\hline
\end{tabular}


OAKMAN.

\begin{tabular}{|c|c|c|c|c|c|c|c|c|c|c|c|c|c|}
\hline & 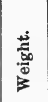 & 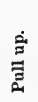 & 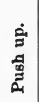 & 薦 & 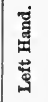 & $\begin{array}{l}\text { 总 } \\
\text { छٌ }\end{array}$ & 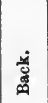 & 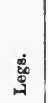 & 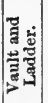 & 这 & 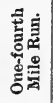 & $\begin{array}{l}\text { 芯 } \\
\text { 范 } \\
\text { 出 }\end{array}$ & \\
\hline Oct. $1,{ }^{\prime} 03$ & 145 & 12 & 4 & 110 & 115 & 95 & 305 & 500 & 1) & 365 & 1.24 & 2320 & 3445 \\
\hline Oct. $12,{ }^{\prime} 03$ & 146 & 9 & 5 & 112 & 111 & 120 & 360 & 507 & D) & 375 & 1.30 & 2044 & 3254 \\
\hline Oct. $26,{ }^{\prime} 03$ & 148 & 10 & 6 & 120 & 115 & 120 & 480 & 580 & F & 400 & 1.40 & 2368 & 3783 \\
\hline Nov. $9, ' 03$ & 150 & 13 & 9 & 123 & 121 & 125 & 390 & 620 & F & 406 & 1.40 & 3150 & 4529 \\
\hline Nov. 23, '03 & 147 & 12 & 5 & 125 & & 125 & 410 & 620 & F & 360 & 1.25 & 2499 & 3779 \\
\hline Dec. $1,{ }^{\prime} 03$ & 147 & 12 & 9 & 135 & 105 & 112 & 340 & 590 & F & 405 & 1.24 & 3092 & 4374 \\
\hline Dec. $15, ' 03$ & 141 & 10 & 6 & 125 & 120 & 115 & 390 & 570 & E & 400 & 1.25 & 2264 & 3584 \\
\hline 1)ec. $29, ' 03$ & 139 & 13 & 9 & 105 & 100 & 110 & 350 & 540 & E & 380 & 1.29 & 3058 & 4263 \\
\hline Jan. $12,{ }^{\prime} 04$ & 143 & 9 & 6 & 106 & 104 & 112 & 345 & 545 & E & 370 & 1.27 & 2152 & 3365 \\
\hline Jan. 26, '04 & 142 & 12 & 6 & 120 & 102 & 105 & 350 & 610 & E & 410 & 1.29 & 2556 & 3843 \\
\hline Feb. $9,{ }^{\prime} 04$ & 138 & 13 & 8 & 110 & 105 & 100 & 425 & 700 & E & 435 & 1.26 & 2913 & 4353 \\
\hline Feb. 23, 04 & 143 & 12 & 7 & 120 & 110 & 100 & 380 & 800 & E & 430 & 1.28 & 2716 & 4226 \\
\hline Mar. $8,{ }^{\prime} 04$ & 137 & 12 & 8 & 105 & 110 & 120 & 400 & 700 & $\mathrm{E}$ & 440 & 1.26 & 2755 & 4190 \\
\hline Mar. 22, '04 & 143 & 12 & 5 & 115 & 90 & 105 & 400 & 575 & E & 440 & 1.25 & 2439 & 3724 \\
\hline Apr. 2, '04 & 137 & 15 & 10 & 130 & 100 & 120 & 560 & 720 & E & 410 & 1.21 & 3425 & 5055 \\
\hline
\end{tabular}


ZOOMAN.

\begin{tabular}{|c|c|c|c|c|c|c|c|c|c|c|c|c|c|}
\hline & $\frac{\frac{2}{3}}{\frac{3}{5}}$ & $\stackrel{\bar{\Xi}}{\equiv}$ & 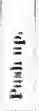 & 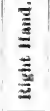 & 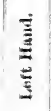 & $\frac{\stackrel{2}{2}}{\frac{2}{5}}$ & 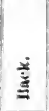 & 总 & 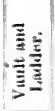 & 产美 & 童 & 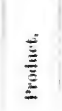 & 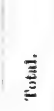 \\
\hline Oct. 1,03 & 129) & $\mathrm{s}$ & 9 & 110 & 90 & 130 & 350 & 350 & $\mathrm{D}$ & 400 & 1.40 & $\therefore 040$ & $30 \div 0$ \\
\hline Oct. 1203 & 121 & 9 & 12 & 100 & 95 & 130 & 300 & $3 \% 0$ & F & 410 & 1.28 & 25.51 & 3616 \\
\hline Oct. $-2 b, 03$ & 124 & 11 & 17 & 115 & 75 & 130 & 400 & 400 & $F$ & 440 & 1.11 & $34: 2$ & $45 \% 2$ \\
\hline Nor. 9, ${ }^{\prime} 03$ & 126 & 9 & 18 & 115 & $10 \%$ & 125 & 365 & 540 & $\mathbf{E}$ & $4: 20$ & 1.14 & 3415 & 4001 \\
\hline Sov. 2.3, 03 & 120 & 13 & 20) & 110 & 100 & $11 \%$ & 350 & 470 & $\mathrm{E}$ & 400 & 1.12 & 3260 & 5115 \\
\hline Dec. 1, 03 & 123 & 12 & 18 & 120 & 105 & 103 & 445 & 520 & $\mathrm{E}$ & 380 & 1.10 & 3000 & 4283 \\
\hline Dec. 15, 0.3 & 120 & 12 & $1 \%$ & 100 & 90 & 110 & 300 & 190 & $\mathrm{E}$ & 410 & 1.14 & 3540 & $46: 0$ \\
\hline Dec. 2n, 03 & 119 & 12 & 17 & 10.5 & 90 & 115 & 350 & 495 & $\mathrm{E}$ & 420 & 1.14 & $34: 2$ & $402=$ \\
\hline Jan. 12,04 & 122 & 11 & 15 & 112 & 102 & 117 & 320 & 520 & $\mathrm{E}$ & $4=0$ & 1.21 & $31 \% 2$ & 4303 \\
\hline $\operatorname{Jan} .20,04$ & 121 & 11 & 14 & 105 & 95 & 115 & 422 & 5335 & $\mathrm{E}$ & 405 & 1.13 & 3043 & 4315 \\
\hline Feb. 9. 'O4 & 122 & 10 & 17 & 95 & 85 & 115 & 460 & 545 & $\mathrm{E}$ & 420 & 1.10 & $331 \%$ & 4013 \\
\hline Feb. 23,24 & 121 & 10 & 17 & 100 & 105 & 112 & 350 & 570 & $\mathrm{E}$ & 408 & 1.12 & 3200 & $442=$ \\
\hline Mar. 8,04 & 119 & 12 & 18 & 105 & 95 & 100 & 425 & 700 & $\mathrm{E}$ & 410 & 1.12 & $3.5 \% 0$ & 4905 \\
\hline Mar. 22,04 & 125 & 12 & 19 & 105 & 94 & 105 & 375 & 050 & $\mathbf{E}$ & 420 & 1.13 & 3575 & $5=204$ \\
\hline Apr. 2, 04 & 122 & 13 & 18 & 115 & 95 & 100 & 440 & 910 & $\mathbf{E}$ & 430 & 1.13 & 3797 & 545 \\
\hline
\end{tabular}


STELTZ.

\begin{tabular}{|c|c|c|c|c|c|c|c|c|c|c|c|c|c|}
\hline & 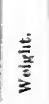 & 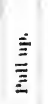 & 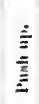 & 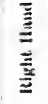 & 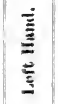 & 訔 & 菩 & 竞 & 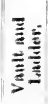 & 差美 & 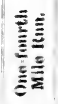 & 竞 & 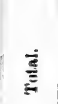 \\
\hline Oct. $1,{ }^{\prime} 03$ & $116^{\circ}$ & 10 & 6 & 80 & 85 & 105 & 300 & 400 & D & 390 & 1.30 & 1868 & $2 \approx 38$ \\
\hline Oct. $\quad 12,{ }^{\prime} 03$ & 118 & 11 & อ & 95 & 78 & 120 & 310 & 520 & D & 320 & 1.22 & 1888 & 2911 \\
\hline Oct. $26,{ }^{\prime} 03$ & 118 & 15 & 10 & 80 & 80 & 120 & 320 & 450 & F & 220 & 1.12 & 2902 & 4012 \\
\hline Nov. 9, '03 & 120 & 15 & 10 & 91 & 96 & $12 \pi$ & 375 & 505 & $F$ & 345 & 1.20 & 3000 & +194 \\
\hline Nov. 23,03 & 118 & 17 & $i$ & 9.5 & 110 & 115 & 310 & +30 & $\mathrm{E}$ & 3.5 & 1.20 & 2844 & 3004 \\
\hline Dec. $1,{ }^{\prime} 03$ & 119 & 10 & $\varepsilon$ & 93 & 85 & is & 330 & 365 & $\mathrm{E}$ & 400 & $1: 24$ & 2145 & 3090 \\
\hline Dec. $15,{ }^{\prime} 03$ & $116^{3}$ & 12 & 4 & 85 & 62 & 115 & $3 \approx 0$ & 3355 & E & 400 & 1.15 & 1584 & 2981 \\
\hline Dec. $29,{ }^{\prime} 03$ & 116 & 15 & 10 & 75 & 65 & 95 & 250 & 300 & $\mathrm{E}$ & 350 & 1.02 & 2912 & $269 \%$ \\
\hline Jan. 12, ${ }^{\prime} 04$ & 119 & 11 & 11 & 8.5 & 90 & 115 & 270 & 415 & E & $3 \leqslant 0$ & 1.10 & 2618 & 3594 \\
\hline Jan. 26,04 & 118 & 13 & 7 & $i 2$ & $\varepsilon 2$ & 13.5 & 365 & 440 & $\mathrm{E}$ & $3 \approx 0$ & 1.07 & $23: 0$ & 3404 \\
\hline Feb. $9,{ }^{\prime} 04$ & 118 & 17 & 11 & 100 & 80 & 130 & 360 & 500 & E & 405 & 1.08 & 3904 & $47 t$ \\
\hline Feb. $23,{ }^{\prime} 04$ & 117 & 17 & 8 & So & 95 & 120 & 370 & 360 & $E$ & $4: 20$ & 1.00 & 2635 & 3022 \\
\hline Mar. $8,{ }^{\prime} 4$ & 116 & 17 & 9 & 90 & 100 & 95 & 375 & 500 & $\mathrm{E}$ & 400 & $1.00^{\circ}$ & 5016 & 4176 \\
\hline Mar. 22, 04 & 117 & 19 & i & 90 & 90 & 100 & 300 & $3 \geq 0$ & $\mathrm{E}$ & 400 & 1.06 & 355 & 3055 \\
\hline Apr. 2, 'Ut & 116 & 19 & 10 & 100 & 90 & 135 & 410 & 490 & $E$ & $3 \subseteq 0$ & 1.00 & 3350 & 4581 \\
\hline
\end{tabular}


HENDERSON.

\begin{tabular}{|c|c|c|c|c|c|c|c|c|c|c|c|c|c|}
\hline & 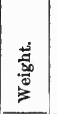 & 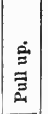 & 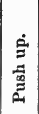 & 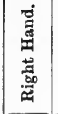 & 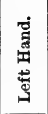 & $\begin{array}{l}\text { 㷰 } \\
\text { ठै }\end{array}$ & 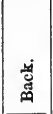 & 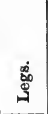 & 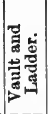 & 童 & 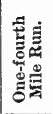 & 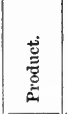 & 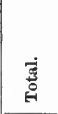 \\
\hline Oct. $\quad 1,{ }^{\prime} 03$ & 157 & 8 & 3 & 103 & 105 & 130 & 340 & 560 & F & 465 & 1.25 & 1727 & 2965 \\
\hline Oct. $12,{ }^{\prime} 03$ & 159 & 6 & 5 & 115 & 115 & 135 & 300 & 500 & F & 485 & 1.19 & 1749 & 2914 \\
\hline Nov. 9 , '03 & 162 & 9 & 9 & 105 & 105 & 140 & 420 & 700 & E & 525 & 1.07 & 2925 & 4428 \\
\hline Nov. 23, '03 & 157 & 11 & 9 & 135 & 115 & 145 & 500 & 750 & $\mathrm{E}$ & 515 & 1.07 & 3140 & 3145 \\
\hline Dec. $15,{ }^{\prime} 03$ & & . & . & & & & & & $\ldots$ & $\ldots$ & $\ldots$ & $\ldots$ & \\
\hline Dec. 29, '03 & 153 & 5 & 4 & 105 & & 125 & 250 & 365 & $\mathbf{E}$ & 520 & 1.16 & 1379 & 2109 \\
\hline Jan. 12, '04 & 153 & 5 & 5 & 85 & 60 & 135 & 320 & 595 & $\mathrm{E}$ & 530 & 1.18 & 1535 & 2730 \\
\hline Jan. 26, '04 & 155 & 5 & 3 & 100 & 65 & 105 & 350 & 460 & $\mathbf{E}$ & 540 & 1.14 & 1244 & 2332 \\
\hline Feb. $9,{ }^{\prime} 04$ & 151 & 5 & 5 & 85 & 80 & 115 & 350 & 400 & $\mathrm{E}$ & 465 & 1.12 & $\mid 1512$ & 2542 \\
\hline Feb. 23, , $^{2}$ & 153 & 9 & 7 & 110 & 115 & 125 & 450 & 610 & $\mathrm{E}$ & 535 & 1.13 & 2460 & 3870 \\
\hline Mar. $8,{ }^{\prime} 01$ & 151 & 8 & 7 & 130 & 110 & 120 & 550 & 875 & $\mathbf{E}$ & 540 & 1.13 & 2265 & 4050 \\
\hline Mar. $22,{ }^{\prime} 04$ & 155 & 9 & 8 & 122 & 100 & 125 & 370 & 570 & E & 550 & 1.12 & 2635 & 3922 \\
\hline Apr. 2, '04 & 153 & 9 & 9 & 135 & 105 & 135 & 600 & 865 & $\mathrm{E}$ & 555 & 1.08 & 2758 & 4598 \\
\hline
\end{tabular}


LOEWENTHAL.

\begin{tabular}{|c|c|c|c|c|c|c|c|c|c|c|c|c|c|}
\hline & 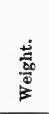 & $\begin{array}{c}\dot{a} \\
\stackrel{3}{\Xi} \\
\stackrel{\Xi}{\sharp}\end{array}$ & 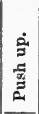 & 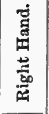 & 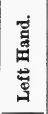 & $\begin{array}{l}\text { 岕 } \\
\text { छٌ }\end{array}$ & 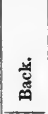 & 㥑 & 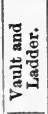 & 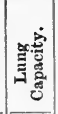 & 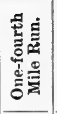 & 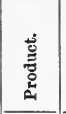 & 趈 \\
\hline Oct. $1,{ }^{\prime} 03$ & 133 & 6 & 5 & 100 & 95 & 85 & 260 & 460 & D & 365 & 1.20 & 1463 & 2463 \\
\hline Oct. $12,{ }^{\prime} 03$ & 133 & 12 & 6 & 120 & 115 & 90 & 340 & 470 & F & 370 & 1.11 & 2403 & 3538 \\
\hline Oct. $26,{ }^{\prime} 03$ & 134 & 7 & $\ldots$ & 125 & 110 & 105 & 370 & 490 & F & 360 & 1.25 & 938 & 2138 \\
\hline Nov. $9, ' 03$ & 135 & 6 & 8 & 126 & 123 & 120 & 365 & 555 & F & 365 & 1.20 & 1897 & 3179 \\
\hline Nov. '23, '03 & 134 & 7 & 8 & 110 & 100 & 120 & 370 & 420 & E & 365 & 1.14 & 2021 & 3137 \\
\hline Dec. $1,{ }^{\prime} 03$ & 135 & 13 & 11 & 125 & 105 & 85 & 350 & 390 & $\mathbf{E}$ & 380 & & 3240 & 4195 \\
\hline Dec. $15,{ }^{\prime} 03$ & 130 & 8 & 4 & 115 & 105 & 85 & 345 & 480 & $\mathrm{E}$ & 360 & 1.15 & 1560 & 2690 \\
\hline Dec. 29, ’03 & 130 & 10 & 6 & 90 & 80 & 105 & 230 & 300 & E & 380 & & 2080 & 2885 \\
\hline Jan. 12, ’04 & 130 & 12 & 9 & 106 & 104 & 117 & 360 & 480 & E & 380 & 1.12 & 2740 & 3908 \\
\hline Jan. 26, '04 & 130 & $\cdots$ & & 60 & 108 & 80 & 410 & 465 & $\mathbf{E}$ & 385 & 1.15 & & \\
\hline Feb. $9,{ }^{\prime} 04$ & 130 & 13 & 8 & 115 & 120 & 115 & 455 & 550 & $\mathbf{E}$ & 420 & 1.09 & 2730 & 4085 \\
\hline Feb. $23,{ }^{\prime} 04$ & 133 & 14 & 6 & 115 & 105 & 100 & 430 & 500 & $\mathbf{E}$ & 385 & 1.08 & 2670 & 3920 \\
\hline Mar. $8,{ }^{\prime} 04$ & 130 & 14 & 9 & 125 & 120 & 115 & 450 & 700 & E & 420 & 1.14 & 3007 & 4517 \\
\hline Mar. 22, '04 & 132 & 6 & 11 & 103 & 113 & 120 & 370 & 500 & $\mathbf{E}$ & 420 & 1.10 & 2244 & 3450 \\
\hline Apr. $2,{ }^{\prime} 04$ & 130 & 16 & 12 & 130 & 115 & 115 & 570 & 700 & E & 425 & 1.08 & 3647 & 5277 \\
\hline
\end{tabular}


SLINEY.

\begin{tabular}{|c|c|c|c|c|c|c|c|c|c|c|c|c|c|}
\hline & 莺 & $\begin{array}{c}\dot{\Xi} \\
\stackrel{\Xi}{\Xi} \\
\dot{\Xi}\end{array}$ & 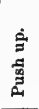 & 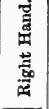 & 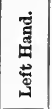 & 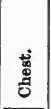 & $\begin{array}{l}\text { 㟧 } \\
\text { m }\end{array}$ & $\begin{array}{l}\dot{\Phi} \\
\Phi \\
\Phi\end{array}$ & 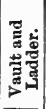 & 蜜 & 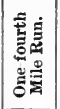 & 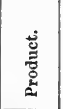 & 䓌 \\
\hline Oet. $12,{ }^{\prime} 03$ & 135 & 8 & 6 & 125 & 130 & 100 & 400 & 600 & D & 380 & 1.15 & 1890 & \\
\hline Oct. $26,{ }^{\prime} 03$ & 136 & 8 & 9 & 140 & 110 & 100 & 350 & 370 & F & 370 & 1.13 & 2260 & \\
\hline Nov. $9,{ }^{\prime} 03$ & 139 & 12 & 10 & 150 & 135 & 105 & 460 & 560 & F & 420 & 1.14 & 3127 & 45 \\
\hline Nov. 23,03 & 136 & 7 & 11 & 130 & 110 & 95 & 330 & 570 & E & 365 & 1.11 & 2448 & 368 \\
\hline Dec. $1,{ }^{\prime} 03$ & 136 & 11 & 11 & 135 & 125 & 110 & 445 & 620 & E & 400 & 1.13 & 3071 & 450 \\
\hline Dec. $15,{ }^{\prime} 03$ & 131 & 6 & 11 & 130 & 155 & 95 & 400 & 590 & $\mathbf{E}$ & 400 & 1.09 & 2231 & \\
\hline Dec. 29, ' 03 & 131 & 14 & 12 & 130 & 120 & 130 & 370 & 555 & $\mathbf{E}$ & 420 & 1.09 & 3419 & \\
\hline Jan. $12,{ }^{\prime} 04$ & 138 & 11 & 12 & 140 & 135 & 115 & 355 & 690 & E & 410 & 1.15 & 3174 & \\
\hline Jan. 26, '04 & 137 & 10 & 10 & 140 & 122 & 100 & 400 & 745 & E & 140 & 1.12 & 2745 & \\
\hline Feb. $9,{ }^{\prime} 04$ & 138 & 11 & 11 & 138 & 132 & 105 & 450 & 575 & $\mathbf{E}$ & 405 & 1.08 & 3105 & \\
\hline Feb $23,{ }^{\prime} 04$ & 139 & 12 & 10 & 140 & 145 & 99 & 430 & 650 & E & 405 & 1.08 & 3069 & 4527 \\
\hline NLar. $8,{ }^{\prime} 04$ & 135 & 14 & 13 & 150 & 130 & 110 & 525 & 825 & $\mathbf{E}$ & 440 & 1.08 & 3651 & \\
\hline Mar. 22, '04 & 139 & 14 & 9 & 145 & 138 & 115 & 340 & 565 & $\mathrm{E}$ & 440 & 1.07 & 3197 & 4500 \\
\hline Apr. $2,{ }^{\prime} 04$ & 133 & 15 & 12 & 145 & 135 & 115 & 502 & 800 & $\mathrm{E}$ & 420 & 1.08 & 3604 & 530 \\
\hline
\end{tabular}


FRITZ.

\begin{tabular}{|c|c|c|c|c|c|c|c|c|c|c|c|c|c|}
\hline & 荌 & $\stackrel{\dot{\Xi}}{\Xi}$ & 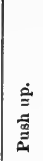 & 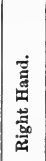 & 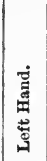 & 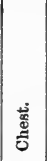 & 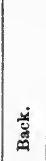 & $\underset{\Phi}{\stackrel{9}{\Phi}}$ & 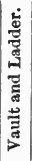 & 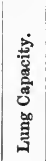 & 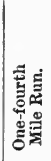 & 苑 & 营 \\
\hline Oct. 31, '03 & 167 & 4 & 3 & 121 & 85 & 120 & 310 & 615 & 1) & 480 & 2.40 & $125 \%$ & 2504 \\
\hline Nov. 23, '03 & 168 & 6 & 4 & 140 & 90 & 120 & 370 & 1050 & $\mathbf{F}$ & 480 & 1.30 & 1685 & 3455 \\
\hline Dec. $1,{ }^{\prime} 03$ & 172 & 10 & 6 & 130 & 95 & 124 & 345 & 565 & $\mathbf{F}$ & 480 & 1.20 & 2752 & 4011 \\
\hline 1)ec. $15, ' 03$ & 165 & 7 & 4 & 135 & 85 & 120 & 350 & 720 & $\mathbf{F}$ & 485 & 1.19 & 1820 & 3230 \\
\hline Dec. 29, ' 03 & 164 & 8 & 9 & 110 & 85 & 90 & 250 & 415 & E & 500 & 1.20 & 2788 & 3538 \\
\hline Jan. 12, '04 & 165 & 6 & 11 & 118 & 72 & 115 & 425 & 560 & $\mathrm{E}$ & 525 & 1.18 & 2809 & 4099 \\
\hline Feb. 9, '04 & 165 & 11 & 5 & 142 & 117 & 125 & 600 & 880 & $\mathrm{E}$ & 510 & 1.25 & 2640 & 4504 \\
\hline Feb. 23, '04 & 165 & 12 & 5 & 130 & 95 & 120 & 580 & 960 & $\mathrm{E}$ & 520 & 1.18 & 2813 & 4678 \\
\hline Mar. $8, ' 04$ & 162 & 11 & 7 & 125 & 80 & 110 & 550 & 875 & $\mathrm{E}$ & 500 & 1.21 & 2916 & 4656 \\
\hline Mar. 22, '04 & 165 & 10 & $2 *$ & 125 & 85 & 110 & 600 & 830 & $\mathbf{E}$ & 500 & 1.16 & 1986 & 3736 \\
\hline Apr. 2,'04 & 161 & 11 & 8 & 140 & 110 & 115 & 720 & 1030 & E & 495 & 1.17 & 3063 & 5178 \\
\hline
\end{tabular}

* Sore arm. 
COHN.

\begin{tabular}{|c|c|c|c|c|c|c|c|c|c|c|c|c|c|}
\hline & 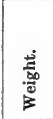 & 音 & 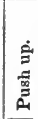 & 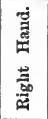 & 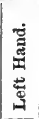 & 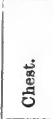 & 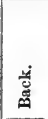 & 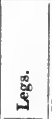 & 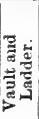 & 站总 & 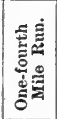 & 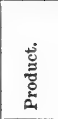 & 总 \\
\hline ov. $13, ' 03$ & 142 & 3 & 6 & 50 & 75 & 80 & 245 & 340 & D & 320 & $|2.30|$ & 1420 & 2188 \\
\hline Nov. $23,{ }^{\prime} 03$ & 144 & 7 & 5 & 105 & 95 & 87 & 270 & 430 & $\mathrm{D}$ & 360 & 1.38 & 1802 & $268 \pi$ \\
\hline Dec. 1, ' 03 & 145 & 7 & 8 & 85 & 70 & 105 & 310 & 490 & D & 350 & 1.28 & 2253 & 3313 \\
\hline Dec. $15,{ }^{\prime} 03$ & 141 & $\cdots$ & & 89 & 65 & 80 & 270 & 370 & $\mathrm{D}$ & 360 & 1.25 & & 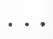 \\
\hline Dec. 29, '03 & 142 & 6 & 7 & 80 & 60 & 87 & 230 & 380 & D & 320 & 1.33 & 1846 & 2513 \\
\hline Jan. $12,{ }^{\prime} 04$ & 141 & 1 & 9 & 70 & 70 & 80 & 280 & 370 & $\mathbf{F}$ & 350 & 1.20 & 1410 & 2290 \\
\hline Jan. 26, '04 & 140 & 6 & 5 & 112 & 73 & 100 & 300 & 370 & $\mathbf{F}$ & 365 & 1.18 & 1542 & 2497 \\
\hline Feb. $9, ' 04$ & 142 & 6 & 10 & 90 & 75 & 90 & 350 & 475 & $\mathbf{F}$ & 360 & 1.19 & 2280 & 3360 \\
\hline Feb. 23, '04 & 143 & 7 & 11 & 85 & 90 & 100 & 260 & 450 & $\mathrm{~F}$ & 370 & 1.16 & 2583 & 3568 \\
\hline Mar. $22,{ }^{\prime} 04$ & 142 & 8 & 10 & 85 & 99 & 100 & 260 & 360 & $\mathrm{E}$ & 360 & 1.16 & 2556 & 3460 \\
\hline Apr. $1,{ }^{\prime} 04$ & 138 & 9 & 11 & 90 & 90 & 97 & 370 & 580 & $\mathbf{E}$ & 400 & 1.14 & 2775 & 4002 \\
\hline
\end{tabular}




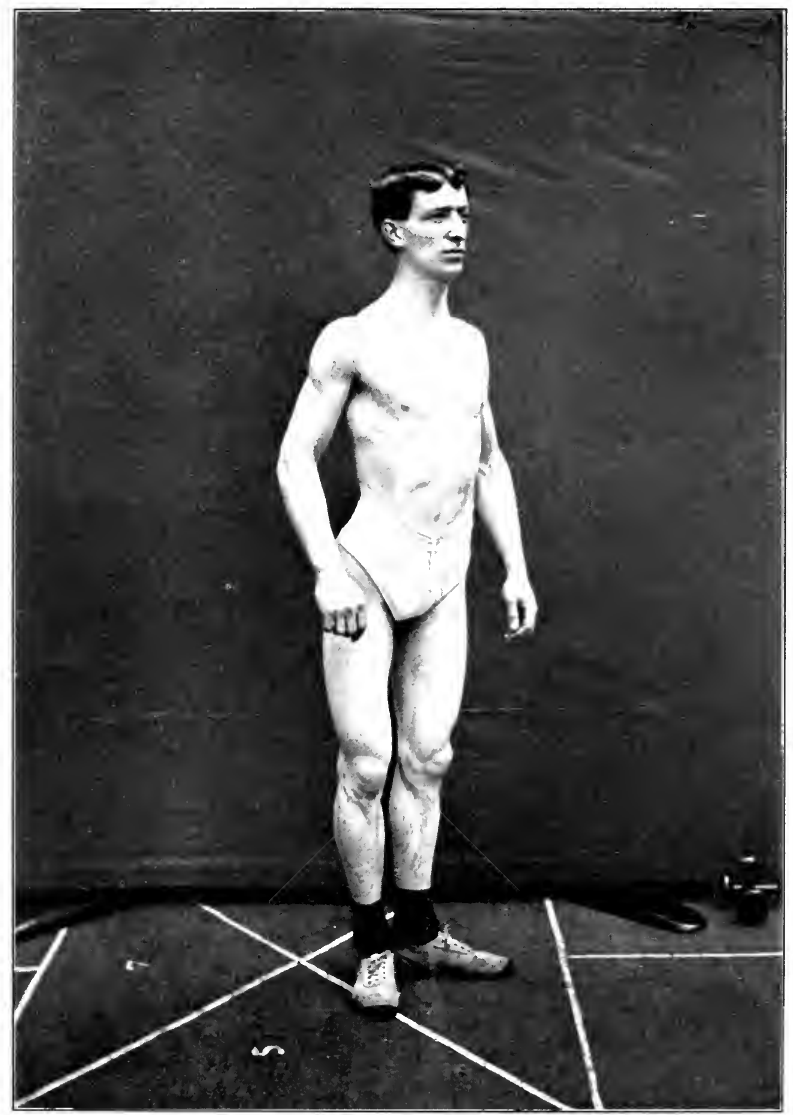

SLINEY

Photograph taten at the close of the experiment. 


$$
\text { . }
$$


BROYLES.

\begin{tabular}{|c|c|c|c|c|c|c|c|c|c|c|c|c|c|}
\hline & 葡 & $\begin{array}{r}\stackrel{\dot{\Xi}}{\Xi} \\
\vec{\Xi} \\
\vec{E}\end{array}$ & 音 & . & 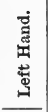 & 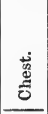 & 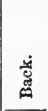 & . & 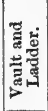 & 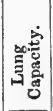 & 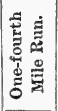 & 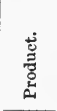 & 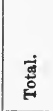 \\
\hline Nov. 13,03 & 130 & 6 & 4 & 105 & 95 & 90 & 340 & 560 & D & 485 & 1.45 & 1370 & 2560 \\
\hline Nov. $23,{ }^{\prime} 03$ & 127 & 9 & 10 & 95 & 100 & 95 & 370 & 630 & $\mathrm{~F}$ & 465 & 1.17 & 2422 & 3007 \\
\hline Dec. $1,{ }^{\prime} 03$ & 130 & 13 & 11 & 130 & 120 & 105 & 420 & 680 & F & 480 & 1.14 & 3126 & 4581 \\
\hline Dec. 15, '03 & 129 & 9 & 13 & 110 & 110 & 125 & 370 & 470 & F & 510 & 1.12 & 2843 & $402 ?$ \\
\hline Dec. $29,{ }^{\prime} 03$ & 123 & 15 & 11 & 105 & 90 & 125 & 300 & 600 & E & 480 & 1.14 & 3204 & 4424 \\
\hline Jan. 12, '03 & 126 & 15 & 12 & 101 & 95 & 130 & 370 & 580 & $\mathbf{E}$ & 485 & 1.14 & 3415 & 4691 \\
\hline Jan. 26,'04 & 130 & 10 & 8 & 103 & 95 & 120 & 470 & 890 & $\mathrm{~F}$ & 480 & 1.15 & 2345 & 4022 \\
\hline Feb. $9,{ }^{\prime} 04$ & 130 & 10 & 10 & 105 & 105 & 115 & 510 & 625 & $\mathbf{E}$ & 500 & 1.15 & 2615 & 4075 \\
\hline Feb. $23,{ }^{\prime} 04$ & 134 & 12 & 6 & 115 & 100 & 115 & 550 & 850 & E & 505 & 1.15 & 2425 & 4155 \\
\hline Mar. $8,{ }^{\prime} 04$ & 132 & 15 & 8 & 110 & 110 & 120 & 525 & 900 & $\mathrm{E}$ & 510 & 1.17 & 3047 & 4812 \\
\hline Mar. 22, '04 & 138 & 12 & 12 & 110 & 110 & 125 & 470 & 850 & $\mathrm{E}$ & 510 & 1.14 & 3320 & 4989 \\
\hline Apr. $2,{ }^{\prime} 04$ & 133 & 15 & 13 & 105 & 110 & 135 & 560 & 875 & E & 515 & 1.15 & 3745 & 5530 \\
\hline
\end{tabular}

The main things in Dr. Anderson's report especially to be emphasized are (1) the gain in self-reliance and courage of the men under training, indicative as they are of the better physical condition of their bodies, and (2) the marked in- 


\section{PHYSIOLOGICAL ECONOMY IN NUTRITION}

crease in their strength as indicated by the steady improvement in the strength or dynamometer tests. Obviously, the daily training to which the men were subjected in the Gymnasium is not to be overlooked as one factor in bringing about the gain in accuracy and skill, and indeed this factor must count for something in explaining the general gain in bodily strength, but increased skill alone will not account for the great gain in muscular power.

The results of these systematic tests make it very evident that the men were not being weakened by the lowered intake of proteid food. On the contrary, their ability to do muscular work was greatly increased; a fact which cannot well be connected with anything other than the physiological economy which was being practised. There must be enough food to make good the daily waste of tissue, enough food to furnish the energy of muscular contraction, but any surolus over and above what is necessary to supply these needs is not only a waste, but may prove an incubus, retarding the smooth working of the machinery and detracting from the power of the muscular mechanism to do its best work.

The figures showing the total strength of the men in October, 1903, on their ordinary diet, and on the second day of April, 1904, when the experiment was nearing completion are certainly very impressive.

TOTAL STRENGTH

\begin{tabular}{|c|c|c|c|c|c|c|c|}
\hline Henderson & . & . & . & . & . & $\begin{array}{c}\text { October } \\
. \quad 2970\end{array}$ & $\begin{array}{c}\text { April } \\
4598\end{array}$ \\
\hline Oakman . & . & . & . & . & . & . 3445 & 5055 \\
\hline Morris . & . & . & . & . & . & . 2543 & 4869 \\
\hline Zooman . & . & . & . & . & . & . 3070 & 5457 \\
\hline Coffman . & . & . & . & . & . & . 2835 & 6269 \\
\hline Steltz . & . & . & . & . & . & . 2838 & 4581 \\
\hline Loewenthal & & • & . & . & . & . 2463 & 5277 \\
\hline Sliney . & . & . & . & . & . & . 3245 & 5307 \\
\hline Fritz. & . & . & . & . & . & . 2504 & 5178 \\
\hline Cohn . & . & . & . & . & . & 2210 & 4002 \\
\hline Broyles & . & . & . & . & . & 2560 & 5530 \\
\hline
\end{tabular}


Here we see gains in strength of 100 per cent in some cases, while Coffman shows an improvement so marked as to be almost marvellous. While there can be no question that a certain amount of this gain is to be attributed to the practice incidental to these months of work in the Gymnasium, it is equally clear that a large part of the gain is due to the improved physical condition of the men's bodies, for which the change in diet must be considered as responsible. In any event, the change from the ordinary diet to a diet comparatively poor in proteid has not resulted in any physical deterioration. On the contrary, there is every indication of a marked improvement in physical condition. In this connection the following note from Dr. DeWitt, commanding the detachment, is of interest :

\section{Temple Street, New Haven, Conn., March 30, 1904.}

Professor Russell H. Chittenden,

Director Sheffield Scientific School,

New Haven, Cons.

SIR, - In compliance with your verbal request $I$ have the honor to inform you that at this date the men of this detachment are all in good physical condition.

Very respectfully,

(Signed) Wallace DeWitt, 1st Lieut. and Asst. Surgeon U. S. Army, Commdg. Det. H. C.

Finally, attention may be called to the photographs of the men, taken just prior to the close of the experiment, from which may be gained some idea of their physical condition so far as it can be judged by external appearance. Certainly, there is no indication in these photographs of any lack of bodily vigor. On the contrary, there is good muscular development, without any undue amount of fat, and indeed every indication of a good bodily condition, coupled with that appearance of quickness and alertness that belongs to the welldeveloped man, in a state of physiological balance. The 
photographs scattered through this section of the book, showing the soldiers at work in the gymnasium, likewise give some idea of the lighter forms of exercise they followed each day in the training of bodily movements.

What now is to be said regarding the nervous condition of the men; i. e., their ability to respond to stimulation or, in other words, their mental quickness or reaction time? To study this question, the soldiers were sent with regularity to the Yale Psychological Laboratory, where their reaction time was studied with great care. The results of this investigation are contained in the following report made by Dr. Charles H. Judd, in charge of the Yale Psychological Laboratory.

\section{REPORT ON REACTION TIME.}

In order to test the quickness of the members of the Hospital Corps Detachment, and to determine whether the changes in diet affected in any way their ability to respond promptly to sensory stimulation, each man was earried through a series of reaction experiments at the Yale Psychological Laboratory. The method of the experiments was that regularly employed in simple reaction time experiments. The person whose reaction time is to be measured is seated in a comfortable position with his finger pressing on an electric key. He is told that he is to lift his finger from the key as quickly as possible when he hears a given sound-signal. The sounder which produces this signal and the electric key are placed in a circuit with a standard time-measuring apparatus the Hipp Chronoscope. This chronoscope is arranged so that it begins to record the instant the sound is given and stops the instant the reactor lifts his finger. The dial of the chronoscope shows in thonsandths of a second (hereafter desiguated by the technical term sigmas) the time that elapses between the sound to which the reactor is to respond and the movement of response. The chronoscope was tested at frequent intervals by means of a standard pendulum and errors in the record are well under two sigmas.

The time which is measured by this method is occupied chiefly by nervous processes. The following factors may be specified: 
First, the auditory organ is aroused by the sound; second, the afferent nerve transmits the stimulation to the central nervous system; third, the central nervous system earries the energy to the motor nerves; fourth, the efferent motor nerves transmit the stimulus to the muscles; and finally, some time is required by the muscle for its contraction. It will be seen, accordingly, that the chief factors of a reaction are nervous processes, and since the external conditions of successive reactions are in all respects uniform, any rariations in the time of a given person's reactions may be regarded as indicating variations in the nervous condition of the reactor. In view of the instability of nervous conditions, it is necessary to eliminate any slight or merely temporary fuctuations by taking each time a given reactor is tested a series of reactions. For this reason, a series of ten reactions was taken with each of the men every two weeks during November, December, and January. After an interval of two months, namely, on March 30, 31 , and April 1, two final series were made with each man.

The results are presented in tables 1 to 5 . The dates in the first column indicate the day on which each individual set of ten reactions was taken. The second column presents the arerages of each ten reactious in sigmas. The third column gives the mean variations of the various single reaction times from the average. The fourth column gives the variations of the day's average, recorded in column 2, from the general average of that individual for all his experiments. These general averages are presented in table 6. At the bottom of each eomplete column of averages will be found the group average. This quantity is obtained by averaging the results from all the members of the squad for periods of, approximately, two weeks.

The mean variations in the third column make it clear that the subjects did not settle down into what could be regarded as trained subjects. Trained subjects are expeeted to give mean variations which are consistently within the limits of 10 per cent of the average. While there are, of course, instanees in which the mean variation falls within this limit, there is no consistent exhibition of the regularity indicative of thorough practice. 'This fact is further confirmed by a comparison of the results of March 30,31, and April 1 with those of the earlier months. At the end of March, all effects of practice in November, December, and January, 


\section{PHYSIOLOGICAL ECONOMY IN NUTRITION}

except the most general, may be regarded as having disappeared : and yet the averages and variations for the March and April dates resemble closely those of the month immediately preceding and also those of November. 'The effects of practice may, accordingly, be regarded as insignificant.

This lack of special training accounts for the large variations which appear in some cases. As is usual in reaction experiments, the signal to which the reactors were to respond was in each case preceded by about two seconds by a bell signal to arouse attention. Conditions were thus rendered as nearly uniform as possible, but the variations indicate in three or four cases exceptional lapses of attention. Such exceptional cases can be eliminated without prejudicing the final validity of the results by substituting the median for the averages. In table 7 , the medians are grouped together and show even more than the tables of average the absence of any general variation during the period of the tests.

The obvious conclusion from these tests is that the quickness of the members of the squad underwent no general change during the whole period covered by the test. Individual membere showed variations from time to time, but these variations are clearly accidental in character, for they show no regular tendencies and are in no way related to the changes in the character and amount of the diet.

April 12, 1904.

(Signed) Charles H. Judd.

The following tables give all the data upon which the foregoing conclusions are based, being furnished by Dr. Judd and Mr. Warren M. Steele, Assistant in Psychology, by whom the observations were made. Dr. Cloyd N. McAllister, Instructor in Psychology, was also associated in the making of these observations. 
TABLE 1.- ОстовER, 1903.

\begin{tabular}{|c|c|c|c|c|c|c|c|c|c|}
\hline \multicolumn{2}{|l|}{ Name. } & Date. & Avg. & M. V. & Var. & Date. & Avg. & M. V. & Var. \\
\hline I. Coffman & . & 17 & 207.4 & 34.1 & 8.7 & . . & . . & $\cdots$ & $\cdots$ \\
\hline II. Henderson & . . & 17 & 179.9 & 31.5 & 21.2 & . & $\ldots$ & $\ldots$ & $\ldots$ \\
\hline III. Loewenthal & . . & 17 & 216.9 & 43.5 & 7.8 & . & $\ldots$ & $\ldots$ & $\ldots$ \\
\hline IV. Morris ., & . . & 17 & 227.7 & 19.8 & 3.7 & . & $\ldots$ & $\cdots$ & .. \\
\hline V. Oakman . & . . & 17 & 222.7 & 65.4 & 4.8 & 27 & 223.5 & 28.8 & 5.6 \\
\hline VI. Sliney . & . . & 22 & 262.4 & 33.1 & 49.9 & 29 & 204.5 & 46.2 & 8.0 \\
\hline VII. Steltz . & . . & 17 & 167.7 & 163 & 20.4 & 27 & 195.0 & 21.1 & 6.9 \\
\hline VIII. Zooman & . . & 17 & 264.9 & 32.1 & 50.0 & . & $\cdots$ & $\cdots$ & .. \\
\hline IX. Fritz & . . & $\cdots$ & $\cdots$ & $\cdots$ & $\cdots$ & $\cdots$ & $\cdots$ & $\cdots$ & $\cdots$ \\
\hline X. Broyles & . . & .. & $\ldots$ & . . & $\ldots$ & . . & $\ldots$ & $\ldots$ & $\ldots$ \\
\hline X1. Cohn . . & . . & . & $\cdots$ & $\cdots$ & $\cdots$ & . & $\cdots$ & $\cdots$ & $\cdots$ \\
\hline Group average $(8 \mathrm{c}$ & nly) & . & 218.7 & & & $\cdots$ & $\cdots$ & $\cdots$ & \\
\hline
\end{tabular}

TABLE 2.- November, 1903.

\begin{tabular}{|c|c|c|c|c|c|c|c|c|c|c|c|c|}
\hline Name. & 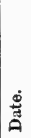 & $\frac{\infty 0}{4}$ & $\vec{z}$ & 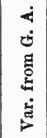 & 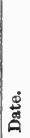 & $\stackrel{\dot{0}}{\dot{C}}$ & $\dot{\vec{z}}$ & 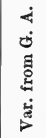 & હٌ & $\underset{4}{\dot{\infty}}$ & $\overrightarrow{\dot{z}}$ & 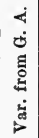 \\
\hline I. Coffinan . & 6 & 303.7 & 37.9 & 87.6 & 20 & 215.9 & 22.8 & 0.5 & . . & $\ldots$ & . . & $\cdots$ \\
\hline II. Henderson & $\bar{j}$ & 248.5 & 72.9 & 47.4 & 19 & 198.2 & 22.0 & 2.9 & . & $\ldots$ & $\ldots$ & $\cdots$ \\
\hline III. Loewenthal & 13 & 190.1 & 23.7 & 34.6 & 30 & 229.7 & 37.4 & 5.0 & . . & $\ldots$ & $\ldots$ & $\ldots$ \\
\hline IV. Morris . & - & $\cdots$ & . . & $\ldots$ & 25 & 218.6 & 45.0 & 17.2 & . & $\ldots$ & $\cdots$ & $\ldots$ \\
\hline V. Oakman & 10 & 185.9 & 13.9 & 32.0 & 24 & 212.1 & 21.9 & 5.8 & . & $\ldots$ & $\ldots$ & $\ldots$ \\
\hline VI. Sliney . & 12 & 200.1 & 25.3 & 11.0 & 26 & 209.2 & 24.6 & 3.3 & . . & $\ldots$ & $\cdots$ & $\ldots$ \\
\hline VII. Steltz & 10 & 2032 & 45.7 & 15.1 & 24 & 163.8 & 31.4 & 24.8 & . . & $\ldots$ & $\ldots$ & $\ldots$ \\
\hline VIII. Zooman & 5 & 192.0 & 29.2 & 22.9 & 19 & 183.8 & 23.4 & 31.1 & $\because$ & $\ldots$ & $\cdots$ & $\ldots$ \\
\hline IX. Fritz • & 2 & 240.1 & 17.3 & 19.5 & 17 & 204.8 & 18.2 & 15.8 & 30 & 223.8 & 52.3 & 3.2 \\
\hline X. Broyles . & . & $\cdots$ & .. & $\cdots$ & 17 & 184.7 & 23.0 & 32 & . & $\cdots$ & $\cdots$ & $\cdots$ \\
\hline XI. Cohn . . & . . & $\ldots$ & $\cdots$ & . & 23 & 279.1 & 50.7 & 70.3 & . . & $\ldots$ & $\cdots$ & $\ldots$ \\
\hline Group a & & & & & . & 211.8 & & & & & & \\
\hline
\end{tabular}


TABLE 3.-December, 1903.

\begin{tabular}{|c|c|c|c|c|c|c|c|c|c|c|c|c|}
\hline Name. & हैं & $\dot{\infty}^{\dot{0}}$ & $\overrightarrow{\dot{z}}$ & 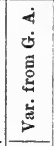 & 苋 & $\dot{\infty}_{4}^{\infty}$ & $\vec{z}$ & 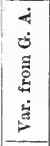 & ڤี & $\frac{30}{4}$ & $\dot{2}$ & 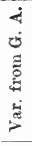 \\
\hline I. Coffman . . & 4 & 230.1 & 22.5 & 14.0 & 18 & 184.7 & 21.4 & 31.4 & . & $\cdot, \cdot$ & $\cdots$ & $\cdots$ \\
\hline II. Henderson & . & $\cdots$ & $\cdots$ & ... & 31 & 187.0 & 10.0 & 14.1 & . & $\cdots$ & $\cdots$ & . \\
\hline III. Loewenthal & 11 & 224.6 & 33.0 & 0.1 & 26 & 217.9 & 10.5 & 6.8 & . & $\cdots$ & $\cdots$ & . \\
\hline IV. Morris . . . & 9 & $2: 37.7$ & 16.4 & 63 & $2: 3$ & 276.6 & 80.8 & 45.2 & . & $\cdots$ & $\cdots$ & . \\
\hline V. Oakman . . & 8 & 233.5 & 19.5 & 15.6 & 22 & 220.5 & 17.5 & 2.6 & . & $\cdots$ & $\cdots$ & . \\
\hline VI. Sliney ... & 10 & 218.3 & 25.4 & 5.8 & 24 & 197.1 & 24.1 & 15.4 & . & $\cdots$ & $\cdots$ & . \\
\hline VII. Steltz. . . . & 8 & 178.3 & 15.9 & 9.8 & 22 & 201.7 & 20.3 & 13.6 & $\cdots$ & $\cdots$ & $\cdots$ & . \\
\hline VIII. Zooman .. & 3 & 292.7 & 42.4 & 77.8 & 17 & 248.1 & 71.1 & 33.2 & 31 & 206.9 & 35.0 & 8.0 \\
\hline IX. Fritz . . . & 14 & 187.4 & 16.1 & 33.2 & 28 & 200.7 & 22.4 & 19.9 & $\cdots$ & $\ldots$ & $\cdots$ & . \\
\hline X. Broyles . . & 1 & 180.3 & 13.8 & 7.6 & 15 & 188.0 & 25.8 & 0.1 & . & $\cdots$ & $\cdots$ & . \\
\hline XI. Cohn .... & 7 & 243.3 & 111.1 & 34.5 & 21 & 177.0 & 16.2 & 31.8 & $\cdots$ & $\cdots$ & $\cdots$ & . \\
\hline Group avera & 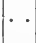 & 222.6 & & & . & 209.0 & & & $\cdots$ & $\cdots$ & $\cdots$ & . \\
\hline
\end{tabular}

TABLE 4. - Jandary and February, 1904.

\begin{tabular}{|c|c|c|c|c|c|c|c|c|c|c|c|c|}
\hline Name. & हึँ & $\stackrel{\infty}{\dot{0}}$ & $\dot{\vec{z}}$ & $\begin{array}{l}\dot{4} \\
\dot{0} \\
\vec{j} \\
\dot{0} \\
\dot{\omega} \\
\dot{j}\end{array}$ & बंँ & $\frac{\dot{\phi}}{4}$ & $\dot{\vec{z}}$ & 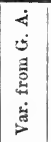 & 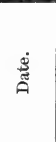 & $\dot{\infty}_{4}^{\dot{0}}$ & $\vec{z}$ & 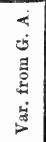 \\
\hline I. Coffnuan. . & 1 & 188.5 & 22.4 & 27.6 & 15 & 246.4 & 60.5 & 30.3 & $\begin{array}{r}29 \\
\text { Feb. }\end{array}$ & 198.2 & 14.2 & 17.9 \\
\hline II. Henderson & 7 & 206.8 & 14.2 & 5.7 & 21 & 180.9 & 8.9 & 20.2 & 4 & 172.1 & 15.0 & 29.0 \\
\hline III. Loewenthal & 8 & 208.0 & 13.2 & 16.7 & 22 & 201.8 & 16.5 & 12.9 & $\cdots$ & $\ldots$ & $\cdots$ & $\cdots$ \\
\hline IV. Morris . & 6 & 260.4 & 39.9 & 29.0 & 20 & 222.3 & 36.0 & 9.1 & 3 & 241.0 & 15.6 & 12.6 \\
\hline V. Oakman & 5 & 235.7 & 33.4 & 17.8 & 19 & 215.5 & 17.8 & 2.4 & 2 & 197.0 & 19.8 & 20.9 \\
\hline VI. Sliney . & 14 & 186.6 & 20.0 & 25.9 & 28 & 167.9 & 11.3 & 44.6 & $\cdots$ & $\cdots$ & $\cdots$ & $\cdots$ \\
\hline VII. Steltz . & 5 & 211.5 & 9.1 & 23.4 & 19 & 200.4 & 29.2 & 12.3 & 2 & 169.9 & 13.9 & 18.2 \\
\hline VIII. Zooman. & 7 & 237.6 & 106.2 & 22.7 & 21 & 197.0 & 13.0 & 17.9 & 4 & 164.5 & 6.9 & 50.4 \\
\hline IX. Fritz. & 11 & 240.5 & 73.9 & 19.9 & 25 & 183.9 & 15.9 & 36.7 & $\ldots$ & $\ldots$ & $\ldots$ & $\ldots$ \\
\hline X. Broyles . & 12 & 211.6 & 33.3 & 23.7 & 26 & 203.6 & 21.7 & 15.7 & $\ldots$ & $\ldots$ & $\ldots$ & $\ldots$ \\
\hline XI. Cohn. . . & 4 & 187.1 & 34.3 & 21.7 & 18 & 195.8 & 23.7 & 13.0 & 1 & 195.4 & 47.2 & 13.4 \\
\hline Group averages &. & 215.8 & & & & 202.3 & & & & & & \\
\hline
\end{tabular}


TABLE 5.- March and April, 1904.

\begin{tabular}{|c|c|c|c|c|c|c|c|c|}
\hline Name. & 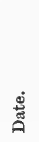 & $\overbrace{}^{\infty}$ & $\dot{\vec{z}}$ & 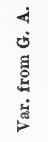 & ڤัँ & $\frac{80}{4}$ & $\dot{\vec{z}}$ & 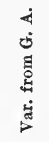 \\
\hline I. Coffman . & 30 & 191.9 & 13.7 & 24.2 & 1 & 194.4 & 25.9 & 21.7 \\
\hline II. Henderson & 31 & 195.2 & 15.2 & 5.9 & 1 & 241.3 & 27.2 & 40.2 \\
\hline III. Loewenthal . . & 31 & 231.9 & 45.9 & 7.2 & 1 & 291.0 & 49.6 & 66.3 \\
\hline IV. Morris . . & 31 & 174.4 & 11.4 & 57.0 & 1 & 190.7 & 18.6 & 40.7 \\
\hline V. Oakman . & 31 & 223.2 & 47.2 & 5.3 & 1 & 226.3 & 52.0 & 8.4 \\
\hline VI. Sliney . & 30 & 239.3 & 47.1 & 16.8 & 31 & 239.6 & 11.8 & 17.1 \\
\hline VII. Steltz . . . . & 30 & 193.5 & 34.0 & 5.4 & 1 & 193.2 & 29.3 & 5.2 \\
\hline VIII. Zooman . . . & 30 & 196.6 & 11.6 & 18.3 & 1 & 179.8 & 15.6 & 35.1 \\
\hline IX. Fritz . & 31 & 244.5 & 48.9 & 23.9 & 1 & 259.7 & 39.3 & 39.1 \\
\hline X. Broyles & 30 & 180.0 & 19.4 & 0.1 & 1 & 182.6 & 23.6 & 5.3 \\
\hline XI. Cohn . & 31 & 210.8 & 21.7 & 2.0 & 1 & 181.7 & 12.0 & 27.1 \\
\hline Group averages . . . & . & 207.4 & . . & . & . & 216.4 & $\cdots$ & \\
\hline
\end{tabular}

TABLE 6.

\begin{tabular}{|c|c|c|c|c|c|}
\hline & 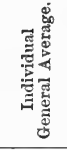 & 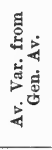 & & 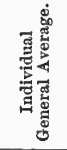 & 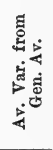 \\
\hline I. Coffman . . & 216.1 & 26.4 & VII. Steltz . . . & 188.1 & 14.0 \\
\hline II. Henderson . & 201.1 & 20.7 & VIII. Zooman . & 214.9 & 33.4 \\
\hline III. Loewenthal . . & 224.7 & 17.5 & IX. Fritz . . & 220.6 & 23.5 \\
\hline IV. Morris . . & 231.4 & 24.5 & X. Broyles. . & 187.9 & 8.8 \\
\hline V. Oakman . . & 217.9 & 11.0 & XI. Cohn & 208.8 & 26.7 \\
\hline VI. Sliney . . . & 212.5 & 19.7 & & & \\
\hline
\end{tabular}

General group average . . . . . . 211.6 


\begin{tabular}{|c|c|c|c|c|c|c|c|c|c|c|c|c|c|c|}
\hline \multirow{2}{*}{ வिं } & 'ив!̣рәук & & $:$ & $\stackrel{20}{\stackrel{20}{N}}$ & 怘 & $\stackrel{\stackrel{0}{\mathrm{D}}}{\mathrm{I}}$ & $\stackrel{\stackrel{2}{\circ}}{\circ}$ & $\begin{array}{l}0 \\
\mathbf{\infty} \\
\stackrel{\infty}{-}\end{array}$ & & $: 8$ & : & $\vdots$ & $\begin{array}{l}20 \\
\dot{े} \\
\hat{े}\end{array}$ & $\stackrel{0}{\infty}$ \\
\hline & •วีย $\alpha$ & : & : & 5 & $n$ & ล1 & 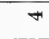 & $\stackrel{\infty}{-\infty}$ & & : & - & : & 5 & - \\
\hline \multirow{2}{*}{ 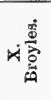 } & •иє!рәџ & & 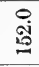 & : & $\stackrel{0}{\stackrel{0}{0}}$ & $\stackrel{29}{+\infty}$ & $\begin{array}{l}20 \\
\text { के }\end{array}$ & 영 & & & $\vdots$ & $\begin{array}{l}0 \\
\text { هil } \\
\stackrel{0}{-1}\end{array}$ & $\vdots$ & $\begin{array}{l}\stackrel{\leftrightarrow}{0} \\
\stackrel{0}{0}\end{array}$ \\
\hline & •əาย & : & $\cong$ & : & - & 10 & 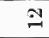 & สิ & & : & 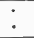 & $\approx$ & : & - \\
\hline \multirow{2}{*}{ 造 } & 'uетрәэк & & $\stackrel{\circ}{\stackrel{E}{S}}$ & $\underset{+}{\stackrel{\circ}{*}}$ & $\begin{array}{l}\stackrel{90}{0} \\
\stackrel{D}{5}\end{array}$ & $\begin{array}{l}0 \\
\infty \\
0 \\
0\end{array}$ & ㅇ. & 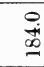 & & & $\vdots$ & $\vdots$ & 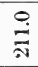 & 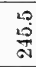 \\
\hline & •əzв $\alpha$ & : & $\approx$ & $\therefore$ & \pm & $\stackrel{\infty}{\sim}$ & $=$ & ลำ & & : & : & : & 30 & - \\
\hline \multirow{2}{*}{ 雪高 } & 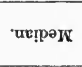 & : & $\begin{array}{l}\stackrel{0}{\dot{0}} \\
\dot{0}\end{array}$ & $\stackrel{\circ}{+}$ & 足 & : & $\begin{array}{l}0 \\
\stackrel{1}{0} \\
-1\end{array}$ & $\begin{array}{l}20 \\
\stackrel{9}{9}\end{array}$ & & $: 5$ & 足 & 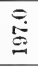 & : & 焉 \\
\hline & 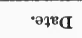 & $\cong$ & 10 & $\stackrel{\rho}{-}$ & $\infty$ & $=$ & $r$ & $\overrightarrow{\mathrm{N}}$ & & $:$ & $\pi$ & ๑ి & : & - \\
\hline \multirow{2}{*}{ 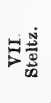 } & 'ut!̣pगJर & $\begin{array}{l}\circ \\
\stackrel{0}{0} \\
\stackrel{0}{0}\end{array}$ & 点 & 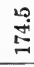 & $\begin{array}{l}\stackrel{\rho}{\infty} \\
\stackrel{\infty}{5}\end{array}$ & $\stackrel{\circ}{\mathscr{S}}$ & $\stackrel{\circ}{\stackrel{0}{*}}$ & @ & & $:$ & 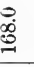 & $\stackrel{\stackrel{\rho}{\circ}}{\stackrel{\infty}{\infty}}$ & & $\begin{array}{l}\stackrel{0}{0} \\
\stackrel{1}{0}\end{array}$ \\
\hline & •ə⿻コ一 & $\cong$ & 응 & $\vec{N}$ & $\infty$ & สิ & 20 & 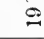 & & : & $\infty$ & $\%$ & : & - \\
\hline \multirow{2}{*}{$\dot{5}$} & 'uв!̣p & 옹 & $\stackrel{\circ}{\mathrm{\sigma}}$ & $\stackrel{10}{8}$ & ㅇ. & $\begin{array}{l}0 \\
\infty \\
\infty\end{array}$ & $\stackrel{20}{8}$ & $\stackrel{\circ}{\mathrm{S}}$ & & & $\vdots$ & $\frac{\stackrel{20}{0}}{\mathrm{~d}}$ & 总 & \\
\hline & $\cdot$ • & ลี & $\stackrel{N}{\sim}$ & के & 은 & $\overrightarrow{\mathrm{N}}$ & $\Xi$ & $\stackrel{\infty}{\sim}$ & & : & $:$ & ๙ิ & $\overline{c 0}$ & : \\
\hline \multirow{2}{*}{ 赔 } & 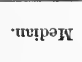 & $\stackrel{\circ}{\Xi}$ & $\stackrel{\stackrel{8}{0}}{\mathscr{0}}$ & $\stackrel{8}{\stackrel{8}{\circ}}$ & 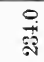 & $\begin{array}{l}\text { O } \\
\text { สิ }\end{array}$ & $\stackrel{10}{\stackrel{10}{\leftrightarrow:}}$ & कृें & & $: 8$ & 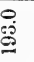 & $\vdots$ & $\begin{array}{l}20 \\
\stackrel{10}{*}\end{array}$ & $\stackrel{19}{\overrightarrow{5}}$ \\
\hline & •әาе & $\cong$ & 은 & ה & $\infty$ & จิ & 20 & 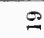 & & : & N & $:$ & $\overline{60}$ & - \\
\hline \multirow{2}{*}{ 视 } & 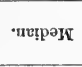 & 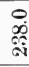 & : & สุ๋ & $\begin{array}{l}\stackrel{\circ}{\circ} \\
\stackrel{i}{*}\end{array}$ & $\begin{array}{l}0 \\
\text { aे } \\
\text { a. }\end{array}$ & $\stackrel{\circ}{3}$ & 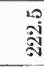 & & & 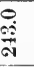 & $\vdots$ & $\stackrel{\circ}{0}$ & $\begin{array}{l}0 \\
0.0 \\
\stackrel{0}{0}\end{array}$ \\
\hline & •əุะ $\alpha$ & $=$ & : & ลิ & 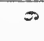 & ค & $\bullet$ & จิ & & $: 0$ & $\infty$ & : & $\bar{\sigma}$ & - \\
\hline \multirow{2}{*}{ 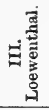 } & 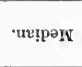 & @̊. & $\stackrel{0}{\infty}$ & $\underset{\text { 空 }}{\stackrel{0}{2}}$ & $\begin{array}{l}\stackrel{\leftrightarrow 0}{\circ} \\
\stackrel{\leftrightarrow}{\text { N }}\end{array}$ & $\frac{\Delta}{\sigma}$ & $\stackrel{\circ}{\stackrel{+}{*}}$ & \&. & & & $\vdots$ & $:$ & 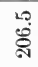 & $\stackrel{8}{\circ}$ \\
\hline & 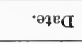 & $=$ & 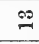 & $\stackrel{\circ}{\circ}$ & $=$ & จึ & $\infty$ & สิ & & : & : & : & $\vec{\sigma}$ & - \\
\hline \multirow{2}{*}{ 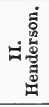 } & 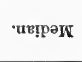 & $\stackrel{2}{\infty}$ & $\underset{\mathrm{I}}{\mathrm{i}}$ & $\begin{array}{l}\stackrel{0}{0} \\
\stackrel{0}{\Phi}\end{array}$ & : & $\begin{array}{l}10 \\
18 \\
0\end{array}$ & is & $\stackrel{20}{\rightarrow \infty}$ & & $:$ & تָ تָ & $\vdots$ & $\stackrel{\circ}{\stackrel{B}{S}}$ & 荬 \\
\hline & •ə઼ะ $\alpha$ & $=$ & 10 & $\stackrel{2}{2}$ & : & $\bar{\sigma}$ & $1-$ & $\vec{\sim}$ & & $:$ & + & $:$ & $\bar{\infty}$ & - \\
\hline \multirow{3}{*}{ - } & 'uв!̣ә & 䒿 & : & 兽 & 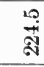 & 8 & $\left\{\begin{array}{l}20 \\
\propto \\
0\end{array}\right.$ & ث্ं & 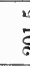 & ถุ & & $\stackrel{\stackrel{\leftrightarrow}{\mathrm{d}}}{\mathrm{G}}$ & & $\stackrel{8}{\mathrm{~g}}$ \\
\hline & 'өде $\alpha$ & $\approx$ & 0 & 오 & $\pi$ & $\stackrel{\infty}{\sim}$ & - & $\stackrel{20}{-1}$ & \% & $\stackrel{5}{*}$ & : & \& & $\vec{\omega}$ & - \\
\hline & •чдиојк & نे & $\vec{z}$ & $\ddot{z}$ & $\stackrel{\Xi}{\varrho}$ & 巳ั & $\stackrel{\dot{\Xi}}{\stackrel{5}{5}}$ & 퐆 & 3 & ฮี่ & هُ & 莺 & $\stackrel{\check{z}}{z}$ & 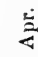 \\
\hline
\end{tabular}




\section{Character of the Blood.}

One question that naturally arises in considering the possible effects of a diminished proteid intake upon bodily health is whether a continued diminution of proteid food will have any influence upon the character and composition of the blood. It might be claimed, for example, that a lowering of the quantity of proteid food below the ordinarily accepted standards will eventually result in a deterioration in the character of the blood. Obviously, if such should prove to be the case, it would at once emphasize the necessity for higher standards of proteid feeding. Further, there might result marked changes in the hremoglobin-content of the blood in connection with a lowered proteid metabolism long continued. With these thoughts in mind, a careful study of the blood of the soldiers has been made from time to time, with special reference to determining the number of erythrocytes and leucocytes in the fluid, attention also being paid to the percentage of hæmoglobin.

Four distinct observations were made, as a rule, upon each man, namely, in the months of October, December, January, and March. The results are tabulated in the accompanying tables. Examination of these results shows that, as a rule, the number of erythrocytes, or red blood corpuscles, was somewhat increased during this period of lowered proteid feeding. We are not disposed, however, to lay very much stress upon this apparent increase, because it is not sufficiently marked to carry much weight, especially in view of the difficulties attending the obtaining of great accuracy in blood counts in general. Regarding the leucocytes, the figures are less definite, but may be fairly interpreted as indicating practically no appreciable change in the number of white corpuscles. Similarly, the hremoglobin-content shows no distinct alteration. Hence, the conclusion is that the physiological economy practised by the soldiers during their six months' stay in New Haven, and especially the marked diminution in the amount of proteid food consumed, did not result in any deterioration of the blood, so far as it can be measured by the number of contained erythrocytes and leucocytes, and by the content of hæmoglobin. 


\begin{tabular}{|c|c|c|c|c|c|c|c|c|c|}
\hline \multicolumn{7}{|c|}{ Date. } & \multirow{2}{*}{$\begin{array}{c}\begin{array}{c}\text { Erythrocytes } \\
\text { per cmm. }\end{array} \\
\end{array}$} & \multirow{3}{*}{$\begin{array}{c}\begin{array}{c}\text { Leucocytes } \\
\text { per cmm. }\end{array} \\
7,300\end{array}$} & \multirow{3}{*}{$\begin{array}{c}\begin{array}{c}\text { Hæmoglobin } \\
\text { per cent. }\end{array} \\
82\end{array}$} \\
\hline \multicolumn{7}{|c|}{ OAKMAN. } & & & \\
\hline Oct. 23,1903 . & & . & . & . & . & . & $5,480,000$ - & & \\
\hline Dec. 1,1903 . & . . & . & . & . & . & . & $6,000,000$ & 9,500 & 82 \\
\hline Jan. 26,1904 . & . . & . & . & . & . & . & $4,670,000$ & 12,500 & $80-81$ \\
\hline Mar. $22,1904$. & & . & . & . & . & . & $6,560,000$ & 6,000 & $84-85$ \\
\hline \multicolumn{7}{|c|}{ ShINeY. } & & & \\
\hline Oet. 22,1903 . . & . . & . & . & . & . & . & $5,450,000$ & 11,500 & 85 \\
\hline Nov. 20,1903 . & - . & . & . & . & . & . & $6,070,000$ & 8,800 & 84 \\
\hline Jan. 19,1904 . . & • . & . & . & . & . & . & $4,058,000$ & 11,100 & 76 \\
\hline Mar. 15,1904 . & . . & . & . & . & . & . & $6,208,000$ & 8,400 & 82 \\
\hline \multicolumn{7}{|c|}{ BAtes. } & & & \\
\hline Oct. 13,1903 . . & . . & . & . & . & . & . & $5,088,000$ & 12,000 & 77 \\
\hline Nov. $10,1903$. & . . & . & . & . & . & . & $7,344,000$ & 13,600 & 96 \\
\hline \multicolumn{7}{|c|}{ Coffuax. } & & & \\
\hline Oct. 13,1903 . & . . & . & . & . & . & . & $6,024,000$ & 9,300 & 84 \\
\hline Nov. 10,1903 . & . . & . & . & . & . & . & $7,544,000$ & 8,600 & 94 \\
\hline Feb. 2, 1904 . . & . & . & . & . & . & . & $3,160,000$ & 11,300 & 78 \\
\hline Mar. 18,1904 . & . . & . & . & . & . & . & $5,568,000$ & 10,000 & 74 \\
\hline \multicolumn{7}{|c|}{ Cons. } & & & \\
\hline Nov. 23,1903 . & . & . & . & . & . & . & $5,952,000$ & 17,200 & 94 \\
\hline Feb. 2,1904 . & . & . & - & . & . & . & $6,000,000$ & 13,600 & $87-88$ \\
\hline Mar. 18, 1904 . & . . & . & . & . & . & . & $7,000,000$ & 9,000 & $85-86$ \\
\hline \multicolumn{7}{|c|}{ Loewential. } & & & \\
\hline Oct. 16,1903 . & . & . & . & . & . & • & $6,392,000$ & 5,900 & 84 \\
\hline Nov. $20,1903$. & . & . & - & . & . & . & $6,780,000$ & 5,000 & 85 \\
\hline Jau. 25, 1904 . . & . & . & . & . & . & . & $6,500,000$ & 11,200 & 85 \\
\hline Mar. 22,1904 . & . . & . & . & . & . & . & $7,000,000$ & 10,200 & $86-87$ \\
\hline \multicolumn{7}{|c|}{ Morris. } & & & \\
\hline Oct. 14,1903 . & . & . & - & . & . & - & $6,728,000$ & 11,300 & $84-85$ \\
\hline Nov. 10,1903 . & . & • & • & • & $\cdot$ & • & $6,620,000$ & 8,100 & $90-91$ \\
\hline Feb. 8,1904 . & . & . & . & . & . & . & $6,000,000$ & 9,600 & $87-88$ \\
\hline Mar. 15, 1904 . & . & . & . & . & . & . & $5,000,000$ & 10,200 & 85 \\
\hline
\end{tabular}




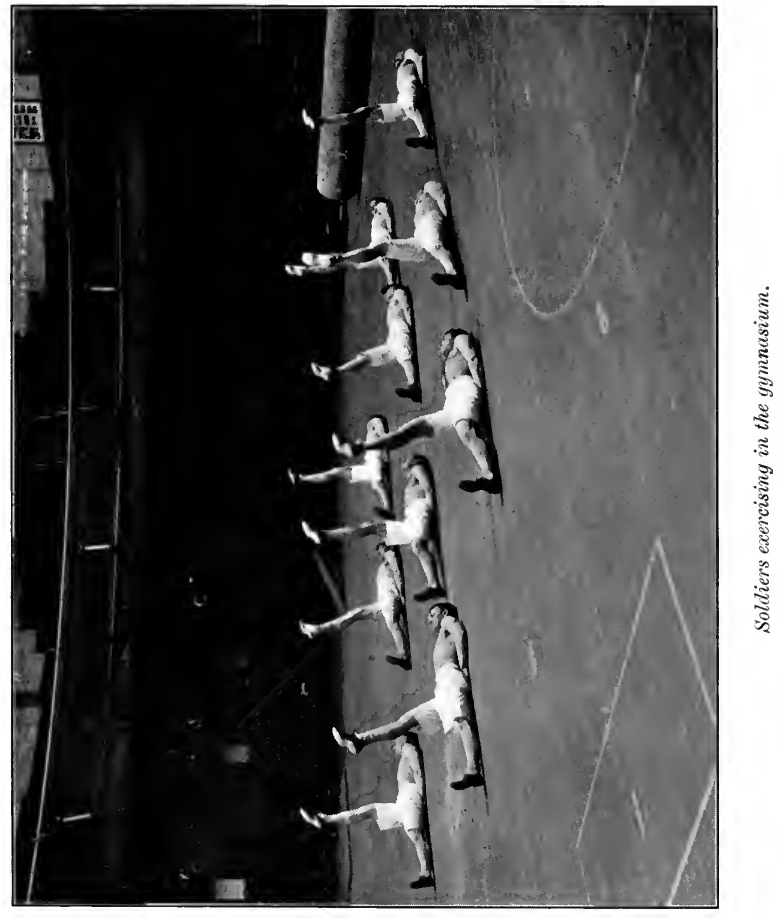





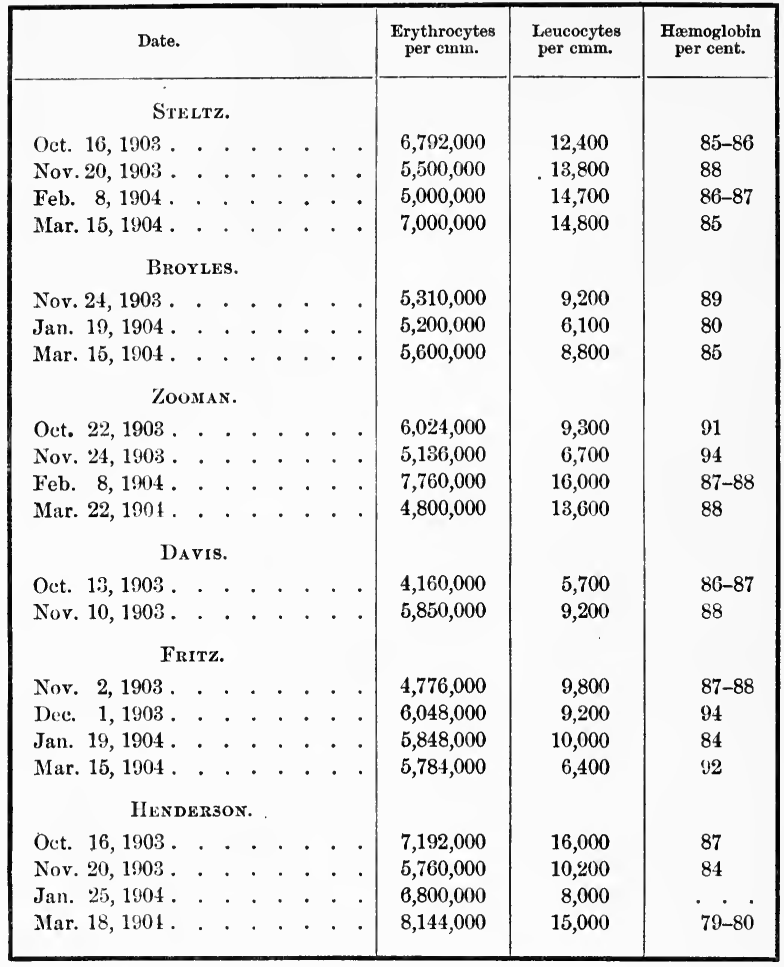

\section{General Conclusions.}

Careful consideration of the foregoing data, taken in their entirety, must lead the unbiassed thinker to admit the possibilities of physiological economy in nutrition. That there is no real need for a daily diet containing 118 grams of proteid food seems clearly indicated. The members of the soldier detachment lived without discomfort for a period of five months on amounts of proteid food not more than one-half that called 
for by the ordinary standard dietaries, and this without inereasing the amount of non-nitrogenous food. Body-weight, nitrogen equilibrium, physieal strength and vigor, ability to respond to sensory stimulation, the eomposition and general condition of the blood, all remained unimpaired under a daily diet involving the metabolism of only 7 to 8 grams of nitrogen per day and with a fuel value of less than 2800 calories per day.

Further, the practice of such economy led to marked improvement in the working of the neuro-museular maehinery, suffieiently noticeable to attract the attention of the men themselves, apart from the reeords of the dynamometer, ete. Indeed, it has been the universal feeling among all the subjeets of experiment that they were less conseious of fatigue than formerly, or that they could do more work without the feeling of fatigue that is usually so conspieuous after heavy work, or long-continued museular strain. IVe thus have for consideration an added factor, viz., the possible improvement of the physical eondition of the body under a lowered proteid intake. This question, however, we shall discuss more fully later on. It is enough for the present to simply emphasize the fact that with a greatly diminished proteid metabolism the body suffers no harm, the museular maehinery is as well able to perform its work as usual, and consequently there would seem to be no adequate reason why our daily dietary should be cumbered with such quantities of proteid matter as are generally eonsidered neeessary for health and strength.

There is one point of great importanee in this eonneetion that should not be overlooked, viz., whether the power of resistance toward disease is diminished in any way by a continued low proteid intake. This is surely a proper question, and one that must be carefully considered. Fortunately or unfortunately, we have no facts at our disposal. We have the belief, however, engendered by the results so far obtained, that there is no good ground for assuming the body to be any more susceptible to disease under eonditions of low proteid metabolism than when supplied with an excess of proteid food. Inrleed, it has been somewhat remarkable how free from all 
troubles - even during a very trying winter - the subjects of this experiment have been. We believe that economy in the use of proteid food, curtailment of proteid metabolism to a degree commensurate with the real needs of the body, will prove helpful to health, but we have no convincing facts to present, -- only the simple statement that all the men have been well and remarkably free from colds and other minor ailments all through the experiment.

It is a remarkable and suggestive fact that when a person has once practised physiological economy in his diet sufficiently long for it to have become in a measure a habit, he has no desire to return to a fuller dietary rich in proteid matter. This, it seems to the writer, is convincing proof that both body and mind are fully satisfied with the smaller amounts of food, and argues in favor of the latter being quite adequate for the physiological needs of the organism. In this connection, the writer presents a few lines received during the summer from one of the soldier detachment. Nine of these men, after completing their work at New Haven early in April, 1904, were detailed for service at St. Louis, and the letter which is quoted was written simply to ask concerning some photographs that had been promised them. In the letter, however, occur two or three sentences which are interesting and suggestive.

World's Fair Grounds, St. Lodis, Mo., July 8, 1904.

Professor Rcssell H. Chittenden:

Dear Sir, - On behalf of the men that were undergoing the "Food Test" conducted by you last winter, I write these few lines asking whether we are entitled to any of the photographs that were taken of us in the Yale Gymnasium the last two days we were there. . . . The men are all in first-class condition as regards their physical condition, and are all very thankful to you. We eat very little meat now as a rule, and would willingly go on another test. Enclosed you will find a list of the men as follows: Private 1st Class Jonah Broyles; Private 1st Class William E. Coffman; Private 1st Class James D. Henderson; Private 1st Class Maurice D. Loewenthal; Private 1st Class 
William Morris; Private 1st Class William F. Sliney; Private 1st Class John J. B. Steltz ; Private 1st Class Ben Zooman; Private 1st Class William Oakman.

Trusting I may hear from you in the near future, I am,

Very respectfully,

Mellical Department Exhibit U. S. Army,

(Signed) John J. B. Steltz.

World's Fair Station.

Daily Dretary of the Soldier Detail from October 2, 1903, то April 4, 1904.

For the first two weeks of their stay in New Haven, the soldiers were given their ordinary army ration, which is rich in meat and consequently had a high content of proteid or nitrogen. The detachment had their own cook and helper, and their food was prepared for them as they had always been accustomed to it. Further, they had at this time perfect freedom as to the quantity of food to be eaten, the figures given in the earlier days representing their own choice of quantity. Later, by the beginning of the third week, the diet was modified somewhat by the introduction of other articles in place of meat, especially at breakfast, so that the total nitrogen intake was diminished in some degree, but the men were still allowed freedom as to quantity. From November to the close of the experiment in April, both the character and quantity of the food for each meal were prescribed, but great care was exercised to see that the men were fully satisfied. Changes were made gradually and no discomfort was felt, or at least no complaint was made, although the men were frequently questioned and encouraged to comment upon the dietary and to make suggestions.

The dietary, however, speaks for itself, and a careful perusal of the daily record, with reference both to the character of the food and the quantities employed, will give clearer and more exact information as to the changes introduced than any verbal description. The only statement that need be made is that the heavier proteid foods were greatly reduced in 


\section{PHYSIOLOGICAL ECONOMY IN NUTRITION 289}

amount, and replaced in a measure by the lighter carbohydrate foods. Finally, it may be said that while vegetable foods eventually predominated, there was at no time a complete change to a vegetable diet.

\section{Friday, October 2, 1903.}

Breakfast. - Beefsteak 222 grams, fried potatoes 234 grams, onions 34 grams, gravy 68 grams, bread 144 grams, coffee 679 grams, sugar 18 grams.

1)inner. - Beef 171 grams, boiled potatoes 350 grams, onions 55 grams, bread 234 grams, coffee 916 grams, sugar 27 grams.

Supper. - Corned beef 195 grams, potatoes 170 grams, onions 21 grams, bread 158 grams, coffee 450 granıs, sugar 21 grams, fruit jelly 107 grams.

\section{Saturday, October 3, 1903.}

Breakfast. - Bacon 162 grams, fried cake 215 grams, bread 72 grams, sugar 21 grams, coffee 550 grams.

Dinner. - Roast beef 250 grams, gravy 133 grams, bread 234 gram grams, coffee 667 .

Supper. - Frankfurters 171 grams, bread 128 grams, nilk 71 grams, silgar 21 grams, coffee 450 grams.

\section{Sunday, October 4, 1903.}

Breakfast. - Beefsteak 299 grams, onions 21 grams, gravy 175 grams, bread 222 grams, milk 83 grams, sugar 21 grams, coffee 491 grams.

Dinner. - Roast beef 221 grams, potatoes 517 grams, gravy 154 grams, bread 148 grams, pie 184 grams, sugar 18 grams, nilk 46 grams, coffee 621 grams.

Supper. - Roast beef 96 grams, potatoes 260 grams, onions 82 grams, jam 92 grams, bread 32 grams, coffee 360 grains, milk 65 grams, sugar 18 grams.

\section{Monday, October 5, 1903.}

Breakfast. - Bacon 185 grains, fried potatoes 277 grams, gravy 93 grams, bread 140 grams, coffee 5.38 grams, sugar 18 grams, milk $6 j$ grams.

Dinner. - Cabbage 304 grams, corned beef $200 \mathrm{grams}$, potatoes $309 \mathrm{grams}$, bread 145 grams, milk 55 grams, sngar 18 grams, coffee 457 grams.

Supper. - Cabbage 130 grams, potatoes 248 grams, onions 27 grams, bacon 35 grams, bread 200 grams, butter 30 grams, milk 55 grams, coffee 500 grams, sugar 20 grams, blackberry jain 135 grams. 


$$
\text { Tuesday, October 6, } 1903 .
$$

Breakfast. - Bologna sausage 150 grams, bread 230 grams, butter 25 grams, milk 55 grams, sugar 20 grams, coffee 334 grams.

1)inner. - Beans 130 grans, onions 27 grams, bacon 90 grams, bread 160 grams, milk 55 grams, sugar 30 grams, coffee 500 grams.

Supper. - Beans 70 grams, beef liver 160 grams, onions 100 grams, bread 132 grams, milk 56 grams, sugar 20 grams, coffee 500 grams.

\section{Wednesday, October \%, 1903.}

Breakfast. - Beefsteak 290 grams, gravy 116 grams, bread 142 grams, milk 55 grams, sugar 20 grams, coffee 500 grams.

Dinner. - Roast beef 240 grams, onions 20 grams, gravy 166 grams, bread 170 grams, milk 56 grams, sugar 20 grams, coffee 550 grams.

Supper. - Potatoes 280 grams, beef 110 grams, onions 32 grams, bread 185 grams, pie 60 grams, milk 55 grams, butter 35 grams, sugar 20 grams, coffee 500 grams, blackberry jam 60 grams.

\section{Thursday, October $8,1903$.}

13reakfast. - Meat 107 grams, eggs 120 grams, bread 117 grams, milk 55 grams, sugar 20 grams, coffee 500 grams.

Dinner. - Bacon 170 grams, cabbage 297 grams, potatoes 360 grams, bread 120 grams, milk 40 grams, sugar 12 grams, coffee 300 grams.

Supper. - Peaches 100 grams, bread 347 grams, butter 35 grams, milk 55 grams, sugar 52 grams, coffee 416 grams.

\section{Friday, October 9, 1903.}

Breakfast. - Beef 120 grams, potatoes 220 grams, onions 50 grams, butter 35 grams, milk 55 grams, bread 175 grams, sugar 20 grams, coffee 500 grams.

Dinner. - Roast beef 203 grams, potatoes 143 grams, gravy 144 grams, bread 108 grams, sugar 18 grams, milk 55 grams, coffee 451 grams.

Supper. - Beef liver 138 grams, onions 93 grams, bacon 86 grams, bread 154 grams, butter 33 grams, sugar 19 grams, milk 55 grams, coffee 500 grams.

\section{Saturday, October 10, 1903.}

Breakfast. - Eggs 86 grams, bacon 89 grams, potatoes 187 grams, bread 128 grams, milk 55 grams, sugar 18 grams, coffee 500 grams.

Dinner. - Fish 233 grams, bacon 65 grams, onions 49 grams, potatoes 140 grams, bread 226 grams, milk 55 grams, sugar 19 grams, coffee 465 grams.

Supper. - Hamburg steak 224 grams, ouions 23 grams, butter 28 grams, bread 147 grams, pie 128 grams, milk 55 grams, sugar 18 grams, coffee 500 grams. 


\section{Sunday, October 11, 1903.}

Breakfast. - Beefsteak 243 grams, bread 105 grams, milk 55 grams, sugar 18 grams, coffee 335 grams.

Dinner. - Roast pork 208 grams, turnips 159 grams, potatoes 201 grams, gravy 133 grams, apple pie 168 grams, bread 89 grams, milk 55 grams, sugar 18 grams, coffee 340 grams.

Supper. - Stewed peaches $2: 35$ grams, bread 291 grams, milk 55 grams, butter 28 grams, sugar 18 grams, coffee 475 grams.

\section{Monday, October 12, 1903.}

Breakfast. - Potatoes 275 grams, beef 131 grams, onions 37 grams, bread 135 grams, milk 50 grams, sugar 18 grams, coffee 350 grams.

Dinner. - Beans 350 granıs, bacon 70 grams, oninns 39 grams, pickles 39 grams, bread $14 i$ grams, milk 55 grams, sugar 18 grams, coffee 500 grams.

Supper. - Frankfurters 149 grams, butter 28 grams, bread 149 grams, blackberry jam 63 grams, milk 55 grams, sugar 18 grams, coffee 500 grams.

\section{Tuesday, October 13, 1903.}

Breakfast. - Beef liver 149 grams, hacon 68 grams, bread 100 grams, milk 55 . grams, sugar 19 grams, coffee 375 grams.

Dinner. - Roast beef 187 grams, potatoes 131 grams, gravy 167 grams, tomatoes 151 grams, bread 112 grams, milk 55 grams, sugar 18 grams, coffee 410 grams.

Supper. - Roast beef 140 grams, apple sauce 350 grams, bread 144 grams, butter 33 grams, milk 55 grams, sugar 18 grams, coffee 500 grams.

\section{Wednesday, October 14, 1903.}

Breakfast. - Bacon 93 grams, apple sauce 299 grams, syrup 58 grams, bread 271 grams, milk 55 grams, sugar 35 grams, coffee 417 grams.

Dinner. - Hamburg ste:lk 186 grams, potatoes 336 grams, gravy 100 grams, onions 37 grams, bread 187 grams, milk 55 grams, sugar 18 grams, coffee 350 grams.

Supper. - Beef 224 grams, potatoes 242 grams, onions 28 grams, prunes 147 grams, bread 135 grams, butter 28 grams, milk 55 grams, sugar 44 grams, coffee 500 grams.

\section{Thursday, October 15, 1903.}

Breakfast. - Beef liver 159 grams, bacon 72 grams, bread 138 grams, milk 55 grams, sugar 18 grams, coffee 500 grams.

Dinner. - Cabbage 401 grams, bacon 156 grams, potatoes 201 grams, bread 121 grams, milk 55 grams, sugar 19 grams, coffee 480 grams.

Supper. - Bologna sausage 154 grams, rice 110 grams, eggs 13 grams, bread 133 grams, butter 28 grams. milk 55 grams, sugar 63 grams, coffee 500 grams. 


\section{Friday, October 16, 1903.}

Breakfast. - Beefsteak 285 grams, bread 140 grams, milk 61 grams, sugar 20 grams, coffee 545 grams.

Dinner. - Fish 226 grams, potatoes 287 grams, tomatoes 135 grams, bread 128 grams, milk 55 grams, sugar 18 grams, coffee 500 grams.

Supper. - Pork sausage 244 grams, apple sauce 204 grams, bread 189 grams, butter 31 grams, milk 61 grams, sugar 20 grams, coffee 545 grams.

\section{Saturday, October 1\%, 1903.}

Breakfast. - Ham 183 grams, potatoes 298 grams, bread 115 grams, sugar 20 grams, milk 61 grams, coffee 545 grams.

Dinner. - Beef 204 grams, potatoes 290 grams, onions 13 grams, bread 145 grams, milk 61 grams, sugar 20 grams, coffee 375 grams.

Supper. - Roast beef 142 grams, apple sauce 112 grams, butter 35 grams, bread 183 grams, pie 104 grams, milk 61 grams, sugar 66 grams, coffee 545 grams.

\section{Sunclay, October 18, 1903.}

- Breakfast. - Hamburg steak 234 grams, onions 31 grams, bread 155 grams, milk 61 grams, sugar 20 grams, coffee 455 grams.

Dinner. - Clicken 326 grams, dressing 142 grams, potatoes 290 grams, tomatoes 453 grams, bread 122 grams, nilk 61 grams, sugar 20 grams, coffee 545 grams.

Supper. - Apple sauce 244 grams, syrup 100 grams, bread 518 grams, nilk 61 grams, sugar 20 grams, coffee 500 grams.

\section{Monday, October 19, 1903.}

Breakfast. — Eggs 79 grams, bacon 43 grams, bread 127 grams, milk 61 grams, sugar 20 grams, coffee 514 grams.

Dinner. - Roast beef 214 grams, sweet potatoes 374 grams, tomatoes 305 grams, onions 23 grams, bread 140 grams, milk 61 grams, sugar 25 grams, coffee 545 grams.

Supper.-Roast beef 173 grams, apple sance 214 grams, bread 163 grams, butter 30 grams, milk 61 grams, sugar 25 grams, coffee 509 grams.

\section{Tuesday, October 20, 1903.}

Breakfast. - Oatmeal 316 grams, bread 95 grams, butter 19 grams, bacon 95 grans, coffee 600 grams, milk 245 grams, sugar $7 j$ grans.

Dinner. - Roast beef 187 grams, boiled potatoes 366 grams, tomatoes 156 grams, bread 79 grams, coffee 600 grams, milk 101 grams, sugar 36 grams.

Supper. - Cold roast beef $176 \mathrm{grams}$, apple sauce $277 \mathrm{grams}$, bread $159 \mathrm{grams}$, butter 36 grams, coffee 370 grams, sugar 39 grams, milk 63 grams. 


\section{Wednesday, October 21, 1903.}

Breakfast. - Fried oatmeal 142 grams, syrup 36 grams, bacon 62 grams, biscuits 155 grams, butter 35 grams, coffee 436 grams, milk 136 grams, sugar 46 grams.

Dinner. - Hamburg steak 275 grams, potatoes 399 grams, onions 63 grams, gravy 145 grams, bread 84 grams, coffee 500 grams, milk 140 grams, sugar 46 grams.

Supper. - Baked beans 336 grams, bread 148 grams, butter 43 grams, stewed prunes 193 grams, coffee 518 grams, milk 173 grams, sugar 48 grams.

\section{Thursday, October 22, 1903.}

Breakfast. - Boiled hominy 178 grams, French fried potatoes 168 grams, toasted bread 109 grams, butter 36 grams, coffee 473 grams, milk 163 grams, sugar 53 grams.

Dinner.-Corned beef 149 grams, boiled cabbage 191 grams, potatoes 189 grams, bread 87 grams, coffee 518 grams, sugar 51 grams, milk 76 grams. Supper. - Bologna sausage 104 grams, Saratoga chips 69 grams, fried hominy 214 grams, syrup 91 grams, bread 75 grams, butter 36 grams, coffee 500 grams, sugar 40 grams, milk 91 grams.

\section{Friday, October 23, 1903.}

Breakfast. - Boiled rice with sugar and milk 221 grams, biscuits 158 grams, butter 38 grams, coffee 536 grams, milk 182 grams, sugar 71 grams.

Dinner. - Fish 288 grams, potatoes 265 grams, tomatoes 193 grams, bread 107 grams, coffee 545 grams, sugar 71 grams, milk 173 grams.

Supper. - Oyster stew with crackers 361 grams, apple sauce 102 grams, bread 43 grams, butter 35 grams, coffee 409 grams, sugar 46 grams, nilk 309 grams.

$$
\text { Saturday, October 24, } 1903 .
$$

Breakfast. - Egg omelette 71 grams, with wheat flour 23 grams, bread 97 grams, butter 27 grams, coffee 545 grams, sugar 63 grams, milk 159 grams.

Dinner. - Hanıurg steak made with bread 163 grams, fat 10 grams, and onions for flavor 90 grams, tomatoes 283 grams, bread 214 grams, butter 48 grams, coffee 454 granıs, milk 182 grams, sugar 48 grams.

Supper. - Bacon 79 grams, potato chips 170 grams, stewed prunes 61 grams, biscuits 173 grams, butter 42 grams, coffee 545 grams, milk 182 grams, sugar 69 grams.

$$
\text { Sunday, October 25, } 1903 .
$$

Breakfast. - Apple 125 grams, fried rice 242 grams, syrup 64 grams, biscuits 127 grams, butter 33 grams, coffee 363 grams, milk 154 grams, sugar 31 grams.

Dinner. - Roast pork 252 grams, apple sauce 145 grams, potatoes 234 grams, 
bread 66 grams, tapioca pudding 265 grams, coffee 363 grams, sugar 38 grams, milk 164 grams.

Supper. - Toasted bread 75 grams, blackberry jam 81 grams, bread 75 grams butter 46 grams, coffee 363 grams, milk 160 grams, sugar 46 grams.

\section{Monday, October 26, 1903.}

Breakfast. - Griddle cakes 305 grams, syrup 67 grams, bread 35 grams, coffee 454 grams, milk 145 grams, butter 23 grams, sugar 41 grams.

Dinner. - Beef stew with potatoes, onions, and thickened with corn starch 560 grams, bread 94 grains, milk 151 grams, coffee 454 granıs, sugar 41 grams. Supper. - Macaroni with cheese 226 grams, stewed tomatoes 282 grams, bread 114 grams, butter 41 grams, stewed prunes 127 grams, coffee 445 grams, milk 90 grams, sugar 20 grams.

\section{Tuesday, October 2\%, 1903.}

Breakfast. - Boiled rice, milk, and sugar 311 grams, toasted bread 114 grams, butter 31 grams, coffee 545 grams, milk 190 grams, sugar 79 grams.

Dinner. - Codfish-balls 369 grams, mashed potatoes 269 grams, pickles 43 grams, bread 72 grams, apple pie 117 grams, coffee 545 grams, milk 91 grams, sugar 25 grams.

Supper. - Apple-rice pudding 397 grams, biscuit 252 grams, butter 48 grams, coffee 500 grams, milk 91 grams, sugar 25 grams.

\section{Wednesday, October 28, 190\%.}

Breakfast. - Apple 252 grams, fried hominy 168 grams, syrup 86 grams, bread 79 grams, coffee 445 grams, milk 100 grams, sugar 25 grams.

Dinner. - Bean porridge with bread 415 grams, boiled onions 99 grams, coffee 545 grams, milk 91 grams, sugar 25 grains, bread 63 grams, bread pudding 282 grams.

Supper. - Apple fritters 371 grams, syrup 67 grams, biscuit 87 grams, butter 36 grams, pickles 23 grams, coffee 454 grams, milk 91 grams, sugar 25 grams.

\section{Thursday, October 99, 1903.}

Breakfast. - Fried rice cakes 201 grams, syrup 54 grams, coffee 545 grams.

Dinner. - Hamburg steak * with bread, fat, and onions 230 grams, boiled potatoes 211 grams, stewed tomatoes 257 grams, bread 61 grams, coffee 363 grams.

Supper. - Apple sauce 277 grams, biscuits 293 grams, butter 56 grams, apple pie 117 grams, tea 527 grams.

* Hamburg steak contained 52 grams meat, 4 grams fat, 63 grams gnions, 111 grams bread, each man eating 230 grams. 


\section{Friday, October 30, 1903.}

Breakfast. - Boiled hominy 364 grams, sugar 47 grams, milk 91 grams, coffee 455 grams.*

Diuner. - Fish 219 grams, French fried potatoes 158 grams, boiled onions 58 grams, bread pudding 333 grams, coffee 436 grams.

Supper. - Bacon 61 grains, Saratoga chips 119 grams, stewed prunes 206 grams, bread 155 grams, butter 53 grams, coffee 454 grams.

\section{Saturday, October 31, 1903.}

Breakfast. - Steamed oatmeal (soft) 349 grams, sugar 76 grams, milk 182 grams, biscuits 109 grams, butter 53 grans, coffee 409 grams.

Dinner. - Macaroni flavored with cheese 345 grams, stewed tomatoes 149 grams, bread 58 grams, apple pie 112 grams, coffee 416 grams.

Supper. - Boiled cabbage 273 grams, bologna sausage 159 grams, bread 79 grams, rice pudding 224 grams, coffee 500 grams.

\section{Sunday, November 1, 1903.}

Breakfast. - Apple 240 grams, rice croquettes 271 grams, syrup 67 grams, bread 41 grams, coffee 417 grams.

Dinner. - Roast pork 294 grams, apple sauce 217 grams, potatoes 352 grams, tapioca pudding 116 grams, coffee 417 grams.

Supper. - Biscuits 415 grams, butter 58 grams, blackberry jam 133 grams, pickles 33 grams, tea 416 grams.

\section{Monday, November 2, 1903.}

Breakfast. - Steamed oatmeal 448 grams, milk 208 grams, sugar 65 grams, bread 70 grams, coffee 375 grams.

1)inner. - Beef stew 187 grams, potatoes 261 grams, onions 51 grams, thickened with corn starch 14 grams, bread 140 grams, coffee 500 grams.

Supper. - Macaroni 149 grams, stewed tonatoes 271 grams, pickles 72 grams, apple pie 109 grams, bread 139 grams, butter 53 grams, coffee 516 grams.

\section{Tuesday, November 3, 1903.}

Breakfast. - Boiled rice 303 grams, sugar 72 grams, milk 225 grams, bread 67 grams, coffee 450 grams.

Dinner. - Baked bean porridge 326 grams, boiled onions 128 grams, potatoes 287 grams, bread 105 grams, coffee 508 grams.

Supper. - Boiled cabbage 217 grams, Saratoga chips 53 grams, stewed prunes

67 grams, fried rice 149 grams, syrup 58 grams, coffee 516 grams, bacon 37 grams, potatoes 179 grams.

* One cup, total weight 454 grams, but containing small portions of milk and sugar. 


\section{Wednesday, November 4, 1903.}

Breakfast. - Apple 250 grams, fried hominy 100 grams, syrup 50 grams, coffee 335 grams.

Dinner. - Hamburg steak with bread, fat, and onions 200 grans, boiled potatoes 250 granıs, stewed tomatoes 250 grams, bread 75 grams, coffee 1 cup. Supper. - Apple fritters 226 grams, syrup 50 grams, biscuit 95 grams, butter 30 grams, coffee 1 cup.

\section{Thursday, November 5, 1903.}

Breakfast. - Banana 114 grams, boiled rice* 250 grams, with milk 181 grams, and sugar 76 grams, coffee 1 cup.

Dinner. - Macaroni and cheese 300 grams, bread 50 grams, applo sauce 200 grams, custard pie 112 grams, coffee 1 cup.

Supper. - Sansage 50 grams, potato chips 100 grams, stewed prunes 165 grams, bread 50 grams, butter 25 grams, coffee 1 cup.

\section{Friday, November 6, 1903.}

Breakfast. - Rice croquettes 200 grams, syrup 50 grams, coffee 1 cup.

Iinner. - Clam chowder with onions, tomatoes, ant potatoes 350 grams, bread

75 grams, coffee 1 eup, tapioca-peach pudding 125 grams.

Supper. - Bread 127 grams, butter 40 grams, jam 125 grams, tea 1 cup.

\section{Saturday, November \%, 1903.}

Breakfast. - Soft oatmeal 300 grams, milk 150 grams, sugar 50 grams, bread 30 grams, coffee 1 cup.

Dinner. - Bean porridge with onions 294 grams, stewed prunes 66 grams, bread 75 grams, coffee 1 cup.

Supper. - Bread pudding 292 grams, stewed peaches 97 grams, crackers 50 grams, butter 25 grams, coffee 1 cup.

\section{Sunday, November 8, 1903.}

Breakfast. - Apple 197 grams, stewed hominy 248 grams, milk 150 grams, sugar 50 grams, coffee 1 cup.

Dinner. - Beef stew thickened with corn starch, onions, and potatoes 405 grams, bread 75 grams, apple sauce 125 grams, coffee 1 cup.

Supper. - Pie 107 grams, chocolate 1 cup, biscuit 200 grams, butter 30 granıs, stewed prunes 160 grams.

* Rice or hominy on being moistened and cooked gains in weight 120 per cent; or rather, after the excess of moisture has evaporated and the rice is fried, it slıows a gain of that amount. But for boiled rice or hominy, without drying or frying, there is an increase in weight of 230 per cent, as usually prepared. 


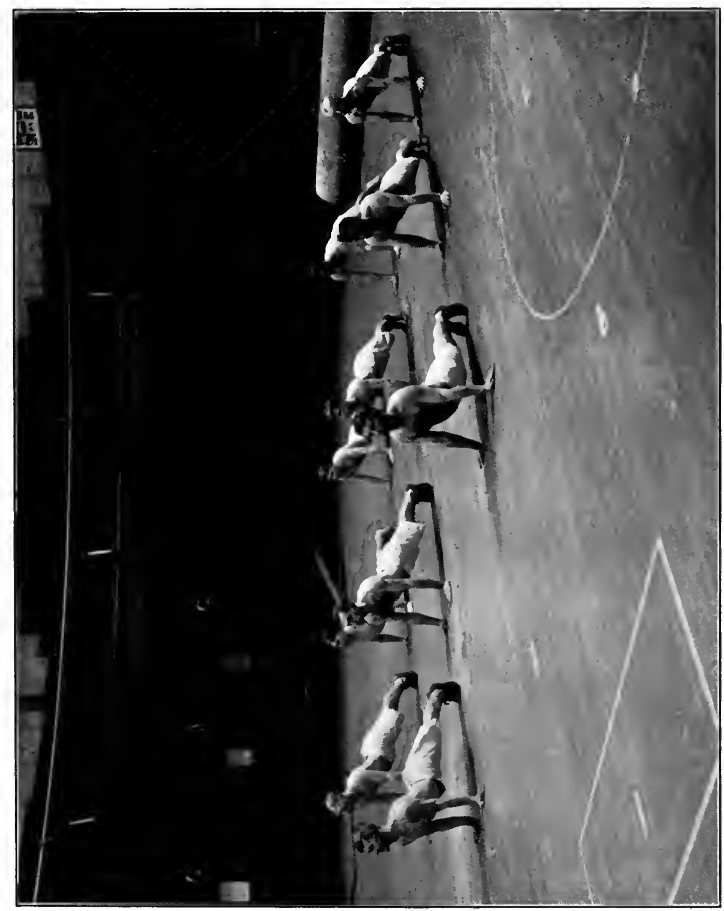

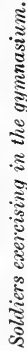





\section{Monday, November 9, 1903.}

Breakfast. - Wheat griddle cakes 200 grams, syrup 40 grains, coffee 1 cup.

Dinner. - Corned beef 125 grams, cabbage 200 grams, potatoes 175 grams, bread

75 grams, coffee 1 cup.

Supper. - Rice pudding 150 grams, stewed peaches 100 grams, crackers 50 grams, butter 25 grams, coffee 1 cup.

\section{Tuesday, November 10, 1903.}

Breakfast. - Toasted bread 200 grams, butter 40 grams, boiled egg 50 grams, coffee 1 cup.

Dinner. - Macaroni baked with cheese 300 grams, bread 50 grams, apple sauce 200 grams, custard pie 112 grams, coffee 1 cup.

Supper. - Bread pudding 300 grams, stewed peaches 100 grams, crackers 50 grams, butter 25 grams, coffee 1 cup.

\section{Wednesday, November 11, 1903.}

Breakfast. - Apple 196 grams, boiled rice 247 grams, milk 125 grams, sugar 50 grams, coffee 1 cup.

Dinner. - Hamburg steak with bread, fat, and onions 200 grams, boiled potatoes 250 grams, stewed tomatoes 250 grams, brend 75 grams, coffee 1 cun.

Supper. - Fried rice 100 grams, syrup 50 grams, biscuit 173 grams, butter 30 grams, tea 1 cup.

\section{Thursday, November 12, 1903.}

Breakfast. - Banana 114 grams, toasted bread 179 grams, butter 50 grams, coffee 1 cup.

Dinner. - Sausage 96 grams, French fried potatoes 200 grams, pickles 50 grams, bread 50 grams, apple and rice pudding 175 grams, coffee 1 cup.

Supper. - Boiled hominy 200 grams, milk 125 grams, sugar 47 grams, stewed prunes 109 grams, bread 50 grams, coffee 1 cup.

\section{Friday, November 13, 1903.}

Breakfast. - Fried hominy 100 grams, syrup 50 grams, coffee 1 cup.

Dinner. - Clam chowder with onions, potatoes, and tomatoes 350 grams, bread 75 grams, coffee 1 cup.

Supper.-Biscuit 277 grams, butter 50 grams, jam 125 grams, sardines 85 grams, coffee 1 cup. 


\section{Saturday, November 14, 1903.}

Breakfast. - Boiled rice 250 grams, milk 125 grams, sugar 50 grams, coffee 1 cup.

Dinner. - Beef stew with onions, potatoes, thickened with corn starch 350 grams, bread 75 grams, apple sauce 125 grams, coffee 1 cup.

Supper. - Rice croquettes 125 grams, syrup 40 grams, biscuit 175 grams, butter 25 grams, tea 1 cup,

\section{Sunday, November 15, 1903.}

Breakfast. - Apple 224 grams, soft boiled oatmeal 200 grams, milk 100 grams, sugar 40 grams, coffee 1 cup.

Dinner. - Macaroni and clieese 300 grams, stewed tomatoes 150 grams, bread 50 grams, pie 92 grams, coffee 1 cup.

Supper. - Fried bacon 30 grams, fried egg 40 grams, potato chips 100 grams, bread 50 grams, coffee 1 cup.

\section{Monday, November 16, 1903.}

Breakfast. - Wheat griddle cakes 150 grams, syrup 40 grams, coffee 1 cup.

Dinner. - Corned beef 75 grams, cabhage 200 grams, mashed potatoes 200 grams, bread 50 grams, coffee 1 cup.

Supper. - lice pudding 150 grams, stewed peaches 100 grams, erackers 50 grams, butter 20 grams, coffee 1 cup.

\section{Tuesday, November 1\%, 1903.}

Breakfast. - Indian-meal pudding 200 grams, milk 125 grams, coffee 1 cup.

Dinner. - Tomato soup with potatoes and onions boiled together 337 grams, bread 100 grams, sausage 44 grams, baked potato 200 grams, coffee 1 cup. Supper. - Fried Indian-meal pudding 100 grams, syrup 50 grams, butter 35 grams, coffee 1 cup, apple sauce 100 grams, biscuit 150 grams.

\section{Wednesday, November 18, 1903.}

Breakfast. - Boiled hominy 150 grams, milk 125 grams, sugar 30 grams, coffee 1 cup.

Dinner. - Bean soup (thick) 200 grams, pickles 35 grams, bread pudding 250 grams, bread 75 grams, coffee 1 cup, stewed peaches 75 grams.

Supper. - Fried hominy 150 grams, butter 25 grams, syrup 50 grans, bread 75 granıs, stewed prunes 100 granıs, coffee 1 cup. 


\section{Thursday, November 19, 1903.}

Breakfast. - Boiled rice 300 grams, milk 150 grams, sugar 50 grams, coffee 1 cup.

Dinner. - Hamburg steak made with plenty of chopped bread, fat, and onions 200 grams, baked potato 250 grams, bread 75 grams, stewed tomatoes 250 grams, coffee 1 cup.

Supper. - Biscuit 275 grams, butter 50 grams, apple sauce 175 grams, tea 1 cup.

\section{Friday, November 20, 1903.}

Breakfast. - Apple 200 grams, fried rice 150 grams, syrup 50 grams, coffee 1 cup.

Dinner. - Codfish-balls made with plenty of potatoes 200 grams, boiled onions 200 grams, bread 75 grams, apple pie 105 grams, coffee 1 cup.

Supper. - Banalla fritters 200 grams, bread 75 grams, butter 50 grams, pickles 30 grams, coffee 1 cup.

\section{Saturday, November 21, 1903.}

Breakfast. - Wheat griddle cakes 200 grams, syrup 50 grams, bread 50 grams, coffee 1 cup.

Dinner. - Split pea soup 200 grams, bread 75 grams, pickles 30 grams, tapiocapeach pudding 150 grams, coffee 1 cup.

Supper. - Biscuit 275 grams, stewed prunes 100 grams, butter 50 grams, tea 1 cup.

\section{Sunday, November 221903.}

Breakfast. - Apple 217 grams, Johnny cake made of corn meal 200 grams, butter 50 grams, coffee 1 cup.

Dinner. - Beef stew with onions, potatoes, and corn starch 350 grams, bread 75 grams, coffee 1 cup, pie 118 grams.

Supper. - Chocolate 1 cup, bread 150 grams, milk 300 grams.

\section{Monday, November 23, 1903.}

Breakfast. - Boiled rice 300 grams, milk 125 grams, sugar 50 grams, coffee 1 cup.

Dinner. - Macaroni boiled 800 grams, stewed tomatoes 250 grams, bread 75 grams, pie 114 grams, coffee 1 cup.

Supper. - Fried rice 150 grams, syrup 50 grams, jam 75 grams, bread 75 grams, tea 1 cup. 


\section{Tuesday, November 24, 1903.}

Breakfast. - Boiled hominy 150 grams, milk 125 grams, sugar 30 grams, coffee 1 cup, orange 200 grams.

Dinner. - Tomato soup witl potatoes and onions boiled together 325 grams, bread 100 grams, fried sausage 50 grams, baked potato 200 grams, coffee 1 cup.

Supper. - Fried hominy 100 grams, syrup 50 grams, biscuit 150 grams, butter 35 grams, apple sauce 100 grams, coffee 1 cup.

\section{Wednesday, November 25, 1903.}

Breakfast. - Boiled Indian-meal 200 grams, milk 125 grams, coffee 1 cup, orange 225 grams.

Dinner. - Split pea soup (thick) 200 grams, bread 75 grams, pickles 30 grams, apple pie 120 grams, coffee 1 cup.

Supper. - Bread pudding 250 grams, stewed peaches 100 grams, crackers 50 grams, butter 25 grams, tea 1 cup.

\section{Thursday, November $26,1903$.}

Breakfast. - Biscuit 250 grams, butter 50 grams, apple sauce 150 grams, coffee 1 cup.

Dinner. - Roast turkey (sliced) 100 grams, cranberry sauce 150 grams, mashed potatoes 150 grams, bread crumb stuffing 100 grams, boiled onions 200 grams, bread 75 grams, corn-starch pudding 125 grams, orange 200 grams, coffee $1 \mathrm{cup}$.

Supper. - Crackers 50 grams, tea 1 cup, stewed prunes 150 grams, butter 50 grams, wheat bread 100 grams.

\section{Friday, November 2\%, 1903.}

Breakfast. - Boiled rice 250 grams, milk 125 grams, sugar 50 grams, coffee 1 cup.

Dinner. - Clam clıwder with onions, potatoes, and tomatoes 350 grams, bread 75 grams, coffee 1 cup.

Supper. - Biscuit 275 grams, butter 50 grams, jam 125 grams, sardine 60 grams, coffee 1 cup.

\section{Saturday, November $28,1903$.}

Breakfast. - Fried rice 100 grams, syrup 50 grams, coffee 1 cup, apple 200 grams.

Dinner. - Boiled macaroni 200 grams, stewed tomatoes 250 grams, bread 50 grams, apple pie 150 grams, coffce 1 cup.

Supper. - Potato chips 100 grams, fried bacon 30 grams, bread 75 grams, jam 75 grams, tea 1 cup. 


\author{
Sunday, November 29, 1903.
}

Breakfast. - Wheat griddle cakes 200 grams, syrup 50 grams, coffee 1 cup.

Dinner. - Bean soup (thick) 200 grams, bread 75 grams, boiled potato 150 grams, bread pudding 250 grams, coffee 1 cup.

Supper. - Stewed peaches 100 grams, butter 35 grams, bread 75 grams, fried sausage 33 grams, coffee 1 cup.

\title{
Monday, November 30, 1903.
}

Breakfast. - Boiled oatmeal 200 grams, milk 125 grams, sugar 30 grams, coffee 1 cup.

Dinner. - Corned beef 75 grams, cabbage 200 grams, mashed potatoes 200 grams, bread 50 grams, coffee 1 cup.

Supper. - Rice pudding 150 grams, stewed peaches 100 grams, crackers 50 grams, butter 25 grams, coffee 1 cup.

\section{Tuesday, December 1, 1903.}

Breakfast. - Boiled hominy 150 grams, milk 125 grams, sugar 30 grams, coffee 1 cup.

Dinner. - Tomato soup with potatoes and onions boiled together 325 grams, bread 100 grams, shaved dried beef 30 grams, baked potato 147 grams, coffee 1 cup.

Supper. - Fried hominy 100 grams, syrup 50 grams, crackers 50 grams, butter 30 grams, coffee 1 cup, apple sauce 100 grams.

\section{Wednesday, December 2, 1903.}

Breakfast. - Boiled Indian-meal 200 grams, milk 125 grams, coffee 1 cup, orange 200 grams.

Dinner. - Split pea soup (thick) 200 grams, bread 75 grams, pickles 30 grams, apple pie 125 grams, coffee 1 cup.

Supper. - Stewed peaches 100 grams, bread pudding 250 grams, crackers 50 grams, butter 25 grams, coffee 1 cup.

\section{Thursday, December 3, 1903.}

Breakfast. - Wheat griddle cakes 200 grams, syrup 50 grams, coffee 1 cup.

Dinner. - Hamburg steak with bread, fat, and onions 150 grams, boiled potatoes 250 grams, stewed tomatoes 250 grams, bread 75 grams, coffee 1 cup. Supper. - Boiled rice 150 grams, milk 125 grams, sugar 30 grams, coffee 1 cup. 


\section{Friday, December 4, 1903.}

Breakfast. - Fried rice 100 grams, syrup 50 grams, coffee 1 cup.

Dinner. - Clam chowder with onions, tomatoes, and potatoes 350 grams, bread 75 grams, coffee 1 cup.

Supper. - Biscuit 275 grams, butter 50 grams, coffee 1 cup, jam 125 grams, sardines 75 grams.

\section{Saturday, December 5, 1903.}

Breakfast. - Boiled oatmeal 175 grams, milk 125 grams, sugar 30 grams, coffee 1 cup.

Dinner. - Boiled macaroni 200 grams, stewed tomatoes 250 grams, bread 50 grams, pie 117 grams, coffee 1 cup.

Supper. - Potato chips 100 grams, fried bacon 30 grams, corn-starch custard 125 grams, bread 40 grams, tea 1 cup.

\section{Sunday, December 6, 1903.}

Breakfast. - Banana 125 grams, toasted bread 150 grams, butter 50 grams, coffee 1 cup.

Dinner. - Sausage 50 grams, French fried potatoes 200 grams, pickles 30 grams, apple-rice pudding 200 grams, coffee 1 cup.

Supper. - Stewed prunes 150 grams, crackers 75 grams, butter 40 grams, coffee 1 cup. .

\section{Monday, December 7, 1903.}

Breakfast. - Corn-meal Johnny-cake 200 grams, butter 50 grams, cofiee 1 cup.

Dinner. - Bean soup (thick) 200 grams, boiled potatoes 200 grams, bread 75 grams, pie 146 grams, coffee 1 cup.

Supper. - Crackers 80 grams, milk 200 grams, stewed peaches 150 grams, coffee 1 cup.

\section{Tuesday, December 8, 1903.}

Breakfast. - Boiled rice 150 grams, milk 125 grams, sugar 30 grams, coffee 1 cup.

Dinner. - Meat pie (made witlı a little meat, flour, etc.) 150 grams, mashed potato 250 grams, stewed prunes 100 grams, bread 75 grams, coffee 1 cup.

Supper. - Fried rice 100 grams, syrup 50 grams, bread 100 grams, cocoa 1 cup. 


\section{Wednesday, December 9, 1903.}

Breakfast. - Boiled oatmeal 175 grams, milk 100 grams, sugar 25 grams, coffee 1 cup.

Dinner. - Boiled macaroni without cheese 200 grams, stewed tomatoes 250 grams, bread 75 grains, pie 110 grams, coffee 1 cup.

Supper. - Bread 200 grams, milk 200 grams, stewed peaches 150 grams, cocoa 1 cup.

\section{Thursday, December 10, 1903.}

Breakfast. - Boiled hominy 125 grams, milk 100 grams, sugar 30 grams, coffee 1 cup.

Dinner. - Roast beef 50 grams, boiled potato 200 grams, bread 75 grams, boiled onions 100 grams, coffee 1 cup.

Supper. - Suet pudding 150 grams, stewed prunes 150 grams, crackers 50 grams, cocoa 1 cup.

\section{Friday, December 11, 1903.}

Breakfast. - Fried hominy 100 grams, syrup 50 grams, coffee 1 cup.

Dinner. - Clam clowder with onions, potatoes and tomatoes 350 grams, bread 100 grams, coffee 1 cup.

Supper. - Biscuit 275 grams, butter 50 grams, sardine 50 grams, jam 125 grams, cocoa 1 cup.

Saturday, December 12, 1903.

Breakfast. - Griddle cakes (with egg) 200 grams, syrup 50 grams, coffee 1 cup.

Dinner. - Cold roast beef 50 grams, French fried potatoes 200 grams, applerice pudding 200 grams, pickles 30 grams, coffee 1 cup.

Supper. - Bread 100 grams, butter 50 grams, stewed prunes 150 grams, cocoa 1 cup.

Sunday, December 13, 1903.

Breakfast. - Boiled Indian-meal 200 grams, milk 100 grams, coffee 1 cup.

Dinner. - Tomato soup with potatoes and onions boiled together 325 grams, bread 100 grams, shaved dried beef 12 grams, baked pota to 110 grams, coffee 1 cup.

Supper. - Bread 150 grams, butter 50 grams, apple sauce 175 grams, cocoa 1 cup.

\section{Monday, December 14, 1903.}

Breakfast. - Fried Indian-meal 100 grams, syrup 50 grams, coffee 1 cup.

Dinner. - Split-pea soup (thick) 175 grams, bread 75 grams, boiled onions 100 grams, mashed potato 150 grams, apple pie 121 grams, coffee 1 cup.

Supper. - Bread 100 grams, milk 200 grams, stewed peaches 150 grams, cocoa 1 cup. 


\section{Tuesday December 15, 1903.}

Breakfist. - Boiled rice 150 grams, milk 125 grams, sugar 30 grams, coffee 1 cup.

Dinner. - Baked macaroni with a little cheese 200 grams, stewed tomatoes 200 grams, bread 50 grams, pie 115 grams, coffee 1 cup.

Supper. - Bread pudding 250 grams, stewed peacles 100 grams, crackers 50 grams, butter 15 grams, coffee 1 cup.

\section{Wednesday, December 16, 1903.}

Breakfast. - Fried rice 100 grams, syrup 50 grams, coffee 1 cup.

Dinner. - Hamburg steak with bread, fat, and onions 150 grams, boiled potatoes

200 grams, apple sauce 200 grams, bread 75 grams, coffee 1 cup.

Supper. - Biscuits 150 grams, butter 20 grams, stewed prunes 150 grams, tea 1 cup.

\section{Thursday, December 17, 1903.}

Breakfast. - Boiled hominy 150 grams, milk 125 grams, sugar 30 grams, coffee 1 cup.

Dinner. - Vegetable soup (thickened with flour) containing potatoes, onions, and tomatoes 300 grams, bread 75 grams, apple-rice pudding 150 grams, coffee 1 cup.

Supper. - Fried bacon 30 grams, baked potato 150 grams, bread 50 grams, butter 15 grams, coffee 1 cup.

\section{Friday, December 18, 1903.}

Breakfast. - Fried hominy 100 grams, syrup 50 grams, coffee 1 cup.

Dinner. - Clam chowder with onions, potatoes, and tomatoes $350 \mathrm{grams}$, bread 75 grams, coffee 1 cup.

Supper. - Shaved dried beef 30 grams, biscuit 150 grams, butter 20 grams, apple sauce 150 grams, tea 1 cup.

\section{Saturday, December 19, 1903.}

Breakfast.-Boiled Indian-meal 150 grams, milk 125 grams, sugar 30 grams, bread 35 grams, coffee 1 cup.

Dinner. - Corned beef 75 grams, cabbage 200 grams, boiled potatoes 175 grams, bread 40 grams, coffee 1 cup.

Supper. - Rice pudding with raisins 150 grams, stewed peaches 100 grams, crackers 50 grams, butter 15 grams, tea 1 cup. 


\section{Sunday, December 20, 1903.}

Breakfast. A Apple 150 grams, fried Indian-meal 100 grams, bread 35 grams, syrup 50 grams, coffee 1 cup.

Dinner. - Split-pea soup (thick) 150 grams, bread 40 grams, boiled carrots 100 grams, mashed potato 150 grams, apple pie 125 grams, coffee 1 cup.

Supper. - Sausage 50 grams, French fried potatoes 100 grams, bread 50 grams, butter 15 grams, tea 1 cup.

\section{Monday, December 21, 1903.}

Breakfast. - Wheat griddle cakes 150 grams, syrup 40 grams, coffee 1 cup.

1)inner. - Beef stew (with onions and potatoes, thickened with corn starch) 350 grams, bread 75 grams, stewed prunes 125 grams, coffee 1 cup.

Supper. - Suet pudding 150 grams, apple sauce 125 grams, tea 1 cup.

\section{Tuesday, December 22, 1903.}

Breakfast. - Apple 150 grams, boiled rice 150 grams, milk 125 grams, sugar 30 grams, bread 30 grams, coffee 1 cup.

Dinner. - Baked macaroni with cheese 200 grams, stewed tomatoes 200 grams, bread 50 grams, pie 110 grams, coffee 1 cup.

Supper. - Bread pudding 250 grams, stewed peaches 100 grams, crackers 50 grams, butter 15 grams, tea 1 cup.

\section{Wednesday, December 23, 1903.}

Breakfast. - Fried rice 100 grams, syrup 50 grams, crackers 30 grams, butter 10 grams, coffee 1 cup.

Dinner - Bean soup (thick) 200 grams, bread 75 grams, pickles 30 grams, tapioca-peach pudding 150 grams, coffee 1 cup.

Supper. - Apple fritters 200 grams, stewed prunes 125 grams, bread 50 grams, butter 15 grams, tea 1 cup.

\section{Thursday, December 24, 1903.}

Breakfast. - Apple 200 grams, boiled hominy 150 grams, milk 125 grams, sugar 30 grams, coffee 1 cup.

Dinner - Tomato soup with potatoes and onions boiled together 325 grams, fried sausage 40 grams, bread 75 grams, baked potato 150 grams, coffee 1 cup.

Supper - Biscuit 175 grams, butter 30 grams, jam 125 grams, tea 1 cup. 


$$
\text { Friday, December 25, } 1903 .
$$

Breakfast. - Apple 200 grams, fried hominy 130 grams, syrup 50 grams, coffee 1 cup.

Dinner. - Roast turkey 100 grams, breal-crumb stuffing 100 grams, cranberry sauce 150 grams, boiled onions 200 grams, maslıed potatoes 150 grams, bread 75 grams, orange 200 grams, corn-starch custard 125 grams, coffee 1 cup.

Supper. - Bread 100 grams, crackers 25 grams, stewed prunes 150 grams, butter 40 grams, tea 1 cup.

\section{Saturday, December 26, 1903.}

Breakfast. - Boiled rice 200 grams, milk 125 grams, sugar 30 grams, coffee 1 cup.

Dinner. - Clam chowder with onions, potatoes, and tomatoes 350 grams, bread 75 grams, pickles 35 grams, coffee 1 cup.

Supper. - Potato chips 100 grams, fried bacon 25 grams, bread 75 grams, jam 75 grams, tea 1 cup.

\section{Sunday, December 27, 1903.}

Breakfast. - Wheat griddle cakes 200 grams, syrup 50 grams, coffee 1 cup, apple 200 grams.

Dinner. - Split-pea soup (thick) 200 grams, bread 75 grams, stewed tomatoes 150 grams, pie 115 grams, coffee 1 cup.

Supper. - Suet pudding (plum duff) 150 grams, apple sauce 125 grams, tea 1 cup.

\section{Monday, December 28, 1903.}

Breakfast. - Boiled Indian-meal 150 grams, milk 125 grams, sugar 30 grams, coffee 1 cup, apple 200 grams.

Dinner. - Corned beef 75 grams, cabbage 200 grams, mashed potatoes 200 grams, bread 50 grams, coffee 1 cup.

Supper. - Rice pudding 150 grams, stewed peaches 100 grams, crackers 40 grams, butter 15 grams, tea 1 cup.

\section{Thesday, December 29, 1903.}

Breakfast. - Fried Indian-meal 100 grams, syrup 50 grams, coffee 1 cup, apple 210 grams.

Dinner. - Boiled macaroni 200 grams, stewed tomatoes 250 grams, bread 50 grams, apple pie 140 grams, coffee 1 cup.

Supper. - Potato clips 100 grams, fried bacon 35 grams, bread 75 grams, jam 75 grams, tea 1 cup. 
Wednesday, December 30, 1903.

Breakfast. - Boiled rice 150 grams, milk 125 grams, sugar 30 grams, coffee 1 cup, apple 150 grams, baked potato 100 grams.

Dinner. - Hamburg steak with bread, fat, and onions $150 \mathrm{grams}$, boiled potatoes 200 grams, apple sauce 200 grams, bread 75 grams, coffee 1 cup.

Supper. - Biscuit 150 grams, butter 20 grams, stewed prunes 150 grams, tea 1 cup.

\section{Thursday, December 31, 1903.}

Breakfast. - Apple 175 grams, fried rice 100 grams, syrup 56 grams, coffee 1 cup, baked potato 90 grams.

Dinner. - Split-pea soup (thick) 200 grams, bread 75 grams, pickles 30 grams, boiled potato 100 grams, coffee 1 cup, pie 115 grams.

Supper. - Bread pudding 250 grams, stewed peaches 100 grams, crackers 20 grams, butter 10 grams, tea 1 cup.

\section{Friday, January 1, 1904.}

Breakfast. - Wheat griddle cakes 200 grams, syrup 50 grams, apple 175 grams, coffee 1 cup, baked potato 100 grams.

Dinner. - Clam clowder with onions, potatoes, and tomatoes $350 \mathrm{grams}$, bread 75 grams, ice cream 200 grams, coffee 1 cup.

Supper. - Suet pudding 150 grams, apple sauce 125 grams, crackers 25 grams, tea 1 cup.

\section{Saturday, January 2, 1904.}

Breakfast. - Boiled rice 150 grams, milk 125 grams, sugar 30 grams, coffee 1 cup, apple 190 grams, baked potato 100 grams.

Dinner.-Baked macaroni with small amount of cheese 200 grams, stewed tomatoes 200 granıs, bread 50 grams, pie 115 grams, coffee 1 cup.

Supper. - Biscuit 125 grams, butter 20 grams, fried bacon 30 grams, baked potato 150 grams, stewed prunes 150 grams, tea 1 cup.

\section{Sunday, January 3, 1904.}

Breakfast. - Apple 190 grams, fried rice 100 grams, syrup 50 grams, baked potato 90 grams, butter 10 grams, coffee 1 cup.

Dinner. - Baked potato 150 grams, dried beef 50 grams, stewed with milk 50 grams, bread 75 grams, butter 20 grams, coffee 1 cup, pickles 20 grams, tapioca-peach pudding 125 grams.

Supper. - Apple fritters 200 grams, stewed prunes 125 grams, bread 50 grams, butter 15 grams, tea 1 cup. 


\section{Monday, January 4, 1904.}

Breakfast. - Boiled Indian-meal 150 grams, milk 125 grams, sugar 30 grams, bread 35 grams, coffee 1 cup.

Dinner. - Tomato soup with potatoes and onions boiled together 325 grams, bread 75 grams, coffee 1 cup, bread pudding 150 grams.

Supper. - Biscuit 175 grams, butter 30 grams, jam 125 grams, tea 1 cup.

$$
\text { Tuesday, January 5, } 1904 .
$$

Breakfast. - Boiled hominy 150 grams, milk 125 grams, sugar 30 grams, baked potato 150 grams, butter 10 grams, coffee 1 cup.

Dinner. - Split-pea soup (thick) 300 grams, bread 75 grams, pickles 30 grams, coffee 1 cup, pie 100 grams.

Supper. - Fried bacon 30 grams, potato chips 100 grams, bread 75 grams, jam 60 grams, tea 1 cup.

\section{Wednesday, January 6, 1904.}

Breakfast. - Fried hominy 100 grams, syrup 50 grams, coffee $1 \mathrm{cup}$, apple 200 grains.

Dinner. - Hamburg steak with plenty of bread, fat, and onions $150 \mathrm{grams}$, boiled potatoes 200 grams, apple sauce 200 grams, bread 75 grams, coffee 1 cup. Supper. - Biscuit 150 grams, butter 20 grams, stewed prunes 150 grams, tea 1 cup.

\section{Thursday, January \%, 1904.}

Breakfast. - Apple 190 grams, boiled rice 150 grams, milk 125 grams, sugar 30 grams, coffee 1 cup, baked potato 100 grams.

Dinner.-Baked macaroni with small amount of cleese 200 grams, stewed tomatoes 200 grams, bread 50 grams, coffee 1 cup, pie 130 grams.

Supper. - Suet pudding 150 grams, apple sauce 125 grams, crackers 25 grams, tea 1 cup.

$$
\text { Friday, January 8, } 1904 .
$$

Breakfast. - Apple 150 grams, wheat griddle cakes 200 grams, syrup 50 grams, coffee 1 cup.

Dinner. - Fish-balls with creamed potatoes 150 grams, stewed tomatoes 200 grams, bread 75 grams, coffee 1 cup, tapioca-peach pudding 125 grams.

Supper. - Biscuit 150 grams, butter 20 grams, stewed peaches 150 grams, tea 1 cup, baked potato 100 grams.

\section{Saturday, January 9, 1904.}

Breakfast. - Apple 200 grams, boiled rice 150 grams, milk 125 grams, sugar 30 grams, butter 10 grams, baked potato 100 grams, coffee 1 cup.

Dinner. - Baked potato 150 grams, dried beef 50 grams, stewed with milk 20 grams, bread 75 grams, butter 20 grams, pickles 20 grams, coffee 1 cup.

Supper. - Apple fritters 200 grams, stewed prunes 125 grams, bread 50 grams, butter 15 grams, tea 1 cup. 


\section{Sunday, January 10, 1904.}

Breakfast. - Fried rice 100 grams, syrup 50 grams, coffee $1 \mathrm{cup}$, apple 250 grams.

Dinner. - Tomato soup with potatoes and onions boiled together 325 grams, bread 75 grams, bread pudding 150 grams, coffee 1 cup.

Supper. - Toasted bread 100 grams, butter 20 grams, sardine 25 grams, stewed prunes 150 grams, tea 1 cup.

\section{Monday, January 11, 1904.}

Breakfast. - Boiled Indian-meal 150 grams, milk 125 grams, sugar 30 grams, bread 35 grams, butter 10 grams, coffee 1 cup.

Dinner. - Boiled fresh beef 75 grams, boiled cabbage 200 grams, mashed potatoes 200 grams, bread 50 grams, coffee 1 cup.

Supper. - Rice pudding 150 grams, stewed peaches 100 grams, crackers 30 grams, butter 10 grams, tea 1 cup.

\section{Tuesday, January 12, 1904.}

Breakfast. - Fried Indian-meal 100 grams, syrup 50 grams, coffee 1 cup $=350$ grams or 367 cc., bread 50 grams, butter 15 grams.

Dinner. - Boiled macaroni 250 grams, stewed tomatoes 250 grams, bread 75 grams, coffee 1 cup, 367 grams.

Supper. - Potato chips 100 grams, fried bacon 25 grams, bread 75 grams, jam 75 grams, tea 1 cup $=350 \mathrm{cc}$.

Total nitrogen, 7.793 grams. Fuel value, 2404 calories.

\section{Wednesday, January 13, 1904.}

Breakfast. - Boiled rice 150 grams, milk 130 cc. 125 grams, sugar 30 grams, butter 10 grams, bread 30 grams, coffee 1 cup $=350 \mathrm{cc}$.

Dinner. - Hamburg steak with plenty of bread, fat, and onions chopped together

150 granıs, boiled potatoes 200 grams, apple sauce $200 \mathrm{grams}$, bread 75 grams, coffee 1 cup $=350$ cc.

Supper. - Fried rice 100 grams, syrup 50 grams, tea 350 cc., bread 50 grams, butter 15 grams.

Total nitrogen, 9.992 grams. $\quad$ Fuel value, 2133 calories.

\section{Thursday, January 14, 1904.}

Breakfast. - Boiled hominy 150 grams, milk 125 grams, sugar 30 grams, butter 10 grams, bread 30 grams, coffee $1 \mathrm{cup}=350 \mathrm{cc}$.

Dinner. - Split-pea soup (thick) 200 grams, bread 75 grams, mashed potatoes

100 grams, pickles 30 grams, coffee $1 \mathrm{cup}=350 \mathrm{cc}$., pie 120 grams.

Supper. - Suet pudding 150 grams, apple sauce 125 grams, crackers 25 grams, tea 1 cup $=350 \mathrm{cc}$.

Total nitrogen, 7.412 grams.

Fuel value, 2000 calories. 


\section{Friday, January 15, 1904.}

Breakfast. - Wheat griddle cakes 200 grams, syrup 50 grams, coffee $1 \mathrm{cup}=$ $350 \mathrm{cc}$.

Dinner. - Codfish-balls (4 parts potato, 1 part fish, fried in pork fat) 158 grams, stewed tomatoes 200 grams, bread 75 grams, coffee $1 \mathrm{cup}=350 \mathrm{cc}$., apple pie 95 grams.

Supper. - Apple fritters 200 grams, stewed prunes (stones not included) 125 grams, bread 50 grams, butter 15 grams, tea 1 cup $=350 \mathrm{cc}$.

Total nitrogen, 8.560 grams. Fuel value, 2030 calories.

$$
\text { Saturday, January 16, } 1904 .
$$

Breakfast. - Soft oatmeal 150 grams, milk 100 grams, sugar 30 grams, bread 30 grams, butter 10 grams, coffee $1 \mathrm{cup}=350 \mathrm{cc}$.

Dinner. - Baked nacaroni with a little cheese 200 grams, stewed tomatoes 200 grams, bread 50 grams, tapioca-peach pudding 150 grams, coffee 1 cup $=350 \mathrm{cc}$.

Supper. - French fried potatoes 100 grams, fried bacon 20 grams, bread 75 grams, jam 75 grams, tea 1 cup $=350 \mathrm{cc}$.

Total nitrogen, 7.282 grams. Fuel value, 1824 calories.

\section{Sunday, January 17, 1904.}

Breakfast. - Boiled Indian.meal 125 grams, milk 125 grams, sugar 30 grams, butter $10 \mathrm{grams}$, bread $30 \mathrm{grams}$, coffee 1 cup $=350 \mathrm{cc}$.

Dinner. - Bean soup (thick) 200 grams, bread 75 grams, mashed potato 100 grams, pickles 25 grams, coffee $1 \mathrm{cup}=350 \mathrm{cc}$., custard pie 105 grams. Supper. - Crackers 50 grams, butter 15 grams, stewed prunes (without stones) 125 grams, sponge cake 100 grams, tea $350 \mathrm{cc}$.

Total nitrogen, 8.349 grams. Fuel value, 2081 calories.

$$
\text { Monday, January 18, } 1904 .
$$

Breakfast. - Apple 150 grams, fried Indian-meal 100 grams, syrup 50 grams, baked potato 90 grams, butter 10 grams, coffee $1 \mathrm{cup}$.

Dinner. - Beef stew with potatoes and onions thickened with corn starch 300 grams, bread 75 grams, coffee 1 cup.

Supper. - Bread pudding 250 grams, stewed peaches 100 grams, crackers 25 grams, butter 10 grams, tea 1 cup.

$$
\text { Tuesday, January 19, } 1904 .
$$

Breakfast. - Apple 180 grams, boiled rice 150 grams, milk 125 grams, sugar 30 grams, baked potato 100 grams, butter 10 grams, coffee 1 cup.

Dinner. - Tomato soup with potatoes and onions boiled together 350 grams, bread 75 grams, mashed potatoes $150 \mathrm{grams}$, pickles $30 \mathrm{grams}$, coffee 1 cup, pie 129 grams.

Supper. - Biscuit 125 grams, butter 20 grams, apple sauce 175 grams, crackers 16 grams, tea 1 cup. 


\section{Wednesday, January 20, 190\%.}

Breakfast. - Apple 150 grams, fried rice 100 grams, syrup 50 grams, biscuit 50 grams, butter 10 grams, coffee 1 cup.

Dinner. - Baked beans with a little salt pork 150 grams, bread 75 grams, boiled onions 100 grams, coffee 1 cup.

Supper. - French fried potatoes 100 grams, fried bacon 20 grams, bread 50 grams, butter 10 grams, tea 1 cup.

\section{Thursday, January 21, 1904.}

Breakfast. - Wheat griddle cakes 150 grams, syrup 50 grams, butter 10 grams, bread 50 grams, coffee 1 cup.

Dinner. - Mashed potatoes 200 grams, fried egg 33 grams, bread 75 grams, butter

15 grams, apple pie 117 grams, coffee 1 cup.

Supper. - Crackers 50 grams, butter 10 grams, stewed prunes 125 grams, tea 1 cup, sponge cake 50 grams.

\section{Friday, January 22, 190\%.}

Breakfast. - Boiled Indian-meal 150 grams, milk 125 grams, sugar 30 grams, coffee 1 cup, baked potato 100 grams, butter 10 grams.

Dinner. - Clam chowder with onions, potatoes, and tomatoes $200 \mathrm{grams}$, bread 75 granıs, mashed potato 100 grams, coffee 1 cup.

Supper. $-\Lambda$ pple fritters 200 grams, jam 75 grams, tea 1 cup, gingerbread 30 grams.

\section{Saturday, January 23, 1904.}

Breakfast. - Boiled rice 150 grams, milk 125 grams, sugar 30 grams, coffee 1 cup, butter 10 grams, baked potato 150 grams.

Dinner. - Boiled macaroni 250 grams, stewed tomatoes 250 grams, bread 75 grams, coffee 1 cup.

Supper. - French fried potatoes 125 grams, fried bacon 30 grams, bread 100 grams, jam 75 grams, tea 1 cup.

\section{Sunday, January 24, 1904.}

Breakfast. - Fried rice 150 grams, syrup 50 grams, baked potato 125 grams, coffee 1 cup, apple 150 grams.

Dinner. - Split-pea soup 200 grams, bread 100 grams, pickles 30 grams, mashed potatoes 200 grams, coffee 1 cup, apple pie 100 grams.

Supper. - Baked apple with sugar 150 grams, crackers 50 grams, butter 20 grams, tea 1 cup, potato chips 50 grams. 


\section{Monday, January 25, 1904.}

Breakfast. - Boiled hominy 150 grams, milk 125 grams, sugar 30 grams, coffee 1 cup, baked potato 100 grams, butter 10 grams.

1)inner. - Meat pie 200 grams (with 30 grams meat), boiled cabbage 200 grams, mashed potatoes 200 grams, coffee 1 cup.

Supper. - Sponge cake 100 grams, stewed peaches 100 grams, crackers 25 grams, butter 10 grams, tea 1 cup, baked potato 115 grams.

\section{Thesday, January 26, 1904.}

Breakfast. - Apple 140 grams, wheat griddle cakes 200 grams, syrup 50 grams, coffee 1 cup, bread 50 grams, butter 10 grams.

Dinner. - Baked beans with a little salt pork $150 \mathrm{grams}$, boilec onions 100 grams, bread 75 granıs, bread pudding 150 grams, coffee 1 cup.

Supper. - Biscuit 175 grams, butter 20 grams, apple sauce 125 grams, tea 1 cup.

\section{Wednesday, January 27, 1904.}

Breakfast. - French fried potatoes 150 grams, fried bacon 20 grams, bread 75 grams, butter 10 grams, coffee 1 cup, apple 170 grams.

Dinner. - Split-pea soup (thick) 200 grams, bread 75 grams, mashed potatoes 100 grams, boiled onions 150 grams, coffee 1 cup.

Supper. - Rice pudding with raisins 200 grams, apple sauce 150 grams, crackers 25 grams, tea 1 cup.

\section{Thursday, January 28, 190/4.}

Breakfast. - Fried rice 100 grams, syrup 50 grams, bread 50 grams, coffee 1 cup, banana 75 grams.

Dinner. - Baked potato 170 grams, dried beef 40 grams, steweri with milk 30 grams, bread 75 grams, butter 20 grams, pickles 20 grams, coffee 1 cup.

Supper. - Apple fritters 200 grams, stewed prunes 125 grams, bread 50 grams, butter 15 grams, peach pie 120 grams, tea 1 cup.

$$
\text { Friday, January 29, } 1904 .
$$

Breakfast. - Wheat griddle cakes 200 grams, syrup 50 grams, coffee 1 cup, French fried potatoes 50 grams.

Dinner.-Oyster soup* 300 grams, crackers 50 granıs, bread 100 grams, coffee

1 cup, salad made of lettuce leaves, chopped apple, and celery with oil, salt, and pepper 75 grams.

Supper. - Biscuit 175 grams, butter 20 grams, jam 125 grams, tea 1 cup, apple 175 grams.

* In each bowl of soup were 90 grams of oysters, 20 grams of butter, and 190 grams of milk. 


\section{Saturday, January 30, 1904.}

Breakfast. - Boiled oatmeal 125 grams, milk 100 grams, sugar 25 grams, coffee 1 cup, baked potato 50 grams, butter 10 grams.

Dinner. - French fried potatoes 200 grams, cold roast beef 40 grams, bread 75 grams, pickles 30 grams, carrots 125 grams, coffee 1 cup.

Supper. - Apple-rice pudding 200 grams, stewed prunes 150 grams, bread 100 grams, butter 30 grams, tea 1 cup.

\section{Sunday, January 31, 190/4.}

Breakfast. - Boiled Indian-neal 200 grams, milk 100 grams, sugar 25 grams, coffee 1 cup, bread 50 grams.

Dinner. - Tomato soup with potatoes and onions boiled together 325 grams, bread 100 grams, fried egg 30 grams, baked potato 140 grams, coffee 1 cup.

Supper. - Lettuce-apple-celery salad 100 grams, bread 100 grams, butter 20 grams, stewed peaches 150 grams, tea 1 cup.

\section{Monday, February 1, 1904.}

Breakfast. - Fried Indian-meal 100 grams, syrup 50 grams, bread 50 grams, butter 10 grams, coffee 1 cup.

Dinner. - Baked beans 120 grams, with salt pork 30 grams, boiled onions 100 grams, mashed potatoes 200 grams, bread 75 grams, apple pie 120 grams, coffee 1 cup.

Supper. - Apple fritters 200 grams, stewed prunes 125 grams, crackers 32 grams, butter 15 grams, tea 1 cup.

\section{Tuesday, February $2,1904$.}

Breakfast. - Fried lominy 100 grams, syrup 50 grams, apple 160 grams, bread 50 grams, butter 10 grams, coffee 1 cup.

Dinner. - Boiled macaroni 250 grams, stewed tomatoes 250 grams, bread 75 grams, pie 120 grams, coffee 1 cup.

Supper. - Biscuit 175 grams, butter 20 grams, crackers 25 grams, stewed prunes 125 grams, tea 1 cup.

\section{Wednesday, February 3, 1904.}

Breakfast. - French fried potatoes 150 grams, fried bacon 20 grams, bread 50 grams, butter 10 grams, coffee 1 cup.

Dinner. - Corned beef 40 grams, cabbage 200 grams, mashell potatoes 200 grams, biead 75 grams, coffee 1 cup, boiled rice 200 grams, syrup 50 grams.

Supper. - Lettuce-apple-celery salad 150 grams, bread 100 grams, butter 20 grams, jam 75 grams, tea 1 cup. 


\section{PHYSIOLOGICAL ECONOMY IN NUTRITION}

\section{Thursday, February 4, 1904.}

Breakfast. - Wheat griddle cakes 200 grams, syrup 50 grams, coffee 1 cup, baked potato 150 grams, butter 10 grams.

Dinner. - Barley broth with potatoes and onions 250 grams, wheat flour dumplings 150 grams, boiled turnips 200 grams, bread 75 grams, tapiocapeach pudding 200 grams, coffee 1 cup.

Supper. - Suet pudding 150 grams, baked apple with sugar 150 grams, crackers 25 grams, stewed prunes 150 grams, tea 1 cup.

\section{Friday, February 5, 1904.}

Breakfast. - Banana 100 grams, French fried potatoes 200 grams, biscuit 175 grams, butter 20 grams, coffee 1 cup.

Dinner. - Boiled codfish 60 grams, mashed potatoes 250 grams, boiled onions 200 grams, bread 75 grams, coffee 1 cup.

Supper. - Bread pudding with raisins 250 grams, stewed peaches 100 grams, crackers 25 grams, butter 10 grams, tea 1 cup.

\section{Saturday, February 6, 1904.}

Breakfast. - Boiled rice 175 grams, milk 125 grams, sugar 25 grams, coffee 1 cup, banana 90 grams.

Dinner. - Baked beans 70 grams, with salt pork 30 grams, bread 75 grams, boiled sweet potato 150 grams, butter 10 grams, coffee 1 cup, apple pie 100 grams.

Supper. - French fried potatoes 125 grams, celery-lettuce-apple salad 150 grams, bread 100 grams, butter 20 grams, jam 75 grams, tea 1 cup.

\section{Sunday, February \%, 1904.}

Breakfast. - Fried rice 150 grams, syrup 50 grams, baked potato 140 grams, butter 10 grams, coffee 1 cup.

Dinner. - Hamburg steak with much bread, fat, and onions 150 grams, boiled potato 150 grams, butter 10 granıs, bread 75 grams, coffee 1 cup.

Supper. - Tapioca-peach pudding 250 grams, sponge cake 75 grams, tea 1 cup.

\section{Monday, February 8, 1904.}

Breakfast. - Boiled hominy 150 grams, milk 125 grams, sugar 25 grams, bread 50 grams, stewed prunes 150 grams, coffee 1 cup.

Dinner. - Baked spaghetti with a little grated cheese 200 grams, mashed potato 200 grams, bread 75 grams, boiled tomato 150 grams, pickles 20 grams, fruit pie, 130 grams, coffee 1 cup.

Supper. - Biscuit 175 grams, fried bacon 20 grams, French fried potatoes 150 grams, butter 20 grams, tea 1 cup. 


\section{PHYSIOLOGICAL ECONOMY IN NUTRITION $31 \tilde{5}$}

\section{Tuesday, February 9, 1904.}

Breakfast. - Fried hominy 125 grams, syrup 50 grams, baked potato 150 grams, butter 10 grams, coffee 1 cup.

Dinner. - Boiled sweet potato 150 grams, butter 10 grams, bread 75 grams, thick pea soup 200 grams, boiled onions 150 grams, coffee 1 cup, apple pie 150 grams.

Supper. - Celery-lettuce-apple salad 150 grams, crackers 32 grams, cheese (American) 20 grams, Saratoga chips 75 grams, tea 1 cup.

\section{Wednesday, February 10, 1904.}

Breakfast. - Wheat griddle cakes 200 grams, syrup 50 grams, butter 10 grams, coffee 1 cup, banana 90 grams.

Dinner. - Boiled salt mackerel 25 grams, boiled potatoes 200 grams, boiled turnips 200 grams, bread 75 grams, coffee 1 cup, apple 140 grams.

Supper. - Chocolate cake 150 grams, cranberry sauce 100 grams, chopped fresh cabbage with salt, pepper, and vinegar 100 grams, bread 75 grams, butter 20 grams, tea 1 cup.

\section{Thursday, February 11, 1904.}

Breakfast. - Breakfast food 40 grams, milk 125 grams, sugar 25 grams, baked potato 150 grams, butter 10 grams, coffee 1 cup, apple 130 grams.

Dinner. - Baked beans 70 grams, salt pork 30 grams, bread 75 grams, boiled cabbage 200 grams, boiled potato 150 grams, coffee 1 cup.

Supper. - Tapioca-peach pudding 250 grams, bread 75 grams, butter 20 grams, tea 1 cup, cranberry sauce 100 grams.

\section{Friday, February 12, 1904.}

Breakfast. - Breakfast food 40 grams, milk 125 grams, banana 90 grams, French fried potatoes 200 grams, sugar 25 grams, coffee 1 cup.

Dinner. - Clam chowder with onions, potatoes, and tomatoes 200 grams, bread

75 grams, mashed potato 200 grams, boiled turnips 150 grams, pie 125 grams, coffee 1 cup.

Supper. - Apple fritters 200 grams, jam 75 grams, tea 1 cup, gingerbread 30 grams.

\section{Saturday, February 13, 1904.}

Breakfast. - Boiled rice 150 grams, milk 125 grams, sugar 25 grams, coffee 1 cup, baked potato 100 grams, butter 10 grams.

Dinner. - Meat pie with meat, potatoes, and onions 200 grams, boiled cabbage 200 grams, boiled potatoes 200 grams, bread 50 grams, coffee 1 cup.

Supper. - Lettuce-apple-celery salad 150 grams, biscuit 150 grams, butter 20 grams, tea 1 cup, stewed prunes 125 grams. 


\section{Sunday, February 14, 190\%.}

Breakfast. - Apple 140 grams, fried rice 125 grams, syrup 50 grams, baked sweet potato 142 grams, butter 10 grams, coffee 1 cup.

Dinner. - Tomato soup with potatoes and onions boiled together, thickened with corn starch 350 grans, bread 75 grams, cauned string beans 100 grams, baked apple with sugar 140 grams, coffee 1 cup.

Supper. - Sinall fried sausage 50 grams, French.fried potatoes 200 grams, bread 50 grams, butter 10 grams, stewed prunes 100 grams, tea 1 cup.

\section{Monday, February 15, 1904.}

Breakfast. - Wheat griddle cakes 200 grams, syrup 50 grams, Johnny cake 50 grams, butter 10 grams, coffee 1 cup.

Dinner. - Hamburg steak, with bread, fat, and onions 150 grams, boiled potato 200 grams, bread 75 grams, butter 10 grams, coffee 1 cup, pickles 25 grams.

Supper. - Boiled Lima beans thoroughly cooked 75 grams, mashed potato 150 grams, bread 75 grams, butter 10 grams, tea 1 cup, stewed peaches 125 grams.

\section{Tuesday, February 16, 1904.}

Breakfast. - Brown bread 50 grams, baked potato 230 grams, butter 20 grams, coffee 1 cup, apple 140 grams.

Dinner. - Boiled macaroni 250 grams, stewed tomatoes 250 grams, French fried potatoes 150 grams, bread 75 grams, coffee 1 cup, pie 130 grams.

Supper. - Fried bacon 25 grams, potatoes stewed in cream 250 grams, rice pudding 200 grams, bread 50 grams, tea 1 cup.

\section{Wednesday, February 1\%, 1904.}

Breakfast. - Fried rice 125 grams, syrup 50 grams, baked sweet potato 190 grams, butter 10 grams, bread 50 grams, coffee 1 cup.

Dinner. - Corned beef 40 grams, cabbage 200 grams, mashed potato 200 grams, bread 75 grams, coffee 1 cup, tapioca-peach pudding 200 grams.

Supper. - Lettuce-apple-celery salad 150 grams, bread 100 grams, butter 20 grams, cranberry sauce 125 grams, tea 1 cup, baked potato 100 grams.

\section{Thursday, February 18, 1904.}

Breakfast. - Boiled hominy 175 grams, milk 125 grams, sugar 25 grams, coffee 1 cup, banana 110 grams.

Dinner. - Split-pea soup (thick) 200 grams, bread 100 grams, mashed potatoes 200 grams, boiled onions 200 grans, coffee 1 cup.

Supper. - Corned-beef hash (mostly potato) 125 grams, bread 50 grams, fried sweet potato 150 grams, butter 20 grams, tea 1 cup, jam 75 grams. 


$$
\text { Friday, February, 19, } 1904 .
$$

Breakfast. - Fried hominy 125 grams, syrup 50 grams, baked potato 150 grams, butter 10 grams, apple 140 grams, coffee 1 cup.

Dinner. - Boiled salt mackerel 25 grams, boiled potatoes 250 grams, boiled turnips 200 grams, bread 75 grams, coffee 1 cup, apple pie 100 grams.

Supper. - Chocolate cake 150 grams, cranberry sauce 125 grams, chopped fresl cabbage with salt, pepper, and vinegar 100 grams, bread 75 grams, butter 20 grams, tea 1 cup.

\section{Saturday, February 20, 1904.}

Breakfast. - Breakfast food 40 grams, milk 125 grams, sugar 25 grams, French fried potatoes 200 grams, coffee $1 \mathrm{cup}$.

Dinner. - Barley broth with potatoes and onions 250 grams, wheat flour dumplings 150 grams, boiled carrots 150 grams, bread 75 grams, boiled sweet potato 180 grams, coffee 1 cup.

Supper. - Suet pudding 150 grams, baked apple with sugar 150 grams, crackers 25 grams, stewed prunes 150 grams, tea 1 cup.

$$
\text { Sunday, February 21, } 1904 .
$$

Breakfast. - Boiled oatmeal (thin) 125 grams, milk 100 grams, sugar 25 grams, baked potato 150 grams, hutter 10 grams, coffee 1 cup.

Dinner. - Roast beef 40 grams, mashed potato 250 grams, bread 75 grams, apple sauce 150 grams, stewed tomatoes 150 grams, coffee 1 cup.

Supper. - Bread pudding 200 grams, cranberry sace 200 grams, potato chips 100 grams, tea 1 cup.

\section{Monday, February 22, 1904.}

Breakfast. - Wheat griddle cakes 200 grams, syrup 50 grams, butter 10 grams, baked potato 130 grams, coffee 1 cup.

Dinner. - Boiled macaroni 200 grams, stewed tomatoes 250 grams, French fried potatoes 200 grams, bread 35 grams, coffee 1 cup, apple sauce 150 grams.

Supper. - Lettuce-apple-celery salad 150 grams, biscuit 150 grams, butter 20 grams, stewed prunes 125 grams, tea 1 cup.

\section{Thesday, February $23,1904$.}

Breakfast. - Boiled rice 175 grams, milk 100 grams, sugar 25 grams, coffee 1 cup, banana 90 grams.

Dinner. - Bean soup (thick) 200 grams, mashed potato 250 grams, bread 35 grams, butter 10 grams, boiled onions 150 grams, coffee 1 cup, apple pie 100 grams.

Supper. - French fried potatoes 100 grams, crackers 25 grams, butter 15 grams, tea 1 cup, stewed peaches 150 grams. 


\section{Wednesday, February 24, 190/.}

Breakfast. - Fried rice 125 grams, syrup 00 grams, baked potato 150 grams, butter 10 grams, bread 35 grams, coffee 1 cup.

Dinner. - Boiled codfish 50 grams, mashed potato 250 grams, boiled carrots 150 grams, bread 50 grams, coffee 1 cup.

Supper. - Bread pudding with raisins 250 grams, jam 75 grams, crackers 25 grams, butter 15 grams, tea 1 cup.

\section{Thursday, February 25, 1904.}

Breakfast. - Boiled hominy 175 grams, milk 100 grams, sugar 25 grams, coffee 1 cup, baked sweet potato 125 grams, butter 10 grams.

Dinner. - Hamburg steak with much bread, fat, and onions 150 grams, boiled potatoes 200 grams, butter 15 grams, bread 50 grams, coffee 1 cup, pickles 35 grams.

Supper. - Tapioca-apple pudding 250 grams, sponge cake 75 grams, cranberry sauce 100 grams, tea 1 cup.

\section{Friday, February 26, 1904.}

Breakfast. - Fried hominy 100 grams, syrup 50 grams, bread 50 grams, butter 10 grams, coffee 1 cup, apple 150 grams.

Dinner. - Oyster chowder with tomatoes, potatoes, and onions 200 grams, bread 75 grams, string beans 150 grams, coffee 1 cup.

Supper. - Suet pudding with plums 125 grams, apple sauce 150 grams, baked sweet potato 200 grams, crackers 25 grams, butter 10 grams, tea 1 cup.

\section{Saturday, February 87, 1904.}

Breakfast. - Soft boiled oatmeal 125 grams, milk 100 grams, sugar 25 grams, coffee 1 cup, butter 10 grams, baked potato 140 grams.

Dinner. - Lyonnaise potato 175 grams, bacon 25 grams, boiled turnips 200 grams, coffee 1 cup, rice pudding 150 grams.

Supper. - Banana fritters 200 grams, stewed prunes 150 grams, crackers 25 grams, butter 10 grams, tea 1 cup.

\section{Sunday, February 28, 1904.}

Breakfast. - Stewed peaches 150 grams, wheat griddle cakes 200 grams, syrup 50 grams, coffee $1 \mathrm{cup}$, baked potato 150 grams, butter 10 grams.

Dinner. - Barley broth with potatoes and onions 250 grams, wheat flour dumplings 150 grams, French fried potatoes 150 granı, bread 35 grams, coffee 1 cup, ice crean 100 grams.

Supper. - Saratoga chips 75 grams, fried sausage 40 grams, butter 15 grams, bread 50 grams, tea 1 cup. 


\section{Monday, February 29, 1904.}

Breakfast. - Boiled rice 175 grams, milk 125 grams, sugar 25 grams, baked potato 150 grams, coffee 1 cup, 350 grams, butter 10 grams.

Dinner. - Baked spaghetti 250 grams, mashed potato 250 grams, bread 75 grams, boiled tomatoes 150 grams, apple pie 112 grams, coffee 1 cup, 350 grams.

Supper. - Biscuit 175 grams, fried bacon 20 grams, fried sweet potatoes 150 grams, butter 20 grams, tea 1 cup, 350 grams.

Total nitrogen, 10.466 grams. Fuel value, 2670 calories.

\section{Tuesday, March 1, 1904.}

Breakfast. - Fried rice 150 grams, syrup 50 grams, baked potato 150 grams, butter 10 grams, coffee 1 cup, 350 grams.

Dinner. - Thick pea-soup 250 grams, boiled onions 150 grams, boiled sweet potato 150 grams, bread 75 grams, butter 20 grams, coffee 1 cup, 350 grams.

Supper. - Celery-lettuce-apple salad 120 grams, crackers 32 grams, American cheese 20 grams, Saratoga chips 79 grams, tea 1 cup, 350 grams, rice eustard 100 grams.

Total nitrogen, 7.825 grams. $\quad$ Fuel value, 2279 calories.

\section{Wednesday, March 2, 1904.}

Breakfast. - Wheat griddle cakes 200 grams, syrup 50 grams, butter 10 grams, coffee 1 cup, 350 granıs, banana 75 grams.

Dinner. - Boiled salt mackerel 25 grams, boiled potatoes 250 grams, boiled turnips 150 grams, bread 75 grams, coffee 1 cup, 350 grams, apple sauce 150 grams.

Supper. - Chopped fresl cabbage with salt, pepper, and vinegar, 100 grams, bread 75 grams, butter 20 grams, chocolate cake 150 grams, cranberry sauce 100 grams, tea 1 cup, 350 grams.

Total nitrogen, 8.487 grams. $\quad$ Fuel value, 2391 calories.

\section{Thursday, March 3, 1904.}

Breakfast. - Boiled hominy 175 grams, milk 125 grams, sugar 25 grams, baked potato 150 grams, butter 10 grams, coffee 1 cup, 350 grams.

Dinner. - Hamburg steak with much bread, fat and onions 150 grams, boiled potato 250 grams, bread 75 grams, butter 10 grams, coffee 1 cup, 350 grams.

Supper. - Tapioca-peach pudding 250 grams, bread 75 grams, jam 75 grams, butter 20 grams, tea 1 cup, 250 grams.

Total nitrogen, 8.750 grams.

Fucl value, 2375 calories. 


\section{Friday, March 4, 1904.}

Breakfast. - Fried hominy 150 grams, syrup 50 grams, baked potato 150 grams, coffee 1 cup, 350 grams, butter 10 grams.

Dinner. - Codfish-balls (1 part fish 4 parts potato) fried in pork fat 150 grams, stewed tomatoes 200 grams, stewed potatoes 150 grams, bread 75 grams, coffee 1 cup, 350 grams, apple pie 130 grams.

Supper. - French fried potatoes 200 grams, fried sausage 50 grams, butter 10 grams, stewed prunes 125 grams, sponge cake 35 grams, bread 50 grams, tea 1 cup, 350 grams.

Total nitrogen, 10.427 grams. Fuel value, 2374 calories.

\section{Saturday, March 5, 1904.}

Breakfast. - Boiled Indian-meal 200 grams, milk 125 grams, sıgar 25 grams, coffee 1 cup, 350 grams, fried sweet potato 150 grams, butter 10 grams.

Dinner. - Tomato soup thick, with potatoes and onions boiled together 325 grams, bread 100 grams, scrambled egg 50 grams, mashed potato 150 grams, coffee 1 cup, 350 grams.

Supper. - Bread pudding with raisins 250 grams, stewed peaches 150 grams, bacon 20 grams, French fried potatoes 150 grams, bread 50 grams, butter 10 grains, tea 1 cup, 350 grams.

Total nitrogen, 10.483 grams. Fuel value, 2302 calories.

\section{Sunday, March 6, 1904.}

Breakfast. - Fried Indian-meal 150 grams, syrup 50 grams, sliced banana 100 grams, baked potato 150 grams, butter 10 grams, coffee 1 cup, 350 grams.

Dinner. - Corned beef 50 grams, boiled cabbage 200 grams, mashed potato 250 grams, bread 75 grams, fried rice 100 grams, jam 75 grams, coffee 1 cup, 300 grams.

Supper. - Sponge cake 150 grams, apple sauce 150 grams, crackers 32 grams, butter 10 grams, sardine 14 grams, tea 1 cup, 350 grams.

Total Nitrogen, 10.265 grams. Fuel value, 3173 calories.

\section{Monday, March 7, 1904.}

Breakfast. - Boiled rice 175 grams, milk 125 grams, sugar 25 grams, baked potato 150 grams, bitter 10 grams, coffee 1 cup.

Dinner. - Baked spaglietti 300 grams, mashed potato 250 grams, bread 75 grams, boiled tomatoes 200 grams, apple pie 125 grams, coffee 1 cup.

Supper. - Biscuit $175 \mathrm{grams}$, fried bacon $30 \mathrm{grams}$, fried sweet potato 200 grams, butter 20 grams, tea 1 cup. 


\section{Tuesday, March 8, 1904.}

Breakfast. - Fried rice 150 grams, syrup 50 grams, baked potato 200 grams, butter 10 grams, coffee 1 cup.

Dinner. - Thick pea-soup 300 grams, boiled sweet potato 250 grams, boiled onions 150 grams, bread 75 grams, butter 20 grams, pickles 30 grams, coffee 1 cup.

Supper. - French fried potatoes 150 granıs, fried bacon 20 grams, crackers 32 grams, apple sauce 200 grams, rice custard 100 grams, tea 1 cup.

\section{Wednesday, March 9, 1904.}

Breakfast. - Wheat griddle cakes 200 grams, syrup 50 grams, butter 10 grams, banana 90 grams, coffee 1 cup.

1)inner. - Boiled salt mackerel 25 grams, boiled potato 250 grams, boiled turnips 200 grams, bread 75 grams, apple sauce 200 grams, coffee 1 cup.

Supper. - Chopped fresh cabbage with salt, pepper and vinegar, 75 grams, bread 75 grams, butter 20 grams, chocolate cake 150 grams, cranberry sauce 100 grams, tea 1 cup.

$$
\text { Thursday, March 10, 1904. }
$$

Breakfast.-Boiled hominy 175 grams, milk 125 grams, sugar 25 grams, baked potato 250 grams, butter 10 grams, coffee 1 cup.

Dinner. - Hamburg steak with much bread, fat, and onions 150 grams, boiled potato, 250 grams, bread 75 grams, butter 10 grams, coffee 1 cup, pickles 30 grams.

Supper. - Tapioca-peach pudding 250 grams, bread 75 grams, jam 100 grams, butter 20 grams, tea 1 cup.

$$
\text { Friday, March 11, 1904. }
$$

Breakfast. - Fried hominy 150 grams, syrup 50 grams, baked potato 250 grams, butter 10 grams, apple sauce 150 grams, coffee 1 cup.

I)inner. - Codfish-balls ( 1 part fish, 4 parts potato, fried in pork fat) 150 grams, stewed tomatoes 200 grams, stewed potatoes 250 grams, bread 75 grams, apple pie 130 grams, coffee 1 cup.

Supper. - French fried potatoes 200 grams, fried sausage 50 grams, bread 50 grams, butter 10 grams, stewed prunes 125 grams, sponge cake 35 grams, tea 1 cup.

$$
\text { Saturday, March 12, 1904. }
$$

Breakfast. - Boiled Indian-meal 200 grams, milk 125 grams, sugar 25 grams, coffee 1 cup, fried sweet potato 150 grams, butter 10 grams.

Dinner. - Tomato soup thick, with potatoes and onions 325 grams, bread 100 grams, fried egg 30 grams, mashed potato 250 grams, coffee 1 cup, pickles 30 grams.

Supper. - Fried bacon 20 grams, French fried potatoes 150 grams, bread 50 grams, butter 10 grams, bread pudding with raisins 250 grams, stewed peaches 200 grams, tea 1 cup. 


\section{Sunday, March 13, 1904.}

Breakfast. - Fried Indian-meal 150 grams, syrup 50 grams, apple sauce 200 grams, baked potato 250 grams, butter 10 grams, coffee 1 cup.

Dinner. - Hamburg steak with much bread, fat, and onions 150 grams, boiled cabbage 200 grams, boiled potatoes 250 grams, bread 75 grams, butter 10 grams, coffee 1 cup.

Supper. - Suet pudding 150 grams, stewed peaches 200 grams, crackers 32 grams, butter 10 grams, sardine 30 grams, tea 1 cup.

\section{Monday, March 14, 1904 .}

Breakfast. - Wheat griddle cakes 200 grams, syrup 50 grams, butter 10 grams, coffee 1 cup, banana 80 grains.

Dinner. - Baked spaghetti 300 grams, nashed potato 250 grams, bread 75 grams, stewed tomatoes 200 grams, coffee 1 cup, baked apple with sugar 150 grams.

Supper. - Biscuit 175 grams, fried bacon 20 grams, fried sweet potato 200 grams, butter 20 grams, tea 1 cup.

$$
\text { Tueslay, March 15, } 1904 .
$$

Breakfast. - Boiled rice 175 grams, milk 125 grams, sugar 25 grams, baked potato 200 grams, butter 10 grams, coffee 1 cup.

Dinner. - Thick pea-soup 300 grams, boiled potatoes 250 grams, boiled onions 150 grams, pickles 30 grams, bread 75 grams, butter 20 grams, coffee 1 cup, rice custard 100 grams.

Supper. - Fried bacon 20 grams, French fried potatoes 200 grams, bread 50 grams, apple sauce 200 grams, tea 1 cup.

\section{Wednesday, March 16, 1904.}

Breakfast. - Fried rice 150 grams, syrup 50 grams, baked potato 200 grams, butter 10 grams, coffee 1 cup.

Dinner. - Codfish-balls ( 1 part fish, 4 parts potato, fried in pork fat) 150 grams, stewed potatoes 250 grams, stewed tomatoes 200 grams, bread 75 grams, coffee 1 cup, apple pie 125 grams.

Supper. - Apple-lettuce-celery salad 100 grams, bread 100 grams, butter 20 grams, stewed peaches 200 granıs, tea 1 cup, sponge cake 50 grams.

\section{Thursday, March 17, 1904.}

Breakfast. - Boiled hominy 175 grams, milk 125 grams, sugar 25 grams, baked potato 250 grams, butter 10 grams, coffee 1 cup.

Dinner. - Hamburg steak with much bread, fat, and onions 150 grams, mashed potato 250 grams, pickles 30 grams, bread 50 grams, butter 10 grams, boiled turnips 150 grams, coffee 1 cup.

Supper. - Tapioca-peach pudding 250 grams, bread 75 grams, jam 100 grams, butter 20 grams, tea 1 cup. 


$$
\text { Friday, March 18, } 1904 \text {. }
$$

Breakfast. - Fried hominy 150 grams, syrup 50 grams, baked potato 250 grams, butter 10 grams, apple sauce 150 grams, coffee 1 cup.

Dinner. - Clam chowder with much potato, tomato and onions 250 grams, bread 75 grams, mashed potato 150 grams, boiled sweet potato 150 grams, coffee 1 cup, pickles 30 grams.

Supper.-Bread pudding with raisins 250 grams, stewed peaches 200 grams, fried baoon 20 grams. French fried potatoes 150 grams, crackers 24 grams, butter 10 grams, tea 1 cup.

\section{Saturday, March 19, 1904.}

Breakfast. - Boiled Indian-meal 200 grams, milk 125 grams, sugar 25 grams, fried sweet potato 150 grams, butter 10 grams, coffee 1 cup.

Dinner. - Tomato soup thick, with potatoes and onions 325 grams, bread 100 grams, mashed potato 250 grams, coffee 1 cup, pickles 30 grams.

Supper. - Fried egg 30 grams, baked potato 250 grams, butter 20 grams, biscuit 175 grams, tea 1 cup, stewed prunes 125 grams.

$$
\text { Sunday, March 20, } 1904 .
$$

Breakfast. - Fried Indian-meal 150 grams, syrup 50 grams, baked potato 250 grams, butter 20 grams, coffee 1 cup, apple 150 grams.

Dinner. - Roast beef 50 grams, mashed potato 250 grams, boiled carrots 100 grams, bread 50 grams, apple pie 130 grams, coffee 1 cup, pickles 30 grams.

Supper. - Apple fritters 200 grams, cranberry sauce 150 grams, gingerbread 30 grams, tea 1 cup.

\section{Monday, March 21, 1904.}

Breakfast. - Wheat griddle cakes 200 grams, syrup 50 grams, butter 10 grams, baked potato 200 grams, coffee 1 cup.

Dinner. - Baked spaghetti 250 grams, mashed potato 250 grams, stewed tomatoes 150 grams, bread 75 grams, apple pie 125 grams, coffee 1 cup.

Supper. - Biscuit 150 grams, fried bacon 20 grams, fried sweet potatoes 150 grams, butter 20 grams, tea 1 cup.

\section{Tuesday, March 22, 1904.}

Breakfast. - Boiled rice 175 grams, milk 125 grams, sugar 25 grams, baked potatoes 150 grams, coffee 1 cup, butter 10 grams.

Dinner. - Thick pea-soup 250 grams, boiled onions 150 grams, boiled sweet potato 150 grams, bread 75 grams, butter 20 grams, coffee 1 cup, pickles 25 grams.

Supper. - Banana with sugar 75 grams, crackers 32 grams, American cheese 20 grams, Saratoga chips 75 grams, tea 1 cup, rice custard 100 grams. 


\section{Wednesday, March 23, 1904.}

Breakfast. - Fried rice 150 grams, syrup 50 grams, baked potato 150 grams, butter 10 grans, coffee 1 cup, apple 150 grams.

Dinmer. - Boiled salt mackerel 25 grams, boiled potato $250 \mathrm{grams}$, boiled turnips 150 grams, pickle 20 grams, bread 75 grams, coffee 1 cup, apple sauce 100 grams.

Supper. - Chopped fresh cabbage with salt, pepper, and vinegar 100 grams, bread 75 grams, butter 20 grams, chocolate cake 100 grams, cranberry sauce 100 grams, tea 1 cup.

\section{Thursday, March 24, 1904.}

Breakfast. - Boiled hominy 175 grams, milk 125 grams, sugar 25 grams, baked potato 150 granıs, butter 10 grams, coffee 1 cup.

Dinner. - Hamburg steak with much bread, fat, and onions 150 grams, boiled potatoes 250 grams, bread 75 grams, butter 10 grams, coffee 1 cup.

Supper. - Tapioca-peach pudding 250 grams, bread 75 grams, jam 75 grams, butter 20 grams, tea 1 cup.

\section{Friday, March 25, 1904.}

Breakfast. - Fried hominy 150 grams, syrup 50 grams, baked potato 150 grams, coffee 1 cup, apple 150 grams.

Dinner. - Codfish-balls ( 1 part fish, 4 parts potato, fried in pork fat) 150 grams, stewed tomatoes 200 grams, stewed potatoes 150 grams, bread 75 grams, coffee 1 cup, apple pie 130 grams.

Supper. - French fried potatoes 200 grams, fried bacon 20 grams, butter 10 grams, bread 50 grams, stewed prunes 125 grams, tea 1 cup.

\section{Saturday, March 26, 1904.}

Breakfast. - Boiled Indian-meal 175 grams, milk 125 grams, sugar 25 grams, butter 10 grams, fried sweet potato 150 grams, coffee 1 cup.

Dinner. - Tomato soup with potato and onions boiled together 325 grams, bread 100 grams, fried egg 40 grams, mashed potato 150 grams, coffee 1 cup.

Supper. - Saratoga chips 50 grams, fried bacon 20 grams, bread 50 grams, butter 10 grams, bread pudding with raisins 250 grams, stewed peaches 150 grams, tea 1 cup.

\section{Sunday, March $27,1904$.}

Breakfast. - Fried Indian-meal 150 grams, syrup 50 grams, baked potato 150 grams, coffee 1 cup, butter 10 grams, banana 90 grams.

1)inner. - Cornell beef 40 grams, boiled cabbage 200 grams, mashed potato 250 grans, bread 75 grams, coffee $1 \mathrm{cup}$, squash pie 130 grams.

Supper. - Suet pudding 150 grams, apple sauce 150 grams, crackers 32 grams, butter 10 grams, clopped cabbage with salt, pepper, and vinegar 60 grams, tea 1 cup. 


$$
\text { Monday, March 28, } 1904 .
$$

Breakfast. - Fried rice 150 grams, syrup 75 grams, baked potato 250 grams, butter 20 grams, coffee, 1 cup, 350 grams.

Dinner. - Thick pea-soup 200 grams, boiled onions 100 grams, boiled sweet potato 250 grams, breal 50 grams, mashed potato 200 grams, butter 20 grams, coffee 1 cup, 350 grams.

Supper. - Biscuit 125 grains, fried bacon 20 grams, French fried potatoes 200 grams, butter 25 grams, banana 150 grams, tea 1 cup, 350 grams.

Total nitrogen, 9.027 grams. Fuel value, 2935 calories.

\section{Tuesday, March 29, 1904.}

Breakfast. - Boiled hominy 175 grams, milk 75 grams, sugar 25 grams, baked potato 250 grams, butter 20 grams, coffee $1 \mathrm{cup}, 350$ grams.

Dinner. - Hanburg steak with much bread, fat, and onions 125 grams, boiled potatoes 300 grams, butter 10 grams, bread 35 grams, boiled carrots 125 grams, coffee 1 cup, 350 grams.

Supper.-Tapioca-peach pudding 300 grams, bread 35 grams, Saratoga chips 75 grams, butter 20 grams, jam 75 grams, tea 1 cup, 350 grams.

Total nitrogen, 8.972 grams. Fuel value, 2840 calories.

\section{Wednesday, March 30, 1904.}

Breakfast. - Fried hominy 150 grams, syrup 75 grams, butter 10 grams, banana 250 grams, coffee 1 cup, 350 grams.

Dinner. - Codfish-balls ( 1 part fish, 5 parts potato, fried in pork fat) 125 grams, bread 35 grams, mashed potatoes 250 grams, stewed tomatoes 200 grams, apple sauce 200 grams, coffee 1 cup, 350 grams.

Supper. - Chopped fresh cabbage with salt, pepper, and vinegar, 75 grams, bread 50 grams, butter 20 grams, fried sweet potato 250 grams, cranberry sauce 200 grams, sponge cake 50 grams, tea 1 cup, 350 grams.

Total nitrogen, 9.356 grams. Fuel value, 2657 calories.

\section{Thursday, March 31, 1904.}

Breakfast. - Fried Indian-meal 100 grams, syrup 75 grams, baked potato 250 grams, butter 20 grams, coffee, 1 cup, 350 grams.

Dinner. - Tomato soup thick, with potato and onions boiled together 300 grams, mashed potato 200 grams, scrambled egg 50 grams, bread 50 grams, butter 10 grams, coffee 1 cup, 350 grams.

Supper. - Fried bacon 20 grams, boiled potato 200 grams, butter 10 grams, bread pudding 150 grams, banana 200 grams, tea 1 cup, 350 grams.

Total nitrogen, 8.420 grams.

Fuel value, 2466 calories. 


\section{Friday, April 1, 1904.}

Breakfast. - Fried hominy 150 grams, syrup 75 grams, baked potato 200 grams, butter 20 grams, coffee 1 cup, 350 grams.

Dinner. - Baked spaghetti 250 grams, mashed potato 250 grams, boiled turnips 150 granıs, bread 35 grams, butter 10 grams, apple sauce 200 grams, coffee 1 cup, 350 grams.

Supper. - Fried sweet potato $200 \mathrm{grams}$, butter $20 \mathrm{grams}$, jam $100 \mathrm{grams}$, fried bacon 25 grams, bread 25 grams, apple-tapioca pudding 300 grams, tea 1 cup, 350 grams.

Total nitrogen, 7.342 grams. Fuel value, 3248 calories.

\section{Saturday, April 2, 1904.}

Breakfast. - Griddle cakes 200 grams, syrup 50 grams, baked potato 200 grams, butter 10 grams, coffee 1 cup, apple 140 granis.

Dinner. - Boiled nackerel 25 grams, boiled potato 250 grams, boiled turnips 150 grams, pickles 35 grams, bread 50 grams, pie 130 grams, butter 10 granis, coffee 1 cup.

Supper. - Suet pudding 125 grams, cranberry sauce 150 grams, baked sweet potato 200 grams, crackers 25 grams, butter 10 grams, tea 1 cup.

\section{Sunday April 3, 1904.}

Breakfast. - Banana 90 grams, boiled rice 175 grams, milk 125 grams, sugar 25 grams, baked potato 200 grams, butter 10 grams, coffee 1 cup.

Dinner. - Corned beef 40 grams, boiled cabbage 200 grams, boiled potatoes 200 grams, bread 75 grams, butter 10 grams, coffee $1 \mathrm{cup}$, stewed prunes 150 grams.

Supper. - Apple-tapioca pudding 250 grams, jam 75 grams, crackers 25 grams, butter 10 grams, pickles 25 grams, tea 1 cup.

$$
\text { Monday, April 4, 1904. }
$$

Breakfast. - Fried rice 150 grams, syrup 50 grams, apple 130 grams, baked sweet potato 200 grams, butter 10 grams, coffee 1 cup.

Dinner. - Lyonnaise potatoes 175 grams, bacon 25 grams, boiled turnips 200 grams, pie 130 grams, coffee 1 cup, bread 75 grams.

Supper. - Biscuit 175 grams, butter 25 grams, egg 40 grains, stewed apples 150 grans, tea 1 cup. 


\section{EXPERIMENTS WITH UNIVERSITY STUDEN'S, TRAINED IN A'THLETICS.}

Men in training for athletic events deem it necessary to consume large amounts of proteid food. Great muscular activity, it is true, calls for the expenditure of corresponding amounts of energy, but it is by no means clear that the energy so liberated comes from the breaking down of proteid material. Indeed, there is more reason for believing that the energy of muscular contraction comes primarily from the oxidation of non-nitrogenous matter. Nevertheless, custom and long experience sanction a high proteid diet, composed largely of meat or of other foodstuffs rich in nitrogen, for the development of that vigor and strength that go to make the accomplished athlete. For the development of new muscle tissue, to make two muscle fibres where before only one existed, to increase the number of available fibres, thereby adding to the bulk of the active tissue, a certain amount of proteid food is absolutely necessary, just as it is for all active tissues and organs of the body. But that this fact constitutes a satisfactory reason for the daily use of such quantities of proteid food as usually enter into the diet of the average athlete is very questionable.

As an illustration of the character of the diet frequently made use of by men doing prolonged muscular work, I may quote a few figures from an article by Professor W. O. Atwater* and H. C. Sherman on "The effect of severe and prolonged muscular work upon Food consumption, Digestion, and Metabolism," in which are recorded observations made upon several professional bicycle riders during a six-day race. On one day subject " $\mathrm{M}$ " rode 334.1 miles, consuming for food on

* U. S. Department of Agriculture, Office of Experiment Stations, Bulletin 98.

See also "Investigations on the Nutrition of Man in the United States." By C. F. Langworthy and R. D. Milner. U. S. Department of Agriculture, Office of Experiment Stations. Washington, 1904, p. 14. 
that day meat extract, 311 grams ; milk, 4937 grams; bread, 35 grams; boiled cereals, 877 grams; pastry, 142 grams; sugar, 53 grams; fruit, 2003 grams. His urine for the day contained 46.2 grams of nitrogen, corresponding to the metabolism of 288.7 grams of proteid matter. Subject "A" on one day rode 352.7 miles, taking as food, meat, 149 grams; meat extract, 24 grams; broth, 283 grams; eggs, 369 grams; butter, 78 grams; milk, 142 grams; malted milk, 78 grams; jelly, 213 grams ; soup, 191 grams ; bread, 361 grams; boiled cereal, 532 grams; sugar, about 400 grams ; fruit, 933 grams; cocoa wine, 198 grams. His day's urine contained 39.0 grams of nitrogen, corresponding to the metabolism of 243.7 grams of proteid material.

Obviously, if such high proteid metabolism as these figures imply is a necessary concomitant of vigorous or excessive muscular activity, then a rich proteid diet is needed to make good the loss of nitrogen to the body; but we are more inclined to believe that the large quantity of nitrogen excreted was the result chiefly of the high proteid ration, and only in small measure connected with the work done. With a sufficiency of non-nitrogenous food, the energy of muscular contraction does not come in any large degree from the breaking down of proteid matter, and there would seem to be no adequate reason for assuming a necessity for such rich and excessive proteid diet as athletes in training ordinarily adopt. Yet the contrary view is almost universally held and followed. As a prominent trainer said to the writer not long ago, "if the men are not fed on a rich meat diet and plenty of it, they will grow soft and lose their strength."

With a view to testing some of these points and thereby broaden the scope of the investigation and enhance the value of the study, a group of eight students in the University, all trained athletes, was secured. These men volunteered to aid in the study, and at considerable self-sacrifice gave intelligent and hearty co-operation in all ways possible. The men were under observation from January 15, 1904, to the middle of June, 1904, a period of five months. From January 15 the 


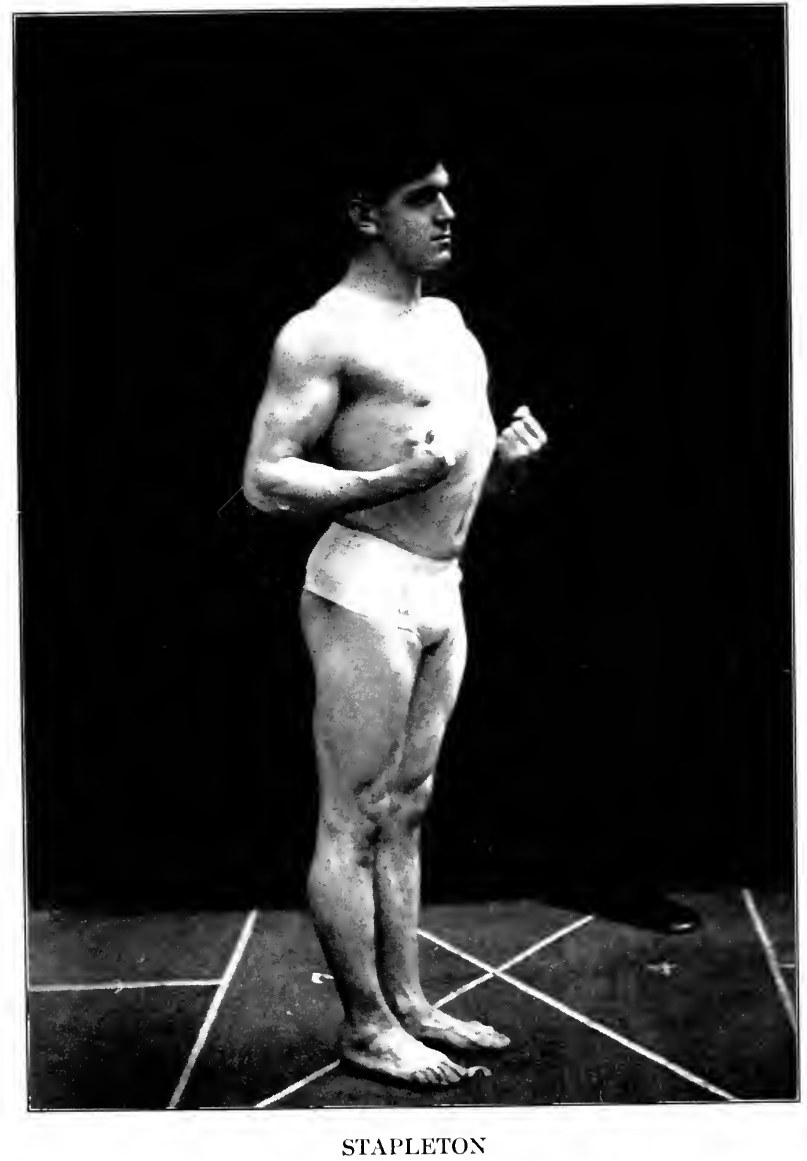

Photograph taken in the middle of the experiment, in April. 
urine was collected daily, and for a period of ten days the regular diet of the men was adhered to without any deviation whatever, with a view to ascertaining the extent of the proteid metabolism characteristic of each individual. No restrictions whatever in diet were suggested, but the ordinary food that the men were accustomed to eat while in training was taken. After this period the men were instructed to diminish somewhat the intake of proteid food, and in following out this plan most of the men diminished quite appreciably the quantity of food consumed at breakfast time, and in some cases stopped taking food of any kind at breakfast other than a cereal, with possibly coffee. No specific diet was imposed, but the men, being willing collaborators in the experiment, gradually cut down the intake of proteid food, diminishing likewise in considerable measure the total volume of food for the twenty-four hours.

The following brief description of the men, taken from Dr. Anderson's report of their physical condition, to be referred to later, will suffice to make clear the characteristics (as athletes) of these subjects of study:

Mr. G. IV. Anderson is a foot-ball, base-ball, and basket-ball player, as well as a crew man (not Varsity). Well built and an all round athlete. 26.5 years of age.

Mr. W. L. Anderson, a "Y" athlete (hurdler), the captain of the Yale Gymnastic Team, University Gymnastic Champion, and American Collegiate Gymnastic Champion. 21.5 years of age.

Mr. H. S. Bellis, a member of the Y. G. A., a gymnast and acrobat and in constant training. 26 years of age.

Dr. W. H. Callahan, Medical Assistant at the Gymnasium, in daily practice in the gymnasium; bowling, hand-ball, and lunning. 27 years of age.

Mr. M. Donahue, a very muscular and versatile athlete, a foot-ball player and a Varsity basket-ball player. 25 years of age.

Mr. C. S. Jacobus, a " Y" athlete, a noted long-distance man, and one of the best University runners. 22.3 years of age. 
Mr. H. R. Schenker, an active member of the Y. G. A., a point winner and intercollegiate competitor in gymnastics. 22 years of age.

Mr. John Stapleton, a wrestler and gymnast. A professional, a man of large body and great strength. 24 years of age.

The results of the daily study of the twenty-four hours' urine of each man for the entire period of five months are to be found in the accompanying tables. By a careful inspection of these data many interesting facts are brought to light. First it is to be observed, in harmony with what has already been stated regarding athletes, that the men, as a rule, were accustomed to the taking of large amounts of proteid fool daily. Thus, during the preliminary period of ten days, $\mathrm{D}_{\mathrm{r}}$. Callahan excreted through the kidneys 22.79 grams of nitrogen as the daily average, corresponding to the metabolism of 142 grams of proteid matter per day, while on one day the nitrogen excretion reached the high figure of 31.99 grams, corresponding practically to the metabolism of 200 grams of proteid material.

G. W. Anderson, during the preliminary period of ten days - on his ordinary diet - showed an average daily excretion of 17.18 grams of nitrogen. W. L. Anderson in this same period excreted on an average 18.22 grams of nitrogen per day, while on one day the excretion reached 23.42 grams of nitrogen. Bellis showed an average daily excretion of 17.64 grams of nitrogen during this same fore period, while Stapleton excreted nitrogen at an average rate of 19.7 grams per day, thus indicating an average daily metabolism of $123 \mathrm{grams}$ of proteid matter on his ordinary diet. With such data before us it is quite clear that we have here, as expected, a group of sturdy men accustomed to the taking of large amounts of proteid food daily; men who clearly believed that their strength and bodily vigor depended in large measure upon the ingestion and utilization of these quantities of proteid food.

After the termination of this preliminary period, the men began to diminish the amount of albuminons food. In doing 
this they were at first given perfect freedom, each man following his own preferences, and making such alterations in his diet as he saw fit. The men were instructed as to the chemical composition of the various foodstuffs, so that they had a general idea of what foods were rich in nitrogen and could act accordingly. Some of the men eut down their intake of proteid food very rapidly, others made more gradual reduction. Some soon eliminated breakfast almost entirely. Others reduced the amount of food at each meal. Some of the men eliminated meat almost completely from their diet, and increased largely the intake of vegetable food. They were all advised, however, not to make too sudden a change in their diet, but to adopt a gradual reduction in the daily food as being less liable to disturb their physiological equilibrium. Naturally, the men knew exactly how much of a reduction in proteid food they were accomplishing each week, from the results of the chemical analysis of the urine. Further, the record of bodyweight furnished evidence of how far the changes in diet were affecting body equilibrium, while their own feelings and ability to do their daily work constituted a check upon a too radical change in living. Careful perusal of the tables will show how far body-weight was changed, and to how great an extent proteid metabolism was reduced during the five months of the experiment. 
ANDERSON, G. W.

\begin{tabular}{|c|c|c|c|c|c|c|}
\hline \multirow{2}{*}{ Date. } & \multirow{2}{*}{$\begin{array}{c}\text { Body- } \\
\text { weight. }\end{array}$} & \multicolumn{5}{|c|}{ Urine. } \\
\hline & & $\begin{array}{l}\text { Volume. } \\
24 \text { hours. }\end{array}$ & Sp. Gr. & Nitrogen. & Uric Acid. & $\mathrm{P}_{2} \mathrm{O}_{5}$ \\
\hline 1904 & kilos & c.c. & & grams & gram & grams \\
\hline Jan. 16 & 75.0 & 1300 & 1022 & 18.02 & 0.470 & $\cdots$ \\
\hline 17 & $\ldots$ & 1300 & 1027 & 18.88 & 1.360 & $\cdots$ \\
\hline 18 & $\cdots$ & 1600 & 1025 & 17.95 & 1.008 & $\cdots$ \\
\hline 19 & $\cdots$ & 1085 & 1030 & 16.27 & 1.139 & $\cdots$ \\
\hline 20 & $\cdots$ & 890 & 1031 & 17.19 & 1.008 & $\cdots$ \\
\hline 21 & $\cdots$ & 1080 & 1030 & 17.69 & 0.940 & $\cdots$ \\
\hline 22 & 75.0 & 1340 & 1027 & 16.32 & 0.814 & $\cdots$ \\
\hline 23 & 75.0 & 1210 & 1028 & 17.42 & 1.020 & $\cdots$ \\
\hline 24 & 75.0 & 990 & 1031 & 14.85 & 0.850 & $\cdots$ \\
\hline 25 & 75.0 & 1020 & 1028 & & & \\
\hline 26 & $\cdots$ & 1035 & 1029 & & & \\
\hline 27 & $\cdots$ & 865 & 1029 & & & \\
\hline 28 & $\cdots$ & 800 & 1029 & 14.19 & 0.768 & 2.70 \\
\hline 29 & $\cdots$ & 690 & 1026 & daily & daily & daily \\
\hline 30 & $\cdots$ & 765 & 1026 & average & average & average \\
\hline 31 & $\cdots$ & 800 & 1024 & & & \\
\hline Feb. 1 & 75.0 & 970 & 1022 & & & \\
\hline 2 & $\cdots$ & 1070 & 1024 & & & \\
\hline 3 & $\cdots$ & 740 & 1029 & & & \\
\hline 4 & $\cdots$ & 870 & 1027 & 11.85 & 0.683 & 1.77 \\
\hline 5 & $\cdots$ & 2660 & 1010 & & & \\
\hline 6 & $\cdots$ & 860 & 1025 & & & \\
\hline 7 & $\cdots$ & 865 & 1027 & & & \\
\hline 8 & 75.0 & 890 & 1027 & & & \\
\hline 9 & 75.0 & 780 & 1028 & & & \\
\hline 10 & 75.0 & 1025 & 1025 & & & \\
\hline 11 & 75.0 & 1240 & 1024 & 10.90 & 0.820 & 1.76 \\
\hline 12 & 75.0 & 815 & 1027 & & & \\
\hline 13 & 75.0 & 940 & 1027 & & & \\
\hline 14 & 75.0 & 1300 & 1017 & & & \\
\hline 15 & $\cdots$ & 945 & 1025 & & & \\
\hline 16 & 73.5 & 1090 & 1029 & & & \\
\hline 17 & 73.0 & 720 & 1031 & & & \\
\hline 18 & 73.0 & 1000 & 1028 & 10.38 & 0.792 & $\cdots$ \\
\hline 19 & 73.0 & 1000 & 1028 & & & \\
\hline 20 & $\cdots$ & 1300 & 1024 & & & \\
\hline 21 & $\cdots$ & 1110 & 1025 & & & \\
\hline 22 & $\cdots$ & 780 & 1026 & & & \\
\hline 23 & 73.0 & 730 & 1030 & 10.00 & 0.699 & 1.72 \\
\hline 24 & $\cdots$ & 730 & 1031 & & & \\
\hline
\end{tabular}


ANDERSON, G. W.

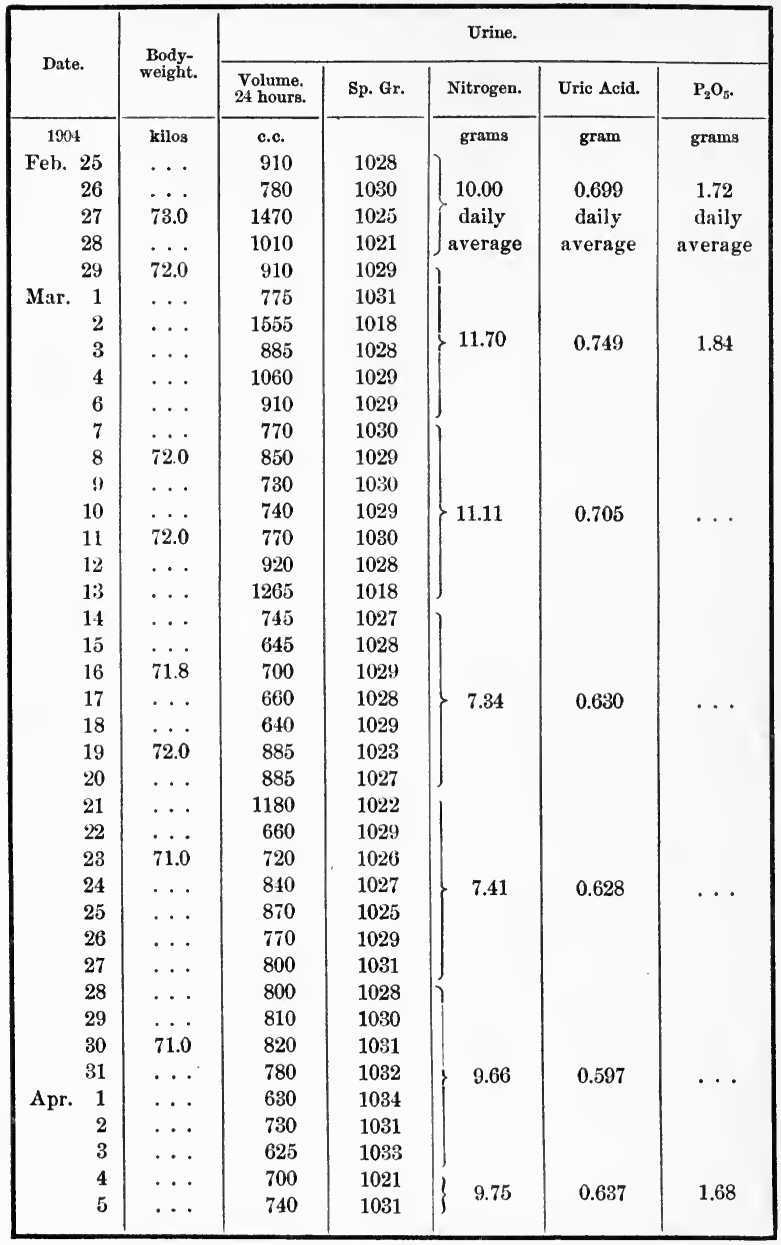


ANDERSON, G. W.

\begin{tabular}{|c|c|c|c|c|c|c|c|}
\hline \multirow{2}{*}{\multicolumn{2}{|c|}{ Date. }} & \multirow{2}{*}{$\begin{array}{c}\text { Body- } \\
\text { weight. }\end{array}$} & \multicolumn{5}{|c|}{ Urine. } \\
\hline & & & $\begin{array}{l}\text { Volume. } \\
24 \text { hours. }\end{array}$ & Sp. Gr. & Nitrogen. & Uric Acid. & $\mathrm{P}_{2} \mathrm{O}_{5^{*}}$ \\
\hline \multicolumn{2}{|c|}{1904} & kilos. & c.c. & & grams & gram & grams \\
\hline \multirow{25}{*}{$\begin{array}{l}1 \\
1 \\
1 \\
1 \\
1 \\
1 \\
1 \\
1 \\
1 \\
1 \\
2 \\
2 \\
2 \\
2 \\
2 \\
2 \\
2 \\
2 \\
2 \\
2 \\
3\end{array}$} & & $\cdots$ & 695 & 1033 & & & \\
\hline & 7 & $\cdots$ & 1220 & 1020 & & & \\
\hline & 8 & $\cdots$ & 670 & 1034 & 9.75 & 0.637 & 1.68 \\
\hline & 9 & $\cdots$ & 590 & 1034 & daily av. & daily av. & daily av. \\
\hline & 10 & $\cdots$ & 510 & 1030 & & & \\
\hline & 11 & 71.0 & 560 & 1033 & & & \\
\hline & 12 & $\cdots$ & 640 & 1030 & 9.23 & & \\
\hline & 13 & $\cdots$ & 530 & 1030 & 8.11 & & \\
\hline & 14 & $\cdots$ & 1195 & 1019 & 10.32 & 0.671 & $\cdots$ \\
\hline & 15 & $\cdots$ & 1005 & 1024 & 9.48 & & \\
\hline & 16 & $\cdots$ & 1140 & 1021 & 10.60 & & \\
\hline & 17 & $\cdots$ & 1050 & 1023 & 9.58 & & \\
\hline & 18 & 71.0 & 870 & 1026 & 9.03 & & \\
\hline & 19 & $\ldots$ & 1110 & 1025 & 11.12 & & \\
\hline & 20 & $\cdots$ & 1170 & 1023 & 9.80 & & \\
\hline & 21 & $\cdots$ & 810 & 1030 & 7.15 & 0.580 & $\cdots$ \\
\hline & 22 & $\cdots$ & 870 & 1029 & 9.55 & & \\
\hline & 23 & $\cdots$ & 660 & 1029 & 8.84 & & \\
\hline & 24 & 700 & 765 & 1029 & 8.49 & & \\
\hline & 25 & $\cdots$ & 640 & 1028 & 8.06 & & \\
\hline & 26 & $\ldots$ & 950 & 1026 & 9.80 & & \\
\hline & 27 & $\ldots$ & 1120 & 1023 & 9.34 & & \\
\hline & 28 & $\cdots$ & 1150 & 1021 & 9.04 & 0.522 & $\cdots$ \\
\hline & 29 & $\cdots$ & 860 & 1027 & 8.93 & & \\
\hline & 30 & 71.0 & 870 & 1028 & 9.71 & & \\
\hline \multirow[t]{15}{*}{ May } & 1 & $\cdots$ & 930 & 1025 & 10.16 & & \\
\hline & 2 & 70.0 & 925 & 1021 & 8.88 & & \\
\hline & 3 & 70.0 & 935 & 1023 & 9.20 & & \\
\hline & 4 & $\cdots$ & 1140 & 1024 & 9.10 & & \\
\hline & 5 & $\cdots$ & 990 & 1026 & 8.32 & 0.451 & $\cdots$ \\
\hline & 6 & $\cdots$ & 960 & 1026 & 8.06 & & \\
\hline & 7 & $\cdots$ & 585 & 1031 & 7.55 & & \\
\hline & 8 & $\cdots$ & 620 & 1031 & 7.48 & & \\
\hline & 9 & $\cdots$ & 660 & 1029 & 820 & & \\
\hline & 10 & $\cdots$ & 740 & 1024 & 8.66 & & \\
\hline & 11 & 70.0 & 1000 & 1023 & 8.10 & & \\
\hline & 12 & 70.0 & 725 & 1025 & 8.09 & 0.530 & $\cdots$ \\
\hline & 13 & 71.0 & 650 & 1029 & 7.83 & & \\
\hline & 14 & $\cdots$ & 780 & 1031 & 9.73 & & \\
\hline & 15 & $\cdots$ & 670 & 1028 & 7.40 & & \\
\hline
\end{tabular}


ANDERSON, G. W.

\begin{tabular}{|c|c|c|c|c|c|c|}
\hline \multirow{2}{*}{ Date. } & \multirow{2}{*}{$\begin{array}{c}\text { Body- } \\
\text { weight. }\end{array}$} & \multicolumn{5}{|c|}{ Urine. } \\
\hline & & $\begin{array}{l}\text { Volume. } \\
24 \text { hours. }\end{array}$ & Sp. Gr. & Nitrogen. & Uric Acid. & $\mathrm{P}_{2} \mathrm{O}_{5}$. \\
\hline & kilos & c.c. & \multirow[b]{2}{*}{1030} & \multirow{2}{*}{$\begin{array}{r}\operatorname{grams} \\
8.50\end{array}$} & gram & grams \\
\hline & $\ldots$ & 730 & & & $\ldots$ & $\cdots$ \\
\hline May $\begin{array}{l}16 \\
\\
17\end{array}$ & $\ldots$ & 1025 & 1025 & 8.98 & $\ldots$ & \multirow{2}{*}{$\ldots$} \\
\hline 18 & $\ldots$ & 930 & 1028 & 8.87 & & \\
\hline 19 & 71.1 & 865 & 1025 & 8.36 & & \\
\hline 20 & 71.0 & 1030 & 1027 & 9.95 & & \\
\hline 21 & 70.2 & 735 & 1030 & 8.51 & 0.523 & $\cdots$ \\
\hline 22 & 70.0 & 570 & 1029 & 6.50 & daily & \\
\hline 23 & $\cdots$ & 625 & 1026 & 6.90 & a verage & \\
\hline 24 & 70.5 & 870 & 1027 & 8.45 & & \\
\hline 25 & $\ldots$ & 665 & 1026 & 10.25 & & \\
\hline 26 & 70.0 & 640 & 1028 & 6.84 & & \\
\hline 27 & 70.5 & 780 & 1024 & 7.58 & 0588 & \\
\hline 28 & 70.0 & 660 & 1032 & 7.53 & 0.000 & $\cdots$ \\
\hline 29 & $\ldots$ & 650 & 1027 & 6.91 & & \\
\hline 30 & 70.0 & 700 & 1028 & 6.97 & & \\
\hline June 1 & $\cdots$ & 940 & 1026 & 8.40 & $\cdots$ & $\cdots$ \\
\hline 2 & $\ldots$ & 726 & 1028 & 7.49 & $\ldots$ & $\cdots$ \\
\hline 3 & 70.9 & 980 & 1020 & 8.65 & $\ldots$ & $\ldots$ \\
\hline 4 & . . & 946 & 1026 & 8.80 & $\ldots$ & $\cdots$ \\
\hline 5 & $\ldots$ & 582 & 1029 & 6.32 & $\ldots$ & $\cdots$ \\
\hline 6 & 70.5 & 718 & 1027 & 7.67 & $\ldots$ & $\cdots$ \\
\hline 7 & $\cdots$ & 670 & 1028 & 8.40 & $\cdots$ & $\cdots$ \\
\hline 8 & $\ldots$ & 1160 & 1021 & 10.44 & $\cdots$ & $\cdots$ \\
\hline 9 & $\ldots$ & 1010 & 1025 & 9.09 & $\ldots$ & $\cdots$ \\
\hline 10 & 70.2 & 1510 & 1020 & 11.33 & $\ldots$ & $\cdots$ \\
\hline 11 & $\ldots$ & 725 & 1029 & 9.70 & $\cdots$ & $\cdots$ \\
\hline 12 & $\ldots$ & 1020 & 1023 & 10.10 & $\ldots$ & $\cdots$ \\
\hline 13 & $\ldots$ & 920 & 1024 & 10.82 & $\ldots$ & $\ldots$ \\
\hline 14 & 70.0 & 740 & 1030 & 10.53 & $\ldots$ & $\ldots$ \\
\hline 15 & 70.9 & 1425 & 1023 & 13.34 & $\cdots$ & $\cdots$ \\
\hline $\begin{array}{c}\text { Daily av } \\
\text { Feb. } 1\end{array}$ & ge from & 879 & 1027 & & 0.632 & 1.75 \\
\hline Daily ave & ge from & & & & & \\
\hline Feb. $1 \mathrm{t}$ & Apr. 12 & $\cdots$ & $\cdots$ & 9.94 & $\cdots$ & $\cdots$ \\
\hline Daily ave & ge from & & & & & \\
\hline Apr. 13 & June 15 & $\cdots$ & $\cdots$ & 8.81 & $\cdots$ & $\cdots$ \\
\hline
\end{tabular}


ANDERSON, W. L.

\begin{tabular}{|c|c|c|c|c|c|c|}
\hline \multirow{2}{*}{ Date. } & \multirow{2}{*}{$\begin{array}{c}\text { Body- } \\
\text { weight. }\end{array}$} & \multicolumn{5}{|c|}{ Urine. } \\
\hline & & $\begin{array}{l}\text { Volume. } \\
24 \text { hours. }\end{array}$ & Sp. Gr. & Nitrogen. & Uric Acid. & $\mathrm{P}_{2} \mathrm{O}_{5}$ \\
\hline 1904. & kilos & c.c. & & grams & gram & grams \\
\hline Jan. 15 & 63.1 & 1240 & 1026 & 16.44 & 0.733 & $\ldots$ \\
\hline 16 & 63.1 & 1720 & 1020 & 18.68 & 0.755 & $\ldots$ \\
\hline 17 & 63.1 & 1470 & 1025 & 18.35 & 1.523 & $\cdots$ \\
\hline 18 & 61.3 & 1940 & 1018 & 19.09 & 0.866 & $\ldots$ \\
\hline 19 & 63.1 & 1850 & 1020 & 23.42 & 0.784 । & $\ldots$ \\
\hline 20 & 63.1 & 600 & 1026 & 16.85 & & \\
\hline 21 & 63.1 & 1720 & 1021 & daily av. & $\cdots$ & $\cdots$ \\
\hline 22 & 62.7 & 1470 & 1017 & 13.41 & 0.584 & $\ldots$ \\
\hline 23 & $\ldots$ & 1210 & 1026 & 19.53 & 0.858 & $\ldots$ \\
\hline 24 & 63.0 & 1130 & 1025 & $\ldots$ & 0.598 & $\ldots$ \\
\hline 25 & 62.9 & 1060 & 1022 & 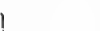 & & \\
\hline 26 & 63.1 & 1025 & 1024 & & & \\
\hline 27 & 63.1 & 1560 & 1014 & & & \\
\hline 28 & 63.6 & 890 & 1024 & 12.47 & 0.497 & 1.95 \\
\hline 29 & 63.6 & 1350 & 1019 & & daily & daily \\
\hline 30 & 63.6 & 1070 & 1020 & & average & average \\
\hline 31 & 63.3 & 1410 & 1018 & & & \\
\hline Feb. 1 & 63.3 & 1425 & 1019 & & & \\
\hline 2 & 62.8 & 940 & 1023 & & & \\
\hline 3 & 62.0 & 865 & 1019 & & & \\
\hline 4 & 62.2 & 1280 & 1020 & 10.65 & 0.493 & 1.99 \\
\hline 5 & 62.2 & 1120 & 1017 & & & \\
\hline 6 & 62.3 & 1390 & 1020 & & & \\
\hline 7 & 62.3 & 1050 & 1019 & & & \\
\hline 8 & 62.3 & 1150 & 1021 & & & \\
\hline 9 & 62.3 & 1430 & 1018 & & & \\
\hline 10 & 60.0 & 910 & 1021 & & & \\
\hline 11 & 60.0 & 1095 & 1018 & 10.82 & 0.505 & 2.07 \\
\hline 12 & 60.0 & 865 & 1023 & & & \\
\hline 13 & 62.1 & 865 & 1014 & & & \\
\hline 14 & 62.1 & 1580 & 1015 & & & \\
\hline 15 & 62.2 & 1270 & 1025 & & & \\
\hline 16 & 61.2 & 690 & 1027 & & & \\
\hline 17 & $\cdots$ & 1070 & 1020 & & & \\
\hline 18 & 61.9 & 990 & 1025 & 12.58 & 0.507 & $\cdots$ \\
\hline 19 & $\cdots$ & 1480 & 1019 & & & \\
\hline 20 & 60.9 & 1450 & 1019 & & & \\
\hline 21 & 62.0 & 2582 & 1011 & & & \\
\hline 22 & 62.0 & 1311 & 1026 & & 0846 & 240 \\
\hline 23 & 62.2 & 1460 & 1013 & 11.70 & 0.846 & 2.40 \\
\hline
\end{tabular}


ANDERSON, W. L.

\begin{tabular}{|c|c|c|c|c|c|c|}
\hline \multirow{2}{*}{ Date. } & \multirow{2}{*}{$\begin{array}{c}\text { Body- } \\
\text { weight. }\end{array}$} & \multicolumn{5}{|c|}{ Urine. } \\
\hline & & $\begin{array}{l}\text { Volume. } \\
24 \text { hours. }\end{array}$ & Sp. Gr. & Nitrogen. & Uric Acid. & $\mathrm{P}_{2} \mathrm{O}_{5}$ \\
\hline 1904 & kilos & c.c. & & grams & gram & grams \\
\hline Feb. 24 & 60.0 & 1085 & 1022 & ) & & \\
\hline 25 & 60.0 & 1215 & 1020 & & & \\
\hline 26 & 62.2 & 835 & 1020 & 11.70 & 0.846 & 2.40 \\
\hline 27 & 62.2 & 1590 & 1021 & daily & daily & daily \\
\hline 28 & 62.2 & 1790 & 1012 & average & average & average \\
\hline 29 & 62.3 & 820 & 1025 & & & \\
\hline Mar. 1 & 61.1 & 770 & 1029 & & & \\
\hline 2 & 62.2 & 670 & 1029 & & & \\
\hline 3 & 62.2 & 1295 & 1023 & 12.91 & 0.669 & 2.32 \\
\hline 4 & $\cdots$ & 1530 & 1020 & & & \\
\hline 5 & 62.2 & 1260 & 1017 & & & \\
\hline 6 & 62.3 & 1340 & 1024 & J & & \\
\hline 7 & 62.3 & 920 & 1025 & ) & & \\
\hline 8 & 62.3 & 1200 & 1013 & & & \\
\hline 9 & $\cdots$ & 880 & 1024 & 921 & 0475 & \\
\hline 11 & $\ldots$ & 1670 & 1019 & 9.21 & 0.475 & $\cdots$ \\
\hline 12 & 62.0 & 1865 & 1022 & & & \\
\hline 13 & $\ldots$ & 1640 & 1030 & j & & \\
\hline 14 & 62.2 & 790 & 1026 & ) & & \\
\hline 15 & 62.2 & 715 & 1023 & & & \\
\hline 16 & 62.2 & 1350 & 1016 & & & \\
\hline 17 & 62.2 & 1140 & 1012 & 9.66 & 0.475 & $\cdots$ \\
\hline 18 & 61.4 & 980 & 1021 & & & \\
\hline 19 & 62.9 & 1050 & 1024 & & & \\
\hline 20 & $\ldots$ & 1012 & 1023 & J & & \\
\hline 21 & 62.0 & 910 & 1026 & 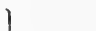 & & \\
\hline 22 & $\ldots$ & 1460 & 1021 & & & \\
\hline 23 & 61.9 & 1310 & 1020 & & & \\
\hline 24 & 61.2 & 1050 & 1022 & 12.25 & 0.713 & $\cdots$ \\
\hline 25 & 62.0 & 860 & 1031 & & & \\
\hline 26 & 61.0 & 975 & 1028 & & & \\
\hline 27 & $\ldots$ & 1080 & 1024 & J & & \\
\hline 28 & $\cdots$ & 1120 & 1022 & ? & & \\
\hline 29 & $\therefore$ & 1690 & 1020 & & & \\
\hline 30 & $\cdots$ & 1580 & 1017 & 1119 & 0.551 & \\
\hline Apr. 1 & 62.3 & 1325 & 1018 & & & $\cdots \cdot$ \\
\hline 2 & 62.9 & 1075 & 1018 & & & \\
\hline 3 & 62.9 & 1500 & 1015 & ) & & \\
\hline 4 & 63.1 & 800 & 1025 & 1091 & 0625 & $19 ?$ \\
\hline 5 & 62.9 & 1000 & 1022 & $\int 10.21$ & 0.620 & 1.92 \\
\hline
\end{tabular}


ANDERSON, W. I.

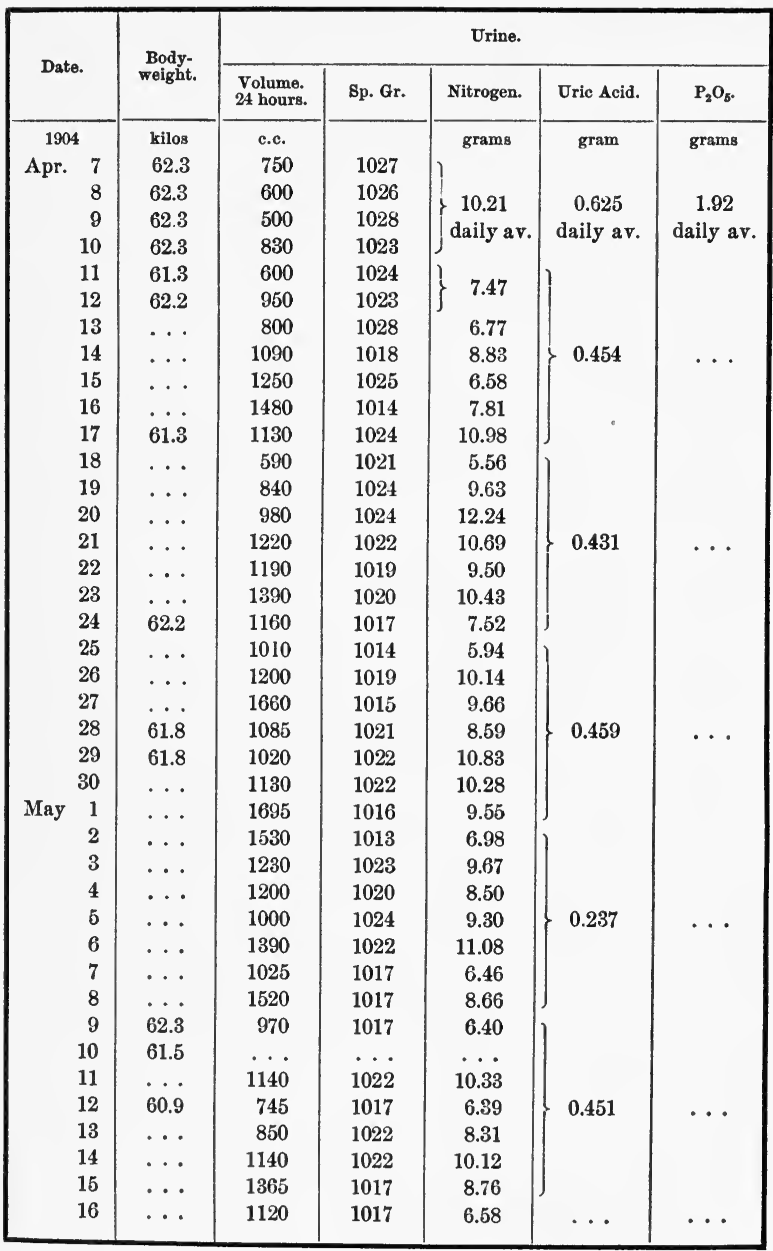


ANDERSON, W. L.

\begin{tabular}{|c|c|c|c|c|c|c|c|}
\hline \multirow{2}{*}{\multicolumn{2}{|c|}{ Date. }} & \multirow{2}{*}{$\begin{array}{c}\text { Body- } \\
\text { weight. }\end{array}$} & \multicolumn{5}{|c|}{ Urine. } \\
\hline & & & $\begin{array}{l}\text { Volume. } \\
24 \text { hours. }\end{array}$ & Sp. Gr. & Nitrogen. & Uric $\Delta$ cid. & $\mathrm{P}_{2} \mathrm{O}_{5}$. \\
\hline \multicolumn{2}{|c|}{1904} & kilos & c.c. & & grams & gram & grams \\
\hline \multirow[t]{15}{*}{ May } & 17 & $\ldots$ & 1940 & 1014 & 10.83 & $\ldots$ & $\ldots$ \\
\hline & 18 & $\ldots$ & 1370 & 1021 & 10.03 & 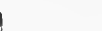 & \\
\hline & 19 & 61.3 & 1120 & 1022 & 10.15 & & \\
\hline & 20 & $\ldots$ & 1170 & 1018 & 8.64 & & \\
\hline & 21 & $\ldots$ & 1530 & 1015 & 8.46 & 0.439 & $\ldots$ \\
\hline & 22 & $\ldots$ & 890 & 1024 & 7.96 & daily & \\
\hline & 23 & $\ldots$ & 1200 & 1017 & 7.49 & average & \\
\hline & 24 & 61.1 & 770 & 1024 & 6.60 & & \\
\hline & 25 & $\ldots$ & 690 & 1024 & 7.04 & & \\
\hline & 26 & 60.2 & 745 & 1025 & 8.09 & & \\
\hline & 27 & $\ldots$ & 970 & 1023 & 10.40 & & \\
\hline & 28 & $\ldots$ & 1160 & 1022 & 10.37 & 0.448 & $\ldots$ \\
\hline & 29 & $\ldots$ & $\ldots$ & $\ldots$ & $\ldots$ & & \\
\hline & 30 & $\ldots$ & 920 & 1025 & 8.94 & & \\
\hline & 31 & $\ldots$ & $\ldots$ & $\ldots$ & $\ldots$ & & \\
\hline \multirow[t]{15}{*}{ June } & 1 & $\cdots$ & 1400 & 1012 & 5.54 & $\cdots$ & $\cdots$ \\
\hline & 2 & 59.5 & 1070 & 1020 & 8.48 & $\ldots$ & $\ldots$ \\
\hline & 3 & $\cdots$ & 1190 & 1018 & 8.78 & $\cdots$ & $\cdots$ \\
\hline & 4 & 59.7 & 1020 & 1022 & 9.00 & $\ldots$ & $\ldots$ \\
\hline & 5 & $\ldots$ & 870 & 1023 & 8.67 & $\cdots$ & $\cdots$ \\
\hline & 6 & $\ldots$ & 870 & 1025 & 8.72 & . . & .. \\
\hline & 7 & . . & 1350 & 1017 & 9.31 & $\cdots$ & $\cdots$ \\
\hline & 8 & 60.4 & 1380 & 1017 & 11.55 & $\ldots$ & . . \\
\hline & 9 & 60.4 & 1520 & 1017 & 9.58 & $\cdots$ & $\ldots$ \\
\hline & 10 & $\ldots$ & 1590 & 1013 & 7.35 & $\ldots$ & $\cdots$ \\
\hline & 11 & 60.4 & 1425 & 1017 & 7.74 & $\ldots$ & $\ldots$ \\
\hline & 12 & $\ldots$ & 870 & 1021 & 7.67 & $\ldots$ & ... \\
\hline & 13 & $\ldots$ & 1410 & 1017 & 10.32 & $\ldots$ & $\ldots$ \\
\hline & 14 & $\ldots$ & 1180 & 1022 & 10.84 & $\ldots$ & $\ldots$ \\
\hline & 15 & 61.0 & 875 & 1019 & 5.67 & $\ldots$ & $\ldots$ \\
\hline \multicolumn{8}{|c|}{ Daily average from } \\
\hline \multicolumn{3}{|c|}{ Feb. 1} & 1156 & 1020 & $\ldots$ & 0.516 & 2.14 \\
\hline \multicolumn{8}{|c|}{ Daily average from } \\
\hline \multirow{3}{*}{\multicolumn{3}{|c|}{$\begin{array}{l}\text { Feb. } 1 \text { to April } 12 \\
\text { Daily average from } \\
\text { April } 13 \text { to June } \\
15\end{array}$}} & $\cdots$ & $\cdots$ & 10.78 & $\cdots$ & $\cdots$ \\
\hline & & & & & & & \\
\hline & & & $\cdots$ & $\cdots$ & 10.05 & $\cdots$ & $\cdots$ \\
\hline
\end{tabular}


BELLIS.

\begin{tabular}{|c|c|c|c|c|c|c|}
\hline \multirow{2}{*}{ Date. } & \multirow{2}{*}{$\begin{array}{c}\text { Body- } \\
\text { weight. }\end{array}$} & \multicolumn{5}{|c|}{ Urine. } \\
\hline & & $\begin{array}{l}\text { Volume. } \\
24 \text { hours. }\end{array}$ & Sp. Gr. & Nitrogen. & Uric Acid. & $\mathrm{P}_{5} \mathrm{O}_{2}$. \\
\hline 1904 & kilos & c.c. & & grams & grams & grams \\
\hline Jan. 15 & 81.8 & 1180 & 1026 & 13.24 & 0.778 & $\ldots$ \\
\hline 16 & 82.2 & 1915 & 1019 & 16.09 & 0.862 & $\ldots$ \\
\hline 17 & 82.2 & 1740 & 1024 & 16.18 & 0.881 & $\cdots$ \\
\hline 18 & 82.2 & 2030 & 1021 & 20.10 & 0.868 & $\cdots$ \\
\hline 19 & 82.2 & 1700 & 1026 & 17.34 & 0.771 & $\ldots$ \\
\hline 20 & 82.2 & 1800 & 1022 & 17.82 & 0.650 & $\ldots$ \\
\hline 21 & 82.2 & 1565 & 1027 & 26.18 & 1.020 & $\cdots$ \\
\hline 22 & 82.2 & 1435 & 1026 & 22.64 & 1.010 & $\ldots$ \\
\hline 23 & 82.2 & 1285 & 1017 & 10.49 & 0.467 & $\ldots$ \\
\hline 24 & $\ldots$ & 1070 & 1026 & 16.37 & 0.786 & $\ldots$ \\
\hline 25 & 80.7 & 590 & 1029 & & & \\
\hline 26 & 81.4 & 1300 & 1020 & & & \\
\hline 27 & 82.1 & 1020 & 1026 & & & \\
\hline 28 & 81.2 & 1190 & 1027 & 13.35 & 0.693 & 2.32 \\
\hline 29 & 81.2 & 1440 & 1018 & daily & daily & daily \\
\hline 30 & 81.3 & 1450 & 1023 & average & average & average \\
\hline 31 & 81.2 & 1000 & 1026 & & & \\
\hline Feb. 1 & 81.2 & 1230 & 1025 & & & \\
\hline 2 & 81.2 & 1145 & 1024 & & & \\
\hline 3 & 81.2 & 1000 & 1030 & & & \\
\hline 4 & 81.2 & 910 & 1030 & 12.98 & 0.674 & 2.29 \\
\hline 5 & 81.2 & 1360 & 1023 & & & \\
\hline 6 & 81.2 & 1160 & 1022 & & & \\
\hline 7 & 81.2 & 1210 & 1027 & & & \\
\hline 8 & 81.2 & 1375 & 1016 & & & \\
\hline 9 & 81.2 & 920 & 1031 & & & \\
\hline 10 & 81.2 & 1775 & 1016 & & & \\
\hline 11 & 81.2 & 1130 & 1026 & 13.03 & 0.659 & 2.44 \\
\hline 12 & 81.2 & 1075 & 1026 & & & \\
\hline 13 & 81.2 & 1405 & 1021 & & & \\
\hline 14 & 81.2 & 1055 & 1024 & & & \\
\hline 15 & 81.0 & 1470 & 1025 & & & \\
\hline 16 & 81.1 & 920 & 1029 & & & \\
\hline 17 & 81.1 & 1530 & 1019 & & & \\
\hline 18 & 81.1 & 1330 & 1023 & 14.15 & 0.750 & $\cdots$ \\
\hline 19 & 81.1 & 1680 & 1020 & & & \\
\hline 20 & 81.1 & 950 & 1029 & & & \\
\hline 21 & 81.1 & 2050 & 1018 & & & \\
\hline 22 & 81.1 & 1450 & 1030 & 14.79 & 0.850 & 2.60 \\
\hline 23 & 81.1 & 1540 & 1027 & 14.79 & 0.800 & \\
\hline
\end{tabular}


BELLIS.

\begin{tabular}{|c|c|c|c|c|c|c|}
\hline \multirow{2}{*}{ Date. } & \multirow{2}{*}{$\begin{array}{c}\text { Body- } \\
\text { weight. }\end{array}$} & \multicolumn{5}{|c|}{ Urine. } \\
\hline & & $\begin{array}{l}\text { Volume. } \\
24 \text { hours. }\end{array}$ & Sp. Gr. & Nitrogen. & Uric Acid. & $\mathrm{P}_{2} \mathrm{O}_{5}$. \\
\hline 1904 & kilos & c.c. & & grams & gram & grams \\
\hline Feb. 24 & 79.4 & 800 & 1030 & & & \\
\hline 25 & 80.0 & 785 & 1033 & & & \\
\hline 26 & 80.4 & 1420 & 1018 & 14.79 & 0.850 & 2.60 \\
\hline 27 & 80.1 & 1250 & 1026 & daily av. & daily av. & daily av. \\
\hline 28 & 80.1 & 1070 & 1025 & & & \\
\hline 29 & 80.1 & 1270 & 1024 & & & \\
\hline Mar. 1 & 80.0 & 1150 & 1024 & & & \\
\hline 2 & 80.0 & 1530 & 1018 & & & \\
\hline 3 & 80.0 & 1320 & 1018 & 10.77 & 0.550 & 2.34 \\
\hline 4 & 80.0 & 1635 & 1018 & & & \\
\hline 5 & 80.0 & 1220 & 1026 & & & \\
\hline 6 & 80.1 & 1550 & 1015 & & & \\
\hline 7 & 80.0 & 1170 & 1020 & & & \\
\hline 8 & 800 & 1120 & 1017 & & & \\
\hline 9 & 80.0 & 1220 & 1020 & & & \\
\hline 10 & 80.0 & 1210 & 1020 & 10.29 & 0.628 & $\cdots$ \\
\hline 11 & 80.0 & 1650 & 1019 & & & \\
\hline 12 & 80.0 & 1355 & 1026 & & & \\
\hline 13 & 80.0 & 1040 & 1025 & & & \\
\hline 14 & 80.0 & 670 & 1027 & & & \\
\hline 15 & 80.0 & 1330 & 1017 & & & \\
\hline 16 & 80.0 & 915 & 1024 & & & \\
\hline 17 & 80.0 & 1600 & 1016 & 10.05 & 0.622 & $\cdots$ \\
\hline 18 & 80.0 & 1510 & 1018 & & & \\
\hline 19 & 80.0 & 1490 & 1018 & . & & \\
\hline 20 & 79.9 & 920 & 1026 & & & \\
\hline 21 & 79.8 & 710 & 1029 & & & \\
\hline 22 & 79.8 & 800 & 1026 & & & \\
\hline 23 & 79.3 & 800 & 1030 & & & \\
\hline 24 & 79.3 & 1100 & 1025 & 10.15 & 0.728 & $\cdots$ \\
\hline 25 & 79.4 & 1060 & 1017 & & & \\
\hline 26 & 79.4 & 1580 & 1020 & & & \\
\hline 27 & 79.2 & 1040 & 1028 & J & & \\
\hline 28 & 79.3 & 1360 & 1019 & & & \\
\hline 29 & 79.2 & 1335 & 1017 & & & \\
\hline 30 & $\cdots$ & 1030 & 1017 & & & \\
\hline 31 & $\ldots$ & 905 & 1019 & 8.52 & $\cdots$ & $\cdots$ \\
\hline Apr. 1 & $\cdots$ & 870 & $\cdots$ & & & \\
\hline 2 & $\cdots$ & 810 & 1029 & & & \\
\hline 3 & 78.6 & 785 & 1028 & & & \\
\hline
\end{tabular}


BELLIS.

\begin{tabular}{|c|c|c|c|c|c|c|c|}
\hline \multirow{2}{*}{\multicolumn{2}{|c|}{ Date. }} & \multirow{2}{*}{$\begin{array}{c}\text { Body- } \\
\text { weight. }\end{array}$} & \multicolumn{5}{|c|}{ Urine. } \\
\hline & & & $\begin{array}{l}\text { Volume. } \\
24 \text { hours. }\end{array}$ & Sp. Gr. & Nitrogen. & Uric Acid. & $\mathbf{P}_{2} \mathbf{O}_{5}$. \\
\hline \multicolumn{2}{|c|}{1904} & kilos & c.c. & & grams & gram & grams \\
\hline Apr. & 4 & $\ldots$ & 720 & 1029 & & & \\
\hline & 5 & $\cdots$ & 730 & 1019 & & & \\
\hline & 6 & $\ldots$ & 790 & 1022 & & & \\
\hline & 7 & $\ldots$ & 880 & 1026 & 7.27 & 0.665 & 1.62 \\
\hline & 8 & $\ldots$ & 790 & 1025 & daily & daily & daily \\
\hline & 9 & $\ldots$ & 860 & 1027 & average & average & average \\
\hline & 10 & $\ldots$ & 890 & 1025 & & & \\
\hline & 11 & $\ldots$ & 890 & 1025 & & & \\
\hline & 12 & $\ldots$ & 590 & 1025 & 8.18 & & \\
\hline & 13 & 77.2 & 960 & 1025 & 7.95 & & \\
\hline & 14 & $\cdots$ & 930 & 1019 & 6.59 & 0.496 & $\ldots$ \\
\hline & 15 & $\cdots$ & 1090 & 1018 & 6.82 & & \\
\hline & 16 & $\cdots$ & 1250 & 1022 & 10.35 & & \\
\hline & 17 & $\ldots$ & 650 & 1025 & 5.97 & & \\
\hline & 18 & $\cdots$ & 970 & 1020 & 7.92 & 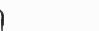 & \\
\hline & 19 & $\ldots$ & 1040 & 1020 & 6.55 & & \\
\hline & 20 & $\ldots$ & 1150 & 1019 & 8.49 & & \\
\hline & 21 & $\ldots$ & 1225 & 1019 & 8.75 & 0.522 & $\cdots$ \\
\hline & 22 & 78.0 & 1380 & 1026 & 10.60 & & \\
\hline & 23 & $\ldots$ & 1150 & 1022 & 10.21 & & \\
\hline & 24 & $\ldots$ & 1130 & 1018 & 9.28 & & \\
\hline & 25 & $\ldots$ & 1170 & 1021 & 11.30 & ) & \\
\hline & 26 & $\ldots$ & 1080 & 1023 & 11.79 & & \\
\hline & 27 & $\ldots$ & 1460 & 1017 & 10.60 & & \\
\hline & 28 & $\ldots$ & 1360 & 1019 & 10.53 & 0.495 & $\cdots$ \\
\hline & 29 & . & 1360 & 1015 & 10.28 & & \\
\hline & 30 & $\ldots$ & 1450 & 1014 & 9.87 & & \\
\hline May & 1 & $\ldots$ & 985 & 1020 & 8.76 & J & \\
\hline & 2 & $\ldots$ & 1200 & 1022 & 8.86 & ) & \\
\hline & 3 & $\ldots$ & 1475 & 1016 & 8.88 & & \\
\hline & 4 & 77.9 & 1150 & 1023 & 7.73 & & \\
\hline & 5 & $\ldots$ & 1400 & 1018 & 9.57 & 0.271 & $\cdots$ \\
\hline & 6 & $\ldots$ & 1340 & 1020 & 7.64 & & \\
\hline & 7 & $\cdots$ & 1040 & 1021 & 8.73 & & \\
\hline & 8 & 78.1 & 895 & 1025 & 6.39 & & \\
\hline & 9 & $\ldots$ & 1480 & 1024 & 6.13 & & \\
\hline & 10 & $\ldots$ & 1125 & 1020 & 7.60 & & \\
\hline & 11 & $\ldots$ & 1290 & 1018 & 8.59 & 0.401 & $\cdots$ \\
\hline & 12 & 78.1 & 845 & 1023 & 8.57 & & \\
\hline & 13 & $\ldots$ & 1170 & 1022 & 8.92 & & \\
\hline
\end{tabular}




\section{PHYSIOLOGICAL ECONOMY IN NUTRITION 343}

BELLIS.

\begin{tabular}{|c|c|c|c|c|c|c|}
\hline \multirow{2}{*}{ Date. } & \multirow{2}{*}{$\begin{array}{c}\text { Body- } \\
\text { weight. }\end{array}$} & \multicolumn{5}{|c|}{ Urine. } \\
\hline & & $\begin{array}{l}\text { Volume. } \\
24 \text { hours. }\end{array}$ & Sp. Gr. & Nitrogen. & Uric Acid. & $\mathrm{P}_{2} \mathrm{O}_{5}$. \\
\hline 1904 & kilos & c.c. & & grams & gram & grams \\
\hline May 14 & $\ldots$ & 1005 & 1020 & 6.09 & & \\
\hline & 77.1 & 855 & 1023 & 7.75 & & \\
\hline 16 & $\ldots$ & 1210 & 1014 & 5.81 & $\begin{array}{l}0.401 \\
\text { daily ax }\end{array}$ & $\cdots$ \\
\hline 17 & $\ldots$ & 1520 & 1014 & 7.93 & dally av. & \\
\hline 18 & $\ldots$ & 1150 & 1023 & 8.35 & & \\
\hline 19 & 77.2 & 1905 & 1015 & 9.60 & & \\
\hline 20 & 77.2 & 1210 & 1020 & 10.67 & & \\
\hline 21 & 76.3 & 815 & 1027 & 8.46 & 0.461 & $\ldots$ \\
\hline 22 & 76.5 & 1020 & 1019 & 7.71 & & \\
\hline 23 & 76.8 & 890 & 1023 & 5.98 & & \\
\hline 24 & 77.1 & 1030 & 1022 & 6.61 & & \\
\hline \multirow{5}{*}{\multicolumn{2}{|c|}{$\begin{array}{l}\text { Daily average from } \\
\text { Feb. } 28 \\
\text { Daily average from } \\
\text { Feb. } 28 \text { to April } 12 \\
\text { Daily average from } \\
\text { April } 13 \text { to May } 24\end{array}$}} & & & & & \\
\hline & & 1127 & 1021 & & 0.531 & 1.98 \\
\hline & & $\cdots$ & & 9.30 & & $\cdots$ \\
\hline & & & & & & \\
\hline & & $\cdots$ & $\cdots$ & 8.45 & $\cdots$ & $\cdots$ \\
\hline
\end{tabular}


CALLAHAN.

\begin{tabular}{|c|c|c|c|c|c|c|c|}
\hline \multirow{2}{*}{\multicolumn{2}{|c|}{ Date. }} & \multirow{2}{*}{$\begin{array}{c}\text { Body- } \\
\text { weight. }\end{array}$} & \multicolumn{5}{|c|}{ Urine. } \\
\hline & & & $\begin{array}{l}\text { Volume. } \\
24 \text { hours. }\end{array}$ & Sp. Gr. & Nitrogen. & Uric Acid. & $\mathrm{P}_{2} \mathrm{O}_{5}$ \\
\hline \multirow{2}{*}{\multicolumn{2}{|c|}{$\begin{array}{c}2904 \\
\text { Jan. } 15\end{array}$}} & kilos & c.c. & & grams & gram & grams \\
\hline & & 92.2 & 1665 & 1023 & 19.48 & 1.008 & $\ldots$ \\
\hline & 16 & 92.7 & 1800 & 1024 & 22.90 & 1.235 & $\cdots$ \\
\hline & 17 & 92.7 & 1500 & 1028 & 18.81 & 0.996 & $\cdots$ \\
\hline & 18 & 92.8 & 1490 & 1027 & 19.58 & 1.393 & $\cdots$ \\
\hline & 19 & 93.6 & 1600 & 1029 & 22.18 & 1.070 & $\ldots$ \\
\hline & 20 & 94.0 & 1610 & 1024 & 23.76 & 0.710 & $\ldots$ \\
\hline & 21 & 94.0 & 1870 & 1025 & 24.68 & 1.040 & $\cdots$ \\
\hline & 22 & 95.0 & 1730 & 1025 & 22.73 & 1.160 & $\ldots$ \\
\hline & 23 & 95.0 & 2150 & 1025 & 31.99 & 1.470 & $\ldots$ \\
\hline & 24 & 95.0 & 1450 & $\cdots$ & 21.84 & 0.952 & $\ldots$ \\
\hline & 25 & 94.0 & 1220 & 1028 & & & \\
\hline & 26 & 94.0 & 1310 & 1027 & & & \\
\hline & 27 & 93.0 & 1310 & 1025 & & · & \\
\hline & 28 & 94.0 & 1400 & 1027 & 17.90 & 0.988 & 3.26 \\
\hline & 29 & 94.0 & 1220 & 1027 & daily & daily & daily \\
\hline & 30 & 93.0 & 1115 & 1030 & average & average & average \\
\hline & 31 & 93.0 & 870 & 1030 & & & \\
\hline \multirow[t]{23}{*}{ Feb. } & 1 & 93.0 & 1170 & 1028 & & & \\
\hline & 2 & 93.0 & 1080 & 1029 & & & \\
\hline & 3 & 93.0 & 1350 & 1027 & & & \\
\hline & 4 & 92.0 & 1150 & 1028 & 16.92 & 0.976 & 2.86 \\
\hline & 5 & 92.0 & 950 & 1029 & & & \\
\hline & 6 & 92.0 & 1160 & 1027 & & & \\
\hline & 7 & 92.0 & 1100 & 1030 & & & \\
\hline & 8 & 91.0 & 850 & 1027 & & & \\
\hline & 9 & 91.0 & 995 & 1023 & & & \\
\hline & 10 & 90.0 & 670 & 1027 & & & \\
\hline & 11 & 89.5 & 615 & 1029 & 12.28 & 0.780 & 2.14 \\
\hline & 12 & 89.5 & 865 & 1028 & & & \\
\hline & 13 & 89.5 & 740 & 1031 & & & \\
\hline & 14 & 90.0 & 1020 & 1024 & & & \\
\hline & 15 & 90.0 & 980 & 1027 & & & \\
\hline & 16 & 89.5 & 715 & 1029 & & & \\
\hline & 17 & 89.0 & 565 & 1030 & & & \\
\hline & 18 & 89.0 & 535 & 1031 & 9.83 & 0.755 & $\cdots$ \\
\hline & 19 & 89.0 & 540 & 1034 & & & \\
\hline & 20 & 89.5 & 880 & 1027 & & & \\
\hline & 21 & 89.0 & 1170 & 1025 & & & \\
\hline & 22 & 89.0 & 820 & 1030 & 10.26 & 0641 & \\
\hline & 23 & 88.0 & 610 & 1031 & 10.26 & 0.641 & 1.52 \\
\hline
\end{tabular}


CALLAHAN.

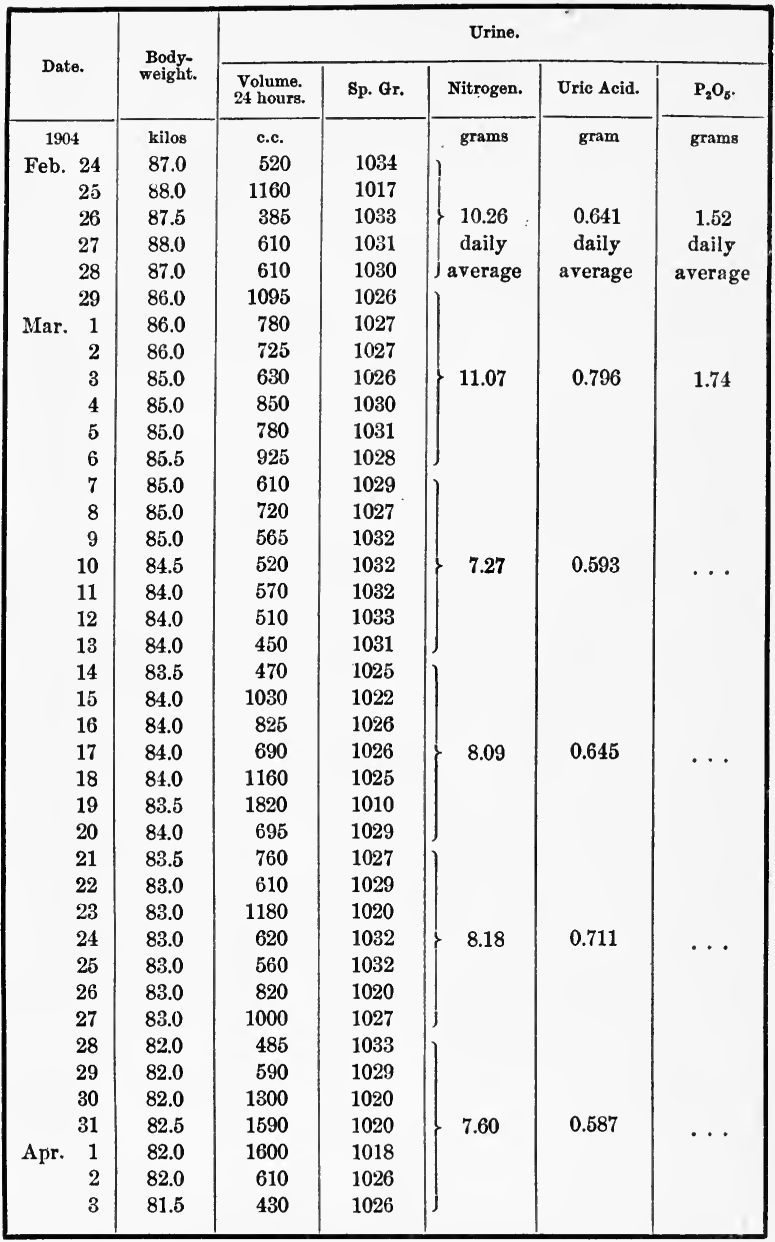


CALLAHAN.

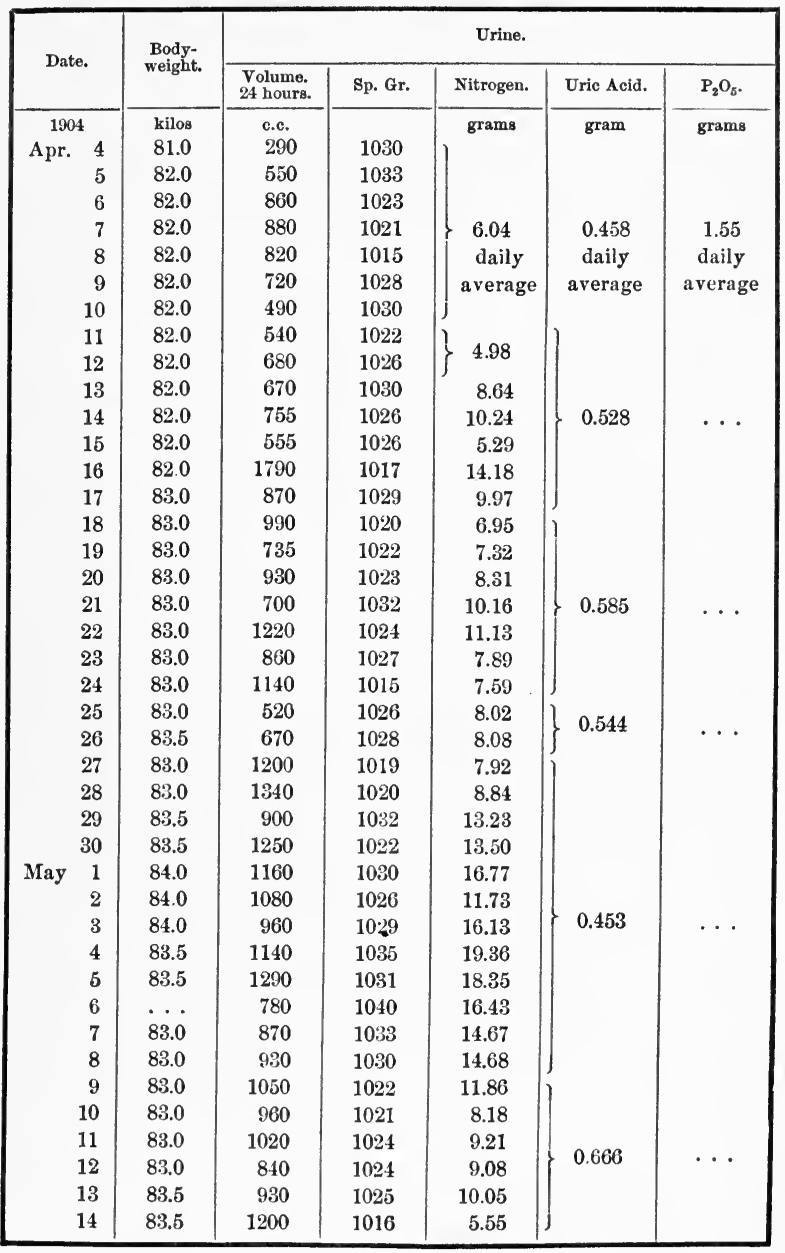


CALLAHAN.

\begin{tabular}{|c|c|c|c|c|c|c|c|}
\hline \multirow{2}{*}{\multicolumn{2}{|c|}{ Date. }} & \multirow{2}{*}{$\begin{array}{c}\text { Body- } \\
\text { weight. }\end{array}$} & \multicolumn{5}{|c|}{ Urine. } \\
\hline & & & $\begin{array}{l}\text { Volume. } \\
24 \text { hours. }\end{array}$ & Sp. Gr. & Nitrogen. & Uric Acid. & $\mathrm{P}_{2} \mathrm{O}_{5}$. \\
\hline \multicolumn{2}{|l|}{1904} & kilos & c.c. & & grams & gram & grams \\
\hline \multirow[t]{17}{*}{ May } & & 83.5 & 1110 & 1018 & 8.99 & & \\
\hline & 16 & 83.5 & 1050 & 1018 & 9.64 & & \\
\hline & 17 & 84.0 & 900 & 1024 & 8.37 & & \\
\hline & 18 & 83.5 & 1020 & 1018 & 8.20 & & \\
\hline & 19 & 84.0 & 945 & 1022 & 9.88 & 0.666 & $\cdots$ \\
\hline & 20 & 84.0 & 870 & 1023 & 8.72 & daily & \\
\hline & 21 & $8: 3.0$ & 1160 & 1014 & 7.24 & average & \\
\hline & 22 & 82.0 & 420 & 1017 & 5.72 & & \\
\hline & 23 & 82.5 & 480 & 1026 & 7.78 & $\cdots$ & .. \\
\hline & 24 & 82.5 & 720 & 1024 & 10.07 & $\ldots$ & $\ldots$ \\
\hline & 25 & 82.0 & 360 & 1030 & 5.64 & $\ldots$ & $\cdots$ \\
\hline & 26 & 82.0 & 510 & 1029 & 7.68 & $\ldots$ & $\cdots$ \\
\hline & 27 & 82.0 & 576 & 1028 & 6.60 & $\ldots$ & $\ldots$ \\
\hline & 28 & 81.5 & 900 & 1016 & 6.59 & $\ldots$ & $\ldots$ \\
\hline & 29 & 81.5 & 570 & 1023 & 6.60 & $\ldots$ & . \\
\hline & 30 & 81.0 & 945 & 1022 & 6.47 & $\ldots$ & $\ldots$ \\
\hline & 31 & 81.5 & 870 & 1026 & 10.44 & $\cdots$ & $\cdots$ \\
\hline \multirow[t]{15}{*}{ June } & 1 & 81.5 & 840 & 1024 & 9.02 & $\ldots$ & .. \\
\hline & 2 & 81.5 & 810 & 1021 & 7.78 & $\ldots$ & $\cdots$ \\
\hline & 3 & 82.0 & 540 & 1021 & 5.67 & $\cdots$ & $\cdots$ \\
\hline & 4 & 82.0 & 450 & 1025 & 6.10 & $\cdots$ & $\cdots$ \\
\hline & 5 & 82.0 & 480 & 1034 & 8.21 & $\ldots$ & $\cdots$ \\
\hline & 6 & 82.5 & 480 & 1030 & 6.91 & $\ldots$ & $\cdots$ \\
\hline & 7 & 82.5 & 570 & 1029 & 9.51 & $\ldots$ & . \\
\hline & 8 & 83.0 & 650 & 1028 & 10.49 & $\ldots$ & $\ldots$ \\
\hline & 9 & 83.0 & 570 & 1024 & 7.46 & $\cdots$ & $\ldots$ \\
\hline & 10 & 83.0 & 620 & 1026 & 8.40 & $\cdots$ & . \\
\hline & 11 & 83.0 & 690 & 1027 & 9.11 & $\cdots$ & $\cdots$ \\
\hline & 12 & 83.0 & 590 & 1025 & 7.90 & $\cdots$ & $\cdots$ \\
\hline & 13 & 83.0 & 840 & 1025 & 10.74 & $\cdots$ & $\cdots$ \\
\hline & 14 & 83.5 & 780 & 1021 & 7.86 & $\cdots$ & . \\
\hline & 15 & 83.0 & 650 & 1029 & 10.37 & $\cdots$ & $\cdots$ \\
\hline \multirow{2}{*}{\multicolumn{3}{|c|}{$\begin{array}{l}\text { Daily average from } \\
\text { Feb. } 8\end{array}$}} & & & & & \\
\hline & & & 809 & 1026 & $\cdots$ & 0.624 & 1.74 \\
\hline \multicolumn{3}{|c|}{ Daily average from } & & & & & \\
\hline \multicolumn{3}{|c|}{ Feb. 8 to April 12} & $\cdots$ & $\cdots$ & 8.56 & $\cdots$ & $\cdots$ \\
\hline \multirow{2}{*}{\multicolumn{3}{|c|}{$\begin{array}{l}\text { Daily average from } \\
\text { April } 13 \text { to June } 15\end{array}$}} & & & & & \\
\hline & & & $\cdots$ & $\cdots$ & 9.52 & $\cdots$ & $\cdots$ \\
\hline
\end{tabular}


DONAHUE.

\begin{tabular}{|c|c|c|c|c|c|c|}
\hline \multirow{2}{*}{ Date. } & \multirow{2}{*}{$\begin{array}{l}\text { Body- } \\
\text { weight. }\end{array}$} & \multicolumn{5}{|c|}{ Urine. } \\
\hline & & $\begin{array}{l}\text { Volume. } \\
24 \text { hours. }\end{array}$ & Sp. Gr. & Nitrogen. & Uric Acid. & $\mathrm{P}_{2} \mathrm{O}_{5}$ \\
\hline 1904 & kilos & c.c. & & grams & gram & grams \\
\hline Jan. 19 & 64.5 & 1500 & 1017 & 17.46 & 0.872 & $\ldots$ \\
\hline 20 & $\ldots$ & 1060 & 1027 & 14.88 & 0.756 & $\ldots$ \\
\hline 21 & 64.5 & 910 & 1033 & 14.41 & 0.525 & $\ldots$ \\
\hline 22 & $\ldots$ & 1150 & 1028 & 1325 & 0.599 & $\ldots$ \\
\hline 23 & $\ldots$ & 810 & 1026 & 11.76 & 0.428 & $\ldots$ \\
\hline 24 & $\ldots$ & 790 & 1030 & 17.91 & 0.672 & $\cdots$ \\
\hline 25 & $\ldots$ & 820 & 1028 & & & \\
\hline 26 & $\ldots$ & 960 & 1024 & & & \\
\hline 27 & $\ldots$ & 800 & 1026 & & & \\
\hline 28 & $\ldots$ & 870 & 1025 & 10.67 & 0.498 & 1.90 \\
\hline 29 & $\ldots$ & 740 & 1025 & daily & daily & daily \\
\hline 30 & 63.5 & 655 & 1029 & average & average & average \\
\hline 31 & $\ldots$ & 790 & 1026 & & & \\
\hline Feb. 1 & $\ldots$ & 570 & 1029 & & & \\
\hline 2 & $\ldots$ & 730 & 1027 & & & \\
\hline 3 & $\cdots$ & 760 & 1029 & & & \\
\hline 4 & $\ldots$ & 680 & 1030 & 10.34 & 0.458 & 1.81 \\
\hline 5 & $\ldots$ & 930 & 1025 & & & \\
\hline 6 & $\ldots$ & 820 & 1026 & & & \\
\hline 7 & $\ldots$ & 600 & 1029 & j & & \\
\hline 8 & 63.0 & 740 & 1025 & & & \\
\hline 9 & $\ldots$ & 565 & 1030 & & & \\
\hline 10 & $\ldots$ & 710 & 1027 & & & \\
\hline 11 & $\ldots$ & 870 & 1025 & 9.24 & 0.470 & 1.76 \\
\hline 12 & $\ldots$ & 705 & 1025 & & & \\
\hline 13 & $\ldots$ & 740 & 1026 & & & \\
\hline 14 & $\ldots$ & 595 & 1027 & j & & \\
\hline 15 & $\ldots$ & 860 & 1026 & ) & & \\
\hline 16 & 63.2 & 830 & 1024 & & & \\
\hline 17 & $\ldots$ & 780 & 1026 & & & \\
\hline 18 & $\ldots$ & 735 & 1026 & 747 & 0485 & \\
\hline 19 & $\ldots$ & 720 & 1028 & 7.47 & 0.465 & $\cdots$ \\
\hline 20 & 63.0 & 690 & 1027 & & & \\
\hline 21 & $\cdots$ & 900 & 1025 & & & \\
\hline 22 & 62.7 & 775 & 1027 & & & \\
\hline 23 & $\ldots$ & 600 & 1028 & & & . \\
\hline 24 & $\ldots$ & 920 & 1027 & & & \\
\hline 25 & $\ldots$ & 700 & 1027 & 7.33 & 0.552 & 1.56 \\
\hline 26 & . . & 1040 & 1023 & & & \\
\hline 27 & $\ldots$ & 600 & 1031 & J. & & \\
\hline
\end{tabular}


DONAHUE.

\begin{tabular}{|c|c|c|c|c|c|c|c|}
\hline \multirow{2}{*}{\multicolumn{2}{|c|}{ Date. }} & \multirow{2}{*}{$\begin{array}{c}\text { Body- } \\
\text { weight. }\end{array}$} & \multicolumn{5}{|c|}{ Urine. } \\
\hline & & & $\begin{array}{l}\text { Volume. } \\
24 \text { hours. }\end{array}$ & Sp. Gr. & Nitrogen. & Uric Acid. & $\mathrm{P}_{2} \mathrm{O}_{5}$ \\
\hline 1904 & & kilos & c.c. & & grams & gram & grams \\
\hline Feb. 2 & & $\ldots$ & 710 & 1024 & 7.33 & 0.552 & 1.56 \\
\hline & & $\ldots$ & 850 & 1026 & & & \\
\hline Mar. & & $\ldots$ & 910 & 1028 & & & \\
\hline & 2 & 62.0 & 740 & 1027 & & & \\
\hline & 3 & $\ldots$ & 710 & 1027 & 7.79 & 0.448 & 1.91 \\
\hline & 4 & $\ldots$ & 910 & 1027 & daily & daily & daily \\
\hline & 5 & $\ldots$ & 725 & . & average & average & average \\
\hline & 6 & $\cdots$ & 940 & 1025 & & & \\
\hline & 7 & 62.7 & 700 & 1025 & & & \\
\hline & 8 & $\cdots$ & 720 & 1024 & & & \\
\hline & 9 & $\ldots$ & 1020 & 1022 & & & \\
\hline & 10 & $\cdots$ & 700 & 1026 & 6.72 & 0.363 & $\cdots$ \\
\hline & 11 & $\cdots$ & 1130 & 1021 & & & \\
\hline & 12 & $\cdots$ & 730 & 1022 & & & \\
\hline & 13 & $\cdots$ & 940 & 1018 & & & \\
\hline & 14 & $\cdots$ & 980 & 1018 & & & \\
\hline & 15 & 62.7 & 985 & 1018 & & & \\
\hline . 1 & 16 & $\cdots$ & 875 & 1019 & & & \\
\hline & 17 & $\ldots$ & 515 & 1024 & 6.33 & 0.504 & $\cdots$ \\
\hline & 18 & $\ldots$ & 960 & 1019 & & & \\
\hline & 19 & $\cdots$ & 880 & 1022 & & & \\
\hline & 20 & 62.7 & 720 & 1025 & & & \\
\hline & 21 & $\cdots$ & 730 & 1023 & & & \\
\hline & 22 & $\cdots$ & 920 & 1024 & & & \\
\hline & 23 & $\cdots$ & 850 & 1020 & 5.61 & 0.363 & , \\
\hline & 24 & $\cdots$ & 720 & 1026 & 0.01 & & $\cdots$ \\
\hline & 26 & 62.7 & 730 & 1024 & & & \\
\hline & 27 & $\cdots$ & 970 & 1026 & & & \\
\hline & 28 & $\cdots$ & 860 & 1021 & & & \\
\hline & 29 & $\cdots$ & 990 & 1022 & & & \\
\hline & 30 & 62.8 & 1250 & 1023 & & & \\
\hline & 31 & $\cdots$ & 990 & 1020 & 7.17 & 0.408 & 1.90 \\
\hline Apr. & 1 & $\cdots$ & 910 & 1022 & & & \\
\hline & 2 & $\cdots$ & 930 & 1028 & & & \\
\hline & 3 & 62.8 & 870 & 1026 & & & \\
\hline & 4 & 62.8 & 1080 & 1025 & & & \\
\hline & 5 & $\cdots$ & 740 & 1028 & & & \\
\hline & 6 & $\cdots$ & 850 & 1027 & 9.91 & 0.593 & 1.79 \\
\hline & 7 & $\cdots$ & 740 & 1028 & & & \\
\hline & 8 & $\cdots$ & 1010 & 1028 & & & \\
\hline
\end{tabular}


DONAHUE.

\begin{tabular}{|c|c|c|c|c|c|c|c|}
\hline \multirow{2}{*}{\multicolumn{2}{|c|}{ Date. }} & \multirow{2}{*}{$\begin{array}{c}\text { Body- } \\
\text { Weight. }\end{array}$} & \multicolumn{5}{|c|}{ Urine. } \\
\hline & & & $\begin{array}{l}\text { Volume. } \\
24 \text { hours. }\end{array}$ & Sp. Gr. & Nitrogen. & Uric Acid. & $\mathrm{P}_{2} \mathrm{O}_{5}$ \\
\hline \multicolumn{2}{|c|}{1904} & kilos & c.c. & & grams & gram & grams \\
\hline Apr. & 9 & $\ldots$ & 700 & 1029 & 9.91 & 0.593 & 1.79 \\
\hline & 10 & $\ldots$ & 900 & 1025 & daily av. & daily av. & daily av. \\
\hline & 11 & $\ldots$ & 1150 & 1020 & 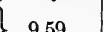 & & \\
\hline & 12 & $\ldots$ & 1230 & 1021 & 9.59 & & \\
\hline & 13 & $\ldots$ & 1000 & 1021 & 7.38 & & \\
\hline & 14 & $\ldots$ & 710 & 1025 & 6.18 & 0.343 & $\cdots$ \\
\hline & 15 & $\cdots$ & 920 & 1022 & 8.78 & & \\
\hline & 16 & 63.0 & 700 & 1025 & 6.89 & & \\
\hline & 17 & $\ldots$ & 775 & 1024 & 8.28 & & \\
\hline & 18 & $\ldots$ & 1050 & 1020 & 7.69 & & \\
\hline & 19 & $\ldots$ & 910 & 1021 & 6.55 & & \\
\hline & 20 & $\ldots$ & 1140 & 1020 & 6.64 & & \\
\hline & 21 & $\ldots$ & 1055 & 1022 & 6.71 & 0.399 & $\cdots$ \\
\hline & 22 & $\ldots$ & 1020 & 1020 & 6.79 & & \\
\hline & 23 & $\cdots$ & 700 & 1025 & 6.34 & & \\
\hline & 24 & $\ldots$ & 825 & 1022 & 7.13 & & \\
\hline & 25 & $\ldots$ & 850 & 1022 & 6.27 & & \\
\hline & 26 & $\ldots$ & 1010 & 1021 & 7.09 & & \\
\hline & 27 & $\ldots$ & 1150 & 1021 & 7.31 & & \\
\hline & 28 & $\ldots$ & 950 & 1021 & 6.38 & 0.411 & $\ldots$ \\
\hline & 29 & $\ldots$ & 950 & 1023 & 8.61 & & \\
\hline & 30 & $\ldots$ & 525 & 1028 & 6.96 & & \\
\hline \multirow[t]{18}{*}{ May } & 1 & 63.0 & 750 & 1022 & 7.65 & & \\
\hline & 2 & $\ldots$ & 775 & 1022 & 6.88 & & \\
\hline & 3 & $\ldots$ & 710 & 1022 & 6.01 & & \\
\hline & 4 & $\cdots$ & 1075 & 1021 & 7.22 & & \\
\hline & 5 & $\ldots$ & 700 & 1021 & 5.34 & 0.120 & .. \\
\hline & 6 & $\cdots$ & 950 & 1024 & 7.41 & & \\
\hline & 7 & $\ldots$ & 950 & 1023 & 6.72 & & \\
\hline & 8 & . . & 745 & 1024 & 5.90 & & \\
\hline & 9 & $\ldots$ & 910 & 1020 & 6.61 & & \\
\hline & 10 & $\ldots$ & 720 & 1023 & 6.91 & & \\
\hline & 11 & 63.0 & 750 & 1024 & 7.11 & & \\
\hline & 12 & 63.0 & 700 & 1022 & 6.51 & 0.365 & $\cdots$ \\
\hline & 13 & $\cdots$ & 710 & 1024 & 6.94 & & \\
\hline & 14 & $\ldots$ & 825 & 1025 & 8.68 & & \\
\hline & 15 & $\ldots$ & 1100 & 1020 & 7.79 & & \\
\hline & 16 & $\cdots$ & 1000 & 1021 & 6.12 & $\cdots$ & $\cdots$ \\
\hline & 17 & $\cdots$ & 1010 & 1020 & 5.94 & . & $\ldots$ \\
\hline & 18 & $\ldots$ & 950 & 1020 & 5.75 & 0.343 & $\ldots$ \\
\hline
\end{tabular}


PHYSIOLOGICAL ECONOMY IN NUTRITION 351

DONAHUE.

\begin{tabular}{|c|c|c|c|c|c|c|}
\hline \multirow{2}{*}{ Date. } & \multirow{2}{*}{$\begin{array}{l}\text { Body- } \\
\text { weight. }\end{array}$} & \multicolumn{5}{|c|}{ Urine. } \\
\hline & & $\begin{array}{l}\text { Volume. } \\
24 \text { hours. }\end{array}$ & Sp. Gr. & Nitrogen. & Uric Acid. & $\mathrm{P}_{2} \mathrm{O}_{5}$. \\
\hline 1904 & kilos & c.c. & & grams & gram & grams \\
\hline May 19 & $\cdots$ & 1025 & 1020 & 6.64 & \multirow{6}{*}{$\begin{array}{c}0.343 \\
\text { daily } \\
\text { average }\end{array}$} & \\
\hline & $\cdots$ & 1100 & 1020 & 8.45 & & \\
\hline 21 & $\ldots$ & 900 & 1027 & 8.64 & & \\
\hline 22 & $\ldots$ & 750 & 1025 & 8.53 & & $\cdots$ \\
\hline 23 & $\cdots$ & 750 & 1022 & 7.69 & & \\
\hline 24 & $\ldots$ & 920 & 1023 & 7.34 & & \\
\hline 25 & $\ldots$ & 750 & 1022 & 10.22 & & \\
\hline 26 & 62.2 & 775 & 1021 & 6.51 & & \\
\hline 27 & $\ldots$ & 880 & 1023 & 8.18 & & \\
\hline 28 & $\ldots$ & 800 & 1023 & 7.06 & 0.406 & $\cdots$ \\
\hline 29 & $\ldots$ & 790 & 1023 & 8.49 & & \\
\hline 30 & $\ldots$ & 850 & 1022 & 7.91 & & \\
\hline 31 & $\ldots$ & 1030 & 1021 & 7.60 & $\cdots$ & $\cdots$ \\
\hline June 1 & $\cdots$ & 800 & 1022 & 6.53 & $\cdots$ & $\cdots$ \\
\hline 2 & $\ldots$ & 1000 & 1021 & 8.16 & $\cdots$ & $\cdots$ \\
\hline 3 & $\ldots$ & 850 & 1022 & 7.40 & $\cdots$ & $\cdots$ \\
\hline 4 & $\cdots$ & $\cdots$ & $\ldots$ & $\cdots$ & $\cdots$ & $\cdots$ \\
\hline 5 & 62.8 & 650 & 1027 & 8.49 & $\cdots$ & $\cdots$ \\
\hline 6 & $\cdots$ & 850 & 1023 & 7.33 & $\cdots$ & $\cdots$ \\
\hline 7 & $\ldots$ & 910 & 1022 & 7.43 & $\cdots$ & $\cdots$ \\
\hline 8 & $\ldots$ & 770 & 1022 & 8.37 & $\cdots$ & $\cdots$ \\
\hline 9 & $\ldots$ & 910 & 1025 & 9.50 & $\ldots$ & $\cdots$ \\
\hline 10 & $\ldots$ & 850 & 1025 & 8.01 & $\cdots$ & $\ldots$ \\
\hline 11 & $\ldots$ & 650 & 1025 & 7.72 & $\cdots$ & $\cdots$ \\
\hline 12 & $\cdots$ & 700 & 1025 & 8.36 & $\cdots$ & $\cdots$ \\
\hline 13 & $\cdots$ & 930 & 1022 & 9.15 & $\cdots$ & . . \\
\hline 14 & $\cdots$ & 800 & 1026 & 8.45 & $\cdots$ & $\cdots$ \\
\hline 15 & 62.2 & 700 & 1027 & 7.90 & $\cdots$ & $\cdots$ \\
\hline \multicolumn{7}{|c|}{ Daily average from } \\
\hline \multirow{3}{*}{\multicolumn{2}{|c|}{$\begin{array}{l}\text { Feb. } 14 \\
\text { Daily average from } \\
\text { Feb. } 14 \text { to Apr. } 12\end{array}$}} & 857 & 1023 & $\cdots$ & 0.395 & 1.79 \\
\hline & & & & & & \\
\hline & & $\cdots$ & $\cdots$ & 7.55 & $\cdots$ & $\cdots$ \\
\hline \multicolumn{2}{|c|}{ Daily average from } & & & & & \\
\hline \multicolumn{2}{|c|}{ Apr. 13 to June 15} & $\cdots$ & $\cdots$ & 7.39 & $\cdots$ & $\cdots$ \\
\hline
\end{tabular}


JACOBUS.

\begin{tabular}{|c|c|c|c|c|c|c|}
\hline \multirow{2}{*}{ Date. } & \multirow{2}{*}{$\begin{array}{c}\text { Body- } \\
\text { weight. }\end{array}$} & \multicolumn{5}{|c|}{ Urine. } \\
\hline & & $\begin{array}{l}\text { Volume. } \\
24 \text { hours. }\end{array}$ & Sp. Gr. & Nitrogen. & Uric Acid. & $\mathbf{P}_{2} \mathbf{O}_{5}$ \\
\hline 1904 & kilos & c.c. & & grams & gram & grams \\
\hline Jan. 15 & 57.3 & 630 & 1032 & 10.70 & 0.542 & $\ldots$ \\
\hline 16 & $\cdots$ & 810 & 1024 & 11.76 & 0.960 & $\ldots$ \\
\hline 17 & $\ldots$ & 880 & 1029 & 11.09 & 0.780 & $\ldots$ \\
\hline 18 & $\ldots$ & 780 & 1030 & 10.67 & 0.600 & $\ldots$ \\
\hline 19 & $\cdots$ & 810 & 1029 & 12.94 & 0.595 & $\cdots$ \\
\hline 20 & . & 670 & 1030 & 11.98 & 0.553 & $\ldots$ \\
\hline 21 & $\cdots$ & 730 & 1029 & 10.91 & 0.586 & $\ldots$ \\
\hline 22 & $\ldots$ & 990 & 1025 & 12.12 & 0.594 & $\ldots$ \\
\hline 23 & 58.7 & 825 & 1021 & 9.55 & 0.436 & $\ldots$ \\
\hline 24 & $\ldots$ & 680 & 1027 & 9.10 & 0.449 & ... \\
\hline 25 & $\ldots$ & 1260 & 1018 & & & \\
\hline 26 & $\ldots$ & 875 & 1022 & & & \\
\hline 27 & $\ldots$ & 680 & 1028 & & & \\
\hline 28 & 57.0 & 850 & 1022 & 9.58 & 0.442 & 1.72 \\
\hline 29 & 58.0 & 760 & 1020 & daily & daily & daily \\
\hline 30 & 57.7 & 560 & 1029 & average & average & average \\
\hline 31 & $\ldots$ & 660 & 1028 & & & \\
\hline Feb. 1 & $\ldots$ & 700 & 1023 & & & \\
\hline 2 & 57.2 & 567 & 1030 & & & \\
\hline 3 & $\ldots$ & 600 & 1030 & & & \\
\hline 4 & 57.5 & 582 & 1026 & 8.30 & 0.548 & 1.60 \\
\hline 5 & . & 740 & 1024 & & & \\
\hline 6 & 56.8 & 470 & 1028 & & & \\
\hline 7 & $\cdots$ & 405 & 1032 & & & \\
\hline 8 & 56.0 & 575 & 1028 & & & \\
\hline 9 & 57.2 & 540 & 1028 & & & \\
\hline 10 & 56.6 & 520 & 1029 & & & \\
\hline 11 & 57.0 & 1000 & 1020 & 7.73 & 0.460 & 1.74 \\
\hline 12 & $\cdots$ & 920 & 1015 & & & \\
\hline 13 & . . & 845 & 1020 & & & \\
\hline 14 & $\cdots$ & 480 & 1028 & & & \\
\hline 15 & . & 750 & 1025 & & & \\
\hline 16 & 56.8 & 810 & 1022 & & & \\
\hline 17 & 56.4 & 760 & 1020 & & & \\
\hline 18 & $\cdots$ & 1100 & 1017 & 6.27 & 0.399 & $\cdots$ \\
\hline 19 & 56.6 & 950 & 1020 & & & \\
\hline 20 & 56.3 & 620 & 1025 & & & \\
\hline 21 & $\cdots$ & 580 & 1027 & & & \\
\hline 22 & 57.3 & 770 & 1020 & 6.96 & 0.521 & 147 \\
\hline 23 & 56.7 & 795 & 1024 & 0.90 & 0.021 & 1.46 \\
\hline
\end{tabular}


JACOBUS.

\begin{tabular}{|c|c|c|c|c|c|c|}
\hline \multirow{2}{*}{ Date. } & \multirow{2}{*}{$\begin{array}{c}\text { Body- } \\
\text { weighit. }\end{array}$} & \multicolumn{5}{|c|}{ Urine. } \\
\hline & & $\begin{array}{l}\text { Volume. } \\
24 \text { hours. }\end{array}$ & Sp. Gr. & Nitrogen. & Uric Acid. & $\mathrm{P}_{2} \mathrm{O}_{5}$. \\
\hline 1904 & kilos & c.c. & & grams & gram & grams \\
\hline Feb. 24 & 56.6 & 890 & 1016 & & & \\
\hline 25 & 56.7 & 880 & 1022 & & & \\
\hline 26 & 56.8 & 690 & 1027 & 6.96 & 0.521 & 1.47 \\
\hline 27 & $\ldots$ & 885 & 1024 & daily & daily & daily \\
\hline 28 & $\ldots$ & 970 & 1019 & average & average & average \\
\hline 29 & 56.8 & 815 & 1024 & & & \\
\hline Mar. 1 & 57.0 & 760 & 1027 & & & \\
\hline 2 & 57.0 & 690 & 1025 & & & \\
\hline 3 & 56.8 & 1720 & 1012 & 8.43 & 0.315 & 1.75 \\
\hline 4 & $\ldots$ & 1010 & 1019 & & & \\
\hline 5 & $\ldots$ & 790 & $\ldots$ & & & \\
\hline 6 & $\ldots$ & 440 & 1033 & & & \\
\hline 7 & 56.6 & 970 & 1019 & & & \\
\hline 8 & $\ldots$ & 1130 & 1018 & & & \\
\hline 9 & $\ldots$ & 440 & 1031 & & & \\
\hline 10 & $\ldots$ & 1480 & 1016 & 7.88 & 0.535 & $\ldots$ \\
\hline 11 & $\ldots$ & 1300 & 1015 & & & \\
\hline 12 & $\ldots$ & 1165 & 1013 & & & \\
\hline 13 & $\ldots$ & 1580 & 1011 & & & \\
\hline 14 & 56.8 & 1200 & 1015 & & & \\
\hline 15 & $\ldots$ & 1330 & 1010 & & & \\
\hline 16 & $\ldots$ & 1065 & 1015 & & & \\
\hline 17 & 56.8 & 1170 & 1013 & 5.98 & 0.454 & $\cdots$ \\
\hline 18 & $\ldots$ & 1030 & 1018 & & & \\
\hline 19 & 56.8 & 1445 & 1012 & & & \\
\hline 20 & 56.8 & 975 & 1020 & & & \\
\hline 21 & $\ldots$ & 870 & 1018 & & & \\
\hline 22 & $\ldots$ & 1400 & 1014 & & & \\
\hline 23 & 57.3 & 840 & 1020 & 830 & 0418 & 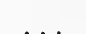 \\
\hline 24 & $\ldots$ & 1020 & 1021 & & & $\cdots$ \\
\hline 25 & $\ldots$ & 690 & 1024 & & & \\
\hline 26 & $\ldots$ & 1195 & 1017 & & & \\
\hline 28 & $\ldots$ & 1170 & 1015 & & & \\
\hline 29 & 57.3 & 1030 & 1023 & & & \\
\hline 30 & $\ldots$ & 1225 & 1021 & & & \\
\hline 31 & $\ldots$ & 1175 & 1020 & 9.59 & 0.471 & $\ldots$ \\
\hline Apr. 1 & $\ldots$ & 1330 & 1016 & & & \\
\hline 2 & $\ldots$ & 775 & 1023 & & & \\
\hline 3 & $\ldots$ & 615 & 1026 & & & \\
\hline 4 & $\cdots$ & 695 & 1029 & 8.71 & 0.310 & 1.82 \\
\hline
\end{tabular}


JACOBUS.

\begin{tabular}{|c|c|c|c|c|c|c|c|}
\hline \multirow{2}{*}{\multicolumn{2}{|c|}{ Date. }} & \multirow{2}{*}{$\begin{array}{c}\text { Body. } \\
\text { weight. }\end{array}$} & \multicolumn{5}{|c|}{ Urine. } \\
\hline & & & $\begin{array}{l}\text { Volume. } \\
24 \text { hours. }\end{array}$ & Sp. Gr. & Nitrogen. & Uric Acid. & $\mathrm{P}_{2} \mathrm{O}_{5}$ \\
\hline \multicolumn{2}{|c|}{1904} & kilos & c.c. & & grams & gram & grams \\
\hline \multirow[t]{25}{*}{ Apr. } & 5 & $\cdots$ & 830 & 1026 & & & \\
\hline & 6 & . & 762 & 1019 & & & \\
\hline & 7 & 57.0 & 1205 & 1026 & & & \\
\hline & 8 & $\cdots$ & 1180 & 1015 & 8.11 & 0.810 & 1.82 \\
\hline & 9 & $\cdots$ & 1035 & 1017 & daily & daily & . daily \\
\hline & 10 & $\ldots$ & 1300 & 1015 & average & average & average \\
\hline & 11 & $\cdots$ & 1045 & 1026 & & & \\
\hline & 12 & $\cdots$ & 610 & 1024 & 1.88 & & \\
\hline & 13 & $\cdots$ & 410 & $10 \div 7$ & 6.81 & & \\
\hline & 14 & $\cdots$ & 600 & 1025 & 6.84 & 0.460 & . \\
\hline & 15 & $\cdots$ & 1160 & 1017 & 8.49 & & \\
\hline & 16 & 56.8 & 820 & 1021 & 7.72 & & \\
\hline & 17 & $\cdots$ & 555 & 1029 & 6.96 & & \\
\hline & 18 & $\cdots$ & 610 & 1026 & 7.36 & & \\
\hline & 19 & $\cdots$ & 515 & 1028 & 6.67 & & \\
\hline & 20 & $\cdots$ & 710 & 1023 & 7.71 & & \\
\hline & 21 & $\cdots$ & 480 & 1026 & 6.94 & 0.441 & $\cdots$ \\
\hline & 22 & 55.0 & 565 & 1026 & 7.19 & & \\
\hline & 23 & $\ldots$ & 460 & 1031 & 7.16 & & \\
\hline & 24 & $\cdots$ & 550 & 1027 & 6.27 & & \\
\hline & 25 & $\cdots$ & 750 & 1020 & 6.30 & 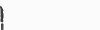 & \\
\hline & 26 & $\ldots$ & 1170 & 1017 & 7.93 & & \\
\hline & 28 & $\ldots$ & 1010 & 1019 & 6.06 & & \\
\hline & 29 & $\ldots$ & 1110 & 1018 & 8.59 & 0.007 & $\cdots$ \\
\hline & 30 & $\cdots$ & 1050 & 1020 & 8.44 & & \\
\hline \multirow[t]{15}{*}{ May } & 1 & $\ldots$ & 715 & 1030 & 9.44 & & \\
\hline & 2 & 56.6 & 1460 & 1014 & 10.50 & & \\
\hline & 3 & $\cdots$ & 1185 & 1019 & 9.45 & & \\
\hline & 4 & . & 1270 & 1019 & 10.52 & & \\
\hline & 5 & 56.6 & 1010 & 1019 & 9.70 & 0.382 & $\cdots$ \\
\hline & 6 & $\ldots$ & 1090 & 1021 & 9.94 & & \\
\hline & 7 & $\cdots$ & 1100 & 1016 & 8.65 & & \\
\hline & 8 & $\cdots$ & 765 & 1024 & 9.78 & & \\
\hline & 10 & $\cdots$ & 555 & 1026 & 7.96 & & \\
\hline & 11 & $\ldots$ & 640 & 1027 & 6.60 & & \\
\hline & 12 & $\ldots$ & 1160 & 1016 & 7.03 & 0.296 & \\
\hline & 13 & $\cdots$ & 665 & 1025 & 7.66 & 0.290 & $\cdots$ \\
\hline & 14 & $\cdots$ & 1240 & 1014 & 6.61 & & \\
\hline & 15 & 56.6 & 595 & 1027 & 7.89 & & • \\
\hline & 16 & $\ldots$ & 1460 & 1012 & 7.45 & $\cdots$ & $\cdots$ \\
\hline
\end{tabular}


JACOBUS.

\begin{tabular}{|c|c|c|c|c|c|c|}
\hline \multirow{2}{*}{ Date. } & \multirow{2}{*}{$\begin{array}{c}\text { Body- } \\
\text { weight. }\end{array}$} & \multicolumn{5}{|c|}{ Urine. } \\
\hline & & $\begin{array}{l}\text { Volume. } \\
24 \text { hours. }\end{array}$ & Sp. Gr. & Nitrogen. & Uric Acid. & $\mathrm{P}_{2} \mathrm{O}_{5}$ \\
\hline \multirow{29}{*}{$\begin{array}{r}1904 \\
\text { May } 17 \\
18 \\
19 \\
20 \\
21 \\
22 \\
23 \\
24 \\
25 \\
26 \\
27 \\
28 \\
29 \\
30 \\
31 \\
1 \\
\text { June } \\
2 \\
3 \\
4 \\
5 \\
6 \\
7 \\
8 \\
9 \\
10 \\
13 \\
14 \\
15\end{array}$} & kilos & c.c. & & grams & gram & grams \\
\hline & $\cdots$ & 1620 & 1012 & 6.80 & $\cdots$ & $\cdots$ \\
\hline & $\cdots$ & 2010 & 1012 & 6.75 & & \\
\hline & $\cdots$ & 2050 & 1010 & 6.27 & & \\
\hline & $\ldots$ & 1180 & 1018 & 7.29 & & \\
\hline & $\cdots$ & 880 & 1020 & 7.07 & 0.376 & $\cdots$ \\
\hline & $\cdots$ & 730 & 1025 & 7.62 & daily & \\
\hline & $\cdots$ & 450 & 1029 & 6.48 & average & \\
\hline & $\cdots$ & 540 & 1028 & 7.64 & & \\
\hline & $\ldots$ & 950 & 1017 & 7.53 & & \\
\hline & 56.8 & 555 & 1023 & 5.83 & & \\
\hline & $\cdots$ & $10 \varangle 0$ & 1014 & 7.25 & & \\
\hline & $\cdots$ & 1020 & 1019 & 6.37 & 0.303 & $\cdots$ \\
\hline & . & 690 & 1022 & 6.84 & & \\
\hline & $\ldots$ & 590 & 1025 & 6.69 & & \\
\hline & $\ldots$ & 1290 & 1015 & 8.36 & J & \\
\hline & $\cdots$ & 1635 & 1010 & 7.85 & $\cdots$ & $\cdots$ \\
\hline & $\ldots$ & 1475 & 1012 & 8.23 & $\cdots$ & $\cdots$ \\
\hline & $\cdots$ & 400 & 1024 & 5.21 & $\cdots$ & $\cdots$ \\
\hline & $\cdots$ & 705 & 1019 & 6.73 & $\cdots$ & $\cdots$ \\
\hline & $\ldots$ & 1010 & 1013 & 6.30 & $\cdots$ & $\cdots$ \\
\hline & $\cdots$ & 600 & 1024 & 5.69 & $\cdots$ & $\cdots$ \\
\hline & $\cdots$ & 925 & 1016 & 6.72 & $\cdots$ & $\cdots$ \\
\hline & $\cdots$ & 1015 & 1014 & 7.30 & $\cdots$ & $\cdots$ \\
\hline & $\cdots$ & 925 & 1019 & 6.05 & $\cdots$ & $\cdots$ \\
\hline & 57.0 & 1285 & 1012 & 5.25 & $\cdots$ & $\cdots$ \\
\hline & $\cdots$ & 855 & 1018 & 8.36 & $\cdots$ & $\cdots$ \\
\hline & $\cdots$ & 735 & 1019 & 6.97 & $\cdots$ & $\cdots$ \\
\hline & 57.0 & 495 & 1028 & 8.32 & $\cdots$ & $\cdots$ \\
\hline \multirow{6}{*}{\multicolumn{2}{|c|}{$\begin{array}{l}\text { Daily average from } \\
\text { Feb. } 1 \\
\text { Daily average from } \\
\text { Feb. } 1 \text { to April } 12 \\
\text { Daily average from } \\
\text { April } 13 \text { to June } 15\end{array}$}} & & & & & \\
\hline & & 916 & 1021 & $\cdots$ & 0.423 & 1.67 \\
\hline & & & & & & \\
\hline & & $\cdots$ & $\cdots$ & 7.74 & $\cdots$ & $\cdots$ \\
\hline & & & & & & \\
\hline & & $\cdots$ & $\cdots$ & 7.43 & $\cdots$ & $\cdots$ \\
\hline
\end{tabular}


SCHENKER.

\begin{tabular}{|c|c|c|c|c|c|c|}
\hline \multirow{2}{*}{ Date. } & \multirow{2}{*}{$\begin{array}{c}\text { Body- } \\
\text { weight. }\end{array}$} & \multicolumn{5}{|c|}{ Urine. } \\
\hline & & $\begin{array}{l}\text { Volume. } \\
24 \text { hours. }\end{array}$ & Sp. Gr. & Nitrogen. & Uric Acid. & $\mathrm{P}_{2} \mathrm{O}_{5}$ \\
\hline 1904 & kilos & c.c. & & grams & gram & grams \\
\hline Jan. 16 & 73.5 & 1140 & 1026 & 16.21 & 0.688 & $\cdots$ \\
\hline 17 & $\cdots$ & 2180 & 1020 & 18.44 & 0.990 & $\cdots$ \\
\hline 18 & $\cdots$ & 1155 & 1024 & 14.97 & 0.745 & $\cdots$ \\
\hline 20 & $\cdots$ & 1090 & 1027 & 19.82 & 0.797 & $\cdots$ \\
\hline 21 & $\cdots$ & 1515 & 1027 & 20.63 & 0.966 & $\cdots$ \\
\hline 22 & $\cdots$ & 1675 & 1019 & 15.38 & 0.653 & $\cdots$ \\
\hline 23 & 71.7 & 1100 & 1022 & 13.40 & 0.631 & $\cdots$ \\
\hline 24 & $\cdots$ & 1390 & 1021 & 14.18 & 0.719 & $\cdots$ \\
\hline 25 & $\cdots$ & 1410 & 1019 & & & \\
\hline 26 & $\ldots$ & 840 & 1027 & & & \\
\hline 27 & $\cdots$ & 925 & $\ldots$ & & & \\
\hline 28 & $\cdots$ & 1140 & 1023 & 13.23 & 0.693 & 2.03 \\
\hline 29 & 72.3 & 1025 & 1024 & daily & daily & daily \\
\hline 30 & $\ldots$ & 1900 & 1015 & average & average & average \\
\hline 31 & $\cdots$ & 1105 & $\cdots$ & & & \\
\hline Feb. 1 & $\cdots$ & 1320 & 1023 & ) & & \\
\hline 2 & 71.6 & 885 & 1029 & & & \\
\hline 3 & $\cdots$ & 1260 & 1023 & & & \\
\hline 4 & $\cdots$ & 1480 & 1020 & 13.86 & 0.693 & 2.16 \\
\hline 5 & $\cdots$ & 970 & 1027 & & & \\
\hline 6 & 71.4 & 1150 & 1026 & & & \\
\hline 7 & $\cdots$ & 1270 & 1022 & j & & \\
\hline 8 & 71.5 & 1270 & 1022 & I & & \\
\hline 9 & 71.2 & 940 & 1028 & & & \\
\hline 10 & $\cdots$ & 930 & 1027 & & & \\
\hline 11 & 71.4 & 845 & 1029 & 12.84 & 0.654 & 2.00 \\
\hline 12 & $\cdots$ & 800 & 1027 & & & \\
\hline 13 & $\cdots$ & 620 & 1031 & & & \\
\hline 14 & $\ldots$ & 890 & 1025 & & & \\
\hline 15 & 70.9 & 1020 & 1029 & & & \\
\hline 16 & $\ldots$ & 1490 & 1019 & & & \\
\hline 17 & $\cdots$ & 1180 & 1024 & & & \\
\hline 18 & $\cdots$ & 1230 & 1022 & 6.34 & 0.633 & $\cdots$ \\
\hline 19 & $\cdots$ & 950 & 1029 & & & \\
\hline 20 & $\cdots$ & 1510 & 1021 & & & \\
\hline 21 & $\cdots$ & 1325 & 1026 & & & \\
\hline 23 & $\cdots$ & 510 & 1030 & & & \\
\hline 24 & 71.9 & 1140 & 1024 & 8.85 & 062 & 217 \\
\hline 25 & $\cdots$ & 1730 & 1016 & 0.00 & 0.024 & 2.16 \\
\hline 26 & $\cdots$ & 1145 & 1022 & & & \\
\hline
\end{tabular}


SCHENKER.

\begin{tabular}{|c|c|c|c|c|c|c|}
\hline \multirow{2}{*}{ Date. } & \multirow{2}{*}{$\begin{array}{c}\text { Body- } \\
\text { weight. }\end{array}$} & \multicolumn{5}{|c|}{ Urine. } \\
\hline & & $\begin{array}{l}\text { Volume. } \\
24 \text { hours. }\end{array}$ & Sp. Gr. & Nitrogen. & Uric Acid. & $\mathrm{P}_{2} \mathrm{O}_{5}$. \\
\hline 1904 & kilos & c.c. & & grams & gram & grams \\
\hline Feb. 27 & $\cdots$ & 2015 . & 1018 & 8.85 & 0.624 & 2.17 \\
\hline 28 & $\cdots$ & 1150 & 1023 & daily av. & daily av. & daily av. \\
\hline 29 & $\ldots$ & 1230 & 1028 & & & \\
\hline Mar. 1 & 71.8 & 1245 & 1026 & & & \\
\hline 2 & $\cdots$ & 770 & 1030 & & & \\
\hline 3 & 70.8 & 1480 & 1016 & 11.49 & 0.799 & 2.43 \\
\hline 4 & $\cdots$ & 1325 & 1028 & & & \\
\hline 5 & $\cdots$ & 1960 & 1014 & & & \\
\hline 6 & $\cdots$ & 1230 & 1021 & & & \\
\hline 7 & $\cdots$ & 1900 & 1016 & & & \\
\hline 8 & 72.4 & 1760 & 1016 & & & \\
\hline 9 & $\cdots$ & 910 & 1026 & & & \\
\hline 10 & $\cdots$ & 2050 & 1015 & 10.11 & 0.734 & $\cdots$ \\
\hline 11 & 72.5 & 940 & 1020 & & & \\
\hline 12 & $\cdots$ & 2200 & 1002 & & & \\
\hline 13 & $\cdots$ & 2790 & 1011 & & & \\
\hline 14 & $\cdots$ & 1880 & 1014 & & & \\
\hline 15 & 72.3 & 1630 & 1012 & & & \\
\hline 16 & $\ldots$ & 1070 & 1022 & & & \\
\hline 17 & $\cdots$ & 2040 & 1012 & 11.08 & 0.797 & $\cdots$ \\
\hline 18 & $\cdots$ & 1655 & 1021 & & & \\
\hline 19 & $\cdots$ & 1485 & 1014 & & & \\
\hline 20 & $\cdots$ & 2550 & 1013 & & & \\
\hline 21 & 71.9 & 2000 & 1014 & & & \\
\hline 22 & $\cdots$ & 2170 & 1012 & 10.14 & 0.551 & $\cdots$ \\
\hline 23 & $\cdots$ & 1670 & 1014 & & & \\
\hline 24 & 72.3 & 2020 & 1015 & & & \\
\hline 26 & $\cdots$ & 875 & $\cdots$ & $\cdots$ & $\cdots$ & $\cdots$ \\
\hline 27 & $\cdots$ & 1520 & 1018 & & & \\
\hline 28 & $\ldots$ & 1675 & 1017 & & & \\
\hline 29 & $\ldots$ & 1175 & 1025 & & & \\
\hline 30 & $\cdots$ & 1110 & 1021 & 10.85 & 0.660 & $\cdots$ \\
\hline 31 & $\ldots$ & 2340 & 1012 & & & \\
\hline Apr. 1 & $\cdots$ & 1440 & 1021 & & & \\
\hline 2 & $\cdots$ & 1200 & 1021 & & & \\
\hline 3 & $\cdots$ & $\cdots$ & 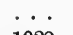 & ) & & \\
\hline 4 & $\cdots$ & 1110 & 1022 & & & \\
\hline 5 & $\cdots$ & 785 & $\cdots$ & 11.64 & 0.782 & $\cdots$ \\
\hline 6 & $\cdots$ & 1130 & 1023 & & & \\
\hline 7 & 74.1 & 945 & 1027 & & & \\
\hline
\end{tabular}


SCHENKER.

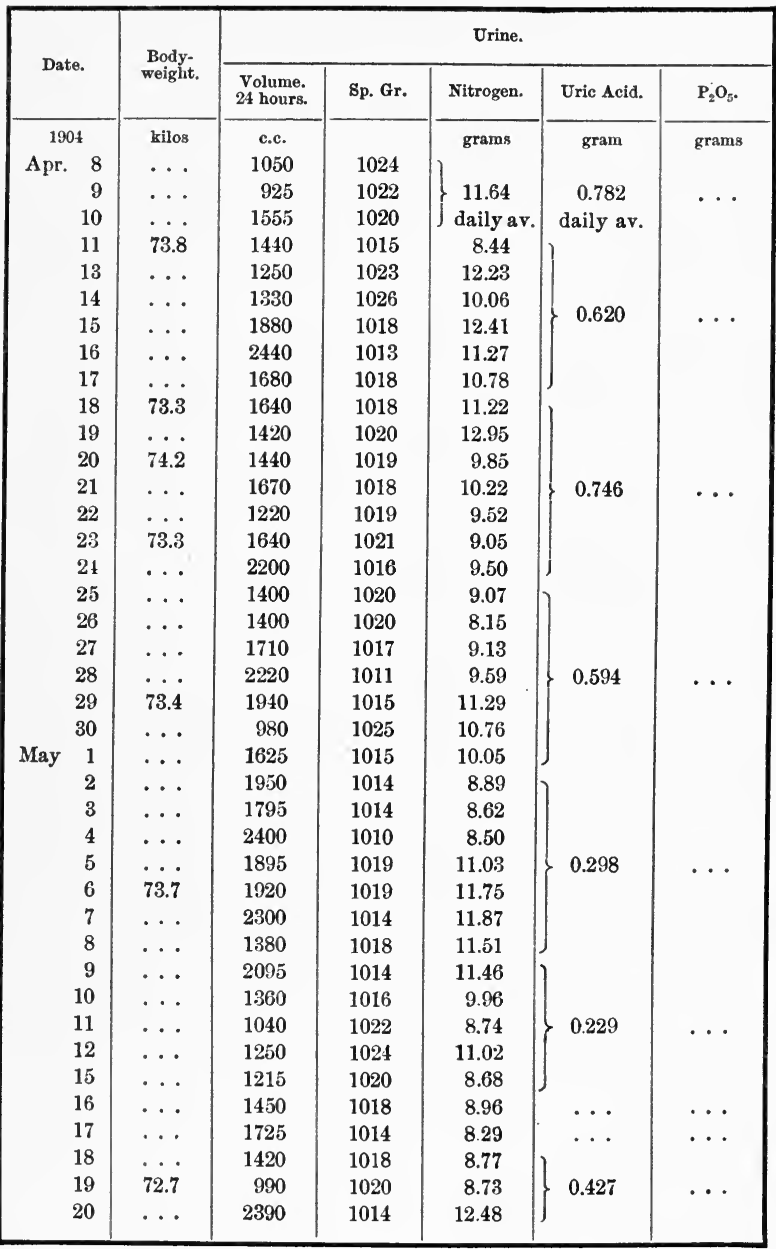


SCHENKER.

\begin{tabular}{|c|c|c|c|c|c|c|c|}
\hline \multirow{2}{*}{\multicolumn{2}{|c|}{ Date. }} & \multirow{2}{*}{$\begin{array}{c}\text { Body- } \\
\text { weight. }\end{array}$} & \multicolumn{5}{|c|}{ Urine. } \\
\hline & & & $\begin{array}{l}\text { Volume. } \\
24 \text { hours. }\end{array}$ & Sp. Gr. & Nitrogen. & Uric Acid. & $\mathrm{P}_{2} \mathrm{O}_{5}$. \\
\hline \multicolumn{2}{|c|}{1904} & kilos & c.c. & \multirow[b]{2}{*}{1025} & grams & grams & grams \\
\hline \multicolumn{2}{|c|}{ May 21} & 72.7 & 1000 & & 8.76 & \multirow{4}{*}{$\begin{array}{l}0.427 \\
\text { daily av. }\end{array}$} & \\
\hline & & $\ldots$ & 1570 & 1018 & 9.98 & & \\
\hline & 23 & $\ldots$ & 1780 & 1015 & 10.04 & & $\cdots$ \\
\hline & 24 & $\cdots$ & 1210 & 1018 & 8.71 & & \\
\hline & 25 & $\cdots$ & 1390 & 1016 & 9.09 & & \\
\hline & 26 & 72.5 & 1380 & 1015 & 9.11 & & · \\
\hline & 27 & 72.1 & 1920 & 1018 & 9.56 & & \\
\hline & 28 & $\ldots$ & 1870 & 1016 & 11.22 & 0.842 & $\cdots$ \\
\hline & 29 & ... & 1635 & 1015 & 8.83 & & \\
\hline & 30 & ... & 1670 & 1017 & 8.52 & & \\
\hline & 31 & $\cdots$ & 2190 & 1013 & 9.46 & $\cdots$ & $\cdots$ \\
\hline June & 1 & $\ldots$ & 1140 & 1016 & 6.02 & $\ldots$ & ... \\
\hline & 2 & $\cdots$ & 1520 & 1018 & 8.94 & $\ldots$ & $\ldots$ \\
\hline & 3 & $\cdots$ & 1610 & 1017 & 8.50 & $\cdots$ & $\cdots$ \\
\hline & 4 & 72.2 & 1380 & 1020 & 8.94 & . . & $\cdots$ \\
\hline & 5 & $\ldots$ & 795 & 1022 & 8.11 & $\ldots$ & $\cdots$ \\
\hline & 6 & $\ldots$ & 1590 & 1018 & 9.83 & . . & $\ldots$ \\
\hline & 7 & $\cdots$ & 2000 & 1012 & 9.48 & $\cdots$ & $\cdots$ \\
\hline & 8 & $\ldots$ & 1800 & 1016 & 12.10 & $\ldots$ & $\ldots$ \\
\hline & 9 & 71.9 & 1500 & 1018 & 9.63 & . & . . \\
\hline \multicolumn{3}{|c|}{ Daily average from } & & & & & \\
\hline \multicolumn{3}{|c|}{$\begin{array}{l}\text { Feb. } 8 \\
\text { Daily average from }\end{array}$} & 1500 & 1019 & & 0.624 & 2.20 \\
\hline \multirow{3}{*}{\multicolumn{3}{|c|}{$\begin{array}{l}\text { Daily average from } \\
\text { Feb. } 8 \text { to April } 10 \\
\text { Daily average from }\end{array}$}} & & & & & \\
\hline & & & $\cdots$ & $\cdots$ & 10.37 & $\cdots$ & $\cdots$ \\
\hline & & & & & & & \\
\hline \multicolumn{3}{|c|}{ April 11 to June 9} & $\cdots$ & . & 9.82 & $\cdots$ & $\cdots$ \\
\hline
\end{tabular}


STAPLETON.

\begin{tabular}{|c|c|c|c|c|c|c|}
\hline \multirow{2}{*}{ Date. } & \multirow{2}{*}{$\begin{array}{c}\text { Body- } \\
\text { weight. }\end{array}$} & \multicolumn{5}{|c|}{ Urine. } \\
\hline & & $\begin{array}{l}\text { Volume. } \\
24 \text { hours. }\end{array}$ & Sp. Gr. & Nitrogen. & Uric Acid. & $\mathrm{P}_{2} \mathrm{O}_{5}$ \\
\hline 1904 & kilos & c.c. & & grams & gram & grams \\
\hline Jan. 15 & 77.2 & 1350 & 1026 & 16.20 & 0.941 & $\cdots$ \\
\hline 16 & 77.2 & 2200 & 1020 & 20.33 & 1.163 & $\cdots$ \\
\hline 17 & 77.2 & 2000 & 1025 & 21.00 & 1.095 & $\cdots$ \\
\hline 18 & 78.1 & 1650 & 1026 & 21.78 & 0.897 & $\cdots$ \\
\hline 19 & 77.1 & 1585 & 1029 & 20.64 & 1.139 & $\cdots$ \\
\hline 20 & 77.0 & 1390 & 1028 & 19.26 & 0.480 & $\ldots$ \\
\hline 21 & 77.1 & 1560 & 1026 & 20.31 & 0.971 & $\cdots$ \\
\hline 22 & 77.1 & 1620 & 1023 & 18.37 & 0.735 & $\ldots$ \\
\hline 23 & 78.0 & 1810 & 1025 & 21.72 & 0.624 & $\cdots$ \\
\hline 24 & 77.0 & 1430 & 1024 & 17.42 & 0.890 & $\cdots$ \\
\hline 25 & 76.0 & 990 & 1029 & & & \\
\hline 26 & 76.0 & 1280 & 1026 & & & \\
\hline 27 & 77.0 & 885 & 1030 & & & \\
\hline 28 & 77.1 & 1660 & 1021 & 14.95 & 0.841 & 2.83 \\
\hline 29 & 76.1 & 1005 & 1029 & daily & daily & daily \\
\hline 30 & 77.1 & 1310 & 1027 & average & average & average \\
\hline 31 & 76.1 & 800 & 1031 & & & \\
\hline Feb. 1 & 76.1 & 1090 & 1028 & & & \\
\hline 2 & 76.1 & 1175 & 1025 & & & \\
\hline 3 & 76.0 & 1120 & 1030 & & & \\
\hline 4 & 76.0 & 950 & 1031 & 13.48 & 0.743 & 2.34 \\
\hline 5 & 76.0 & 1150 & 1023 & & & \\
\hline 6 & 76.0 & 1165 & 1029 & & & \\
\hline 7 & 76.0 & 770 & 1033 & & & \\
\hline 8 & 76.0 & 825 & 1030 & & & \\
\hline 9 & 76.0 & 1160 & 1026 & & & \\
\hline 10 & 76.0 & 1140 & 1023 & & & \\
\hline 11 & 76.0 & 1160 & 1023 & 12.72 & 0.712 & 2.74 \\
\hline 12 & 76.0 & 970 & 1026 & & & \\
\hline 13 & 76.0 & 1115 & 1024 & & & \\
\hline 14 & 76.0 & 1360 & 1023 & & & \\
\hline 15 & 76.0 & 1040 & 1026 & & & \\
\hline 16 & 76.0 & 1020 & 1023 & & & \\
\hline 17 & 76.0 & 1380 & 1021 & & & \\
\hline 18 & 76.0 & 880 & 1029 & 12.36 & 0.755 & $\cdots$ \\
\hline 19 & 76.0 & 945 & 1030 & & & \\
\hline 20 & 76.0 & 1940 & 1017 & & & \\
\hline 21 & 76.0 & 2670 & 1016 & & & \\
\hline 22 & 76.0 & 1590 & 1023 & 13.03 & 0.967 & 2.56 \\
\hline 23 & 76.0 & 1870 & $\cdots$ & & 0.000 & \\
\hline
\end{tabular}


STAPLETON.

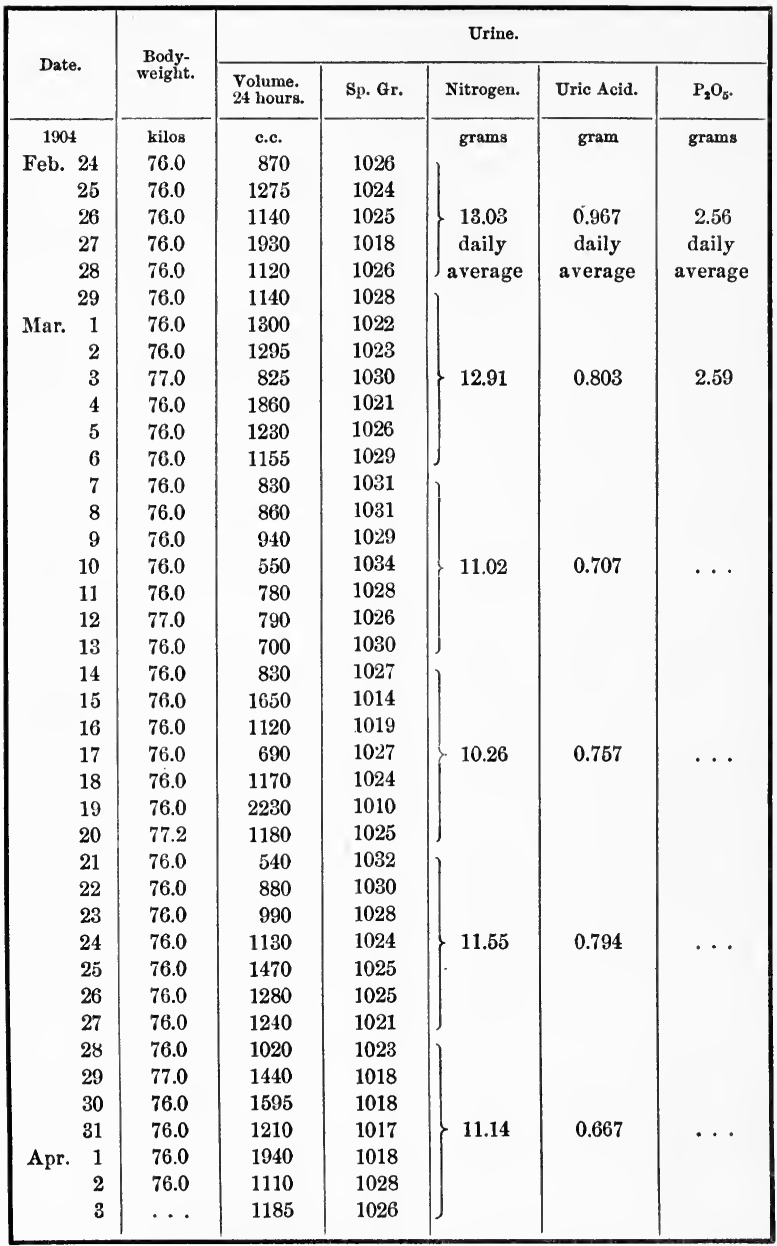


STAPLETON.

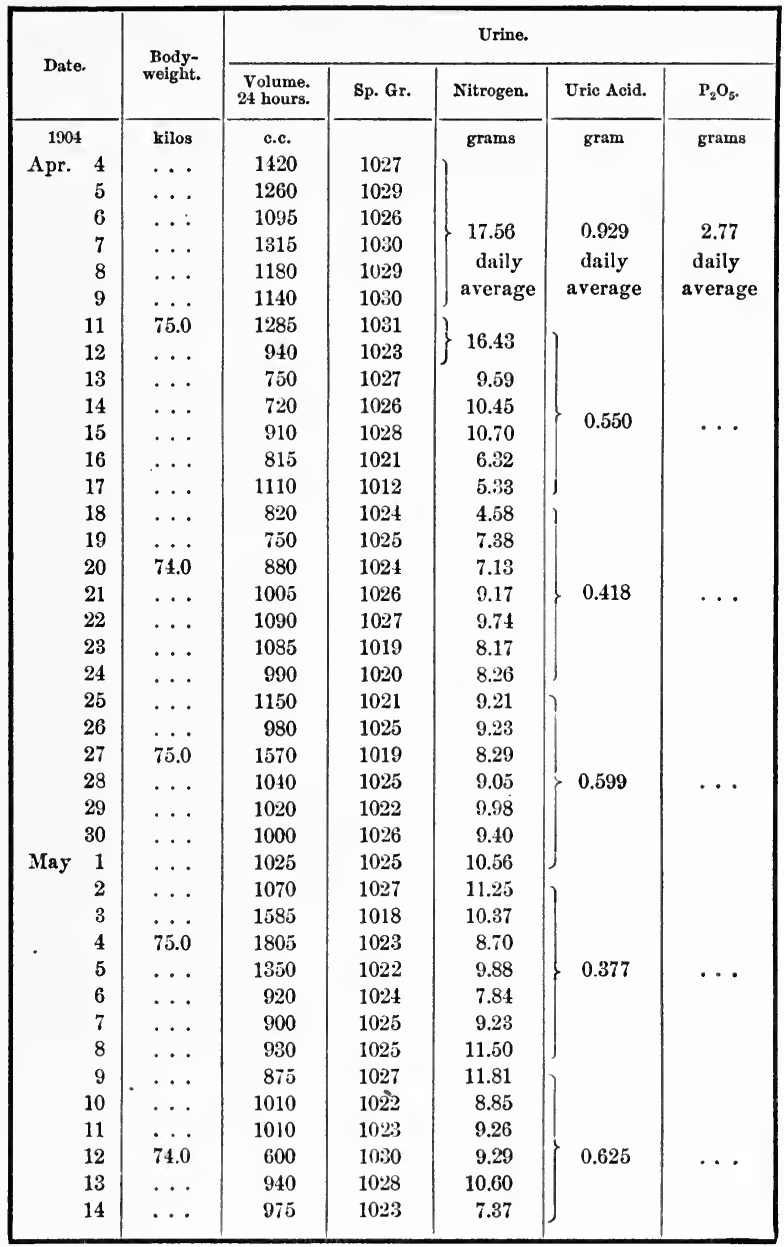


PHYSIOLOGICAL ECONOMY IN NUTRITION 363

STAPLETON.

\begin{tabular}{|c|c|c|c|c|c|c|c|}
\hline \multirow{2}{*}{\multicolumn{2}{|c|}{ Date. }} & \multirow{2}{*}{$\begin{array}{c}\text { Body- } \\
\text { weight. }\end{array}$} & \multicolumn{5}{|c|}{ Urine. } \\
\hline & & & $\begin{array}{l}\text { Volume. } \\
24 \text { hours. }\end{array}$ & Sp. Gr. & Nitrogen. & Uric Acid. & $\mathrm{P}_{2} \mathrm{O}_{5}$ \\
\hline & kilos & c.c. & & grams & gram & grams \\
\hline \multicolumn{2}{|c|}{ May 15} & $\ldots$ & 800 & 1025 & 6.63 & 0.625 & $\ldots$ \\
\hline \multicolumn{2}{|c|}{16} & $\ldots$ & 1200 & 1019 & 8.14 & $\ldots$ & $\ldots$ \\
\hline & 17 & $\ldots$ & 515 & 1030 & 6.58 & $\ldots$ & $\ldots$ \\
\hline & 18 & $\ldots$ & 790 & 1029 & 9.67 & & \\
\hline & 19 & 74.1 & 745 & 1029 & 8.58 & & \\
\hline & 20 & 74.1 & 880 & 1022 & 9.51 & & \\
\hline & 21 & 74.1 & 1100 & 1027 & 9.64 & 0.691 & $\cdots$ \\
\hline & 22 & $\ldots$ & 890 & 1028 & 9.56 & daily & \\
\hline & 23 & $\cdots$ & 690 & 1020 & 8.03 & verage & \\
\hline & 24 & 76.0 & 905 & 1025 & 9.04 & & \\
\hline & 25 & $\cdots$ & 665 & 1031 & 8.46 & & \\
\hline & 26 & 74.5 & 630 & 1026 & 7.45 & & \\
\hline & 27 & $\ldots$ & 950 & 1024 & 8.83 & 0.663 & 2.27 \\
\hline & 28 & 73.0 & 850 & 1027 & 10.60 & 1 & daily av. \\
\hline & 30 & $\cdots$ & 1060 & 1020 & 10.88 & $\cdots$ & $\ldots$ \\
\hline & 31 & $\ldots$ & 1640 & 1015 & 8.56 & $\cdots$ & $\ldots$ \\
\hline June & 1 & $\ldots$ & 1230 & 1013 & 9.37 & $\ldots$ & $\ldots$ \\
\hline & 2 & $\ldots$ & 1180 & 1019 & 10.34 & $\ldots$ & $\cdots$ \\
\hline & 3 & $\ldots$ & 620 & 1024 & 6.96 & $\cdots$ & $\cdots$ \\
\hline & 4 & $\ldots$ & 910 & 1020 & 11.47 & $\ldots$ & $\cdots$ \\
\hline & 5 & . & 880 & 1019 & 11.09 & $\ldots$ & $\cdots$ \\
\hline & 6 & $\ldots$ & 855 & 1025 & 11.14 & $\ldots$ & $\cdots$ \\
\hline & 7 & $\cdots$ & 1250 & 1017 & 8.78 & $\cdots$ & $\cdots$ \\
\hline & 8 & $\cdots$ & 885 & 1025 & 11.10 & $\cdots$ & $\cdots$ \\
\hline & 9 & 74.0 & 730 & 1020 & 6.35 & $\ldots$ & $\cdots$ \\
\hline & 10 & $\ldots$ & 1540 & 1017 & 8.87 & $\cdots$ & $\cdots$ \\
\hline & 11 & $\ldots$ & 750 & 1015 & 5.85 & $\cdots$ & $\cdots$ \\
\hline & 12 & 73.4 & 1265 & 1015 & 9.71 & $\cdots$ & $\cdots$ \\
\hline Daily a & ave & ge from & & & & & \\
\hline Jan. & & & 1094 & 1024 & $\cdots$ & 0.699 & 2.64 \\
\hline Daily a & aver & ge from & & & & & \\
\hline Jan. 2 & $25 \mathrm{tc}$ & April 12 & $\cdots$ & $\cdots$ & 13.12 & $\cdots$ & $\cdots$ \\
\hline Daily & aver & ge from & & & & & \\
\hline April & 13 & June 12 & $\cdots$ & $\cdots$ & 9.00 & $\cdots$ & $\cdots$ \\
\hline
\end{tabular}


It is plain from the foregoing results, that all the men of this group, like the members of the professional group, experienced no difficulty in reducing in large measure their rate of proteid metabolism. The intake of proteid food was steadily diminished, with a corresponding diminution in the extent of nitrogen metabolism. Take as an illustration the average daily output of nitrogen from April 13 to June 15, a period of sixty-three consecutive days:

AVERAGE DAILY EXCRETION OF METABOLIZED NITROGEN

FOR THE LAST TWO MONTHS OF THE EXPERIMENT.

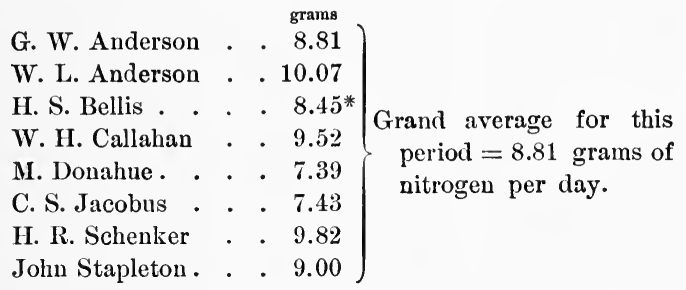

An excretion of 8.81 grams of nitrogen through the kidneys corresponds to the metabolism of 55 grams of proteid matter. Compare this average amount of proteid matter metabolized each day with the figures obtained during the preliminary period of ten days, when the men were living on their ordinary diet. Then, many of the men were excreting nitrogen at the rate of 17 to 22 grams per day. In a general way, we may safely say that all these men during the last two months of the experiment were living on about one-half the proteid food they were formerly accustomed to take.

Further, the average daily excretion of nitrogen for the preceding seventy-three days, $i$. e., from February 1 to April 13, was in most instances nearly, if not quite, as low as during the last two months of the experiment, so that we are certainly justified in the statement that these men - trained

* This average covers the period from April 13 to May 24 only, as Mr. Bellis was compelled to withdraw from the experiment on the latter date, owing to an accident in the gymnasium. 
athletes, doing athletic work more or less strenuous - were able to practise during this long period marked physiological economy in the use of proteid food, equal approximately at least to a saving of full fifty per cent in proteid matter.

The individual tables must be carefully studied, however, in order to trace out the changes in detail in the rate of nitrogen metabolism, and in so doing much information will be obtained regarding modification in the excretion of uric acid, a matter to be discussed in another connection, later on. Further, it is interesting to note in the tables the changes in bodyweight of the men. Some of the men, like Dr. Callahan, who were abundantly supplied with adipose tissue, lost very considerably in body-weight, but eventually came to a standstill, with establishment of body equilibrium, under the changed dietary habits. Some of the men reached this condition of equilibrium much more quickly than others. Dr. Callahan who suffered a large loss in body-weight - to his great gain, as he expressed it - dropped from 92.2 kilos to 83 kilos in two months, but from March 22 to June 15 his bodyweight, while naturally showing fluctuation, did not fall again permanently.

What now was the amount of metabolized nitrogen per kilo of body-weight in these men toward the close of the experiment? Taking the average daily nitrogen excretion for the period from April 13 to June 15, and the bodyweights of the men at this same period, as indicated in the accompanying table, we have the following figures:

\begin{tabular}{|c|c|c|c|c|c|c|}
\hline & & & & $\begin{array}{c}\text { Body- } \\
\text { weight. } \\
\text { kilos }\end{array}$ & $\begin{array}{c}\text { Average daily } \\
\text { Nitrogen } \\
\text { excreted. } \\
\text { grams }\end{array}$ & $\begin{array}{l}\text { Metabolized Nitro- } \\
\text { gen per kilo of } \\
\text { body-weight. } \\
\text { gram }\end{array}$ \\
\hline Bellis . & . & . & . & . 78 & 8.45 & 0.108 \\
\hline Callahan . & . . & - & . & . 83 & 9.52 & 0.114 \\
\hline Donahue. & . & . & . & 62 & 7.39 & 0.119 \\
\hline Stapleton & & . & . & 75 & 9.00 & 0.120 \\
\hline Anderson, G & G. W & & . & 71 & 8.81 & 0.124 \\
\hline Jacobus . & . . & . & . & 56 & 7.43 & 0.132 \\
\hline Schenker. & . & . & . & 73 & 9.82 & 0.134 \\
\hline Anderson, & W. L & & . & 61 & 10.07 & 0.165 \\
\hline
\end{tabular}


These figures, with one exception, show as low a proteid metabolism per kilo of body-weight as was obtained with the soldiers on a prescribed diet, yet these men were athletes accustomed to vigorous muscular exercise, and likewise accustomed to the eating of relatively large amounts of proteid food. Theoretically, it might not be expected that these men would drop to as low a level as men who were not addicted to the consumption of excessive amounts of proteid foods, yet for two months, and practically for a period of four months, these University students easily maintained themselves at this lower level of nitrogen metabolism.

From April 26 to June 13, at the request of the students themselves, the daily diet was prescribed; not, however, as regards the quantity of food to be eaten, but merely as to its character. The men ate at the University Dining Hall, and it was a simple matter to have their table supplied with a special dietary. The following dietary was therefore prepared for their use.

It is not to be understood that the men took all that the daily list provided, but they made their selections from the menu, and in quantity took what they deemed necessary, or what satisfied their appetites. It may be added that the men were all well content with the variety provided and expressed themselves, many times, as better pleased with a simple dietary of this kind than with the heavier proteid foods of earlier days. It should be added that Dr. Callahan was compelled to be absent from New Haven during a large portion of the period covered by this dietary, hence his nitrogen excretions do not correspond in quantity with the nitrogen of the above rations.

\section{Tuesday, April 26, 1904.}

Breakfast. - Banana, boiled hominy with sugar and cream, coffee, rolls, butter.

Lunch. - Spaghettr, stewed tomatoes, potatoes, boiled onions, bread, butter, coffee, fried hominy with syrup.

Dinner. - Split-pea soup, fried bacon with French fried potato, spinach, bread, butter, stewed prunes, lettuce-celery-apple salad, cream puffs, coffee. 


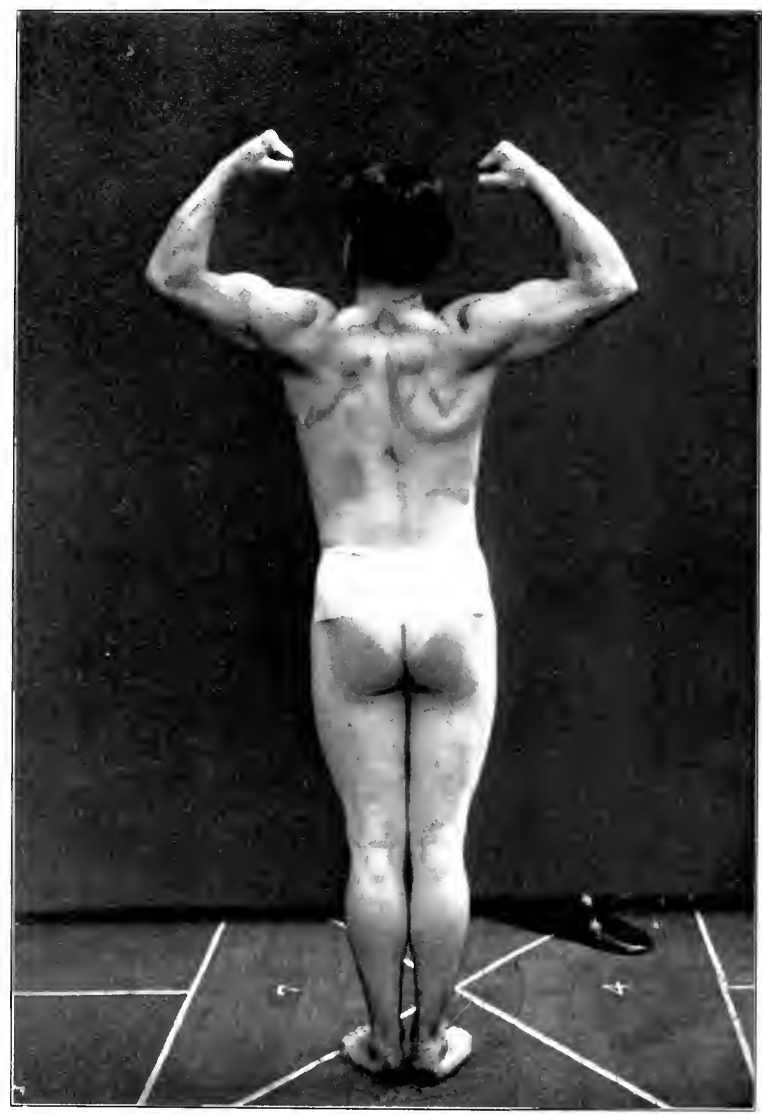

STAPLETON

Photoyraph taken in the middle of the experiment, in April. 



\section{Wednesday, April 2\%, 1904.}

Breakfast. - Fruit, farina with cream, coffee, rolls, butter, baked potato.

Lunch. - Fried oysters, mashed potato, bread, butter, coffee, string beans, sliced banana with cream.

Dinner. - Cream of celery soup, codfish-cakes, boiled potato, boiled lima beans lettuce-orange salad, ice cream, coffee.

\section{Thursday, April 28, 1904.}

Breakfast. - Banana, coffee, rolls, cream, butter, fried hominy and syrup.

Lunch. - Fried sweet potato, cold tongue, baked potato, bread, butter, coffee, baked apple witl cream.

Dinner. - Vegetable soup, Hamburg steak made with plenty of bread, etc., Lyonnaise potato, baked potato, spinach, pie, coffee.

\section{Friday, April 29, 1904.}

Breakfast. - Fruit, Indian meal, boiled, with sugar and cream, baked potato, rolls, coffee.

Lunch. - Clam chowder with crackers, farina croquettes, stewed tomato, griddle cakes with syrup, coffee, bread, butter.

Dinner. - Soup, fish, mashed potato, radishes, string beans, cranberry sauce, bread, butter, lettuce salad, lemon pie, coffee.

\section{Saturday, April 30, 1904.}

Breakfast. - Banana, fried Indian-meal, syrup, baked potato, coffee, rolls.

Lunch. - Tomato purée, baked macaroni, baked potato, sliced ham, baked apple and cream, bread, butter, coffee.

Dinner. - Soup, small sausage fried, mashed potato, boiled sweet potato, spinach, stewed tomato, strawberry short cake, coffee.

\section{Sunday, May 1, 1904 .}

Breakfast. - Fruit, boiled rice, sugar, cream, coffee, rolls, butter.

Dinner. - Vegetable soup, stewed chicken, cranberry sauce, boiled potato, boiled onion, stewed corn, water jce, coffee, bread, butter.

Supper. - French fried potato, bacon, Waldorf-salad, bread, butter, pie.

$$
\text { Monday, May 2, } 1904 .
$$

Breakfast. - Banana, malto-rice, cream, coffee, rolls.

Lunch. - Baked beans, catsup, baked potato, stewed prunes, apple pudding.

Dinner. - Barley soup, string beans, boiled onion, mashed potato, fried bacon, cranberry sauce, bread, butter, sliced banana, cream, coffee. 


\section{Tuesday, May 3, 1904.}

Breakfast. - Fruit, boiled Indian-meal, sugar, cream, baked potato, butter, rolls, coffee

Lunch. - Baked macaroni, French fried potato, boiled spinach, stewed prunes, coffee, bread, butter, fried rice with syrup.

Dinner. - Split-pea soup, fried sausage with Lyonnaise potato, boiled sweet potato, butter, lettuce-orange salad, baked apple with cream, coffee.

\section{Wednesday May 4, 1904.}

Breakfast. - Banana, farina with sugar and cream, baked potato, coffee, rolls, butter.

Lunch. - One egg on toast, string beans, boiled potato, bread, butter, coffee, pie. Dinner. - Tomato purée, codfish-cakes, baked potato, boiled lima beans, lettuceapple salad, bread, butter, cream puffs, coffee.

\section{Thursday, May 5, 1904.}

Breakfast. - Fruit, boiled hominy, sugar, cream, coffee, rolls, butter.

Lunch. - Cold ham, fried sweet potato, baked potato, cream, butter, coffee, cabinet pudding, vanilla sauce.

Dinner. - Scotch broth, one lamb chop, mashed potato, fried sweet potato, spinach, bread and butter, baked apple and cream, coffee.

$$
\text { Friday, May 6, 1904. }
$$

Breakfast. - One apple, fried hominy with syrup, baked potato, rolls, butter, coffee.

Lunch. - Clam chowder with crackers, potato croquettes, sliced tomatoes, bread, butter, griddle cakes and syrup, coffee.

Dinner. - Bean soup aux croutons, boiled halibut, mashed potato, boiled onions with creain, radishes, cranberry sauce, lettuce salad, bread, butter, coffee, one orange.

\section{Saturday, May 7, 1904.}

Breakfast. - Banana, boiled rice, sugar, cream, baked potato, coffee, rolls, butter.

Lunch. - Consommé, spaghetti à l'italienne, boiled sweet potato, bread, butter, cakes, preserves, coffee.

Dinner. - Split-pea soup, roast beef, mashed potato, boiled spinach, boiled sweet potato, breal and butter, strawberries and cream, coffee. 


\section{Sunday, May 8, 1904.}

Breakfast. - Banana, fried rice, syrup, coffee, corn bread and butter, baked potato.

Dinner. - Vegetable soup, stewed chicken, cranberry sauce, string beans, boiled or mashed potato, water ice, bread and butter, cakes, coffee.

Supper. - French fried potato, bacon, lettuce-orange salad, bread and butter, cake, preserves, and coffee.

$$
\text { Monday, May 9, 1904. }
$$

Breakfast. - Fruit, boiled Intlian-meal, sugar and cream, coffee, rolls, butter.

Iunch. - Calf's liver, baked potato, stewed prunes, boiled onion, bread and butter, coffee, apple pudding.

Dinner. - Consommé, baked macaroni, fried sweet potato, stewed tomato, preserves, lettuce, bread, butter, cakes, coffee.

$$
\text { Tuesday, May 10, } 1904 .
$$

Breakfast. - Fruit, farina, milk, sugar, baked potato, rcoffee, bread, butter.

Lunch. - Egg omelette witl jelly, fried bacon, mashed potato, spinach, apple pudding, bread, butter, coffee.

Dinner. - Small fried sausage, boiled potato, rice custard, lettuce-orange salad, bread, butter, coffee, baked apples with cream.

$$
\text { Wednesday, May 11, 190\%. }
$$

Breakfast. - Banana and cream, fried honiny, syrup, baked potato, coffee, bread, butter.

Lunch. - Cream of tomato soup, mashed potato, lima beans, bread, butter, prune soufflé, coffee.

Dinner. - Hamburg steak made with much bread, boiled sweet potato, boiled onions, lettuce, lemon pie, bread, butter, coffee.

$$
\text { Thursday, May 12, 1904. }
$$

Breakfast. - Fruit, baked potato, boiled Indian-meal, sugar, cream, coffee, rolls, butter.

Lunch. - Consommé, French fried potato, one egg on toast, rice pudding, apple sauce, coffee, bread, butter.

Dinner. - One chop, boiled or maslied potato, string beans, apple-lettuce salad, lemon pie, bread, butter, coffee.

$$
\text { Friday, May 13, } 1904 .
$$

Breakfast. - Banana and cream, fried rice with syrup, rolls, butter, coffee.

Lunch. - Clam chowder, boiled potato, boiled onions, fried bacon, carrots, apple diumpling, bread, butter, coffee.

Dinner. - Split-pea soup (thick), frizzled beef, fried sweet potato, spinach, cranberry tart, bread, butter, coffee, cakes. 


\section{Saturday, May 14, 1904.}

Breakfast. - Baked apple and cream, boiled hominy, with sugar and cream, baked potato, coffee, rolls, butter.

Lunch. - Cream of celery soup, farina croquettes, with tomato sauce, stewed corn, mashed potato, bread, butter, coffee, fruit.

Dinner. - Fish, boiled potato, boiled onions, bread pudding, preserves, lettuce. tomato salad, small cakes, bread, butter, coffee.

\section{Sunday, May 15, 1904.}

Breakfast. - Fruit, baked potato, boiled oatmeal with sugar and cream, coffee, rolls, butter.

Lunch. - Consommé with croutons, fried rice with syrup, French fried potato, strawberry short-cake with whipped cream, bread, coffee.

Dinner. - Stewed chicken, fried sweet potato, cranberry sauce, celery, string beans, bread, butter, coffee, ice cream, cakes.

\section{Monday, May 16, 1904.}

Breakfast. - Banana, griddle cakes and syrup, baked potato, coffee, rolls, butter.

Lunch. - Fried bacon, maslied potato, spinach, bread, butter, rice croquettes with preserves, apple pie, coffee.

Dinner. - Consommé, one lamb chop, mashed potato, string beans, boiled onions, orange-lettuce salad, bread, butter, tapioca pudding, coffee.

\section{Tuesday, May 17, 1904.}

Breakfast. - Banana, farina, cream, sugar, baked potato, rolls, butter, coffee. Lunch. - Vegetable soup, French fried potato, one egg on toast, rice pudding, apple sauce, bread, butter, coffee.

Dinner. - Small fried sausage, boiled potato, lima beans, lettuce salad, bread, butter, baked apples with cream, rice custard, coffee.

\section{Wednesday, May 18, 1904.}

Breakfast. - Sliced banana, fried rice, syrup, baked potato, bread, butter, coffee.

Lunch. - Cream of celery soup, farina croquettes, tomato sauce, fried sweet potato, string beans, bread, butter, prune soufflé, coffee.

Dinner. - Split-pea soup, Hamburg steak made with much bread, mashed potato, spinach, bread, butter, lemon pie, coffee. 


\section{Thursday, May 19, 1904.}

Breakfast. - Sliced banana, boiled hominy, cream, sugar, baked potato, bread, butter, coffee.

unch. - Egg omelette, jelly, French fried potato, boiled onions, fried hominy, syrup, bread, butter, apple pudding, coffee.

Dinner. - Tomato purée, baked macaroni, fried bacon, fried sweet potato, spinach, bread, butter, Indian-meal pudding, coffee.

\section{Friday, May 20, 1904.}

Breakfast. - Sliced orange, fried hominy, syrup, baked potato, bread, butter, coffee.

Lunch. - Fish cakes, boiled sweet potato, mashed potato, lima beans (boiled), bread, butter, bread pudding, coffee.

Dinner. - Consommé, boiled halibut, mashed potato, string beans, bread, butter, rice croquettes, cranberry jam, coffee.

\section{Saturday, May 21, 1904.}

Breakfast. - Sliced banana, cream, sugar, boiled Indian-meal, baked potato, bread, butter, coffee.

Lunch. - One lamb chop, potato croquettes, fried Indian-meal, syrup, stewed tomatoes, bread, butter, coffee, water ice.

Dinner. - Bean purée, scrambled egg, bacon, French fried potato, lettuceorange salad, farina pudding, prunes, bread, butter, coffee.

\section{Sunday, May 2\%, 1904.}

Breakfast. - Sliced orange, sugar, boiled oatmeal, cream, baked potato, bread, butter, coffee.

Luncl. - Boiled macaroni, fried rice, syrup, mashed potato, boiled onions, bread, butter, ice cream, cake, coffee.

Dinner. - Cream of celery soup, stewed chicken, French fried potato, mashed potato, spinach, bread, butter, cranberry sauce, strawberry short-cake, cream, coffee.

\section{Monday, May 23, 1904.}

Breakfast. - Sliced banana, griddle cakes, syrup, baked potato, bread, butter, coffee.

Lunch. - One egg on toast, consommé, French fried potato, lettuce, rice croquettes, syrup, apple sauce, bread, butter, coffee.

Dinner. - Vegetable soup, baked macaroni, fried bacon, potato croquettes, string beans, bread, butter, water ice, coffee. 


\section{Tuesday, May 24, 1904.}

Breakfast. - Banana, boiled rice, cream, sugar, baked potato, bread, butter, coffee.

Lunch. - Cream of celery soup, farina croquettes, tomato sauce, boiled onions, mashed potato, bread, butter, stewed prunes, coffee.

Dinner. - Tomato purée, Hamburg steak made with much bread, French fried potato, spinach, farina croquettes, bread, butter, lemon pie, coffee.

\section{Wednesday, May 25, 1904.}

Breakfast. - Banana, boiled hominy, cream, sugar, baked potato, bread, butter, coffee.

Lunch. - Small fried sausage, boiled potato, lettuce salad, fried hominy, syrup, bread, butter, apple sauce, coffee.

Dinner.-Consommé, scrambled eggs, French fried potato, lettuce-orange salad, lima beans, bread, butter, bread pudding, coffee.

\section{Thursday, May 26, 1904.}

Breakfast. - Banana, boiled oatmeal, sugar, cream, baked potato, rolls, butter, coffee.

Lunch. - One egg on toast, spinach, maslied potato, apple sauce, bread, butter, rice pudding, coffee.

Dinner. - Tomato purée, boiled macaroni, boiled onions, French fried potato, lettuce, bread, butter, tapioca pudding, coffee.

$$
\text { Friday, May 2\%, } 1904 \text {. }
$$

Breakfast. - Orange, boiled Indian-meal, sugar, cream, rolls, coffee.

Lunch. - Clam chowder, potato croquettes, lima beans, bread, butter, strawberries, cream, coffee.

Dinner. - Bean soup, boiled halibut, mashed potato, string beans, rice croquettes, cranberry jam, bread, butter, water ice, coffee.

\section{Saturday, May 28, 1904.}

Breakfast. - Banana, breakfast flakes, sugar, cream, baked potato, rolls, butter, coffee.

Lunch. - One boiled egg, French fried potato, stewed tomatoes, fried Indianmeal, syrup, bread, butter, coffee.

Dinner. - Split-pea soup, baked beans, Boston brown bread, lettuce-orange salad, stewed prunes, bread, butter, ice cream, coffee. 


\section{Sunday, May 29, 1904.}

Breakfast. - Orange, boiled oatmeal, sugar, cream, baked potato, rolls, butter, coffee.

Luncl. - Boiled spaghetti, mashed potato, boiled onions, fried rice, syrup, bread, butter, strawberries, cake, coffee.

Dinner. - Cream of celery soup, stewed chicken, boiled potato, spinach, bread, butter, cranberry sauce, custard pie, coffee.

\section{Monday, May 30, 1904.}

Breakfast. - Banana, boiled rice, sugar, cream, baked potato, rolls, butter, coffee.

Lunch. - Consommé, French fried potato, bacon, lettuce-orange salad, wheat griddle cakes, syrup, bread, butter, coffee.

Dinner. - Barley broth, one lamb cliop, mashed potato, fried sweet potato, apple sauce, bread, butter, bread pudding, coffee.

\section{Tuesday, June 7, 1904.}

Breakfast. - Banana, boiled rice, cream, sugar, baked potato, rolls, butter, coffee.

Lunch. - Vegetable soup, French fried potato, one egg on toast, apple sauce, rice pudding, bread, butter, tea.

Dinner.- One small fried sausage, boiled potato, lima beans, lettuce-orange salad, bread, butter, ice cream, cake, coffee.

\section{Wednesday, June 8, 1904.}

Breakfast. - Banana, breakfast flakes, sugar, cream, baked potato, rolls, butter, coffee.

Lunch. - Cream of celery soup, potato croquettes, string beans, two slices bacon, bread, butter, bread pudding, coffee.

Dinner.-Split-pea soup, boiled halibut, mashed potato, asparagus, bread, butter, cream pie, coffee.

\section{Thursday, June 9, 1904.}

Breakfast. - Orange, boiled hominy, cream, sugar, baked potato, rolls, butter, coffee.

Lunch. - Egg omelette, jelly, French fried potato, boiled onions, bread, butter, wheat griddle cakes, syrup, coffee.

Dinner. - Tomato purée, baked macaroni, dried beef stewed with milk, boiled potato, spinach, bread, butter, Indian-meal pudding, coffee. 


\section{PHYSIOLOGICAL ECONOMY IN NUTRITION}

$$
\text { Friday, June 10, } 1904 .
$$

Breakfast. - Banana, fried hominy, syrup, rolls, butter, coffee.

Lunch. - Clam chowder, mashed potato, boiled lima beans, bread, butter, tapioca pudding, coffee.

Dinner. - Consommé, bluefish (broiled), Lyonnaise potato, asparagus, bread, butter, cranberry jam, lemon pie, coffee.

\section{Saturday, June 11, 1904.}

Breakfast. - Orange, boiled Indian-meal, cream, sugar, baked potato, rolls, butter, coffee.

Lunch. - Barley broth, corn fritters, mashed potato, two slices bacon, bread, butter, stewed tomatoes, strawberries, cream, coffee.

Dinner. - Bean pureé, scrambled egg, rice croquettes, French fried potato, lettuce-orange salad, stewed prunes, bread, butter, farina pudding, coffee.

$$
\text { Sunday, June 12, } 1904 .
$$

Breakfast. - Banana, boiled oatmeal, sugar, cream, baked potato, rolls, butter, coffee.

Lunch. - Boiled macaroni, string beans, mashed potato, farina croquettes, water ice, cake, coffee.

Dinner. - Cream of celery soup, stewed chicken, French fried potato, lettuce salad, bread, butter, strawberry short-cake, cream, coffee.

\section{Monday, June 13, 1904.}

Breakfast. - Orange, breakfast flakes, sugar, cream, baked potato, rolls, butter, coffee.

Lunch. - Vegetable soup, one egg on toast, fried potatoes, apple sauce, rice croquettes, bread, butter, cottage pudding, tea.

Dinner. - Clam broth, beef stew, with potatoes, carrots and onions, boiled potatoes, bread, butter, apple-lettuce salad, apple pie, cheese, coffee. 


\section{Nitrogen Balance.}

We may now consider whether these men, who had so greatly reduced the extent of their proteid metabolism, and who had apparently attained a condition of body equilibrium, were truly in nitrogenous equilibrium, or free from any daily loss of nitrogen. To test this point, a careful and exact comparison of the nitrogen intake and output was made for a perial of seven days, commencing on May 18. This was not easy to accomplish, as the men were still allowed freedom in the quantity of food eaten, and also in the choice of food, within the limits of the menu provided, so that a large number of food analyses had to be made. A greater difficulty, however, in obtaining proof of equilibrium lay in the laudable ambition of the men to make a good showing, - for they had all become interested in the main problem, and had acquired great faith in the efficiency of a low proteid ration, - which led them to great caution in the matter of eating during the balance trial, thereby running the risk of diminishing in too great degree the fuel value of the food.

The following data obtained with Donahue are self-explanatory. The figures showing the quantities of food at each meal are instructive, as indicating the general makeup of the daily dietary, both as to quality and quantity. 


\section{DONAHUE.}

Wednesday, May $18,1904$.

Breakfast. - Banana 141 grams, bread 60 grams, butter 15 grams, coffee 150 grams, cream 80 grams, sugar 31 grams.

Luncl. - Soup 247 grams, string beans 65 grams, bread 21 grams, butter 30 grams, coffee 150 grams, sugar 21 grams, fried potato 222 grams.

Dinner. - Consommé 150 grams, bread 45 grams, butter 10 grams, mashed potato 150 grams, spinach 200 grams, apple pie 103 grams, coffee 150 grams, cream 75 grams, sugar 28 grams.

Food. Gramg. Per cent Nitrogen. Total Nitrogen.

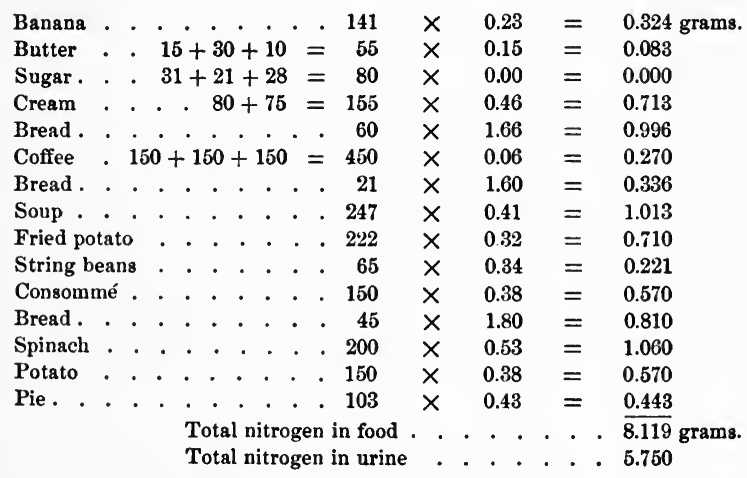

Fuel value of the food . . . 2676 calories. 


\section{DONAHUE.}

Thursday, May 19, 1904.

Breakfast. - Banana 98 grams, boiled hominy 150 grams, bread 60 grams, butter 10 grams, coffee 150 grams, cream 125 grams, sugar 45 grams.

Lunch. - Bread 61 grams, butter 19 grams, potato 100 grams, fried hominy 114 grams, syrup 48 grams, boiled onion 139 grams, coffee 150 granı, sugar 21 grams.

Dinner. - Tomato pureé 200 grams, bread 40 grams, fried sweet potato 77 grams, macaroni 100 grams, spinach 100 grams, bacon 21 grams, bread pudding 100 grams, cream 50 grams, sugar 7 grams.

Food. Grams. Per cent Nitrogen. Total Nitrogen.

\begin{tabular}{|c|c|c|c|c|c|c|c|c|c|c|c|c|}
\hline Banana & . & & & . & . & . & . & 98 & $\times$ & 0.23 & $=$ & 0.225 grams. \\
\hline Bread. & . & . & & . & . & & . & 60 & $x$ & 1.54 & $=$ & 0.924 \\
\hline Butter & . & . & . & 10 & +19 & & $=$ & 29 & $x$ & 0.15 & $=$ & 0.044 \\
\hline Sugar. & . & . & 45 & +21 & $1+7$ & & $=$ & 73 & $x$ & 0.00 & $=$ & 0.000 \\
\hline Coffee & . & . & & $50+$ & +150 & & $=$ & 300 & $x$ & 0.06 & $=$ & 0.180 \\
\hline Cream & . & . & . & 125 & +50 & & $=$ & 175 & $x$ & 0.47 & $=$ & 0.823 \\
\hline Hominy & . & . & . & . & . $\cdot$ & . & - & 150 & $x$ & 0.20 & $=$ & 0.300 \\
\hline Bread . & . & . & . & . & . & . & . & 61 & $x$ & 1.60 & $=$ & 0976 \\
\hline Potato & . & . & . & . & . & . & . & 100 & $x$ & 0.49 & $=$ & 0.490 \\
\hline Fried hon & $\min$ & $y$ & . & . & . & . & . & 114 & $\times$ & 0.67 & $=$ & 0.764 \\
\hline Syrup & . & . & . & . & . & . & . & 48 & $x$ & 0.024 & $=$ & 0.012 \\
\hline Onion . & . & . & . & . & . & . & . & 139 & $x$ & 0.27 & $=$ & 0.375 \\
\hline Bread. & . & . . & . & . & . & . & . & 40 & $x$ & 1.74 & $=$ & 0.696 \\
\hline Tomato $\mathrm{p}$ & pure & 'ée & . . & . & . & . & . & 200 & $x$ & 0.53 & $=$ & 1.060 \\
\hline Fried swe & eet & pot & tato & . & . & . & . & 77 & $x$ & 0.38 & $=$ & 0.293 \\
\hline Macaroni & & . & . & . & . & . & . & 100 & $\times$ & 0.93 & $=$ & 0.930 \\
\hline Spinach & . & . & . & . & . & 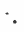 & . & 100 & $x$ & 0.56 & $=$ & 0.560 \\
\hline Bacon & . & . & . & . & . & . & . & 21 & $x$ & 3.00 & $=$ & 0.630 \\
\hline Pudding & . & • & - & . & . & . & . & 100 & $\times$ & 0.20 & $=$ & 0.200 \\
\hline & & & & $\begin{array}{l}\text { otal } \\
\text { otal }\end{array}$ & nitr & & gen & $\begin{array}{l}n \text { food } \\
\text { n urine }\end{array}$ & • & $\cdot \cdot \cdot \cdot$ & $\dot{.}$ & $\begin{array}{l}9.482 \text { grams. } \\
6.640\end{array}$ \\
\hline
\end{tabular}

Fuel value of the food . . . . 2753 calories. 


\section{DONAHUE.}

Friday, May 20, 1904.

Breakfast. - Orange 70 grams, baked potato 87 grams, roll 59 grams, butter 32 grams, sugar 7 grams.

Lunch. - Bread 67 grams, butter 15 grams, fish cake 88 grams, potato 150 grams, bread pudding 150 grams, cream 50 grams.

Dinner. - Consommé 150 grams, fish 70 grams, string beans 70 grams, potato 155 grams, cranberry sauce 102 grams, bread 32 grams, coffee 100 grams, sugar 14 grams.

Food.

Grams. Per cent Nitrogen. Total Nitrogen.

\begin{tabular}{|c|c|c|c|c|c|c|c|c|c|c|c|c|c|}
\hline Orange & . & . & . & - & . . & • & • & - & 70 & $x$ & 0.20 & $=$ & 0.140 grams. \\
\hline Butter & . & . & . & . & $32+$ & -15 & $=$ & $=$ & 47 & $x$ & 0.15 & $=$ & 0.071 \\
\hline Roll . & . & . & . & . & . . & . & . & - & 59 & $x$ & 1.72 & $=$ & 1.015 \\
\hline Sugar. & . & . & . & . & $.7+$ & -14 & 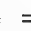 & $=$ & 21 & $x$ & 0.00 & $=$ & 0.000 \\
\hline Potato & . & . & . & . & . . & . & . & . & 87 & $x$ & 0.40 & $=$ & 0.348 \\
\hline Bread . & . & . & . & . & . & . & . & . & 67 & $x$ & 1.71 & $=$ & 1.146 \\
\hline Fish-cake & & . & . & . & . & . & . & • & 88 & $x$ & 1.22 & $=$ & 1.074 \\
\hline Potato & - & . . & - & . & . & . & . & . & 150 & $x$ & 0.30 & $=$ & 0.450 \\
\hline Bread pu & ddi & ing & & . & . & . & . & . & 150 & $x$ & 0.99 & $=$ & 1.485 \\
\hline Cream & . & . . & . & . & . & . & . & . & 50 & $x$ & 0.44 & $=$ & 0.220 \\
\hline Potato & . & . & . & . & . & . & . & . & 155 & $x$ & 0.34 & $=$ & 0.527 \\
\hline Consomm & & . & . & . & . & . & . & . & 150 & $x$ & 0.59 & $=$ & 0.885 \\
\hline Bread . & . & . & . & . & . & . & . & & 32 & $x$ & 1.97 & $=$ & 0.630 \\
\hline String be & & & . & . & . & . & . & & 70 & $x$ & 0.36 & $=$ & 0.252 \\
\hline Cranberr & ys & sauc & ce & . & . & . & - & • & 102 & $x$ & 0.03 & $=$ & 0.031 \\
\hline Fish . & . & . . & . & . & . & . & . & & 70 & $x$ & 3.18 & $=$ & 2.226 \\
\hline Coffee & • & . & . & . & .. & - & . & • & 100 & $x$ & 0.06 & $=$ & 0.060 \\
\hline
\end{tabular}

Fuel value of the food . . . . 1911 calories. 


\section{DONAHUE.}

Saturday, May 21, 1904.

Breakfast. - Banana 106 grams, boiled Indian-meal 150 grams, sugar 21 grams, cream 50 grams, bread 59 grams, butter 16 grams.

Lunch. - Bread 55 grams, butter 13 grams, lamb chop 37 grams, potato croquette 105 grams, tomato 216 grams, sugar 14 grams, water ice 143 grams.

Dinner. - Bean soup 100 grams, fried egg 22 grams, bacon 10 grams, lettuce salad 63 grams, fried potato 100 grams, coffee 100 grams, cream 50 grams, sugar 21 grams, stewed prunes 247 grams.

Food. Grams. Per cent Nitrogen. Total Nitrogen.

\begin{tabular}{|c|c|c|c|c|c|c|c|c|c|c|c|}
\hline Bread. & & & & ${ }^{\circ}$ & - & . . & 59 & $x$ & 1.65 & $=$ & 0.974 grams. \\
\hline Butter & & . & . & . & 16 & $+13=$ & 29 & $x$ & 0.15 & $=$ & 0.044 \\
\hline Banana & & . & . & . & . . & . . & . 106 & $x$ & 0.23 & $=$ & 0.244 \\
\hline Boiled Inc & dia & in- & nes & & . & . . & . 150 & $x$ & 0.17 & $=$ & 0.255 \\
\hline Sugar . & . & . & & 21 & +14 & $+21=$ & $=56$ & $x$ & 0.00 & $=$ & 0.000 \\
\hline Cream. & . & . & - & . & 50 & $+50=$ & 100 & $x$ & 0.43 & $=$ & 0.430 \\
\hline Bread . & . & . & . & . & . . & . . & 55 & $x$ & 1.82 & $=$ & 1.001 \\
\hline Potato cr & oqu & uet & te & . & . & . . & 105 & $x$ & 0.71 & $=$ & 0.746 \\
\hline Lamb cho & & . & . & - & . & ." & 37 & $x$ & 4.63 & $=$ & 1.713 \\
\hline Tomato. & . & . & . & . & .. & . & . 216 & $x$ & 0.17 & $=$ & 0.367 \\
\hline Water ice & & . & - & . & . & . & . 143 & $x$ & 0.012 & $=$ & 0.017 \\
\hline Prunes & . & . & . & . & . & . . & 247 & $x$ & 0.16 & $=$ & 0.395 \\
\hline Bean soup & & . & . & . & . & . . & 100 & $x$ & 1.21 & $=$ & 1.210 \\
\hline Fried pot & ato & & . & . & . & . . & 100 & $x$ & 0.60 & $=$ & 0.600 \\
\hline Egg . & . & . & . & . & . & . . & 22 & $x$ & 2.27 & $=$ & 0.499 \\
\hline Bacon & . & . & . & . & . & . . & 10 & $x$ & 3.05 & $=$ & 0.305 \\
\hline Salad . & . & . & . & . & . & . & 63 & $x$ & 0.21 & $=$ & 0.132 \\
\hline Coffee & . & - & . & . & . . & . & 100 & $x$ & 0.06 & $=$ & 0.060 \\
\hline
\end{tabular}

Fuel value of the food . . . 2294 calories. 


\section{DONAHUE.}

Sunday, May 22, 1904.

Breakfast. - Orange 60 grams, oatmeal 207 grams, roll 46 grams, butter 14 grams, coffee 150 grams, cream 150 grams, sugar 35 grams.

Lunch. - Potato 150 grams, boiled onions 145 grams, macaroni 130 grams, fried rice 138 grams, syrup 48 grams, ice cream 160 grams, cake 26 grams.

Dinner. - Celery soup 150 grams, spinach 100 grams, mashed potato 100 grams, bread 19 grams, coffee 100 grams, cream 50 grams, sugar 7 grams, strawberry short-cake 169 grams.

\begin{tabular}{|c|c|c|c|c|c|c|c|c|c|c|c|}
\hline Food. & & & & & & & Grams. & & Per cent Nitr & gen. & Total Nitrogen. \\
\hline Orange & - & • & - & - & . & - & . 60 & $x$ & 0.20 & $=$ & 0.120 grams \\
\hline Oatmeal & . & . & . & . & . & . & 207 & $x$ & 0.43 & $=$ & 0.890 \\
\hline Sugar . & . & . & . & 35 & + & $7=$ & 42 & $x$ & 0.00 & $=$ & 0.000 \\
\hline Cream. & . & . & . & 150 & +5 & $50=$ & 200 & $x$ & 0.45 & $=$ & 0.900 \\
\hline Roll . & . & . & . & . . & . & . . & 46 & $x$ & 1.67 & $=$ & 0.768 \\
\hline Coffee . & . & . & . & $.150+$ & +10 & $00=$ & 250 & $x$ & 0.06 & $=$ & 0.150 \\
\hline Butter. & . & . & . & . . . & . & . & 14 & $x$ & 0.15 & $=$ & 0.021 \\
\hline Potato & . & . & . & . & . & . & . 150 & $x$ & 0.30 & $=$ & 0.450 \\
\hline Onions & & . & . & . & . & . & . 145 & - $x$ & 0.25 & $=$ & 0.363 \\
\hline Macaroni & & . & . & . & . & . & . 130 & $x$ & 0.46 & $=$ & 0.598 \\
\hline Fried rice & & . & . & . & . & . & 138 & $x$ & 0.75 & $=$ & 1.035 \\
\hline Syrup . & . & . & . & . & . & . & 48 & $x$ & 0.024 & $=$ & 0.012 \\
\hline Ice cream & & . & . & . & . & . & 160 & $x$ & 0.53 & $=$ & 0.848 \\
\hline Cake . & & . & . & . & . & . & 26 & $x$ & 1.20 & $=$ & 0.312 ! \\
\hline Bread . & & & . & . & . & . & 19 & $x$ & 1.57 & $=$ & 0.298 \\
\hline Celery sor & & & . & . & . & - & 150 & $x$ & 0.33 & $=$ & 0.495 \\
\hline Spinach & & & . & . & . & . & . 100 & $x$ & 0.55 & $=$ & 0.550 \\
\hline Short-cak & & & . & . & . & . & . 169 & $x$ & 0.50 & $=$ & 0.845 \\
\hline Mashed p & otat & & & . . & . & . & 100 & $x$ & 0.37 & $=$ & 0.370 \\
\hline
\end{tabular}

Fuel value of the food . . . 2781 calories. 


\section{DONAHUE.}

\section{Monday, May 23, 1904.}

Breakfast. - Banana 201 grams, cream 100 grams, sugar 28 grams, griddle cakes 103 grams, syrup 48 grams.

Lunch. - Consommé 150 grams, rice croquette 140 grams, syrup 48 grams, fried potato 100 grams, bread 36 grams, butter 15 grams, apple sauce 90 grams, coffee 75 grams, sugar 7 grams.

Dinner. - Vegetable soup 100 grams, potato croquette 50 grams, string beans 120 grams, macaroni 104 grams, bacon 20 grams, bread 26 grams, water ice 184 grams.

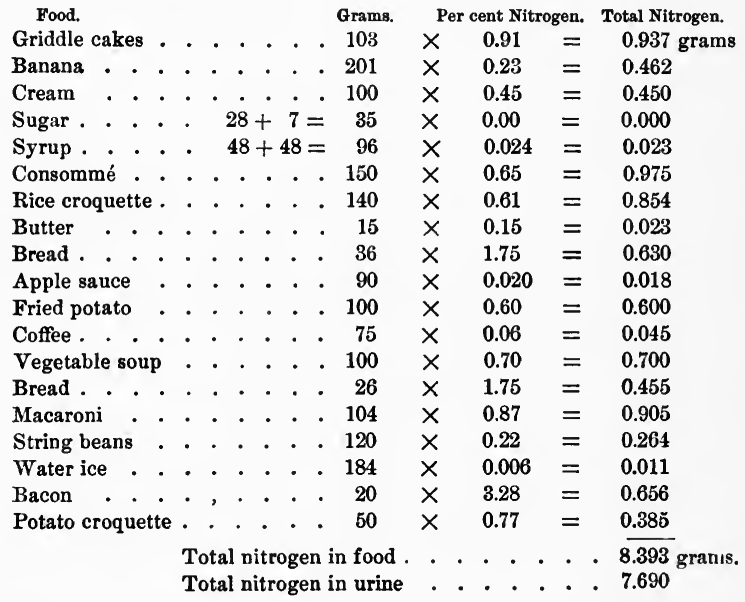

Fuel value of the food . . . . 2319 calories. 


\section{DONAHUE.}

Tuesday, May 24, 1904.

Breakfast. -Orange 80 grams, fried rice 186 grams, syrup 72 grams, coffee 100 grams, cream 50 grams, sugar 21 grams.

Lunch. - Celery soup 125 grams, bread 34 grams, butter 19 grams, boiled onion 127 grams, potato 150 grams, tomato sauce 50 grams, stewed prunes 189 grams, cream 50 grams.

Dinner. - Tomato soup 125 grams, bread 20.5 grams, fried potato 100 grams, spinach 130 grams, coffee 100 grams, cream 50 grams, sugar 14 grams, cream pie 158 grams.

Evening. - Ginger ale 250 grams.

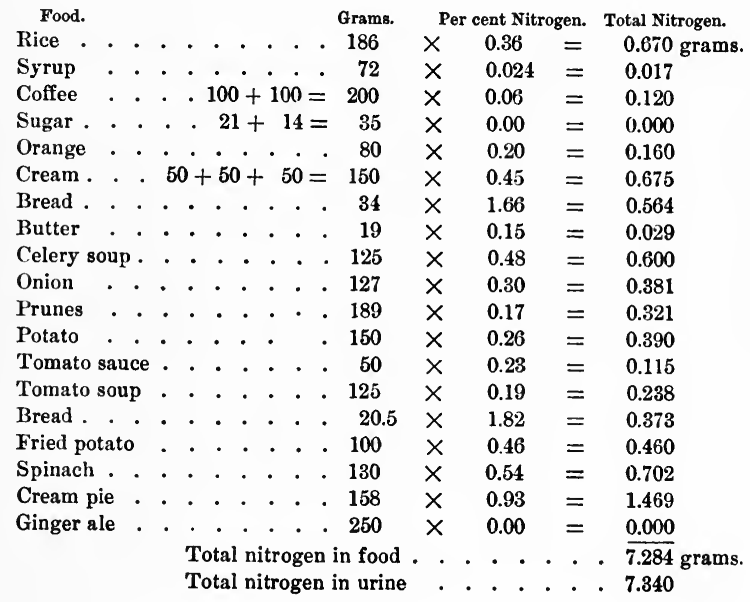

Fuel value of the food . . . 2422 calories. 


\section{NITROGEN BALANCE-Donahue.}

Nitrogen

Taken in

May 18

19

20

21

22

23

24
8.119 grams.

9.482

10.560

8.992

9.025

8.393

7.284

61.855
Output. Nitrogen in Urine. Weight of Fæces* (dry).

5.75 grams.

6.64

15 grams.

8.45

8.64

8.53

7.69

89

7.34

$\frac{24}{128}$ grams contain

$6.40 \% \mathrm{~N}$.

$53.04+8.192$ grams nitrogen.

61.855 grams nitrogen.

61.232 grams nitrogen.

Nitrogen balance for seven days $=\quad+0.623$ grams.

Nitrogen balance per day $\quad=\quad+0.089$ grams.

Average Intake.

Calories per day . . . . . . . 2450.

Nitrogen per day . . . . . . 8.83 grams.

* The fæces of the period were separated as customary by the ingestion of lampblack. 
Examination of these data shows that the total amount of nitrogen ingested for the seven days was 61.855 grams, while there were eliminated in the urine 53.04 grams and through the freces 8.192 grams of nitrogen, thus showing a plus balance for the period of 0.623 gram of nitrogen. In other words, with an average daily intake of 8.83 grams of nitrogen and with an average fuel value of the food amounting to only 2450 calories per day, the body was not only kept from loss, but was able to store up a little nitrogen for future needs. Surely, one could not ask for any better demonstration of physiological economy in nutrition than these data, for this seven days' period, afford.

Further, it should be mentioned, as confirmatory of the view that this subject had long been in a condition of nitrogenous equilibrium on about this quantity of food, that the average daily excretion of metabolized nitrogen during this seven days' period was 7.57 grams, while the average daily excretion from April 13 to June 15 was 7.39 grams of nitrogen. Finally, attention may be called to the fact that the ingestion of 8.83 grams of nitrogen corresponds to 55.18 grams of proteid food, while an excretion of 7.57 grams of nitrogen means the metabolism of 47.3 grams of proteid matter. A saving of more than fifty per eent in proteid food and proteid metabolism, with maintenance of body and nitrogen equilibrium with its possible physiological gains is not to be ignored.

With Jacobus, a similar trial for nitrogen balance gave the following results : 


\section{JACOBUS.}

Wednesday, May 18, 1904.

Breakfast. - Banana 73 grams, fried rice 100 grams, syrup 58 grams, bread is graus, butter 15 grams, coffee 150 grams, cresm 118 grams, sugar $\$ 5$ grams.

Lunch. - Tomsto soup 105 grams, sweet potato 61.3 grams, fsrìs cropuette 91 grams, syrup 49 grams, bread 35 grams, butter 23 graus, coffee 150 grams. cream 46 grams, sugar 91 grams.

Dinner. - Consomme 155 grams, Hamburg steak 67 grams, spinach 30 grams. potato 150 grams, bresd 97 grams, butter 8 grams, pie 110 grams, cream 61 grams, sugar 10 grams.

Fuod. Grams Per cent Nitrogen. Tutal Nitrugen.

\begin{tabular}{|c|c|c|c|c|c|c|c|c|c|c|}
\hline Butter & & - & - & $15+98$ & $3+8=$ & 46 & $x$ & 0.15 & $=$ & 0.069 grams \\
\hline แแนเกล & . & . & . & . . . & . . & 73 & $x$ & 0.23 & $=$ & 0.168 \\
\hline Fried ric & & . & - & . . & - & .100 & $x$ & 0.75 & $=$ & 0.730 \\
\hline IBread. & . & . & . &. & . . & - 43 & $x$ & 1.66 & $=$ & 0.797 \\
\hline Cream & . & . & 11 & $18+46$ & $+61=$ & 925 & $x$ & $0 \$ 6$ & $=$ & 1.055 \\
\hline Sugar. & . & . & & $35+21$ & $+10=$ & 66 & $x$ & 0.00 & $=$ & 0.000 \\
\hline Cottice & - & . & - & . $150+$ & $+150=$ & $=300$ & $x$ & 0.06 & $=$ & 0.180 \\
\hline Syrup. & . . & & & $58+$ & $+49=$ & 107 & $x$ & 0.024 & $=$ & 0.026 \\
\hline Tomito s & sou & & . & . . & . . . & 103 & $x$ & 0.41 & $=$ & 0.431 \\
\hline Bread & $\cdot$ & . & . & . & - & 35 & $x$ & 1.60 & $=$ & 0.560 \\
\hline Furims er & rod & guet & te & . & - & 91 & $x$ & 1.09 & $=$ & 0.901 \\
\hline Sweet po & otat & to & . & - & - & 61.5 & $x$ & 0.39 & $=$ & 0.197 \\
\hline Consomn & & . & . & . & . & 155 & $x$ & 0.38 & $=$ & 0.589 \\
\hline Potato & $\cdot$ & . & . & - . & . . & . 150 & $x$ & 0.58 & $=$ & 0.570 \\
\hline Ilsmburg & $g s t$ & teal & & . . & . & 67 & $x$ & 8.64 & $=$ & 2.439 \\
\hline Bresd & . & . & . & . . & . & 97 & $x$ & 1.80 & $=$ & 0.456 \\
\hline Spinach & . & . & . & . & . & - $\quad 30$ & $x$ & 0.53 & $=$ & 0.150 \\
\hline Pie. & - & . & - & $\cdot$. & $\cdot$ & 110 & $x$ & 0.43 & $=$ & 0.473 \\
\hline & & & & $\begin{array}{l}\text { Total n } \\
\text { Total ni }\end{array}$ & $\begin{array}{l}\text { aitrogen } \\
\text { itrogen }\end{array}$ & $\begin{array}{l}n \text { in food } \\
\text { in urine }\end{array}$ & . & $\begin{array}{l}\cdot \cdot \cdot \\
. \\
.\end{array}$ & $\cdot$. & $\begin{array}{l}9.9 \times 0 \\
6.750\end{array}$ \\
\hline
\end{tabular}

Fuel value of the food . . . 9846 calories. 


\section{JACOBUS.}

Thursday, May 19, 1904.

Breakfast. - Banana 105 grams, baked potato 79 grams, bread 40 grams, butter 15 grams, coffee 225 grams, cream 85 grams, sugar 24 grams.

Lunch. - Omelette (plain) 60 grams, fried hominy 68 grams, syrup 48 grams, potato 100 grams, boiled onion 81 grams, bread 45 grams, butter 14.5 grams, apple pudding 117 grams, sugar 10 grams, cream 40 grams.

Dinne. - Soup 100 grams, bacon 31 grams, baked macaroni 53 grams, fried sweet potato 55 grams, boiled Indian-meal 50 grams, bread 35 grams, butter 15 grams, coffee 155 grams, cream 96 grams, sugar 31 grams, chocolate $\mathbf{4 0}$ grams.

Food.

Grams. Per cent Nitrogen. Total Nitrogen.

\begin{tabular}{|c|c|c|c|c|c|c|c|c|c|c|}
\hline Banana & - & - & - & - & - & . 105 & $x$ & 0.23 & $=$ & 0.242 grams \\
\hline Bread & . & . & . & . . & . . & . 40 & $x$ & 1.54 & $=$ & 0.616 \\
\hline Cream & . & . & 85 & +40 & $+96=$ & 221 & $x$ & 0.47 & $=$ & 1.038 \\
\hline Coffee & . & . & $\cdot$ & $225+$ & $+155=$ & 380 & $x$ & 0.06 & $=$ & 0.228 \\
\hline Sugar. & . & & 10 & +24 & $+31=$ & 65 & $x$ & 0.00 & $=$ & 0.000 \\
\hline Potato & . & & $\cdot$ & . & . . & 79 & $x$ & 0.49 & $=$ & 0.387 \\
\hline Butter & . & & $5+$ & -14.5 & $+15=$ & 44.5 & $x$ & 0.15 & $=$ & 0.067 \\
\hline Bread & - & - & - & . . & . . . & 45 & $x$ & 1.60 & $=$ & 0.720 \\
\hline Onion . & & . & . & . & . . & 81 & $\times$ & 0.27 & $=$ & 0.219 \\
\hline Fried lor & $\min$ & $y$. & . & . . & . . & 68 & $x$ & 0.67 & $=$ & 0.456 \\
\hline Eggs (om & nele & tte) & . & . . & . . & 60 & $x$ & 1.58 & $=$ & 0.948 \\
\hline Potato & . & . . & . & . . & . . & . 100 & $x$ & 0.49 & $=$ & 0.490 \\
\hline Syrup & . & - . & . & . & . & 48 & $x$ & 0.024 & $=$ & 0.012 \\
\hline Apple pu & addi & & . & . . & . . & 117 & $x$ & 0.28 & $=$ & 0.328 \\
\hline Soup . & . & . . & . & . & . . & . 100 & $\times$ & 0.53 & $=$ & 0.530 \\
\hline Bread & . & . . & . & . & . . & 35 & $x$ & 1.74 & $=$ & 0.609 \\
\hline Fried sw & eet & pota & to & . & . . & 55 & $x$ & 0.38 & $=$ & 0.209 \\
\hline Bacon . & . & . . & • & . & . & 31 & $x$ & 3.00 & $=$ & 0.930 \\
\hline Baked $\mathrm{m}$ & aca & roni & i . & . & . & 53 & $x$ & 0.93 & $=$ & 0.493 \\
\hline Boiled In & ndia & & leal & . & . . & 50 & $x$ & 0.20 & $=$ & 0.100 \\
\hline Cliocolat & & . . & • & . & . . & 40 & $x$ & 0.73 & $=$ & 0.292 \\
\hline
\end{tabular}

Fuel value of the food . . . . 2831 calories. 


\section{JACOBUS.}

Friday, May 20, 1904.

Breakfast. - Orange 70 grams, fried hominy 67 grams, syrup 48 grams, baked potato 113 grams, bread 34 grams, butter 16 grams, coffee 75 grams, cream 33 grams, sugar 10 grams.

Lunch. - Fish-cake 88 grams, fried hominy 61 grams, syrup 32 grams, potato 100 grams, bread 45 grams, butter 22.5 grams, coffee 75 grams, cream 35 grams, sugar 10 grams, bread pudding 81 grams.

Dinner. - Consommé 75 grams, boiled fish 99 grams, potato 132 grams, rice croquette 83 grams, syrup 50 grams, bread 49 grams, butter 19 grams, coffee 150 grams, cream 48 grams, sugar 20 grams.

Evening. - Beer 375 grams.

Food.

Grams. Per cent Nitrogen. Total Nitrogen.

\begin{tabular}{|c|c|c|c|c|c|c|c|c|c|}
\hline Butter & . . & & $16+22.5+$ & $+19=$ & 57.5 & $\times$ & 0.15 & $=$ & 0.086 grams. \\
\hline Orange & . . & . & . . . . & . . . & 70 & $x$ & 0.20 & $=$ & 0.140 \\
\hline Coffec. & . & . & $75+75+$ & $-150=$ & 300 & $x$ & 0.06 & $=$ & 0.180 \\
\hline Cream & . & & $33+35+$ & $-48=$ & 116 & $x$ & 0.44 & $=$ & 0.510 \\
\hline Sugar. & . & & $10+10+$ & $-20=$ & 40 & $x$ & 0.00 & $=$ & 0.000 \\
\hline Potato & . . & . & . . . . & . . . & 113 & $x$ & 0.40 & $=$ & 0.452 \\
\hline Fried ho & $\min y$ & & . . . . & . . & 57 & $x$ & 0.74 & $=$ & 0.422 \\
\hline Bread . & . . & & . . . . & . . . & 34 & $x$ & 1.72 & $=$ & 0.585 \\
\hline Syrup & . & & $48+32+$ & $-50=$ & 130 & $x$ & 0.024 & $=$ & 0.031 \\
\hline Potato & . . & & . . . . & . . . & 100 & $x$ & 0.30 & $=$ & 0.300 \\
\hline Bread & . . & & . & - & 45 & $x$ & 1.71 & $=$ & 0.770 \\
\hline Fried hor & miny & & . . . & . . & 61 & $x$ & 0.57 & $=$ & 0.348 \\
\hline Fish-cak & & & - & - & 88 & $\times$ & 1.22 & $=$ & 1.074 \\
\hline Bread pu & uddin & & . & . . & 81 & $x$ & 0.99 & $=$ & 0.802 \\
\hline Bread. & - . & - . & . & . & 49 & $x$ & 1.97 & $=$ & 0.965 \\
\hline Fish . & . & & . & . & 99 & $x$ & 3.18 & $=$ & 3.148 \\
\hline Potato & . . & & - & . & 132 & $\times$ & 0.34 & $=$ & 0.449 \\
\hline Rice cro & quett & & . . . & . . & 83 & $x$ & 1.06 & $=$ & 0.880 \\
\hline Beer . & . . & • & . & . . & $37 \check{0}$ & $x$ & 0.069 & $=$ & 0.259 \\
\hline Consomn & mé . & • & . . . . & . . & 75 & $x$ & 0.59 & $=$ & 0.443 \\
\hline
\end{tabular}

Fuel value of the food . . . 2914 calories. 


\section{JACOBUS.}

\section{Saturday, May 21, 1904.}

Breakfast. - Banana 72 grams, roll 48 grams, butter 7 grams, boiled Indianmeal 100 grams, cream 90 grams, sugar 17 grams.

Lunch. - Lamb chop 49 grams, potato 95 grams, tomato 91 grams, beans 45 grams, bread 49 grams, butter 13.5 grams, coffee 150 grams, sugar 28 grams, water ice 153 grams.

Dinner. - Soup 75 grams, bacon 12 grams, fried egg 50 grams, potato 100 grams, bread 40 grams, butter 9 grams, prunes 175 grams, coffee 75 grams.

Food.

Grams. Per cent Nitrogen. Total Nitrogen.

\begin{tabular}{|c|c|c|c|c|c|c|c|c|c|c|c|}
\hline Butter & . & . & . & $7+$ & +13.5 & $5+9=$ & 29.5 & $x$ & 0.15 & $=$ & 0.044 grams. \\
\hline Banana & & . & & . & .. & . . & 72 & $x$ & 0.23 & $=$ & 0.167 \\
\hline Boiled I & ndi & an & -me & eal & . & - & 100 & $x$ & 0.17 & $=$ & 0.170 \\
\hline Cream & · & . & . & . & .90 & $+45=$ & 135 & $x$ & 0.43 & $=$ & 0.581 \\
\hline Sugar . & . & . & . & . & .17 & $+28=$ & 45 & $x$ & 0.00 & $=$ & 0.000 \\
\hline Roll . & - & - & - & . & $\cdot$. & . . . & 48 & $x$ & 1.65 & $=$ & 0.792 \\
\hline Bread. & . & . & . & . & . . & . . & 49 & $x$ & 1.82 & $=$ & 0.892 \\
\hline Lamb cl & lop & . & . & . & . & . & 49 & $x$ & 4.63 & $=$ & 2.269 \\
\hline Potato & . & . & . & . & . & . . & 95 & $x$ & 0.71 & $=$ & 0.675 \\
\hline Coffee. & . & . & . & . & 150 & $+75=$ & 225 & $x$ & 0.06 & $=$ & 0.135 \\
\hline Tomato & . & . & . & . & . . & . . & 91 & $x$ & 0.17 & $=$ & 0.155 \\
\hline Water I & & . & . & . & . & . & 153 & $x$ & 0.012 & $=$ & 0.018 \\
\hline Bread. & - & . & . & . & . & . & 40 & $x$ & 1.62 & $=$ & 0.648 \\
\hline Soup . & . & . & . & . & . & . & 75 & $\times$ & 1.21 & $=$ & 0.908 \\
\hline Prunes & . & - & . & . & - & . & 175 & $x$ & 0.16 & $=$ & 0.280 \\
\hline Potato & . & . & . & . & . & . & 100 & $x$ & 0.60 & $=$ & 0.600 \\
\hline Egg . & . & - & . & . & . & . & 50 & $x$ & 2.27 & $=$ & 1.135 \\
\hline Bacon. & . & . & . & . & . & . . & 12 & $x$ & 3.05 & $=$ & 0.366 \\
\hline & & & & & $\begin{array}{l}\text { otal n } \\
\text { otal n }\end{array}$ & $\begin{array}{l}\text { itroger } \\
\text { itroge }\end{array}$ & $\begin{array}{l}\text { in food } \\
\text { in urine }\end{array}$ & • & $\begin{array}{lll}\cdot & \cdot & \cdot \\
\cdot & \cdot & \text {. }\end{array}$ & $\begin{array}{ll}\cdot & \cdot \\
\cdot & \cdot\end{array}$ & $\begin{array}{l}9.835 \text { grams. } \\
7.070\end{array}$ \\
\hline
\end{tabular}

Fuel value of the food . . . 2167 calories. 


\title{
PHYSIOLOGICAL ECONOMY IN NUTRITION 389
}

\author{
JACOBUS.
}

Sunday, May 22, 1904.

Breakfast. - Orange 44 grams, oatmeal 130 grams, roll 52 grams, coffee 150 grams, cream 120 grams, sugar 30 grams.

Lunch. - Fried rice 72 grams, syrup 48 grams, boiled onions 70 grams, potato 100 grams, bread 33 grams, butter 14.5 grams, coffee 150 grams, cream 45 grams, sugar 20 grams, ice cream 147 grams.

Dinner. - Soup 100 grams, chicken 75 grams, fried potato 50 grams, spinach 15 grams, bread 48 grams, butter 12 grams, coffee 75 grams, cream 50 grams, sugar 14 grams, strawberry short-cake 201 grams.

Food. Grams. Per cent Nitrogen. Total Nitrogen.

\begin{tabular}{|c|c|c|c|c|c|c|c|c|c|c|}
\hline Orange & . & . & - & - & . & 44 & $x$ & 0.20 & $=$ & 0.088 \\
\hline Oatmeal & • & - & . & . & . . & . 130 & $x$ & 0.43 & $=$ & 0.559 \\
\hline Roll . & - & - & . . & •. & . & - 52 & $x$ & 1.67 & $=$ & 0.868 \\
\hline Cream & . & 4 & $5+$ & 120 & $+50=$ & 215 & $x$ & 0.45 & $=$ & 0.968 \\
\hline Sugar. & . & - 3 & $0+$ & 20 & $+14=$ & 64 & $x$ & 0.00 & $=$ & 0.000 \\
\hline Coffee & . & $\cdot 15$ & $0+$ & 150 & $+75=$ & 375 & $x$ & 0.06 & $=$ & 0.225 \\
\hline Bread. & . & $\cdot \cdot$ & . . & . & . & 33 & $x$ & 1.57 & $=$ & 0.518 \\
\hline Butter & - & . & . 1 & 14.5 & $+12=$ & 26.5 & $x$ & 0.15 & $=$ & 0.040 \\
\hline Onions & • & . & . . & • & . . & . 70 & $x$ & 0.25 & $=$ & 0.175 \\
\hline Potato & . & . & . . & . & . & . 100 & $x$ & 0.30 & $=$ & 0.300 \\
\hline Ice cream & & . & . . & . & . & . 147 & $\times$ & 0.53 & $=$ & 0.779 \\
\hline Fried rice & e & . & . $\cdot$ & . & . . & - 72 & $\times$ & 0.75 & $=$ & 0.540 \\
\hline Syrup & . & . & . . & . & . & 48 & $x$ & 0.024 & $=$ & 0.012 \\
\hline Bread . & . & . & . . & - & . & 48 & $\times$ & 1.91 & $=$ & 0.917 \\
\hline Soup . & . & . & . . & . & . . & . 100 & $x$ & 0.30 & $=$ & 0.300 \\
\hline Chicken & . & . & . . & . & . . & . 75 & $x$ & 3.02 & $=$ & 2.265 \\
\hline Fried pot & ato & . & . . & . & . . & 50 & $x$ & 0.37 & $=$ & 0.185 \\
\hline Spinach & . & . & . . & - & . . & 15 & $x$ & 0.55 & $=$ & 0.083 \\
\hline Strawber & ry & short- & cake & e. & . & 210 & $x$ & 0.50 & $=$ & 1.005 \\
\hline
\end{tabular}

Fuel value of the food . . . . 2836 calories. 


\section{JACOBUS.}

Monday, May 23, 1904 .

Breakfast. - Banana 70 grams, roll 64 grams, butter 9 grams, coffee 75 grams, cream 85 grams, sugar 10 grams.

Lunch. - Boiled eggs 73 grams, fried potato 75 grams, bread 58 grams, butter 11.5 grams, apple sauce 90 grams, coffee 75 grams, cream 35 grams, sugar 21 grams.

Dinner. - Bacon 35 grams, potato croquette 47 grams, bread 39 grams, butter 9.5 grams, chocolate 45 grams, coffee 100 grams, cream 50 grams, sugar 15 granıs, water ice 151 grams.

Food.

Grams. Per cent Nitrogen. Total Nitrogen.

\begin{tabular}{|c|c|c|c|c|c|c|c|c|c|c|c|c|}
\hline Banana & a. . & . & & • & - & - & - & 70 & $x$ & 0.23 & $=$ & 0.161 grams. \\
\hline Butter & & 9 & +1 & 11.5 & + & 9.5 & $=$ & 30 & $x$ & 0.15 & $=$ & 0.045 \\
\hline Cream & . & & $35+$ & +35 & $5+$ & 50 & $=$ & 170 & $x$ & 0.45 & $=$ & 0.765 \\
\hline Sugar & . & & 10 & +21 & $1+$ & -15 & $=$ & 46 & $x$ & 0.00 & $=$ & 0.000 \\
\hline Roll . & . & . . & . & . & . & . & . & 64 & $x$ & 1.63 & $=$ & 1.043 \\
\hline Coffee & . . & . 72 & $2+$ & -75 & + & 100 & $=$ & 250 & $x$ & 0.06 & $=$ & 0.150 \\
\hline Fried $\mathrm{p}$ & potatc & to. & . & · & . & - & . & 75 & $x$ & 0.60 & $=$ & 0.450 \\
\hline Bread & - . & - . & . & . & . & . & . & 58 & $\times$ & 1.64 & $=$ & 0.951 \\
\hline Eggs & . & . & . & . & . & . & . & 73 & $x$ & 2.07 & $=$ & 1.511 \\
\hline Apple & sauce & e. & • & - & . & . & - & 90 & $x$ & 0.02 & $=$ & 0.018 \\
\hline Potato & croq & quet & tte & . & . & . & . & 47 & $x$ & 0.77 & $=$ & 0.362 \\
\hline Bacon & . . & - . & . & . & . & . & . & 35 & $\times$ & 3.28 & $=$ & 1.148 \\
\hline Bread & & . & . & . & . & - & $\bullet$ & 39 & $x$ & 1.75 & $=$ & 0.683 \\
\hline Chocol & ate. & . & . & . & . & . & . & . 45 & $x$ & 0.73 & $=$ & 0.329 \\
\hline Water & ice. & . $\cdot$ & • & . & . & . & - & . 151 & $x$ & 0.006 & $=$ & 0.009 \\
\hline
\end{tabular}

Fuel value of the food . . . . 2041 calories. 


\section{JACOBUS.}

Tuesday, May 24, 1904.

Breakfast. - Orange 80 grams, boiled rice 105 grams, roll 55 grams, butter 9 grams, coffee 100 grams, cream 50 grams, sugar 30 grams.

Lunch. - Soup 100 grams, fried pota to 80 grams, boiled onions 130 grams, bread 44.5 grams, butter 12.5 grams, stewed prunes 108 grams, coffee 100 grams, cream 50 grams, sugar 21 grams.

Dinner. - Hamburg steak 84 grams, mashed potato 135 grams, bread 14 grams, butter 3 grams, cream pie 153 grams.

Food. Grams. Per cent Nitrogen. Total Nitrogen.

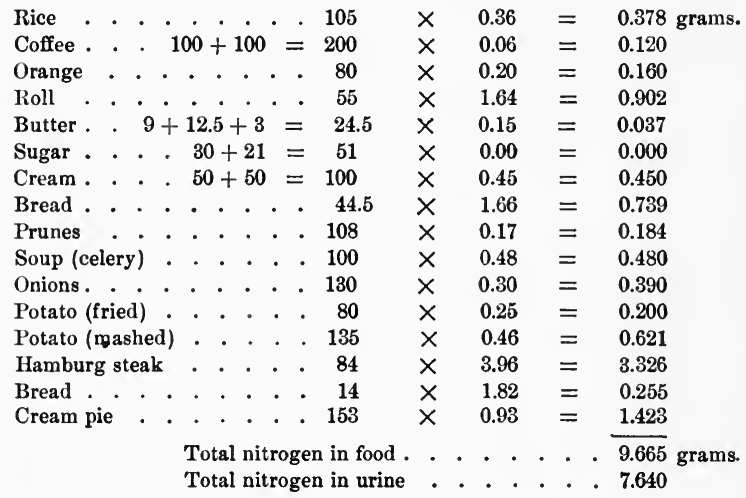

Fuel value of the food . . . 2174 calories. 


\section{NITROGEN BALANCE. - Jacobus.}

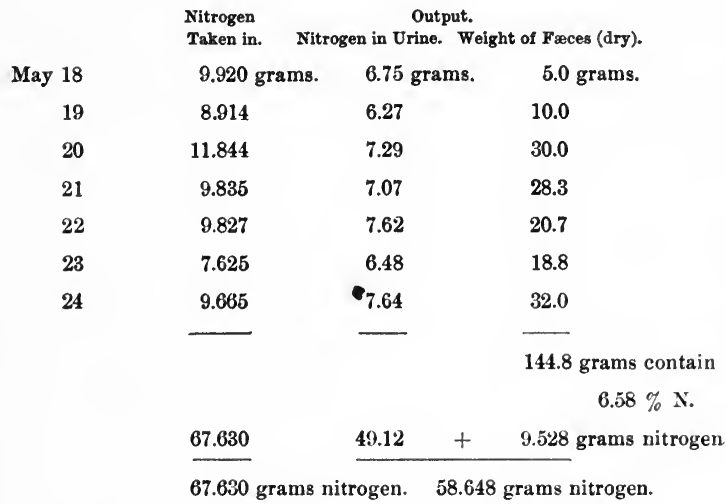

$\begin{array}{lll}\text { Nitrogen balance for seven days } & =\quad+8.982 \text { grams. } \\ \text { Nitrogen balance per day } & =\quad+1.283 \text { grams. }\end{array}$

Average Intake.

Calories per day . . . . . . . 2542.

Nitrogen per day . . . . . . 9.661 grams.

During this balance period of seven days, 67.630 grams of nitrogen were taken in with the food, while 49.12 grams of nitrogen were excreted through the urine and 9.528 grams were passed out through the fæces. 'This means a large plus balance of 8.98 grams of nitrogen for the entire period, showing that the body was being supplied with considerably more proteid than was necessary for the establishment of nitrogen equilib- 
rium. The average daily intake of nitrogen was 9.661 grams, whereas this might have been reduced to 8.4 grams per day with perfect assurance of nitrogen equilibrium being maintained. Further, it is to be noticed that the average daily intake of food for this period had a fuel value of only 2542 calories. The average daily excretion of metabolized nitrogen during the balance period was only 7.01 grams, while the average daily excretion for the last two months of the experiment amounted to 7.43 grams.

With Schenker the following results were obtained:

\section{SCHENKER.}

Wednesday, May 18, 1904.

\section{Breakfast. - None.}

Lunch. - Bread 53 grams, butter 22 grams, stewed potato 148 grams, string beans 110 grams.

Dinner. - Consommé 200 grams, bread 81 grams, butter 35 grams, Hamburg steak 119 grams, boiled potato 200 grams, spinach 100 grams, apple pie 138 grams.

Food. Grams. Per cent Nitrogen. Total Nitrogen.

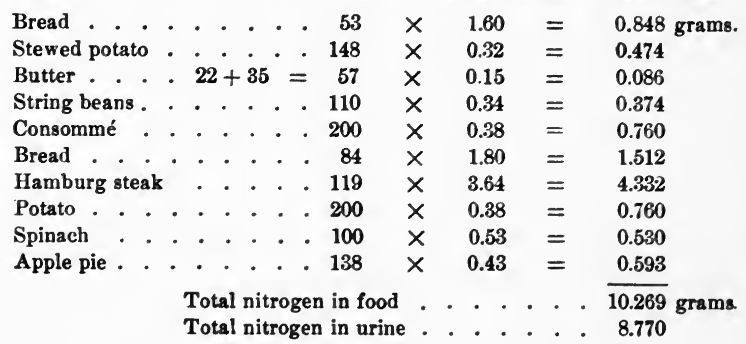

Fuel value of the food . . . 2006 calories. 


\title{
394 PHYSIOLOGICAL ECONOMY IN NUTRITION
}

\author{
SCHENKER.
}

\section{Thursday, May 19, 1904.}

Breakfast. - None.

Lunch. - Bread 82 grams, butter 32 grams, potato 232 grams, omelette 60 grams, apple-tapioca 180 grams.

Dinner. - Tomato soup 200 grams, bread 57 grams, butter 15 grams, macaroni 107 grans, fried sweet potato 100 grams, bacon 28 grams.

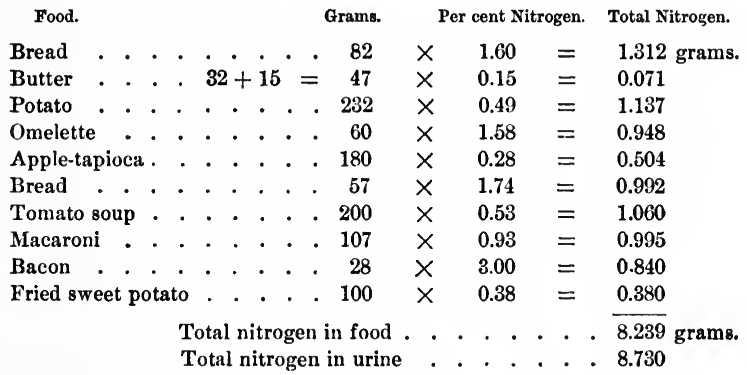

Fuel value of the food . . . 1900 calories. 


\section{SCHENKER.}

Friday, May 20, 1904.

Breakfast. - Orange 70 grams, baked potato 142 grams, roll 84 grams, butter 32.5 grams, coffee 150 grams, cream 50 grams, sugar 21 grams.

Lunch. - Fish-ball 85 grams, potato 175 grams, lima beans 60 grams, bread 57 grams, butter 17 grams, bread pudding 336 grams.

Dinner. - Consommé 150 grams, lualibut 110 grams, potato 186 grams, string beans 50 grams, bread 72 grams, butter 18 grams, cranberry sauce 163 grams, sugar 19 grams.

\begin{tabular}{|c|c|c|c|c|c|c|c|c|c|c|c|}
\hline \multirow{2}{*}{$\begin{array}{r}\text { Food. } \\
\text { Orange }\end{array}$} & \multirow[b]{2}{*}{ - } & \multirow{2}{*}{\multicolumn{2}{|c|}{..}} & \multirow[b]{2}{*}{$\cdot \cdot$} & \multicolumn{3}{|r|}{ Grams. } & \multicolumn{3}{|c|}{ Per cent Nitrogen. } & \multirow{2}{*}{$\begin{array}{c}\text { Total Nitrogen. } \\
0.140 \text { grams. }\end{array}$} \\
\hline & & & & & . & - & 70 & $\times$ & 0.20 & $=$ & \\
\hline Butter & - & & 32.5 & +17 & +18 & $8=$ & 67.5 & $x$ & 0.15 & $=$ & 0.101 \\
\hline Roll . & - & . & . & - . & . . & . . & 84 & $\times$ & 1.72 & $=$ & 1.445 \\
\hline Coffee & . & - & . & - & . & . & 150 & $\times$ & 0.06 & $=$ & 0.090 \\
\hline Cream & . & - & . & . . & . & . . & 50 & $x$ & 0.44 & $=$ & 0.220 \\
\hline Sugar & . & - & . & .21 & +19 & $9=$ & 40 & $x$ & 0.00 & $=$ & 0.000 \\
\hline Potato & - & - & - & - . & - . & - . & 142 & $x$ & 0.40 & $=$ & 0.568 \\
\hline Potato & . & . & . & . & . & . & 175 & $x$ & 0.30 & $=$ & 0.525 \\
\hline Fish-ball & & . & . & - & & . & 85 & $x$ & 1.22 & $=$ & 1.037 \\
\hline Bread & . . & . . & . & . & . & . & 57 & $x$ & 171 & $=$ & 0.975 \\
\hline Bread pu & addir & & . & . & . & . & 336 & $x$ & 0.99 & $=$ & 3.326 \\
\hline Lima bea & ans & . & . & . & . & . & 60 & $x$ & 0.76 & $=$ & 0.456 \\
\hline Bread & . . & - & - & - & - & . & 72 & $x$ & 1.97 & $=$ & 1.418 \\
\hline Potato & & $\cdot \cdot$ & . & - & . & - & 186 & $x$ & 0.34 & $=$ & 0.632 \\
\hline Fish (hal & libut & & - & . & . & . & 110 & $x$ & 3.18 & $=$ & 3.498 \\
\hline String be & eans & . & • & . & - & - & 50 & $x$ & 0.36 & $=$ & 0.180 \\
\hline Cranberr & ry sa & auce & e. & . . & . & . & . 163 & $x$ & 0.03 & $=$ & 0.049 \\
\hline Consomm & & $\cdot \cdot$ & • & . . & . . & - . & . 150 & $x$ & 0.59 & $=$ & 0.885 \\
\hline & & & $\begin{array}{l}\text { To } \\
\text { To }\end{array}$ & $\begin{array}{l}\text { otal } n \\
\text { otal } n\end{array}$ & $\begin{array}{l}\text { itrog } \\
\text { itrog }\end{array}$ & $\begin{array}{l}\text { gen } \\
\text { ggen }\end{array}$ & $\begin{array}{l}\text { in food } \\
\text { in urine }\end{array}$ & & $\begin{array}{l}\cdot \cdot \\
\cdot \\
\cdot\end{array}$ & $\begin{array}{l}\cdot \cdot \\
\cdot \quad \cdot\end{array}$ & $\begin{array}{l}15.545 \text { grams. } \\
12.480\end{array}$ \\
\hline
\end{tabular}

Fuel value of the food . . . . 2798 calories. 


\author{
SCHENKER.
}

Saturday, May 21, 1904.

Breakfast. - Banana 184 grams, cream 80 grams, boiled Indian-meal 155 grams, baked potato 140.5 grams, butter 15 grams, sugar 7 grams.

Lunch. - Lamb chop 25 grams, tomato 148 grams, potato croquette 147 grams, fried Indian-meal $\mathbf{4 7 . 5}$ grams, syrup 48 grams, bread 35 grams, water ice 162 grams.

Dinner. - Bean soup 150 grams, bread 25 grams, butter 19 grams, bacon 29 grams, fried potato 150 grams, orange salad 67 grams, stewed prunes 208 grams, cream 50 grams.

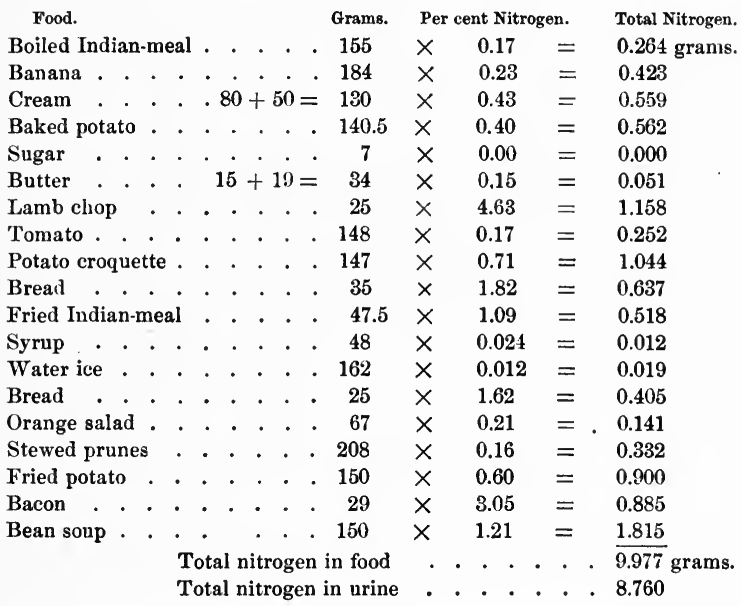

Fuel value of the food . . . 2661 calories. 


\section{SCHENKER.}

Sunday, May 22, 1904.

Breakfast. - Orange 126 grams, baked potato 169 grams, roll 43 grams, butter 15 grams.

Lunch. - Bread 53 grams, butter 15.5 grams, macaroni 165 grams, potato 150 grams, fried rice 114 grams, syrup 48 grams, ice cream 148 grams, cake 45 grams.

Dinner. - Celery soup 150 grams, fried potato 50 grams, spinach 40 grams, mashed potato 50 grams, chicken 85 grams, strawberry short-cake 213 grams.

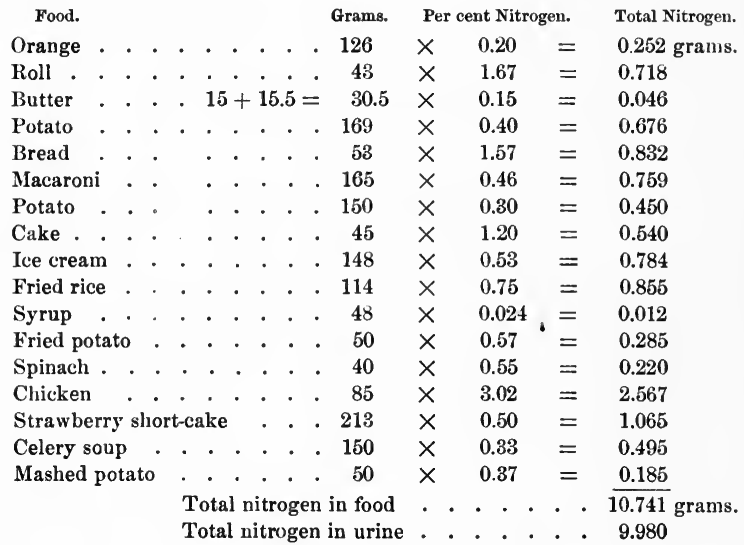

Fuel value of the food . . . . 2788 calories. 


\section{SCHENKER.}

Monday, May 23, 1904.

Breakfast. - Banana 225 grams, griddle cakes 127 grams, syrup 96 grams, roll 62 grams, butter 9.5 grams.

Lunch. - Consommé 100 grams, scrambled eggs 82 grams, fried potato 150 grams, rice croquette 150 grams, syrup 72 grams, bread 24 grams, butter 15 grams, apple sauce 125 grams.

Dinner. - Vegetable soup 100 grams, bread 51 grams, butter 17 grams, bacon 59 grams, potato croquette 80 grams, macaroni 100 grams, water ice 184 grams.

Food.

Grams. Per cent Nitrogen. Total Nitrogen

\begin{tabular}{|c|c|c|c|c|c|c|c|c|c|c|c|c|}
\hline Banana & & • & & • & . & - & - & - 225 & $x$ & 0.23 & $=$ & 0.518 grams. \\
\hline Griddle & cak & & & . & . & • & . & . 127 & $x$ & 0.91 & $=$ & 1.156 \\
\hline Butter & . & & .9 . & $5+$ & +15 & + & $17=$ & 41.5 & $x$ & 0.15 & $=$ & 0.062 \\
\hline Roll . & . & . & . & • . & .. & . & . & 62 & $x$ & 1.63 & $=$ & 1.011 \\
\hline Syrup & . & . & • & * & .96 & + & $72=$ & 168 & $x$ & 0.024 & $=$ & 0.040 \\
\hline Scrambl & ed e & gg & s & . & · $\cdot$ & - & . & 82 & $\times$ & 2.07 & $=$ & 1.697 \\
\hline Fried po & tato & 0 & . & 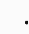 & . & . & . & 150 & $x$ & 0.60 & $=$ & 0.900 \\
\hline Rice cro & que & tte & & . & . & . & . & . 150 & $x$ & 0.61 & $=$ & 0.915 \\
\hline Apple sa & uce & & & . & . & . & . & . 125 & $x$ & 0.020 & $=$ & 0.025 \\
\hline Consom & & & . & . & . & - & . & . 100 & $\times$ & 0.65 & $=$ & 0.650 \\
\hline Bread & . & - & & • & . & . & . & 24 & $\times$ & 1.64 & $=$ & 0.394 \\
\hline Bread & - & . & • & . & . & . & . & 51 & $x$ & 1.75 & $=$ & 0.893 \\
\hline Bacon & . & . . & & . & . & . & . & 59 & $x$ & 3.28 & $=$ & 1.935 \\
\hline Potato & roqu & uett & & & . & . & . & 80 & $x$ & 0.77 & $=$ & 0.610 \\
\hline Macaron & & . . & . & . & . & ${ }^{\circ}$ & . & . 100 & $x$ & 0.87 & $=$ & 0.870 \\
\hline Water i & & . . & & • & . & . & . & . 184 & $x$ & 0.006 & $=$ & 0.011 \\
\hline Vegetab & le $s$ & oup & & • & - & & . & . 100 & $x$ & 0.48 & $=$ & 0.480 \\
\hline & & & & $\begin{array}{l}\text { Tot } \\
\text { Tot }\end{array}$ & $\begin{array}{l}\operatorname{tal} n i \\
\operatorname{tal} n\end{array}$ & & $\begin{array}{l}\text { ogen } \\
\text { ogen }\end{array}$ & $\begin{array}{l}\text { in food } \\
\text { in urine }\end{array}$ & . $\cdot$ & $\begin{array}{lll}\cdot & \cdot & \cdot \\
\cdot & \cdot & -\end{array}$ & . & $\begin{array}{l}12.167 \text { grams. } \\
10.040\end{array}$ \\
\hline
\end{tabular}

Fuel value of the food . . . 3100 calories. 


\section{SCHENKER.}

\section{Tuesday, May 24, 1904.}

\section{Breakfast. - None.}

Lunch. - Cream of celery soup 100 grams, bread 35 grams, butter 10 grams, farina croquette 88 grams, potato 150 grams, stewed prunes 176 grams.

Dinner. - Tomato soup 150 grams, Hamburg steak 77 grams, potato 150 grams, spinach 75 grams, farina croquette 107 grams, syrup 48 grams, bread 30.5 grams, butter 7.5 grams, cream pie 162 grams.

Food. Grams. Per cent Nitrogen. Total Nitrogen.

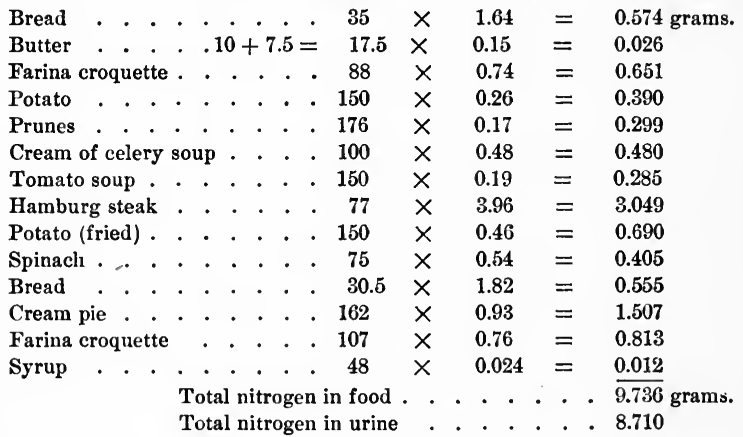

Fuel value of the food . . . 2151 calories. 


\section{NITROGEN BALANCE. - Schenker.}

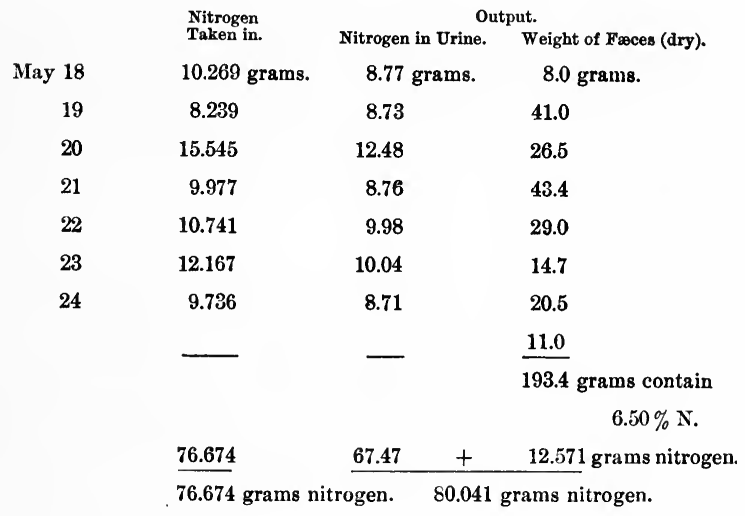

$\begin{array}{lll}\text { Nitrogen balance for seven days } & =-3.367 \text { grams. } \\ \text { Nitrogen balance per day } & =-0.481 \text { gram. }\end{array}$

Average Intake.

Calories per day . . . . . . . . 2486.

Nitrogen per day . . . . . . 10.95 grams.

In this seven days' balance trial, there were taken in with the food 76.674 grams of nitrogen, with an output of 67.47 grams of nitrogen through the urine and 12.571 grams through the fæces, thus showing a minus balance of 3.367 grams of nitrogen for the seven days. The fuel value of the food averaged 2486 calories per day, while the average daily excretion of metabolized nitrogen amounted to 9.63 grams. Schenker's daily nitrogen excretion for the last two months of the experiment averaged 9.82 grams. Presumably, the slight minus 
balance of nitrogen was due to the relatively small fuel value of the food, which doubtless was not quite sufficient for the body-weight, and the degree of bodily activity then prevailing.

With G. W. Anderson, a plus balance was obtained as follows :

G. W. ANDERSON.

\section{Wednesday May 18, 1904.}

Breakfast. - Banana 103 grams, coffee 150 grams, sugar 42 grams, cream 125 grams, fried rice 45 grams, baked potato 92 grams, roll 65 grams, butter 11 grams.

Lunch. - Soup 150 grams, farina croquette 88 grams, sweet potato 206 grams, string beans 75 grams, bread 62 grams, butter 15.5 grams, coffee 150 grams, sugar 14 grams, cream 30 grams.

Dinner. - Consommé 200 grams, bread 59 grams, butter 20 grams, Hamburg steak 109 grams, mashed potato 150 grams, coffee 200 grams, cream 30 grams, sugar 24 grams, spinach 100 grams, apple pie 150 grams.

Food.

Grams. Per cent Nitrogen. Total Nitrogen.

\begin{tabular}{|c|c|c|c|c|c|c|c|c|c|c|}
\hline Butter . & $.11+1$ & 15.5 & $5+20$ & & $=$ & 46.5 & $x$ & 0.15 & $=$ & 0.070 grams. \\
\hline Sugar . & $.42+2$ & & +14 & & $=$ & 80.0 & $x$ & 0.00 & $=$ & 0.000 \\
\hline Banana & ( & &. & - & . & 103.0 & $x$ & 0.23 & $=$ & 0.237 \\
\hline Cream . & $125+3$ & & +50 & & $=$ & 185.0 & $x$ & 0.46 & $=$ & 0.851 \\
\hline Fried rice & . . & - & . . & & . & 45.0 & $x$ & 0.75 & $=$ & 0.338 \\
\hline Roll. . & . . & . & . & . & . & 65.0 & $x$ & 1.66 & $=$ & 1.079 \\
\hline Potato . & . . . & . & . . & . & . & 92.0 & $x$ & 0.39 & $=$ & 0.359 \\
\hline Coffee . & $150+15$ & $50+$ & +200 & & $=$ & 500.0 & $x$ & 0.06 & $=$ & 0.300 \\
\hline Bread . & . . . & . & . . & . & . & 62.0 & $x$ & 1.60 & $=$ & 0.992 \\
\hline Soup . & . . . & . & . & . & . & 150.0 & $x$ & 0.41 & $=$ & 0.615 \\
\hline Farina cro & quette & . & . & ${ }^{\circ}$ & . & 88.0 & $x$ & 1.09 & $=$ & 0.959 \\
\hline Sweet pota & ato. . & - & . & . & . & 206.0 & $x$ & 0.32 & $=$ & 0.659 \\
\hline String bea & ans. & . & . & & . & 75.0 & $x$ & 0.34 & $=$ & 0.255 \\
\hline Bread . & . . . & . & . & . & . & 59.0 & $x$ & 1.80 & $=$ & 1.062 \\
\hline Soup (con & (sommé) & . & . . & . & . & 200.0 & $x$ & 0.38 & $=$ & 0.760 \\
\hline Hamburg & steak . & . & . . & . & . & 109.0 & $x$ & 3.64 & $=$ & 3.968 \\
\hline Potato. & . . . & . & . & - & . & 150.0 & $x$ & 0.38 & $=$ & 0.570 \\
\hline Spinach & . . & . & . & . & . & 100.0 & $x$ & 0.53 & $=$ & 0.530 \\
\hline Apple pie & . & - & . . & . & . & 150.0 & $x$ & 0.43 & $=$ & 0.645 \\
\hline & & $\begin{array}{l}\text { Tota } \\
\text { Tots }\end{array}$ & $\begin{array}{l}\text { tal nit } \\
\text { tal nit }\end{array}$ & & $\begin{array}{l}\text { gen } \\
\text { gen }\end{array}$ & $\begin{array}{l}\text { in food } \\
\text { in urine }\end{array}$ & & $\cdot \cdot \cdot$ & $\begin{array}{l}\cdot . \\
. \quad\end{array}$ & $\begin{array}{l}\overline{14.249} \text { grams. } \\
8.870\end{array}$ \\
\hline
\end{tabular}

Fuel value of the food . . . 3323 calories. 


\author{
G. W. ANDERSON.
}

Thursday, May 19, 1904.

Breakfast. - Banana 170 grams, cream 140 grams, sugar 28 grams, coffee 150 grams, baked potato 127 grams, rolls 47 grams, butter 15 grams.

Lunch. - Bread 50 grams, butter 18 grams, fried potato 150 grams, fried hominy 100 grams, syrup 48 grams, coffee 150 grams, cream 50 grams, sugar 14 grams.

Dinner. - Soup 200 grams, fried sweet potato 70 grams, macaroni 125 grams, spinach 105 grams, bacon 13 grams, butter 15 grams, coffee 150 grams, sugar 14 grams, cream 40 grams.

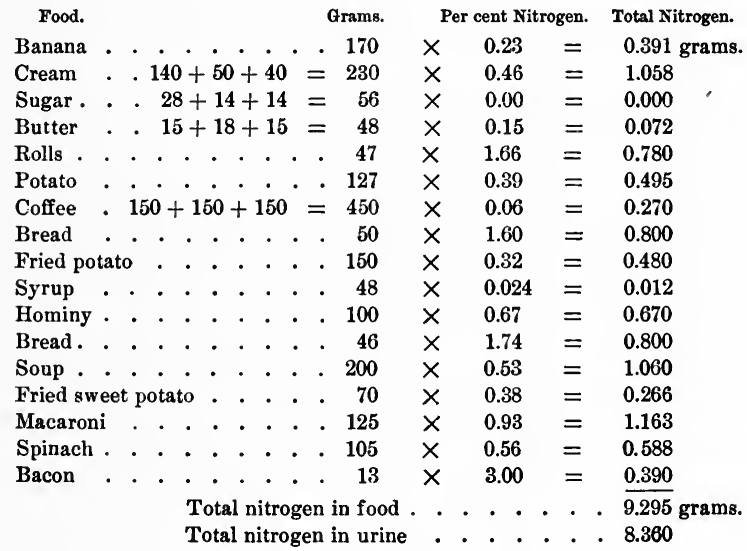

Fuel value of the food . . . 2932 calories. 


\author{
G. W. ANDERSON.
}

\title{
Friday, May 20, 1904.
}

Breakfast. - Orange 70 grams, roll 120 grams, butter 33 grams, coffee 150 grams, sugar 28 grams, cream 50 grams.

Lunch. - Bread 48 grams, butter 19 grams, fish-cake 81 grams, potato 200 grams, lima beans 50 grams, fried hominy 118 grams, syrup 96 grams, coffee 150 grams, cream 50 grams, sugar 14 grams.

Dinner. - Consommé 100 grams, boiled halibut 143 grams, mashed potato 177 grams, string beans 90 grams, stewed eranberry 76 grams, bread 56 grams, butter 16 grams, coffee 150 grams, cream 50 grams, sugar 14 grams.

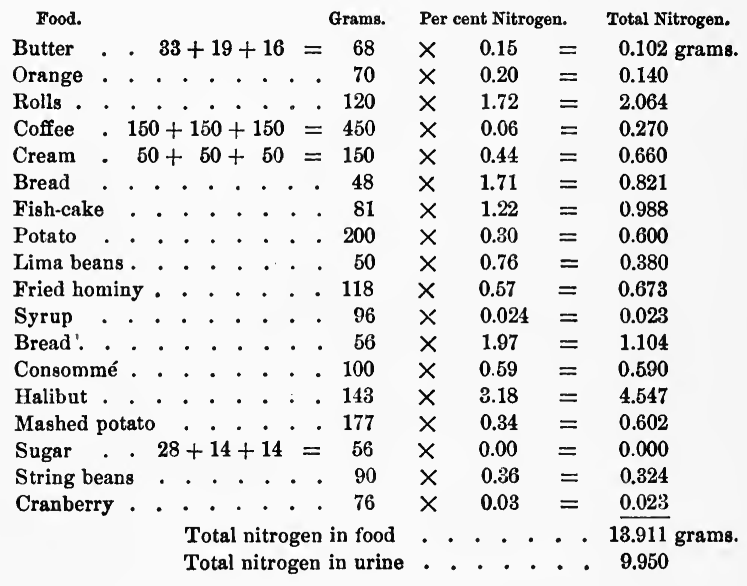

Fuel value of the food . . . 3052 calories. 


\author{
G. W. ANDERSON.
}

Saturday, May 21, 1904.

Breakfast. - Banana 157 grams, roll 61 grams, butter 15 grams, coffee 150 grams, cream 150 grams, sugar 28 grams.

Lunch. - Bread 58 grams, butter 17 grams, lamb chop 33 grams, potato croquettes 138 grams, tomato 161 grams, water ice 162 grams, coffee 150 grams, cream 50 grams, sugar 21 grams.

Dinner. - Soup 75 grams, bread 59 grams, butter 22.5 grams, bacon 15 grams, lettuce salad 64 grams, fried potato 100 grams, stewed prunes 283 grams, coffee 150 grams, cream 50 grams, sugar 14 grams.

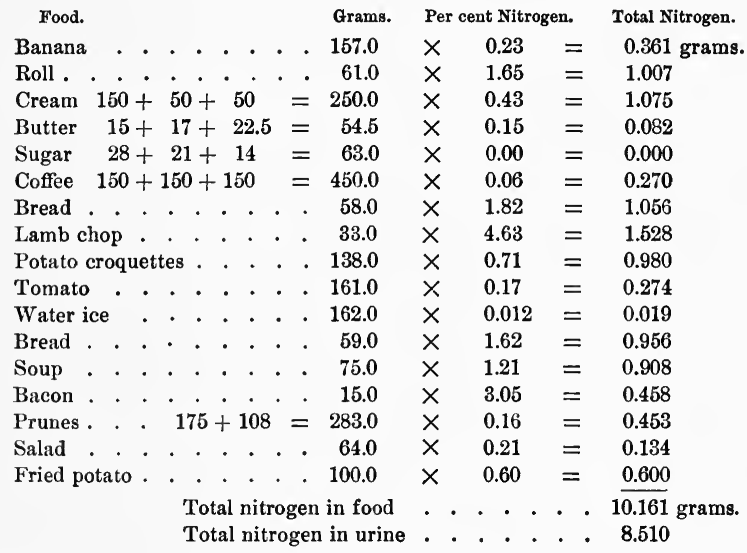

Fuel value of the food . . . 2826 calories. 


\section{G. W. ANDERSON.}

Sunday, May 2Q, 1904.

Breakfast. - Orange 80 grams, ontmeal 100 grams, potato 103 grams, butter 16 grams, roll 50 grams, coffee 150 grams, cream 125 grams, sugar 35 grams. Lunch. - Bread 47 grams, butter 14.5 grams, macaroni 116 grams, potato 150 grams, fried rice 85 grams, syrup 48 grams, ice cream 169 grams, coffee 150 grams, cream 50 grams, sugar 14 grams.

Dinner. - Soup 100 grams, bread 40.5 grams, butter 16 grams, fried potato 50 grams, mashed potato 100 grams, coffee 150 grams, cream 100 grams, sugar 21 grams, strawberry short-cake 214 grams.

\begin{tabular}{|c|c|c|c|c|c|c|c|c|c|c|}
\hline Food. & & & & & & Grams. & & cent Nitr & gen. & Total Nitrogen. \\
\hline Orange & . & . & - & . & . . . & 80 & $x$ & 0.20 & $=$ & 0.160 grams. \\
\hline Butter. & . & . $16+$ & -14 & $1.5+$ & $+16=$ & 46.5 & $x$ & 0.15 & $=$ & 0.070 \\
\hline Oatmeal & . & . . . & - & . & . . . & 100 & $x$ & 0.43 & $=$ & 0.430 \\
\hline Sugar. & - & $35+1$ & $4+$ & & $+7=$ & 70 & $x$ & 0.00 & $=$ & 0.000 \\
\hline Potato & . & . . . & • & . & . . . & 103 & $x$ & 0.40 & $=$ & 0.412 \\
\hline Cream & . & . 125 & +50 & $0+$ & $100=$ & 275 & $x$ & 0.45 & $=$ & 1.238 \\
\hline Roll . & . & . . . & . & . & . . . & 50 & $x$ & 1.67 & $=$ & 0.835 \\
\hline Coffee & . & $150+$ & 150 & $0+$ & $150=$ & 450 & $x$ & 0.06 & $=$ & 0.270 \\
\hline Bread . & - & . . . & $\cdot$ & $\cdot$ & . . . & 47 & $x$ & 1.57 & $=$ & 0.738 \\
\hline Macaroni & i & . . & . & . & . . . & 116 & $x$ & 0.46 & $=$ & 0.534 \\
\hline Potato. & - & . . & · & - & . . . & 150 & $x$ & 0.30 & $=$ & 0.450 \\
\hline Fried rice & e & . & - & . & . & 85 & $x$ & 0.75 & $=$ & 0.638 \\
\hline Syrup. . & & . & . & . & . & 48 & $x$ & 0.024 & $=$ & 0.012 \\
\hline Ice cream & $n$ & - & . & . & . . & 169 & $x$ & 0.53 & $=$ & 0.896 \\
\hline Bread. & . . & . & . & · & . . & 40.5 & $x$ & 1.91 & $=$ & 0.774 \\
\hline Celery sou & & . & . & . & . . . & 100 & $x$ & 0.33 & $=$ & 0.330 \\
\hline Fried pota & & $\cdot$ & . & $\cdot$ & . . & 50 & $x$ & 0.57 & $=$ & 0.285 \\
\hline Mashed p & potat & to . & & . & . . . & 100 & $x$ & 0.37 & $=$ & 0.370 \\
\hline Strawberr & ry 8 & short-ce & & & . $\cdot$ & 214 & $x$ & 0.50 & $=$ & 1.070 \\
\hline
\end{tabular}

Fuel value of the food . . . 3429 calories. 


\author{
G. W. ANDERSON.
}

Monday, May 23, 1904.

Breakfast. - Banana 211 grams, roll 59 grams, butter 15 grams, coffee 150 grams, cream 150 grams, sugar 28 grams.

Lunch. - Consonmmé 100 grams, bread 63 grams, butter 15 grams, rice 113 grams, syrup 48 grams, sugar 14 grams, fried potato 170 grams, apple sauce 125 grams.

Dinner. - Vegetable soup 100 grams, bread 70 grams, butter 16 grams, bacon 42 grams, potato croquettes 49 grams, macaroni 105 grams, string beans 184 grams, water ice 148 grams.

\begin{tabular}{|c|c|c|c|c|c|c|c|c|c|c|}
\hline Food. & & & & & - & Grams. & & cent Nitr & ggen. & Total Nitrogen. \\
\hline Banana & . & . . & . & • & . . & . 211 & $x$ & 0.23 & $=$ & 0.485 grams. \\
\hline Butter & . . & .15 & $15+$ & -15 & $+16=$ & $=46$ & $x$ & 0.15 & $=$ & 0.069 \\
\hline Cream & . & . . & . . & . . & . . & . 150 & $x$ & 0.45 & $=$ & 0.675 \\
\hline Roll . & & . & . & . & . & . 59 & $x$ & 1.63 & $=$ & 0.962 \\
\hline Sugar & . & . & . & .28 & $+14=$ & 42 & $x$ & 0.00 & $=$ & 0.000 \\
\hline Coffee . & . & . & . & . $\cdot$ & . . & . 150 & $x$ & 0.06 & $=$ & 0.090 \\
\hline Bread . . & . & . & . & . & . & . 63 & $x$ & 1.64 & $=$ & 1.033 \\
\hline Consomme & lé . & . & . & . & . & . 100 & $x$ & 0.65 & $=$ & 0.650 \\
\hline Apple sauc & & . & . & . & . . & . 125 & $x$ & 0.02 & $=$ & 0.025 \\
\hline Fried rice & . & . & - & . & - & . 113 & $x$ & 0.61 & $=$ & 0.689 \\
\hline Syrup. . & .. & . & . & . & . & . 48 & $x$ & 0.024 & $=$ & 0.012 \\
\hline Fried pota & & . & . & . & . & . 170 & $x$ & 0.60 & $=$ & 1.020 \\
\hline Bread. . & . . & . & . & . & . & . 70 & $x$ & 1.75 & $=$ & 1.225 \\
\hline Vegetable & e sou & up & . & . & . & . 100 & $x$ & 0.70 & $=$ & 0.700 \\
\hline Macaroni & . & . & . & . & . & . 105 & $x$ & 0.87 & $=$ & 0.914 \\
\hline Bacon . & . . & . . & . & . & . & 42 & $x$ & 3.28 & $=$ & 1.378 \\
\hline Potato cro & oque & ettes & 3 & • & . & . 149 & $x$ & 0.77 & $=$ & 1.147 \\
\hline String bea & & . . & & . & . & . 184 & $x$ & 0.22 & $=$ & 0.405 \\
\hline Water ice & . & . & . & . & . . & . 148 & $x$ & 0.006 & $=$ & 0.009 \\
\hline
\end{tabular}

Fuel value of the food . . . 3057 calories. 


\author{
G. W. ANDERSON.
}

Tuesday, May 24, 1904.

Breakfast. - Orange 80 grams, roll 55 grams, butter 16 grams, potato 91 grams, coffee 150 grams, cream 50 grams, sugar 21 grams.

Lunch. - Celery soup 150 grams, bread 62 grams, butter 19 grams, mashed potato 200 grams, farina croquettes 87 grams, syrup 48 grams, stewed prunes 138 grams.

Dinner. - Soup 150 grams, bread 43 grams, butter 15 grams, Hamburg steak 82 grams, fried potato 150 grams, spinach 85 grams, rice croquettes 57 grams, syrup 48 grams, coffee 150 grams, cream 50 grams, sugar 14 grams, lemon pie 125 grams.

Food. Grams. Per cent Nitrogen. Total Nitrogen.

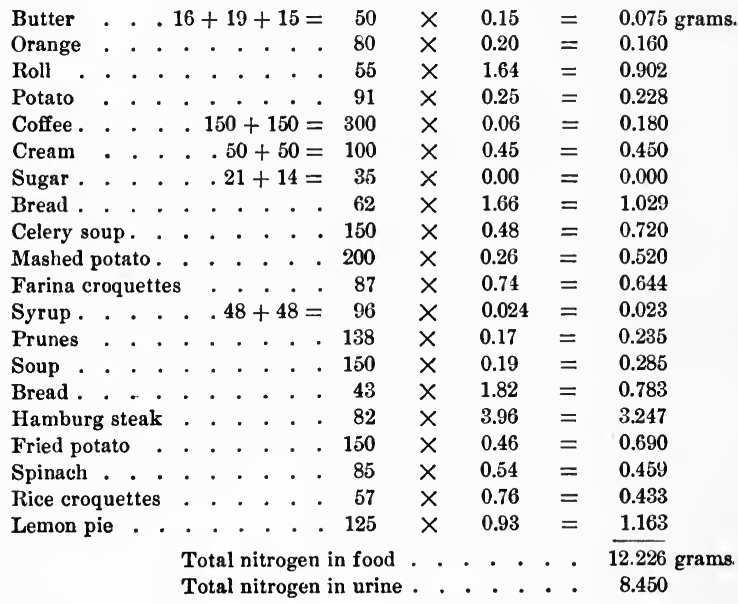

Fuel value of the food . . . 3022 calories. 


\section{NITROGEN BALANCE. - G. W. Anderson.}

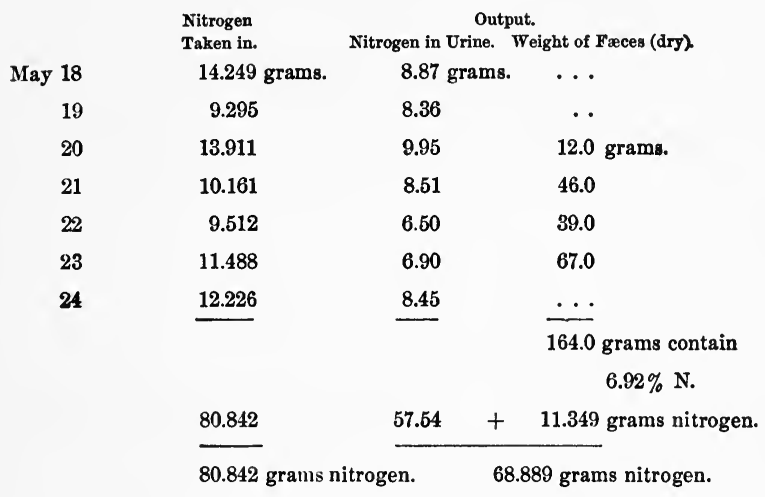

Nitrogen balance for seven days $=+11.953$ grams.

Nitrogen balance per day $\quad=+1.707$ grams.

Average Intake.

Calories per day . . . . . . 3091

Nitrogen per day . . . . . 11.55 grams

With G. W. Anderson, the balance trial was characterized by an intake of 80.842 grams of nitrogen, with an output for the seven days of 57.54 grams through the urine and 11.349 grams through the fæces, thus making a total excretion of 68.889 grams of nitrogen, and showing a plus balance of 11.953 grams. In other words, the body of this subject, under the conditions prevailing, was storing up nitrogen for future use at the rate of 1.7 grams per day. This also means that a daily intake of 9.8 grams of nitrogen would have been quite sufficient to maintain nitrogen equilibrium, certainly with the large fuel value of the food taken, $i$. e., 3091 calories per day as the average value. 


\section{PHYSIOLOGICAL ECONOMY IN NUTRITION 409}

The average daily excretion of metabolized nitrogen during the balance period amounted to 8.22 grams, while the average daily excretion for the last two months of the experiment was 8.81 grams.

With Stapleton, the following results were obtained, showing a distinct positive balance :

\section{STAPLETON.}

\section{Wednesday, May 18, 1904.}

Breakfast. - Banana 118 grams, bread 29 grams, butter 11 grams, sugar 56 grams, cream 125 grams.

Lunch. - Tomato soup 247 grams, bread 37 grams, butter 9 grams, croquettes 97 grams, potato 100 grams, string beans 46 grams, coffee 150 grams, cream 50 grams, sugar 21 grams.

Dinner. - Bread 109 grams, butter 40 grams, Hamburg steak 87 grams, potato 150 grams, spinach 100 grams, coffee 150 grams, cream 100 grams, sugar 30 grams, apple pie 110 grams.

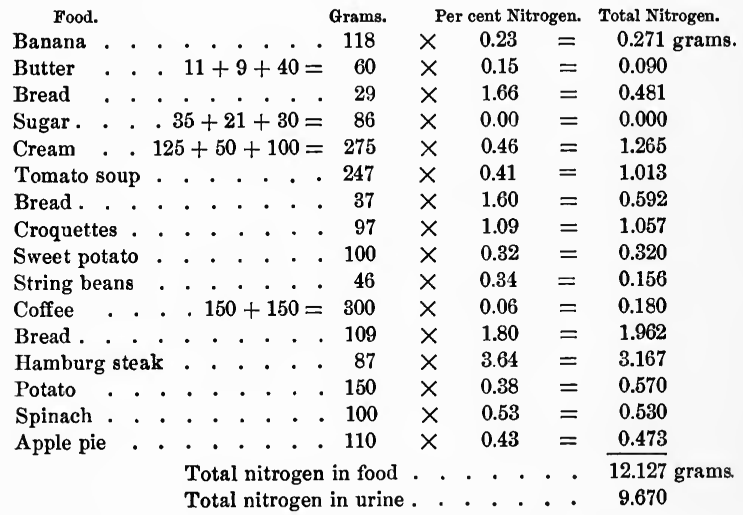

Fuel value of the food . . . . 3109 calories. 


\section{STAPLETON.}

Thursday, May 19, 1904.

Breakfast. - None.

Lunch. - Bread 48 grams, butter 14 grams, omelette 125 grams, boiled onion 63 grams, fried sweet potato 100 grams, coffee 300 grams, cream 150 grams, sugar 56 grams, apple pudding 146 grams.

Dinner. - Tomato soup 200 grams, bread 42 grams, butter 9 grams, macaroni 75 grams, potato 36 grams, spinach 70 grams, bacon 16 grams, coffee 150 grams, cream 50 grams, sugar 21 grams.

\begin{tabular}{|c|c|c|c|c|c|c|c|c|c|c|c|c|}
\hline Food. & & & & & & & & Grams. & & cent $\mathrm{Ni}$ & ogen. & Total Nitrogen. \\
\hline Coffee & . & . & & $300+$ & 150 & & $=$ & 450 & $x$ & 0.06 & $=$ & 0.270 grams. \\
\hline Butter & . & . & . & 14 & +9 & & $=$ & 23 & $x$ & 0.15 & $=$ & 0.035 \\
\hline Breaả. & . & - & . & . . & - & . & . & 48 & $x$ & 1.60 & $=$ & 0.768 \\
\hline Omelette & & . & . & . & . & . & . & 125 & $x$ & 1.58 & $=$ & 1.975 \\
\hline Onions & . & . & . & . & . & . & . & 63 & $x$ & 0.27 & $=$ & 0.170 \\
\hline Sugar & . & . & . & $56+$ & -21 & & $=$ & 77 & $x$ & 0.00 & $=$ & 0.000 \\
\hline Cream & . & . & . & $150+$ & -50 & & $=$ & 200 & $x$ & 0.47 & $=$ & 0940 \\
\hline Potato & . & - . & - & . . & · & · & . & 100 & $x$ & 0.49 & $=$ & 0.490 \\
\hline Apple pu & uddi & ing & . & . & . & . & . & 146 & $\times$ & 0.28 & $=$ & 0.409 \\
\hline Bread & . & . . & . & . & . & 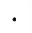 & . & 42 & $\times$ & 1.74 & $=$ & 0.731 \\
\hline Tomato & souy & p & . & . & . & . & . & 200 & $x$ & 0.53 & $=$ & 1.060 \\
\hline Macaron & & . & . & . & . & . & . & 75 & $x$ & 0.93 & $=$ & 0.698 \\
\hline Fried sw & reet & pot: & & . & . & . & . & 36 & $x$ & 0.38 & $=$ & 0.137 \\
\hline Spinach & . & . . & . & . & . & . & . & 70 & $x$ & 0.56 & $=$ & 0.392 \\
\hline Bacon & - & - & - & - & . & . & - & 16 & $x$ & 3.00 & $=$ & 0.480 \\
\hline & & & & otal $n$ & nitro & oge & & n urin & & $\begin{array}{l}\cdot \\
\cdot\end{array}$ & & $\begin{array}{l}\text {. } 8.555 \text { grams. } \\
\text {. } 8.580\end{array}$ \\
\hline
\end{tabular}

Fuel value of the food . . . . 2072 calories. 


\author{
STAPLETON.
}

Friday, May 20, 1904.

Breakfast. - Orange 150 grams, roll 65 grams, coffee 150 grams, cream 50 grams, sugar 35 grams.

Lunch. - Bread 64 grams, butter 18 grams, fish-cake 72 grams, potato 150 grams, lima beans 50 grams, coffee 150 grams, cream 100 grams, sugar 21 grams, bread pudding 150 grams.

Dinner. - Fish 113 grams, string beans 62 grams, potato 150 grams, rice croquettes 102 grams, syrup 48 grams, stewed cranberry 95 grams, bread 33 grams, butter 16 grams, coffee 300 grams, cream 100 grams, sugar 42 grams.

Evening. - Beer 750 grams.

Food. Grams. Per cent Nitrogen. Total Nitrogen.

\begin{tabular}{|c|c|c|c|c|c|c|c|c|c|c|c|}
\hline Orange & - & - . & . $\cdot$ & - & . & - $\cdot$ & 150 & $x$ & 0.20 & $=$ & 0.300 grams. \\
\hline Sugar & • & - 3 & $5+21$ & $21+$ & 42 & $=$ & 98 & $x$ & 0.00 & $=$ & 0.000 \\
\hline Roll . & . & . . & . . & • & . & . . & 65 & $\times$ & 1.72 & $=$ & 1.118 \\
\hline Coffee & - & $150-$ & +150 & +3 & 300 & $=$ & 600 & $x$ & 0.06 & $=$ & 0.360 \\
\hline Cream & . & 50 & +100 & +1 & 100 & $=$ & 250 & $\times$ & 0.44 & $=$ & 1.100 \\
\hline Bread . & - & . $\cdot$ & . . & . & . & . . & 64 & $x$ & 1.71 & $=$ & 1.094 \\
\hline Butter & . & . & . 18 & $8+$ & 16 & $=$ & 34 & $x$ & 0.15 & $=$ & 0.051 \\
\hline Fish-cake & e & - & - & • & . & - . & 72 & $\times$ & 1.22 & $=$ & 0.878 \\
\hline Potato & . . & . & . & . & . & . . & 150 & $x$ & 0.30 & $=$ & 0.450 \\
\hline Lima bea & & • & - & - & . & . $\cdot$ & 50 & $x$ & 0.76 & $=$ & 0.380 \\
\hline Bread puc & addir & ing & . & . & . & . . & 150 & $x$ & 0.99 & $=$ & 1.485 \\
\hline String be & eans & . & . & . & . & . . & 62 & $x$ & 0.36 & $=$ & 0.223 \\
\hline Fish . & . . & . & . & . & . & . . & 113 & $x$ & 3.18 & $=$ & 3.593 \\
\hline Bread & . & . & - & - & . & . $\cdot$ & 33 & $x$ & 1.97 & $=$ & 0.650 \\
\hline Potato & . . & . . & . & • & - & . . & 150 & $\times$ & 0.34 & $=$ & 0.510 \\
\hline Rice croq & quet & ttes & - & . & . & . . & 102 & $x$ & 1.06 & $=$ & 1.081 \\
\hline Cranberry & & . & - & - & - & . $\cdot$ & 95 & $x$ & 0.030 & $=$ & 0.029 \\
\hline Syrup & . & . & . . & . & . & . . & 48 & $x$ & 0.024 & $=$ & 0.012 \\
\hline Beer . & - & - & . $\cdot$ & $\cdot$ & . & . $\cdot$ & 750 & $x$ & 0.069 & $=$ & 0.518 \\
\hline & & & $\begin{array}{l}\text { Tota } \\
\text { Tota }\end{array}$ & $\begin{array}{l}\text { al } \mathrm{N} \\
\text { al } \mathrm{N}\end{array}$ & $\begin{array}{l}\text { Titro } \\
\text { Nitro }\end{array}$ & $\begin{array}{l}\text { ogen } \\
\text { ogen }\end{array}$ & $\begin{array}{l}\text { in food } \\
\text { in urine }\end{array}$ & $\begin{array}{l}\cdot \\
\cdot\end{array}$ & 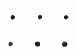 & $\begin{array}{l}\cdot \\
\cdot\end{array}$ & $\begin{array}{l}13.832 \text { grams. } \\
9.510\end{array}$ \\
\hline
\end{tabular}

Fuel value of the food . . . 2999 calories. 


\title{
412 PHYSIOLOGICAL ECONOMY IN NUTRITION
}

\author{
STAPLETON.
}

Saturday, May 21, 1904.

Breakfast. - Banana 74 grams, baked potato 95 grams, roll 71 grams, butter 18 grams, coffee 150 grams, cream 100 grams, sugar 30 grams.

Lunch. - Bread 48 grams, butter 14 grams, lamb chop 27 grams, potato croquette 91 grams, tomato 105 grams, coffee 150 grams, cream 50 grams, sugar 21 grams, water ice 185 grams..

Dinner. - Bean soup 150 grams, fried egg 127 grams, bacon 2 grams, fried potato 108 grams, bread 77 grams, butter 18 grams, coffee 150 grams, cream 50 grams, sugar 21 grams, jelly roll 56 grams.

Evening. - Beer 600 grams.

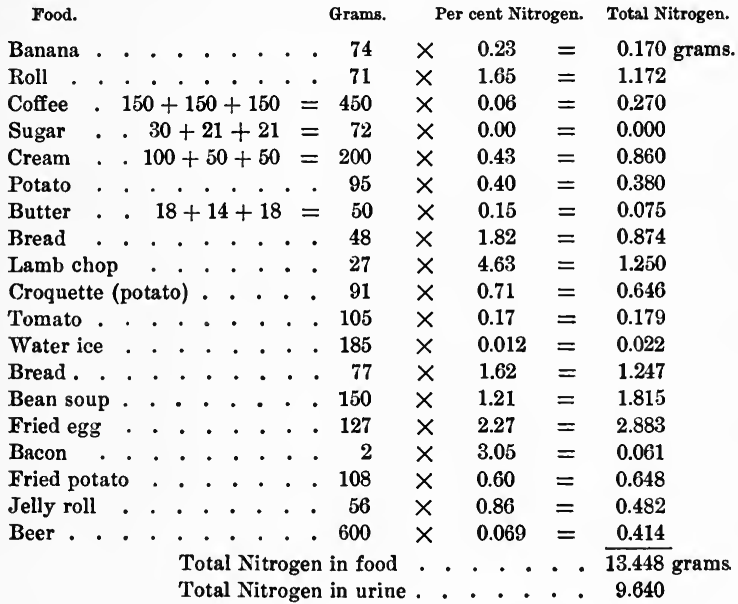

Fuel value of the food . . . 2871 calories. 


\section{STAPLETON.}

Sunday, May 22, 1904.

Breakfast. - Orange 60 grams, oatmeal 150 grams, wheat roll 51 grams, butter 17 grams, coffee 150 grams, cream 100 grams, sugar 49 grams.

Lunch. - Bread 37 grams, butter 13 grams, potato 114 grams, macaroni 115 grams, fried rice 92 grams, coffee 300 grams, cream 100 grams, sugar 42 grams, ice cream 104 grams, cake 37.5 grams.

Dinner. - Chicken 89 grams, spinach 100 grams, fried potato 70 grams, bread 46 grams, butter 12 grams, coffee 150 grams, cream 100 grams, sugar 30 grams, strawberry short-cake 195 grams.

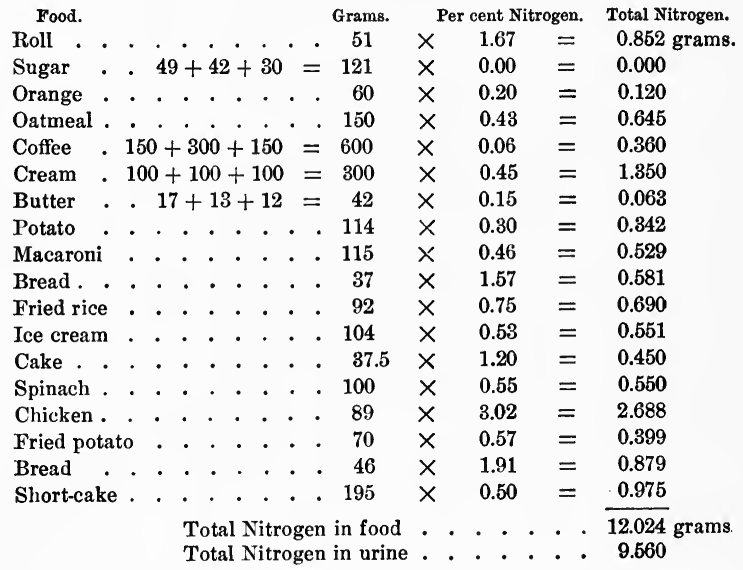

Fuel value of the food . . . 3442 calories. 


\section{STAPLETON.}

Monday, May 23, 1904.

Breakfast. - Banana 98 grams, roll 68 grams, butter 15 grams, coffee 150 grams $_{1}$ cream 100 grams, sugar 40 grams.

Lunch. - Bread 53 grams, butter 17.5 grams, boiled eggs 101 grams, apple sauce 130 grams, coffee 150 grams, cream 50 grams, sugar 17 grams.

Dinner. - Bread 28 grams, butter 7 grams, bacon 40 grams, macaroni 62 grams, potato croquette 69 grams, coffee 150 grams, cream 50 grams, sugar 21 grams, water ice 116 grams.

Food. Grams. Per cent Nitrogen. Total Nitrogen.

\begin{tabular}{|c|c|c|c|c|c|c|c|c|c|c|}
\hline Banana & - & . & . & . . & . & 98 & $x$ & 0.23 & $=$ & 0.225 grams. \\
\hline Butter & . 15 & $5+1$ & 17.5 & $5+7$ & $=$ & 39.5 & $x$ & 0.15 & $=$ & 0.059 \\
\hline Coffee & 150 & +150 & $60+$ & -150 & $=$ & 450 & $x$ & 0.06 & $=$ & 0.270 \\
\hline Cream & 10 & $0+5$ & 50 & +50 & $=$ & 200 & $\times$ & 0.45 & $=$ & 0.900 \\
\hline Sugar & - 4 & $0+1$ & $17-$ & +21 & $=$ & 78 & $x$ & 0.00 & $=$ & 0.000 \\
\hline Roll . & - . & . . & . . & · $\cdot$ & . . & 68 & $x$ & 1.63 & $=$ & 1.108 \\
\hline Bread & . . & - & . & . & . . & 53 & $x$ & 1.64 & $=$ & 0.869 \\
\hline Apple sa & uce & . & . & . & . . & 130 & $\times$ & 0.02 & $=$ & 0.026 \\
\hline Boiled eg & & . & . & . & . . & 101 & $\times$ & 2.07 & $=$ & 2.091 \\
\hline Bread & & . . & . & . . & . . & 28 & $x$ & 1.75 & $=$ & 0.490 \\
\hline Macaroni & & 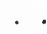 & . & - & . . & 62 & $\times$ & 0.87 & $=$ & 0.539 \\
\hline Bacon & . . & . . & . & . . & . . & 40 & $x$ & 8.28 & $=$ & 1.312 \\
\hline Potato cr & roque & ette. & . & . & . & 69 & $x$ & 0.77 & $=$ & 0.531 \\
\hline Water ice & e & • & • & . & . . & 116 & $x$ & 0.006 & $=$ & 0.007 \\
\hline
\end{tabular}

Fuel value of the food . . . 2346 calories. 


\author{
STAPLETON.
}

Tuesday, May 24, 1904.

Breakfast. - Orange 80 grams, roll 118 grams, butter 23 grams, coffee 150 grams, cream 50 grams, sugar 25 grams.

Lunch. - Soup 100 grams, bread 59 grams, butter 15.5 grams, potato 100 grams, farina croquettes 109 grams, tomato sauce 75 grams, boiled onions 107 grams, stewed prunes 105 grams, coffee 150 grams, cream 100 grams, sugar 18 grams.

Dinner. - Celery soup 150 grams, Hamburg steak 63 grams, potato 100 grams, spinach 50 grams, bread 32 grams, butter 15 grams, coffee 150 grams, cream 50 grams, sugar 16 grams, cream pie 79 grams.

Evening. - Beer 750 grams.

Food. Grams. Per cent Nitrogen. Total Nitrogen.

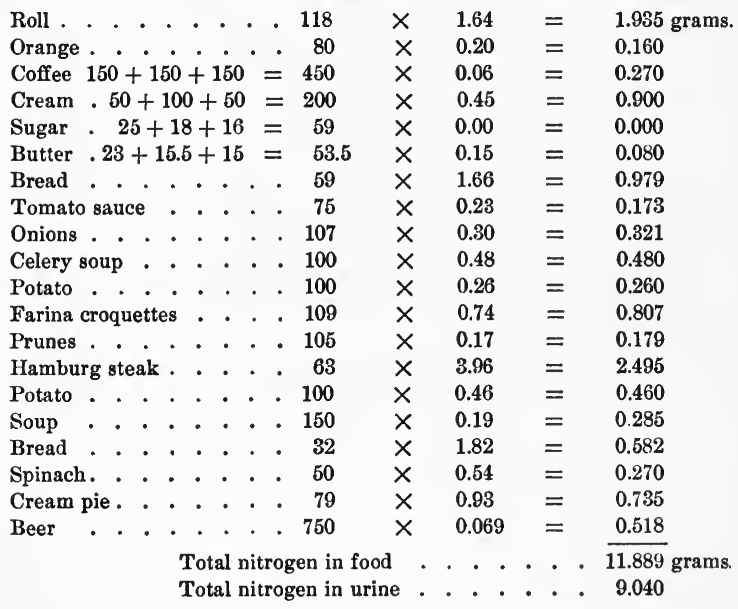

Fuel value of the food . . . 2822 calories. 


\section{NITROGEN BALANCE. - Stapleton.}

\begin{tabular}{|c|c|c|c|}
\hline \multirow[b]{3}{*}{ May 18} & \multirow{2}{*}{$\begin{array}{l}\text { Nitrogen } \\
\text { Taken in. }\end{array}$} & \multirow{2}{*}{$\begin{array}{l}\text { Outpu } \\
\text { Nitrogen in Urine. }\end{array}$} & \\
\hline & & & Weight of Freces (dry). \\
\hline & 12.127 grams. & 9.67 grams. & 39.6 grams. \\
\hline 19 & 8.555 & 8.58 & 34.5 \\
\hline 20 & 13.832 & 9.51 & 65.3 \\
\hline 21 & 13.448 & 9.64 & 17.8 \\
\hline 22 & 12.024 & 9.56 & 11.4 \\
\hline 23 & 8.427 & 8.03 & 27.7 \\
\hline \multirow[t]{4}{*}{24} & 11.889 & 9.04 & $\ldots$ \\
\hline & & & 196.3 grams contain \\
\hline & & & $7.08 \% \mathrm{~N}$ \\
\hline & 80.302 & 64.03 & 13.898 grams nitrogen. \\
\hline
\end{tabular}

$\begin{array}{lll}\text { Nitrogen balance for seven days } & =+2.374 \text { grams. } \\ \text { Nitrogen balance per day } & =\quad+0.339 \text { gram. }\end{array}$

Average Intake.

Calories per day . . . . . . . 2809.

Nitrogen per day . . . . . . 11.47 grams.

With this subject, the total intake of nitrogen for the seven days' period was 80.302 grams. The output of nitrogen through the urine amounted to 64.03 grams, while 13.898 grams were passed out through the fæces, making a total output of 77.928 grams of nitrogen. This shows a plus balance of 2.374 grams of nitrogen for the seven days, indicating a gain to the body of 0.339 gram per day. The fuel value of the food averaged 2809 calories per day, while the daily excretion of metabolized nitrogen averaged 9.14 grams. This is in close agreement with the average daily excretion of nitrogen through the urine of this subject for the last two months of the experiment, viz., 9.00 grams of nitrogen. 
With W. L. Anderson, the following results were obtained:

\author{
W. L. ANDERSON.
}

Wednesday, May 18, 1904.

Breakfast. - Banana 90 grams, fried rice 150 grams, syrup 50 grams, wheat roll 64 grams, butter 11 grams, coffee 150 grams, cream 125 grams, sugar 21 grams.

Lunch. - Tomato soup 247 grams, bread 19 grams, butter 16.5 grams, sweet potato 105 grams, farina croquette 115 grams, syrup 60 grams, coffee 150 grams, milk 50 grams, sugar 14 grams.

Dinner. - Consommé 250 grams, bread 52 grams, butter 20 grams, Hamburg steak 117 grams, boiled potato 150 grams, coffee 150 grams, cream 50 grams, sugar 14 grams.

\begin{tabular}{|c|c|c|c|c|c|c|c|c|}
\hline \multicolumn{3}{|l|}{ Food. } & \multicolumn{3}{|c|}{ Grams. } & \multicolumn{2}{|c|}{ Per cent Nitrogen. } & Total Nitrogen. \\
\hline Banana & . . & . . & . & 90 & $x$ & 0.23 & $=$ & 0.207 grams. \\
\hline Cream & $.125+5$ & $50+50$ & $=$ & 225 & $x$ & 0.46 & $=$ & 1.035 \\
\hline Sugar & . $21+14$ & $14+14$ & $=$ & 49 & $x$ & 0.00 & $=$ & 0.000 \\
\hline Coffee & $150+150$ & +150 & $=$ & 450 & $x$ & 0.06 & $=$ & 0.270 \\
\hline Roll . & • $\cdot$. & . . & . . & 64 & $x$ & 1.66 & $=$ & 1.063 \\
\hline Butter & $11+16$ & $.5+20$ & $=$ & 47.5 & $x$ & 0.15 & $=$ & 0.071 \\
\hline Rice. & . . . . & . . & . . & 150 & $x$ & 0.75 & $=$ & 1.125 \\
\hline Syrup & . . . 5 & $50+60$ & $=$ & 110 & $x$ & 0.024 & $=$ & 0.026 \\
\hline Tomato & soup . & . . & . & 247 & $x$ & 0.41 & $=$ & $\bullet 1.013$ \\
\hline Bread & . . . & . & . & 19 & $x$ & 1.60 & $=$ & 0.304 \\
\hline Sweet pc & otato . & . & . & 105 & $x$ & 0.32 & $=$ & 0.336 \\
\hline Farina c & croquette & . & . & 115 & $x$ & 1.09 & $=$ & 1.690 \\
\hline Bread & . . . . & . & . & 52 & $x$ & 1.80 & $=$ & 0.936 \\
\hline Consomr & mé . & . & . & 250 & $x$ & 0.38 & $=$ & 0.950 \\
\hline Hambur & rg steak & . & . & 117 & $x$ & 3.64 & $=$ & 4.259 \\
\hline Potato & . . . . & . & . & 150 & $x$ & 0.38 & $=$ & 0.570 \\
\hline
\end{tabular}

Fuel value of the food . . . 2946 calories. 


\author{
W. L. ANDERSON.
}

Thursday, May 19, 1904.

Breakfast - Banana 158 grams, roll 122 grams, butter 15 grams, boiled hominy 150 grams, syrup 48 grams, coffee 150 grams, cream 100 grams, sugar 28 grams.

Lunch. - Bread 50 grams, butter 12 grams, fried hominy 100 grams, syrup 48 grams, boiled onions 80 grams, omelette 60 grams, coffee 150 grams, cream 50 grams, sugar 14 grams.

Dinner. - Tomato soup 200 grams, bread 43 grams, butter $1 \dot{0}$ grams, potato 50 grams, baked macaroni 202 grams, coffee 150 grams, sugar 14 grams, cream 25 grams.

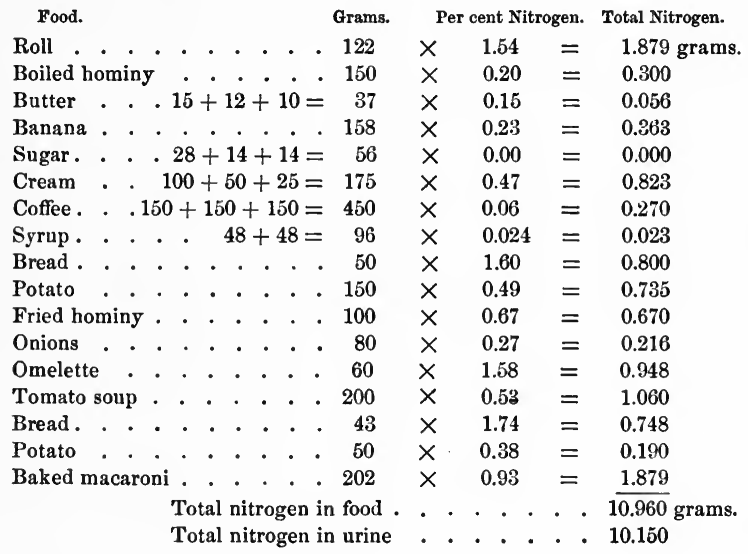

Fuel value of the food . . . 3013 calories. 


\author{
W. L. ANDERSON.
}

Friday, May 20, 1904.

Breakfast. - Coffee 150 grams, cream 25 grams, sugar 14 grams, roll 70 grams, butter 9 grams.

Lunch. - Potato 100 grams, butter 3 grams, lima beans 50 grams, hominy 69 grams, syrup 48 grams, coffee 150 grams, cream 25 grams, sugar 14 grams. Dinner. - Consommé 150 grams, bread 28 grams, butter 15 grams, string beans 56 grams, potato 200 grams, rice croquette 65 grams, syrup 48 grams, coffee 150 grams, sugar 14 grams, cream 25 grams.

Evening. - Beer 450 grams.

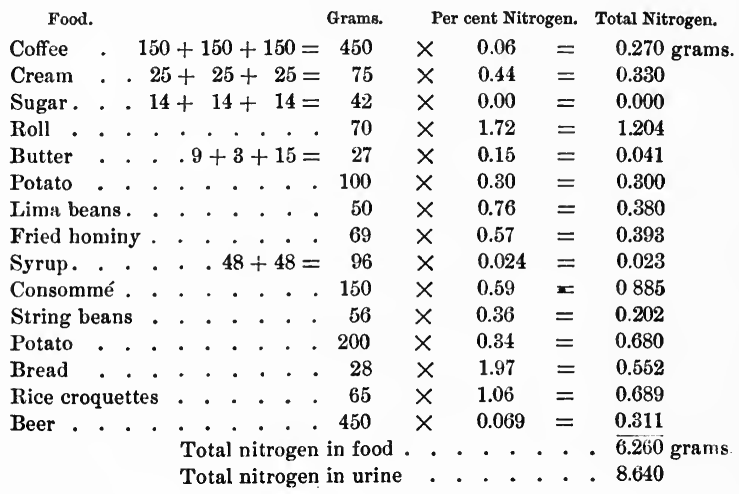

Fuel value of the food . . . 1748 calories. 


\author{
W. L. ANDERSON.
}

Saturday, May 21, 1904.

Breakfast. - Banana 73 grams, bread 63 grams, butter 7 grams, coffee 150 grams, cream 50 grams, sugar 28 grams.

Lunch. - Potato 150 grams, tomato 145 grams, fried Indian-meal 81 grams, syrup 48 grams, coffee 150 grams, sugar 21 grams, cream 25 grams, water ice 165 grams.

Dinner. - Bean soup 150 grams, bread 29 grams, butter 16 grams, bacon 15 grams, fried potato 150 grams, cake 36 grams, coffee 150 grams, sugar 14 grams, cream 45 grams.

Evening. - Beer 600 grams.

Food. Grams. Per cent Nitrogen. Total Nitrogen.

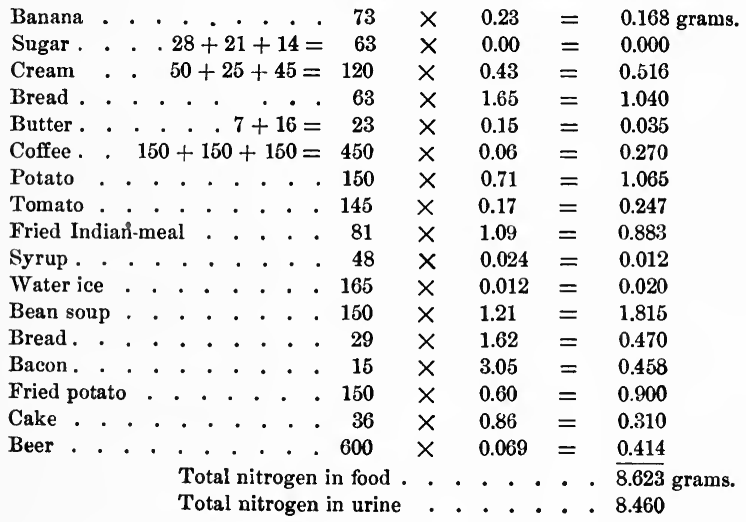

Fuel value of the food . . . 2393 calories. 


\author{
W. L. ANDERSON.
}

Sunday, May 22, 190\%.

Breakfast. - Oatmeal 200 grams, sugar $28^{\prime}$ grams, coffee 150 grams, roll 60 grams, butter 6 grams.

Lunch. - Fried rice 140 grams, syrup 48 grams, potato 100 grams, macaroni 155 grams, boiled onions 80 grams, butter 5 grams, coffee 150 grams, cream 25 grams, sugar 14 grams, ice cream 185 grams, cake 34 grams.

Dinner. - Cream of celery soup 150 grams, mashed potato 134 grams, butter 11 grams, spinach 100 grams, strawberry short-cake 185 grams, cream 70 grams, sugar 28 grams.

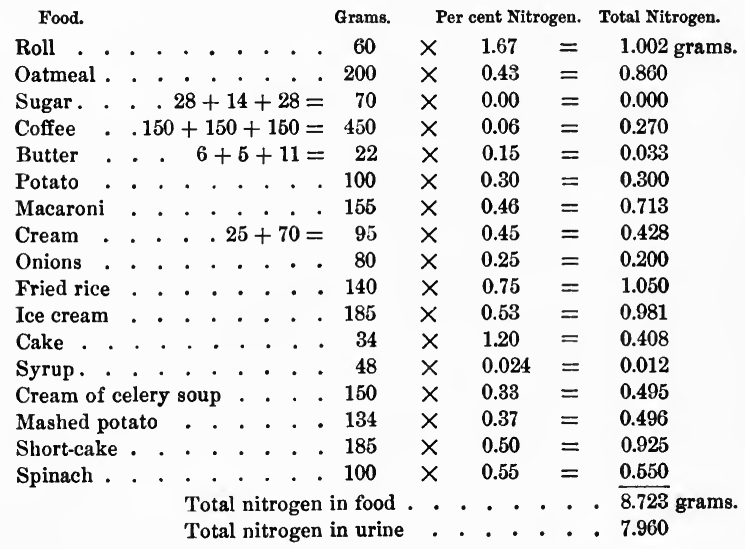

Fuel value of the food . . . 2812 calories. 


\section{W. L. ANDERSON.}

$$
\text { Monday, May 23, 1904. }
$$

Breakfast. - Banana 115 grams, wheat griddle cakes 87 grams, syrup 48 grams, butter 7 grams, coffee 150 grams, sugar 28 grams, cream 50 grams.

Luncl. - Fried potato 100 grams, rice croquette 115 grams, syrup 48 grams, apple sauce 125 grams, coffee 150 grams, sugar 14 grams.

Dinner. - Macaroni 270 grams, potato croquette 134 grams, coffee 150 grams. sugar 14 grams, water ice 154 grams.

Food.

Grams. Per cent Nitrogen. Total Nitrogen.

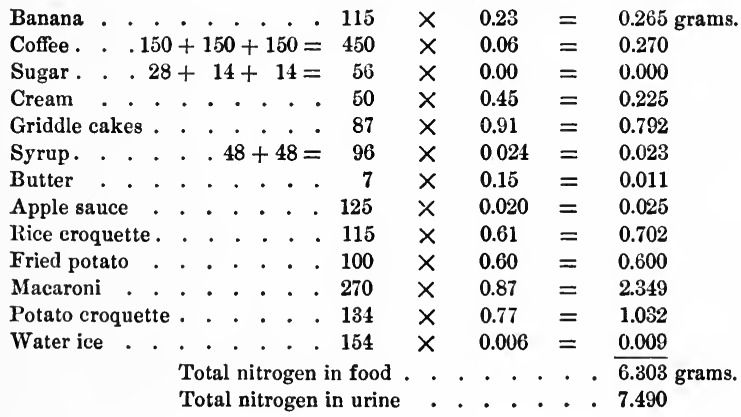

Fuel value of the food . . . 2224 calories. 


\author{
W. L. ANDERSON.
}

Tuesday, May 24, 1904.

Breakfast. - Fried rice 115 grams, syrup 48 grams, roll 60 grams, butter 14 grams, coffee 150 grams, sugar 14 grams.

Lunch. - Celery soup 150 grams, farina croquette 108 grams, syrup 48 grams, fried potato 200 grams, bread 22 grams, butter 7 grams, coffee 150 grams, sugar 14 grams.

Dinner. - Fried potato 200 grams, cream pie 167 grams, coffee 150 grams, cream 25 grams, sugar 14 grams.

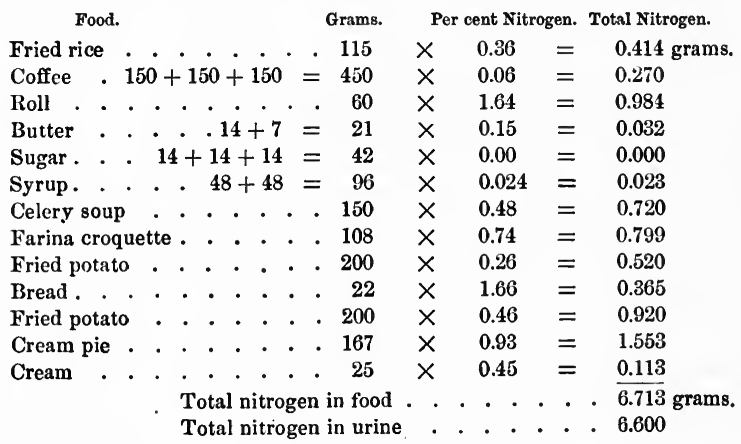

Fuel value of the food . . . . 2324 calories. 


\section{PHYSIOLOGICAL ECONOMY IN NUTRITION}

NITROGEN BALANCE. - W. L. Anderson.

\begin{tabular}{|c|c|c|c|}
\hline \multirow[b]{2}{*}{ May 18} & \multirow{2}{*}{ 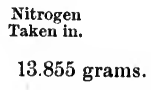 } & \multicolumn{2}{|c|}{$\begin{array}{l}\text { Output. } \\
\text { Nitrogen in Urine. Weight of Fæces (dry). }\end{array}$} \\
\hline & & 10.03 grams. & 42.3 grams. \\
\hline 19 & 10.960 & 10.15 & $\cdots$ \\
\hline 20 & 6.260 & 8.64 & 17.5 \\
\hline 21 & 8.623 & 8.46 & $\cdots$ \\
\hline 22 & 8.723 & 7.96 & 42.7 \\
\hline 23 & 6.303 & 7.49 & 41.0 \\
\hline 24 & 6.713 & 6.60 & 29.2 \\
\hline & & & 172.7 grams contain \\
\hline & & & $6.30 \% \mathrm{~N}$ \\
\hline & $\overline{61.437}$ & 59.33 & 10.880 grams nitrogen \\
\hline
\end{tabular}

Nitrogen balance for seven days $=-8.773$ grams.

Nitrogen balance per day $\quad=-1.253$ grams.

Average Intake.

Calories per day . . . . . . . 2494.

Nitrogen per day . . . . . . 8.777 grams. 
Here, we find a minus balance of 8.773 grams of nitrogen for the seven days' period. The total intake of nitrogen amounted to 61.437 grams, while there were excreted through the urine 59.33 grams, and through the fæces 10.880 grams of nitrogen, making a total output of 70.210 grams as contrasted with an intake of 61.437 grams of nitrogen. This loss of body material is to be attributed to the small fuel value of the food,- only 2494 calories as the day's average, - though perhaps in part to the relatively small intake of nitrogen. In this connection it is to be noted that the average daily excretion of metabolized nitrogen for the seven days' period amounted to only 8.777 grams, while the average daily excretion for the last two months of the experiment was as high as $\mathbf{1 0 . 0 7}$ grams. Undoubtedly, the subject did not eat as much food during the week of this balance trial as was needed to maintain equilibrium, under the conditions of bodily activity then prevaiiing.

The same statement applies to Mr. Bellis, whose balance trial likewise shows a deficiency of ingested nitrogen over the nitrogen output. Here, however, the deficiency is more manifestly due to the small fuel value of the daily food, which averaged only 2174 calories. Bellis showed an average daily excretion of metabolized nitrogen amounting to 8.45 grams for the last six weeks of the experiment, while in the balance period the excretion of metabolized nitrogen was 8.19 grams per day. The daily intake of nitrogen in the food, however, averaged only 7.76 grams, obviously too small a quantity to meet the wants of the body, especially with the low fuel value of the food. It is quite plain that during the week of this balance trial, the amount of food consumed was not equal to the necessities of the body, neither was it equal in nitrogen or fuel value to what the subject had been taking during the last few months of the experiment, and on which he had practically maintained body-weight for at least the last month of the experiment. It is further noticeable that during the balance week the body-weight dropped off somewhat. 
Owing to the absence of Dr. Callahan from New Haven during this period, no attempt was made to determine experimentally whether he was in nitrogen equilibrium or not.

The following tables give the data in the experiment with Bellis : -

\section{BELLIS.}

\section{Wednesday, May 18, 1904.}

Breakfast. - Banana 94 grams, wheat roll 53 grams, butter 11 grams, coffee 150 grams, cream 75 grams, sugar 21 grams.

Lunch. - Soup 150 grams, farina croquette 100 grams, syrup 50 grams, string beans 75 grams, fried sweet potato 117 grams, bread 36 grams, butter 7 grams, coffee 150 grams, sugar 14 grams.

Dinner. - Hamburg steak 53 grams, potato 250 grams, spinach 100 grams, bread 55 grams, butter 10 grams, coffee 150 grams, cream 75 grams, sugar 21 grams, apple pie 142 grams.

Food.

Grams. Per cent Nitrogen. Total Nitrogen.

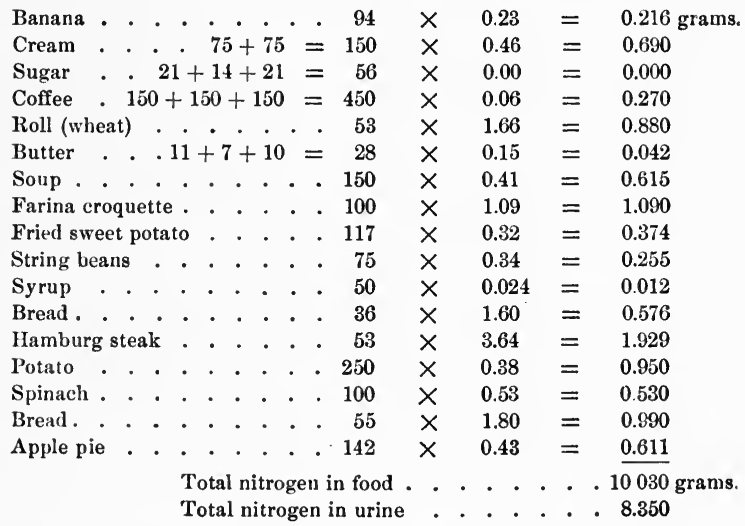




\section{BELLIS.}

\section{Thursday, May 19, 1904.}

Breakfast. - Banana 155 grams, roll 53 grams, butter 10 grams, coffee 150 grams, sugar 28 grams, cream 70 grams.

Lunch.-Fried hominy 60 grams, syrup 48 grams, potato 100 grams, boiled onion 82 grams, coffee 150 grams, cream 35 grams, sugar 21 grams, bread pudding 134 grams.

Dinner. - Tomato soup 200 grams, macaroni 75 grams, mashed potato 54 grams, spinach 70 grams, boiled Indian-meal 100 grams, coffee 150 grams, cream 80 grams, sugar 21 grams.

\begin{tabular}{|c|c|c|c|c|c|c|c|c|}
\hline Food. & & & & Grams. & & cent Nitr & gen. & Total Nitrogen. \\
\hline Roll . & . & . & . & 53 & $x$ & 1.54 & $=$ & 0.816 grams. \\
\hline Banana . & . & . & . & 155 & $x$ & 0.23 & $=$ & 0.357 \\
\hline Butter . & . & . & . & 10 & $x$ & 0.15 & $=$ & 0.015 \\
\hline Coffee & 150 & +150 & & 450 & $x$ & 0.06 & $=$ & 0.270 \\
\hline Sugar. & 21 & +21 & & 70 & $x$ & 0.00 & $=$ & 0.000 \\
\hline Cream & $35+$ & 80 & & 185 & $x$ & 0.47 & $=$ & 0.870 \\
\hline Potato . . . & . & . & . & 100 & $x$ & 0.49 & $=$ & 0.490 \\
\hline Fried hominy . & . & . & . & 60 & $x$ & 0.67 & $=$ & 0.402 \\
\hline Boiled onion . & . & . & . & 82 & $x$ & 0.27 & $=$ & 0.221 \\
\hline Bread pudding & . & . & • & 134 & $x$ & 0.28 & $=$ & 0.375 \\
\hline Syrup . . & . & . & & 48 & $x$ & 0.024 & $=$ & 0.012 \\
\hline Tomato soup . & . & . & . & 200 & $x$ & 0.53 & $=$ & 1.060 \\
\hline Macaroni . & . & . & • & 75 & $x$ & 0.93 & $=$ & 0.698 \\
\hline Mashed potato & . & . & . & 54 & $x$ & 0.38 & $=$ & 0.205 \\
\hline Spinach . . . & . & . & - & 70 & $x$ & 0.56 & $=$ & 0.392 \\
\hline Boiled Indian-mea & . & . & . & 100 & $x$ & 0.20 & $=$ & 0.200 \\
\hline & $\begin{array}{l}\text { Total } \\
\text { Total }\end{array}$ & $\begin{array}{l}\text { nitro } \\
\text { nitro }\end{array}$ & & $\begin{array}{l}n \text { in food } \\
n \text { in urine }\end{array}$ & . & $\begin{array}{l}\cdot \\
.\end{array}$ & . & $\begin{array}{l}6.383 \text { grams } \\
9.600\end{array}$ \\
\hline
\end{tabular}

Fuel value of the food . . . . 2075 calories. 


\section{BELLIS.}

Friday, May 20, 1904.

Breakfast. - Orange 150 grams, roll 57 grams, butter 17 grams, coffee 159 grams, sugar 14 grams.

Lunch. - Fried farina 74 grams, syrup 48 grams, potato 250 grams, lima beans 50 grams, coffee 150 grams, sugar 14 grams.

Dinner. - Rice croquette 92 grams, syrup 48 grams, string beans 93 grams, mashed potato 352 grams, bread 40 grams, butter 8 grams, coffee 150 grams, sugar 14 grams.

Evening. - Beer 450 grams.

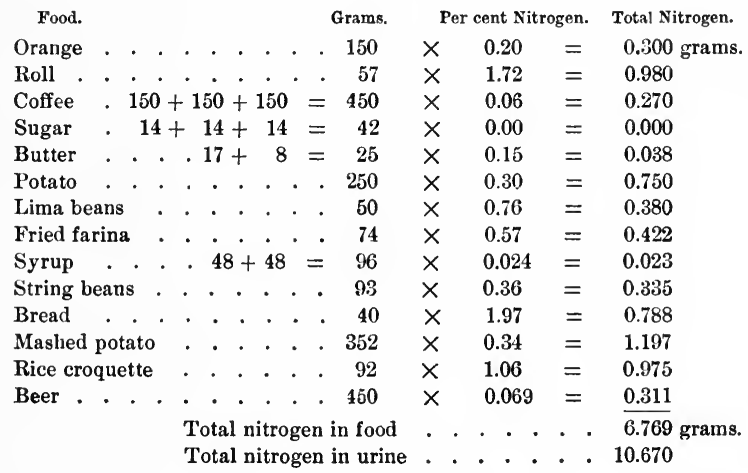

Fuel value of the food . . . 1980 calories. 


\section{BELLIS.}

Saturday, May 21, 1904.

Breakfast - Banana 69 grams, baked potato 57 grams, bread 59 grams, butter 8 grams, coffee 150 grams, sugar 14 grams.

Lunch. - Fried Indian-meal 80 grams, syrup 48 grams, potato croquette 152 grams, tomato 147 grams, coffee 150 grams, sugar 14 grams, water ice 163 grams.

Dinner. - Bean soup 150 grams, bacon 13 grams, fried egg 50 grams, fried potato 206 grams, lettuce salad 45 grams, bread 38 grams, butter 8 grams, coffee 150 grams, sugar 14 grams.

Evening. - Beer 600 granıs.

Food.

Banana . . . . . . . . 69

Bread . . . . . . . . . . 59

Coffee $.150+150+150=450$

Sugar. $.14+14+14=42$

Baked potato . . . . . . . 57

Butter . . . $8+8=16$

Potato croquette . . . . . 152

Tomato . . . . . . . . . 147

Fried Indian-meal . . . . . 80

Syrup . . . . . . . . . 48

Water ice . . . . . . . . 163

Bread . . . . . . . . . . 38

Bacon . . . . . . . . 13

Fried egg . . . . . . . . . 50

Bean soup . . . . . . . . 150

Lettuce salad . . . . . . . 45

Fried potato . . . . . . . 206

Beer . . . . . . . . . . $600 \times$

Total nitrogen in food . Total nitrogen in urine
Per cent Nitrogen. Total Nitrogen.

$$
\times \quad 0.23=0.159 \text { grams. }
$$$$
\times \quad 1.65=0.974
$$$$
\times \quad 0.06=0.270
$$$$
\times \quad 0.00=0.000
$$$$
\times \quad 0.40=0.228
$$$$
\times \quad 0.15=0.024
$$

$\times \quad 0.71=1.079$

$\times \quad 0.17=0.250$

$\times \quad 1.09=0.872$

$\times \quad 0.024=0.012$

$\times \quad 0.012=0.020$

$\times \quad 1.62=0.616$

$\times \quad 3.05=0.397$

$\times \quad 2.27=1.135$

$\times \quad 1.21=1.815$

$\times \quad 0.21=0.095$

$\times \quad 0.60=1.236$

$\times \quad 0.069=0.414$ 


\section{BELLIS.}

Sunday, May 22, 1904.

Breakfast. - Orange 100 grams, oatmeal 100 grams, roll 50 grams, butter 8 grams, coffee 150 grams, cream 40 grams, sugar 21 grans.

Lunch. - Macaroni 112 grams, potato 200 grams, onions 143 grams, coffee 150 grams, sugar 7 grans, ice cream 170 grams, cake 31 grams.

Dinner. - Cream of celery soup 150 grams, mashed potato 182 grams, spinach 100 grams, coffee 150 grams, sugar 7 grams, strawberry short-cake 97 grams.

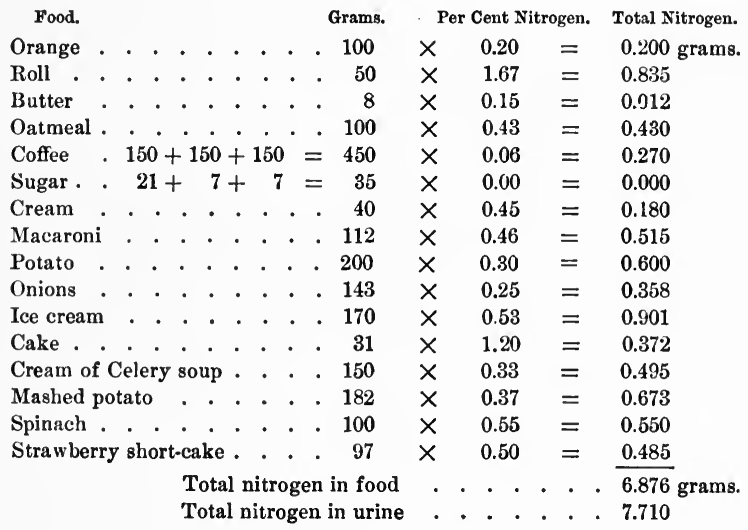

Fuel value of the food . . . 1929 calories. 


\title{
BELLIS.
}

\author{
Monday, May 23, 1904.
}

Breakfast. - Banana 219 grams, coffee 150 grams, cream 80 grams, sugar 28 grams.

Lunch. - Rice croquette 143 grams, syrup 45 grams, potato 200 grams, coffee 150 grams, sugar 7 grams, apple sauce 250 grams.

Dinner. - Vegetable soup 150 grams, bacon 37 grams, string beans 100 grams, potato 101 grams, macaroni 86 grams, coffee 150 grams, water ice 184 grams.

Food. - Grams. Per cent Nitrogen. Total Nitrogen.

\begin{tabular}{|c|c|c|c|c|c|c|c|c|c|c|c|c|c|}
\hline Banana & & - & . & . & - & . & - & - & 219 & $x$ & 0.23 & $=$ & 0.504 grams. \\
\hline Cream & . & . & . & • & 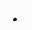 & • & . & . & 80 & $x$ & 0.45 & $=$ & 0.360 \\
\hline Sugar & • & . & . & & 28 & +7 & & $=$ & 35 & $x$ & 0.00 & $=$ & 0.000 \\
\hline Coffee & & 150 & +1 & 150 & & 150 & & $=$ & 450 & $\times$ & 0.06 & $=$ & 0.270 \\
\hline Apple sau & & 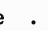 & . & . & . & . & . & . & 250 & $x$ & 0.02 & $=$ & 0.050 \\
\hline Rice croq & uet & tte & . & . & . & . & . & . & 143 & $x$ & 0.61 & $=$ & 0.872 \\
\hline Syrup. & . . & . . & . & . & . & . & . & . & 45 & $x$ & 0.024 & $=$ & 0.011 \\
\hline Potato & - & . & . & . & . & . & . & - & 200 & $x$ & 0.60 & $=$ & 1.200 \\
\hline Macaroni & & . . & . & . & . & . & . & . & 86 & $x$ & 0.87 & $=$ & 0.748 \\
\hline Vegetable & e 80 & oup & . & . & . & . & . & . & 150 & $x$ & 0.70 & $=$ & 1.050 \\
\hline Bacon & . . & . & . & . & . & . & . & . & 37 & $x$ & 3.28 & $=$ & 1.214 \\
\hline String be & ans & $s$. & • & - & . & . & . & . & 100 & $x$ & 0.22 & $=$ & 0.220 \\
\hline Potato cr & oqu & uette & e. & . & . & . & . & . & 101 & $x$ & 0.77 & $=$ & 0.778 \\
\hline Water ice & & . . & . & . & . & . & . & . & 184 & $x$ & 0.006 & $=$ & 0.011 \\
\hline
\end{tabular}

Fuel value of the food . . . 2226 calories. 


\section{BELLIS.}

\section{Tuesday, May 24, 1904.}

Breakfast. - Orange 100 grams, baked potato 138 grams, butter 5 grams, coffee 150 grams, sugar 14 grams.

Lunch. - Celery soup 150 grams, farina croquette 91 grams, syrup 48 grams, boiled onions 110 grams, potato 200 grams, stewed prunes 113 grains.

Dinner. - Tomato soup 150 grams, farina croquette 107 grams, syrup 48 grams, potato 200 grams, spinach 180 grams, cream pie 140 grams.

Food. Grams. Per cent Nitrogen. Total Nitrogen.

\begin{tabular}{|c|c|c|c|c|c|c|c|c|c|c|}
\hline Orange $\cdot$ & • & - & - & - & • & 100 & $x$ & 0.20 & $=$ & 0.200 grams. \\
\hline Baked potato & . & . & . & . & . & 138 & $x$ & 0.25 & $=$ & 0.345 \\
\hline Coffee. . . & . & . & . & . & . & 150 & $x$ & 0.06 & $=$ & 0.090 \\
\hline Sugar. & . & . & - & . & . & 14 & $x$ & 0.00 & $=$ & 0.000 \\
\hline Butter . . & - & . & . & . & . & 5 & $x$ & 0.15 & $=$ & 0.008 \\
\hline Boiled onions & & - & . & • & . & 110 & $x$ & 0.30 & $=$ & 0.330 \\
\hline Celery soup & . & . & . & . & . & 150 & $x$ & 0.48 & $=$ & 0.720 \\
\hline Potato. . & . & . & . & . & . & 200 & $x$ & 0.26 & $=$ & 0.520 \\
\hline Farina croquet & te & . & . . & . & . & 91 & $x$ & 0.74 & $=$ & 0.673 \\
\hline Syrup . . & & . & $48+$ & -48 & $=$ & 96 & $x$ & 0.024 & $=$ & 0.023 \\
\hline Stewed prunes & & - & . . & . & . . & 113 & $x$ & 0.17 & $=$ & 0.192 \\
\hline Spinach . . & • & • & . & . & . & 180 & $x$ & 0.54 & $=$ & 0.972 \\
\hline Tomato soup & & - & . & . & . & 150 & $x$ & 0.19 & $=$ & 0.285 \\
\hline Potato . . & & . & . & - & . & 200 & $x$ & 0.46 & $=$ & 0.920 \\
\hline Farina croquet & & . & . & . & . & 107 & $x$ & 0.76 & $=$ & 0.813 \\
\hline Cream pie & & . & . & . & . & 140 & $x$ & 0.93 & $=$ & 1.302 \\
\hline & & & tal $n$ & nitro & ger & $\begin{array}{l}\text { in food } \\
\text { in urine }\end{array}$ & & $\dot{.} \cdot$ & · & $\begin{array}{l}7.393 \text { grams. } \\
6.610\end{array}$ \\
\hline
\end{tabular}

Fuel value of the food . . . 2254 calories. 


\title{
NITROGEN BALANCE. - Bellis.
}

\author{
Nitrogen Output. \\ Taken in. Nitrogen in Urine. Weight of Fæces (dry).
}

\begin{tabular}{|c|c|c|c|}
\hline May 18 & 10.030 grams. & 8.35 grams. & $\cdots$ \\
\hline 19 & 6.383 & 9.60 & $\ldots$ \\
\hline 20 & 6.769 & 10.67 & $\ldots$ \\
\hline 21 & 9.596 & 8.46 & 51.0 grams. \\
\hline 22 & 6.876 & 7.71 & 46.0 \\
\hline 23 & 7.288 & 5.98 & 27.2 \\
\hline \multirow[t]{4}{*}{24} & 7.393 & 6.61 & 57.5 \\
\hline & & & 181.7 grams contain \\
\hline & & , & $6.38 \% \mathrm{~N}$. \\
\hline & 54.335 & 57.38 & 11.592 grams nitrogen \\
\hline
\end{tabular}

Nitrogen balance for seven days $=\quad-14.637$ grams.

Nitrogen balance per day $\quad=\quad-2.091$ grams.

Average Intake.

Calories per day . . . . . . 2174.

Nitrogen per day . . . . . 7.762 grams. 


\section{The Physical Condition of the Subjects.}

Having considered the marked decline in the extent of proteid metabolism which these subjects have exhibited for a period of five months, and having shown the possibility of their maintaining body-weight and nitrogen equilibrium on a low proteid intake, coupled with a relatively small amount (low fuel value) of non-nitrogenous food, it is appropriate to consider next their physical condition under this changed mode of living. So much has been written upon the necessity of a rich proteid diet, with a corresponding rate of proteid metabolism, for the maintenance of bodily strength and vigor, that it becomes a question of vital importance to obtain data bearing upon the effect of a lowered proteid intake upon bodily strength. If, as is so widely believed, diminishing the daily proportion of proteid food below the standards set by Voit and other physiologists will result in a weakening of the muscles of the body, in decreasing the strength, vigor, and endurance of the individual, then obviously physiological economy in this direction would in the long run be uneconomical, and indeed injurious. 'The maintenance of body-weight and of nitrogen equilibrium on a small amount of proteid food would count for little, when compared with a gradual loss of bodily strength and vigor.

It was truly a great surprise when the systematic strength tests applied month after month to the soldiers indicated a marked gain in muscular power, which seemingly increased as the rate of proteid metabolism diminished, coincident with the decrease in the amount of proteid food fed. The dynamometer tests were applied primarily to make sure there was no falling off in strength, and when the marked gains already referred to were recorded, it was thought at first that they must be the result mainly of the systematic training the soldiers were undergoing in the gymnasium. Undoubtedly, this daily training, with the more regular and systematic methods of living, did contribute in some measure to the beneficial results obtained, but as the improvement and general gain in 
strength became more and more apparent, it was equally clear there were other factors involved than mere training.

The opportunity presented by the present subjects therefore was particularly desirable. These men had been in training for many months, some of them for several years, and naturally had acquired a high degree of proficiency in all kinds of athletic work, in the handling of themselves and in the handling of the apparatus, by use of which the strength tests are made.

The tests, etc., were applied exactly in the same manner as in the case of the soldier detail, description of which will be found on pages 259 and 260 .

The following tables give the results of the tests - made at the Yale Gymnasium, and reported by Dr. Anderson - from January to June, for the eight men. It will be noted, however, that the record of Mr. Bellis is incomplete. This was owing to an injury to his hand, which prevented his working with the apparatus during the months of May and June.

The results presented by these tables are very important and suggestive. Every man, without exception, showed a decided improvement in his muscular power as measured by the strength tests. With many of the men the gain was progressive, with others there was noticeable - as in the case of W. L. Anderson and G. W. Anderson in the March test - a drop in some one test. This could generally be explained by some temporary cause. Thus, the March test taken by W. L. Anderson was at a time when he was under great strain in connection with an intercollegiate meet, etc. However, it is clear from the figures presented that all these men, though living on a greatly reduced amount of proteid food, and with certainly no increase in the quantity of non-nitrogenous food, showed at the end of the experiment a decided gain in muscular power. Note for example the great gain in strength shown by Schenker; in January his dynamometer tests, etc., indicated a total of 5728, while at the close of the experiment in June his record was 7135. Again, Bellis increased from 5993 to 8165, and W. L. Anderson from 6016 to 9472 . Further, the 


\section{STRENGTH OR DYNANOMETER TESTS.}

\begin{tabular}{|c|c|c|c|c|c|c|c|c|c|c|c|c|c|}
\hline \multicolumn{14}{|c|}{ Anderson, G. W. } \\
\hline & 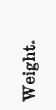 & 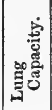 & 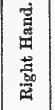 & 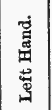 & $\begin{array}{l}\text { 总 } \\
\text { త్ }\end{array}$ & 总 & 念 & $\begin{array}{l}\stackrel{\dot{3}}{3} \\
\dot{\bar{\Xi}}\end{array}$ & 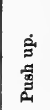 & 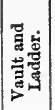 & 竎 & 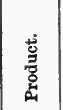 & 离 \\
\hline Jan. 20 & 163 & 500 & 108 & 97 & 85 & 425 & 900 & 8 & 11 & $\mathbf{E}$ & 1.05 & 3300 & 4913 \\
\hline Feb. 20 & 163 & 535 & 109 & 105 & 70 & 380 & 570 & 10 & 14 & $\mathrm{E}$ & 1.07 & 3972 & 5206 \\
\hline Mar. 20 & 159 & 530 & 110 & 103 & 75 & 410 & 720 & 10 & 9 & $\mathrm{E}$ & 1.07 & 3021 & 4439 \\
\hline Apr. 20 & 161 & 500 & 101 & 97 & 85 & 490 & 810 & 13 & 11 & . & 1.05 & 3864 & 5387 \\
\hline May 26 & 159 & 532 & 120 & 100 & 80 & 475 & 885 & 9 & 15 & $\ldots$ & $\ldots$ & 3816 & 5476 \\
\hline June 17 & 157 & 530 & 100 & 90 & 80 & 530 & 840 & 12 & 14 & . & $\cdots$ & 4082 & 5722 \\
\hline \multicolumn{14}{|c|}{ Anderson, W. L. } \\
\hline Jan. 20 & 139 & 420 & 95 & 88 & 145 & 410 & 625 & 13 & 20 & $\mathrm{E}$ & 0.48 & 4553 & 6016 \\
\hline Feb. 20 & 136 & 440 & 95 & 80 & 137 & 550 & 560 & 15 & 25 & $\mathbf{E}$ & 0.45 & 5520 & 6942 \\
\hline Mar. 20 & 135 & 430 & 95 & 85 & 140 & 510 & 570 & 11 & 15 & $\mathrm{E}$ & 0.47 & 3510 & 4890 \\
\hline Apr. 20 & 138 & 460 & 93 & 75 & 165 & 650 & 730 & 12 & 30 & $\ldots$ & 1.04 & 5806 & 7519 \\
\hline May 26 & 134 & 450 & 90 & 70 & 155 & 570 & 880 & 25 & 31 & . & $\cdots$ & 7504 & 9267 \\
\hline June 17 & 137 & 450 & 95 & 85 & 160 & 600 & 860 & 30 & 26 & . & $\cdots$ & 7672 & 9472 \\
\hline \multicolumn{14}{|c|}{ Bellis. } \\
\hline Jan. 20 & 180 & 550 & 130 & 130 & 155 & 550 & 825 & 10 & 13 & $\mathbf{E}$ & 1.06 & 4653 & 599 \\
\hline Feb. 20 & 174 & 500 & 155 & 135 & 135 & 580 & 925 & 11 & 15 & E & 1.08 & 4615 & 6445 \\
\hline Mar. 20 & 176 & 550 & 150 & 135 & 155 & 500 & 900 & 12 & 20 & E & 1.08 & 5728 & 7568 \\
\hline Apr. 20 & 177 & 510 & 160 & 150 & 150 & 560 & 1111 & 13 & 21 & $\cdots$ & $\cdots$ & 6035 & 8165 \\
\hline \multicolumn{14}{|c|}{ Callahan. } \\
\hline Jan. 20 & 204 & 565 & 105 & 110 & 145 & 450 & 620 & 2 & 1 & D & 1.20 & 724 & 2154 \\
\hline Feb. 20 & 193 & 560 & 120 & 120 & 145 & 440 & 590 & 4 & 3 & $\mathbf{F}$ & 1.18 & 1365 & 2780 \\
\hline Mar. 20 & 185 & 565 & 125 & 115 & 145 & 420 & 650 & 5 & 4 & $\mathbf{E}$ & 1.15 & 1692 & 3142 \\
\hline Apr. 20 & 181 & 580 & 120 & 120 & 145 & 530 & 685 & 5 & 4 & . & 1.16 & 1629 & 3229 \\
\hline June 18 & 184 & $\ldots$ & 120 & 115 & 140 & 520 & 890 & 7 & 5 & . & 1.14 & 2208 & 3983 \\
\hline
\end{tabular}




\section{Donahue.}

\begin{tabular}{|c|c|c|c|c|c|c|c|c|c|c|c|c|c|}
\hline & 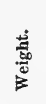 & 离 & 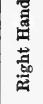 & 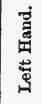 & $\begin{array}{l}\text { 芯 } \\
\text { むే }\end{array}$ & 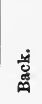 & 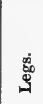 & 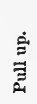 & 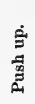 & 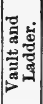 & 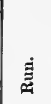 & 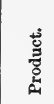 & $\begin{array}{l}\text { ङ્ } \\
\text { स्ञ }\end{array}$ \\
\hline Jan. 20 & 142 & 320 & 95 & 100 & 74 & 330 & 500 & 12 & 12 & $\mathbf{E}$ & 1.04 & 3480 & 4584 \\
\hline Feb. 20 & 136 & 345 & 105 & 115 & 95 & 340 & 490 & 13 & 14 & $\mathbf{E}$ & 1.04 & 3753 & 4905 \\
\hline Mar. 20 & 137 & 400 & 110 & 95 & 100 & 340 & 710 & 15 & 16 & E & 1.06 & 4309 & 5664 \\
\hline May 1 & 138 & 420 & 95 & 80 & 115 & 360 & 650 & 17 & 16 & $\cdots$ & $\ldots$ & 4554 & 5854 \\
\hline May 26 & 137 & 425 & 108 & 90 & 135 & 430 & 570 & 17 & 16 & $\cdots$ & $\ldots$ & 4589 & 5917 \\
\hline
\end{tabular}

JасовUs.

\begin{tabular}{|l|l|l|l|l|l|l|l|l|l|l|l|l|l|}
\hline Jan. 20 & 126 & 350 & 97 & 93 & 96 & 250 & 300 & 14 & 14 & E & 1.00 & 3712 & 4548 \\
Feb. 20 & 124 & 380 & 97 & 97 & 75 & 460 & 470 & 15 & 15 & E & 1.02 & 3683 & 4883 \\
Mar. 20 & 125 & 370 & 95 & 95 & 80 & 430 & 490 & 15 & 15 & E & 1.03 & 3810 & 5000 \\
May 2 & 124 & 350 & 85 & 90 & 100 & 350 & 510 & 15 & 14 & $\ldots$ & 1.03 & 3610 & 4740 \\
May 26 & 125 & 360 & 95 & 95 & 110 & 360 & 600 & 14 & 17 & $\ldots$ & $\ldots$ & 3875 & 5135 \\
June 16 & 125 & 375 & 95 & 85 & 120 & 400 & 700 & 15 & 19 & $\ldots$ & $\ldots$ & 4267 & 5667
\end{tabular}

Schenker.

\begin{tabular}{|c|c|c|c|c|c|c|c|c|c|c|c|c|c|}
\hline Jan. 20 & 161 & 485 & 112 & 90 & 135 & 410 & 440 & 14 & 14 & $\mathbf{E}$ & 1.06 & 4771 & 5728 \\
\hline Feb. 20 & 159 & 490 & 115 & 90 & 125 & 530 & 730 & 14 & 15 & E & 1.07 & 4748 & 6338 \\
\hline Mar. 20 & 158 & 500 & 100 & 95 & 120 & 550 & 780 & 15 & 15 & E & 1.12 & 4830 & 6475 \\
\hline Apr. 20 & 164 & 490 & 90 & 90 & 127 & 410 & 580 & 17 & 15 & . & 110 & 5248 & 6545 \\
\hline May 26 & 159 & 500 & 125 & 105 & 155 & 470 & 850 & 16 & 15 & . & 1.08 & 5104 & 6809 \\
\hline June 9 & 160 & 500 & 110 & 110 & 155 & 570 & 910 & 17 & 16 & . & $\ldots$ & 5280 & 7135 \\
\hline
\end{tabular}

Sta Pleton.

\begin{tabular}{|l|r|r|r|r|r|r|r|r|r|r|r|r|r|}
\hline Jan. 20 & 170 & 520 & 105 & 105 & 155 & 455 & 570 & 11 & 12 & $\mathrm{~F}$ & 1.21 & 3961 & 5351 \\
Feb. 20 & 167 & 520 & 105 & 110 & 160 & 550 & 690 & 6 & 10 & $\mathrm{E}$ & 1.22 & 2704 & 4319 \\
Mar. 20 & 170 & 500 & 100 & 100 & 145 & 350 & 600 & 7 & 12 & $\mathrm{E}$ & $\ldots$ & 3268 & 4563 \\
Apr. 20 & 162 & 500 & 100 & 105 & 155 & 410 & 670 & 9 & 14 & $\ldots$ & $\ldots$ & 3726 & 5886 \\
May 26 & 164 & 515 & 100 & 95 & 150 & 470 & 770 & 12 & 20 & $\ldots$ & $\ldots$ & 5248 & 6833 \\
\hline
\end{tabular}


men all agree in the good effect the changed conditions have had upon them, and they have, without exception, been able to do their athletic work and maintain their athletic supremacy.

Naturally, in the case of these men the gain in strength recorded cannot be assigned to systematic training. The only change in their mode of living which can in any sense be considered as responsible for the improvement is the change in diet. The main fact to be emphasized, however, is that these men - trained athletes, accustomed to living on relatively large amounts of proteid food - for a period of five months reduced their intake of proteid food more than fifty per cent without loss of bodily strength, but, on the contrary, with a marked improvement in their muscular power.

Most striking is this gain in strength when compared with the very marked decline in the rate of proteid metabolism. Thus, in the case of Jacobus, the excretion of metabolized nitrogen was reduced to 7.43 grams per day as the average for the last two months of the experiment, yet his strength test showed an increase from 4548 in January to 5667 for June. Further, it must be recalled that an excretion of 7.43 grams of nitrogen means the metabolism of only 46.4 grams of proteid matter. Similarly, in the case of Donahue, a very active man whose work on the Varsity basket-ball team called for vigorous exercise, his strength test rose from 4584 to 5917 on a daily diet which led to the metabolism of only 7.39 grams of nitrogen per day, or about 46 grams of proteid matter. Further, Donahue frequently referred to the far greater freedom from fatigue he experienced on the low proteid diet, and he was clearly conscious of a distinct improvement in his physical condition.

The following letter from Dr. Anderson, the Director of the Yale Gymnasium, gives his estimate of the men at the end of the first three months of the experiment: 


\section{Yale University Gymnasium, New Haven, Conn., April 12, 1904.}

\section{Professor Russell H. Chitrenden,}

Director of the Sheffield Scientific

School, Yale University.

Dear Sir, - Herewith find a brief report of the physical condition and ability of the eight Yale students who are taking the special diet while engaged in active exercise.

These men, with one exception, Dr. Callahan, are experts in their special lines of avocation.

Mr. G. W. Andenson is a foot-ball, base-ball, and basket-ball player, as well as a crew man (not Varsity), well built and an all round athlete.

Mr. W. L. Anderson, a "Y" athlete (hurdler), the captain of the Yale Gymnastic Tean, University Gymnastic Champion, and American Collegiate Gymnastic Champion.

Mr. H. S. Bellis, a member of the Y. G. A., a gymnast and acrobat and in constant training.

Dr. W. H. Callahan, Medical Assistant at the Gymnasium, in daily practice in the gymnasium; bowling, hand-ball, and running.

Mr. M. Donahue, a very muscular and versatile athlete, a football player and a Varsity basket-ball player.

Mr. C. S. JACoBus, a "Y" athlete, a noted long-distance man, and one of the best University runners.

Mr. H. R. Schenker, an active member of the Y. G. A., a point winner and intercollegiate competitor in gymnastics.

Mr. Join Stapleton, a wrestler and gymnast. A professional, a man of large body and great strength.

These eight men are in constant practice and in the "pink of condition." They were in "training form" when they began the changed diet. All have lost in weight, especially Dr. Callahan, who has dropped from 204 pounds to $18 \mathfrak{5}$ pounds in two months. Dr. Callahan is not an athlete, but is a vigorous worker in the gymnasium, being in daily and constant practice. He is liberally supplied with adipose tissue and can well afford to drop in weight. 
As to the loss of weight in the other cases, it would not be wise to attribute this to the diet alone. We find that most athletes who represent the University in the big contests lose in body-weight, but $I$ attribute this loss as much to worry and responsibility as to strict bodily activity.

These students are in a different class from the soldiers, first, because they are well educated young men, secondly, because their development was towards a specific end, the attainment of strength and skill as representative Yale athletes, and thirdly, on account of college requirements of fifteen hours per week, which time stands for study and laboratory attendance aside from the recitations. We have here a double drain on the body energy. All mental work is expensive, hence the demand upon the corporeal machinery has been very constant and strenuous.

I notice little change in the condition of the men over that of a year ago, when I had most of them with me and under like physical training.

In the case of W. L. Anderson, captain of the Yale Gymnastic Association, there was a noticeable falling off in the strength tests in February and March, but I believe the worry incident to the intercollegiate contests, the steady training, and the business cares of the Association went far towards producing a fatigued state. W. L. Anderson is only a freshman in the Medical School; he did his studying at night, and this combined with his youth doubtless caused the loss of weight as much as any change in diet. He has shown the same symptoms before this year. At this writing he is in good physical condition. I speak with certainty in his case because I have had good opportunity to study him at home. It was while under the restricted diet that he won both championships, these being the Collegiate and All-around Intercollegiate Championship of America.*

Schenker won points for the first time in the intercollegiate contests while on the diet; he showed no falling off, rather to the contrary, made a steady gain in ability.

Jacobus complained of a pain in his side but in spite of this he has entered a number of events, has kept up his training and is in good condition. Jacobus is a long-distance runner; great endurance is required for these events, and this endurance he has

* Italics inserted by R. H. C. 


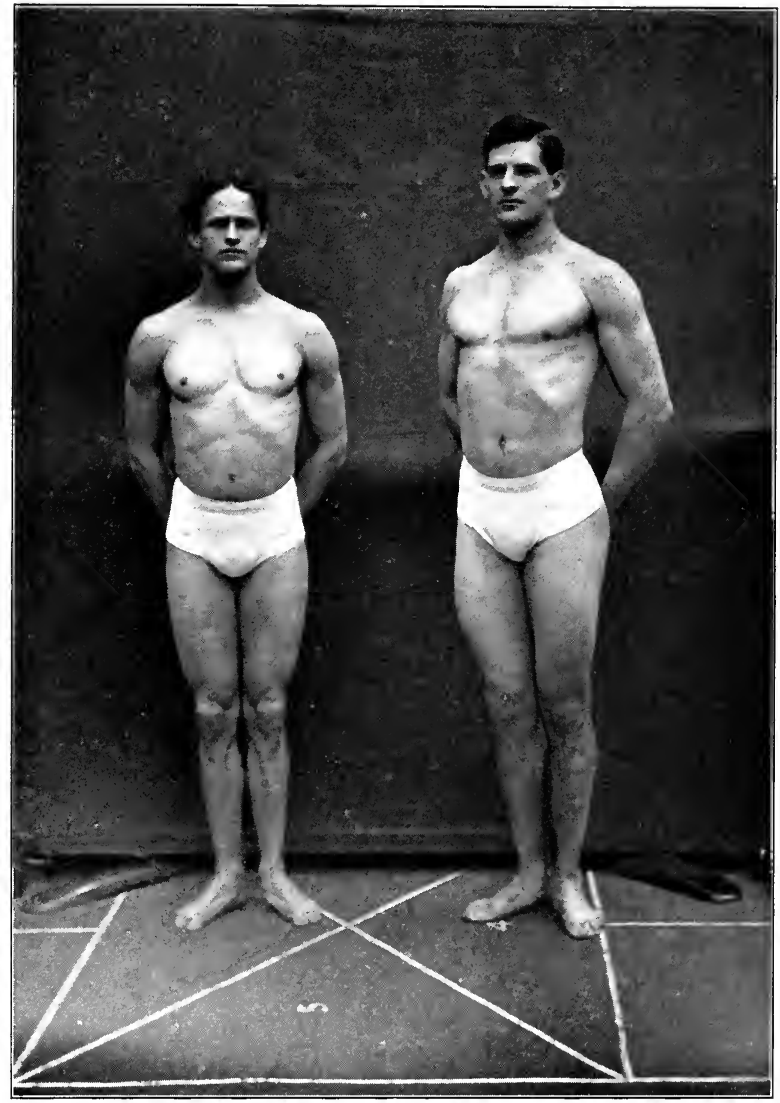

W. L. ANDERSON

BELLIS

Photographs taken prior to the experiment. 

kept up. He tells me his stomach is in better condition than it has been during his three years of work at Yale.

Donahue has steadily improved in ability. He has kept his position on the Varsity Basket Ball Team, and has put up strong and aggressive games, and says he is as well as ever.

Stapleton shows no falling off at all. He keeps up wrestling, which is a drastic exercise; he works at heavy gymnastics and gains steadily.

One matter must be reported in reference to the strength tests. The first trial was made when all members of the squad were present. College men are very sensitive to competition, hence the great exertion put forth. The other trials were made when the men were by themselves. The "spur" was missing.

I have watched the efforts of these men with interest and care, especially as two of them live in my own family. I fail to see any falling off in strength, the case of W. L. Anderson excepted. The fellows report being in satisfactory shape and claim that the "ups and downs" are no more in evidence this year than in the past.

These picked men, representing several kinds of competitive sports, have gained in ability and skill on the more limited diet they are now using, and are not showing any signs of deterioration from the diminished intake of proteid food. I pronounce them, from a physical standpoint, in good shape.

\section{Respectfully yours,}

(Signed) William G. Anderson.

It must be remembered that this letter from Dr. Anderson was written after the March strength test was taken, and prior to the test of April 20. Dr. Anderson was not in New Haven at the close of the experiment, consequently it was not possible to obtain his estimate of the men at that date, but there can be no question that there was a distinct improvement from the middle of April to the middle of June; certainly as marked as the improvement from the beginning of the experiment in January, to April 12, the date of Dr. Anderson's letter.

Finally, attention may be called to the photographs of Messrs. Stapleton, Bellis, and W. L. Anderson, which are in- 
troduced primarily to show the physical make-up and muscular development of the men composing this student group. The photographs of Stapleton were taken in April, 1904, after he had been under experiment for three months. The photographs of Bellis and W. L. Anderson were taken prior to the experiment. They all afford a good illustration of the highly developed muscular mechanism of different types, with a corresponding adaptability for different lines of muscular effort.

\section{Reaction Time.}

Through the courtesy and kind co-operation of Dr. Charles H. Judd, in charge of the Yale Psychological Laboratory, these students were subjected to the same careful tests during the five months of their experiment as were applied to the soldier detail. The results which are presented in the following report, kindly prepared by Dr. Judd, indicate quite clearly that there was no general nervous change in the reactors as a result of the low proteid diet. The data presented by Dr. Judd in this connection will be found in the accompanying tables, which, while indicating no noticeable improvement in the nervous condition of the men, make it quite plain that no deterioration whatever occurred as the result of the lowered proteid metabolism.

\section{REPORT ON REACTION}

Reaction tests with the group of University students were conducted in essentially the same way as were the reaction tests with the soldiers. Details in regard to the method and apparatus employed need not be repeated. They can be found on pages 274 to 276 .

Two new tests were added to the regular reaction determinations. One of these consisted in taking a record of the number of taps which could be executed in ten seconds. The reactor was seated before a table on which was fastened a telegraph key. He held the key between his thumb and first two fingers, and at a given signal began tapping as rapidly as possible until told to stop. Each time he tapped he closed an electric circuit. The 


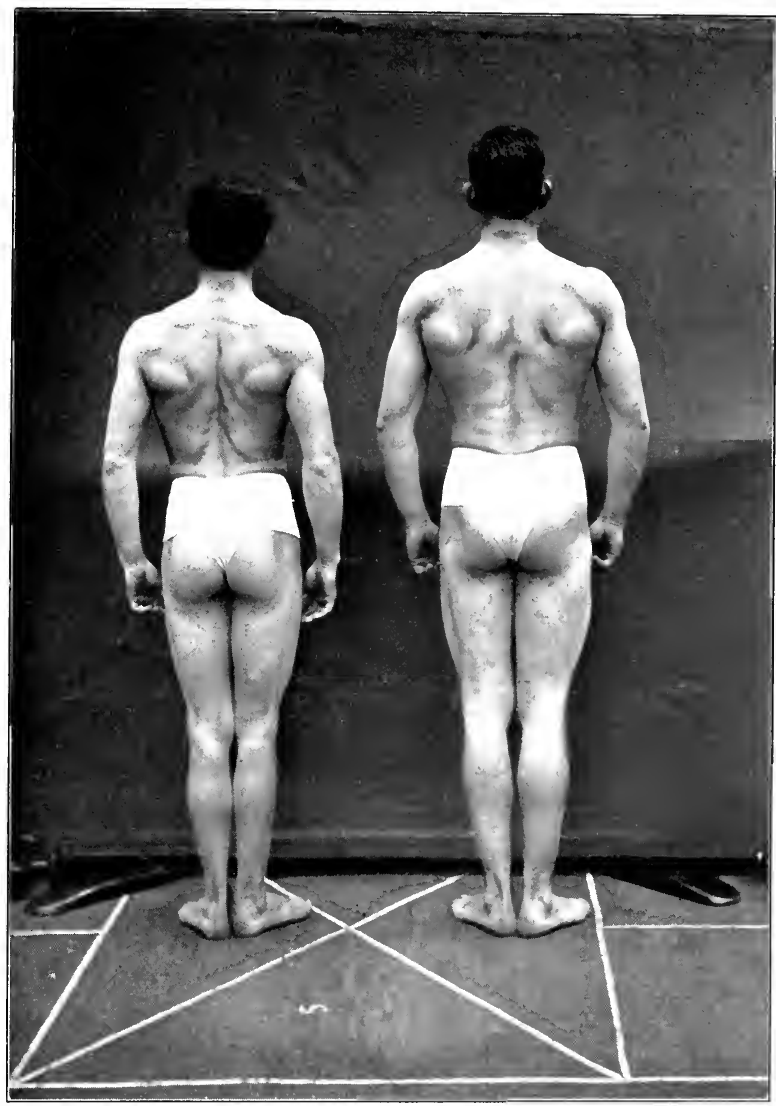

W. L. ANDERSON

BELLIS

Photographs taken prior to the experiment. 
current thus made was carried through a marker which indicated on a smoked paper each make and break at the key. A time line from a rod vibrating at the rate of once every twentieth of a second was traced on the smoked paper parallel with the marker record. By a comparison of the time line with the marker record, it was easy to determine the number of taps made in ten seconds. At first, the number of taps per second were counted, but the results showed such uniformity from second to second on a given day that only the net results for the whole ten seconds are given in the tables.

The second test added to the reaction tests was undertaken to determine the steadiness of the subjects. Two brass rods $40 \mathrm{~cm}$. long were beld in a vertical position at a distance of $7 \mathrm{~mm}$. from each other. The snbject took in his right hand a brass rod $40 \mathrm{~cm}$. long and $5 \mathrm{~mm}$. in diameter and tried to pass the end of this rod up and down between the rertical rods without touching them. The subject's relation to the vertical rods may be further defined by saying that he stood directly in front of them and reached out nearly at arm's length. The vertical rods were at about the height of his chest. In order to get a record of the accuracy with which the subject moved the hand-rod up and down without touching the vertical rods, the vertical rods and the hand-rod were connected with the two poles of an electric circuit. Whenever they touched they closed the circuit, and a marker placed in the same circuit recorded the fact on a smoked paper record. The time was recorded in parallel with this record, so that any long continued contact could be measured. For the most part, contacts were only of very brief duration. In reporting the results of this test, every contact made while passing the rod once downward and once upward is counted as at least one. Continued contacts are recorded as two, three or more, according to the period of duration. Where there are such added counts becanse of continued contacts, a second quantity is given in the tables after the first. This second. quantity, which is enclosed in parenthesis, indicates merely the number of contacts without reference to whether they are long or short.

No special comments are necessary to explain the tables. Tables 1-5 report in sigmas, or thousandths of a second, the average time of ten reactions on the date, and for the subject, 


\section{PHYSIOLOGICAL ECONOMY IN NUTRITION}

indicated. In the third column, is the mean variation for the series of ten reactions.

Table 6 shows the general averages by the month for a given individual, and in the sixth column the general average of all the determinations for each reactor. The fourth column in each of the earlier tables shows how much the results of a given day vary from the final general average. All the tables give, at the bottom, group averages whenever the full series is present.

Table 7 gives the number of taps executed in ten seconds at each successive test. The dates are not given in detail, but are the same as those of the reaction tests.

Table 8 gives the monthly averages of taps.

Table 9 presents the results of the steadiness tests.

The three sets of results, namely, those from reaction, tapping, and steadiness, differ from each other. On the whole, the reactions grow longer; the tapping varies, but shows neither decided improvement nor deterioration; while steadiness improves very decidedly.

The comment made on the results obtained with the soldiers applies here so far as the reaction tests are concerned. These tests were not repeated with sufficient frequency to reduce the reaction to automatic performance.

The tapping is such a simple performance that improvement is not to be expected. The absence of any general improvement or deterioration argues for an absence of any general nervous change in the reactors.

The improvement in steadiness is in part at least, probably in very large measure, due to the fact that the subjects became more familiar with the test and approached it with less of the embarrassment which attends a new and unfamiliar test.

The lengthening of the reaction times indicates a less intense concentration of the subject upon the work in hand. The slightest relaxation of attention puts the subject behind in responding to the signal. It was clear to superficial observation, especially in certain individual cases, that the subjeet was giving less attention in the later experiments. This lack of concentration is not obviously related to the changes in diet. Indeed, the fact that no corresponding falling off appears in the tapping would seem to argue that the lack of attention in the reaction tests was not due 
to deep-seated nervous conditions, so much as to growing impatience on the part of the reactors with the ordeal of being tested. The tapping experiment is less likely to be affected by lack of interest on the part of the subject, because here the subject is called upon to be constantly active, and there is no such opportunity for attention to lapse as is furnished by the intervals which intervene between successive reactions. The tapping is accordingly perhaps the best series on which to base final judgment as to the nervous condition of the men. Here, there appear the variations which show in any ordinary series, but there is no steady improvement through growing familiarity with the test, nor any laxness of attention to produce relatively unfavorable results.

Mr. Steele and Dr. McAllister are largely responsible for the actual collection of the data on which this report is based.

(Signed) C. H. JudD.

TABLE 1. - Febrdary, 1904.

\begin{tabular}{|c|c|c|c|c|c|c|c|c|}
\hline Name. & 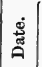 & Avg. & M. v. & \begin{tabular}{|c|} 
Var. \\
from \\
G. A.
\end{tabular} & 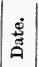 & Avg. & M. v. & $\begin{array}{l}\text { Var. } \\
\text { from } \\
\text { G. A. }\end{array}$ \\
\hline I. Anderson, G. W. . . & 19 & 153.5 & 13.8 & 31.4 & 26 & 192.2 & 19.4 & 7.3 \\
\hline II. Anderson, W. L. . . . . & 18 & 261.0 & 82.5 & 32.5 & 27 & 293.6 & 71.0 & 65.1 \\
\hline III. Bellis . . . & 16 & 189.3 & 40.0 & 8.2 & 26 & 182.3 & 18.5 & 0.5 \\
\hline IV. Donahue & 17 & 173.6 & 43.0 & 28.4 & 24 & 182.7 & 14.5 & 19.3 \\
\hline V. Jacobus. . & 17 & 197.3 & 14.7 & 27.6 & 24 & 178.2 & 18.3 & 46.7 \\
\hline VI. Schenker . & 17 & 162.3 & 29.7 & 67.6 & 24 & 209.8 & 46.6 & 20.1 \\
\hline VII. Stapleton . . . . & 19 & 185.1 & 31.6 & 23.9 & . . & .. & $\ldots$ & $\cdots$ \\
\hline Group averages . . & & 188.8 & & & & & & \\
\hline VIII. Callahan* & 18 & 156.2 & 10.4 & 37.0 & 25 & 210.8 & 27.2 & 17.6 \\
\hline
\end{tabular}

* Kept separate because series of tests is not complete. 


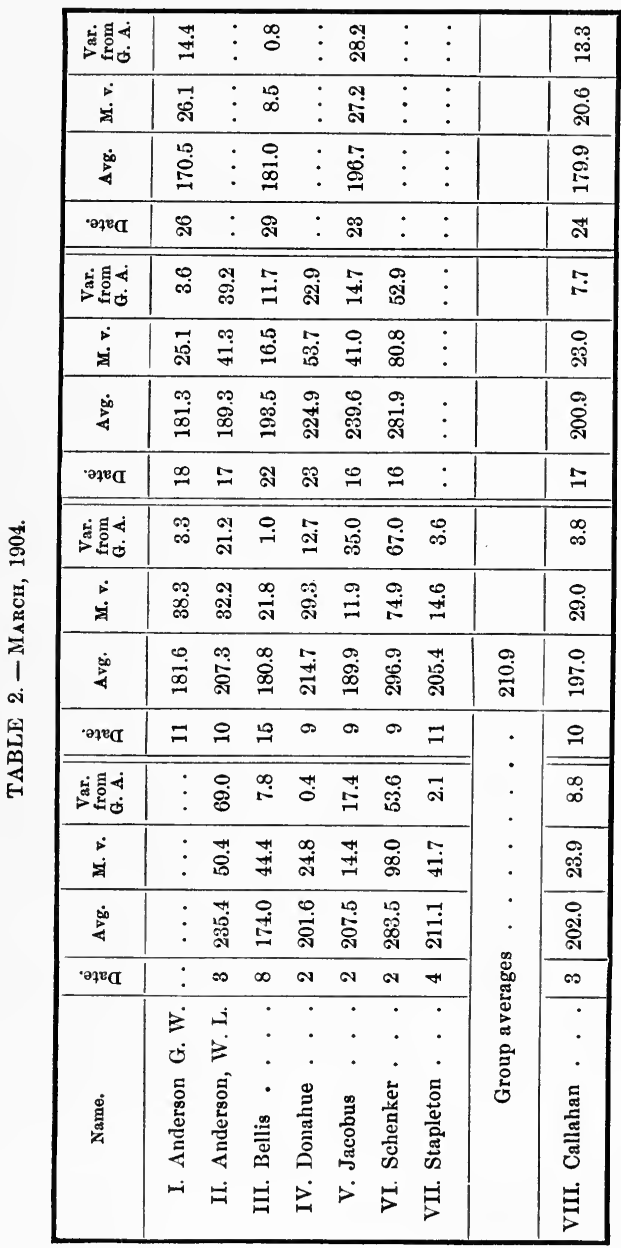


TABLE 3.-APRIL, 1904.

\begin{tabular}{|r|r|r|r|r||r|r|r|r|}
\hline \multicolumn{1}{|c|}{ Name. } & Date. & Avg. & M. v. & $\begin{array}{r}\text { far. } \\
\text { from } \\
\text { G. A. }\end{array}$ & Date. & Avg. & M. v. & $\begin{array}{r}\text { Var. } \\
\text { from } \\
\text { G. A. }\end{array}$ \\
\hline I. Anderson, G. W. & 22 & 202.8 & 10.6 & 17.9 & 29 & 182.9 & 6.7 & 2.0 \\
II. Anderson, W. L. & $\ldots$ & $\ldots$ & $\ldots$ & $\ldots$ & 29 & 195.0 & 20.3 & 33.5 \\
III. Bellis . . . . & 19 & 193.0 & 27.2 & 11.2 & 26 & 182.5 & 18.2 & 0.7 \\
IV. Donahue . . . & 20 & 198.4 & 7.0 & 36 & 27 & 191.6 & 37.6 & 10.4 \\
V. Jacobus . . . & 20 & 253.1 & 70.7 & 28.2 & 27 & 221.3 & 14.7 & 3.6 \\
VI. Schenker . . . & 21 & 229.4 & 33.0 & 0.5 & 28 & 250.1 & 78.3 & 20.2 \\
VII. Stapleton . . & $\ldots$ & $\ldots$ & $\ldots$ & $\ldots$ & 29 & 217.1 & 30.5 & 8.1 \\
\hline
\end{tabular}




\begin{tabular}{|c|c|c|c|c|c|c|c|c|}
\hline 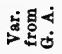 & $\begin{array}{l}\infty \\
\qquad .0\end{array}$ & $\stackrel{9}{\sigma}$ & $\stackrel{10}{\circ}$ & 75 & ๙ุ. & 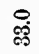 & $\stackrel{\infty}{\infty}$ & \\
\hline$\dot{\vec{d}}$ & సี & ले & $\stackrel{\leftrightarrow}{\circ}$ & $\stackrel{10}{\stackrel{10}{\Xi}}$ & ז্ণ & $\stackrel{9}{0}$ & مُ0ِ & \\
\hline$\ddot{\infty}$ & 용 & 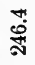 & $\stackrel{\oplus}{=}$ & స్요 & 궁 & $\begin{array}{l}\stackrel{\circ}{\circ} \\
\stackrel{\oplus}{\oplus}\end{array}$ & $\stackrel{\infty}{\stackrel{\infty}{*}}$ & 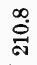 \\
\hline •ə7е & 兴 & הే & సี & ง & ลิ & ผి & ลง & . \\
\hline 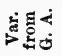 & 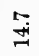 & : & $\stackrel{0}{+}$ & ํํำ & $\stackrel{\leftrightarrow}{\circ}$ & $\underset{\sim}{*}$ & $\stackrel{\circ}{\circ}$ & . \\
\hline$\dot{\vec{z}}$ & 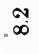 & $\dot{ }$ & $\ddot{\circ}$ & $\stackrel{0}{\infty}$ & $\stackrel{\oplus}{\mathscr{\rho}}$ & $\stackrel{\leftrightarrow}{\circ}$ & 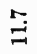 & • \\
\hline$\dot{0}$ & $\stackrel{0}{\mathscr{E}}$ & : & $\begin{array}{l}\infty \\
\stackrel{\infty}{15} \\
\infty \\
\sim\end{array}$ & 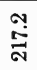 & 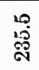 & $\frac{\infty}{\text { : }}$ & ন্ণ & . \\
\hline${ }^{\circ}$ əาย $\alpha$ & శి & : & $\stackrel{\infty}{\sim}$ & $\stackrel{\infty}{=}$ & $\stackrel{\infty}{\sim}$ & $\stackrel{9}{2}$ & $\stackrel{\infty}{\sim}$ & . \\
\hline نं & $\vec{c}$ & बें & $\stackrel{s}{s}$ & : & $\mathscr{\rho}$ & $:$ & 苞 & . \\
\hline$\dot{\vec{j}}$ & $\stackrel{0}{0}$ & $\overrightarrow{\text { जิ }}$ & 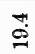 & $:$ & $\stackrel{\circ}{\circ}$ & $:$ & $\stackrel{90}{10}$ & . \\
\hline$\ddot{0}$ & $\underset{\sim}{\stackrel{\infty}{\infty}}$ & $\overrightarrow{\widehat{\sigma}}$ & $\begin{array}{l}19 . \\
10 \\
90\end{array}$ & $:$ & 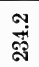 & $\dot{ }$ & ホั & - \\
\hline •өุช & 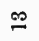 & 이 & 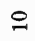 & : & $\Rightarrow$ & : & $=$ & . \\
\hline में & $\because$ & : & $\dot{.}$ & $\dot{.}$ & $=$ & $\ddot{0}$ & : & . \\
\hline 寄 & $\vdots$ & : & : & : & $\underset{\text { พั }}{*}$ & $\stackrel{\circ}{\stackrel{N}{*}}$ & : & 总 \\
\hline$\dot{0}$ & $:$ & $\dot{ }$ & $\dot{.}$ & $:$ & 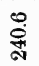 & $\underset{\sim}{\stackrel{\infty}{N}}$ & $:$ & $\begin{array}{l}\vec{z} \\
\text { 节 }\end{array}$ \\
\hline •จุช & : & $:$ & : & $\dot{ }$ & 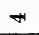 & مמ & : & \\
\hline 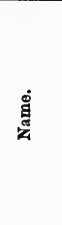 & 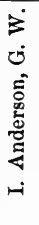 & 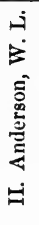 & 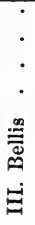 & 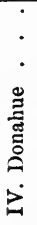 & 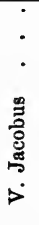 & 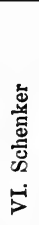 & 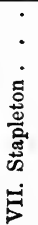 & \\
\hline
\end{tabular}


TABLE 5. - JUNE, 1904.

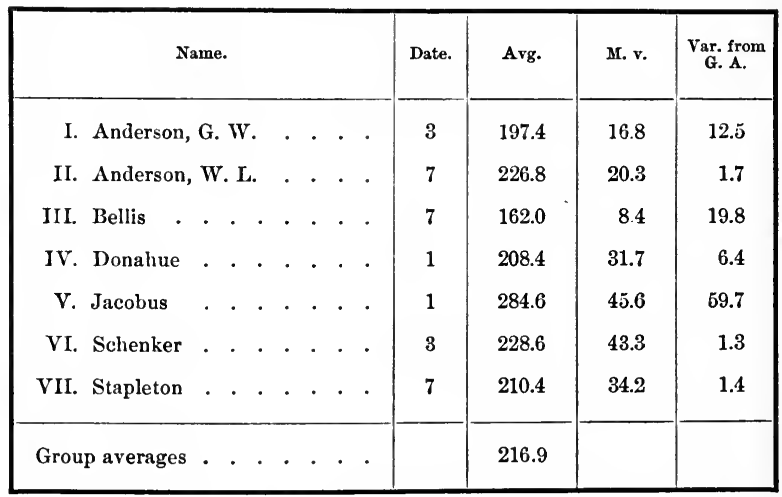


TABLE 6 .

\begin{tabular}{|c|c|c|c|c|c|c|c|c|c|}
\hline \multirow{2}{*}{\multicolumn{3}{|c|}{ Name. }} & & February. & March. & April. & May. & June. & \multirow[b]{2}{*}{ 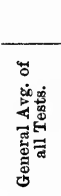 } \\
\hline & & & & 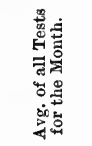 & 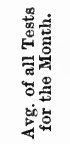 & 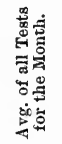 & 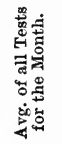 & 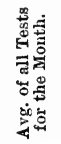 & \\
\hline I. Anderson, & G. W & & . & 177.9 & 177.8 & 192.9 & 190.5 & 197.4 & 184.9 \\
\hline II. Anderson, & W. I. & & . . & 277.3 & 210.7 & 195.0 & 224.3 & 226.8 & 228.5 \\
\hline III. Bellis & . . & 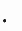 & . . & 185.8 & 182.3 & 187.8 & 178.5 & 162.0 & 181.8 \\
\hline IV. Donahue & . & 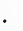 & . & 178.1 & 213.4 & 195.0 & 212.2 & 208.4 & 202.0 \\
\hline V. Jacobus . & . & . & . . & 187.8 & 208.4 & 237.2 & 238.9 & 284.6 & 224.9 \\
\hline VI. Schenker & . . & . & . & 186.1 & 200.7 & 239.8 & 215.2 & 228.6 & 229.9 \\
\hline VII. Stapleton & . & . & . & 185.0 & 208.3 & 217.1 & 214.4 & 210.4 & 209.0 \\
\hline Monthly avera & ages & . & . & 196.8 & 200.2 & 209.3 & 210.6 & 216.9 & \\
\hline VIII. Callahan & . & & . & 183.5 & 194.9 & 205.5 & & & 193.2 \\
\hline
\end{tabular}




\begin{tabular}{|c|c|c|c|c|c|c|c|c|c|c|}
\hline & & 웅 & $\stackrel{8}{\infty}$ & $\begin{array}{l}0 \\
\infty\end{array}$ & $\stackrel{2}{\infty}$ & $\stackrel{\infty}{1}$ & $\ddot{0}$ & $\underset{5}{5}$ & : & $\mathscr{\infty}$ \\
\hline$\stackrel{\Xi}{\Xi}$ & $\begin{array}{c}\text { •əəs 0I u! } \\
\text { gdeI Jo }\end{array}$ & $\stackrel{0}{0}$ & $\stackrel{\infty}{1}$ & 注 & $\stackrel{\infty}{\infty}$ & $\mathbb{E}$ & 19 & N & $\frac{10}{20}$ & : \\
\hline \multirow{4}{*}{ 昆 } & \multirow{4}{*}{ 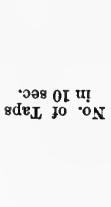 } & $\stackrel{N}{\mathbb{N}}$ & $\infty$ & 5 & 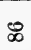 & 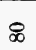 & 요 & 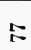 & 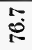 & : \\
\hline & & $E$ & $:$ & $\stackrel{\infty}{\sim}$ & 8 & $\stackrel{2}{10}$ & 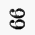 & R & : & : \\
\hline & & $\stackrel{\infty}{\Gamma}$ & $\stackrel{\infty}{\not}$ & $\varnothing$ & : & $\&$ & $:$ & $\vec{\infty}$ & : & : \\
\hline & & : & : & : & : & 19 & 5 & : & : & : \\
\hline \multirow{2}{*}{ 范 } & \multirow{2}{*}{ 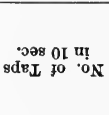 } & พ & $\mathscr{\infty}$ & ఠో & $\infty$ & $\stackrel{\infty}{\sim}$ & $\mathscr{8}$ & $\therefore$ & is & : \\
\hline & & $\stackrel{\infty}{1}$ & : & $\underset{1}{\infty}$ & $\infty$ & $E$ & $\mathscr{\wp}$ & : & : & $\infty$ \\
\hline \multirow{4}{*}{ 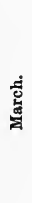 } & \multirow{4}{*}{ 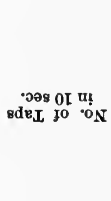 } & $\underset{\mathbb{N}}{\mathbb{N}}$ & : & $\mathbb{1}$ & : & $\stackrel{P}{P}$ & : & : & : & $\infty$ \\
\hline & & $\stackrel{R}{0}$ & E & 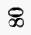 & $\infty$ & ヘ & తొ & : & : & $\stackrel{\infty}{\infty}$ \\
\hline & & పै & ळ & $\underset{1}{\infty}$ & 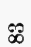 & $E$ & J & $\approx$ & tiّ & $\mathscr{\infty}$ \\
\hline & & & $\stackrel{0}{1}$ & $\stackrel{\infty}{\infty}$ & $\vec{\infty}$ & $\stackrel{20}{2}$ & 용 & $\mathscr{8}$ & : & 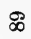 \\
\hline \multirow{2}{*}{ 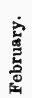 } & \multirow{2}{*}{ 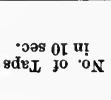 } & $\stackrel{\infty}{1}$ & 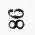 & 8 & 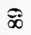 & $\mathscr{\infty}$ & 3 & : & : & 19 \\
\hline & & $\infty$ & $\vec{\infty}$ & $\not{\infty}$ & ஓ & 尺 & ชิ & $\infty$ & $\begin{array}{l}\infty \\
\infty \\
\infty \\
1\end{array}$ & న్ \\
\hline \multicolumn{2}{|r|}{ 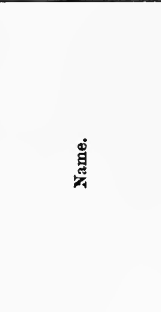 } & 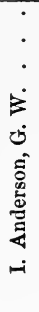 & 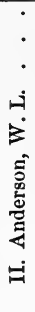 & $\begin{array}{l}\dot{ } \\
\dot{\cdot} \\
\dot{\cdot} \\
\dot{\cdot} \\
\dot{0} \\
\ddot{\Xi} \\
\ddot{\Xi}\end{array}$ & 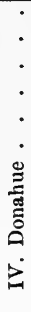 & 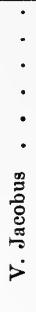 & 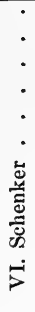 & $\begin{array}{l}\dot{ } \\
\dot{ } \\
\dot{ }\end{array}$ & 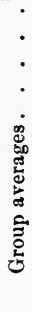 & 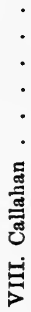 \\
\hline
\end{tabular}


TABLE 8.

\begin{tabular}{|c|c|c|c|c|c|}
\hline & February. & March. & April. & May. & June. \\
\hline Name. & $\begin{array}{l}\text { Avg. of all } \\
\text { Determina- } \\
\text { tions for } \\
\text { the Month. }\end{array}$ & $\begin{array}{l}\text { Avg. of all } \\
\text { Determina- } \\
\text { tions for } \\
\text { the Month. }\end{array}$ & $\begin{array}{l}\text { Avg. of all } \\
\text { Determina- } \\
\text { tions for } \\
\text { the Month. }\end{array}$ & $\begin{array}{l}\text { Avg. of all } \\
\text { Determina- } \\
\text { tions for } \\
\text { the Month. }\end{array}$ & $\begin{array}{l}\text { Avg. of all } \\
\text { Determina } \\
\text { tions for } \\
\text { the Month. }\end{array}$ \\
\hline I. Anderson, G. W. & 83 & 71 & 75 & 74 & 76 \\
\hline II. Anderson, W. L. & 84 & 79 & 83 & 81 & 78 \\
\hline III. Bellis . . . . & 87 & 78 & 69 & 74 & 72 \\
\hline IV. Donahue . . & 85 & 83 & 85 & 90 & 88 \\
\hline V. Jacobus . . & 76 & 74 & 78 & 80 & 74 \\
\hline VI. Schenker . & 64 & 66 & 65 & 69 & 74 \\
\hline VII. Stapleton . . & 87 & 70 & 79 & 78 & 74 \\
\hline Monthly averages & 81 & 74 & 76 & 81 & 75 \\
\hline VIII. Callahan . . & 79 & 85 & 86 & . & \\
\hline
\end{tabular}




\begin{tabular}{|c|c|c|c|c|c|c|c|}
\hline \multirow{2}{*}{ 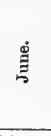 } & & 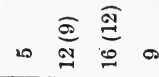 & $\underset{\infty}{\stackrel{\nexists}{ \pm}}$ & 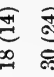 & 愈 & & \\
\hline & 这 & $\infty \times r$ & -7 & $\Rightarrow \quad$ \% & & 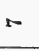 & : \\
\hline \multirow{4}{*}{ 离 } & & $\vdots \quad \vdots \quad \vdots$ & $\vdots:$ & : & & & : \\
\hline & มี & $:::$ & $:$ & เึ & : & : & : \\
\hline & & 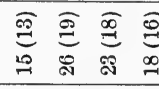 & $\underbrace{\infty}_{\substack{0 \\
\hdashline}}$ & 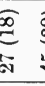 & $\frac{\widehat{a}}{\stackrel{0}{o g}}$ & $\stackrel{\varrho}{\Xi}$ & $\vdots$ \\
\hline & 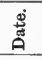 & ㅇ $\stackrel{\infty}{\sim} \stackrel{\infty}{\sim}$ & \& $=$ & $\exists$ & 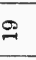 & 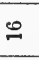 & : \\
\hline \multirow{2}{*}{ 离 } & & 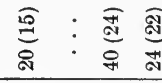 & 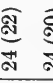 & & & ส্ৰ & : \\
\hline & 递 & ๙ : : ષ & ลิ & ลे & ส & \& & : \\
\hline \multirow{4}{*}{ 总 } & & 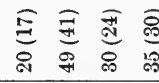 & $\frac{6}{0}$ & $\frac{c}{d 0}$ & : & & $\vdots$ \\
\hline & 递 & $\mathscr{్}$ & ถ⿻ & 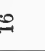 & : & : & : \\
\hline & & 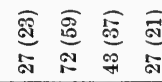 & 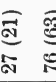 & 露 & 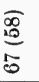 & & 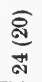 \\
\hline & 焉 & $\Rightarrow \propto \infty \sim$ & a 0 & $\infty$ & $\infty$ & 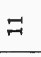 & $\approx$ \\
\hline \multirow{2}{*}{ 离 } & & 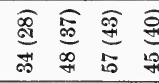 & $\frac{0}{0}$ & 感 & $\frac{\overline{8}}{6}$ & $\begin{array}{l}\text { 品 } \\
\text { F }\end{array}$ & 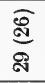 \\
\hline & ڤัँ & 9 ล & $=7$ & $\approx$ & $=$ & S & $\stackrel{\infty}{=}$ \\
\hline \multicolumn{2}{|c|}{$\stackrel{d}{\frac{d}{4}}$} & 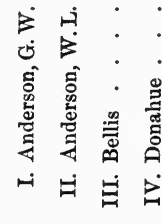 & 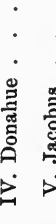 & 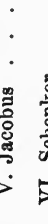 & 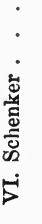 & 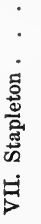 & 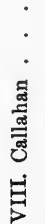 \\
\hline
\end{tabular}




\section{General Summary.}

It is quite evident from a study of the results obtained in the foregoing experiments that young, vigorous men of the type under observation, trained in athletics, accustomed to the doing of vigorous muscular work, can satisfy all the true physiological needs of their bodies and maintain their physical strength and vigor, as well as their capacity for mental work, with an amount of proteid food equal to one-half, or one-third, that ordinarily consumed by men of this stamp. As the results show, all these men reduced their rate of proteid metabolism in such degree that the amount of nitrogen excreted daily during the period of the experiment averaged 8.8 grams, implying a metabolism of about 55 grams of proteid matter per day.

In other words, these athletes were able to reduce their nitrogenous metabolism to as low a level as many of the men of the professional group and of the soldier group, and this with not only maintenance of health and strength, but with a decided increase in their muscular power.

Metabolized nitrogen per kilo of body-weight for all these men, with one exception, during the experiment amounted to 0.108 to 0.134 gram per day, fully as low as was obtained with the members of the soldier detail on their prescribed diet. It is clear, therefore, that physiological economy in nutrition is as safe for men in athletics as for men not accustomed to vigorous exercise. There is obviously no physiological ground for the use of such quantity of proteid food, or of total nutrients, as the prevalent dietary standards call for.

The athlete, as well as the less active man (physically), or the professional man, can meet all his ordinary requirements with an intake of proteid food far below the quantities generally consumed, and this without increasing in any measure the amount of non-nitrogenous food. 


\section{THE SYSTEMIC VALUE OF PHYSIOLOGICAL ECONOMY IN NUTRITION.}

It is one of the axioms of physiology that the majority of the diseases of mankind are due to, or are connected with, perversions of nutrition. General or local disturbances of metabolism are broadly responsible for disease, and with a due recognition of this fact it may be well to consider more specifically whether greater economy in the consumption of food, $i$. e., a restriction of the daily diet to amounts more commensurate with the physiological needs of the body, may not be of value in preventing disease, or prove of use in combating disease when the latter has manifested itself.

Broadly speaking, the extent and character of the metabolic processes of the body are dependent in large measure upon the amount and character of the diet. Further, it is equally certain that the chemical composition of the blood and lymph is quickly affected by the amount and character of the food materials absorbed from the alimentary canal. Even in the matter of secretion of the digestive juices, we have learned, through the recent experiments of Pawlow, that the chemical composition and solvent action of these fluids may be modified by the amount and character of the food fed. How much more, then, may we expect the intricate processes of cell and tissue metabolism to be modified by changes in the chemical composition of the blood and lymph that bathe them.

Further, recognizing as we must the extreme sensitiveness of the central and peripheral parts of the nervous system to changes in the composition of the blood, we see suggested indirect ways by which metabolism, both general and local, may be modified by influences exerted upon the nervous system, whereby the nutritive condition of individual structures may undergo change. Vasomotor influences, controlled as they are by nerve fibres, which in turn are sensitive to the conditions of their environment, likewise indirectly affect the 
rate and character of tissue metabolism; a fact which may serve to emphasize the many ways whereby the metabolism of an organ or tissue may be modified through the primary influence of a diet which, controlling in a measure the volume and character of the circulating blood and lymph, must of necessity exert an influence more or less extended.

The one factor above all others that tends to increase the extent of proteid katabolism is the amount of proteid food ingested. Increase in the amount of the albuminous foodstuffs is at once, or speedily, followed by an increase in the output of nitrogenous waste products, the latter constituting a good measure of the extent of proteid metabolism going on in the body. We have been taught to believe that the healthy adult under ordinary conditions of life needs for the maintenance of health, strength, bodily and mental vigor, about 118 grams of proteid food daily. This amount of albuminous food, if metabolized, means at least 16 grams of nitrogen in the urine, in the form of urea, uric acid, creatinin, purin bases, and other nitrogenous products more or less closely related. Under the stress of modern conditions and following the dictates of an acquired taste, the daily intake of proteid food in many individuals at least far exceeds the above figures, with an increase of proteid katabolism equal to 18 or more grams of nitrogen in the 24 hours' urine.

When we recall that these 18 grams, or more, of nitrogen in the urine reach the final stage of urea, etc., only by passing through a series of stages, each one of which means the using up of a certain amount of energy, to say nothing of the energy made use of in digestion, absorption, etc., we can easily picture to ourselves the amount of physiological labor which the daily handling by the body of such amounts of proteid food entails. Further, it needs very little imagination to see that a large amount of energy is used up in passing on these nitrogenous waste products from organ to organ, or from tissue to tissue, on the way to elimination, and we can fancy that liver and kidneys must at times rebel at the excessive labor they are called upon to perform. 
Moreover, the thought suggests itself that possibly these waste products of proteid metabolism, the leucomaines so abundantly formed in the breaking down of proteid material, are not wholly free from objectionable features. If so, an excess of such products might be advantageously dispensed with. Indeed, we have what seems abundant evidence tending to show that many of the nitrogenous waste products elaborated in the body through the breaking down of proteid materials are possessed of more or less physiological action. Even that direct antecedent of urea, ammonium carbamate, which we have reason to believe is formed more or less generally throughout the tissues of the body, is not above suspicion. To be sure, Nature has provided a mechanism in the hepatic cells whereby it is quickly transformed into the harmless urea, but it is only necessary to join the portal vein to the hepatic vein, thereby throwing the liver out of the circuit, in order to see the effect of an excess of proteid food. Under such conditions, this is followed by the appearance of all the symptoms of poisoning with ammonium carbamate, i.e., convulsions ending in death.*

Further, we may refer to the observations of Mallet $†$ with creatin and creatinin, two conspicuous nitrogenous bases present in muscle, which show unmistakably that these bodies tend to retard slightly the action of the heart. This seems to be their most decided physiological effect, although large doses likewise cause a slight frontal headache, with some general nervous agitation. Attention may also be called to the extremely important experiments of Minkowski, $\ddagger$ in which he found that adenin - one of the purin bases formed in the breaking down of cell nuclei - has a most marked toxic action, both on man and on dogs. Adenin affects the circulatory ap-

\footnotetext{
* See Hahn, Massen, Nencki, und Pawlow: Archiv f. exper. Pathol. u. Pharm. Band XXXII. (1893), p. 161. Also, Nencki, Pawlow, und Zaleski : Ibid. Band XXXVII., p. 26.

$\dagger$ The physiological effect of creatin and creatinin, etc. Bulletin No. 66 . U. S. Department of Agriculture, Office of Experiment Stations.

$\ddagger$ Untersuchungen zur Physiologie und Pathologie der Harnsäure bei Säugethieren. Archiv f. exper. Pathol. u. Pharm. Band XLI., p. 406.
} 
paratus very strikingly, increasing the heart's action, etc.; it acts on the mucous membrane of the duodenum, causing an acute inflammation, thus leading to continuous vomiting, and in addition it has a local action on the kidneys, giving rise to a deposition in the kidney itself of spheroliths of uric acid, or urates, which leads to an acute nephritis with albuminuria, from which the animal speedily dies.

The alloxuric bases likewise cause fever when injected into the circulation or taken per os, ${ }^{*}$ and according to the recent observations of Mandel $\dagger$ there is a very noticeable relationship between the amount of alloxuric bases eliminated through the urine and the temperature of the body in cases of aseptic fevers, indicating that these substances, with possibly other incomplete products of tissue metabolism, are important factors in the production of febrile temperatures.

Reference may also be made to our general knowledge regarding the relationship between uric acid and gouty affections, including rheumatism, to say nothing of the possible relationship between uric acid and many other diseases less clearly established. The broader question deserving attention just here, however, is that all of the so-called leucomaines which, as Gautier states, are being formed continuously in the animal tissues side by side with the formation of urea and carbonic acid, and at the expense of the nitrogenous elements or proteid matter, are more or less toxic in their properties, at least under certain conditions of the body. It is perfectly clear that there are a large number of leucomaines, or nitrogenous waste products, which are indissolubly connected with the metabolism of cell protoplasm, and the formation of these substances is augmented by a diet rich in proteid matter.

It is well understood that the excretions of all living organisms, both plant and animal, are more or less poisonous to the

* See Burian and Schur., Archiv f. die. gesammte Physiologie. Band LXXXVII., p. 239.

t The alloxuric bases in aseptic fevers. Amer. Journal of Physiology Vol. X., p. 452. 
organisms which produce and excrete them. The substances so formed originate in the metabolic changes by which complex organic molecules are broken down into simpler compounds. As stated by Vaughan and Novy," "we have good reason for believing that the proteid molecule has certain lines of cleavage along which it breaks when certain forces are applied, and that the resulting fragments have also lines of cleavage along which they break under certain influences, and so on until the end-products, urea, ammonia, water, and carbon-dioxide, are reached; also that some of these intermediate products are highly poisonous has been abundantly demonstrated." It would therefore seem self-evident that the nitrogenous waste products of the body, i. e., the products of proteid katabolism, may be more or less dangerous to the welfare of the body, and consequently there would seem to be reason in the assumption that greater freedom from disease-especially from the so-called autogenous diseases - might be expected where greater care is exercised in the amount of proteid food consumed.

It is generally understood, or at least is frequently stated by medical writers, that certain febrile conditions are autogenous, and Brunton has made the assertion that the condition termed "biliousness," and which is most prone to occur in persons who eat largely of proteid foods, is due to the formation of poisonous alkaloidal-like substances which might well be classified under the broad term of leucomaines. To repeat, there are a great many observations and some facts which warrant the view that the nitrogenous waste products of the body - the products of proteid katabolism - are more or less dangerous to the well-being of the organism, and hence there seems justification for the belief that there is greater safety for health and longevity in adopting dietetic habits that are more in accord with the real needs of the body.

The writer's opinion upon this question has been greatly strengthened by the large numbers of letters he has received

* Ptomaines and Leucomaines, or the Chemical Factors in the Causation of Disease. Third Edition, 1896 . Lea Brothers. p. 550. 
- during the course of this inquiry - from persons all over the world, many of whom in their search for health and strength have adopted more frugal methods of living, and who have found relief in an abstemiousness which, compared with ordinary dietetic standards, would seem quite inadequate to support life, yet they have recovered health and strength, and by the judicious practice of physiological economy in their diet have maintained health and vigor, with capability for work that has proved a perpetual surprise to themselves and their friends. The writer's faith in these spontaneous statements made by persons wholly unknown to him has been augmented by his personal knowledge of people suffering with various troubles, who have found relief by the simple use of - reason and judgment in the taking of food, with a view to lowering the rate of proteid metabolism. There is no question in the mind of the writer that excessive proteid decomposition within the body entails possible danger.

If it is true, on the other hand, that the healthy organism needs a daily intake of 118 grams of proteid food more or less, in order to maintain physiological equilibrium, to keep up physical and mental vigor, and to preserve the normal power of resistance to the incursions of disease, then we must consider that the good overbalances the evil, and that evil exists in order that good may be accomplished. We are certainly justified, however, in saying, on the basis of our daily observations made on a large number of individuals and extending over many months, that there is no apparent need for any. such amount of proteid food as is ordinarily consumed by the average individual.

We can point to various persons who, for periods ranging from six months to a year, have metabolized daily 5.5 to 7.5 grams of nitrogen instead of 16 to 18 grams, $i$. e., they have subsisted quite satisfactorily on an amount of proteid food daily, equal to one-third or one-half the amount ordinarily considered as necessary for the maintenance of health and strength, and this without unduly increasing the amount of non-nitrogenous food. Further, our observations have shown 


\section{PHYSIOLOGICAL ECONOMY IN NUTRITION 461}

that with this great reduction in the consumption of proteid food, with corresponding diminution of proteid katabolism, body-weight can be maintained at a stationary figure, after the body has once adjusted itself to the new conditions. Moreover, there is marked increase in physical strength as demonstrated by repeated dynamometer tests on many individuals, which may perhaps be ascribed to the greater freedom of blood and lymph, as well as of muscle-plasma, from nitrogenous extractives. Lastly, we have failed to find any falling off in physical or mental vigor, any change in the hæmoglobincontent of the blood, or in the number of erythrocytes. In fact, all our observations agree in showing that it is quite possible to reduce with safety the extent of proteid katabolism to one-third or one-half that generally considered as essential to life and strength. In other words, there is perfect safety in a lowered proteid metabolism, and we are inclined to raise the question whether a daily diet containing one-half, or even less, the amount of proteid food ordinarily consumed does not come nearer to the normal and natural requirements of the healthy body than the more elaborate standards we have gradually adopted.

Here, then, we have suggested a radical change in diet which experiment shows is perfectly safe, and we are disposed to urge that there is great systemic value, both in health and in many forms of disease, in such a change. It is obvious, as previously stated, that the smallest amount of food that will serve to maintain bodily and mental vigor, keep up bodily strength, and preserve the normal powers of resistance to disease, is the ideal diet. Any excess over and above what is really needed for these purposes imposes just so much of an unnecessary strain upon the organism. It entails a wasteful expenditure of energy that might better be preserved for future emergencies. It imposes upon the excretory organs the needless labor of removing waste products which could well be dispensed with, to say nothing of the possible physiological action of these products as they circulate through the body. 
Dr. Walker Hall,* in his interesting article in "The Practitioner" on "Metabolism in Gout," states that "under nornal circumstances a man weighing eleven stone and performing average work requires twenty grams of nitrogen and three hundred grams of carbon per day." This statement is in perfect harmony with generally accepted views, but I should like to emphasize the fact that all of the twenty-six men we have been experimenting with at New Haven, representing different types, ages, and degrees of activity, have been able to maintain health, strength, and vigor, from six months to a year on a daily quantity of nitrogen equal to one-half, one-third, and even one-quarter the amount of this so-called necessary twenty grams. Further, nitrogenous equilibrium was easily maintained on such quantities of proteid food, and, as before stated, there was great gain in physical strength. Are we not justified, therefore, in raising the broad question whether such a radical change in diet as these facts suggest might not be of systemic value in gout, and especially in cases where there is a predisposition to gout. Speaking as a physiologist, the writer is strongly of the opinion, based in part upon his own observations and in part upon both the voluntary and unconscious testimony of others, that there is possible great gain to the gouty and rheumatic individual by a practice of physiological economy in nutrition.

Physiological economy, as the writer defines it, is not prohibition, but temperance. Moderation in diet, especially in the taking of proteid foods, means a great saving in the wear and tear of the body machinery. It must presumably mean greater freedom from many diseases in which individual organs, such as the liver and kidneys, are frequently involved. It suggests, likewise, greater freedom from many disturbances of general metabolism which eventually terminate in a perversion of nutrition, so marked as to constitute a serious condition of disease. More specifically, lowered proteid metabolism means diminished introduction and diminished

* The Practitioner. London. July, 1903. p. 61. 
formation of nitrogenous products of the purin type, such as xanthin, hypoxanthin, guanin, adenin, etc., as well as of other nitrogenous bodies less clearly defined. Consequently, we have as one of the results of such a systemic change in diet a decreased formation of uric acid, or at least a diminished output of uric acid through the urine.

Obviously, a lowered proteid intake means, in some measure at least, a decreased consumption of meat and similar products more or less rich in free and combined purin bases. This quite plainly must result in a diminished production of uric acid, but the writer is strongly of the opinion that we do not as yet possess sufficiently full knowledge regarding all the ways in which uric acid results in the body. It is true, we differentiate between endogenous and exogenous uric acid, and further, we understand quite clearly that variations in the intake of free and combined purin bases exercise a potent influence upon the output of uric acid through the urine. We still lack, however, concise information as to the various ways in which uric acid may be produced, and its ultimate fate in the body. This is well illustrated by a recent paper from the Marburg laboratory, in which Kutscher and Seemann* point out the possibility of a production of uric acid in the animal body synthetically, and likewise suggest that uric acid may be utilized for the formation of nuclein bases, i.e., a reversal of the oxidative process by which uric acid results from the ingestion of free or combined nuclein bases, suggesting indeed the possibility of uric acid and the nuclein bases being produced from each other, according to the circumstances. Thus, when nucleins or free purin bases are taken with the food, the organism may utilize this material at once in the synthesis of nucleins for the use of the body cells. There is no need of a reduction of the formed uric acid to nuclein bases, and consequently there is an increased excretion of uric acid through the urine, but this does not result from a direct transformation of the ingested purin material into uric

* Centralblatt für Physiologie. Band XVII, p. 715. 1904. 


\section{PHYSIOLOGICAL ECONOMY IN NUTRITION}

acid, but is the result of a sparing of the already formed uric acid. The nuclein bases thus act as sparers of uric acid. This view explains, according to Kutscher and Seemann, why feeding with nuclein bases increases the output of uric acid, and feeding with uric acid - a sudden overflow of uric acid into the circulation - is followed, as a rule, by an increased elimination of urea, the uric acid being thus transformed by energetic oxidation. This hypothesis is brought forward not merely because it is an interesting suggestion, but mainly because it illustrates that we do not as yet know fully all the steps in the production of uric acid, nor do we know how far the uric acid we find and determine in the urine is a measure of the formation of uric acid in the body.

Taking our knowledge on these matters as it stands to-day, however, we find by experiment that lowering the intake of proteid food, with its consequent corresponding diminution in proteid katabolism, is followed at once by a marked decrease in the output of uric acid. Let us consider a few of the data obtained in our experiments. The first case I will refer to is that of a college athlete (Callahan). For a period of ten days on his ordinary diet, the average amount of nitrogen in the urine per day was 22.8 grams, equal to the metabolism of 142.5 grams of proteid food. During this same period the average daily output of uric acid was 1.103 grams. For the following four months and a half, on a more restricted diet, with a marked cutting down of the proteid food, but with no exclusion of meat, the average daily output of nitrogen through the urine was 9.04 grams. In other words, for this period of over four months the extent of proteid katabolism was reduced considerably more than 50 per cent. The average daily output of uric acid for this same period was 0.624 gram, equal to a reduction of about 40 per cent from his normal excretion.

Another college athlete (Stapleton), on his normal diet, showed an average excretion of nitrogen through the urine per day, for ten days, of 19.70 grams, while the daily average 
excretion of uric acid for the same period was 0.893 gram. On a more restricted diet, with diminished proteid katabolism, the daily average excretion of nitrogen through the urine for a period of over four months was $\mathbf{1 1 . 0 6}$ grams, while the daily average excretion of uric acid for the same period fell to $0.699 \mathrm{gram}$. In the first of these two cases the average daily ratio of uric acid to total nitrogen during the period of lowered proteid metabolism was $1: 14$. In the second case the ratio was $1: 16$.

A third college student (G. W. Anderson), on his ordinary diet, excreted through the urine for a period of nine days 17.17 grams of nitrogen as the daily average, while the average daily output of uric acid for the same period was 0.956 gram. On the more restricted diet of the next four or five months his average daily excretion of nitrogen fell to 9.37 grams per day, while the average daily excretion of uric acid was reduced to 0.632 gram. On his ordinary diet, the ratio of uric acid to nitrogen was $1: 18$, while later with the diminished proteid metabolism the ratio was $1: 14$.

Turning to another class, viz., professional men, reference may be made to the writer, whose average daily nitrogen excretion through the urine for a period of nearly nine months was 5.699 grams, corresponding to the metabolism of 35.6 grams of proteid per day. During this same period of nearly nine months the average daily excretion of uric acid amounted to $0.392 \mathrm{gram}$, the ratio of uric acid to total nitrogen being $1: 14$. In passing, it may be repeated that the subject of this experiment succeeded in maintaining a constant body-weight, and he further avers that in physical and mental vigor he can find no evidence of deterioration, although the amount of proteid food consumed daily during this long period was less than 40 grams per day. Further, he was in nitrogenous equilibrium during this period, although the nitrogen metabolized daily amounted to only 99 milligrams per kilo of body-weight. Another case in this same group may be mentioned, principally because the subject for over a year became a vegetarian, abstaining from all meat. During the last nine months, this 
man (Beers) eliminated 8.28 grams of nitrogen through the urine as the daily average, indicating a metabolism of 51 grams of proteid material per day. During this same period, the average daily excretion of uric acid was $0.349 \mathrm{gram}$, the ratio of uric acid to total nitrogen being $1: 23$.

The main point to be emphasized in these results is that they show quite conclusively how greatly the daily output of uric acid may be reduced by diminishing the intake of proteid food, and thereby restricting the extent of the proteid metabolism. The ratio of uric acid to the total nitrogen excreted may or may not be altered; this will depend in large measure upon the character of the diet, the relative proportion of free and combined purin bases introduced with the food, etc. As already stated, we do not know with certainty how far the excreted uric acid represents the formation of uric acid in the body, but presumably there is a more or less close relationship, and hence we are doubtless warranted in saying that the formation of uric acid is diminished, in essentially the same proportion as its excretion is reduced, with a lowered proteid intake. Certain it is that several of the persons under observation, who had troubles of a gouty and rheumatic nature in the past, have during the course of the experiment experienced relief, with complete and permanent abeyance of all symptoms. The writer is firmly of the opinion that ordinary gout and rheumatism are entirely preventable by reasonable care and judgment in the matter of diet. Whether, when once firmly established, in aggravated form, they will prove amenable to dietetic treatment is not so certain, but undoubtedly mild cases will respond to the beneficial influences of a rational diet, reinforced by treatment adapted to the removal of urates already deposited. In any event, due regard for the well known deleterious effects of purin-containing foods as a source of exogenous uric acid, and with restriction of proteid metabolism to the true necessities of the body, should serve as an effective means of preventing all those troubles for which uric acid is generally held responsible.

The two following tables give a summary of results bearing 
upon the excretion of uric acid and its relation to nitrogen and body-weight, for all the subjects belonging to the "professional group" and the "student group." Emphasis should be laid upon the fact that these figures represent the average daily excretion for the different individuals through the entire period of the experiment.

AVERAGE DAILY EXCRETION THROUGH THE URINE FOR SEVEN-NiNe MONTHS. - Professional Group.

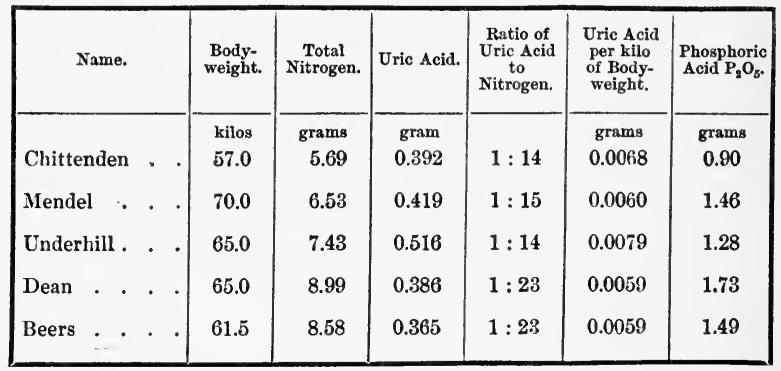

AVERAGE DAILY EXCRETION THROUGH THE URINE FOR FOUR-FIVE MONTHS. - Student Groep.

\begin{tabular}{|c|c|c|c|c|c|c|}
\hline Name., & $\begin{array}{c}\text { Body- } \\
\text { weight. }\end{array}$ & $\begin{array}{c}\text { Total } \\
\text { Nitrogen. }\end{array}$ & Uric $\boldsymbol{A}$ cid. & $\begin{array}{l}\text { Ratio of } \\
\text { Uric Acid } \\
\text { to } \\
\text { Nitrogen. }\end{array}$ & $\begin{array}{l}\text { Uric Acid } \\
\text { per kilo } \\
\text { of Body- } \\
\text { weight. }\end{array}$ & $\begin{array}{l}\text { Phosphoric } \\
\text { Acid } \mathrm{P}_{2} \mathrm{O}_{5} \text {. }\end{array}$ \\
\hline & kilos & grams & gram & & grams & grams \\
\hline Anderson, G. W. & 71.0 & 9.37 & 0.632 & $1: 14$ & 0.0089 & 1.75 \\
\hline Anderson, W. L. & 61.0 & 10.41 & 0.516 & $1: 20$ & 0.0084 & 2.14 \\
\hline Bellis . . & 78.0 & 8.88 & 0.531 & $1: 16$ & 0.0068 & 1.98 \\
\hline Callahan . & 83.0 & 9.04 & 0.624 & $1: 14$ & 0.0075 & 1.74 \\
\hline Donahue . . & 62.0 & 7.47 & 0.395 & $1: 19$ & 0.0063 & 1.79 \\
\hline Jacobus . & 56.0 & 7.58 & 0.423 & $1: 17$ & 0.0075 & 1.67 \\
\hline Schenker. . & 73.0 & 10.09 & 0.624 & $1: 16$ & 0.0085 & 2.20 \\
\hline Stapleton & 75.0 & 11.06 & 0.699 & $1: 16$ & 0.0093 & 2.64 \\
\hline
\end{tabular}


Turning now to the third group of men, $i$. $e$, the soldier detail, under observation for a period of six months, during five months of which time they lived on a prescribed diet with diminished content of proteid food, but with no exclusion of animal food, the following average results are to be noted:

AVERAGE DAILY EXCRETION THROUGH THE URINE FOR fIVE MONTHS - Soldier Detail.

\begin{tabular}{|c|c|c|c|c|c|c|}
\hline Name. & $\begin{array}{c}\text { Body- } \\
\text { weight. }\end{array}$ & $\begin{array}{c}\text { Total } \\
\text { Nitrogen. }\end{array}$ & $\begin{array}{l}\text { Uric } \\
\text { Acid. }\end{array}$ & $\begin{array}{l}\text { Ratio of } \\
\text { Uric Acid } \\
\text { to } \\
\text { Nitrogen. }\end{array}$ & $\begin{array}{l}\text { Uric Acid } \\
\text { per kilo } \\
\text { of Body- } \\
\text { weight. }\end{array}$ & $\begin{array}{l}\text { Phosphoric } \\
\text { Acid } \\
\mathbf{P}_{2} \mathrm{O}_{5} .\end{array}$ \\
\hline & kilos & grams & gram & & gram & grams \\
\hline Oakman. . & 62 & 7.42 & 0.405 & $1: 18$ & 0.0065 & 1.39 \\
\hline Morris . . & 59 & 7.03 & 0.450 & $1: 15$ & 0.0076 & 1.25 \\
\hline Broyles . & 60 & 7.26 & 0.398 & $1: 18$ & 0.0066 & 1.41 \\
\hline Coffman . & 58 & 8.17 & 0.379 & $1: 21$ & 0.0065 & 1.23 \\
\hline Sliney & 60 & 8.39 & 0.647 & $1: 13$ & 0.0107 & 1.32 \\
\hline Steltz. . & 53 & 7.13 & 0.416 & $1: 17$ & 0.0078 & 1.24 \\
\hline Henderson & 71 & 8.91 & 0.488 & $1: 18$ & 0.0068 & 1.42 \\
\hline Fritz . . & 72 & 7.84 & 0.642 & $1: 12$ & 0.0089 & 1.58 \\
\hline Colın . . & 62 & 8.05 & 0.512 & $1: 15$ & 0.0082 & 1.28 \\
\hline Loewenthal & 59 & 7.38 & 0.372 & $1: 19$ & 0.0063 & 1.28 \\
\hline Zooman . & 55 & 8.25 & 0.457 & $1: 18$ & 0.0083 & 1.19 \\
\hline Bates. . & 65 & 8.08 & 0.387 & $1: 20$ & 0.0059 & 1.23 \\
\hline Davis. . & 57 & 8.61 & 0.414 & $1: 20$ & 0.0072 & 1.42 \\
\hline
\end{tabular}

These figures are interesting in many ways. First, they make clear that on the diet prescribed, these men were manufacturing or excreting about the same amount of uric acid per kilo of body-weight as the men of the two preceding groups, living more or less with free cho:ce of food. In other words, all these men, with one and possibly two exceptions, were practically throwing out only uric acid of endogenous origin, $i$. e., that which came from the breaking down of the man's 
own tissue cells. Second, it is to be noted that the ratio of uric acid to nitrogen in the men of this group varies only within narrow limits.

It is very evident from these figures, reinforced by those of the previous groups, that we can diminish greatly the output of uric acid by simply restricting the extent of proteid katabolism, through reduction in the amount of proteid food. Further, we now know that this general lowering of proteid metabolism can be accomplished not only without danger to the body, but with a distinct betterment of the physical condition.

Just here I should like to emphasize one point that appears to me of primary importance in any consideration of the influence of diet in gouty affections, and in so doing I merely echo a statement made by Sir Dyce Duckworth*, viz., "that the subject of gout, either by inheritance or acquirement, is so far peculiar in his constitution that he reacts differently to various agencies, such as climate, food, etc., from persons not so disposed." In this connection, let me refer again to the foregoing table of results obtained with the soldier detachment, remembering that these thirteen men were living under exactly the same conditions and consuming the same kind of food each day, and in essentially the same amounts. Yet notice the striking variation in the output of uric acid by one of these men (Sliney), - a variation which shows itself especially when the uric acid is calculated per kilo of bodyweight. How can this variation be accounted for except on the assumption that there may be personal idiosyncrasies, personal coefficients of nutrition, natural or acquired, that modify to some extent the production of uric acid, the oxidation of uric acid, or the elimination of uric acid from the body?

Lastly, in advocating the possible systemic value of a lowered proteid metabolism as of value in the prevention of gout, and of other disorders which have their origin in per-

* The Practitioner, July, 1903, p. 83. 
verted nutrition, I am inclined to emphasize the desirability of using common-sense in the application of dietetic rules, remembering that man is an omnivorous animal, and that Nature evidently never intended him to subsist solely on a " cereal diet," or on any specific form of food to the exclusion of all others. On matters of diet every man should be a law unto himself, using judgment and knowledge to the best of his ability, reinforced by his own personal experiences. Vegetarianism may have its virtues, as too great indulgence in flesh foods may have its serious side, but there would seem to be no sound physiological reason for the complete exclusion of any one class of food stuffs, under ordinary conditions of life. Far more rational is temperance in place of prohibition, and I am inelined to emphasize the systemic value of a daily diet so reduced in quantity that the metabolic processes may be largely decreased, in eloser harmony with true physiological needs, especially those which involve the breaking down of proteid matter; and in making this suggestion I can add the assurance, based upon these observations on many individuals, that there is not only perfect safety but gain to the body, in diminishing proteid metabolism to a level somewhere near the actual requirements of the individual. 


\section{ECONOMIC AND SOCIOLOGICAL IMPORTANCE OF THE RESULTS.}

The importance of the foregoing results from an economic and sociological standpoint is perhaps worthy of a brief consideration. We have learned that a much smaller amount of albuminous or proteid food than is ordinarily consumed will suffice for the daily needs of the body. It remains to be seen whether this fact will gain the popular recognition it would seem to deserve. Ignoring for the time the matter of physiological economy and its possible bearing upon health and strength, it is a fair question to ask why should people indulge in such wasteful extravagance in the matter of diet when there is no real physiological need for it? Why not accustom the body to a smaller consumption of food, thereby saving for other purposes the expenditure which this excess of food involves?

The question of the daily diet is one of the most important for the family of small means, and there is no reason why the family treasury should be so heavily drained for this imaginary need. Simplicity of living might well be given more careful consideration, and now that we have convincing proof of much smaller dietetic requirements on the part of the body, it might be well to consider the practical application these results naturally suggest. It is obvious from our data, that it is quite safe to diminish by one-half the amount of albuminous or proteid food ordinarily consumed, and this without any apparent detriment to health, and with even gain to the economy. The ordinary forms of proteid food are, as a rule, the most costly of dietetic articles, and since this restriction of albuminous food calls for no great increase in the amount of nonnitrogenous food, it is quite apparent that a great saving in the daily expenditure can be accomplished.

Obviously, however, there must be a decided change in the attitude of the public on this question before any great im- 
provement can be hoped for. Habit and sentiment play such a part in our lives that it is too much to expect any sudden change of custom. By a proper system of education commenced early in life it may, however, be possible to establish new standards, which in tir te may prevail and eventually lead to more enlightened methods of living, whereby there will be less drain upon the resources of the people. With habits firmly fixed and palates calling for new sensations, reinforced by the prevalent opinion that by hearty eating lies the road to health and strength, it is easy to foresee difficulty in the advance of new doctrines along the lines indicated. The pleasure of eating is not to be minimized. The palate serves as the gateway through which food passes, and its sensitiveness and power of appreciation are not to be despised.

Simplicity of diet, however, does not diminish but rather increases the pleasure of eating, especially when daily restriction in diet - indulged in until a new habit is formed - has created a greater keenness of appetite, since under such conditions the palate takes on a new sensitiveness, and manifests a fuller appreciation of the variations of even a simple dietary. There is therefore no hardship, nor curtailment of the pleasure of eating in the restriction of the diet to the real needs of the body. Neither is there implied any cessation of that kindly hospitality that delights in the 'breaking of bread' with one's friends. With enlightened methods of living, on the other hand, will come a truer appreciation of the dignity of the body, and a lessened desire to manifest one's feelings of hospitality by a lavish intemperance that is as unphysiological as it is wasteful.

For the rich, as well as for the poor, there is need for careful consideration of this question of intemperance in the daily dietary. Were this the proper place, it would be easy to adduce figures showing the great waste which the consumption of food beyond the physiological requirements of the body entails. It needs no great imagination to picture the enormous saving per capita, in dollars and cents, by a reduction of the daily food to a true physiological basis. 
The saving to the community, to the family, might well amount to enough to constitute the difference between pauperism and affluence. The resources of a community, as well as the resources of the family, are not to be lightly thrown away. We count the cost of this or that necessity, of this or that luxury, with aareful consideration of the relative need and expense, but in the matter of living we pay little heed except it may be to exclude certain dietetic luxuries which seem beyond our purse. We are prone to fancy that health and strength are fostered by great liberality in the amount and variety of the daily food provided, and we are apt to express great concern if all the family and our guests do not avail themselves to the utmost of the foods so lavishly spread before them. The poorer man emulates his richer neighbors as soon as his circumstances will permit, and resources that could be much more advantageously expended for the good of the family and the home life are practically wasted - to say nothing of possible injury to health - under the mistaken idea that this more generous method of living is the surest road to health and strength.

Further, there is ground for thought in the possible economy of time which an improved condition of health would result in for the working members of the family. If greater economy in diet will diminish the number of sick days in the year, thereby increasing the working power of the wage earner, and if greater strength and efficiency can be acquired at the same time, the economic value of the proposition is at once apparent.

Finally, happiness and contentment, which usually appear in direct proportion to the health and prosperity of the individual, may be counted upon as becoming more conspicuous in the life of the community. So we see suggested various ways in which the application of the principles herein laid down, if consistently adopted and followed, may lead to a betterment of economic and sociological conditions. The writer, however, leaves to others, more familiar with sociological problems, the fuller development of this line of thought. 


\section{GENERAL CONCLUSIONS.}

When this investigation, the results of which have been detailed in the foregoing pages was first planned, it was intended to be simply a physiological study of the minimal proteid requirement of the healthy man, extended over sufficient time to render the results of scientific and practical value. There were no special theories involved, no special system of dietetics in view, but the object was simply to ascertain experimentally the minimum amount of proteid or albuminous food necessary for the maintenance of health and strength, under ordinary conditions of life. The impression in the mind of the writer was that there was no satisfactory scientific evidence to support the views held by most, if not all, physiologists regarding the needs of the body for food, especially nitrogenous or proteid food, and that the dietary standards universally adopted by scientific men were of very questionable accuracy, being founded mainly upon the customs and habits of mankind rather than upon any systematic study of what the actual necessities of the body are.

The results attained have certainly thrown a great deal of light upon this question of minimal proteid requirement, and the experimental study has been throughout a purely physiological one, but as the work has progressed the writer has been more and more impressed with the importance and significance of the results in their bearing upon the broader problem of general physiological economy in nutrition. There is no question, in view of our results, that people ordinarily consume much more food than there is any real physiological necessity for, and it is more than probable that this excess of food is in the long run detrimental to health, weakening rather than strengthening the body, and defeating the very objects ' aimed at.

Confining our conclusions to general statements, it may be said that our results, obtained with a great diversity of sub- 
jects, justify the conviction that the minimal proteid requirement of the healthy man under ordinary conditions of life is far below the generally accepted dietary standards, and far below the amounts called for by the acquired taste of the generality of mankind. Expressed in different language, the amount of proteid or albuminous food needed daily for the actual physiological wants of the body is not more than one-half that ordinarily consumed by the average man. Bodyweight (when once adjusted to the new level), health, strength, mental and physical vigor, and endurance can be maintained with at least one-half of the proteid food ordinarily consumed; a kind of physiological economy which, if once entered upon intelligently, entails no hardship, but brings with it an actual betterment of the physical condition of the body. It holds out the promise of greater physical strength, increased endurance, greater freedom from fatigue, and a condition of wellbeing that is full of suggestion for the betterment of health.

Physiological economy in nutrition means temperance, and not prohibition. It means full freedom of choice in the selection of food. It is not cereal diet nor vegetarianism, but it is the judicious application of scientific truth to the art of living, in which man is called upon to apply to himself that same care and judgment in the protection of his bodily machinery that he applies to the mechanical products of his skill and creative power.

Food requirements must of necessity vary with changing conditions, but with due recognition of this fundamental principle, all the results so far obtained in this investigation, with a great variety of persons, point to the conclusion that the real demands of the body for proteid food do not exceed fifty per cent of the amount generally consumed. One-half of the 118 grams of proteid food called for daily by the ordinary dietary standards is quite sufficient to meet all the real physiological needs of the body, certainly under ordinary conditions of life ; and with most individuals, especially persons not leading an active out-of-door life, even smaller amounts will suf- 
fice. Excess means waste, but of far greater importance is the unnecessary strain placed upon the body by this uncalledfor excess of food material, which must be gotten rid of at the expense of energy that might better be conserved for more useful purposes.

Further, the total consumption of food by the average individual, non-nitrogenous as well as nitrogenous, is considerably greater than the real needs of the body demand, although here we must give closer heed to the varying requirements of the body incidental to varying degrees of activity. The man whose work is mainly mental has no real need for high fuel values in his daily ration. For such a man, a high potential energy in the daily intake of food is an incubus and not a gain. Body equilibrium ean be maintained on far less than 3000 calories per day by the brain worker, and in the interest of health, strength, and vigor, as well as scientific truth, why teach the doctrine that a healthy man needs, on an average, foodstuffs to furnish 3000 calories or more per day, with 16 to 18 grams of nitrogen in the form of proteid? Moreover, as our experiments have clearly indicated, even the man who is called upon to perform considerable physical work has no apparent need for a fuel value-in his food of 3000 calories per day. No doubt, the man who works at hard labor for ten or twelve hours a day will require a larger intake of fats and carbo-hydrates, sufficient to yield even more than 3000 calories, but this is not true of the moderate worker, nor of the average man whose work is in large measure mental rather than physical.

Finally, the writer may be permitted to express the hope that the outcome of this experimental work will serve to arouse scientific and intelligent interest in a subject which promises fruitful results for the individual, and for the community. 


\section{DESCRIPTION OF. ILLUSTRATIONS}

Photographs of the soldiers were taken a few days prior to the close of the experiment, just before the men left New Haven at the termination of their work. Consequently, the pictures show the physical condition of the men after their long period of low nitrogen diet. Study of these photographs, especially those of the individuals, gives a correct idea of the appearance of the men, and shows the eharacter of their muscular development at the close of their experimental work.

In considering these photographs, it must be remembered that the men as a class, as stated by Dr. Anderson in his Report, were not particularly well set up. It is evident, however, that the subjects were in good physical condition and had not lost any undue amount of flesh or fat. The two photographs of Fritz, facing pages 198 and 203, show him to have been in fine physical condition, with even a superabundance of fat. Steltz, on the other hand, whose photograph is shown facing page 211, was somewhat fine. This man, however, is of quite different build from his companion, Coffman, and was in excellent physical condition for certain lines of gymnastic work.

It may be well at this point to refer the reader to the photographs of W. L. Anderson and Bellis, facing pages 440 and 442. These men, typical Yale athletes, were in prime physical condition, and the photographs were taken prior to the experiment, at a time when they were consuming their ordinary, rich proteid diet. It is plain, by a comparison of these photographs, that Steltz was not trained to a much finer point than W. L. Anderson, although he does lack the full muscular development characteristic of the Yale athlete.

Sliney, whose photograph is found facing page 272 , was likewise in a somewhat fine condition. He, however, like Steltz, was in splendid physical shape, so far as can be judged by his general health, spirits and aptitude for work. The 
other men of the soldier group, whose photographs are shown, were not trained down to quite the same degree. Both Sliney and Steltz, however, had essentially the same body-weight at the close of the experiment, as on their arrival in New Haven. Steltz, indeed, weighed a trifle more in April, 1904, than he did in October, 1903. Sliney, on the other hand, had lost about one pound in weight. It is obvious, therefore, that these two men do not owe their spare condition to the low proteid diet.

The photographs facing pages 136, 261, 284 and 296 illustrate some of the methods employed in attempts to improve the bodily movements of the soldiers.

Among the group of University athletes, the photographs of Stapleton, facing pages 328 and 366, show the muscular development of a typical athlete endowed with more than the usual amount of muscular tissue. These two photographs of Stapleton were taken in April, after the subject had been for several months on a low proteid diet. There is in the photographs certainly no suggestion of any loss of muscle tissue, and no evidence of physical weakness. Stapleton, as has been previously stated, was an expert in wrestling and events of that character, for which his heavy muscular build well fitted him.

The photographs of W. L. Anderson and Bellis, facing pages 440 and 442, show, on the other hand, two athletes whose characteristic build is indicative of ability as gymnasts. More graceful in form, with smaller joints, and less heavy musculature, these men, at the time the photographs were taken, were in the pink of condition, and in a high degree of training for their special fields of athletic work. Emphasis should be laid upon the fact that at the time these two photographs were taken, the men in question had not commenced to lower their daily amount of proteid food. These two photographs are introduced especially to illustrate the general physical makeup of the men belonging to the group of University athletes made use of in the experiments. 


UNIVERSITY OF CALIFORNIA LIBRARY

\section{Los Angeles}

This book is DUE on the last date stamped below. 907

DEC 30 1955 DEC 241958 DEC2 $1 \mathrm{RECO}$ APD $20 \overline{1964}$ APR 1 REC'D

NOV 4968 Blommortion OCT 26 RECT BIOMED WOV $1 \mathrm{C}$ I I I ? BOMEO Lis NoV 20 hete

2 WK from Receipt LETREAN SAN 231975

\section{ILL.PSRMLS}


S. c.

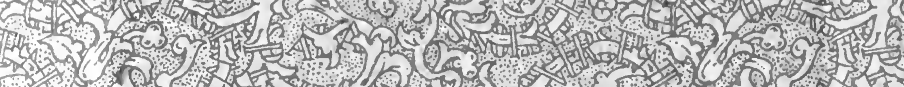
Co (3) 15. 2. 2.

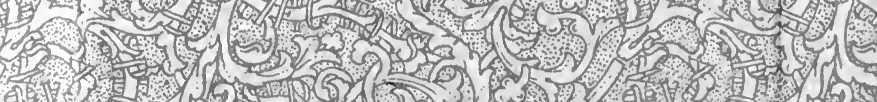
(1) (5) 76 .

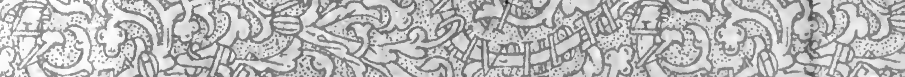

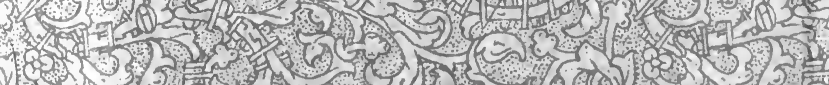


3) $184:-$.

is
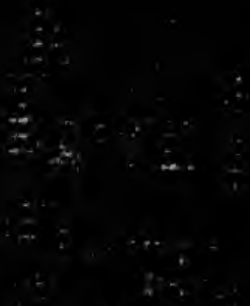